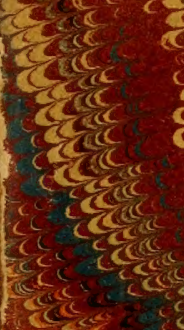

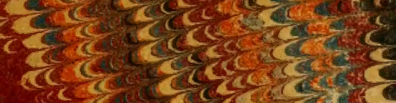

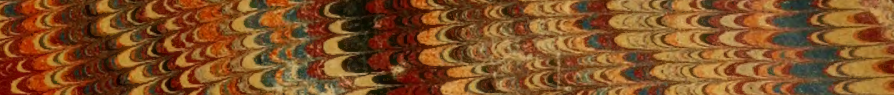

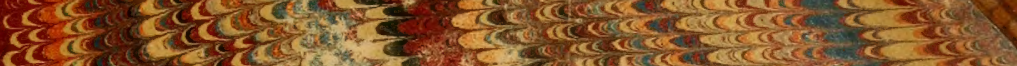

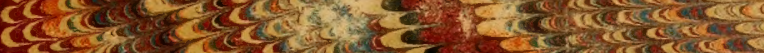

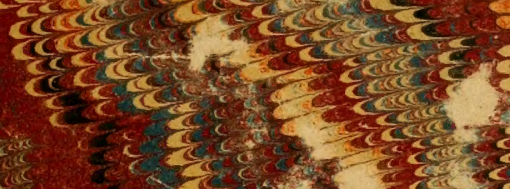

(1)

-

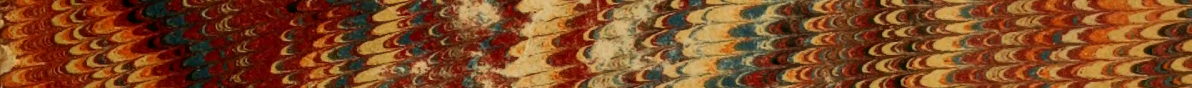

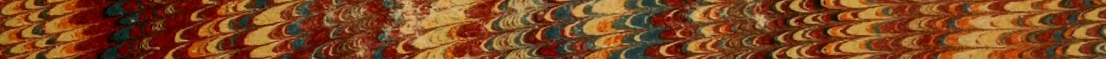

ce.

cres

ces

cिice

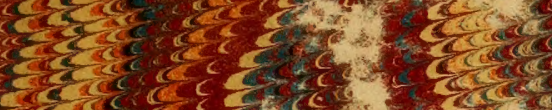

जिएकि

करेखा की

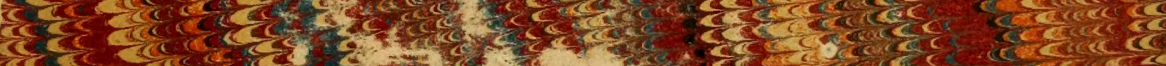

क्षे

c.

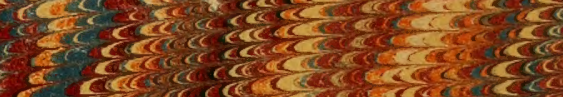

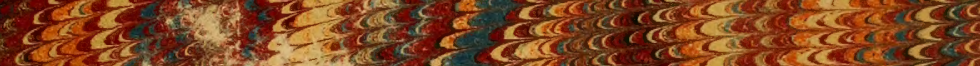

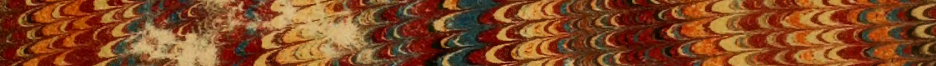

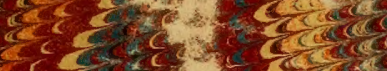

coses

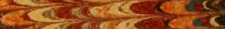

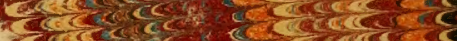

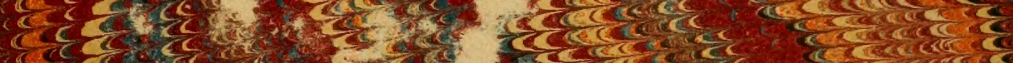

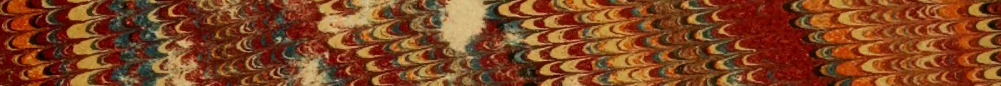

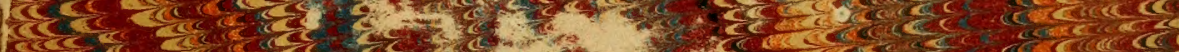

लिखे की

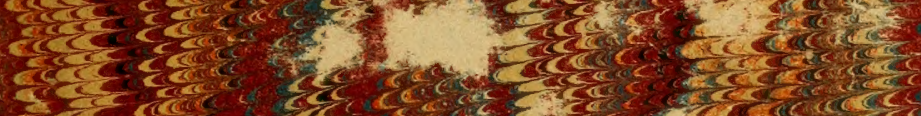

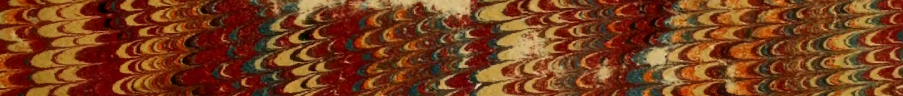

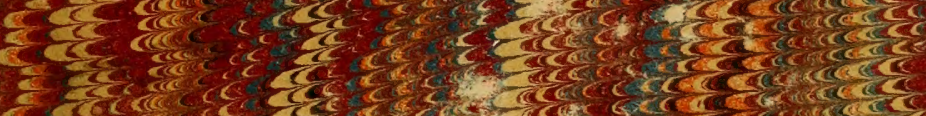

कर

स्टिए

बिरे दि

की एक

cines

ing

तो

करे

बिले से

है है

(a)

$\operatorname{cic} 2$

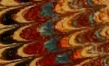

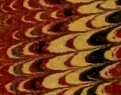

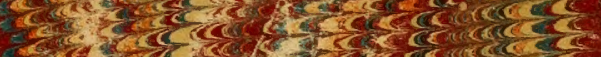

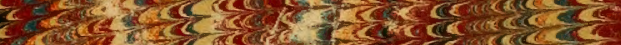

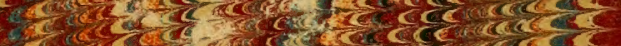

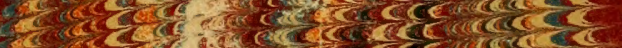

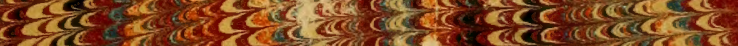

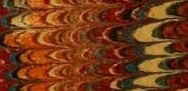

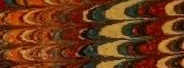

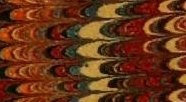

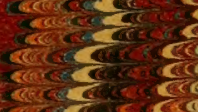

encereng

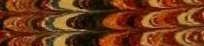
मद

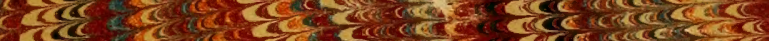

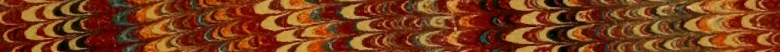

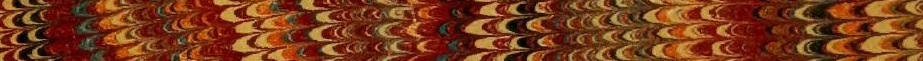

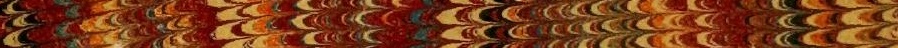

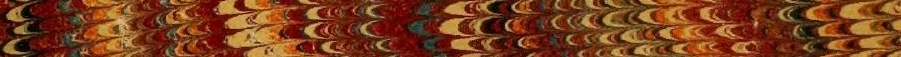

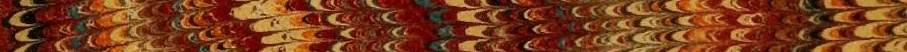

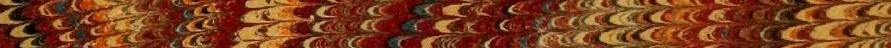

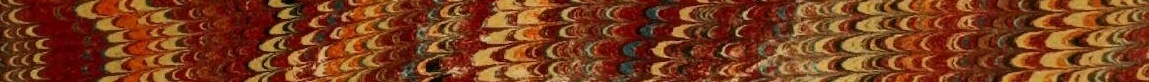

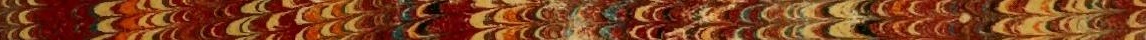

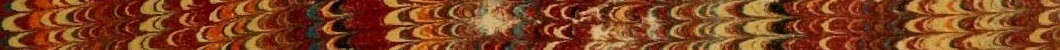

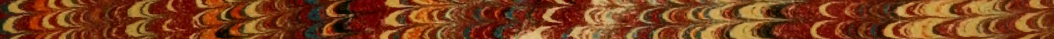

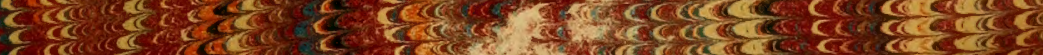

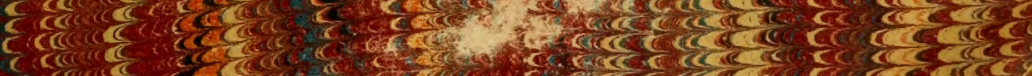

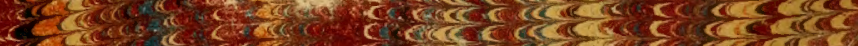

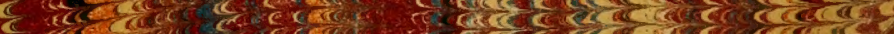

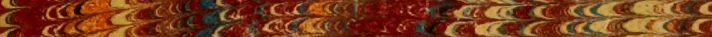

cese

rese

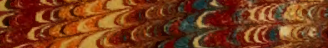

aces

acencerich

corre resere

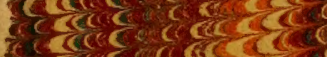

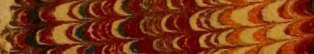

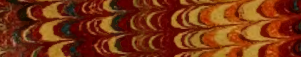

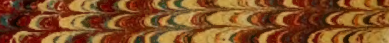

$c$ re

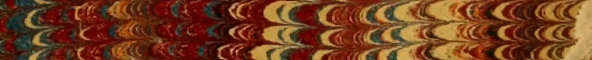

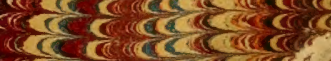

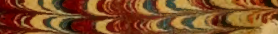

mencesces

acesencest

cre बाin 


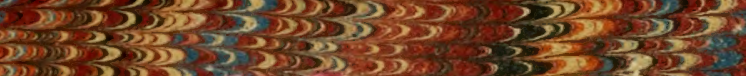

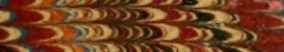
3500035 sins?

(2)

53,323 . 35

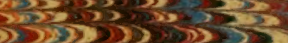
mis 3,353

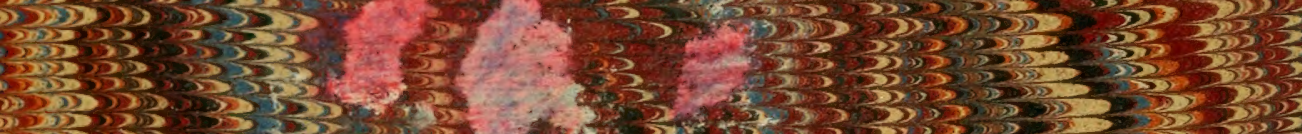

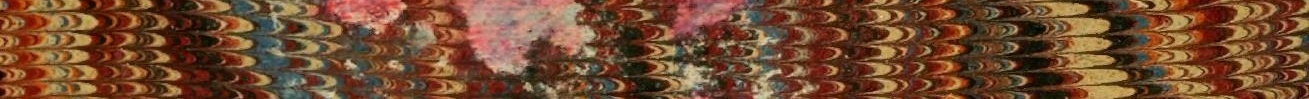

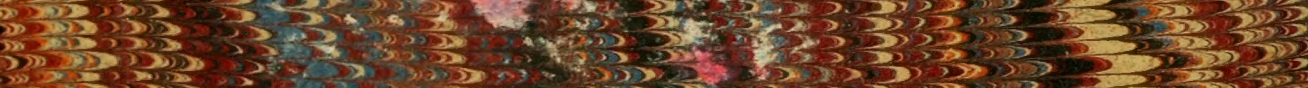
3) 2035353

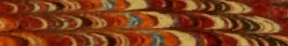

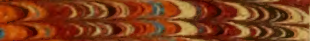

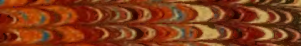
(5) $22003>35$ S. $\rightarrow 32,3,3$ 35053030323 $3 .-2035$

3.

(2) is 63035203 $5-390.53$ 303

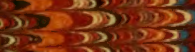

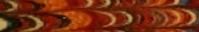
$35035>1003$ 33353,35 $353 \times 2000$ 37325 3 35205 ग5

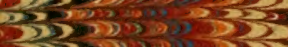

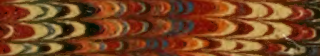

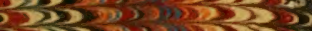
S 350 D

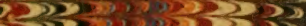
335 . 35 ins 3535050353 $3>253$

335 .

3 in 350353

in

? 203.0353

(x) 3 $\sum_{i \rightarrow 3} \rightarrow \frac{13}{3}$

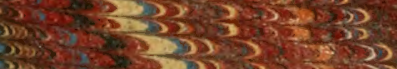

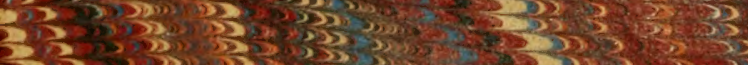

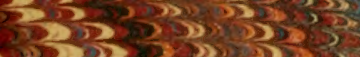

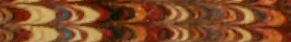

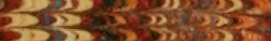

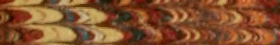

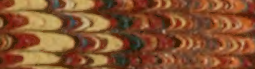

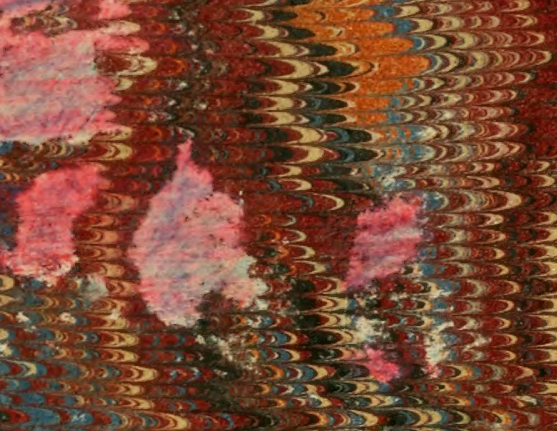
Sisis:

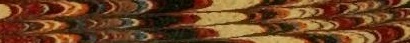

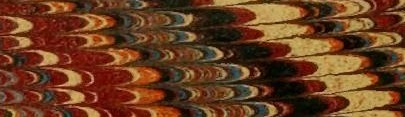

(3) 35350

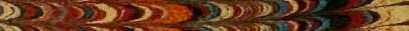

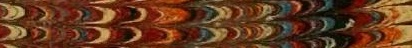
S

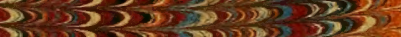

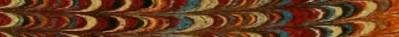
3). 35 ,

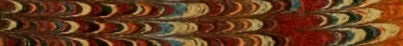

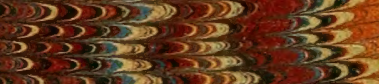

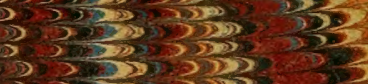

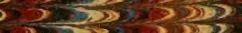
303030 $\rightarrow$ in a) 35351323 यक्या 32053 2) 3503 2530253

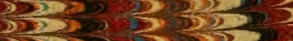
3030203

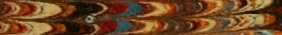
i)

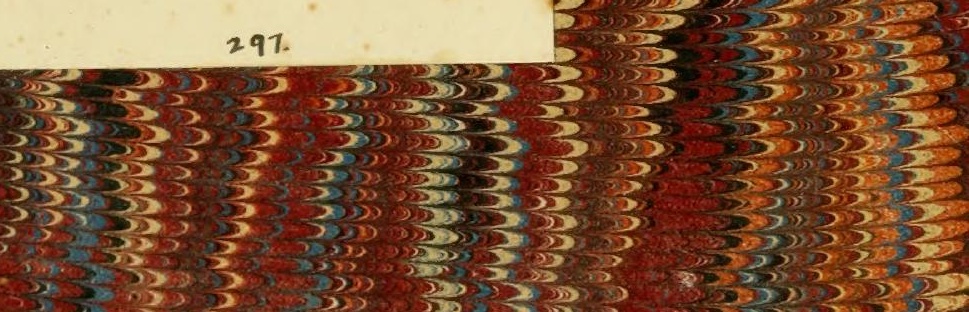

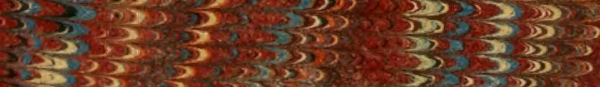

(3) 353,303

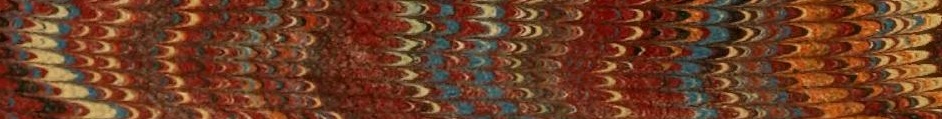

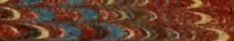
3 333 in 33 3.5005 .

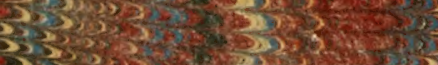

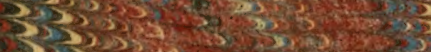

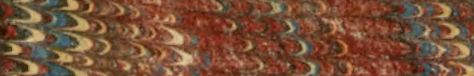

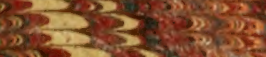
$\lim _{3 \rightarrow \infty}$

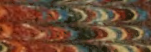

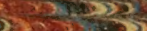

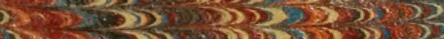
50253505350

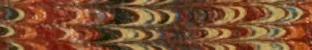

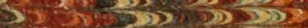
S. 5 . 505000

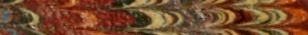

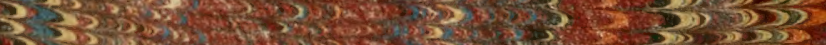

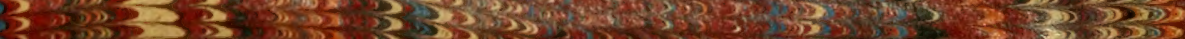




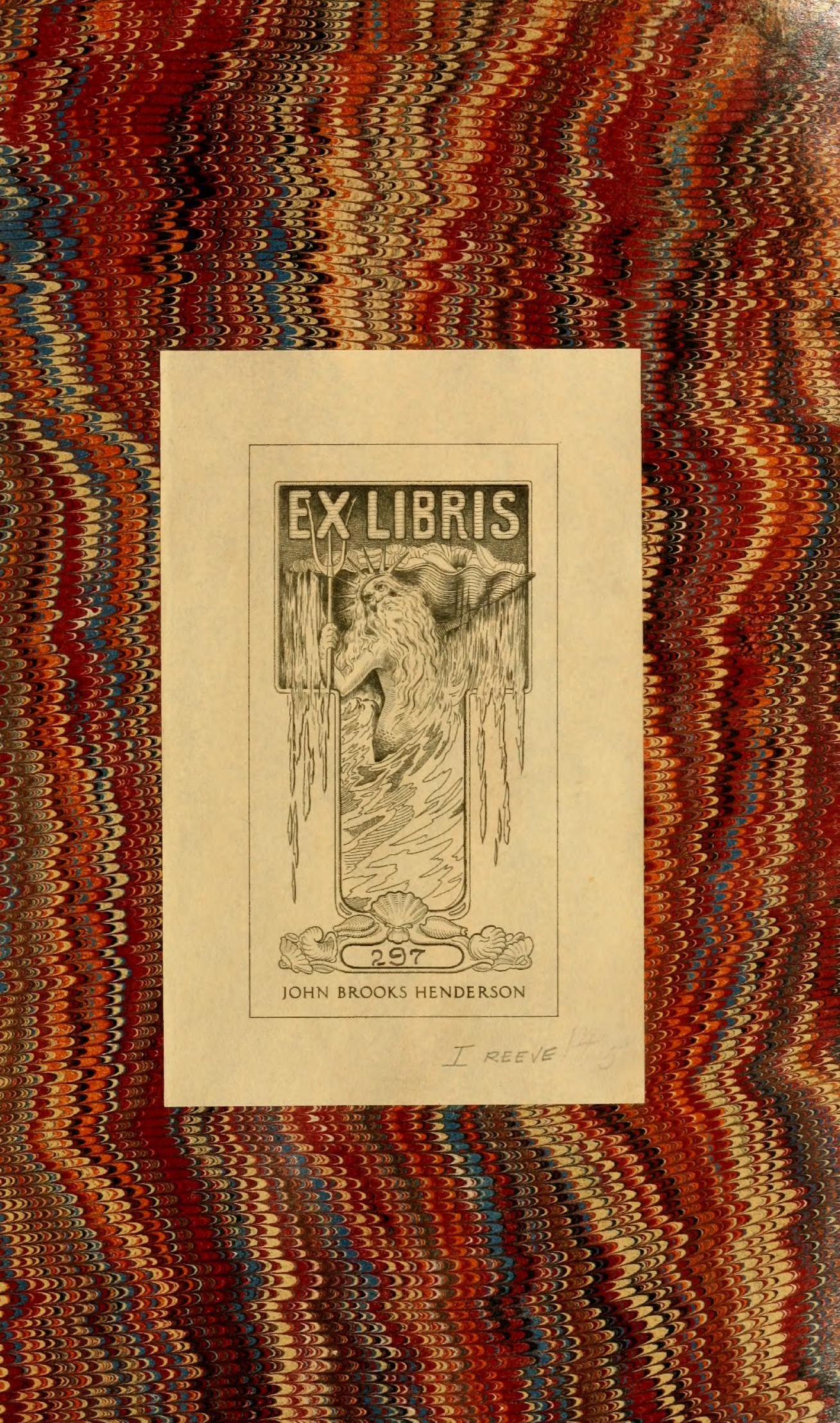




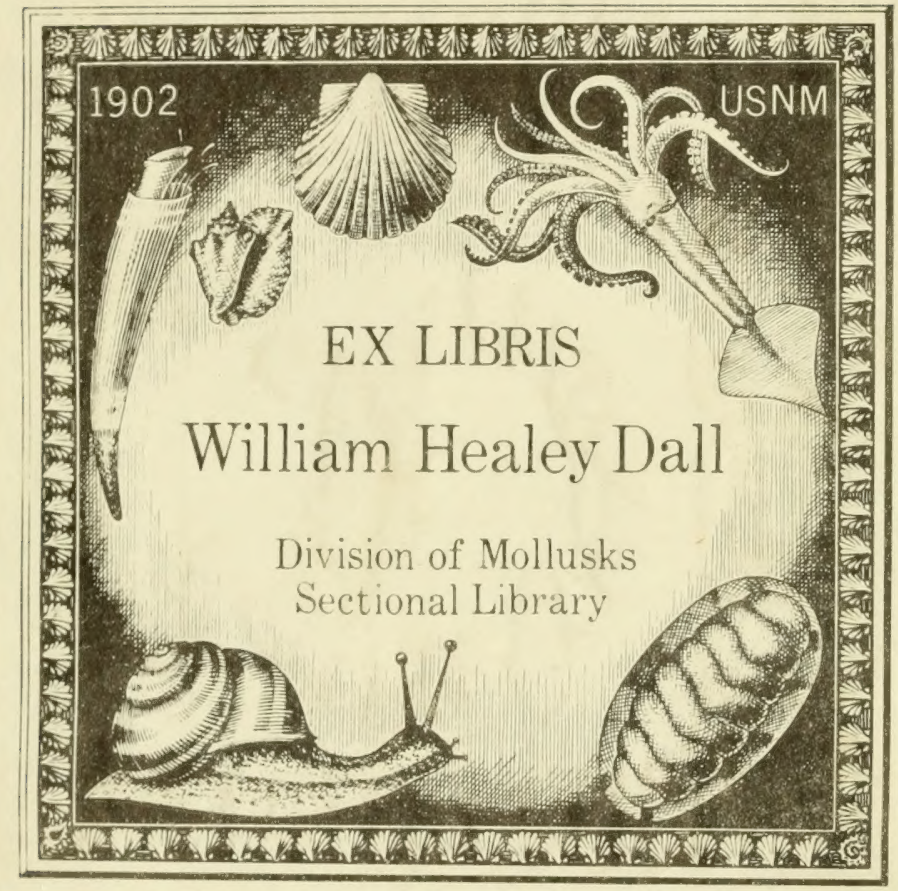


Sher S. dewateren Hesteringlex

Division of Niollueiks Sectional Librory 



\section{ELEMENTS OF CONCHOLOGY;}

sN IXIzODECTrox To

THE NATURAL HISTORY OF SHELLS

THE ANTMLALS WHICH FORM THEM.

BY

\section{LOVELL REEVE, F.L.S., F.G.S.}

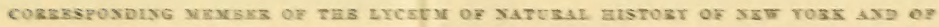

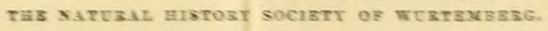

IN TWO VOLUMES.

Dtvidion of Mollusias

Gestional Librory VOL. I.

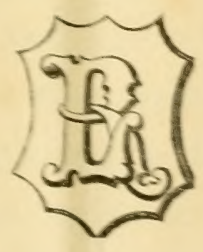

PUBLISHED BY THE AUTHOR,

LONDON; 5, HENRIETTA STREET, COVENT GARDEN. 1860. 
"Beneath the waves there are many dominions yet to be visited and kingdoms to be discovered; and he who venturously brings up from the abyss enough of their inhabitants to discover the physiognomy of the country, will taste that cup of delight, the sweetness of whose draught those only who have made a discovery know."-Edward Forbes. 


\section{PREFACE.}

EDward Forbes, in his delightful ' Natural History of the European Seas,' remarks that " in this age of volumes, a man had needs offer a good excuse before adding a new book, even though it be a small one, to the heap already accumulated. He should either have something fresh to say, or be able to tell that which is old in a new and pleasanter way." The imperfect knowledge which Conchologists have of the natural history of their Shells would seem to argue that there is yet room for something to be said in reference to the objects of their admiration; and if I have not much to say in the following pages that is fresh, I have, at least, done my best to tell what is in them in a pleasant way.

To guide the collector in arranging his specimens, I submit a classification, on the Lamarckian system, of the genera, each with its list of species; and to lead him to meditate, whilst pondering over the treasures of his cabinet, upon the too little remembered fact of their once living existence, a description is given of the structural peculiarities and habits of the animals. For figures of shells, with the live mollusk, I have resorted chiefly to the zoologies of exploring expeditions, published under the auspices of the French Government. The figure of Spirula is, however, an original one, from a specimen captured at Port Nicholson, New Zealand, by Mr. Percy Earl; and so also are those of 
Carinaria and Panopaa, from specimens collected by the Rev. L. B. Larking, during a residence at Messina. The latter powerful mollusk he kept alive in vigorous health in a washing-tub. For information on the interesting subject of geographical distribution I am mainly indebted to the retentive memory and careful notation of habitats, during fourteen years of enterprising personal research in both the western and eastern hemispheres, of Mr. Cuming.

It is not so much for the zoologist as for the 'collector of shells' that the work is written. May I venture to hope that it will lead him to a more thoughtful consideration of the life of those beautiful objects which mark-

"The wisdom infinite

That brought them forth, but hid their causes deep."

L. R.

Hutton, Brentwood,

November 30th, 1859. 


\section{CONTENTS OF VOL. I.}

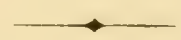

INTRODUCTORY REMARKS

Page

Class 1. Cephatopoda . . . . . . . . . . . y

Class 2. Gasteropoda . . . . . . . . . . . . . 24

Family 1. Convoluta . . . . . . . . . . . . 31

2. Columellata . . . . . . . . . . . . . 44 44

3. Purpurtfera . . . . . . . . . . . . . . . 54

4. Alata . . . . . . . . . . 86

5. Canalifera . . . . . . . . . . . . . . 94

6. Parasitica . . . . . . . . . . . . . 127

7. Turbrnacea . . . . . . . . . . . . . . 129

S. Plicheea . . . . . . . . . . . . . . 151

9. IANThinea . . . . . . . . . . . 154

10. Neritacea . . . . . . . . . . . . . 156

i1. Peristomata . . . . . . . . . . . . 165

12. Melaniana . . . . . . . . . . . 172

13. LyMneANa . . . . . . . . . . . 177

14. Auriculacea . . . . . . . . . . . 181

15. Cyclostomacea . . . . . . . . . . . 184 
Family 16. Colmmacea

17. Limacinea

\section{ILLUSTRATIONS.}

Anmals, Plates $A$. to $H$.

Shelds, Plates 1 to 21; Fig. 1 тo 122. 


\title{
ELEMENTS
}

\author{
$O F$ \\ C ONCHOLOGY.
}

Definition of the Science.

Coxchology is that science which treats of the natural history, and arrangement of Shells and their animal inhabitants:-not of Shells alone, but of Shells and the animals which produce them. The former are so beautiful and easy of prescrvation, the latter so unsightly and difficult of access, that the Conchologist has been greatly perplexed to know how to stucly the Shell and its Mollush with equal regard to the characters of both, and with a proper estimation of their physiological comncction. Drawings of many in their native condition have, however, been published by intelligent travellers*, and a sufficient number of typical kinds have been described and figured in the magnificent works of those naturalists to exhibit the true method of arranging shells according to their zoological affinity.

Many erroneous impressions have prevailed in regard to systematic arrangement, for want of duly considering the important relation that must necessarily exist between the shell and its fabricator. One classifies his shells according to their varieties of form and external aspect, forgetting that he has merely a collection of skeletons before him;-the calcified portions of animals possessing an organization far superior to that of the Bee, and a thousand creatures, whose structure and sagacity of habits have so often excited his admiration. Another of more abstruse habits of investigation, competing with the incorrectness of these views, professes the study of the soft parts mainly, and he even needs to be reminded that the shell, on the other hand, is an integral portion of the animal,-an outer or exo-skeleton,

\footnotetext{
* Lesson, 'Voyage de la Coquille'; Quoy and Gaimard, 'Voyage de l'Astrolabe '; D'Orbigny,
} Voyage dans l'Amerique Meridionale; Deshayes, 'Mollusques de l'Algerie'. 
which though inferior in organic development to the imner or endo-skeleton of the highererders, nevertheless exhibits certain characters and impressions inclicative of preuliar structures, and affording good subsidiary characters for the distinction of groups.

The Conchologist must look upon his shells, in the absence of the living parts, as a portion of those imperishable "Medals of Creation" * whose history is sugerested by their structure and animal impressions. The Comrey shell may be known by its highly polished porecllanous surface, to be more or less entirely enveloped by some appendage of the animal; the Siphonaria shell oflers inclications of a siphon; the Tenns shell shows the form of the lobes of the mantle; and who that regards the Thutiotis shell with a discerning eye, can fail to surmise that there must be some special design in its series of holes, which he may learn have been perforated by the animal in its progress of growth for the passage of the breathing organs. To show, too, that the most opposite forms may yet exhibit indications of zoological affinity, it may be observed that the Siliquaria shell possesses a structure similarly adipted, and of the same nature, ats that first spoken of in the IIaliotis. Here is an mulooked for affinity! An intimate zoological relation between shells exhibiting the two extremes of convoluted forms ; - the depressed spire, and the tubular spire.

\section{Comparative Rank in the Animal System.}

A brief survey should now be taken of the Animal Kingrom in order to show the rank and comparative importance of the Mollusca in the general range. We are encompassed by a mass of living beings, of whom we ourselves constitute the grand type, whose nature and properties present a strunge complication of affinities. For the sake of studying the several atoms of this complicated mass, and arranging them in order for reference, each individual is described and naned according to what is called a binomial methor ; that is, a method of two names, one denoting its general or generic character, the other its particular or specific character. And that the nomenclature may he of universil application, and acknowledged by all tongues and countries, it is adopted in the Latin.

'The modifications of nature are of that nice and delicate character, that we may trace a certain gradation of affinity from man to the animalcule. Although objects of extrencly anomalous nature occur to disturb the subtile reasomings of the philosopher, yet, there is a wonderful link of relationship between the highest animal, man, in whom the beauty of organization is (omplete, and the lowest creature, the animalcule, in which organization is so sinuple as to prescut nothing more than a globule multiplying with com- 
pound rapidity by the force of spontaneous fission. It was a favorite proverb with Linnæus "Natura non facit saltum"-Nature makes no leap - and if the great author of the 'Systema Nature' felt the force of this axiom in a time when the knowledge of species was extremely limited, how much stronger may the truth of it be now demonstrated when so many of the links then wanting in the chain of affinity have been revealed to observation. Every day we are invited to the contemplation of some new form, some new contribution to the general harmony of the series; and it is this inexhanstible source of novelty that imparts such a charm to the study. There is a modifying force in nature, that seems ever labouring to increase the participation of characters that were hitherto unapproachable. She telights in confounding the systematist; - she does not choose to be defined.

Limmus lived in a time when the researches into the comparative organization of the inferior animals were not very profound. The characters distinguished by the modem Aristotle exhibit, frequently, a violation of natural affinity; whilst they are too often artificial and void of equivalency. As soon as the immortal Cuvier began to look into the nervous and other complicated portions of the animal frame, the results proved to be such as to materially affect the prevailing method of classification. The physiological generalizations deduced from this new field of enquiry presented somnder combinations of character; and we are indebted to as great a comparative amatomist of our own day*, for having matured and added to the investigg:tions of his illustrious predecessor.

Cuvier did not, however, enter so minutely into the discrimination of species, as did his contemporary Lamarck; the first distinction which the great author of the 'Histoire des animaux sans vertèbres' recogmised in the primary distribution of the Animal Kingdom, was that of the higher orders, which include Mammals, Birds, Reptiles, and Fishes, being furnished with a vertebral column supporting an internal frame or skeleton, whilst the remainder are destitute of any; and he divided accordingly the levtebrule from the Invertebrate. "Now it will be observed", says Professor Owen, "that the invertebrate animals are here grouped together by a negative chilracter, and I know not any instance where such a character has been cmployed in zoology in which very differenly organized species have not been associated together. What indeed can be predicated in common of the Snail, the Bee, and the Polype, than that they are animals and have no vertebral columns, and the like negations?" $†$

Although Lamarck, therefore, may be followed in the detail of classification, it is necessary for the primary distribution to follow the method adopted by Cuvier and Owen, who divide the Animal Kingdon into four Sulb-kingrloms, the Vertebrata, the Moldusca, the Articulata, and the Rablats;

\footnotetext{
* Owen.

$\uparrow$ Hunterian Lectures 1544.
} 
the last three divisions of invertebrate animals occupying each an equal degree of rank with the vertebrate.

These four primary divisions of the AnmaL KingDom may be subdivided into classes as follows :-

\section{Sub-kingdom I. VERTEBRATA.}

Class 1. Mammalia ........ Mammals.

2. Aves .......... Birds.

3. Reptilia . . . . . . . Frogs, Lizards, Tortoises, Snakes \&e.

4. PIsces........... Fishes.

\section{Sub-kingdom II. MOLLUSCA.}

Class 1. Cephalopoda ...... Mollusks that walk with their head downwards.

2. Gasteropoda...... That acquire motion by the aid of a contractile and expansile disk.

3. PTeropoda...... That swim by means of a pair of wing-like fins.

4. Lameldibranchiata*. That have the branchia, or breathing organs, in thin plates.

5. Brachiopoda...... That are provided with a pair of spirally twisted arms.

Sub-kingdom III. ARTICULATA.

Class 1. Lepades ........... Barnacles.

2. Anellides ......... Leaches, Earth-ivorms, \&c.

3. Crustacea ........ Crabs, Lobsters, Shrimps \&c.

4. Arachidida....... Spiders, Scorpions \&c.

5. Insecta ......... Bees, Beetles, Butterflies, Centipedes \&c:

Sub-kingdom IV. RADLATA.

Class 1. Radtaria ......... Sea Eggs, Star Fishes \&c.

2. Polypi .......... Polypes or coral insects.

3. Entozoa .......... Intestinal Worms.

4. Infusoria ........ Animalcules.

* In order to distinguish the classes of Mollusca by an equivalency of terms throughout, I introduced in my 'Conchologia Systematica ' the word Tropiopoda in reference to this class, founded on the most prominent form of the foot-the narrow keel-shape; and it was adopted by Professor Macgillivray of Aberdeen in his Report of the Mollusca of that coast. It has, however, been since demonstrated by Professor Owen, in his Hunterian Lectures, that the foot whose modifications offer so excellent a character for the distinction of classes in the higher orders of Mollusea, is not only too variable in its formation and uses for that purpose in the Bivalves, but is sometimes altogether wanting. The lamellated character of the branchix, or breathing organs, has been preferred, and I now readily adopt it. Although an equivalency of terms is a great assistance to the memory, Nature is so variable in her characters that it cannot be embraced to any extent with accuracy. 


\section{Growth and Structure of Shells.}

It will be seen by the foregoing arrangement that the Mollusea occupy the second grand division of the Animal Kingdom, and, ranging next in order to the Fishes, are the most highly organized of the invertebrate series. They are termed Mollusks, from the Latin word mollis, soft, on account of their fleshy unjointed nature, withont bone, or, except in the Cephalopod, any intemal cartilaginous skeleton; and are furnished with organs of motion, vision, muscular contraction \&c. Their chief energies are, however, devoted to the formation of a shelly covering presenting great variety of form, colour, and sculpture. Some mollusks, as the Aplysiana, have only a rudimentary shell, whilst others, as the Eolida, are entirely naked.

The shell is formed by the deposite of a slimy juice which exudes from the glands of a filmy cloak-like organ called the mantle, and thickening in successive layers, becomes hardened and moulded on the body, with the addition of such ornanental structure, as the various filamentous modifications of the organ promote.

'This mucous exudation consists, not, as at one time supposed, of calcacareous particles held together by a sort of animal glue, but of a meinbranous tissue, consolidated by an admixture of carbonate of lime. All shells are therefore composed of two distinct elements,-animal matter and calcareous matter. The animal matter constitutes a membranous basis which is either cellular or laminary ; in some cases it is formed in cells of membranous walls, mostly hexagonal, into which the calcareous matter is infused; in others it is deposited in membranous laminx, more or less wrinkled like morocco leather, with the calcarcons matter in alternate laycrs, the lime in both eases imparting solidity to what would otherwise be a flexible stratum. These elements vary in their relative proportions according to circumstances; -in those shells which are of a fibrous laminary structure such as Pinna, and the whole of the margaritaceous group, there is a large proportion of the membranous constituent; whilst in the solid porcellanous shells, such as the Olives and Covries, the calcareous matter preponderates, the parts in immediate contact with the acetose juices of the mantle becoming vitrified, as it were, to a highly polished state of enamel. Great importance has been attached to the elementary structure of shells by the recent microscopical investigations of Dr. Carpenter*; his experiments have been most successfully conducted by grinding down a thin layer of shell, and placing it in dilute acid, the result being that the calcareous matter or lime decomposes, leaving a residuum of membranous tissue. On the other hand, he deseribes an instance of a mass in which the animal basis, a cellular tissue, had

* Report of the fourtecnth Mecting of the British Association p. 1. pl. 1 to 20. 
decayed, and left the calcarcous portion standing in basaltiform columns, (casts of the cells) not in auy way held together, and separable by the touch.

The optical irridescence of the nacreous portion of shells, commonly called mother-o-pearl, has been found by the same distinguished physiologist to be produced by the refraction of rays of light falling on the edges of the morocco-like wrinkles of laminary membranous substance. Under a high magnifying power, the nacreous surface exhibits a number of irregularly waved lines which Sir Jolm Herschell has not unaptly likened to the appearance of the woody layers on the surface of a planed deal board. The brightest nacre is that with which the large Avicula of the Pacific lines its shell; and the round pearls so highly esteemed by ladies as articles of jewellery, are occasioned by its superabundant flow. Those which are most lighly valued are found within and around the fleshy part of the adductor muscle, arising from disease or irritation. The proprictors of Pearl Fisheries are said to preserve these animals alive, for the sake of irritating them by the introduction of a stick or other sharp instrument, producing thereby a disorganization of the secreting gland, which causes the pearly nacre to accumulate in little pea-like balls in different parts of the body.

\section{Reproduction and Habits.}

The reproductive system of the Mollusca is in some viviparous, in others oviparous; and every knd has its allotted period and uniformity of growth. The shell in embryo, emerging either from the parent directly or from the egg, increases by the gradual deposition of mucus from the mantle in such varieties of form as are suitable to the habits and destiny of the animal. In the Cephalopods, as in the Nuutilus, it assumes a discoidal growth, coiling upon itself on a plane with the point of the spire; in the Gastropods it either revolves obliquely round an axis in the form of an enlarging spiral, as in the Turbo, or it takes a simple conical structure of which the Patella and the Dentalium may be regarded as the extreme forms; in the Pteropods it presents the shape of a depressed sphere, as in the Hyalaa, or of a cylinder, as in the Cuvieria; whilst in the Bivalves (Lamellibranchiates and Brachiopods) the testaccous matter is deposited on a flat, simply convex, or concave surface, as in different species of Pecten, most of which modifications of structure are induced by some corresponding economy in the habits and organization of the sabjects. Some shells, such as the Cyjrea, Mugilus, Pterocera and a few others, present different appearances at different stages of growth.

'The habits of the Molluscr are extremely varied and curious. In the sea they are found dwelling in zones of different depths, cither free or attached to foreign substances. About the shore, and at the depth of a few fathoms, where they are most prolific, they are found in mud, among simd and gravel, 
on coral reefs, under stones at low water, in the crevices of rocks, adhering to sea-weeds and other bodies, or imbedded in wood, coral, or limestone rocks. In ponds and marshes they are of a dull and stagnant nuture, and live either floating on the surface or attached to weeds. In rivers they flut up and down with the tile, or allere to plants growing on the banks. Ant on hills and in forests they live upon the branches of trees, or creep about the roots of shrubs and amongst the decared and fillen leares scattereil on the earth. The Mollusea, therefore, live both in and out of water; they swim, dive, float, bore, leap, climb, prey upon each other, and appear indeed to possess habits amalogous in some way or other to all that have been noticed in the higher orders of animals, except that of flying.

One of the most remarkable features in the matural history of the Mollusea is the solvent property of their juices. By little or no expenditure of muscular power they are enabled to effect grat changes in their condition. The Curey, after haring arrived at maturity, has still the porrer of dissolving a great portion of its shell, and renewing it. The Photules pierce the hartest limestone rocks, and increase in bulk without any apparent terebrating force, being found with the most delicate carring of their shell uminjured. Indentures are also produced by Shrils in limestone walls, whilst in a state of quiescence. Wany naturalists still adhere to the opinion that the perforations of shells are due to some mechanical action, some rotatory or oscillatory attrition; and Professor Oren attributes the formation of these carities to the action of constant currents of water romel the sledls, produced by minute ribratile cilia or hars, covering certain parts of the animal, which are in a constant state of activity in attracting the water necessary to its natural existence*. That there may be a constant current of water Howing around these imbedded mollushs for the promotion of vitility and nourishment is highly probuble, but the extraordinary progress which is made, with so much apparent ease, into the harlest substances, could not be accomplished without the collateral agency of some powerful solvent. The Mollusca, as already shown in speaking of the Courey, possess extraordinary powers of partially dissolving their own shells; the inner spiral partitions of a Cone in an early stage of growth are thick and solid, but in an adult specimen they are mostly absorbed to a degree of temuity which would not have given sufficient support to the primitive structure. In the varicose genera of Gastropods, such as ILurer, the mollusk has the power of removing any portion of the varices presenting an obstacle to its revolution of growth. In the Murex crimutus, for example, this mole of operation may be traced, by observing, on the left side of the aperture, the base of a spine which has been removed for the purpose of paving the boundary of the aperture with the usual coating of enamel.

* Elerenth Report of the Meeting of the British Association for the Adrancement of Science. 
SYSTEMATTC ARRANGEMEN'T.

\section{Sub-kingdom MOLLUSCA.}

At the commencement of the Molluscous series we have a group of active voracious animals, the Cephalopods*, whose physiological condition is not much inferior to the Fishes; and whose history is of especial interest, on account of their being the living representatives of a gigantic fossil race, the Ammonites, \&c., belonging to an incalculably remote period of the world's history. They are all marine, inlabitants of deep water, and only a limited number produce a shell of any particular substance. The head and body have the appearance of an oblong bag, the upper portion of which is crowned with a number of arms or tentacles covered with suckers, and, as their name indicates, they walk with the head downwards. We now descend in the scale of organization to an extremely numerous class, the Gastropods $†$ whose habits are of a more sluggish character, and whose powers of calcification are freely and multifariously exercised. They have a distinctly formed head and eyes, and, as their name indicates, acquire motion by the dilatation and contruction of an expanded gastric disc. They are marine, lacustral, and terrestrial; and all are locomotive. The next group in the order of arrangement is that of the Pteropods $\neq$, a limited class of small twilight deep-water swimmers, which obtain their powers of locomotion, as their name indicates, by the aid of a pair of wing-like fins; these only produce a small brittle glass-like shell. The next class in the descending order is that of the Lamellibranchiates $\$$, an extensive tribe whose mantle is divided into two lobes, each of which produces a separate piece of shell connected together by a horny ligament. None of this group have any head, and a large proportion of them are incapable of motion. The last of the Molluscous series, the Braclioporls | have also a shell of two distiuct pieces and are destitute of any head. Their peculiarity consists in being furnished with a pair of spiral arms, and they are differently placed within the shell. All live attached to foreign bodies.

\footnotetext{
* From $\kappa \epsilon \phi a \lambda \dot{~(k e p h a l e) ~ h e a d, ~ a n d ~ \pi o u ̂ s ~(p o u s) ~ f o o t . ~}$

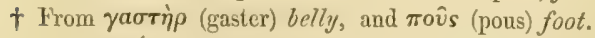

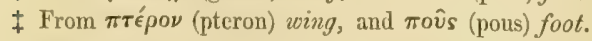

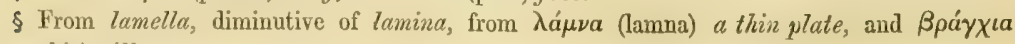
(bragchia) gills.

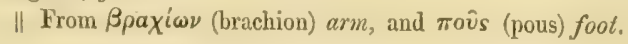




\section{Class 1. CEPHALOPODA.}

Animal ; abdominal portion of the bodly enveloped in an ample baglike mantle, at the opsening of which is the head with two conspicuous eyes and a pair of horny mandibles, the whole being crowned with arms and tentacles. Branclice two or four in number. Body furnished either with fins or with a shell. Shell; an involuted spire, open, or chankered.

The Cephialopods or Head-walking mollusks, so called from their manner of crawling upon their arms and tentacles with the head dowuwards, present an interesting link of affinity between the vertebrate and invertebrate divisions of the Animal Kingdom, between the Fishes on one side, and the operculated Gastropods on the other. Like the former, they have an internal cartilaginous skeleton, and by the aid of a caudal and pair of lateral fins, are endowed with great powers of locomotion; like the latter, they possess the faculty of secreting a testaceons mucus, and, unprovided with fins, obtain their subaqueous powers of flight by the use of a calcareous apparatus consisting of an involuted shell.

The body presents exactly the appearance of an oblong bag crowned with arms and tentacles, provided with a number of suckers, with which they enlace their prey ; the suckers acting like cupping-glasses. The head at the opening of the bag is furnished with a strong pair of horny mandibles like the beak of a parrot, and on each side is a large conspicuous eye endowed with a strong power of vision. The sexes are separate, and in one species, the Argonant, the fomale has the faculty of sccreting a light papyraceous shell for the preservation of her eggs. They are most formidable enemies of the fishes; their hard beaked mandibles are situated at the summit of the body, and by rising under a fish with their arms and tentacles uppermost, they are enabled to enlace and seize it in a moment. The tentacles in some instances are of immense length, and the animal thows them out like a hunting-noose to entangle its prey.*

We find mention of these remarkable animals in the earliest records of natural history, they were described by Aristotle, and have been the theme

* "Those alone," says Mr. Owen, "who have witnessed the persevering activity, power, and velocity of motion exercised by the Octopus, when engaged in its destructive practices amongst a shoal of fishes, and who have seen it with its beak buried in the flesh of a victim held fast in the irresistible embrace of its numerous arms, in an instant simultaneously dissolve the attachment of its thousand suckers, and disengaging itself from its prey, dart like an arrow from the net that has been cautiously moved towards it for its capture, can form an adequate idea of the acnteness of visual perception and powers of action with which this singular and unshapely Cephalopod is endowed." - Trans, Zool. Soc. vol. ii. 1838. 
of naturalists and poets in all ages. Little was, however, known of their immediate relation with the testaceous mollusks until the appearance, during the list century, of the living Nautilus; the discovery of this well-known and remarkable shell with the soft parts was hailed with peculiar interest by the scientific world, because it opened a clue to the history of those extraordinary concamerated fossils which are found imbedded in the crust of our globe. The comnection between this Cephalopod and its chambered engine, at once demonstrated that the hideous Calanary and Cuttle Fish are the living types of the lost race of Ammonites, Belemnites, Scaphites, Turrilites, and others, whose many-chambered shells remain to us, in a fossil state, in such abundance and variety of forms.

Some of the naked Cephalopods afford a transition between the two kinds by the formation of an internal rudimentary shell; the Cuttle Fish (Sepia) produces an oval plate; the Calamary (Loligo) a long horny shell like a quill-pen, and the Onychotenthis a thin oblong shell like a three-edged sword. The more highly organized, finned, Cephalopods naturally enjoy much more rapid porrers of locomotion than those encumbered with a shell, but are less adapted to dwelling in very deep water. The Sepia is less protected against the attacks of enemies, but it is on the other hand provided with an ingenious mode of self-defence which the well-armed Nautilus does not possess. In the interior of the body is a small bag in which an intense black inky fluid is generated, and the animal has the faculty of discharging it under any alarm for the purpose of darkening the surrounding water. It is thus enabled to escape the vigilance of its pursuers by darting off in an opposite direction; and it is said to baffle its enemies by changing colour like the chameleon. The paint Sepia, so well known to artists, derives its name from the Cuttle Fish (Sepia); and the celebrated Chinese painting-ink is entirely made from the war-fluid of the Cephalopod. It is a curious feature, too, in the economy of these mollusks that the Nautilus with its protective shell should have no ink-bag, whilst the Belemnite whose shell is enveloped by the mantle is provided with one; a modification even ensues in the ink-bags of the shell-less kinds; those which wander defenceless on the bosom of the ocean laving a more powerful and intense discharge of ink than those of more solitary habits which seek refuge in the cavities of rocks.

If any testimony were wanting beyond the only two living witnesses, the Nautilus and the Spirula, to establish the cephalopodic nature of the great fossil Ammonites and their multifarious congeners, we have it in the recent discovery of the soft parts of the Belemnite, an animal long since extinct. $\Lambda$ specinen of Belemnite has been lately discovered in the Oxford-clay formation, a stratum of very ancient date, with not only the ink-bag, but the muscular mantle, the hearl, and its crown of arms, all preserved in connection with the Belemnitic shell.* It happened to be the peculiar property

* Owen, IItunterian Lectures, 1844. 
of the earth in which this Cephalopod was imbedded to favour the preservation of the soft parts; yet, from the very nature of the deposit in which it was found, it must have become imbedded during a period of our planet's existence long antecedent to all human history and tradition.

The fossil shells of the chambered Cephalopods, of which the Nautilus and Spirula are the solitary living remnants, are so peculiarly adapted to dwelling in very deep water, that they seem to tell, by their very construction, of an age in which marine must liave greatly more preponderated over terrestrial space than at present; as if, indeed, they had lived with the gigantic Saurians in the midst of the waters, "before the progressive course of the world, as we now see it, took its first departure" *.

An extensive tribe of very minute chambered bodies called the Foraninifera was referred to this class until very recently, on account of the relation which they were thought to exhibit with the Nautilus shell; and the structure of the Spirula, on its discovery by Pèron and Lesueur, was regarded as an undeniable proof of their cephalopodic nature. M. D’Orbigny investigated their extraordinary varieties of formation with the most patient ingenuity ; and divided them into upwards of fifty genera. " $\Lambda$ important service has been rendered to science by the discovery of the Spirula," said Lamarck, and M. Deshayes, amongst others, exclaimed, "it is without contradiction one of the most important facts with which science has been enriched." It has, however, been fully demonstrated by M. Dujardin, on the shores of the Mediterrariean, that these many-shaped microscopic bodies are nothing more than the cells of an inferior group of Zoophytes called Rhizopods. $\dagger$

The class of Cephalopods is divided by Mr. Owen and M. Deshayes into two orders, according to the number of their branchix or gills ; one group, in which the Argonaut and Spirula occur, having only one pair of breathing organs, Dibranchiata $\ddagger$, the other of which the Nautilus is the only living example having two pairs, Tetrabranchiata $\S$. I shall not, however, avail myself of this arrangement, bccause a difference in the number of the branchir seems scarcely of sufficient importance to warrant the association of the Spirula with the Argonaut, separate from the Nautilus. Lamarck associated the Spirula with the Nautilus, separate from the Argonaut, by reason of their many-chambered shells, but a subsequent investigation of the soft parts has shown that arrangement to be still more open to objection. Are not these mollusks sufficiently distinct to constitute the types of three respective Orders? The Argonaut has eight arms, each having two rows of suckers, the shell being simply involuted and not chambered;-the Spirula lias eight short arms, with minute promiscuous suckers, and two tentacles with a club at the end, the shell being involuted, tubular, chambered, and

* Whewell, Hist. Induct. Sci.

† Two-gilled.
† Deshayes, Anim. sans vert., vol. xi. p. 177.

$\S$ Four-gilled. 
cuclosed within the lower part of the mantle;-the Nautilus has no arns, but a mass of some thirty or forty sheathed tentacles, a hood or covering, an aditional pair of gills, and a chambered shell with the whorls involuted one upon the other, containing the animal in its outer porch. I proceed at once, therefore, to the consideration of them as genera.

Argonauta. Spirula. Nautilus.

\section{Genus 1. ARGONAUTA, Linncus.}

Animal ; body subglobose, crowned with eight long arms, each having two rows of suckers, the two front ams furnished with minute secretive vessels and developed at the extremity into an elastic membranous web. Two branchice.

Shell; very thin, elastic and permeable to light, boat-shaped, not chambered, stightly convoluted into a discoid spire, which is double-keeled and partially immersed within the aperture; keels more or less tuberculated.

The Paper Nautilus and the Pearly Nautilus Shells, thongh both of cephalopodic origin, are of very different composition and design. The Pearly Nautilus is a shell of rather elaborate structure, presenting a formidable protection to the soft parts, partitioned off into chambers by the aid of which a vacuum is produced of sufficient buoyancy to sustain the great pressure of water to which the animal is exposed in its deep region of habitation. The Paper Nautilus, or Argonaut, is merely a light elastic case, constructed by the female of a naked Cephalopod, for the preservation of her eggs; a sexual provision subservient to the generative economy. No Argonaut shell has been discovered with a male inhabitant, although many have been taken in the Mediterranean with the female, in company with the well-known octopod of the Neapolitan market.

Assuming the Argonant to be really the mate of the Octopus, I scarcely know a more beautiful adaptation of means to an end than is to be found in this lideous-looking animal. The two front arms with its suckers are furnished with minute secretive glands and each extremity is modified into an expansile membranous web, endowed with a feeble power of calcification, similar to that in the mantle of other mollusks. They are capable of very considerable expansion, and deposit at thin wavy layer of shell matter forming a symmetrical boat or car, the discoid portion of which serves as a receptacle for the eggos. According to the observations of M. Rang, who relates the circumstance of his having seen several living $\Lambda$ rgonauts whilst rowing in a hoat in the Port of Algirers, the velamentous arms are extended 
to the top of the keel, so as to form a bridge * over the cavity which contains the eggs, the suckers corresponding to the tubercles, with the membranes expanded over the shell and the arms floating in a horizontal mass, as represented in Plate $B$. He describes the Argonaut as obtaining its progress through the element, shell foremost, not by any exertion of the arms, but by the successive injection and ejection of water in and out of the branchial cavity, the shell being firmly sustained within the embrace of the velamentous membranes.

The Argonaut shell, it may be observed, is not moulded on the body, but is secreted from without, with little or no attachment to the animal; and, on this account, it was a long time before naturalists could bring their minds to believe that the animal usually found in this shell was any other than a parasite; a naked octopod which took up its dwelling, like the Crabs, in this particular hind of shell, of which the fabricator and lawful owner had escaped detection. The matter has, however, been entirely set at rest by the observations of M. Rang, above quoted, and by the praiseworthy exertions of a lady, Madame Jeanette Power, resident at the port of Messina. She captured a number of Argonauts on the coast, and, keeping them alive in a large cistern, performed such a course of experiments as left no doubt of their relationship. It was noticed, for example, that the animal, exactly at the moment of sexual stimulus, withdrew its body from the discoid portion of the shell which it had hitherto filled, and there deposited its eggs; - that in twenty-five days after oviposition the young Argonaut came forth from the egg, a naked octopod:- and that in twelve days more the two front arms became dilated at the extremity into a pair of membranous webs, and commenced forming a thin filmy shell.

These experiments were not, however, conducted without great perseverance on account of the difficulty of preserving the animals alive. The cephalopodic nature of the Argonaut has been so fully established by the enterprising researches of Marlame Power, that it is quite unnecessary to repeat the numerous arguments that have been since adduced in support of her conclusions. The most remarkable is that recently put forth by $\mathbf{M}$. Deshayes, and derives additional interest from the circumstance of that illustrious naturalist, together with M. De Blainville, having been for more than fifteen years a supporter of the parasitic theory. "I have found," says M. Deshayes, "a special system of secretion throughout the whole of the anterior portion of the brachial membranes," and he goes on to relate that the shell, upon being subject to a chemical analysis, proves to be composed of two distinct laminæ, different from that of the Gastropods; and that the calcareous portion being removed by acid, the parenchymatous residuum

* La partie inférieure des deux grands bras, bien tendue, formait comme un pont sur la cavité laissée entre le dos du mollusque et la portion rentrante de la spire ou flottait l'extrémité d'une grappe d'wufs." - liang, Documents pour servir à l'hist. nat. des Céphalopodes, p. 21. 
consists of a number of vesicles, such as are presented in the microscopic structure of the Cuttle-bone, agreeing both in size and number with the minute organs of secretion dispersed throughout the calcifying membranes*.

The membranous webs are not, therefore, expanded aloft as sails to catch the breeze, as represented, not only by Pope $†$ and Byron $\neq$, but by Cuvier $\$$; I camnot, indeed, learn upon what authority the animal has ever been seen to uplift its membranes at all $\|$; on the contrary, the structure of these pseudo-sails has been shown to be incompatible with the notion $\%$. The Rev. L. B. Larking, a most enthusiastic lover of natural history, to whom my thanks are due for much valuable information on the habits and economy of this animal, happened to be on a visit at Messina some two or three years since during a tempestuous season, peculiarly favourable to the observation of the deep-water inhabitants of the ocean. In the space of a few months he collected more than twelve hundred Argonaut shells of all sizes, many of which with the animals preserved in spirits I have had the pleasure of examining. He never saw one floating on the sea; they were thrown up from deep water, and such as retained the animals were brought to him alive in pails. The velamentous arms were not stretched over the keel of the shell, as described by M. Rang, but were merely expanded, from fright probably, through the nick on each side; the animals protruded considerably from their shell and endeavoured to make their escape by performing a

* Animaux sans vertèbres, vol. xi. p. 354 .

+ "For thus to man the voice of Nature spake,

Go, from the creatures thy instruction take,

Learn of the little Nautilus to sail,

Spread the thin oar, and catch the driving gale."

‡"The tender Nautilus who steers his prow,

The sea-born sailor of this shell-canoe,

The Ocean-Mab, the fairy of the sea

Seems far more fragile, and, alas, more free;

$\mathrm{Hc}$, when the lightning-winged tornadoes sweep

The surf, is free, his post is in the deep,

And triumphs o'er the armadas of mankind,

Which shake the world, yet crumble in the wind."

$\S$ Quand la mer est calme on en voit des troupes naviguer à la surface, employant six de leurs tentacules au lieu de rames, et relevant, dit-on, les deux qui sont elargis pour en faire des voiles; si les vagues s'agitent ou qu'il paraisse quelque danger, l'argonante retire tous ses bras dans sa coquille, s'y concentre et redescend au fond de l'eau." - Cuvier, Le Règne Animal, nouv. edit, 1830. p. 13.

II Ce que l'on a débité depuis Aristote, mais surtout dans ces deniers temps, sur la manœvre habile du poulpe de l'Argonaute voguant à l'aide de voiles et de rames à la surface de l'eau, est faux. Nous le déclarons, nous n'avons rien $\mathrm{vu}$, dans les habitudes et les manovres de ces animaux, qui resemblât au choses qui en ont été dites, véritables fables qui n'ont été conservès, chez quełques auteurs, que par leur amour du marveilleux.-Rang, Doc. Nat. Hist. Ceph. p. 18 and 14.

If "These membranes have been described by naturalists and poets, from Aristotle and Callimachus down to Cuvier and Byron, as serving the office of sails; the animal being supposed to lave the power of rigidly extending the soft fleshy arms which support the membranes, and maintaining the latter tensely outstretched to meet the breeze. It is scarcely necessary to observe, that the structure of the parts in question is incompatible with this hypothesis of the use of the vela in navigating the frail boat of the Argonaut. It has been ascertained, indeed, by direct observation, that these vela, or xather velamenta, have not only a rclation of co-existence, but one of direct physiologienl import to the development of the shell, serving as the organs both of secreting and of retaining this part."-Oven, Observations on the Argonout. 
constant succession of muscular jerks, driving the ked of the shell with great violence against the side of the pail. They rarely lived more than a day or two, and by shaking them out of the shell they died in a few hours.

From the delightful intercourse and correspondence which I have enjoyed with my excellent friend on the subject of this vexata animalia, I should suppose the Argonaut to be an animal exceedingly sensitive of danger ; that under any alarm the velamentous arms are partially, if not altogether, withdrawn through the lateral nicks of the shell, and that under these circumstances it has great difficulty in maintaining its attacliment. It has, moreover, been established beyond the possibility of contradiction, that the animal being disengaged from its shell has not the power of re-entering it; and that being liberated, it languishes and dies in the course of a few hours.

The geographical distribution of the Argonaut is confined, as far as we know at present, to the old world; the $A$. argo is an inhabitant chiefly of the Mediterranean, and the A.tuberculosa of the Cape of Good Hope, New Holland, and the Molluccas. I have not seen the animal of the latter species; it was, however, figured more than a hundred years ago by Rumphius*, and Dr. Hooker, the learned author of the 'Flora Antarctica', informs me that several living specimens were seen during the Antarctic Expedition off the Cape of Good Hope.

Argonauta ARgo. Plate $A$.-View of the animal having relaxed its prehensile embrace of the shell and about to die, showing the eight arms with two rows of suckers on each, the two front of which are represented with the membranous webs contracting, to the left; the mouth and horny mandibles, in the centre; and the funnel or organ of secretion, to the right; $a$, a sucker, enlarged. From a specimen taken alive at Messina by the Rev. L. B. Larking.

Plate B.-View of the animal in full health and vigour under water, showing the manner in which it swims with the shell, keel foremost, held within the embrace of its velamentous arms. From the figure of a specimen observed at Algiers by $M$. Rang, slightly altered from observations made by the Rev. L. B. Larking at Messina.

\section{Species. $\dagger$}
1. argo, Lim.
3. haustrum, E. Méth.
5. raricosta, Blainv.
2. cymbium, Linn.
4. nitida, Lam.
6. tuberculosa, Lam.

* Thesaurus imaginum, \&c., pl. xviii. f. 1 to 3. The Hague, 1739.

$\uparrow$ For references to where the species throughout the work are described and figured, syno. nymes, \&c., see 'The Conchologist's Nomenclator' by Agues Catlow. 


\section{Genus 2. SPIRULA, Lamarck.}

Animal; bodly contained in an oblong mantle, entirely free at the opening, and terminating at the edge in three short festooned processes, two behind, between which the fumel protrudes, and one in front; lower half of the mantle enclosing a tubulur shell convoluting over towards the fiont, with the narrow portion at the back; base of the mantle furnished underneath with a dark leathery gland, having a round cavity or orifice in the centre and a short semicircular fin on either side; head prominently rising out of the opening of the mantle, entirely free from it, crovned with eight short acuminated arms and two rather long tentacles; arms promiscuously furmished on the inner surface with minute gramular suckers; tentacles terminated by a small rounded indented club.

Shell; a thin transparent diminishing tube comvoluted into a discoid spire of which the whorls are not contiguous, and partitioned into chambers by concave septa, with a contimuous siphon passing through the inner side.

The history of the Spirula is one of especial interest from the circumstance of its shell, as in the case of the Nautilus, having been collected in great abundance long antecedent to any discovery of the soft parts. The shell was figured during the latter part of the seventeenth century by our countryman Lister, but we find no vestiges of the animal until the appearance in Paris of a somewhat mutilated specinen, collected by an eminent French voyager, M. Pèron. In M. Pèron's example of the Spirula the tentacles were broken off to about the length of the surrounding arms, but it was sufficiently perfect in other respects to assist Lamarck in establishing the cephalopodic relation which the chambered construction of its shell had suggested with the Nautilus. An important difference, however, presented itself in the relative position of the animal and its shell as compared with the Nautilus. Instead of the lower portion of the body being capable of fitting into an aperture or outer chamber, as Rumphius' figure of the Nautilus indicated by its size and the appearance of a ligament fitting to the siphonic tube, it was found to contain the shell, or chief portion of it, within, - a decapodous Cephalopod having the well-known little spiral shell enflanked within the lower part of the mantle. No other eximple of the Spirulit presented itsclf for upwards of thirty years, when a 
decapitated specimen was brought to Paris by M. M. Robert and Léclincher, which enabled M. De Blainville to declare, in addition to the observations of Lamarck, that the animal has a pair of terminal fins, and that the branchial cavity contains only one pair of gills.* Another specimen was brought home by Mr. Cranch, in the Congo Expedition, still more mutilated; indeed, Mr. Gray informs us that it had only a fragment of the mantle remaining attached to the shell, but sufficient to show that the microscopic structure of the skin is similar to that of the Cuttle-fish. Nothing is added to the foregoing account in the eleventh volume of M. Deshayes' edition of the 'Animaux sans vertèbres', recently published in Paris; and it is, therefore, with peculiar satisfaction that I am cnabled, through the kindness of Mr. Cuming, to present my readers with the description of a magnificent specimen, now before me, perfect in all its parts except in the termination of one of the tentacles; and considerably larger than that found floating on the sea by M. Pèron, represented in the Encyclopédie Méthodique. Mr. Cuning's specimen, figured in plate $A$, was obtained about a twelvemonth since in New Zealand by an intelligent traveller and lover of natural history, Mr. Percy Earl; he was standing one day on the beach at Port Nicholson when the animal was washed ashore in his presence, and he innmediately secured it and put it in spirits. A notice of it was published on its arrival by Mr. Gray in the 'Ammals of Natural History', for April, 1845.

This interesting little Cephalopod partakes in very slight degree of the character of the proximate gencra. It has the same number of arms as the Argonaut, but there are two tentacles in addition as in the Cuttle-fish, about five or six times the length of the arms, and terminated by a sinall rounded indented club. The suckers are not arranged in a double row, as in the Argonaut, but are sprinkled in a somewhat irregular manner over the inner surface of the arms; they are, moreover, exceedingly sinall, and have more the appearance of a sprinkling of course sand. Like the Nautilus the Spirula has a chambered siphonated shell, but instead of it being external and serving as a protective shield to the soft parts, it is intermal, imbedded within the lower part of the mantle, and the siphon instead of passing through the centre of the chambers, is on the inner side. It is somewhat difficult, under these circunstances, to account for the shell being found in such abundancet, whilst the animal has so long evaded the pursuit of naturalists. The shell is not dependent on the attachment of a muscle as in the Nautilus, nor on the prehensile embrace of a pair of arms as in the Lrgonaut; the soft parts must apparently decompose before the shell can be

* Annales francaises et ètrangères d'Anatomie et de Physiologie pour l'annèe 1837, rol.1. 1.369.

+ Dr. Hooker, the enterprising Botanist of the Antaretic Expedition, informs me that at Paroah Bay, New Zealand, he saw thousands of the Spirula shell seattered on the shore; and M. Menke describes it as being frequent on the coast of New IIolland. 
released. In the specimen before me, the shell is exposed to view on each side as represented in the plate; but I quite agree with Mr. Gray, in believing that it is entirely concealed during the life of the animal; from the ragged edges of the skin it has all the appearance of having contracted and burst, rither in drying, or from its contact with the spirits in which it was plunged.

In perusing the Menoirs above alluded to of M. De Blainville, in 1837, and Mr. Gray, in 1S45, it may be observed that the second proposition established by the former in reference to the Spirula, is, that it has a pair of terminal lateral fins " $2^{\circ}$ il a une paire de nageoires laterales et tout-àfait termimales"; whilst the latter author affirms on the other hand "it differs from the Cuttle-fish in being entirely destitute of any fins." The terminal fins are so much contracted in this specimen that $\mathrm{Mr}$. Gray appears to have overlooked them; they are clearly definable, one at each lateral extremity, on either side of the terminal gland, so that I am fully able to confirm the observation made by M. De Blainville.

The use and comnection between the shell of Spirula and the soft parts still remain to be explained*; ${ }^{*}$ a curious vignette is given by Martini, Conch. (al), vol. i. p. 260, representing a fossil slab, in which the shell is elongated into a straight tube, but nothing certain can be ascertained until the animal is fairly dissected. At present Mr. Cuming is desirous of preserving the specimen under consideration entire, fully anticipating that with the instructions forwarded to some gentlemen in New Zealand, it will not be long before others are obtained.

Spirula Peronir. Plate A.-Fig. a, Back view of the animal showing the funnel protruding from the upper part of the mantle, the narrow end of the shell, with the terminal fins very much contracted. $\quad$. Side view showing the eye, rather obscured, and the lateral extent of the shell. $c$. Front view showing the broad end of the shell the terminal fins at the base, \&c. $d$. Under view of the basal gland. e. Back view of the shell, showing the siphon in the outer chamber. $f$. Lateral view of the shell. From a specimen in the possession of Mr. Cuming, collected by Mr. Percy Earl at Port Nicholson, New Zealand.

No other species known at present.

\footnotetext{
* Mr. Gray says on this head, in his Memoir in the 'Annals Nat. Hist.', "I am informed by 11. Clausen that he had several specimens of this animal alive, aud kept them some time in a vessel filled with sea-water, and that they had the power of ascending aud descending at pleasure." This assertion, though highly probable, should, however, be received with eaution; it seems difficult to imagine huw any one with the olservation displayed by M. Clausen, in lieeping several of the Spirulac alive in sea-water, could have failed to communicate specimens accompanied with that intelligeuce of their structure and habits which naturulists have so lung desired to receive.
} 


\section{Genus 3. NAUTILUS, Aristotle.}

Animal ; body forming an oblong mass a little compressed at the sides, the upper half enclosing the head and muscular portion, the lower half the soft and visceral portion, contained in a thin bag-litie mantle, rounded at the base in a manner adapted to the cavity of the shell, encircled by a hormy girdle by which it is attached to the inner wall of the shell, and terminating with a central tubular membranous process or artery which passes thronghont the siphon of the shell to the nuclens of the imnermost chiamber. Head at the upper opening of the manlle furmished (according to Owen **) with ninety tentacles, thirty-eight digital, four opthatmic, and forty-eight labial. No arms or suckers. Back of the mantle extending into a broad fold, falling back on the black imvoluted comexity of the shell. Front of the mantle with an opening through which passes the funnel or vent-tube consisting of a thin flestry substance the lateral edges of which overlap one another. Back of the head sumounted by a dense leathery lid or hood, which being hollow behind appears to fall backwards on the shell, and forwards over the head, closing in the tentacles and all the delicate structures after the manner of the operculum in the Gastropods. Four branctice. No ink-bladder.

Shell; orbicular, consisting of a compressed cone, convoluted, in symmetrical order, in close spiral whorls one over the other upon the same plane; more or less umbilicated externally at the axis of convolution. Three-fourths of the shell partitioned into chambers, about thirty-five to thirty-eight in number, by thin internally convex septa, in the centre of each of which is a short siphon or spouted appendage. Inner surface of the shell pearly, outer surface dull white, the involuted portion being painted with conspicuons chesmut-brown flames striking out of the umbilicus, which is sometimes overlaid with matter deposited by the hind fold of the mantle.

The Pearly Nautilus, as observed in treating of the Cephalapods generally, is an object of especial interest to the Conchologist, on account of it being 
the chief living remnant of a vast tribe of mollusks which must have existed at a very early period of the world's history ; and whose shells exhibit a structure peculiarly indicative of their being inhabitants of very deep water. The arrhitype of this fossil race is itself an animal of comparatively ancient date, for it is mentioned with brief but marvellous accuracy in the oldest record ritant on the subject of Natural IIistory. The first scientific Experlition of which we have any account, is one in which the philosopher Aristotle was sent by Alexander the Great, more than three humdred years before Christ, for the purpose of collecting subjects for a History of Animals. In this enterprise he appears to have met with both the Paper and the Pearly Nautili ; for in Scaliger's translation of the 'Historia Animalium', he says, after describing the different forms of naked Cephalopods which no doubt abounded in the Asiatic seas, "there are also two other kinds of Polypes which are in shells, the one (meaning the Paper Nautilus) has a shell which is not naturally adherent to it, it feeds very frequently near the land, and being cast by the waves on the sand, the shell slips, and it dies; but the other (the Pearly Nautilus) is in a shell in which it exists after the manner of a Snail, and outwardly extends its arms." * Nothing was added to this account during the dark ages that succeeded Aristotle, nor till some time after the revival of letters. No further information respecting the Nautilus was obtained until the discovery of a living specimen about the commencement of the eighteenth century, by a Dutch merchant and naturalist, resident at Amboyna, of the name of Rumphius. His drawing of the soft parts separated from the shellt was greatly valued; for more than a century elapsed before another specinen was found, although the shells were cast ashore in comparative abundance. This specimen, which was transmitted to Professor Oren of the Royal College of Surgeons, formed the subject of an elaborate Memoirt, and may be said to have been the first to confirm the history of this remarkable animal given more than 2000 years before by Aristotle.

The great Cuvier, who achieved so much for the natural history of the Animal Kingrdom, looked with anxious solicitude, no doubt, for the soft and living portion of the Nautilus, but the dessection was reserved, for a no less skilful operator of the present day. A female Nautilus was captured in 1.2.s by Mr. Cicorge Bemett in Marekini Bay, at the Island of Erromanga, New Hebrides; it was seen floating alive on the surface of the water, and was just about to sink when a sailor caught hold of it with a boat-hook. 'The right eye was almost, shattered in the struggle to secure it, and the shell bring much broken it was injudiciously removed. Two years unfortunately

* Aristot. de Animal, Scaliger, 1619.

+ Thesaurns imaginum, \&c., Pl. xvii. f. B.; The Hagne, 1739. Reproduced by Martini, Conch. Cab. vol. 1. p. 222. vign, Nurnberg, 1769.

$\ddagger$ Owen, Memoir on the Pearly Natutilus, 1832. 
chapsed before the soft parts, preserved in spirits, reached England; they were presented to Professor Owen; and although a minute portion of shell adhering to one of the lateral expansions of the belt was all that remained of the original framework, he succeeded by a train of analogy to establish the relation of the whole. His celebrated 'Memoir', which was the result of this investigation, appeared in 183:, and to the severe disappointment of the author, the illustrious Cuvier, who would have hailed the discovery with so much real delight, died only a few days before it issued from the press.

The soft parts of the Nautilus, of which, as in the case of the Argonaut, no male has been found, form a kind of oblong mass such as may be supposed capable of fitting into the porch or aperture of the well-known shell. The outer portion encloses a well-developed head furnished with a pair of strong homy mandibles, a number of sheathed tentacles, a pair of large eyes, and a number of delicate structures including the organs of hearing, smelling, \&c., and over all there is a capacious leathery hood which has been likenel by Professor Owen to the operculum in the Gastropods. The lower portion of the body contains the viscera from which proceed a fumel or venttube bencath the tentacles. The back part of the mantle is produced into a fold which overlaps the convexity of the shell, and at the lower extremity of the body is a central tubular membrane which passes into the siphonic aperture. The animal is attached to the shell by this flexible membrane which passes through all the whorls to the immer wall of the first-formed chamber, and by a broad muscular belt around the circumference of the abdominal sack. At the back of the hood is a concavity fitting to the convexity of the shell, so that it appears to have a hinge-like movement like the lid of a box, and is adapted to close over the tentacles and all the delicate parts of the head. There is no ink-bag in the Nautilus*. The growth of the shell may be supposed as follows:- the amimal in embryo constructs a simple hollow

* In mentioning the circumstance (p. 15) of the paint Sepia, so well known to artists, having derived its name from the Cuttle-fish (Sepia officinalis), I most incautiously gave currency to a popular error that the celebrated Chinese ink is manufactured from the ink-fluid of the Cephalopod. I am enabled, however, thus early, to correct this absurd notion, throngh the kindness of a most zealous patron of the natural sciences, John Reeves, Esq., F.R.S., \&c.; a gentleman whose life and energies have been so intimately associated with all that concerns the physical history of China, that I am sure the following extract from his communication will be read with much interest.

"With whom the idea originated that the China ink was made from the liquor of a Lotigo I do not know, it has been handed down from book to book for a very long time; but I am sure you would not intentionally continue the error, especially in such a work as you have commenced.

"The Jesuits, who were permitted free access in China during the reign of the Emperor Kang $\mathrm{He}$, and who then made many proselytes, had opportunities which none other had of acquiring an insight into the various manufactures; and the result of their enquiries is given in Du Halde's 'History of China,' fol., Paris, 1735.

"The English folio edition of this was published in two volumes, London, 1738 ; and, in the first volume, p. 370-2, you will find a full account of the manufacture of ink. I have the means of knowing from the manulacturers themselves that his account is correct; - that the basis is the soot from the smoke of oil-lamps, a sample of which I brought from China, and of which I send you a specimen.

"Clapham,
March 2nd, 1846."

"J.R. 
shell, forming the nucleus of a spiral coil, in which it produces a vacuum by the secretion of a transverse septum, in order to meet the increasing pressure of the surrounding element consequent on its increase of bulk. This operation is repeated between thirty and forty times during the growth of the animal by a periodical slipping of the muscular girdle from the shell, precaution having been first taken to secure itself to the first-formed chamber by the flexible tubular membrane which passes through a short spouted pipe or siphon in the centre of each. The marks of attachment of the girdle may be seen in every chamber. The Nautilus thus chambers in the vacated portion of the shell in order to assist its specific gravity under the different variations of pressure to which it is liable in its passage through the ocean. The natural position of the animal when crawling at the bottom of the ocean being, as in other Cephalopods, with the head downwards, the shell is uppermost and buoys it up, and the periodical slip of the muscle of attacliment most probably takes place when in this supine position. With every relaxation of the membrane and muscle the shell must naturally rise and coil upon itself; and I think the use which I here venture to assign to the membrane, the remains of which may be found in shells, extending throughout the entire length of the siphon, admits of very reasonable construction.

Little is knomn of the habits of the Nautilus beyond the circumstance of Mr. Bemnett's specimen having been seen floating alive on the water and preparing on alarm to descend, and that contained in the curious narrative of Rumphius quoted by Owen*. The accounts are, however, considered by

The following extracts relating to the manufacture of China Ink are from the work alluded to.

"The ink the Chinese use is made of lampblack, which they get by burning several sorts of matter, but chiefly pine-wood or oil. They mix perfumes with it, to correct the strong and disagreeable smell of the oil. They incorporate together these ingredients till they come to the consistence of a paste, which they put into divers wooden moulds. These moulds are well and variously wrought in order to print upon the paste what figures they please. The usual impressions are of men, dragons, birds, trees, flowers, and the like.

"The best ink is made at Whey chew, a town in the province Kyang nan. There are many things to be observed in the making of it, and it has several degrees of goodness; according to which it is dearer or cheaper.

"They put five or six lighted wicks in a vessel full of oil, and lay upon this vessel an iron cover made in the shape of a funnel, which must be set at a certain distance so as to receive all the smoke. When it has received enough they take it off, and with a goose's feather gently brush the bottom, letting the soot fall upon a dry shcet of strong paper; it is this which makes their fine and shining ink. When they have in this manner taken off the lampblack, they beat it in a mortar and mix with it some odoriferous water, with a thin size to unite the particles.

"We are assured that in the eity of Whey chew, where the ink is made which is most esteemed, the merchants have great numbers of little rooms, where they keep lighted lamps all day; and that every room is distinguished by the oil which is burnt in it, and consequently by the ink which is made therein."-DU HaLDE, History of China, fol. ed. 1738, vol. i. p. 370-1

* "When he thus floats on the water, he puts out his head and all his barbs (tentacles), and spreads them upon the water, with the poop (of the shell) above water; but at the bottom he creeps in the reverse position, with his boat above him, and with his head and barbs upon the gromu, making a tolerably quick progress. He lieeps himself chiefly upon the ground, creening sometimes also into the nets of the fishermen, but after a storm, as the weather becomes calm, they are scen in troops floating on the water, being driven up by the agitation of the waves. Whence one may infer, that they congregate in troops at the bottom. This sailing, howercr, is not of long continuance; for having taken in all their tentacles, they upset their boat and so return to tire bottom."-D'Amboinische liuriteit-linmer, p. 91. fol. Amsterdam, 1741. 
the same author sufficient to state that the animal "makes his way along the sand with a moderate degree of rapidity, with his house above him; and though in general dwelling in the deep, has the power of rising and floating on the surfice."* And M. Valenciennes considers that its motion in swimming may be attributed to the same force as that ascribed by M. Rang to the Argonat; namely the injection and ejection of water in and out of the branchial cavity. $\dagger$ It now only remains to be ascertained whether the different mutations of pressure which the Nautilus must have to sustain in its passage through the element, are not counteracted by the alternate production of vacua and introduction of water in the chambers of the shell. Certain it is that the Nautilus in its floating position has neither arms capable of rowing nor membranes adapted for sailing, as so prettily described by a poetical philosopher of the present day. $f$

Nautilus Ponpilius. Plate C.-Lower figure, lateral view of the shell. Upper figure, lateral section of the shell showing the chambers, siphou, and full extent of the animal; $a$, the funnel; $b$, the tentacles; $c$, the hood; $d$, the hind fold of the mantle. Reduced from Professor. Owen's figure of the specimen captured by Mr. Bennett in Marekini Bay.

\title{
Species.
}
1. Pompilius, Linn.
2. scrobiculator, Gray.
2. umbilicatus, Linn.

\begin{abstract}
* "In whatever degree the shell is developed in the Cephalopodous Mollusks, we find it invariably characterized by the symmetry so peculiar to the disposition aud general form of their soft parts: but the extent to which the Pearly Nautilus is covered by its shell, and its close attachment to it, indicated the affinity to the Gasteropods in too strong a manner to escape the penetration of Aristotle, who directly compares it in this respect to a snail; and the general resemblance must be sufficiently striking when, with his house above him and in the supine position, he makes his way along the sand with a moderate degree of rapidity."

"Respecting the economy of the fossil genera, we may infer from Nautilus that they were chiefly confined by the limitation of their locomotive faculties to creeping at the bottom of the sea, and that one of the offices assigned to them in the scheme of nature was to restrain within due limits the crustaceous and testaceous tribes around them. Granting them, indeed, the porver of rising and floating on the surface, yet their navigation was in all probability of a passive kind, or influenced only by the re-action of the respiratory currents when expelled by the funnel upon the surrounding medium; and at all events it can no longer be supposed to have been aided by the fabled sails and oars of the Argonaut."-Owen, Memoir on the Pearly Nautilus, p. 52-3.

† II nage avec facilité dans le sein des eaux en faisant sortir avec force la grand quantité d'eau contenue dans sa cavité branchiale.-VALENCrennes, Archives du Mruséum d'Hist. Nat., 1839.

‡ "The Nautilus and the Ammonite

Were launched in storm and strife;

Each sent to float, in its tiny boat,

On the wild, wild sea of life.

And each could swim on the ocean's brim, And anon, its sails could furl;

And sink to sleep in the great sea deep, In a palace all of pearl."

Richandson; Sletches in Prose and Verse.
\end{abstract}

Erratum. In speaking of the geographical distribution of the Argonaut at p.15, it is described as being confined, as far as we know at preseut, to the old world. Mr. Cuming has since informed me that he has received specimens of that genus from Valparaiso, Bahia, and Panama, as well as from Curacao, one of the Caribbeau Islands. 


\section{Crass 2. GASTEROPODA.}

Animal ; borly clongated, anterior extremity furmished with a more or less prominent head, posterior extremity mostly developed into an attenuating spiral, invested with a lubricons mantle, producing a shell of varied structure and solidity; head mostly furnished with tentacles, varying from two to six in number, with a pair of eyes situated at different parts of the tentacles; mouth furnished with hard parts, or with a flexible retractile trunk of various length, armed at the extremity with small teeth. Branchice respiring air or water, either concealed or exposed.

Shell; calcareous, in some instances hormy, cither simply conical, or convoluted into an enlarging spire, mostly enclosing the animal, but sometimes internal, or covering only a limited portion of it.

The Gastropods comprise that extensive series of mollusks which acquire motion by the alternate dilatation and contraction of a gastric or ventral disc. Their typical structure is that of a long drawn out conical mass, of which the attenuated portion, contained in an enlarging spiral shell, is occupied by the soft and visceral parts, whilst the broad extremity, protruding from the aperture of the shell, comprises the heal, mantle, nerves, muscles, gills, \&c., and also a broad fleshy muscular expansile disc, mostly attached to the neck, called the foot, by which they acquire motion.

By far the greater portion of the class are of this structure; those inhabiting a spiral shell are, indeed, necessarily so. In the spiral Gastropods, the abdominal portion of the mollusk is contained within the shell, whilst the fleshy disk, attached to the neck, is exserted for the purpose of locomotion; but in the non-spiral Gastropods, such as the Chitons, Limpets, and Slugs, the abdominal parts are all of a mass, and not separated from the disk. Lamarck confined the term Gasteropoda to the latter division; the former section he distinguished by the title of Trachelipoda* or neckmoving Mollusks, but the affinity between the Snail (IIelia) and the Slug (Limax) is of too intimate a character to allow of so important a separation.

The Gastropods are extremely numerous in species, and of considerable interest, both on account of their extraordinary varieties of form, colour, and sculpture, and of their curious diversity of habit. Most of them are marine, some are fluviatile, some dwell in lakes and stagnant pools, whilst in large proportion are terrestial, or arboreal; and as their breathing appa-

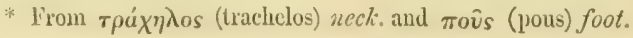


ratus is necessarily adapted to the different media they inhabit, the corresponding conditions of the respiratory organs, together with certain modifications in their arrangement, have been selected as characters for the primary distribution of the class into Orders; before speaking, however, of the systematic arrangement of the Gastropods, a brief account should be given of their structure and general economy.

The heal, as in the higher orders of animals, forms the anterior extremity of the body, and is mostly rounded and prominent. It is furnished with from two to six tentacles, or feelers, and the eyes, never exceeding two in number, are situated sometimes at the base of the tentacles, in some instances at the summit, and often at some intermediate part. The tentacles are rather sensitive to the touch, and in some genera the mollusk possesses the faculty of withdrawing them by inversion, an action which Lamarck describes as being accomplished by the aid of a nerve reaching internally to the summit.

The nervous system of the Gastropods is represented by three ranges of cords or ganglions, termed the cerebral, as relating to the head, the pallial, as relating to the mantle, and the branchial, as relating to the gills; the principal of these, the cerebral ganglions, seated in the head and vicinity of the osophagus, or gullet, and called on that account by M. Deshayes the œsophageal circle, was termed by Lamarck the brain; but their relation with that organ in the vertebrate animals is one of very remote analogy.

The respiratory apparatus of the class consists, in the water-breathing kinds, of two or more branchix or gills, sometimes exposed, but mostly concealed; in the air-breathing kinds it consists of a net-bag or lung; and in those which are amphibious it presents a modification of both.

As the breathing organs of the Gastropods are necessarily modified to the different media they respire, so are the mouth and alimentary organs adapted to the diversified nature of the food they devour. Most of the terrestrial kinds are herbivorous, feeding upon leaves; of the large proportion of marine species some few are fucivorous, feeding upon seed-weed, whilst the rest are carnivorous, devouring many of their own nature and other living organized matter, besides offal in all stages of putrifaction. The mouth of the herbivorous kind is furnished with a horny armature on the upper lip only; in the carnivorous species, the mouth is furnished with a rasping plate or tongue, or a pair of dentated jaws, or a flexible retractile trunk, susceptible of elongation or concealment within the body, the extremity of which is cleft and supplied with numerous small recurved tecth capable of considerable execution. 'The common Whelk of our market has a retractile trunk; and the circular hole which is sometimes found drilled in bivalve shells is supposed to be due to the agency of this destructive organ.

Of the muscles it is only necessary for the present purpose to speak of such as serve for the attachment of the shell. In the simple univalves, the 
muscle of adhesion sometimes encircles the back in the form of a horse-shoe, as in Siphlionaria, whilst in the cup-and-sancer Limpets (Calyptrea) it is attiched to the cup-shaped appendage by which that group is characterized. In the spiral Gastropods the shell is connected by a thin riband-like muscle which has its point of attachment on the axial pillar or columella; and it is by the elasticity of this muscle that the animal advances its head and foot and again retires within the last whorl. There are, however, instances in which the spiral Gastropod, desirous of evacuating a portion of its shell, has the power of sliding the attachment of the columellar muscle, without relaxing it, independent of the requirements of its increase of growtl, in a mauner similar to the periodical slipping of the muscular girdle in the growing Nautitus. In the Hetix decollatus and many species of Pupa, the early portion of the shell is allowed to fall away, and the whorls of occupation are roofed in by a new concentric layer; in many species of Melania, and other inhabitants of fresh and stagnant water, the apical extremity of the shell becomes eroded and consumed; whilst that singular tenant of the coral rock, the Magilus, fills up the evacuated portion of its shell, to a considerable extent, with solid testaceous matter; an operation which would produce an incumbrance incompatible with the locomotive faculties of a free agent. There is also an additional muscle in those species which are operculated for the purpose of drawing the operculum within the aperture.

The operculum is a shelly or horny plate adapted in most species to close over the soft parts when retracted within the shell; it is, however, often represented by merely a small thin horny plate, in no wise fitting the aperture of the shell, and not apparently answering any purpose in the life and economy of the mollusk. The variations in the growth and substance of the operculum, moreover, afford characters of very secondary importance; as we find it sometimes shelly, and sometimes horny, in the same natural group. The geuus Trochus, for example, offers some species with the former, some with the latter; and among the Cones and Tolutes the operculum, though a rudimentary one, is present in some species and not in others.

The Gastropods evince a very low degree of sensibility ; in many species the tentacles, and with the tentacles the eyes, and even some parts of the head are reproduced after amputation, provided there is no displacement of the ccrebral ganglious.* Some are also capable of suspending all signs of vitality for a very considerable period. I remember an instance of some Helices having been received from a distant locality and kept in a dry lumber box for two years in a state of torpor, from which they were fully released upou being placed on a moist fresh leaf. All the Gastropods exhibit great skill in the repair of any injuries done to their shell, and considerable cconomy is exercised in absorbing or smoothing down any spines or

* Baron Fèrussac states that he has seen the terrestrial Gastropods or Slugs allow their skins to be eaten by others, and in spite of large wounds thus produced show no sign of pain.-OWEN. 
irregularities that obstruct their progress of growth; they are, however, constantly liable to distortion, disease of the calcifying glands, and all " the numerous ills that flesh is heir to."

The seres in the highest order of Gastropods, (Pectinibranchiata) are scparate, male and female; the remainder are hermaplurodite, both sexes combined in the same individual. The oviparous species have various modes of producing their young. The Whelk (Buccinum undatum.) deposits her egos in masses of thin bladder-like capsules ; the Turbinella in a long chambered nidus, in each compartment of which are from twenty to thirty embryos completely calcified; and the Ianthina encloses her ova in a delicate film of albumen attached to her curious float.* In the early development of the Aplysia the shell is of a distinctly turbinated form, containing the embryo closed in by an operculum; a curious metamorphosis then ensues; the shell assumes an entirely internal position, which in the adult forms little more than a protective shicld over the branchix, a flattened or slightly convex horny plate, with only the remotest trace of its primitive nucleus. A somewhat similar phenomenon has also been noticed in the Tritonia and Doris, which, though destitute of any horny or testaceous parts, either external or internal, in the adult state, are provided in an early stage of their development with a delicate little horny nautiloid shell. The eggs of the fresh-water species mostly consist of a transparent mucust; and of the terrestrial species, the Helices deposit their eggs in the earth, whilst the arboreal Bulimi cement together a little nest of leaves for their beautifully white eggs, which are sometimes nearly as large as those of a pigeon.

In taking a general review of the habits of the Gastropols, many interesting phenomena present themselves to our contemplation. The greater portion of them live attached to masses of stone, in concealed situations, such as the under surfaces, and in cavities and crevices; also in coral sand and mud, not, however, imbedded in such a state of torpor generally as the acephalous or head-less tribes (the Bivalves), unless in the curious instance of the Magilus. It is the peculiar property of this mollusk to become the

* To this float the parent Ianthina commits her little progeny, and having securely fastened their several cradles or nursery cells, she detaches the float, which bears the ova to the surface, and sustains them where they may best receive the full influence of solar light and heat.-OwEN.

+ In relating some experiments made by M. Jacquemin on the development of the Planorbis, Professor Orren continues, "The rudiments of the head and foot are sufficiently obvious on the sixth day; the respiratory organs are formed on the sixth or eight day, according to the warmth of the weather. On the eighth day the characteristic tentacles begin to sprout from the rudimental head. On the tenth day all that part of the vitellus or embryo which is not occupied by the head, the foot, and the breathing organ, is covered by a thin and transparent pellicle, which is the rudiment of the shell. On the eleventh day one of the large central globules of the yolk begins to distinguish itself from the alimentary mass by feeble contractions and dilatations, of which about sixty may be counted in a minute; this is the heart. The mouth can now be discerned, and the small eye-specks appear like black granules at the base of the tentacula. On the twelfth day the embryo moves by its own contractions independently of the rotation produced by the cilia. On the thirteenth day acts of deglutition are discernible; the embryo swallows the remaining albumen, the anus is completed, and the genital organs begin to be formed. On the fourteenth day the young Planorbis ruptures by more violent contractions the chorion, and escapes into the water, protected by its own flexible shell."-Hunterian Lectures, 1844. 
fixed tenant of growing masses of white coral, but requiring at the same time to be in relation with the surrounding element, it alters its spiral plan of growth upon the increase of the coral, and pursues a nearly straight course, in order to keep pace with the advancing surface of its rocky bed. The Ianthina or Sea-Snail, is also an animal of peculiar habits, floating on the bosom of the ocean by means of a number of albuminous air-bladders attached to the foot, after the manner of a float; and the parasitic habit of the Stylifer, living on the juices of the Star-Fish, is curious.

The shell of the Gastropods is either of a spiral, or of a simple conical structure; the spiral series is by far the more numerous in species, but it does not include any of such weight or dimensions as the Giant Clam (Tridacna gigas) among the Bivalves. Neither among the fossil shells of the extinct species are there any so large as in the preceding class. The form of the non-spiral gastropods varies from the depressly flattened cone of the Unbrella to the extreme conical elevation of Dentalium; in one genus, Chiton, the shell consists of eight distinct pieces moving upon each other within a cartilaginous frame, like plate armour; and in other genera, such as Aplysia, the shell is merely represented by a concealed horny plate, deposited by an internal fold of the mantle. In this group is also contained an interesting series called Nuditranchiata, or naked-gilled mollusks, in which the gills are exposed in the most beautiful varieties of tufted and ramified structure along the back: these have no shell.* The Limpet tribe afford a curious phenomenon in the peculiarity of two of the genera, Lithedaphus and Hipponyx, depositing a shelly plate at their base of attachment.

In treating of the parts of the spiral univalve shell it may be observed, in the first place, that the typical structure, of which all the different generic forms are modifications, is that of an enlarging conical tube, winding obliquely from left to right (viewing the mollusk as moving forward from the observer) by reason, probably, of some peculiar winding tendency in the vital organs of the animal. The axis upon which the tube winds, is called the axial pillar or columella; every turn around this axis is called a whorl; and when the columella is hollow, it is said to be umbilicated. Among the terrestrial Gastropods the most simple plan of convolution is exhibited in the Cyclostoma gigantenm; for an elongated modification of this, the Pupa Ruschenbergiana may be quoted as a remarkible example, the diameter of the tube in this shell is very small, and the volutions are performed within a very limited area ; and there being as many as five and twenty whorls the shell assumes the form of a peculiarly attenuated cylinder. For a depressed modification of the univalve, the Caracolla parmula may be regarded as a most characteristic example; in this shell the spiral tube is so depressly flattened as to present the form of a slightly convex lens. In the

\footnotetext{
* Although the Nudibranchial Mollusks furnish no ornaments for the cabinet and do not cuter, therefore, into the category of animals treated of in this work, I canuot refrain from noticing Alder and IIancock's beautiful figures of them recently published by the Ray Society.
} 
marine tribes, the Turbo variabilis might be selected as a specimen of simple convolution, the elongated modification being represented by the Turritella or Terelira, and the depressed by Solarium or Rotella. The land species offer the most extreme modifications of depressed growth, because the visceral parts of the herbivorous tribes may very possibly be restrained within a nore limited area than the carnivorous kinds; they have no occasion for the armature of teeth and rasped plates required for the assimilation of animal food, nor is the digestive apparatus of so complicated a character.

The carnivorous tribes have no such limitation of growth as is found in the Caracolla, their range of habits furnishes them with nore vigour, and their calcifying energies are exercised in many instances to an excess which is truly astonishing. A ponderous massive shell is often found to be the production of an animal occupying but a very limited portion of it. The shells of the terrestrial species have no external ramifications and very little variety of sculpture, whilst those of the marine kinds are ornamented with ribs, tubercles, laminx, spines, and fronds. The first departure from the fluted Dentatium, or the smooth tube of Turitella, is presented in the Scalaria, where the lip of the aperture is reflexed in its earliest stage of development; the course of the tube proceeds with the reflexed margin remaining on its circumference; and this operation is continued at intervals until the shell and its inhabitant arrive at maturity. This is the simple plan upon which the ornamental structure of all shells is developed. To take a more complicated example, let us examine the growth of the Murex. Not only is there a periodical reflexion and thickening of the edge of the tube, which in this genus has an ovate or pyriform area, but certain calcifying filaments or processes are exserted from the edge of the mantle, capable of producing most elegantly formed spines and fronds. As soon as this architectural border is finished the filaments are withdrawn, and the tube pursues its regular growth until they are again exserted for a similar purpose. These borders, technically called carices, thus encircle the tube at intervals, and are supposed to indicate seasons of rest; the lip of the shell being probably thickened in this manner for protection during a period of relaxation. The varices are formed at various intervals; in Triton only two or three occur during the entire growth of the shell, in Ranella one is deposited on every half whorl, in such a manner as to range obliquely one under the other, and in Murex they occur three or more times on every whorl. In Harpa and other genera of the family Purpurifera, the entire shell is formed of a close succession of marginal borders like the varices of the Canalifera.

There are many varieties in the tubular growth of the shell besides those above enumerated; in the Cone, for example, the tube is of a longitudinally compressed form, winding upon itself almost on the same vertical plane, but as the different modifications of form and sculpture will be treated of under the different genera, it only remains to notice the varieties of the res- 
piratory organs selected to characterize the subdivision of the class into seven Orders, as follows:- the first group, Pectinibranchiata, have a pair of pectinated gills of the shape of a comb; the second, Pulmolranchiata, which includes the terrestrial and lacustral species perform the functions of respiration by a pulmoniferous net-bag; the third, Pleurolranchiata, are distinguished by the gills being situated on the right side only; the fourth, Cervicobranchiata, have their gills situated in a special cavity in the neck; in the fifth, Cyclobranchiata, the gills are placed in a circle round the edge of the body; in the sixth they are cirrous or hair-like; and in the Nucleolranchiata, which are the most aberrant form of the class and afford a link to that of the Pteropods, the branchix, together with the visceral mass, are concentrated within a nucleus protruding from the ventral part of the body which is almost wholly gelatinous. Numerous modifications of the breathing organs of minor importance have been selected for the distinction of orders ; those which have the gills ranged around the lower part of the body, between the disc and the mantle, have been associated under the term Inferolranchiata, those in which the gills and entire body are contained in a strictly tubular shell, Tubulibranchiaix, and those in which they are protected by a shield-like shell under that of Scutibranchiata; all these are, however, comprehended in the seven Orders here adopted.

\section{Order 1. PECTINIBRANCHIATA.}

\section{Branchiæ; pectinated, contained within a cavity in the upper part} of the neck, into which the water is sometimes conveyed by a siphon or siphonal appendage.

Having alrearly spoken of the nature and habits of the pectinibranchial Gastropods in treating of the class, I have only to remark under this head that the branchix or gills of the present order, which includes a very numerous series, are arranged for the most part in parallel lamine, like the tecth of a comb, and are contained within a cavity in the upper part of the neck. Some of the pectinibranchial tribe are carnivorous, and some are herbivorous; and the former are distinguished from the latter by a siphon or siphonal appendage passing out at the basal channel of the shell, for the purpose of conveying the water to the branchial cavity.

Camivora.

$\begin{array}{ll}\text { Convoluta } & \text { Alata } \\ \text { Columellata } & \text { Canalifera } \\ \text { Purpurifera } & \text { Parasitica }\end{array}$

Herbivora.

$\begin{array}{ll}\text { Turbinacea } & \text { Neritacea } \\ \text { Plicacea } & \text { Peristomata } \\ \text { Ianthinea } & \text { Melaniana }\end{array}$




\section{Family 1. CONVOLUTA.}

Shell; with the whorts convoluted upon nearly a vertical plane.

In this family is associated an interesting series in which the whorls of the shell are convoluted one over the other, mithout obliquely descending, so that the sutural extremity remains ahnost upon a plane with the top of the spire. It is grouped upon rather an artificial basis, because the Olives which exhibit a nearly similar arrangement of the whorls are referred by their affinities to the family Purpurifera. The Cones have likewise been removed to various situations in the natural order, Mr. Gray places them next to Pleurotoma, M. De Blainville in the immediate vicinity of Strombus, and M. Deshayes refers them to his family of Buccinida. The Cowrey with its enveloping mantle, is certainly very different in appearance from the Cone, in which the mantle is of very limited proportions; but the Ovulum and the Cowrey are very closely allied. The following are the genera referred to this family :-

$\begin{array}{lll}\text { Conus. } & \text { Terebellum. } & \text { Ovulum. } \\ \text { Cyprea. } & \text { Erato. }\end{array}$

\section{Genus 1. CONUS.}

Animal; disc oblong, rather thin, double-edged, oval behind, abruptly truncated in front; head obtusely cylindrical, with a rather short trunk; tentacles short and stout, with the eyes placed upon them at a distance of about one fourth of their length from the summit. Operculum very small, hormy, sometimes wanting.

Shell; conical, slightly emarginated at the base, spire sometimes flat and obtuse, sometimes sharply acuminated; aperture longitudinal, mostly narrow; lip simple.

The Cones constitute one of the most natural and best defined gencric groups throughout the class; they present a great similarity of structure, and the species are remarkable for the elaborate design and brilliancy of their colours. The differences of form consist chiefly in the depression or elevation of the spire, the attenuation or inflation of the whorls, and in their spiral edges being plain or coronated; there are, however, many striking variations, which though apparently of marked specific importance are yet common to different individuals of the same species. Some, for example, are found with the spire at one time plain, at another coronated; 
and many, in like manner, have the surface sometimes smooth and sometimes gramulated, but never punctured. Granulated specimens are invariably of smaller size than smooth examples of the same species; the same observation does not, however, hold good in reference to those which are coromated. The beautiful Admiral Cone (C. ammiralis) is found either smooth, or granulated, or coronated; and there are many species whose specific character is almost solely maintained, through different modifications of form, by the general affinity of their colour and markings. The $C$. magnes, on the contrary, is mostly variable in colour, yet its specific integrity is preserved throughout by the unity of design in its markings.

The Cones are mostly inlabitants of deep water, and nearly all are tropical; one or two are found as far north as the Mediterranean, but they essentially require a warmer region. Like all tropical fauna they present a most vivid display of colours, and the mechanism of their calcifying filaments must be of very exquisite workmanship. In order to produce the wondrous detail of pattem portrayed in the C.gloria-maris, or in the banded net-work of the $C$. ammiralis, which is scarcely discernible without the aid of a lens, the mollusk must be endored with an astonishing ingenuity of design; and for the simultaneous production of so many colours as are exhibited in the $C$. aurisiacus or imperialis, its molecular fluid must have many more sources of colouring matter than a weaver at his loom. Where, indeed, do we find so rich a brocade of gold as in the $C$. textile, or a web of such elaborate meshes as in the $C$. abbas or Fictoria?

The genus Conus is very numerous in species, and many of them, particularly the C. magus, omaria, venulatus, princeps, thalassiarchus, cedo-nulli, spectrum Mozambicus, Guinaicus, and one or two others, are extremely variable, both in form and colour; they may, nevertheless, be readily discriminated by attentive study.

\section{Species.}

1. abbas, Hwass. $\quad$ 14. ambiguus, Reeve.

2. abbreviatus, Nuttall. 15. ammiralis, Linn.

3. achatinus, Chemn. 16. anemone, Lam.

4. aculeiformis, Reeve. 17. aplustre, Reeve.

5. acuminatus, Hivass.

6. acutangulus, Chemn.

7. Adamsoni, Gray.

8. Adansoni, Lam.

9. æmulus, Reeve.

10. albimaculatus, Sow.

11. Algoensis, Sow.

12. amabilis, Lam.

13. Amadis, Martini.
18. araneosus, Hwass.

19. archiepiscopus, $H w$.

20. archon, Brod.

21. arcuatus, Brod.

22. arenatus, Hwass.

23. artoptus, Sow.

24. attenuatus, Reeve.

25. augur, Hwass.

26. aulicus, Iinn.
27. aurantius, Hwass.

28. auratus, Lam.

29. aureus, Hwass.

30. aurisiacus, Lim.

31. aurora, Lam.

32. australis, Chemn.

33. bæticus, Reeve.

34. balteatus, Sow.

35. Bandanus, Hwass.

36. Barbadensis, $H w$.

37. betulinus, Linn.

38. Broderipii, Reeve.

39. brunneus, Wood. 
40. bulbus, Reeve.

41. bullatus, Linn.

42. buxcus, Reeve.

43. Caledonicus, Hwass.

44. Californicus, Hinds.

45. cancellatus, Lam.

46. canonicus, Hwass.

47. capitaneus, Linn.

48. cardinalis, Hwass.

49. carinatus, Swain.

50. *castrensis, Gould.

51. castus, Reeve.

52. catus, Hwass.

53. cedo-nulli, Klein.

54. centurio, Born.

55. cervus, Lam.

56. Ceylanensis, Hwass.

57. characteristicus, $\mathrm{Ch}$.

58. cinereus, Hwass.

59. cingulatus, Lam.

60. classiarius, Hwass.

61. clavus, Linn.

62. Clerii, Reeve.

63. cocceus, Reeve.

64. colubrinus, Lam.

65. columba, Hwass.

66. concinnus, Brod.

67. concolor, Sow.

68. consors, Sow.

69. conspersus, Reeve.

70. crepusculum, Reeve.

71. crocatus, Lam.

72. cuneolus, Reeve.

73. cylindraceus, Brod.

74. daucus, Hwass.

75. Delessertianus, Recl.

76. Deshayesii, Reeve.

77. *discrepans, Sow.

78. *dispar, Sow.

79. distans, Hwass.

80. dux, Hwass.

81. eburneus, Hwass.

82. elongatus, Reeve.

83. emarginatus, Reeve.

84. episcopus, Lam.

85. epistomium, Reeve.

86. *eques, Lam.

87. erythræensis, Beck.
88. exaratus, Reeve.

89. fabula, Sovo.

90. figulinus, Linn.

91. flavescens, Gray.

92. flavidus, Lam.

93. Hloccatus, Sow.

94. Franciscanus, Hro.

95. *fulgurans, Lam.

96. fulmen, Reeve.

97. fumigatus, Hwass.

98. furvus, Reeve.

99. fuscatus, Born.

100. *fusiformis, Lam.

101. generalis, Lim.

102. genuanus, Linn.

103. geographus, Linn.

104. gladiator, Brod.

105. glans, Hwass.

106. glaucus, Linn.

107. gloria-maris, Chemn.

108. gradatus, Gray.

109. granulatus, Linn.

110. Grayi, Reeve.

111. Gruneri, Reeve.

112. gubernator, Hwass.

113. Guinaicus, Hwass.

114. Hebræus, Linn.

116. imperialis, Limn.

117. incarnatus, Reeve.

118. *inflatus, Sov.

119. informis, Hwass.

120. inscriptus, Reeve.

121. intermedius, Reeve.

122. interruptus, Brod.

123. iodostoma, Reeve.

124. Janus, Hwass.

125. *Japonicus, Lam.

126. lacteus, Lam.

127. *lamellosus, Lam.

128. lautus, Reeve.

129. legatus, Lam.

130. lentiginosus, Reeve.

131. leoninus, Hwass.

132. lignarius, Rereve.

133. lineatus, Chenn.

134. liratus, Reeve.

135. literatus, Linn.
136. lithoglyhus, Meusch.

137. lividus, IIwass.

138. Lorenzianus, Chemn.

139. luteus, Brod.

140. *Luzonicus, Lam.

141. maculiferus, Sow.

I42. Madurensis, Hwass.

143. magnificus, Reeve.

144. magus, Linn.

145. mahogani, Reeve.

146. Malaccanus, Hivass.

147. Maldivus, Hwass.

148. Marchionatus, Hinds.

149. marmoreus, Linn.

150. Martinianus, Reeve.

151. *Mauritianus, Hwass.

152. *maurus, Gray.

153. Mediterraneus, $H w$.

154. melancholicus, Lam.

155. mercator, Linn.

156. Metcalfii, Reeve.

157. miles, Linn.

158. miliaris, Hwass.

159. millepunctatus, Lam.

160. Mindanus, Hwass.

161. minimus, Linn.

162. minutus, Reeve.

163. mitratus, Hroass

164. monachus, Linn.

165. monile, Hwass.

166. monilifer, Brod.

167. Mozanbicus, Hwass.

168. mucronatus, Reeve.

169. muriculatus, Sow.

170. mus, Hwass.

171. musicus, Hwass.

172. mustelinus, Hwass.

173. mutabilis, Chemn.

174. nanus, Brod.

175. Narcissus, Lam.

176. nebulosus, Soland.

177. Nemocanus, ITwass.

178. Neptunus, Reeve.

179. Nicobaricus, Hwass.

180. nimbosus, Hwass.

181. nitidus, Reeve.

182. nobilis, Lim.

183. nocturnus, Hwass. 
184. Nussatella, tinn.

185. nux, Brod.

186. obesus, Hwass.

187. obscurus, Humph.

188. Omaicus, Hwass.

189. omaria, Hwass.

190. Orbignyi, Ardouin.

191. orbitatus, Reeve.

192. Orion, Brod.

193. panniculus, Lam.

194. papilionaceus, Hwass.

195. Parius, Reeve.

196. pastinaca, Lam.

197. patricius, Hinds.

198. pauperculus, Sow.

199. pertusus, Hwass.

200. pictus, Reeve.

201. piperatus, Reeve.

202. plumbeus, Reeve.

203. pontificalis, Lam.

204. Porto-Ricanus, Hwo.

205. prefectus, Hwass.

206. prælatus, Hwass.

207. princeps, Linn.

208. Prometheus, Hwass.

209. Proteus, Hwass.

210. pulchellus, Swain.

211. pulicarius, Hwass.

212. punctatus, Chemn.

213. puncticulatus, Hwass.

214. puncturatus, Hwass.

215. purpurascens, Brod.

216. pusillus, Chemn.
217. pygmæus, Reeve. 218. *pyramidalis, Lam. 219. pyriformis, Reeve. 220. quercinus, Hwass. 221. regalitatis, Sow. 222. regularis, Sow. 223. reticulatus, Sow. 224. roseus, Lam. 225. rutilus, Menke. 226. scalptus, Reeve. 227. Senator, Linn. 228. Siamensis, Hwass. 229. sindon, Reeve. 230. *Sinensis, Chenu. 231. Sinensis, Sow. 232. Solandri, Brod. 233. solidus, Sozo. 234. spectrum, Linn. 235. sphacelatus, Sow. 236. splendidulus, Sow. 237. sponsalis, Chemn. 238. Stainforthii, Reeve. 239. stercus-muscarum, $L$. 240. stramineus, Lam. 241. striatus, Linn. 242. strigatus, Lam. 24.3. sugillatus, Reeve. 244. sulcatus, Hwass. 245. Sumatrensis, Lam. 246. Suratensis, Hwass. 247. suturatus, Reeve. 248. tabidus, Reeve. 249. tæniatus, Hwass.
250. Taheitensis, Hwass. 251. tendineus, Hwass. 252. terebellum, Mart. 253. terminus, Lam. 254. tessellatus, Born. 255. testudinarius, Mart. 256. textile, Linn. 257. thalassiarchus, Gray. 258. Timorensis, Hwass. 259. Timianus, Huass. 260. tornatus, Brod. 261. tristis, Reeve. 262. trochulus, Reeve. 263. tulipa, Lam. 264. *unicolor, Sow. 265. ustulatus, Reeve. 266. varius, Linn. 267. venulatus, Hwass. 268. verriculum, Reeve. 269. verrucosus, Lam. 270. vexillum, Mart. 271. vicarius, Lam. 272. victor, Brod. 273. Victorix, Reeve. 274. vidua, Reeve. 275. violaceus, Reeve. 276. virgo, Linn. 277. viridulus, Lam. 278. vittatus, Lam. 279. vitulinus, Hwass. 280. voluminalis, Hinds. 281. zebra, Lam. 282. zonatus, IIwass.

** The species marked thus (*) are unknown to me, and may be considered doubtful, if not synonymous with others; for figures and a critical examination of the remainder see Monograph of the Genus in Conchologia Iconica.

\section{Figures.}

Conus textile. Plate F. Fig. 4.- Shell with the animal, showing its mottled disc, branchial siphon, head, tentacles and eyes. From the 'Zoology of the Voyage de l'Astrolabe.

Conus Victoris. Plate 3. Fig. 14.-Shell. From the collection of Dr. Knapmp. 


\section{Genus 2. TEREBELLUM, Lamarck.}

Animal ; unknown.

Shell ; cylindrically elongated, spire acuminated, last whorl stightly inflated towards the base, where it is abruptly curtailed and emarginated; columella smooth, produced at the base; lip simple.

Nithough the Terebellum shell was known to Klein, Lister, and one or two other writers antecedent to Limmous, and is not unfrequently collected on the shores of the eastern seas, no specimen has yet been found with its molluscous inhabitant. It is of a very isolated form, intermediate, in a manner, between Conus and Bulla, to both of which genera Linnæus at different times referred it in 'Systema Naturx.' Sowerby in his 'Genera of Shells' considers the Terebellum most nearly allied to Strombus, I do not think, however, that will prove to be the case ; there are certainly one or two species of the latter in which the shell bears a striking resemblance to the former, but there is a peculiarity in its light Bulla-like convolution which indicates the presence of a very different animal from that of Strombus; though probably one of equally remote affinity with either Conus or Ovulum.

'Terebellum subulatum. Plate 1. Fig.6. From Mr. Cuming's collection.

\section{Genus 3. OVULUM, Bruguière.}

Animal; disc ample, oblong-ovate, somewhat acuminated at the ends, in slight folds; head somewhat obscure, with the siphonal appendage produced into a broad wrinkled fold; tentacles long and stout, eyes situated upon a prominent subramose thickening at about the middle; mantle extended on each side into a lobe, sprinkled with short spinous processes, enveloping the shell.

Shell ; oval or oblong, smooth, more or less produced at the extremities; spire concealed; aperture longitudinal, columella smooth, lip mostly thickened and infexed, sometimes wrinkled; pure white, sometimes pink or violet tinged.

There is so close an affimity between the amimals of Ovulum and Cyprea, especially between the $O$. ovum and the $C$. Mauriticna, that it would be impossible to refer them to separate genera were it not for the marked difference in the shells. M. De Blainville proposed, in conformity with this resemblance of the soft parts, to regard the Ovuli as merely a section of the genus Cyprace it is certain, however, that animals producing two such 
obvious and characteristic assemblages of shells as refer to the genera in question, though differing in no other respect, are equally entitled to generic distinction. $\Lambda$ system of arrangement based upon the characters of the soft parts of the mollusk alone, without reference to the shell or hard parts, is scarcely less objectionable than one founded upon the shell alone, without reference to the organic structure of the animal.

The shell of Oculum differs from that of $\mathrm{Cyprec}$ in having the extremities more or less prolonged, and in the lip and columella being destitute of the prominent rows of tecth with which that genus is so remarkably characterized; the outer lip, as in the O. ovum and imperialis is in one or two instances a little wrinkled, but never toothed. Another distinction consists in the Orulum not being provided with any pattern or design of colour, nor with colour in any form beyond a faint tinge of pink, violet, or yellow.

The genus Orulum is somewhat limited in species, and they are mostly small; the $O$. ovum is the only one of large size, and the $O$. imperiatis the only species of intermediate size; the well-known Chinese species, the $O$. volva, presents a remarkable example of prolongation of the extremities, and the $O$. verrucosa, the nearest approach to Cyprea, is characterized by the presence of tro small wart-like callosities like those of the $C$. Licallusa.

\section{Species.}

1. aciculare, Sow.

2. Adriaticum, Sow.

3. xquale, Sow.

4. album, Dufo.

5. avena, Soro.

6. birostre, Lam.

7. breve, Sow.

8. carneum, Lam.

9. corrugatum, Hinds.

10. dorsuosum, Hinds.

11. emarginatum, Sow.

12. formicarium, Sow.
13. frumentum, Sow.

14. gallinaceum. Hinds.

15. gibbosum, Lam.

16. hordeaceum, Lam.

17. inflexum, sow.

18. intermedium, Sow.

19. lacteum, Lam.

20. longirostratum, Sow.

21. margarita, Sow.

22. marginatum, Sow.

23. nigerinum, $D u f o$.

24. obtusum, Sow.
25. ovum, Sow.

26. patulum, Sow.

27. pyriforme, Sow.

28. rufum, Sow.

29. secale, Sow.

30. seminulum, Soro.

31. spelta, Lam.

32. striatulum, Soiv.

33. tortile, Des.

34. triticeum, Lam.

35. vernucosa, Sovo.

36. volva, Lam.

\section{Figures.}

Ovulum ovus. Plate F.-Fig. 3. Shell with animal, showing the expanded disc, in slight folds; the right lobe of the mantle with its spinous processes partially extended; the broad wrinkled siphonal appendage; the tentacles proceeding from the concealed head; and the cyes on the thickened part of the tentacles. From the Zoology of the Voyage le l'Astrolabe.

Ovulum volva. Plate 1. Fig. 5.- Shell. From Mr. Cuming's collection. 


\section{Genus 4. CYPR AA, Linncus.}

Animal ; disc oblong-ovate, in ample folds, more or less acuminated at the extremitics, front extremity sometimes truncated; head obtuse, cylindrical, siphonal, appendage broad, short, sometimes fringed at the edlge, and disposed in the form of a fan; tentacles long, stout, eyes siluated on a subramose thickening at about one third clistance from the base; mantle produced into two lobes, capable of emeloping the shell, furmished with warts, spinons mocesses, forked tufted or ramified filaments, or tubular papilla. Shell; ovate or oblong-ovate, ventricose, potished, somctimes nodiferous or ribbed, with the extremities emarginated; spire very sliort, partially or entirely concealed; aperture nearly central, longitudinal, narrow; lip and columella toothed.

There is probably no group throughout the series which offers matter of so much beauty and interest as the genus Cyprea, whether we regard the animal or the shell. The Cowrey presents the most striking example of a mollusk forming its shell by the outward application of a number of successive layers of highly vitrified enamel, constituting a superb arch of as many strata, of different colours and design. The changes both of form and colour which the Cyprea shells exhibit at different periods of growth are so dissimilar, that writers of the last century have referred the same species, in different states, to genera widely separated in the system; and there are instances of three and four species having been founded upon one under different phases of colour. It is, therefore, lighly necessary that the collector should assemble specimens of each species of Correy characteristic of its different stages of growth, and observe the gradual variations of form and colour that present themselves between the embryo and the adult.

The first stage of advancement produces a simple convolution of shell around the columella axis in the form of a long drawn out Bullu, the columella being smooth, the outer lip thin, and the colour usnally diffused in bands of waves. In the second epoch of growth the shell solidifies, the lip and colunella begin to thicken, and present gradual indications of teeth, the teeth become more and more perfectly developed, and the dorsal surface is overlaid with a strong coat of livid colouring matter, also diffused in obscure bauds or waves. The calcifying energies of the mantle, which, extending in tro unequal lobes, one from either side of the shell's aperture, have been chiefly excreised during the second epoch of growth upon the back, or dorsal surfice, are now more particularly directed to the base and sides. The teeth are strengthened, the sides become thickened with a rich 
coating of enamel, and the growth of the shell is completed by a light fabric of colouring matter deposed in lines, blotches, waves, or reticulations, of various hues and patterns. These are not, however, the only physiological changes that take place in the Cowrey. From observations made by a gentleman who worthily employs the opportunities afforded him, as a Naval officer, in the pursuit of science, I have strong reasons for believing that there is some truth in the argument set forth many years since by Bruguière and Lamarck, relative to the Cyprea possessing the faculty of partially dissolving and renewing its shell after having arrived at maturity. *

Lamarck says in reference to the re-calcification of the Cyprea shell, "I possess obscrvations which tend to prove that the Cowrey, arrived at the power of forming a complete shell, has still the faculty of enlarging its habitation, and is then obliged to quit the shell in order to form a new one. It results from this that the same individual has the power of forming a successive number of shells during both the second and third stages of growth; and which accounts for our often meeting with so many different sizes in the same species" !

M. Deshayes argues against the possibility of an entire re-modelling of the shell, and justly regards the statement of Lamarck as a theory opposed to the common laws of organization. To the supposition of Bruguière that the Cowries cast their shells after the manner of Crabs, M. Deslayes very properly replies that there can be no analogy between them. The new shell of the Crustacea is formed by a secretion of equal consistency from all parts of the body, whereas the Mollusca have a muscular attachment to the columella, and increase the growth of their shell by an exudation, not from the whole body, but from a particular organ; the mantle being the sole agent charged with that faculty. It is further argued by the same distinguished naturalist that the Cowrey must lose the power of forming the inner chambers of the columella anew, after having once passed that early process of development which induces their formation. " How is it possible," asks M. Deshayes, "that the animal can, under the circum-

\section{* Lieut. L. B. Hankey, R.N., to Lovell Reeve.}

Will you allow me to offer you a few remarks on the habits of the Cyprea as regards the fact of its making a new shell, at an advanced age, of which process I have been myself in more than one instance an eye-witness. I have seen the Cowrey crawl into some bollow or sheltered place, evidently for some predetermined purpose. The growth of the animal appears to increase too large for its cell; it gradually swells and cracks the shell, and I think that some powerful solvent or decomposing fluid is distributed over the outer surface by the mantle of the fish, for it gets thinner in substance, and the colours duller in appearance. The shell then entirely disappears, the Cowrey becomes, to all appearance, a naked mollusk, with no other covering than its membranous mantle, and in a short time secretes a thin layer of glutinous matter which in a ferv days obtains the fragile consistency of shell-lac. From this step its growth is more rapid, and it becomes more and more consolidated into the adult shell. When in the first stage of renewal it las the appearance of shell-lac it is always of the Cymba form, but I have never sueceeded in preserving any specimens in this state on account of their extreme fragility.

II.M.S. Collingwood, August 6th, 1844.

F.B. H.

Conchologia Iconica, Cyprea Plate $\mathbf{I}$. 
stances of its nature, secrete a new shell from all parts of the borly at once, and with all the different phases of colour exhibited in carly growth, when it has reached to an advanced condition of its existence?"

The animal does not appear to quit the shell, as Lamarck supposed, but dissolves the outer portion with its acetose juices. All visible trace of the shell may be thus removed mithout weakening M. Deshayes' proposition founded on the circumstance of the mantle being the only organ charged with the secretive fluid. The mantle is always capable of extension over the shell; and the same power which furnishes the adult with its last conting of enamel can be exerted to the formation of as many superincumbent liayers as may be necessary to replace all that has been decomposed. That a dissolution takes place there can be no doubt:- "the shell gradually swells," says Lieut. Hankey, "and cracks, becomes thinner, and duller in colour, and finally disappears;" a circumstance which may be casily credited when it is remembered that the Murex possesses the faculty of removing spines or any similar obstacles to its advancement of growth, and that the Pholades, and other terebrating mollusks, exercise a power of absorbing which enables them to penetrate the hardest limestone rock. The microscopical structure of the Cowrey shell is, moreover, of a nature peculiarly tenacious of absorption; it is composed of a large quantity of carbonate of lime in proportion to the amount of membranous substance; and this accounts for its surface becoming vitrified to so highly a polished state of enamel, when in contact with the acidity of the soft parts.

There is another circumstance in Lieut. Hankey's narrative to which attention should be given, respecting the formation of a new shell:- the glutinous matter which has the appearance of shell-lac, and is so fragile that it yields to the touch, does not assume the narrow cylindrical Bulla form, but is of the wide, ventricose shape of a $C y m b$, and rapidly consolidates into the adult shell.

With these generalizations I think it may be assumed that the Cowrey possesses, upon an emergency, the faculty of decomposing, during one or more periods of its existence, any portion of the shell that is liable to resist its advancement of growth; that the renewal of the shell is accomplished within a comparatively short space of time; and that the columella with its internal spiral partitions remains undisturbed. It may, however, be inferred that it is an operation of extremely rare occurrence, and one which only happens under peculiar conditions.

In most species of Cyprea three separate phases of colour may be defined at different periods of gromth. In the $C$. Mauritiana, for example, the colour of its first state, or Bulla form, is a pale yellow, over which the fulvous brown spreads in bands of waves; in an intermediate state the waves become agglomerated, and leave the yellow in triangular flame-like spots; and when the teeth are fully developed, the sides become thickened with a 
rich dark blackish-brown coating which is thinly spreat over the dorsal surface, opening into irregular reticulations just as if its flow had been disturbed by the intermixture of some oily liquid. In the $C$. Scottii the first growth is a clear milky orange colour (Conch. Icon. Cyprea, Pl. XXVII. Fig. 10.), it then assumes a blucish tinge disposed inobscure bands, and begins to show a few bright tortoise-shell-brown blotelies, which rapidly accumulate, as exhibited in the arlult, long before there is any indication of tecth. This is an arrangement difierent to that of most Cowries, in which the teeth are chiefly developed before the last liyer of colouring matter is deposited. The sides and base then become thickened with an extremely rich pitchy-brown coating of enamel, and the extremities compressed and turned upwards. The most striking change, however, takes place in the shell of $C$.tigris: first it is an uniform chesnut bay, the colour then breaks up, as it were, into bands of close-set waved blotches of a richer hue, a coating of white is then superimposed, and upon that is deposited a series of rather distant zigzag flames upon a white ground; the teeth are forming in the mean time, and a few spots of colour make their appearance round the outer side. In the next state of the shell, a second layer of white enamel is superimposed, a thinner and more delicate stratun than the precering, through which the zigzag flames may be seen of a milky hue; and, upon this surface a number of dark spots are deposited. These are again overspread by a third white coating, intermixed with numerous rich black and brown spots, showing, for the first time, a narrow dorsal hiatus, mostly edged with reddish brown, with the first deposit of dark spots, thus overspread, of a milky hue.*

The ornamental character with which the dorsal surface of the Cowries is mostly painted, appears to be the last effort in the formation of the shell. The previous infusions of colour rarely exhibit anything more than a dull confusion of waves, clouds, or bands; no ornamental device appears until the shell is on the eve of maturity: the most richly variegated layers of cnamel are reserved for the final decoration. The $C$. mappa presents, however, a curious exception to this order of arrangement ; a layer of pale lieroglyphical painting, greatly resembling, except in colour, that of the $C$. Arabica, is deposited by the animal on the left side chiefly, while yet in a

* "Mr. Samuel Stutchbury, who had an opportunity of examining many individuals of $C$. ligris at the Pearl Islands, informed me that these Cowries lived there in very shallow water, and always under rolled masses of Madrepore. They never were to be seen exposed to the sun's rays. On lifting one of these masses, a Tiger Cowrey was generally observed with its shell entircly covered by the large mantle which was moltled with dark colours, the intensity of which the animal seemed to have the power of changing; for the colour varied in the same light and in the same medium, after the manner of the spots on the Cephalopodous Mollusea, or, to use a more familiar instance, somewhat in the manner that the hues of a turkey-cock's wattle vary. On touching the mantle, it was immediately withdrawn within the shell, which became exposed in all its brilliancy. So firmly did the soft parts adhere to the shell, that, in no instance, (and the experiment was often made) did Mr. Stutchbury suceed in extracting them by force, cither during life, or before decomposition took place. He was obliged to let the animal die, and suffer the soft parts to decay, in order to remove them." - Broderip, Zool. Joumal, vol, iv. p. 153. 
very immature state of growth, and on arriving at maturity, another and richer layer of the same pattem is superimposed upon the former, which in most specimens may be faintly seen beneath it. Another exception occurs in the C. carneola, ventriculus, arenosa, sulcidentata, and one or two others; in these species the dorsal surface has no ornamental layer of pattern on arriving at maturity; the calcifying energies of the mantle, at an advanced stage of growth, are directed exclusively, and with more than usual force, to the thickening of the sides of the shell, and it is mostly accompanied with a dull deposit of sand-like dots or strix.

The Cypraa present two very distinct groups; the larger species in which the surface of the shell is highly enamelled, and the smaller species in which it is disposed in grooves and ridges, of a more opake cliaracter and more delicate texture. They offer little variety of form, but a diversity of colouring; and among them are several very distinct and characteristic species of unusual rarity, which our country can alone boast of possessing. Of these the Cyprea princeps and leucorlon, in our national collection, are perfectly unique; it seems curious that nature should not have exercised her accustomed prodigality in the perpetuation of these species, for instead of being the remuants of an extinct group, they appear to be the solitary instances of a creation possessing an exuberance of character quite unapproached by any other species. They are both in the finest possible condition, and may certainly be regarded as the most valuable shells yet discovered. The next in value are the $C$. Broderipii and guttata; of the former, three specimens are known, two of which are in this country; of the latter, five, of which we possess four. Of distinguished rarities of smaller size may be mentioned $C$. Cuningii, Saule, xanthorlon, similis, contaminata and fusco-dentata, all in our collections.

There is little to be said on the geographical distribution of the Cowries except that they are mostly tropical. Only one or two very small grooved species are found on our own coast, and none larger than $C$. lurida in the Mediterranean. The C. Scottii may be quoted as a fine example of the New Holland region, and the $C$. aurantium (the orange Cowrey), of the Pacific. The $C$. pantherina is brought in great abundance from the Red Sea, but the greater portion of the species are from Mauritius, Ceylon, and other parts of the eastern world.

\section{Species.}

1. Adamsoni, Gray.

2. albuginosa, Mawe.

3. Algoensis, Gray.

4. angustata, Gray.
5. annulata, Gray.

6. annulus, Linn.

7. Arabica, Linn.

8. Arabicula, Lam.
9. arenosa, Gray.

10. Argus, Limn.

11. asellus, Linn.

12. aurantium, Mart. 
13. australis, Lam.

14. Beckii, Gaskoin.

15. bicallosa, Gray.

16. Broderipii, Gray.

17. Californica, Gray.

18. candidula, Gaskoin.

19. Capensis, Gray.

20. caput-serpentis, Limn.

21. carneola, Limn.

22. caurica, Linn.

23. cervus, Linn.

24. Childreni, Gray.

25. cicercula, Linn.

26. cinerea, Gmetin.

27. citrina, Gray.

28. clandestina, Linn.

29. contaminata, Gray.

30. costata, Gmelin.

31. cribraria, Linn.

32. cruenta, Gmelin.

33. Cumingii, Gray.

34. cylindrica, Born.

35. depauperata, Sow.

36. diluculum, Reeve.

37. eburna, Barnes.

38. edentula, Sow.

39. erosa, Linn.

40. errones, Linn.

41. erythræensis, Beck.

42. esontropia, Duclos.

43. Europra, Mont.

44. exanthema, Linn.

45. exusta, Sow.

46. felina, Gray.

47. fimbriata, Gmelin.

48. flaveola, Linn,

49. formosa, Gaskoin.

50. fusca, Gray.

51. fusco-dentata, Gray.

52. gangrenosa, Soland.

53. Gaskoinii, Reeve.

54. globosa, Gray.

55. globulus, Linn.

56. Goodalli, Gray.

57. guttata, Gray.

58. helvola, Linn.

59. hirundo, Linn.

60. interrupta, Gray.
61. irrorata, Soland.

62. isabella, Linn.

63. labiosa, Gaskoin.

64. Lamarckii, Gray.

65. lentiginosa, Gray.

66. leucodon, Brod.

67. leucostoma, Gaskoin.

68. Listeri, Gray.

69. lurida, Limn.

70. lutea, Gronov.

71. lynx, Linn.

72. Madagascariensis, Gm. 119. Reevei, Gray.

73. mappa, Linn.

74. margarita, Soland.

75. Maugeriæ, Gray.

76. Mauritiana, Linn.

77. melanostoma, Leath.

78. microdon, Gray.

79. miliaris, Gmelin.

80. moneta, Linn.

81. mus, Linn.

82. napolina, Duclos.

83. neglecta, Sow.

84. nigropunctata, Gray.

85. nivea, Gray.

86. nivosa, Brod.

87. nucleus, Linn.

88. obvallata, Lam.

89. ocellata, Linn.

90. oniscus, Lam.

91. onyx, Linn.

92. oryza, Lam.

93. ovula, Lam.

94. Pacifica, Gray.

95. pallida, Gray.

96. pantherina, Soland.

97. pediculus, Linn.

98. pellucidula, Gaskoin.

99. physis, Brocchi.

100. picta, Gray.

101. piperata, Soland.

102. pisum, Gaskoin.

103. poruria, Linn.

104. princeps, Gruy.

105. producta, Gaskoin.

106. pulchella, Swain.

107. pulchra, Gray.
108. pulex, Soland.

109. pulicaria, Reeve.

110. pulla, Gaskoin.

111. punctata, Linn.

112. punctulata, Gray.

113. pustulata, Lam.

114. pyriformis, Gray.

115. pyrum, Gmelin.

116. quadrimaculata, Gray.

117. quadripunctata, Gray.

118. radians, Lam.

120. reticulata, Mart.

121. rubescens, Gray.

122. rubinicolor, Gasȟoin.

123. sanguinea, Gray.

124. sanguinolenta, Gmel.

125. Saulæ, Gaskoin.

126. Scottii, Brod.

127. scurra, Chemn.

128. similis, Gray.

129. Solandri, Gray.

130. Sowerbyi, Kiener.

131. spadicea, Swain.

132. spurca, Limn.

133. staphylæa, Limn.

134. stercoraria, Linn.

135. stolida, Linn.

136. subrostrata, Gray.

137. subviridis, Reeve.

138. suffusa, Gray.

139. sulcidentata, Gray.

140. tabescens, Soland.

141. talpa, Limn.

142. teres, Gmelin.

143. tessellata, Swain.

144. testudinaria, Limn.

145. tigris, Limn.

146. tremeza, Duclos.

147. turdus, Lam.

148. ventriculus, Lam.

149. vesicularis, Gaskoin.

150. vitellus, Linn.

1丂̆1. Walkeri, Gray.

152. xanthodon, Gray.

153. zizac, Limn.

154. zonata, Chemn. 


\section{Figures.}

Crpran tigris. Plate D. Fig. 3.-Shell with the animal, showing its expanded green-spotted disk, cylindrical head surmonnted by the fringed fan-shaped siphonal appendage, tentacles and prominent eyes, and left lobe of the mantle with its forked processes, partially expanded over the shell. From the Zoology of the Toyage de l'Astrolabe.

Crprea leucostoma. Plate. 2. Fig. 9, $a$ and b. - Shell, showing, $a$, the dorsal, b, the under surface. From Mr. Cuming's collection.

\section{Genus 5. ERATO, Risso.}

Animal; simitar to the Cypraa, with the lobes of the mantle very thin and speckled.

Shell; small, ovately oblong, smooth, emarginated at the base, spire vather prominent, last whorl a little inflated; aperture narrow, lip and columella more or less finely denticulated, lip thickened, generally swollen towards the middle.

The genus Erato was originally founded by M. Risso, a distinguished conchologist of Nice, with a small shell, chiefly inhabiting the Mediterranean, intermediate in its characters between Cyprea and Marginella, and forming a striking link between the families Columellata and Convoluta. It has the form and general aspect of Marginella, but the most important distinguishing claracter of that genus, the row of plaits which twine aromin the columella through the entire growth of the shell, is replaced by a minute series of denticulations, which only make their appearance on its arriving at maturity; and it is not surprising, therefore, under these circunstances, that one Limnean author, Montagu, should have regarded the E. loevis as a Voluta, whilst another, Donovan, should have referred it to the genus Cyprea. Seven other interesting species have since been added.

\section{Species.}
1. angistoma, Sow.
4. lævis, Gray.
7. sulcifera, Gray.
2. guttata, Sow.
5. Maugeriæ, Gray.
8. vitellinum, Hinds.
3. lachryma, Gray.
6. scabriuscula, Gray.

\section{Figure.}

Erato uzvis. Plate 1. Fig. 3. (magnified). From Mr. Cuming's collection. 


\section{Family 2. COLUMELLA'TA.}

Shell; emarginated at the base, with the columella strongly obliquely plaited.

The genera of pectimibranchial gastropods constituting the family Columellata, all included by Linnæus under the head of Voluta, are mainly characterized by the presence of four or five conspicuous plaits winding obliquely round the columella, with a notch at the base, or rather front edge of the shell, viewing it in its natural position upon the animal, for the passage of the respiratory siphon. $\Lambda$ modification of this structure appears also in some genera of Canalifera, as in Turtinella, and Cancellaria; not only, however, are the plaits in that family more limited in number and more feebly developed, but the genera are allied by other characters of greater importance. The Auricula shells are, in like manner, characterized by a plaited columella, but they again are the production of animals dwelling in fresh and stagnant water, whose physical condition is necessarily adapted to the different medium they inhabit*.

In reviewing the soft parts of the Columellata it may be observed that they are very much larger and more expansile in some species than in others; the Marginelle have the mantle expanded entirely over the shell, as in Cyprea; in Cymbinm the disc is very large and muscular, the shell light and ventricose, whilst the mantle of that genus, as well as of Folute, is in some instances partially expanded over the shell. The animal of Mitra, on the other hand, is small, the shell often solid and ponderous, with a thick fibrous epidermis, and there is no outward expansion of the mantle, whilst the proboscis is capable of extraordinary elongation.

The genera of this family are extremely rich in species, but of those referred to it by Lamarck and Deshayes, I remove Columbella to the family Purpurifera: first, on account of the absence of plaits on the columella, and, secondly, because of its nearer affinity with Purpura and Ricinula; in place of this a new and interesting genus has to be inserted after Marginella, founded by M. Deshayes upon a little inhabitant of the Mediterranean, under the name of Ringicula.

$\begin{array}{lll}\text { Cymbium. } & \text { Mitra. } & \text { Ringicula. } \\ \text { Voluta. } & \text { Marginella. } & \end{array}$

\footnotetext{
* Mr. Swainson had a notion that every character in Zoology, however unimportant, is represented in complete analogy throughout the different classes of animals, within very prescribed limits; he conceived, for example, that the Volutes and Iritres represent the Rasorial type among Birds, the Ungulata among Quadrupeds, and the Thysanura among Insects. These flights of analogy he proposed to exhibit in circles; and they revolved in his imagination in such mystical order as to reveal the most incomprehensible affinities.
} 


\section{Genus 1. CYMBIUM, De Montford.}

Animal ; disc large and muscular capable of considerable expansion, head furmished with an obtuse trunk, tentacles short, broad, dilated at the base into two lobes; respiratory siphon short, stout. Shell; oblong-ovate, very large, thin and ventricose, whorls elevated around the spire, which is papillary and sunken, with the suminit sometimes coronated, sometimes concavely flattened; plaits of the columella strongly developed, the lower being the larger.

The present genus was founded by De Montford, under the name of Cymbinm, for the reception of that portion of the Volutes commonly known to collectors by the term 'Melons', and which Lamarck distinguished as a particular section of his genus Voluta, under the sub-title of 'Les Gondolières.' The generic arrangement of this group has, however, been a matter of some difference of opimion; for whilst M. Deshayes considers the adoption of Cymbinm, as a genus of the same rank with the Volute proper, quite uncalled for, on account of the similarity of the animals; Mr. Broderip and Mr. Sowerby have still further divided it into Cymba and Melo, for the sake of observing a generic listinction between the coronated and the flattened species. After weighing the merits of these opinions, I propose to take the middle course, and return to the method originally introduced by De Montford, of including both varieties of 'Melons' under the same head.

The animal of Cymlium varies to a certain extent from that of Voluta in the size and extensive muscular expansion of the disk; the shells are, moreover, distinguished by their light inflated growtlı, and sunkeu papillary spire, around which the whorls are elevated, with their summit sometimes concavely flattened, sometimes coronated with a diadem of vaulted scales.

One or two species of Cymbium are found in Australia, but the chicf portion are from the coast of Africa; they burrow in the sand at low water, and live mostly concealed from view.

\section{Species.}

1. Athiopicum, Brod. 7. Indicum (Vol.), Gmel. 13. patulum, Brod.

2. $\operatorname{armatum}\left(V_{0}\right.$ l.), Lan. 8. Linnæi, Reeve. 14. porcina (Vol.), Lam.

3. Broderipii, Gray. 9. Miltonis $\left(V_{0} l_{0}\right)$, Kien. 15. proboscidale $\left(V_{0} l_{0}\right), L_{\text {。 }}$

4. diadema $\left(V_{o l} l_{0}\right)$, Lam. 10. nauticum $\left(V_{0} l_{0}\right)$, Lam. 16. rubiginosum $\left(V_{o} l_{0}\right)$, $S$.

5. ducale (Vol.), Lam. 11. Neptuni (Vol.), Lam. 17. tessellatum, Brod.

6. gracile, Brod. 12. olla (Vol.), Linn. 18. Tritonis, Brod. 


\section{Figures.}

Crmbuum Linnai. (Voluta cymbium, Limn.). Plate 2. Fig. 8.-Shell, showing the papillary spire, and the summit of the whorls flattened.

Cmubur Broderter. Plate 2. Fig. 10.-Shell, showing the papillary spire, and the summit of the whorls coronated with vaulted scales.

\section{Genus 2. VOLU'TA, Linncens.}

Animal; clisc oval or oblong, head obtuse or rounded, tentacles short, eyes a little removed from the tentacles; respiratory siphon stout, auriform, dilated at the base into two lobes.

Shell; ovate or oblong, emarginated at the base, spire short and mostly papillary at the apex; whorls smooth or ribbed, sometimes tuberculated at the summit; aperture oblong, columella callons, lower plaits the larger: lip but slightly thickened.

Linmens included under the head of Toluta all shells having a row of plaits winding round the columella, without considering the nature or habits of their animal occupants; the Tomatella, whose shells are entire at the base, the Anricula, which inlabit the banks of stagnant waters and are amphibious, the Turlinelle, which are canaliculated, and the Marginelle, in which the shell is entirely enveloped by the animal, were all associated in the 'Systema Nature' under the same generic type. This heterogeneous group has, however, been gradually dismembered, until only those species reinain which present the charncters strictly typified in the well-known $V$. scapha, musica, or vespertilio. The ancient genus Toluta is, therefore, circumscribed within very narrow limits, and some of the species are of such rare occurrence, that only a few individuals of the shells of each have yet been discovered; the $T$. Junonia, aulica, reticulata, megaspira, papillosa, Mitraformis, pulchra, and marmorata are examples.

The animal of Toluta scarcely differs from that of Cymbium except in being smaller, less expansile, and more brilliantly coloured; it presents the same peculiar lobed dilation of the respiratory siphon, and the eyes, as in that genus, are quite removed from the tentacles. The species hitherto discovered in a living state, exhibit as brilliant a variation of colour in the soft parts as in the shell. The $T$. respertilio is characterized by a bright yellow disc, marked with longitudinal interrupterl black lines, the $T$. angulata, by a rusty orange tint, marked throughout with dark leopard spots, the $T$. nicosu, purple, marked with unequal black spots with white edges, and the 
T. angulate with netted waved red-brown lines. The colours and markings of molluscous animals never correspond with those of their shells.

The Tolute are strictly tropical, none inhabit the European seas, and not a single species has been found in any part of the Mediterranean, the richest, and most highly esteemed, are from Australia, New Guinea and New Zealand; there are one or two species from Brazil, and some from Ceylon, Timor, and Western Africa, but the well-known $V$. musica, of which the $T$. levigata, cameolata, Gunaica and thiarella of Lamarck are varieties, is principally found in the West Indies.

The Volutes rarely inhabit localities where Mitres abound; at the Philippine Islands, for example, Mr. Cuning collected between two and three hundred species of that genus, whilst scarcely a Volute presented itself.

\section{Species.}

1. ancilla Soland.

2. angulata, Soland.

3. aulica, Soland.

4. Beckii, Brod.

5. Brasiliana, Soland.

6. bullata, Swain.

7. chlorosina, Lam.

8. concinna, Brod.

9. costata, Swain.

10. Cumingii, Brod.

11. Cylleniformis, Soro.

12. cymbiola, Chemn.

13. Delessertiana, Petit.

14. dubia, Brod.

15. elongata, Swain.

16. Ferussacii, Donov.

17. festiva, Lam.

18. fulgetrum, Sow.

19. fusiformis, Swain.

20. gracilis, Swain.

21. Guildingii, Sow.
22. harpa, Barnes.

23. Hebræa, Linn.

24. imperialis, Lam.

25. Junonia, Chemn.

26. Lapponica, Linn.

27. Largilliertiana, D'Orb. 48. punctata, Swain.

28. luteostoma, Chemn.

29. lyræformis (Mitra), Sw. 50. xeticulata, Reeve.

30. maculata, Swain. 51. rupestris Gmel.

31. Magellanica, Chemn. 52. rutila, Broci.

32. magnifica, Chemn.

33. mamilla, Gray.

34. marmorata, Swain.

35. megaspira, Sow.

36. Mitræformis, Sow.

37. musica, Linn.

38. nivosa, Lam.

39. nodulosa, Lam.

40. Norrisii, Sow.

41. nucleus, Lam.

42. Pacifica, Soland.
43. pallida, Gray.

44. papillosa, Swain.

45. piperita, Sow.

46. polyzonalis, Lam.

47. pulchra, Soro.

53. scapha, Gmel.

54. subnodosa, Leach.

55. sulcata, Lam.

56. tuberculata, Swain.

57. Turneri, Gray.

58. undulata, Lam.

59. vespertilio, Linn.

60. vexillum, Chemn.

61. volvacea, Lam.

62. zebra, Leach.

\section{Figures.}

Voluta angulata. Plate D.-Shell with animal, showing its rounded head, short tentacles, remote eyes, auriform respiratory siphon, and mantle expanded over the left side of the shell. From D'Orbigny's Voyage dans l'Amèrique Mèridionale.

Voluta volvacea. Plite 1. Fig. 7.--Shell, showing the winding plaits. 


\section{Genus 3. MITRA, Lamarck.}

Animal; disc small, oblong, oval behind, squarely truncated in front; head and tentacles small, eyes situated sometimes towards the middle of the tentacles, sometimes pedunculated and towards the base; respiratory siphon thin; trunk susceptible of very considerable elongation.

Shell ; turreted or fusiform, emarginated at the base, spire mostly sharply acuminated, apex narrow, varying in length; columella a little recurved at the base, lower plaits the smaller.

The Mitres constitute a numerous division of the family Columellata, distinguished from the Volutes by a very important association of character; their shells are long and turriculated, and there is a marked change in the arrangement of the columellar plaits, which, instead of increasing, diminish in size as they descend; the animal is very small; the head is of the form of a triangle, at the basal corners of which are the tentacles, with the eyes situated sometimes towards the middle, sometimes towards the base, upon short peduncles; the respiratory siphon is small and not dilated into lobes at the base, and the trunk is capable of remarkable elougation; Iastly, their habits vary, and they differ in their geographical limits.

It is easy to conceive that a small mollusk, producing a ponderous turriculated shell like the 'Bishop's Mitre', (M. episcopalis) would naturally be of a much more sluggish disposition than one whose shell is supported by an ample muscular dise like the 'Bat Volute' $(V$. vespertilio); and the Mitre is accordingly described by M. Quoy and Gaimard as an "animale apathique", a creature of limited sensibility, whose activity is necessarily restrained by the over-balancing proportions of its shell. It is related by these illustrious circumnavigators, who were the first to discover the Mitre in a living state, that they kept several healthy individuals for some time without observing any decided movement; they are, however, provided in this comatose state with the faculty of elongating their trunk to an extent not enjoyed by any other genus; the extremity of it is furnished with a kind of dentated chewing apparatus, and the animal is cnabled to exert this destructive organ in all directions for the capture of food, with little apparent effort, and without altering its position.

The peculiarity alluded to in the geographical distribution of the Mitres, is, that they are rarely found in places inhabited by Volutes; the Philippine Islands, for example, are probably the richest spot in the world for Mitres; during NLs. Cimning's four years sojoum in that locality, he collected between two or three hundred species, yet scarcely a Volute presented itself; 
and on the western coasts of Africa and New Holland, where the Melous and Volutes abound, very few Mitres have made their appearance.

In a monograph of this genus recently published in the 'Conchologia Iconica', I have described upwards of three hundred and thirty species, as follows:-

\section{Species}

1. abbatis, Chemn.

2. acuminata, Swain.

3. acupicta, Reeve.

4. Adamsoni, Gray.

5. adusta, Lam.

6. ægra, Reeve.

7. Ethiops, id.

8. affinis, $i d$.

9. alveolus, $i d$.

10. amabilis, $i d$.

11. amanda, $i d$.

12. ambigua, Swain.

13. amphorella, Lam.

14. analogica, Reeve.

15. Ancillides, Swain.

16. angulosa, Küster.

17. annulata, Reeve.

18. anthracina, $i d$.

19. arenosa, Lam.

20. armiger, Reeve.

21. armillata, $i d$.

22. articulata, $i d$.

23. astricta, $i d$.

24. attenuata, $i d$.

25. aurantia, Desh.

26. aureolata, Reeve.

27. Auriculoides, id.

28 . australis, Swain.

29. avenacea, Reeve.

30. bacillum, Lain.

31. badia, Reeve.

32. balteolata, $i d$.

33. Belcheri, Hinds.

34. bilineata Reeve.

35. Bovei, Kiener.

36. brumalis, Reeve.

37. Bulimoides, id.

38. cadaverosa, $i d$.
39. cælata, Reeve.

40. cæligena, $i d$.

41. cærulea, $i d$.

42. caffra, Lam.

43. caliginosa, Reeve.

44. callosa, $i d$.

45. cancellata, Swain.

46. candida, Reeve.

47. Capensis, Dunker.

48. carbonacea, Reeve.

49. cardinalis, Gronov.

50. carinata, Swain.

51. carnicolor, Reeve

52. casta, Lam.

53. catenata, Reeve.

54 . cavea $i d$.

55. chalybeia, $i d$.

56. chelonia, $i d$.

57. Chinensis, Gray.

55. choava, Reeve.

59. chrysalis, $i d$.

60. chrysostoma, Swain.

61. cimelium, Reeve.

62. cinctella, Lan.

63. cineracea, Reeve.

64. circulata, Kiener.

65. cithara, Reeve.

66. citrina, $i d$.

67. clanciestira, id.

65. clathrata, $i d$.

69. coaretata, Swain.

70. coccinea, Reeve.

70. coccinea, Reeve. 108. effusa, Swain.
71. Columbellæaformis, Kie. 109. elegans, Reeve.

.

72. concentrica, Reeve.

73. concinna, $i d$.

7t. conica, Desh.

75. consanguineus, Reeve.

76. Conus, $i d$.
77. corallina, Reeve.

78. coriacea, $i d$.

79. cornicula, Desh.

80. coronata, Lam.

81. corrugata, $i d$.

82. costellaris, id.

83. crassa, Swain.

84. crebrilirata, Reeve.

85. cremans, $i d$.

86. crenata, $i d$.

87. crenifera, Lam.

88. crenulata, $i d$.

89. crocata, $i d$.

90. crocea, Reeve

91. cruentata, $i d$.

92. cucumerina, Lam.

93. Cumingii, Reeve.

94. cylindracea, $i d$.

95. dactylus, Lam.

96. dædala, Reeve.

97. declivis, $i d$.

98. decora, $i d$.

99. decurtata, $i d$.

100. Defrancii, Payr.

101. Dennisoni, Reeve.

102. dermestina, Lam.

103. Deshayesii, Reeve.

104. digitalis, $i d$.

105. discoloria, $i d$.

106. duplilirata, $i d$.

107. ebenus, Lam.

110. episcopalis, Argen.

111. exasperata, Desh.

112. exilis, Reeve.

113. fastigium, $i d$.

114. fenestrata, Lam. 
115. ferruginea, Lam.

116. festa, Reeve.

117. ficulina, Lam.

118. filosa, $i d$.

119. filum, Reeve.

120. fissurata, Lam.

121. flammea, Quoy.

122. flammigera, Reeve.

123. flavescens, $i d$.

124. floccata, $i d$.

125. forticostata, $i d$.

126. fulgetrum, $i d$.

127. fulgurita, $i d$.

128. fulva, Swain.

129. fulvescens, Reeve.

130. funerea, $i d$.

131. funiculata, $i d$.

132. fusca, Reeve.

133. fusiformis, Kiener.

134. gausapata, Reeve.

135. gigantea, Swain.

136. glabra, Swain.

137. glandiformis, Reeve.

138. glans, $i d$.

139. gracilis, $i d$.

140. Graja, $i d$.

141. granata, $i d$.

14.2. granulosa, Lam.

143. granum, Forbes.

144. gratiosa, Reeve.

145. Grœnlandica, Gray.

146. Gruneri, Reeve.

147. guttata, Swain.

148. hebes, Reeve.

149. Hindsii, $i d$.

150. histrio, $i d$.

151. ignobilis, $i d$.

152. impressa, Anton.

153. incarnata, Reeve.

154. inermis $i d$.

155. infausta, $i d$.

156. infecta, $i d$.

157. inquinata, $i d$.

158. interlirata, $i d$.

159. intermedia, Kiener.

160. isabella, Reeve.

161. lachryma, $i d$.

162. lactea, Lam.
163. lacunosa, Reeve.

164. Lamarckii. Desh.

165. latruncularia, Reeve.

166. lauta, $i d$.

167. lens, $i d$.

168. leucodesma, $i d$.

169. lignaria, $i d$.

170. limata, $i d$.

171. limbifera, Lam.

172. lineata, Reeve,

173. literata, Lam.

174. littoralis, Forbes.

175. livida, Reeve.

176. loricata, $i d$.

177. lota, $i d$.

178. lubens, $i d$.

179. lucidi, $i d$.

180. luculenta, $i d$.

181. lugubris, Swain.

182. lyrata, Lam.

183. maculosa, Reeve.

184. mresta, $i d$.

185. melongena, Lam.

186. mica, Reeve.

187. micans, $i d$.

188. microzonias, Lam.

189. militaris, Reeve.

190. milium, $i d$.

191. millecostata, $i d$.

192. mirifica, $i d$.

193. modesta, $i d$.

194. mucronata, $i d$.

195. multicostata, $i d$.

196. muricata, $i d$.

197. muriculata, Lam.

198. mutabilis, Reeve.

199. nanus, $i d$.

200. nebulosa, Swain.

201. nigra, Reeve.

202. nivea, $i d$.

203. nodosa, $i d$.

204. Norrisii, $i d$.

205. nucea, $i d$.

206. nucleola, Lam.

207. nympha, Reeve

208. obeliscus, $i d$.

209. obesa, $i d$.

210, ocellata, Swain.
211. oleacea, Reeve.

212. Olivæformis, $i d$.

213. orientalis, Gray.

214. ossea, Reeve.

215. Pacifica, $i d$.

216. papalis, Lam.

217. pardalis, Küster.

218. patriarchalis, Lam.

219. patula, Reeve.

220. paupercula, Lam.

221. peculiaris, Reeve.

222. pediculus, Lam.

223. pellis-serpentis, Reeve.

224. peregra, $i d$.

225. Phillippiana, Forbes.

226. pica, Reeve.

227. picta, $i d$.

228. pinguis, $i d$.

229. planilirata, $i d$.

230. plicata. Lam.

231. plumbea, $i d$.

232. polita, Reeve.

233. pontificalis, Lam.

234. porcata, Humph.

235. porphyretica, Reeve.

236. pretiosa, $i d$.

237. proscissa, $i d$.

238. pruinosa, $i d$.

239. puella, $i d$.

240. pulchella, $i d$.

241. pullata, $i d$.

242. punctata, Swain.

243. puncticulata, Lam.

244. purpurata, Reeve.

245. pyramidalis, $i d$.

246. Quoyi, Desh.

247. radius, Reeve.

248. recurva, $i d$.

249. regina, Sozv.

250. retusa, Lam.

251. rhodia, Reeve.

252. rigida, Swain.

253. roborea, Reeve.

254. robusta, $i d$.

255. rosacea, $i d$.

256. rosea, $i d$.

257. Rossiæ, id.

258. rotundilirata, $i d$. 
259. rubiginosa, Reeve.

260. rubra, $i d$.

261. rubricata, $i d$.

262. rubritincta, $i d$.

263. rugosa, Sow.

264. rupicolor, Reeve.

265. Rüppellii, $i d$.

266. rustica, $i d$.

267. sanguisuga, Lan.

265. Savignii, Payr.

269. scabriuscula, Gray.

270. Schroeteri, Dest.

271. sculptilis, Reeve.

272. scutulata, Lam.

273. semen, Reeve.

274. semicostata, Lam.

275. semifasciata, $i d$.

276. semiferruginea, Jonas. 301. Ticaonica, Reeve.

277. Senegalensis, Reeve. 302. tornata, $i d$.

278. serpentina, Lam.

279. Sinensis, Reeve.

280. Solandri, $i d$.

281. solida, $i d$.

282. solidula, $i d$.

283. speciosa, $i d$.
284. sphærulata, Martyn.

285. spicata, Reeve,

286. Stainforthii, $i d$.

287. stigmataria, Lam.

288. striatula, $i d$.

289. strigata, Swain.

290. subulata, Lam.

291. sulcata, Kiener.

292. suturata, Reeve.

293. Swainsoni, Brod.

294. tabanula, Lam.

295. tæniata, $i d$.

296. telescopium, Reeve,

297. terebralis, Lam.

298. tessellata, Martyn.

299. testacea, Swain.

300. texturata, Lam.

303. Tornatelloides, $i d$.

304. tristis, Swain.

305. tuberosa, Reeve.

306. tumida, $i d$.

307. turben, $i d$.
308. turgida, Reeve.

309. turriger, $i d$.

310. tusa, $i d$.

311. typha, $i d$.

312. undulosa, $i d$.

313. ustulata, $i d$.

314. Vanikorensis, Quoy.

315. variabilis, Reeve.

316. variata, $i d$.

317. variegata, $i d$.

318. venustula, $i d$.

319. versicolor, Martyn.

320. verrucosa, Reeve.

321. vexillum, $i d$.

322. virgata, $i d$.

323. virgo, $i d$.

324. vittata, Swain.

325. vulpecula, Lam.

326. vultuosa, Reeve.

327. Woldemarii, Kiener.

328. Zebuensis, Reeve.

329. zelotypa, $i d$.

330. Ziervogeliana, Kiener.

331. zonata, Marryatt.

Figure.

Mitra Stanxfonthi. Plate 3. Fig. 13.-An extremely rare species from the collection of Thomas Norris, Esq.

\section{Genus 4. MARGINELLA, Lamarck.}

Animal; disc large, thin, videly expanded behind; mantle extending over the shell in two lobes, by which it is nearly enveloped, sometimes furnished with flaments; head flat, small, with a pair of short tentacles, behind which are the eyes; respiratory siphon cylindrical, very short.

Shell; ovately oblong or pyriform, emarginated at the base, spire short, more or less depressed; aperture oblong, often equalling the length of the shell; columella plaited nearly equally; outer. lip rolled back and solidified.

Regarding the general aspect of the Marginella, it is not surprising that Linnæus should have referred them to the genus Voluta; the shell differs, 
however, from the type of that group in being uniformly smaller, in the occasional Correy-like extension of the aperture to the summit of the spire, and in the outer surface being of the same highly polished enamel, as the Cypraa and Oliva. We learn from the last of these characters, that the shell is enveloped by the mantle of its animal inhabitant; a description of which was published by M. Adanson towards the close of the last century, in lis 'Voyage en Sénégal', and it has been recently confirmed with greater accuracy by the observations of M. Deshayes on the shores of the Mediterrunean; he describes it as having a thin capacious dise reflected over the edge of the shell, with the mantle extended on either side, as in the Cowrey, into a thin lobe, closing together chiefly behind, so as to leave a narrow opening on the back.

The soft parts of the Marginelle, like the Cowries, exhibit a brilliant variety of colouring; the shells are also similarly characterized; they are tolerably numerous in species, and are mostly found within the Tropics.

\section{Species.}

1. Adansoni, Kiener:

2. affinis, Beck.

3. amygdala, Kiener.

4. apicina, Menke.

5. aurantia, Lam.

6. auriculata, Ménard.

7. avellana, Lam.

8. avenacea, Valen.

9. Belangeri, Kiener.

10. Belcheri, Hinds.

11. Bellii, Sow.

12. bifasciata, Lam.

13. bivaricosa, $i d$.

14. blanda, Hinds.

15. bullata, Lam.

16. cærulescens, $i d$.

17. callosa, Sow.

18. catenata, Sow.

19. cincta, Kiener.

20. cingulata, Swainson.

21. clandestina, Brong.

22. Cleryi, Petit.

23. conoidalis, Kiener.

24. cornea, Lam.

25. Cumingiana, Petit.

26. curta, Sow.
27. cylindrica, Brown.

28. Cypræola, Sow.

29. dactylus, Lam.

30. Delessertiana. Récluz.

31. diaphana, Kiener.

32. elegans, Kiener.

33. evanida, Sow.

34. faba, Lam.

35. festiva, Kiener.

36. formicula, Lam.

37. frumentum, Sow.

38, fulminata, Kiener.

39. fusiformis, Hinds.

40. glabella, Lam.

41. Goodalli, Sow.

42. guttata, Swains.

43. helmatina, Rang.

44. inconspicua, Sow.

45. interrupta, Lam.

46. irrorata, Menke.

47. Kieneriana, Petit.

48. labiata, Valen.

49. lactea, Kiener.

50. Largillieri, Kiener.

51. limbata, Lam.

52. lineata, $i d$.
53. liturata, Menke.

54. longivaricosa, Lam.

55. maculosa, Kiener.

56. margarita, Kiener.

57. marginata, Sow.

58. miliacea (Volv.), Adan.

59. monilis, Sow.

60. muscaria, Lam.

61. musica, Hinds.

62. neglecta, Sow.

63. nodata, Hinds.

64. nubeculata, Lam.

65. oblonga, Swainson.

66. Olivæformis, Kiener.

67. oryza (Volv.), Lam.

68. pallida, Sorv.

69. persicula, Lam.

70. Petitii, Duval.

71. prunum, Sivainson.

72. pseudo-faba, Sow.

73. pulchella, Kiener.

74. pulchra, Gray.

75. punctulata, Petit.

76. quinqueplicata, Lam.

77. retusa, $i d$.

78. rosea, id. 
79. sapotilla, Hinds.

80. sarda, Kiener.

81. Sauliæ, Sow.

82. scripta, Hinds.

83. splendens, Humph.
84. strigata, Chemn.

85. tæniata, Sow.

86. tessellata, Lam.

87. tricincta, Hinds.

88. triticea, Sow.
89. undulata (Voluta), Ch.

90. varia, Sow.

91. vitrea, Hinds.

92. zonata, Kiener.

\section{Figure.}

Marginella nubeculata. Plate 1. Fig. 1.-From the collection of H. Cuming. Esq.

\section{Genus 5. RINGICULA, Deshayes.}

Animal; unknown.

Shell; small, globose, very solid, sinuated at the base, spire short, sharply acuminated, columella short, with a plait-like callosity at the upper part, and two strong plaits beneath; aperture small; lip remarkably thickened.

The genus Ringicula was instituted by MI. Deshayes for the reception of a solid marine shell, about the size of a small pea, the fossil analogue of which had been erroneously placed by Lamarck among the fresh-water, or rather amphibious, Auriculce. It was first discovered in a living state by M. Ménard de la Grove in the gulf of Tarentum, and, upon noticing its affinity with the fossil Auricula ringens of Lamarck, he at once observed that from its marine nature and sinuated aperture, the fossil species to which it was related had been referred to the wrong genus. The characters which his shell exhibited were more intimately allied to Irarginella, and he named it accordingly Marginella auriculata. M. Deshayes, however, has justly observed that its general form, and the disposition of the plaits, are not like those of Marginella, though closely allied to them, and I fully concur in the course he has adopted. It is a small white porcellanous shell, of very solid growth, the spire of which, though short, is sharply acuminated; the columella is peculiarly characterized by a rude plait-like callosity round the upper part, and two very prominent winding plaits beneath; there is a broad sinus at the base of the shell, and the lip is very considerably thickened. The following is the only recent species at present known.

\section{Figure.}

Rivgicula auriculata. Plate 1. Fig. 2. (Magnified),-From the collection of II. Cuming, Esq. 


\section{Family 3. PURPURIFERA.}

Shell ; terminating at the base, either with a short slightly ascending canal, or with a deep simus.

The genera enumerated under the head of Purpurifera, are grouped together upon a very artificial basis; the animal is characterized by a variation of form which it is difficult to reconcile with the propriety of their being associated in the same natural family, and the shell is scarcely less dissimilar in its general aspect. In Terebra the shell is of a smooth elongated lanceolate growth, whilst in Harpa it is of an ovate ventricose structure, thickly studded with varices; the only distinguishing character of the family, therefore, as constituted by Lamarck, resides in the basal sinus, that posterior portion of the shell which is fitted to the passage of the respiratory siphon, conveying water to the branchial cavity.

The soft parts of the Purpurifera, as in most of the molluscous tribe, display a striking contrast of colouring compared with the shell, and the relation of form is equally remote; in Dolium, the animal is green or mottled-blue, colours of which there is not the slightest approximating tinge in the shell; it is also characterized by an ample muscular disc, and a remarkable elongation of the proboscis, terminating in the $D$. perdix with a flattened fumel-like rosette, whilst the shell is chiefly distinguished for: its comparative tenuity. The animal of Havpa has a beautifully coloured ocellated disc, extending in a remarkable degree beyond the posterior extremity of the shell to nearly a peak. In some of the Buccina the disc is expanded on either side of the aperture, and truncated behind forming a flat square; in Oliva and Ancillaria we have a modification of the ventral disc somewhat analogous to the lobate structure of the Cowrey, which being reflected into an ample fold, though generally partially retracted, is sufficiently capacious to envelope the shell; in Magilus, on the other hand, the locomotive and calcifying organs are extremely limited in their dimensions, owing to the confined nature of its habitation, although the latter is exercised with a degree of energy which is truly wonderful.

The genera at present referred to this family are as follows :-

$\begin{array}{lll}\text { Terebra. } & \text { Pollia. } & \text { Concholepas. } \\ \text { Oliva. } & \text { Phos. } & \text { Monoceros. } \\ \text { Ancillaria. } & \text { Buccinum. } & \text { Purpura. } \\ \text { Eburna. } & \text { Leptoconchus. } & \text { Columbelia. } \\ \text { Planaxis. } & \text { Magilus. } & \text { Ricinula. } \\ \text { Quoyla. } & \text { Trichotropis. } & \text { Cassis. } \\ \text { Nassa. } & \text { Dolium. } & \text { Oniscra. } \\ \text { Cyllene. } & \text { Harpa. } & \text { Cassidaria. }\end{array}$




\section{Genus 1. TEREBRA, Bruguière.}

Animal; disc short, very thick and muscular; head proboscisshaped, cylindrical, tentacles short and conical with an eye situated on the outer side of each at the base; respiratory siphon cylindrical, rather prolonged.

Shell; eiongated, turriculated, sinuated at the base; whorls very munerous, but slightly convex, apex very sharp and elevated; aperture small; columella swollen, contorted, terminating in a point; lip simple. Operculum lorny, imbricated.

The genus Terebra is one of those well-defined groups which cannot easily be confounded with any other; it is distinguisher by a long subulate shell, composed of a number of small whorls tapering gradually to a point, as sharp as a needle, and the base of the aperture is invariably sinuated. The shell of Turritella has very much the form of Terebra, but the aperture is rounded and entire; so that Terebra may be likened to a very long drawn-out Buccinum, and Turritellu to a similarly elongated Turbo. The shells of these genera may, however, be readily distinguished from each other without referring to the generic peculiarities of the aperture. The calcilying function of the animal is much the more vigorously exercised in the genus under consideration, the shell is more solid, it exhibits a greater variety of structural embellishment, and whilst the colours are vivid and less obscure, they display a more pleasing variety of pattern and design.

The soft parts of Teretror are naturally very limited, the head and tentacles are small, and the entire mass when fully exserted, rarely extends beyond a tenth of the shell. But although the animal is cumbered with a shell ten times the length of its exserted borly, it is not of the sluggish character of the Britie; the shell of Teretia, though longer, is not of such overbalancing proportions, it is nore truly acuminated, the weight is chiefly at the base, and the animal obtains a comparative facility of locomotion by the force with which it is able to secure its muscular dise to the place of attachment.

The Terebre chicfly inhabit the eastern world, and are confined to warm temperatures; one small species, only, reaching so far north as the Mediterranean. The well-known T. maculata of Ceylon is the largest of the genus, the greater number of species vary from three to four inches in length, and are characterized by an interesting variety of sculpture and design. The most elongated and remarkable species is the T.pretiosu, which I have selected as an example on account of its rarity ; only two or three specimens have yet been seen. 


\section{Species.}

1. aciculata, Gray

2. affinis, $i d$.

3. alba, id.

4. albida, $i d$.

5. albula, Menke.

6. alveolata, Hinds.

7. amanda, $i d$.

8. anomala, Gray.

9. argus, Hinds.

10. armillata, $i d$.

11. aspera, $i d$.

12. Babylonia, Lam.

13. bicincta, Hinds.

14. bifrons, $i d$.

15. cærulescens, Lam.

16. cancellata, Quoy.

17. casta, Hinds.

18. castanea, Kiener.

19. cerithina, Lam.

20. cinerea, Basterot.

21. chlorata, Lam.

22. cingula, Kiener.

23. cingulifera, Lam.

24. columellaris, Hinds.

25. commaculata, Pfeiff.

26. consors, Hinds.

27. conspersa, $i d$.

28. copula, $i d$.

29. corrugata, Lam.

30. Cosentini, Philippi.

31. crenulata, Lam.

32. cuspidata, Hinds.

33. dimidiata, Lam.

34. duplicata, $i d$.

35. Dussumierii, Kiener.

36. eburnea, Hinds.

37. elata, $i d$.
38. fatua, Hinds.

39. fenestrata, $i d$.

40. fictilis, $i d$.

41. flammea, Lam.

42. flava, Gray.

43. frigida, Hinds.

44. fumiculata, $i d$.

45. granulata, Kiener.

46. glauca, Hinds.

47. hastata, Kiener.

48. inconstans, Hinds.

49. intertincta, $i d$.

50. lævigata, Gray.

51. lanceata, Lam.

52. larvæformis, Hinds.

53. laurina. $i d$.

54. lepida, $i d$.

55. ligata, $i d$.

56. lingualis, $i d$.

57. luctuosa, $i d$.

58. maculata, Lam.

59. mera, Hinds.

60. micans, $i d$.

61. monilis, Quoy.

62. muscaria, Lam.

63. Nassoides, Hinds.

64. nebulosa, Sow.

65. nimbosa, Hinds.

66. nitida, $i d$.

67. nubeculata, Sow.

68. obesa, Hinds.

69. oculata, Lam.

70. ornata, Gray.

71. Patagonica, $D^{\prime} \mathrm{Or} b$.

72. penicillata, Hinds.

73. pertusa, Basterot.
74. picta, Hinds.

75. plicata, Gray.

76. plombea, Dufo.

77. plumbea, Quoy.

78. pretiosa, Reeve.

79. pulchra, Hinds.

80. pygmæa, $i d$.

81. radula, $i d$.

82. raphanula, Lam.

83. robusta, Hinds.

84. rudis, Gray.

85. rustica, Hinds.

86. Sandwizensis, Sow.

87. Senegalensis, Lam.

88. specillata, Hinds.

89. spectabilis, $i d$.

90. straminea, Gray.

91. strigata, Sow.

92. strigilata, Lam.

93. stylata, Hinds.

94. subulata, Lam.

95. succinea, Hinds.

96. tenera, $i d$.

97. tessellata, Gray.

98. textilis, Hinds.

99. tigrina, Gray.

100. tricolor, Sow.

101. triseriata, Gray.

102. tuberculosa. Hinds.

103. tuberosa, $i d$.

104. undulata, Gray.

105. varicosa, Hinds.

106. variegata, Gray.

107. venosa, Hinds.

108. violascens, $i d$.

109. vittata, Lam.

\section{Figure.}

Teirebra pretiosa. Plate 3. Fig. 15. An extremely rare species, in the collection of E. G. L. Gruner, Esq., of Bremen. 


\section{Genus 2. OLIVA, Bruguière.}

Animal; disc widely expanded, reflected on either side orer the anterior portion of the shell, forming a capacions fold, sometimes rounded, sometimes acuminated behind, front extremity furmished with a pair of wing-like lobes, anterior to the head; head very small, tentacles thickened about half-ucay, at the summit of which thickened portion is the eye: mantle small, lind extremity furnished with a filament or cord which passes into a groove in the spire of the shell, front portion forming an ample siphon for conveying the water to the branclial cavity, with a flowing triangularly pointed appendage betind it .

Shell; polished, more or less cylindricul, emarginated at the base; spire short, sharp at the apex; whorls closely convoluted, with a deep narrow channel round the spire, in the place of the suture; aperture narrow, extending nearly the length of the shell; columella obliquely grooved, terminating with a callosity, lip simple.

The Olives were arranged by Lamarck in the same family with the Cowries on account of their polished exterior; they have been removed to the Purpurifera, because of their affinity with Ancilluria and Eburna. The whorls of the shell are convoluted on nearly the same vertical plane with the spire, and the columella is obliquely grooved, as if it had been bound, as it were, with cords, sufficient to swell the base into a callosity; the most striking character, however, is the presence of a deep narrow groove, encircling the spire in the place of the suture, the use of which I. have now to explain.

The enamelled exterior of the Olive-shell indicates that it is more or less enveloped, like the Cowrey, with a portion of the animal; but it is not covered by the mantle, it is protected by a modification of the dise; the calcifying organ of these mollusks differs both in structure and function. In the Correy, the office of calcification is performed by a lobate extension of the mantle from either side of the aperture, sufficient to cover the shell, and only retracted under a state of alarm. In Olive the mantle is limited to the interior and aperture of the shell; it appears to be furled over the edge of the lip, and is held, as it were, in a state of tension by a cord or filament passing from the posterior extremity into a deep narrow channel, which is excavated round the spire of the shell in place of the suture. The result of this difference in the condition of the calcifying organ, is, that in 
the Comrey the testaceous fluid is deposited from the outside, in layers at different intervals, whilst in the Olive it is secreted in layers simultaneously at the lip, and the porcellanous surface of the shell is preserved in its course of retrovolution, as well as after maturity, by a reflexion of the ventral disc, in a manner somewhat analogous to the reflected mantle of the Cowrey; bearing no part in the formation of the shell, however it may minister to its preservation by the tendency of its viscid humour.

It now remains to ascertain whether the distinction here assigned to the calcifying functions of these mollusks, is borne out by the physical condition of their shells at different stages of growth. Each period in the life of the Cowrey (as described at page 40 ) is illustrated by a different design of colouring; the shell ceases its course of retrovolution long before arriving at the adult state, and increases in substance and variety of colouring by the outivard expansion of the mantle. It is not so in the case of the Olive; the shell of this mollusk exhibits the same appearance at all stages of growth, the different layers of colouring matter must of necessity be deposited simultaneously, because the organ of calcification reaches only to the lip, from which the shell gradually recedes in its progress of growth. The Olive-shell has no periodical change of colour to mark its advancement, yet it will be found on removing the outer coat by chemical agency, that there is a superincumbent layer of different colour and design. The external coating of the Otiva utriculus is of an obscure milky blue colour, but the removal of this layer by the application of an acid, reveals a dark ashy ground, sprinkled with numerous triangular opal-like dashes ; the removal of the outer layer of the Oliva Brasiliensis exhibits a longitudinally striped pattem, and other varieties of design may be found in different species.

The Olives are confined exclusively to the tropical regions, we have none on our own coast, nor is there a single species in any part of the Mediterranean. They are described by M. Quoy, in the 'Voyage de l'Astrolabe', as possessing an unusual degree of activity, and able to regain their position when placed upon their backs; and Mr. Gray observes in Beechey's Voyage, that they live partially buried in the sand, though easily taken by lines baited with flesh.

\section{Species *.}

1. acuminata, Chemn.

5. aniomina, Duclos.

9. australis, Duclos.

2. alectona, Duclos.

6. araneosa, Lam.

10. avellana, Lam.

3. anaxora, $i d$.

7. atelina, Duclos.

11. bicincta, $i d$.

4. angulata, Chemn.

8. auricularia, Lam.

12. biplicata, Sow.

* The species of Oliva have been so inefliciently described, and so many nonsensical names have been introduced by $M$. Duclos, that a complete monograph of the genus with a change of nomenclature, would, I think, be au admissible and most acceptable contribution. 
13. Braziliana, Chemn.

14. caldania, Duclos.

15. canalifera, $i d$.

16. candida, Lam.

17. carneola, $i d$.

18. columba, Duclos.

19. columellaris, Sow.

20. conoidalis, Lam.

21. dama, Duclos.

22. eburnea, Lam.

23. elegans, $i d$.

24. episcopalis, $i d$.

25. erythrostoma, $i d$.

26. esmilota, Duclos.

27. Esther, $i d$.

28. fabagina, Lam.

29. fallotina, Duclos.

30. flammulata, Lam.

31. flaveola, Duclos.

32. funebralis, Lam.

33. fusifera, Dufo.

34. fusiformis, Lam.

35. glandiformis, $i d$.

36. gracilis, Brod.

37. granitella, Lam.

38. guttata, $i d$.

39. harpularia, $i d$.

40. hepatica, $i d$.

41. hiatula, id.

42. inflata, Chemn.

43. irisans, Lam.

44. ispidula, Linn.

45. kaleotina, Duclos.

46. Laumontiana, $i d$.

47. lepida, Dufo.
48. lepta, Duclos.

49. leucophæa, Lam.

50. leucostoma, Dufo.

51. leucozonias, Gray.

52. lineolata, $i d$.

53. literata, Lam.

54. lugubris, $i d$.

55. luteola, $i d$.

56. mandarina, Duclos.

57. Marminii, $i d$.

58. maura, Lam.

59. mica, Duclos.

60. miriadina, Duclos.

61. mitreola, $i d$.

62. mustelina, Lam.

63. mutica, Say.

64. nana, Lam.

65. nebulosa, id.

66. nedulina, Daclos.

67. nitelina, .id.

68. nitidula, $i d$.

69. obtusa, Lam.

70. olorinella, Duclos.

71. oriola, Lam.

72. oryza, $i d$.

73. ozodona, Duclos.

74. panniculata, $i d$.

75. Peruviana, Lam.

76. pica, $i d$.

77. polpasta, Duclos.

78. porphyria, Lam.

79. puelcha, Duclos.

80. puelchana, D'Orb.

81. pulchella, Duclos.

82. puersolina, $i d$.
83. razamola, $i d$.

84. reticularis, Lam.

85. rosolina, Duclos.

86. sanguinolenta, Lam.

87. scripta, $i d$.

88. selasia, Duclos.

89. semistriata, Gray.

90. Senegalensis, Lam.

91. sepulturalis, Lam.

92. splendidula, Soro.

93. stellata, Duclos.

94. subulata, Lam.

95. tehuelchana, $D^{\prime}$ Orb.

96. tergina, Duclos.

97. tessellata, Lam.

98. testacea, $i d$.

99. textilina, Lam.

100. tigridella, Duclos.

101. tigrina, Lam.

102. tricolor, Chemn.

103. tringa, Duclos.

104. triticea, $i d$.

105. tunquina, $i d$.

106. undata, Lam.

107. undatella, $i d$.

108. ustulata, $i d$.

109. utriculus, $i d$.

110. ventricosa, Duclos.

111. venulata, Chemn.

112. volutella, Lam.

113. zanoeta, Duclos.

114. zenopira, $i d$.

115. Zeylanica, Lam.

116. zigzag, Duclos.

117. zonalis, Lam.

\section{Figure.}

Oliva maura. Plate F.-Shell with animal, showing its ample reflected disc, the broad lobes in front, the tentacles and eyes, the respiratory siphon, and floating appendage, and the filamentary cord proceeding from the posterior extremity of the concealed mantle and passing into the groove of the spire. Froin the Zoology of the Voyage de l'Astrolabe.

Oliva angulata. Plate 1. Fig. 4. Shell, showing the grooved columella and basal sinus. 


\section{Genus 3. ANCILLARIA, Bruguière.}

Animal ; disc oblong, bifurcated belind, triangularly lobed in front, partially reffected over the shell, under surface furnished beneath the head with an orifice; head and tentacles small, with a cylindrical trunk; respiratory siphon rather prominent.

Shell; oblong, cylindrical, widely emarginated at the base; spire rather short, suture obtuse; columella obliquely grooved, sometimes umbilicated, slightly twisted; operculum small, hormy.

The Ancillarice are a limited group of mollusks allied to the Olives, yet possessing characters very much opposed to those recorded in that peculiar genus. According to M. Quoy's figure of the $A$. allisulcatu, the shell is partially imbedded in the substance of the disc, somewhat after the manner of Natica, the middle portion of it being reflected over the shell, not the outer edge as in the Olive. There is, moreover, no filamentary cord passing from the extremity of the mantle around the spire; the spire of Ancillaria being distinguished, on the contrary, by a callous deposit of enamel, a condition the very reverse of that indicated by the deeply excavated groove in the Olive. The hinder extremity of the disc is peculiarly bifurcated; the front exhibits a similar lobed appearance, and the head and tentacles are small, concealed within the fold of the disc, probably from the animal's habit of burrowing in the sand.

The shell of Ancillaria differs equally in its lesser detail from that of the Olive; it exhibits no pattern or desigu, and is mainly characterized by an uniform bright golden yellow, passing into a bright cimmamon red.

The rarest species are from New Holland.

\section{Species}

1. albifasciata, Sucains.

2. albisulcata, Sow.

3. aperta, $i d$.

4. australis, $i d$.

5. candida, Lam.

6. castanea, Sow.

7. cingulata, $i d$.

8. cimnamomea, Lam.
9. eburnea, Deshayes. 10. effusa, Swainson.

11. exigua, Sow.

12. fulva, Swainson.

13. glabrata, $i d$.

14. mamillata, Hinds.

15. marginata, Lam.

16. Mauritiana, Soro.
17. mucronata, Sow.

18. nivea, Swainson.

19. oblonga, Sow.

20. obtusa, Swainson.

21. rubiginosa, $i d$.

22. Tankervillii, id.

23. ventricosa, Lam.

\section{Figure.}

Anchlarim Maviritrasa. Plate 4. Fig. 21. Showing the aperture and white twisted columella. 


\section{- Genus 4. EBURNA, Lamarck.}

Animal; disc stout and thick, oval in front, pointed behind, carrying a horny operculum at the posterior extremity which fits exactly to the aperture of the shell ; head large, bifurcated in front into two elongated tentacles, at the outer base of which are the eyes; mouth armed with a cylindrical trunt; respiratory siphon rather long.

Shell; oblong-ovate, spire acuminated, with the sutures more or less deeply chamnelled; whorts forming a deep umbilicus which is rarely filled up; colour ivory white, tessellated and spotted with orange-brown.

The genus Eburna includes a natural, though extremely limited group of species, but M. Deshayes questions whether it is entitled to rank higher than as a section of Buccinum ; from his description of the animal, above recorded, we learn that it has a strong natural affinity with that genus, yet there is a curious peculiarity of design in the structure and colonr of the shells. It is not usual to regard colour as an element in the character of a genus, but in the case before us it constitutes a feature which cannot be overlooked. Divested of the E. glabruta, plumbea, and spiratu, which have been erroneously referred to this genus, the species are each distinguished by a blotched and tessellated painting of orange brown upon a white ground, which is very characteristic; the apex throughout is black, and the columella and interior of the aperture white.

The E. spirata and Zeylanica are found in Ceylon in great abundance; the species selected for illustration are from Japan, and of great rarity.

\section{Species.}
1. ambulacrum, Sow.
4. Japonica, Reeve.
7. Valentiana, Sicainson.
2. areolata, Lam.
5. lutosa, Lam.
8. Zeylanica, Lam.
3. australis, Sov.
6. papillaris, Sow.

\section{Figures.}

Eburna papillaris. Plate 4. Fig. 19 a. -From Irr. Cuming's collection. Eburna Japonica. Plate 4. Fig. 19 b. From 1 r. Chming's collection. 


\section{Genus 5. PLANAXIS, Lamarck.}

Animal; disc short, thick, furnished at its posterior extremity with a horny operculum; head proboscidiform, with two elongated tentacles, each having an eye on the outer side of the base, edge of the mantle simple, not canaliculated, open in front to give access to the branchial cavity.

Shell ; solid, ovately conical, terminating at the base with a narrow sinus; columella depressly concave, will a callosity at the upper part; interior of the aperture grooved.

I cannot agree with M. Deshayes in transferring the little group of mollusks, associated under the title of Planaxis, to a place among the vegetable-feeders, Littorince, Melanice, and Paludince. The shell is not much unlike that of Nassa, nor is there sufficient variation in the soft parts to influence the propriety of their being arranged in the same family with the Purpura. The animal is distinguished by its ringed proboscis-shaped head, and the free opening of the mantle communicating with the branchial cavity, and the shell exhibits that peculiar solidity of structure which is so characteristic a type of carnivorous habits; it has a prominent callosity on the upper part of the columella, and the interior of the aperture is more or less strongly grooved.

MM. Quoy and Gaimard have figured a shell with its molluscous inhabitant, in the Zoology of the 'Voyage de l'Astrolabe', under the title of Planaxis decollatus, which has been elevated to the rank of a new genus, with the name of Quoyia; the characters of this shell are very similar to those of the genus under consideration, but its subulate form and grooved columella are peculiar and characteristic.

Very few Planaxes have been collected; they are not, however, uncommon.

\section{Species.}
1. areolata, Lesson.
5. Buccinoides, Desh.
9. semisulcata, $i d$.
2. atropurpurea, Récluz.
6. circinata, Lesson.
10. undulata, Lam.
3. Brasiliana, Deshayes.
7. niger, $i d$.
11. sulcata, Lam.
4. brevis, Quoy.
8. planicostata, Sow.

Figure.

Planaxis planicostata. Plate 3. Fig. 17.-From Mr. Cuming's collection. 


\section{Genus 6. QUOYIA, Gray.}

Animal; disc small, ovate, folded across and crumpled in front, hind part furnished with a semi-ovate operculum, side of the body simple; proboscis short and ringed; tentacles slender, conical, far apart at the base; eyes placed on short tubercles at their outer base; mantle simple, with a groove on the left angle.

Shell; subelongated, aperture short, slightly sinuated at the base, columella peculiarly cut away at the top, interior finely grooved.

The shell of this mollusk, figured by MII. Quoy and Gaimard in the 'Voyage de l'Astrolabe', has very much the appearance of an elongated Planaxis, and we learn from the characters of the soft parts above recited, from Mr. Gray's 'Zoology of Beechey's Voyage', that the animals of these genera are in reality very closely allied. There is, however, a great dissimilarity in the form of the shell, and the upper portion of the columella is characterized by a curious broad groove or cutting away of the white enamelled surface in place of any callosity; from whence, I think, with Mr. Gray, that it may be entitled to rank as a separate genus.

\section{Figure.}

Quoyia decollata. Plate 3. Fig. 18.-From Mr. Cuming's collection.

\section{Genus 7. NASSA, Lamarck.}

Animal; disc large and thin, nearly semicircular in front, terminated on each side by a short ear-shaped appendage, hind extremity bifurcated; head flattened, very large, with a conical tentacle on each side, swollen at the outer side of the base and haviny the eye situated at the top of the swollen portion.

Shell; ovate, slightly turreted, terminating at the base with a deep sims or very short canal; aperture orbicular, angulated at the upper part; columella smooth, sometimes broadly effused, with a tooth or callosity at the upper part; lip toothed, sometimes crenulated within. Operculum very small, hormy.

The Nassa are an interesting group, distinguished alike from the Buccina, with which they were formerly associated, both in respect to the 
animal and the shell. The deseription above quoted, from the observations of M. Deshayes, informs us that there is a peculiarity in the structure of the dise, beautifully illustrated by M. Quoy in the 'Voyage de l'Astrolabe', in having the front extremity furnished with two ear-shaped appendages, and the hind part bifurcated, the corners presenting a tentacle-like appearance.

There is a singular uniformity in the form and colour of the shells of Nussa; they are all small, and mostly distinguished by a remarkably thickened deposit of enamel in the vicinity of the aperture.

Some time after Lamarck introduced the genus $N$ assa, he abandoned it except as a sectional division of the Buccina; the generic peculiarities of this comparatively extensive group were, however, too obvious to escape attention.

They are confined to the southern and tropical regions.

\section{Species.}

1. abbreviata, Desh.

2. achatina, $i d$.

3. acuta, Say.

4. ampullacea, Desh.

5. annulata, $i d$.

6. arcularia, Lam.

7. Ascanias, Desh.

8. attenuata, Gray.

9. Belangeri, Desh.

10. callosa, Gray.

11. canaliculata, Desh.

12. candens, Hinds.

13. coccinella, Desh.

14. complanata, Powis.

15. concinna, $i d$.

16. conoidalis, Dest.

17. coronata, Lam.

18. crenata, Hinds.

19. crenulata, Desh.

20. dentifera, Powis.

21. exilis, $i d$.

22. fasciata, Desh.

23. fasciolata, $i d$.
24. festiva, Ponis.

25. gaudiosa, Hinds.

26. gemmulata, Desh.

27. gibbosula, Lam.

28. glans, Desh.

29. globosa, $i d$.

30. grana, $i d$.

31. granifera, $i d$.

32. Grayi, $i d$.

33. inflata, $i d$.

34. limata, $i d$.

35. luteostema, Br. \& Sow.

36. marginulata, Lan.

37. mæsta, Hinds.

38. Melanoides, Desh.

39. miga, $i d$.

40. muricata, Quoy.

41. mutabilis, Desh.

42. myristicata, Hinds.

43. neritea, Lam.

44. nodata, Hinds.

45. nodifera, Powis.

46. obsoleta, Say.
47. olivacen, Desh.

48. Olivæformis, $i d$.

49. pallida, Powis.

50. papillosa, Sow.

51. pauperata, Lam.

52. perpinguis, Hinds.

53. polita, Desh.

54. polygonata, Lam.

55. pulla, $i d$.

56. reticulata, Desh.

57. retusa, $i d$.

58. Roissyi, $i d$.

59. scabriuscula, Porvis.

60. stolata, Desh.

61. subspinosa, $i d$.

62. suturalis, $i d$.

63. texta, $i d$.

64. Thesites, Lam.

65. tricarinata, Des/.

66. trivittata, Say.

67. unicincta, $i d$.

68. vibex. id.

\section{Figne.}

Nassa luteostona. Plate 3. Fig. 11.-From Mr. Caming's collection. 


\section{Genus 8. CYLLENE, Gray.}

Animal ; unknown.

Shell; small, ovate, swollen, truncate, and a little recurved at the base, spire rather short, acute, with the sutures minutely channelled, columella concave, smooth or fincly grooved; lip stightly notched near the base, emarginated at the summit; interior finely radiately grooved.

The genus Cyllene was introduced by Mr. Gray in his 'Synopsis' of our national collection, for the sake of distinguishing a few small shells exhibiting an association of character of remarkable peculiarity, and of which the Buccinum lyratum of Lamarck, figured by M. Kiener in his illustration of that genus, (Pl. 22. Fig. 35.) may be regarded as the type. It may be observed on reference to our figure, that the shell is of a small Voluta-like structure, without plaits, however, on the columella, which is a little excavated, and slightly grooved, the spire being short though sharply acuminated; the lip is very characteristic; at its junction with the body whorl, it is emarginated in a manner similar to that of Oliva, and near the base, it is distinguished by a small notch, like that which constitutes one of the principal generic features in Phos; the interior is deeply radiately grooved, as in many of the Purpura. I am not aware that the two or three species referable to this type, have been yet described; it therefore only remains to record the one included under. Buccinum by Lamarck, and that selected for illustration which I dedicate to the founder of the genus.

\section{Species.}

1. Grayi, Reeve. 2. lyratum, (Buc.) Lamarck.

\section{Figures.}

Cylume Grayi. Plate 3. Fig 12.-Showing the front portion of the shell. From Mr. Cuming's collection.

\section{Genus 9. BULLIA, Gray.}

Animal: disc very large, thin, flatly expanded, head flattened, with the tentacles long, subulale, and rather distant; no eyes. Shell; ovate, turretert, spire more or less subulately acuminated, sutures fiequently callous; columella callous towards the upper part, excavated; aperture emarginated above and below. 
The shells assembled under the title of Bullia by Mr. Gray, are deserving of generic distinction, not only on account of their peculiar affinity of form and colour, but because of the curious expanded structure of the animal-disc, as represented by M. M. Quoy and Gaimard in their figure of the Buccinum lavissimum of Lamarck.* The Buccinum cochlidinm of Chemnitz is the largest and most conspicuous of the group, whilst the B. annulatum of Lamarck, is characteristic of the Terebra-like portion of the species.

Mr. Gray notices in his observations on this genust, that the Bullice "are found crawling on the sand in bays; they generally remain at the bottom of the water, and are easily caught alive with a bit of meat tied at the end of a string, as they immediately attach themselves to it."

In confirmation of the importance of this genus, it only remains to notice that M. Deshayes proposes to remove those species hitherto arranged under the head of Buccimum, to a place amongst the Nassa, to which they are apparently still more remotely allied.

$\begin{array}{lll}\text { 1. achatina. } & \text { 7. hastata. } & \text { 13. Paytense. } \\ \text { 2. annulata. } & \text { 8. lævigata. } & \text { 14. polita. } \\ \text { 3. armata. } & \text { 9. lævis. } & \text { 15. semiplicata. } \\ \text { 4. cochlidium. } & \text { 10. lævissima. } & \text { 16. terebralis. } \\ \text { 5. globulosa. } & \text { 11. lineolata. } & \text { 17. turrita. } \\ \text { 6. granulosa. } & \text { 12. Mauritiana. } & \text { 18. vittata. }\end{array}$

Genus 10. PHOS, De Montford.

Animal; disc oblong, expanded, carrying a small horny operculum, head small, tentacles ligh up, very long, slender, eyes situated at the tips of the tentucles.

Shell; oblong, mostly acuminated, and longitudinally ribbed, outer lip notched towards the base; columella somewhat obsoletely one-plaited.

The Buccinum senticosum Limneus, Cancellaria senticosa Lamarck, was figured by De Montford in his 'Conchyliologie Systematique' as the type of a new genus, under the laconic title of Phos; and it is one of the few genera introduced by that author, the propriety of which has been confirmed by subsequent discoveries. The species above referred to, is not,

* Voyage de l'Astrolabe.

$\uparrow$ Zoology of Beechey's Voyage.

¥ A monograph of this genus will shortly appear in the 'Conchologia Iconica'; I can give but an undigested list of species at present, and refrain from attaching any authorities. 
however, the most characteristic of the group; in the exhaustless stores of Hugh Cuming, Esq. are thirty or more distinct kinds, collected by that indefatigable traveller in the course of his prolific researches, nearly the whole of which remain to be described. Suffice it to say, that the chief peculiarity consists in the notch near the base of the lip, though independent of this, the species are characterized throughout by a marked degree of generic affinity.

\section{Species ${ }^{*}$.}

1. articulatus, Hinds.

5. pyrostoma, Reeve.

8. senticosus, Montf.

2. crassus, Hinds.

6. reticosus, Hinds.

9. Veragueusis, Hinds.

3. Cumingii, Reeve.

4. gaudens, Hinds.

7. roseatus, Hinds.

10. virgatus, Hinds.

Figure.

Pros Cuminair. Pl. 3. Fig. 16. Showing the front portion of the shell.

\section{Genus 11. BUCCINUM, Linnaus.}

Animal; disc oval, sometimes elongated in front; head narrow, flattened, with two cylindrical tentacles, at the base of which are two slightly pedunculated eyes; trunk cylindrical, more or less elongated.

Shell; ovate or oblong, emarginated and sometimes a little channelled at the base, columella for the most part smooth; aperture oblong-ovate, sometimes furnished on each side at the upper part with a callosity or denticles; lip very slightly, if at all, thickened, serrated or crenated.

The Latin word Buccinum, a trumpet, was applied indiscriminately by the ancients, to almost any sort of spiral univalve shell; Limmeus made a more restricted application of the word, but his genus still included species of very anomalous character. Lamarck, the great reformer of the Limnean system of classification, divided the Buccina of that author, into several excellent acknowledged genera, including nearly the whole of those enumerated under the present family, reserving the Buccinum undutum, (the common Whelk of our market) for the type of his genus. This has been since dismembered of the groups Nassa, Bullia, Cyllene, and Phos, and M. Deshayes further distinguishes the Whelk, and its congeners, by the

* The species above referred to in Mr. Cuming's collection, will shortly be described ant illustrated in the "Conchologia Iconica." 
title of Tritonium, once assigned to them by Muller. These latter, however', I propose to retain in the prescnt genus, together with all those species of which the upper part of the aperture is distinguished by the presence of a callosity or denticles, such as the B. undosum and others, added to which I include the Purpure sertuni, Francolina, and lagenaria of Lamarck, as well as the Fusus articulatus of the same author. *

\section{Species}

1. aciculatum, Lam.

2. acuminatum, Menke.

3. affinis, Less.

4. alveolatum, Kiener.

5. ambiguum, Mont.

6. Anglicanum, Lam.

7. angulosum, Gray.

8. articulatum (Fins.), L.

9. aurantium, Lam.

10. Australe, Chemn.

11. boreale, Brod.

12. Boysii, Nuttall.

13. breve, Adams.

14. catenatum, Powis.

15. cinctum, Quoy.

16. clavula, Menke.

17. Coromandelianum, $L$

18. costatum, Quoy.

19. Cuvierii, Payr.

20. Delalandi, Kiener.

21. distortum, Gray.

22. D'Orbignii, Payr.

23. elegaris, Reeve.

24. Francolinum(Purp.)L.52. ovum, Turton.

25. fasciculare, Menke.

26. Floridanum, Less.

27. fuscatum, Lam.

28. Genetta, Less.

30. glaciale, Lam.

42. macula, Mont.

46. melo, Less.

51. ornatum, Say.
29. Gervilii, Kiener.

31. gradatum, Desh.

32. graniferum, Kiener.

33. Gualterianum, Kiener.

34. hepaticum, Mont.

35. hirtum, Kiener.

36. Humphreysianum, Bt.

37. Jacksonianum, Kiener.

38. lagenarium (Purp.),L. 65. sertum (Purp.), L.

39. lineatum, Soro.

40. lineolatum, Lam.

41. lutestoma, Kiener.

43. maculatum, Martyn.

44. maculosum, Lam.

45. melanostoma, Lam.

47. metula, Hinds.

48. modestum, Powis:

49. moniliferum, Valen.

50. obsoletum, Say.

53. papyraceum. Lam.

54. pediculare, Lam.

55. phalæna, Lesson.
56. plicatulum, Nuttall.

57. polaris, Gray.

58. porcatum, Gmel.

59. Poulsoni, Nuttall.

60. pulicaris, Lesson.

61. rufulum, Kiener

62. scaralinum, Soro.

63. Schroeteri, Beck.

66. sepimentum, Rang.

67. serratum, Dufresne.

68. succintum, Powis.

69. tenue, Gray.

70. tenuiplicatum, Lam.

71. testudineum, Chemn.

72. tigrinum, Kiener.

73. Tranquebaricum, Lam.

74. Triton, Less.

75. tulipa, Less.

76. undatum, Lam.

77. undosum, Quoy.

78. varicosum, Chemn.

79. vinosum, Lam.

80. viverratum, Kiener.

81. vittatum, Linn.

82. zebra, Lam.

\section{Figure.}

Buccinum melanostoma. Pl. 4. Fig. 22. Showing the front portion of the shell with its black-enamelled columella.

* These and several new allied species, arranged in part by Mr. Gray, in the British Museum, under the head of Pollia, will appear shortly in a Monograph of Buccinum in the "Conchologia Iconica'; the list of species given herewith is necessarily incomplete. 


\section{Genus 12. LEPTOCONCHUS, Rä̈ppell.}

Animal; proboscis elongated, retractile; tentacles two, smooth, triangular, jointed internally at the base, and bearing the eyes externally in the middle; disc middling, no operculum; mantle circular at the edge, without any siphonal appendage, a little produced on the left side; branchial orifice rather large.

Shell; thin, pellucid, nearly globose, spire depressed, rather obsolete; aperture large, suboval, extremities turned contrariwise, margins disjointed, right margin thin, a little expanded anteriorly; umbilicus none, truncated anteriorly, contorted.

Such are the descriptions of Leptoconchus recorded by Dr. Rüppell, in his communication to the Zoological Society of London in September, 1834. It is allied to the Magilus, with this difference, the margins of the aperture are not united, and by reason of its dwelling in exposed cavities of madrepore, forms no extended tubular growth.

"The colour of the shell," says the leurned traveller, "which constitutes the type of this new genus, is constantly a slightly sordid milk-white. It is suleated externally by numerous longitudinal undulated closely-set lines, the outer whorls encroaching on the spire of the earlier ones so as almost to obliterate it. Individuals of all ages have the shell thim and fragile, and constantly occur imbedded in the calcarcous mass of polypes, having a communication with the sea by only a moderate opening. The animals of Magilus and Leptoconchus are distinguished by the presence and absence of an operculum, and by the difference in the proboscis; the siphon of the former, moreover, does not occur in the latter."*

Dr. Riippell suggests that Leptoconcluts might be arranged in the vicinity of Tanthina, I cannot, however, subscribe to this opimion, the habits and structure of these mollusks being so totally dissimilar.

\section{Figure.}

Leptoconchius striatus. Pl. 4. Fig. 20. Showing, $a$ and $b$, back and front view of the shell; $c$, as it appears imbedded in a mass of coral.From Mr. Cuming's collection.

\footnotetext{
* Pro Zool. Soc. 1834. p. 105.
} 


\section{Genus 13. MAGILUS, De Montford.}

\section{Animal; disc muscular, furnished posteriorly with a small oblong elliptic horny operculum; head small, somewhat obscure, pro- longed on each side into two short tentacles, on the outer side, at the base, of which are the eyes; proboscis obtuse.}

Shell; ovate, spiral for three or four whorls, then continued in a straight or flexuous direction to a considerable extent, the tube forming a keel on the lower side and a corresponding siphon at the aperture.

The Magilus affords a striking example of the fallacy of arranging shells according to their external form and aspect, without reference to the nature and habits of their animal inhabitants; it presents also a remarkable instance of intelligent economy. Lamarck concluded from the vermiform structure of this shell, that it must be formed by an Annelide, after the manner of a Serpula, upon some foreign body, and he arranged it accordingly in the same natural group with the Testaceous Worms, the Earth Worms, Leeches, \&c. It was, however, discovered by Dr. Rüppell, during his researches on the coast of Abyssinia, that the animal in question is a true pectinibranchiate mollusk, inhabiting masses of Nadrepore; the vermiform structure of whose shell is induced by its confined situation of growth. The formation of the shell originates in the same spiral plan of volution as that of other pectinibranchiate mollusks, but the animal finding it necessary to be in immediate communication with the surrounding fluid, is obliged to leave its spiral plan of growth in order to follow the enlarging surface of the coral. To accomplish this, it pursues a straight, or flexuous growth, solidifying the posterior portion of the shell in its progress, to enable it to reside within the vicinity of the aperture*; the soft parts of this mollusk scarcely exceed two inches in length, although its shell is prolonged to the extent of from twelve to fifteen inches, by a gradual slipping of the muscle of attachment along the colu-

* Peu à peu la partie du corps de l'animal qui repose sur la columelle sécrète en abondance de la matière calcaire qui remplit non-seulement tout l'intérieur des premiers tours de spire, mais qui force méme, par sa surabondance, l'animal à douner une autre direction aux nouveaux tours de sa coquille, de manière que celle-ci, qui jusqu'au quatrième tour de spire est héliciforme, prend au-delà un accroisssement obsolument irrégulier : tantot les nouvenux tours se contournent en tire-bouchon, et tantot la coquille se continue en ligne presque droite ou coudée. On reconnait cependant toujours la cause de cet accroissement irrégulier, qui est la copieuse sécrétion de substancc calcaire faite par le rebord gauche du manteau. Il se forme par lì une arete èmoussée le long de la gouttière de l'ouverture, et la partie des nouveaux tours qui reposerait sur la columelle prend tantot une surface lisse, et tantot elle présente des lames irrégulières. Pendant que la coquille s'alonge ainsi par son accroissement, la cavité des premiers tours se renplit progressivement de manière que la cavité de la coquille dépasse rarement deux pouces de profondeur, quoique le tube cutier ait souvent douze i quinze pouces." - RUPPLLL, Mem. 1832. 
mella, accompanied by a copious secretion of calcareous matter from the mantle.

It may be observed that the growth of the Magitus presents a sort of negative analogy with that of the Nantilus; the animal of each advancing in the outer porch of its shell by the aid of a relaxing muscle; and their mode of operation is curiously adapted to the difference in their circumstances of habitation. The former, in order to sustain the increasing pressure of the coral, fills up the vacated portion of its shell with solid matter, the latter, having a different medium to contend with, chambers in its shell by a succession of light partitions to give it buoyancy ; if the Magilus pursued its course by the deposit of light transverse partitions, after the manner of the Nautilus, the increasing growth of the coral would probably crush it (unless the effect be nullified, as in the case of the Pholades, by a circulating current of solvents), and if the Nautilus advanced in its shell by solidifying the vacated portion, after the manner of the Magilus, it would produce an incumbrance incompatible with its locomotive faculties.

Like all mollusks inhabiting coral, the Magitus is almost devoid of colouring matter; the shell is of a transparent alabaster white, whilst the edge of the mantle of the animal is tinged with violet. I am not aware that this mollusk has been found in any other locality than the shores of the Red Sea, or in any other species of coral than the Meandrina phrrygia.

\section{Figure.}

Magilus avtiques. Pl. 6. Fig. 25. Showing its vermiform structure, keel, and siphonated aperture.-From the cabinet of $H$. Cuming Esq ; collected by Dr. Rïppell, at the Red Sea.

\section{Genus 14. TRICHOTROPIS, Broderip.}

Animal; unknown.

Shell; thin, turbinated, umblicated, and stightly canaliculated at the base, covered with a strong horny epidermis, sometimes furnished with spiral rows of fine bristles, spire angularly turreted; aperture triangularly ovate; operculum thin, laminated.

Although a specimen of this remarkable shell was collected with the soft parts by Captain Belcher, I am not aware that the animal has ever been described; its true relation in the molluscous system still remains to be 
determined. Of the species at present known, the $T$. bicarinata, is the only one at all remarkable for its size and bristly appcarance; it is of a fragile texture, and unlike the shell of any other genus.

The species above alluded to is from Icy Cape; those collected by Mr. Hinds, are from a much warmer region.

\section{Species}

1. acuminata, Jeffreys. 4. borealis, Broderip. $\quad$ 7. flavida, Hinds.

2. Atlantica, Muller. 5. cancellata, Hinds. $\quad$ 8. inermis, Hinds.

3. bicarinata, Broderip. 6. costellata, Courth. 9. umbilicata, Magill.

\section{Figure.}

Trichotropis bicarinata. Pl. 7. Fig. 33. Showing the aperture and bristly epidermis.

\section{Genus 15. DOLIUM, Lamarck.}

Animal; disc ovately oblong, large, very thick and muscular, subauriculated on each side in front; head large and rather flattened, with an unusually long conical tentacle on each side, at the base of which are the eyes, fixed upon short peduncles; trunk capable of considerable clongation, branchial siphon ample, reflexed.

Shell; thin, rotundately swollen, light and ventricose, ribbed transversely, but not longitudinally; columellar lip thin, widely expanded, outer lip fimbriated or crenated.

The Dotia constitute a limited, but very characteristic group, distinguised by their size and muscular strength, and by the voracity and comparative activity of their habits. The head is furnished with a long retractile trunk, which they have the capacity of rapidly protruding and withdrawing; they have also an ample disc, and "when the animal desires to swim," says M. Deshayes, who had an opportunity of observing the Dotizm on the shores of the Mediterranean, in the course of his expedition to Algeria, "lhe swells it out with an cnormous quantity of water, which is imbibed through certain pores". I have given representations of three different species of this genus with the soft parts, in order to show how much grenter variety and brightness of colour is exhibited in the animal, than in the shell; in the D. perctix, we find a bright blue-striped animal with a dull brown shell, and the D. olearium and pomm, with pale sallow yellowish shclis, have 
one an animal of a bright blue colour, the other of a rich coppery green; in the first of these, the proboscis appears to be furnished with a sort of grappling rosette, analogous to the dentated extremity of the trunk in Mitra, the animal has not, however, the sluggish habits of that genus, by reason of the light and portable structure of its shell.

The Dolium shell is, for its size, the lightest of spiral univalves, approaching somewhat in form to that of Cassis, but fully distinguished by its tenuity and want of varices, as well as by the absence of any recurvature at the base.

\section{Species.}
1. Chinense, Desh.
5. galea, Lam.
9. perdix, Lam.
2. costatum, Desh.
6. maculatum, Lam.
10. pomum, Lam.
3. fasciatum, Lam.
7. melanostoma, Jay.
8. olearium, Lam.
11. variegatum, Lam.
4. fimbriatum, Sow.

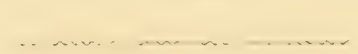

\section{Figures.}

Dolium pendx. Plate $E$. Shell with animal, showing its expanded bluestriped disk, with the auriculated structure in front, the conspicuous head and tentacles, with the eyes on short peduncles at the base, the respiratory siphon for conveying water to the branchial cavity, reclining back upon the shell, and the extended trunk with its dilated rosette-like extremity.

Doliux posux. Plate $G$. Shell with animal, showing its blue-striped disk, the proboscis only partially exserted, tentacles, eyes, siphon, \&c.

Doumu olearium. Plate $G$. Shell with animal, showing its coppery green disk, tentacles, eyes, siphon \&c, the trunk being wholly withdrawn.-All from the 'Voyage de l'Astrolabe'.

Doliun finbriatu. Plate 5. Fig. 24. Shell, shoming the aperture and excavated columella._From Mr. Cuming's collection.

\section{Genus 16. HARPA, Lamarck.}

Animal ; disc very large, elongated, semicircular in front, terminuting posteriorly in a point; head flattened, anriculated on either side, tentacles not very long, with the eyes situated on the outer side lowards the base; respiratory siphon very long. Shell; ovate, ventricose, sprier short, with the apex clevated and acute; whorls longitudinally varicose or ribbed; columella smooth, highly enamelled; aperture lurge. 
The "Many-ridged Harp", the "Rose Harp" the "David's Harp" and others, are shells of such familiar occurrence, that it will be interesting to form some atcquaintance with the animal from which they derive their existence. It will be seen on reference to plate $E$ that the soft parts of Harpa are of unusually large size, the disk being elongated posteriorly to a point, and widely auriculated in front; indeed, it is described as being so large and muscular as to be scarcely susceptible of being contracted within the aperture of the shell. The animal of the 'Harps', like that of the 'Tuns', appears to exhibit a rather more than ordinary degree of activity; it is related both by M. Reynaud and M. Quoy, to have the faculty of spontaneously divesting itself of a portion of the disk, under irritation or emergency, after the manner of the Annelicles, which it is well known often separate in pieces from violent contraction. The colours of the animal are scarcely less vivid than those of the shell, being of yellowish-green and rose, curiously ocellated throughout, whilst the respiratory siphon is striped across.

The shells of this beautiful and very limited genus are too well known to require mention; it may be added, however, that the prominent longitudinal ribs, which impart the harp-like symmetry of structure to the shell are regarded as so many varices; analogous in structure to the varices in the shell of Murex, each forms in its turn the margin of the aperture, and the intervals between them are probably of rapid growth.

The Harpe mostly inhabit the shores of Ceylon, the Mauritins, and the Philippine Islands; one species, the $H$. crenata, is from Mexico. They are all extremely rich in colour, and are not less remarkable for the bright curmelling of the body-whorl, in the inmediate vicinity of the aperture.

\section{Species.}

1. articuluris, Lam.

4. gracilis, Brod.

7. nobilis, Rumph.

2. conoidalis, Lam.

3. crenata, Sicain.

5. imperialis, Chemn.

6. minor, Rumpll.

8. rosea, Lam.

9. ventricosa, Lam.

\section{Figures.}

Harpa ventricosa. Plate $E$. Shell with animal, showing its large elongated disc, auricular appendage in front, tentacles, eyes, and erect branchial siphon.-From the 'Voyage de l'Astrolabe'.

Harpa miperialis. Plate 5. Fig. 26. Shell, showing its many-ridged structure, arising from the rapid succession of varices. 


\section{Genus 17. CONCHOLEPAS, Lamarck.}

Animal ; disc oval, large, furnished posteriorly with an operculum; head flattened, protonged on each side into two tentucles, the lower portion of which is thickened and truncated; eyes situated at the summit of the truncated portion; proboscis obtuse; respiratory siphon rather small.

Shell ; ovate, spire very short, minute, apex sharp; whorls ribbed and imbricated; aperture very large and inflated, lip furmished at the base with two or three projecting teeth.

The term Concho-Lepas, applied to this shell in a generic sense by Lamarck, seems to have cmanated from the difficulty which our conchological ancestors found in determining whether it was of a spiral or nonspiral structure; shells of the former growth, being designated by the title of Cochlea or Conchs, of the latter, meaning the Limpets, by that of Lepus or rock shells. The spire is extremely minute, and the shell has all the appearance of a compressed cornucopia, with the margin of the aperture reflected outwards like the mouth of a trumpet.

The animal appears to differ in no respect from that of Purpuru, and our continental neighbours are unwilling that it should occupy any higher rank than as a section of that genus; the characteristic variation in the growth of the shell is sufficient, however, to warrant its separate arrangement, according to the method originally adopted by Lamarck.

The genus is only represented by the following species, found at Peru.

\section{Fïgure.}

Concriolepas Peruviands. Plate 5. Fig. 27. Shell, showing its widely inflated, Limpet-like, aperture.

\section{Genus 18. MONOCEROS, Lamarck.}

\section{Animal ; similar to that of Purpura.}

Shell; ovate, spire sometimes elevated, sometimes rather depressed, columella wide and flattish, sometimes indistinctly plaited, lip) armed near the base with a sharp prominent recurved tooth. Operculum hormy.

The genus ILonoceros of Lamarek, introduced almost simultaneously by De Montford under the title of Unicomus, is characterized solely by the 
very conspicuous tooth which becomes developed at the lower portion of the lip; the distinction is not, however, universilly admitted, as several of the Purpure exhibit indications of a tooth, and the animals of the two genera, are identical.

\section{Species}

1. acuminatum, Soro.

6. cymatum (Buc.), Sol. 11. maculatum, Gray.

2. brevidens, Conrad.

7. giganteum, Less.

12. punctatum, Gray.

3. calcar, Desh.

8. glabratum, Lam.

13. truncatum, Reeve.

4. cingulatum, Lam.

9. grande, Gray.

14. tuberculatum, Gray.

5. crassilabrum, Lam.

10. imbricatum, Lam.

\section{Figure.}

Monoceros grande. Plate 6. Fig. 29. Shell, showing the aperture and prominent tooth.

\section{Genus 19. PURPURA, Lamarck.}

Animal; disc large, stightly acuminated in front, acuminately rounded behind, carrying at the extremity a thin hormy semilunur operculum; head rather small and flattened, prolonged at. each extremity into two pedunculated tentacles, at the summit of the thickened portion of which, extending to one half or two thirds of the length, are the eyes; respiratory siphon of mode. rate length; proboscis small.

Shell; ovate, or oblong-ovate, generally noduled or tuberculated, spire short; last whorl swollen, more or less widely inflated, with the aperture dilated and mostly grooved; base emarginated; columella more or less depressly flattened; lip generally denticulated.

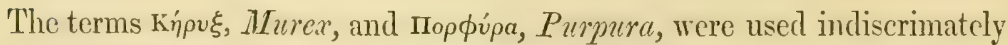
by ancient Greek writers in reference to all mollusks yielding a purple juice, and they became objects of especial interest in that remote age, on account of the limited sources then known of obtaining colour. Who has not heard of the purple dye, produced by the 'Tyrius murex' of Ovid, (Murex trunculus Limm.), which no doubt abounded on the shores of the ancient Phænician city of Tyros.

The purple juice of the mollusk affords, however, no assistance to the systematist; it abounds alike in amimals of very dissimilar character; in 
Scalaria and Ianthina, as well as in Murex and Purpura; hence the term Purpura was adopted by Lamarck to distinguish the genus under consideration, regardless of any property with which the animal might be endowed of secreting a purple juice. The most striking feature in the soft parts of Purpura is that of the head being a little flattened, and prolonged at each extremity into the tentacles, without any prominence in the centre; approximating in this respect to Buccinum. The tentacles are pedunculated to generally two thirds of their extent, and at the summit of the pedunculated portion are the eycs. The operculum which the animal carries on the hind extremity of its disk, is invariably horny, and fits closely to the aperture of the shell.

The shell of Purpura is mainly distinguished by an ovate dilated growth, emarginated at the base, with a more or less flattened columella, the spire being sometimes extremely short, sometimes a little acuminated. There are three closely allied genera, Concholepas, Monoceros, and Ricimula, which the French authors propose to fuse into the present; I have not considered it prudent, however, to follow this course, as they afford good typical distinctions, and their amalgamation under the head of Purpura would only tend to confusion by involving a change of names.*

The Purpure vary exceedingly in their detail of sculpture, but are somewhat constant in colour; the well-known P. lapillus of Europe varies in both respects to an almost inconceivable degree; indeed, no one who has not thoroughly examined a numerous series of specimens can form an adequate idea of its Protean character.

\section{Species.}

1. ægrota Reeve.

2. affinis, $i d$.

3. alveolata, $i d$.

4. anaxares, Duclos.

5. aperta, De Blainv.

6. armigera, Lam.

7. Ascensionis, Quoy.

8. attenuata Reeve.

9. bicostalis, Lam.

10. biserialis, De. Blainv.

11. bitubercularis, Lan.

12. Blainvillii, Desh.

13. buccinea, $i d$.

14. bufo, Lam.
15. Callaoensis, Gray.

16. carinifera, Lam.

17. Carolensis, Reeve.

18. cataracta, (Buc.) Ch.

19. chocolatum, Duclos.

20. columellaris, Lam.

21. consul, Lam.

22. coronata, Lam.

23. costularis (Mnrex.), L. 37. haustrum, Quoy.

24. deltoidea, Lam.

25. diadema, Lan.

26. D'Orbignii, Reeve.

27. echinata, De. Blainv.

28. echinulata, Lam.
29. emarginata, Desh.

30. fasciata, Reeve.

31. Floridana, Conrad.

32. Freycinetii, Desh.

33. galea, Reeve.

34. gibbosa, $i d$.

35. gigantea, $i d$.

36. hæmastoma, Lam.

38. hippocastanum, Lam.

39. hystrix, $i d$.

40. imperialis, De Blainv.

41. inerma, Reeve.

42. intermedia, Kiener.

* In the monographs of Purpura and Ricinula just published in the 'Conchologia Iconica ', I have added to the importance of the latter genus by the introduction of some small species intermediate between Purpura and Columbella, the greater portion of which were not previously described. 
43. Janellii, Kiener.

44. kiosquiformis, Duclos.

45. lapillus, Lam.

46. lineata, $i d$.

47. luteostoma, Desh.

48. Madreporarum, Sow.

49. mancinella, Lam.

50. melones, Duclos.

51. muricina, De Blainv.

52. musiva, Kiener.

53. Neritoidea, Desh.

54. nux, Reeve.

55. patula, Lam.
56. persica, Lam.

57. piea, De. Blainv.

58. planospira, Lam.

59. pupillata, Reeve.

60. Quoyi, id.

61. Rudolphi, Lam.

62. rustica, $i d$.

63. sacellum (Murex), Ch.

64. Scalariformis, Lam.

65. scobina, Quoy.

66. septentrionalis, Reeve.

67. speciosa, Talenc.

68. spiralis, Reeve.
69. squamosa, Lam.

70. squamulosa, Reeve.

71. succincta, Lam.

72. textilosa, $i d$.

73. thiarella, $i d$.

74. trigona, Reeve.

75. trochlea, Lam.

76. tumulosa, Reeve.

77. undata, Lam.

78. unifascialis Lam.

79. violacea, Kiener.

80. xanthostoma, Brod.

\section{Figure.}

Purpula aperta. Plate. 6. Fig. 30. Shell showing its depressed spire, dilated aperture, and flattened columella.

\section{Genus 20. COLUMBELLA, Lamarck.}

Animal; disc elongated and narrow, truncated and a litlle ditated in front, hind extremity furnished with a small horny operculum, head small, flattened, triangular, prolonged into tuo conical cylindrical tentacles, pedunculated to about a third of their extent, at the summit of which portion are the eyes; trunk: rather long.

Shell; small, ovately oblong or triangular, sometimes fusiform, columella arched and denticulated, rarely smooth; outer lip thickened, swollen. gibbous and most frequently denticulated in. the midalle.

The genus Columbella includes a very numerous series whose shells are uniformly small, and distinguished by a greater or less number of plait-like denticles on the lip and columella after the manner of Ricinula. From the circumstance of Lamarck laving confounded $a$ few of the small Mitres with the Columbelle, he was induced to refer the genus to the family Columellata, assuming the existence of a plaited columella; the plaits by which the genera of that family are characterized are, however, of very different structure, from the protuberances which are here designated plait-like denticles; the first being developed on the columella throughout its entire growth so as to form a continuous winding of spiral plaits around the columella axis, whilst the last are merely developed along the inner side of the columella, on arriving at maturity. 
M. Beshayes affirms that notwithstanding this error, Lamarck "has discerned with the greatest sagacity the place which this genus should occupy in the system", and goes on to demonstrate that its affinity with the Mitres is incontestible.

I certainly camnot compete with M. Deshayes on the advantages he has had of examining the Columbelle alive on the shores of the Mediterranean, but I think his opinion of their possessing a more intimate relation with the Mitre than with the Ricinule, or Ricinuloid Purpure, is not bome out by his description of the animal. Like the soft parts of the latter, the head of the Columbellee is flattened and prolonged at each extremity into the tentacles, the proboscis is, moreover, of moderate dimension, for though said to be "very long", it is only described as "often exceeding the length of the aperture of the shell "; and the disk is furnished with a small operculum. The proboscis of the Mitre, as already mentioned at p. 48, is susceptible of very considerable elongation, many times the length of the shell's aperture, and it camnot be supposed that the Purpura have not the faculty of elongating their proboscis to any greater extent than is represented in the few drawings hitherto obtained of them in a living condition, in some of which it is most probably only partially extended, whilst in others it is altogether retracted.

The following species are chiefly described in a recently published monogrraph in Mr. Sowerby's 'Thesaurus Conchyliorum'; and it only remains to refer to the admirable figures of that work for illustration.

\section{Species.}

1. achatina, Soro.

2. acleonta, Duclos.

3. acuminata, Nuttall.

4. adiastina, Duclos.

5. albina, Kiener.

6. ambigua, $i d$.

7. ampla, Less.

8. anacteola, Duclos.

9. angularis, Sow.

10. apthægera, Less.

11. araneosa, Kiener.

12. aspersa, Sovo.

13. athadona, Duclos.

14. atomella, $i d$.

15. atramentaria, Sow.

16. aurantia, Duclos.

17. avara, Say.

18. azora, Duclos.
19. bicanaliculata, Duclos. 37. costata, Duclos.

20. bicanalifera, Sow. 38. costellata, Sow.

21. bicolor, Kiener.

22. bidentata, Menke.

23. blanda, Sow.

24. Boivinii, Kiener.

25. Broderipii, Sow.

26. Buccinoides, $i d$.

27. castanea, $i d$.

28. catenata, $i d$.

29. chlorostoma, $i d$.

30. Chrisopsis, Duclos.

31. clathra, Less.

32. concinna, Soro.

33. cornea, Kiener.

34. comiculata, Sow.

35. corniformis, Sow.

36. coronata, Sow.
39. cribraria, $i d$.

40. daliola, Duclos.

41. decussata, Sow.

42. denticulata, Duclos.

43. dermestoides, Sow.

44. dichroa, $i d$.

45. digitata, Lesson.

46. dormitor, Sow.

47. dorsata, $i d$.

48. Duclosiana, $i d$.

49. electona, Duclos.

50. elegans, Sow.

51. fabula, $i d$.

52. falconta, Duclos.

53. fasciata, Sow.

54. festiva, Kiener. 
55. flavida, Lam.

56. flexuosa, Duclos.

57. fluctuata, Sow.

58. fulgurans, Lam.

59. fulva, Soro.

60. fuscata, $i d$.

61. fusiformis, Nuttall.

62. fusiformis, Hinds.

63. fustigata, Kiener.

64. gibberula, Sow.

65. gibbosa, Duclos.

66. gibbosula, Brod.

67. Guildingii, Sow.

68. guttata, $i d$.

69. gutturosa, Duclos.

70. hæmastoma, Soro.

71. harpæformis, Sow.

72. idalina, Duclos.

73. idulia, $i d$.

74. ionida, $i d$.

75. iphis, $i d$.

76. isomella, $i d$.

77. jaspidea, Soro.

78. kirostra, Duclos.

79. Kraussii, Soro.

80. labiosa, $i d$.

81. lactea, Duclos.

82. lævigata, $i d$.

83. lanceolata, Kiener.

84. lentiginosa, Hinds.

85. lepida, Duclos.

86. ligula, $i d$.

87. lineolata, Kiener.

88. livida, Soro.

89. lugubris, Kiener.

90. lunata, Sovo.

91. lutea, Quoy.

92. luteola, Kiener.

93. lyrata, Sow.

94. maculosa, $i d$.

95. major, $i d$.

96. marmorata, Gray.

97. maura, Sov.

98. meleagris, Duclos.

99. mercatoria, $i d$.

100. miser, Sow.

101. Mitraformis, King.
102. modesta, Kiener.

103. moleculina, Duclos.

104. monilifera, Sow.

105. nana, Michaud.

106. nasioletta, Duclos.

107. naxia, $i d$.

108. nigricans, Sow.

109. nigropunctata, $i d$.

110. nisitella, Duclos.

111. nitida, Lam.

112. nivea, Sow.

113. nodulina, Duclos.

114. nodulosa, Nuttall.

115. nucleus, Kiener.

116. nympha, $i d$.

117. obscura, Sow.

118. obtusa, $i d$.

119. oselmonta, Dnclos.

120. ovulata, Lam.

121. pæcila, Sow.

122. pandonosta, Duclos.

123. pardalina, Lam.

124. pariolida, Duclos.

125. parva, Sow.

126. pavonina, Hinds.

127. Paytalida, Duclos.

128. Peleei, Kiener.

129. pelotina, Duclos.

130. phasinola, Duclos.

131. Philippinarum, Reeve. 177. Tyleri, Gray.

132. procera, Sow.

133. puella, $i d$.

134. pulchella, $i d$.

135. pulcherrima, $i d$.

136. pulicaris, Less.

137. punctata, Lam.

138. pusilla, Sow.

139. pygmea, $i d$.

140. pyrostoma, $i d$.

141. rasolia, Duclos.

142. recurva, Sow.

143. reticulata, Lam.

144. rubicundula, Quoy.

145. rugosa, Sow.

146. rugulosa, $i d$.

147. rustica, Lam.
148. sbina, Kiener.

149. scalarina, Sow.

150. scripta, Lam.

151. semiconvexa, Sow.

152. semipunctata, Lam.

153. sertularianum, $D^{\prime}$ Orb.

154. sordida, $i d$.

155. splendidula, Soro.

156. spongiarum, Duclos.

157. strenella, $i d$.

158. striata, $i d$.

159. Strombiformis, Lam.

160. subulata, Duclos.

161. subulata, Sow.

162. suffusa, $i d$.

163. sulcata, Duclos.

164. sulcosa, Sow.

165. suturalis, Gray.

166. Tamelana, Duclos.

167. Terpsichore, Leathes.

168. testina, Duclos.

169. Ticaonis, Sovo.

170. tigrina, Duclos.

171. triga, id.

172. triumphalis, $i d$.

173. tumida, id

174. turbida, $i d$.

175. turrita, Sow.

176. turturina Lam.

178. uncinata, Sow

179. undata, Duclos

180. unicolor, Sow.

181. unifascialis, Lam.

182. unizonalis, Gray.

183. uvania, Duclos.

184. valveta, $i d$.

185. varia, Sow.

186. varians, $i d$.

187. virginea, Duclos.

188. vulpecula, Sow.

189. xiphitella, Duclos.

190. Yoldina, $i d$.

192. zebra, Gray.

191. zelina, Duclos.

193. zonalis, Lam. 


\section{Genus 21. RICINULA, Lamarck.}

\section{Animal; similar to that of Purpura.}

Shell; orbicularly or fusiformly ovate, most frequently tuberculated or spined, spire sometimes very short and depressed, sometimes acuminated; aperture rather narrow, columella a little excavated, sometimes wrinkled or toothed, lip toothed within, teeth nodulous or plait-like, edge of the lip sometimes but rarely aigitated.

In adopting the genus Ricinula, which has been abandoned by several continental authors, I propose to include a much wider range of species than has been litherto referred to it; namely, that fusiform series distinguished from the true Buccinum and Purpura by the inner nodulous dentition of the lip, arranged by M. Kiener as a section of the latter genus cinder the significant title of "Les Pourpres semi-ricinules", and of which the $P$. fiscellum of authors may be regarded as the type. It cannot be disputed that there are species in the genera Ricinula, in its limited acceptation, and Purpura, in which it is not easy to define any generic difference, as for example, between the $P$. hystrix and the $R$. arachnoides, or between the $P$. aperta and certain varieties of the $R$. clatlrata, but the alteration of names in familiar usage should as far as possible be avoided. A large proportion of the species recently characterized by me as Ricinula were not hitherto named, and their connection with the Purpura proper is so apparently remote, that I have preferred elevating the genus under consideration into one of more importance, to the creation of a new genus, or to the fusion of the whole into one after the manner of the French naturalists.

The animal of Ricinula is similar in most respects to that of Purpura, alreadly described, the head being flattened and prolonged at each corner into the tenticles, and bearing a snall elliptical operculum at the posterior extremity of the disk.

\section{Species.}

1. acuminata, Reeve. 8. bicatenata, Reeve. 15. concinna, Reeve.

2. alveolata, (Purp.) Kien. 9. carbonaria, id.

16. contracta, $i d$.

3. arachnoides, Lamarck. 10. cavernosa, $i d$.

17. crocostoma, $i d$.

4. armillata, Reeve.

11. chaidea, (Purp.) Ducl. 18. dealbata, id.

5. aspera, Lamarck.

12. chrysostoma, Deshayes. 19. deformis, $i d$.

6. astricta, Reeve.

13. clathrata, Lam.

20. digitata, Lamarck.

7. bella, $i d$.

14. concatenata (MFur.), L. 21. echinata, Reeve. 
22. elata (Purp.), De Blain. 33. iodostoma, Lesson.

23. elegans, Broderip. 34. iostoma, Reeve.

24. elongata (Purp.) De B1. 35. lauta, id.

25. eximia, Reeve. 36. lineata, id.

26. ferruginosa, $i d$.

27. fiscellum (MLurex.) Ch. 38. morus, Lamarck.

28. forticostata, Reeve.

29. funiculata, $i d$,

30. heptagonalis, $i d$.

31. histrio, $i d$.

32. horrida, Lamarck.

\section{3. . lineata, id.}

44. porphyrostoma, eeve.

45. pulchra, $i d$.

46. recurva, $i d$.

47. rosea, $i d$.

48. rutila, $i d$,

49. siderea, $i d$.

50. spectrum, $i d$.

51. trifasciata, $i d$.

52. tuberculata, De Blain.

53. turbinella (Purp.)Kien.

54. zonata, Reeve.

\section{Figure.}

Ricinula iodostoma. Pl. 7. Fig. 32. Front view of the shell, showing the aperture and plait-like denticles of the columella and inner lip.

\section{Genus 22. CASSIS, Lamarck.}

Animal ; disc oval, rather thin, flattened, carrying a small crescentshaped operculum at the posterior end; head stout, obtuse, prolonged into two slender tentacles, with the eyes on the outer side near the base; respiratory siphon large and elongated, proboscis short, cylindrical.

Shell; ovate or triangularly ovate, terminating at the base with a short peculiarly recurved and ascending canal; spire short, and often crossed at intervals with varices; last whorl of the shell inflated, sometimes remotely strengthened with varices; aperture large, thongh often narrow; columellar lip frequently wrinkled or granulated, outer lip thickened, reflected and more or less toothed.

The Cassides or Helmets are a strong, muscular, but inactive group of mollusks, whose shell is mainly distinguished by its solid or inflated growth and short spire, and by the abrupt ascending recurvature of the canal, through which the siphon for conveying the water to the breathing organs passes, and is of more than ordinary dimensions. The head is stout and fleshy, and prolonged into the tentacles after the mamer of Purpura or Buccinum, the eyes being situated on the outer surface near the base; it appears, however, from the observations of M. Deshayes, that in the Cersis sirlcosa they are surmounted on a short pedicle. The calcifying properties of this genus are somewhat vigorously exercised, the mantle which lines the 
interior of the shell extends in ample folds about the aperture, and secretes that rich display of enamel which aflords so beautiful a material for the engraving of Cameos. The $C$. tuberosa from the West Indies, is the species commonly used for this purpose from its delicate purity of colour ; the rellknow Bull's Mouth, Cassis rufa, is a familiar example of the great power which this genus exhibits in the formation of shell, but the enamel is not so suitable for gem-engraving on account of its deep blood-red colour.

M. Deshayes informs us, from his observations of the Cassis sulcosa on the shores of the Mediterranean, that it is very probable the animal lives upon the juices of different Bivalve Mollusks, whose shells it pierces with its probosis after the manner of the Murices, being found dwelling in the sand, and just in those places where Bivalves abound; he describes the Cassis, however, as not possessing much activity. The operculum, which is rarely obtained with the shell, is horny and of a peculiar crescent shape, crenulated at the edge and rayed with deep strix.

The Cassides are not very numerous, they inhabit chiefly the Mauritius, Ceylon, the Philippines and West Indies; two species are found in the Mediterranean, but none on our own coast.

\section{Species.}
1. abbreviata, Lam.
13. fimbriata, Quoy.
24. ringens, Swain.
2. achatina, $i d$.
14. flammea, Lam.
25. rufa, Lam.
3. areola, $i d$.
15. glauca, $i d$.
26. saburon, $i$.
4. canaliculata, $i d$.
16. granulosa, Bruguière.
27. semigranosum, id.
5. cicatricosa, Desh.
17. lactea, Kiener.
28. sulcosa, $i d$.
6. coarctata, Sow.
18. Madagascariensis,Lam.29. tenuis, Gray,
7. cornuta, Lam.
8. coronulata, Sow.
19. Massenæ, Kiener.
30. testiculus, Lam.
20. paucirugis, Menke.
31. tuberosa, $i d$.
9. crumena, Lam.
10. decussata, id.
11. erinaceus, $i d$.
21. pennata, Lam.
22. plicaria, $i d$.
23. pyrum, id.
32. vibex, $i d$.
33. zebra, id.
34. Zelanica, $i d$.

12. fasciata, $i d$.

\section{Fignes.}

Cassis glauca. Pl. D. Shell with animal, showing the thin flattened disk with its crescent-shaped radiated operculum, head and tentacles with sessile eyes, proboscis partially withdrawn, and prominently devcloped respiratory siphon proceeding from a fold in the front edge of the mantle, and passing through the recurved ascending canal of the shell.From the 'Voyage de l'Astrolabe.'

Cassis areora. Pl. 6. Fig. 25. Shell, showing the aperture, varices, and wrinkled structure of the outer and columellar lips. 
Genus 23. ONISCIA, Sowerby.

Animal; unknown.

Shell; oblong, somewhat cylindrical, or conical, spire short and depressed, base emarginated and a little recurved; aperture narrow, extending nearly to the apex; columellar lip displayed over the body whorl, more or less profusely covered with small granular pimples; outer lip irregularly denticulated, thickened, sometimes a little contracted in the middle.

This is one of the few genera established by modern authors which it is desirable to maintain; though unacquainted with the soft parts, the shell sufficiently indicates the presence of some concurrent peculiarities worthy of distinction, and I am glad to observe that the scruples formerly entertained by M. Deshayes to the adoption of this genus, noticed by me in the 'Conchologia Systematica', have been removed in the 'Anim. sans vert.' by his unqualified acceptation of it. Even Linmæus referred the typical species of this group to a different genus from that in which he included the Helmets * and Lamarck in placing it with the Cassidarice, describes it as being a "very singular" shell $†$; Mr. Sowerby first separated it under the above title and it is now universally adopted.

The Oniscia are very limited in number; they are most elaborately sculptured, and distinguished chiefly by the profusely granulated character of the columella, which in the species tigured, O. Dennisoni, is of a remarkably deep scarled-red colour.

\section{Species.}

1. cancellata, Sow.

3. oniscus, Sow.

5. tuberculosa, Sow.

2. Dennisoni, Reeve,

4. Strombiformis, Reeve.

\section{Figures.}

Oniscia Dennisoni. Pl. 7. Fig. 35. Shell, a, front view, showing the aperture and granulated columella; $b$, back view, showing the rich latticed sculpture.

* MI. Deshayes has somewhat incautiously affirmed, that the shell selected for the type of this genus is not the Strombus oniscus of Linnæus, but one differing even generically from it. "There are two species" says the learned editor of the "Anim. sans vert." one of which he retains in Cassidaria, whilst he refers the other to Oniscia with a complimentary dedication to Lamarck, "closely approximating, which may be easily distinguished by the denticulations of the outer lip and a difference of colour, for whilst Linnæus characterized the aperture of his species as being white, Lamarck says it is red." These modifications cannot, I think, be accounted of specific, much more of generic value; and I see nothing in the figures of Gualter or Seba to indicate otherwise.

$\dagger$ "Petite coquille assez commune, mais très singulière; car, quoique son ouverture soit celle des Casques, sa queue n'est point brusquement retroussèe comme dans ce dernier genre". 


\section{Genus 24. CASSIDARIA, Lamarck.}

Animal ; disc large, oval, slightly truncated in front, with a small. oblong horny operculum near the posterior part; head large and thick, prolonged into a pair of elongated tentacles, at the base of which are the eyes; proboscis cylindrical, rather long; respiratory siphon of only moderate length.

Shell; oval, ventricose, contracted towards the base and attenuated into a curved canal which is reflexed posteriorly; columella lip smooth and expanded over the body whorl; outer lip reflected, sometimes crenated.

The Cassidarice, distinguished originally by De Montford under the title of Morio, and which name according to the strict rules of priority shonld have been adopted, differ principally from the Cussides in the light inflated growth of the shell, with its contracted, attenuated structure towards the base, and recurved folding canal; they approximate in this respect to Cussis, partaking somewhat of the character of Dolium, for not only is the shell distinguished by the same tenuity as the latter genus, but there is some affinity in the soft parts, to judge by the ample growth of the disk, and length of the proboscis.

The Oniscia were referred to the genus Cassidaria by Lamarck, but their shell is uniformly of snaller size, and of more solid growth, independently of its granulated columella and other characters just observed under that head; it is likewise highly probable that a difference will be found in the animal of Oniscic of sufficient generic importance to confirm the propriety of its being adopted.

Of the following half dozen species hitherto recorded I am only acquainted with three, and of these, C.striata, Tyrrhena, and echinophoru, the last two are regarded by some authors as varieties; I have no doubt, however, myself, of their specific difference.

\section{Species.}

1. acuta, Gray.

3. Deshayesii, Duval.

5. striata, Lam.

2. cingulata, Lam.

4. echinophora Lam.

6. Tyrrhena, Lam,

\section{Figure.}

Cassidaria Tyrrhena. Pl. 6. Fig. 31. Shell, showing the aperture, recurved folding canal, and expanded columellar lip. 


\section{Family 4. ALA'TA.}

Shell; emarginated or channelled at the base, outer lip expanded or digitated at maturity, and more or less sinuated near the base for the passage of the animal's proboscis-like head.

The family Alata was instituted by Lamarck for the purpose of associating in one natural group, the three genera Rostellaria, Pterocera, and Strombus, dismembered from the Linnæean genus Strombus, and distinguished by that marked peculiarity of growth, which the shell of each exhibits in the wing-like expansion of the outer lip, on arriving at maturity. The researches, of subsequent naturalists, aided by much increased zeal and opportunities of studying the animal, have, however, discovered an affinity with the above-named genera, in species arranged hitherto in a more remote part of the system. The Aporrhais pes-Pelicani has long been generically distinguished, and a difference has been recently observed in the soft parts approximating to Struthiolaria, a genus necessarily transported to this family by M. Deshayes upon the discovery of the animal by M. M. Quoy and Gaimard, and I now feel it expedient, as indicating a link between Struthiolaria and the Purpurifera, to introduce an important genus founded by Dr. Beck, a distinguished naturalist of Copenhagen, under the name of Priamus, upon a shell regarded by Lamarck and others as an inhabitant of the land or marshes,* but now strongly suspected, if not ascertained, to be living in the seas of Spain and Portugal. Were it not for the transition afforded by the Aporrhais occidentalis, between Struthiolaria and the Lamarkican Alata, I should have ventured to propose a new family for the reception of that genus with Priamus; but as the animal of the latter is still unknown, the grounds for this separation are insufficient.

The genera referable to this family are as follows :-

Priamus.

Aporrhats.

Pterocera.

Struthiolaria. Rostellaria.

Stromisus.

\section{Genus 1. PRIAMUS, Beck.}

Animal; unknown.

Shell; oblong-ovate, ventricose, rather thin, diaphonous, somewhat homy or porcellanous, spire exserted, apex obluse, a little depressed, as if manillary; columella curved, truncated; outer lip simple, effused, stightly sinuated towards the base.

\footnotetext{
* Bulimus Priamus Bruguic̀re, Achatina Priamus Lamarck, Helix Priamus Ferussac.
} 
The shell on which this genus is founded, though long known to Conchologisis, is one of very rare occurrence; having been described nearly a century since by Meuschen and Gronovius as a Helix, in the unlimited sense of that period, its peculiarities were strikingly noticed by the latter in his interrogatory as to its being a river shell *; Favanne mentions it in his Catalogue as a rare Buccimum called 'La Chiure de Puce,' and Chemnitz published a formal description of it in the 'Conchylien Cabinet' under the name of Bucinum stercus-pulicum. It does not appear to have been known to Linnæus, the last edition of whose 'Systema Naturæ' appeared simultaneously with the 'Zoophylacium' of Gronovius, but Dillwyn referred the shell under consideration, in his Linnæan arrangement of shells, to the genus Bulla; Bruguière consigned it to Butimus, and Lamarck, De Ferussac, and others, adopted the same view, by retaining it with those species subsequently distinguished as Achatince, on account of the truncature of their columclla, and especially with that portion more recently separated under the titles of Polyphemus and Glandina. The name Buccinum used by the original describers of this shell, was thus more in conformity with its present assumed marine character, than that employed by modern writers, the situation to which it has been assigned in the system as the representative of a pulmoniferous air-breatling mollusk, being incompatible with the nature anticipated, on the authority of Dr. Beck, of its being an inhabitant of the seas of Spain and Portugal. $\dagger$

From the light horny semi-porcellanous character of this shell, the absence of epidermis, and the wide-spread stain which exhibits its contact with the soft parts, I think it may be anticipated that the animal is of large size, and able to envelope its shell to some considerable extent, it is probably an iuhabitant of deep water, and an examination of the microscopic structure of the shell would no doubt detect a larger proportion of membranous tissue and less of calcareous matter than is usually secreted by mollusks of the order to which it is referred. It only remains to urge upon the attention of all who may have an opportunity of dredging the shores of those countries upon which it is supposed to exist, that in the event of their researches after Priamus meeting with success, they should be careful to preserve the animal.

\section{Figure.}

Priamus stercus-pulicumir. Pl. 8. Fig. 39. Shell, showing its curved and truncated columella, and slightly simuated lip, as in Struthiolaria.

* "An fluviatilis?" Gronovius, Zoophylacium, Fasc. 3. No. 146

† Deshayes, Anim. sans vert. vol. viii. p. 299, note. 


\section{Genus 2. STRUTHIOLARIA, Lamarck.}

Animal; disc large, thick, carrying a small hormy rudimentary operculum behind, supported in the centre by a stout pedicle which passes into the shell, and serves to support the head; head rather large, prolonged into a cylindrical trunk enclosing the mouth, at the base of which on either side are two long pointed tentacles with eyes at the lower outer side; no respiratory siphon.

Shell; oblong-oval, spire exserted, rather obtuse at the apex; columella curved, truncated at the base, outer lip thickened, slightly simuated towards the lower part.

A limited genus of mollusks, inhabiting the shores of New Holland, for a description and figure of whose soft parts we are indebted to the researches of MI. M. Quoy and Gaimard. Their chief peculiarity consists in the disk being supported on a stout peclicle which passes into the shcll, in the truncated proboscidiform prolongation of the head, indicative of the relation of this mollusk with Aporrhais, and in the absence of any respiratory siphon, which is so conspicuous a feature in the Pupurifera, and is formed, as observed in treating of that family, by an clongated fold of the mantle, protuding in an erect position through the basal notch of the shell, for the purpose of supplying water to the breathing organs.

From the circumstance of the outer lip of the shell of Struttiolaria being unusually thickened and rolled back, whilst a corresponding thickness is displayed in the superincumbent deposit of enamel on the opposite side, described as the columellar lip, the genus was referred by Lamarck to the immediate vicinity of the Tritons and Ranella, regarding, this structure as an analogue of the varices by which those genera are characterized; Mr. Gray and M. Deshayes, however, observing the marked

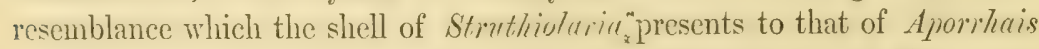
in the sinuated lip and truncature of the columella, removed the genus under consideration, almost simultaneously, to the family Alat.n, and their anticipations of its true character have been confirmed in a striking manner by the observations of Philippi and M. M. Quoy and Gaimard.

\section{Species.}

1. crenulata Lam.

3. papulosa (Buc.) Mart. 5. straminea (Murex.) Gm.

2. microscopia, Gray.

4. scutulata (Buc.) Mart.

\section{Figure.}

Strutmiolaria straminea. Pl s. Fig. 38. Shell, showing the thickence outer and columellar lips and truncature of the columella. 


\section{Genus 3. APORRHAIS, De Montford.*}

Animal; disc truncated in front, acuminated behind, carrying at the extremity a small oblomy hormy operculum, head very large, proboscidiform, somevhat cylindrical, obliquely truncated; mouth longitudinal, occupying the length of the truncated portion of the head; tentacles very long and pointed, pedunculated at the base, at the summit of which pedunculuted portion is the eye; mantle thin, simple, or lobed.

Shell; elongated, fusiform, slightly crnaliculated at the base; columella straight, rather callous; onter lip dilated and thickened, detached from the spire at the upper part, and either simple or expancied into claws, or digitations.

The Strombus pes-Pelicani was set apart as the type of a new genus by De Montford, under the name of Aporrhais, by which it had been distinguished in the earliest records of Natural History; and Lamarck, uniting it with the Linnæan Strombus fusus and its congeners, proposed a new genus for their reception, under the name of Rostellaria; the researches of M. M. Ehrenberg, Quoy and Gaimard, Poli, Deshayes, and Philippi, have, however, demonstrated not only that there is an important generic difference between the animals of the Lamarckian Rostellurice rectirostrinn (Strombus fusus, Linn.), and pes-Pelicani, but that whilst the former is characterized by the same peculiarity of structure as the true Strombus, the latter is wanting in that peculiarity and presents an unexpected atinity with Struthioluria, in having a large proboscidiform head and anple mouth, withont the bifurcated tentacles and divided disc, which is to be found in Rostellaria, Pterocera, and Strombus.

The mantle of the Aporrlaides, as in the remaining genera of Alata, is

* The Aristotelian title of Aporrhais, adopted by Sowcrby after the example of De MIontford, has been objected to by Philippi, substituting that of Chenopus, on the grounds of its more especial reference to the Pterocerce. It is true that Rondelet, one of the earliest writers on Natural History after the revival of letters, has figured a $P$.lambis for Aporrhais; but it seems evident, upon his own testimony, that the name, derived from 'A was suggested to the Athenian philosopher by the spouted $A$. pes.Pelicani of the Mediterranean, from whence the materials for the 'Historia Animalium' of antiquity, were mainly derived:"Dicam preterca quod suspicionibus et conjecturis tantum inductis de 'A $\pi$ oṕpaíd€ $\sigma$ sentio; nimirum Muricum generis sunt quæ rocant Græci Colycia, turbinata æque sed minora multo". I consider, therefore, that the word Aporrlatis may be maintained without prejudice, for the group under consideration, the type of which was, no doubt, the particular shell referred to by the great father of zoology. It should perhaps be added, that the word "MIuricum " just cited, is not used in the sense in which we understand it; in Gaza's translation of Aristotle, quoted by Rondelet, the 'A

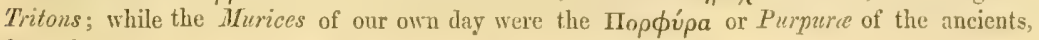
from the circumstance of their obtaiuing the Tyrian purple from that geus. 
expanded at maturity into a lobe; in one of the three only recent species known, A.occidentalis, from the northern shores of Western America, the lobe is simple, in the remaining two A.pes-Pelicani, and pes-Carbonis of the Mediterranean, it is digitated, the shell being of a corresponding structure.

\section{Species.}

1. occidentalis, Beck. 2. pes-Carbonis, Brong. 3. pes-Pelicani(Rost.) Lam.

\section{Genus 4. ROS'TELLARIA, Lamarck.}

Animal; elongated, disc divided into two parts, the posterior cylindrical, obliquely truncated, and carmying a horny unguiform operculum upon the truncature, the anterior flattened and rounded, serving the animal to attach itself to solid bodies; head large and thich, prolonged into a proboscis-shaped mus re, slit in front; tentacles diverging, cylindrical, two-forked, the inner branch being stim and pointed, the outer truncated at the summit, with the eye situated upon the truncature.

Shell ; fusiform, prolonged at the base into a canal which is sometimes very long and stender; whorls stightly convex, sometimes furnished here and there with a varix; lip toothed, or digitated.

It appears from Lhrenberg's characters of the animal above noticed, that the Rostellarice whose graceful fusiform shells are so much admired by the collector, and are the pricle of his cabinet, have a much closer affinity with the Pterocerce and Strombi, than with the Aporrhaides which have been hitherto associated with them, or the Fusi, to which they were approximated by Ferussac and De Blainville. The disc presents the same peculiar modification of structure as in Pterocera and Strombus; divided into two prirts, the animal is said to acquire motion by executing a succession of leaps, instead of the ordinary mode of prosressing by dilatation and contraction.

The Rostellarie may be easily recognized by the elegant fusiform growth of the shell, with its peculiarly dentated, or fincly digitated lip; they are very limited in species, and are principally from China and the Moluceas.

\section{Species.}

1. curta, Sow.

3. fissa, Desh.

5. Powisii, Petit.

2. curvirostrum, Lam.

4. fusus (Stromb.), Linu. 
Figure.

Rostellaria fusus. Plate 7. Tig. 36. Shell, showing its graceful fusiform growth, and digitated lip.-From the collection of Dr. Knapp, of Edinzurgh.

\section{Genus 5. P'TEROCERA, Lamarck.}

\section{Animal; similar to that of Rostellaria.}

Shell; ovately oblong and ventricose, the last whorl being considerably inflated, and ending in an elongated canal of a structure similar to the digitations of the tip; columella and aperture peculiarly ridged; onter lip developed at maturity into a conspicnonsly clawed or digitated wing, and simuated towards the lower part.

The soft parts of Rostellaria, Pterocera, and Strombus, are so exactly similar in character, that M. Deshayes almost doubts the propriety of their being clivided into separate genera, and more especially as they are distinguished in a notable manner from the proximate kinds by a modification of structure, of which there is no analogy in any other genus of the class. The disc is divided in a manner which obliges the animal to leap*, as it were, instead of to crawl, and the tentacles are curiously two-forked, the stouter branch, a modification of that portion which is commonly pedunculated, being destined for the support of an eye of unusually large proportions.

The eye of these genera appears to be more highly developed than in any other of the Gastropods ; it is described as covering the summit of this stout, truncated, tentacular branch, and composed of a transparent horny material containing an iris, differing in colour according to species, for the transmission of rays of light into an imner chamber; an organism plainly adapted for seeing.

The distinguishing peculiarity of this family, as regards the shell, the ring-like expansion of the mature lip, presents itself under such different phases in the genera just spoken of in reference to the animal, that it cannot but be regarded as a feature calling for generic notice, notwithstanding the similarity of the soft parts. In the genus under consideration, the

* With regard to their habits of locomotion, it must not be imagined that the gigantic Strombs and Fountain Shells, with their attendant Spiders and Scorpions, are in the habit of leaping about the shore; they are not remarkable, I conceive, for any such activity; the word "leap" must be understood in a very restricted sense, and ouly so far as may be necessary to explain a mode of progression differing, to a limited extent, from the ordinary inert method of contraction and dilatation. 
mantle when about to suspend its function of calcification, expands itself into several digitations, of considerable length in some species, each secreting a massive claw, which it ultimately fills with calcareous matter, the hinder one being thrown orer the spire so as almost to conceal the primitive growth of the shell from the observer; the mantle then withdraws, and subsiding in wrinkles, deposits that richly coloured layer of corresponding wrinkled cnamel with which the colimella and aperture are always adorned at maturity.

The Pterocerce, or 'Spider Shells', are few in number, but well charactcrized by their distinctions of colour, and the number and growth of their claws; they are all inhabitants of the tropical seas.

\section{Species.}
1. aurantia, Lam.
5. millepeda, Lam.
8. rugosa, Soro.
2. chiragra, $i d$.
6. multipes, Desh.
9. scorpio, Lam.
3. elongata, * Swain.
7. pseudo-scorpio, Lam. 10. truncata, id.

4. lambis, Lam.

\section{Figure.}

Pterocera multipes. Pl. 8. Tig.40. Shell, showing the digitated expansion of the lip, and wrinkled surface of the aperture.

\section{Genus 6. STROMBUS, Linnœus.}

Animal; similar to that of Rostellaria, and Pterocern.

Shell; oblong-ovate, cmarginated and recurved at the base; spire conical, somewhat turreted; lip expanded, not digitated, and simuated towards the base; aperture oblong, rather narrow, slightly emarginated at the upper part.

Regarding the soft parts, the Stromli are identical with the Rostellarice and Pterocerce already described, and the peculiarities of which it is unnecessary here to repeat; but the shell presents an uniformity of character sufficiently distinct from cither to merit attention. The base is not pro-

* I cannot agree with M. Deshayes in the propriety of naming this shell "Pterocera novem dactylis"; the noun-ablative is ungrammatical in the sense required by the binomial form of nomenclature. Chemnitz was undoubtedly the first describer of the species, and a very characteristie figure is it accompanied with; but, as was almost invariably the case with his precursor Martini, he omitted to distinguish it by any specific name. The words above quoted, form part of Chemnitz's description, - "Strombus novem dactylis instructus", Se., and Swainson is therefore justly entitled to the priority of having named the species. 
longed into a sender channel or claw, but is short, and suddenly curved back, whilst the winged expansion of the lip is simple, though developed in a variety of ways in different species. Even the early Greek fathers of zoology distinguished the Strombi from the Pterocerce, separating the latter as Aporaides, so called in recent times by Lister, Gualter, and Aldrovandi, notwithstanding the A.pes-Pelicani must have been alone the subject to which Aristotle originally applied the term 'A the first anthor who may be said to have published the genus Strombus in its integrity; Linnæus, as M. Deshayes observes, included several shells under this head, independent of the Aporrhaides of antiquity, which have proved to belong to mollusks of different organization and habits; such, for example, as a Melanopsis which had, nevertheless, been noted as a freshwater Buccinum; a Pleurotoma is also to be found among the Linnæan Strombi, an Oniscia, a Volute, and several Cerithia; whilst not one of those enumerated by Lamarck has evoked a claim to any better arrangement.

The Strombi are pretty generally distributed throughout the globe; the largest species, the well-known $S$. gigas, is from the West Indies, and several others abound in the same locality; they are also tolerably abundant in the Eastern world, China, Ceylon, the Moluccas, \&c.; and we have species from Australia, New Zealand, Peru, California, Sandwich Islands, the Red Sea, and other places equally widcly separated. They have been beautifully illustrated by Mr. Sowerby in his 'Thesaurus Conchyliorum'; the figures of which, though much diminished in size, are not the less effective to one familiar with the genus.

\section{Species.}

1. accipitrinus, Lam.

2. alatus, Gm.

3. auris-Dianæ, Limn.

4. australis, Sow.

5. bituberculatus, Lam.

6. bubonius, $i d$.

7. bulbulus, Sow.

8. Camplelli, Gray.

9. canarium, Linn.

10. cancellatus, Lan.

11. columba, $i d$.

12. coniformis, Sow.

13. crenatus, $i d$.

14. crispatus, $i d$.

15. deformis, Gray.

16. dentatus, Linn.
17. dilatatus, Lam.

18. dubius, Sow.

19. elegans, $i d$.

20. epidromis, Linn.

21. fasciatus, $G m$.

22. fissurella, Linn.

23. floridus, Lam.

24. fusiformis, Sow.

25. galeatus, IV ood.

26. gallus, Linn.

27. gibberulus, $i d$.

28. gigas, $i d$.

29. glabratus, Sow.

30. Goliath, Chemn.

31. gracilior, Wood.

32. granulatus, $i d$.
33. hemastoma, Sow.

34. inermis, $i d$.

35. Isabella, Lam.

36. labiosus. $W_{0 o d}$.

37. laciniatus, Chemn.

38. Lamarckii, Gray.

39. latissimus, $\operatorname{Linn}$.

40. lentiginosus, $i d$.

41. lineatus, Lam.

42. Luhuanus, Linn.

43. maculatus, Nutt.

44. marginatus, Limn.

45̃. Mauritianus, Lam.

46. melanostoma, Swain.

47. Novæ'Zelandix, Chemn.

48. papilio, $i d$. 
49. Peruvianus, Sroain.

50. plicatus, Lam.

51. ponderosus, Phil.

52. pugilis, Linn.

53. rugosus, Sow.

54. Scalariformis, Ducl.
55. Sibbaldii, Sow.

56. succinctus, Linn.

57. terebellatus, Sovo.

58. Thersites, Gray.

59. tricornis, Lam.

60 . tridentatus, $i d$.
61. troglodytes, id.

62. turritus, $i d$.

63. urceus, Linn.

64. Vanikorensis, Quoy.

65. variabilis, Swain.

66. vittatus, Linn.

\section{Figure.}

Strombus Note Zetandie. Pl. 8. Fig. 37. Shell, showing its expanded wing-like lip, wrinkled aperture, and sinus.

\section{Family 5. CANALIFERA.}

Shell; canaliculated, canal sometimes very long, sometimes very short; lip not changing with age.

The family Canalifera comprises an extensive range of mollusks whose shells exhibit great diversity of structure, but are all more or less channelled at the base; this channel is, however, extremely variable; in some InIrices, for example, it almost rivals that of the Rostellaria fusus in length and tenuity, whilst in most of the Ranella and Cancellaria it is comparatively obsolete. There are other characters of no less importance distinctive of groups; the genera Fasciolaria, Cancellaria and Turlinella are characterized by a row of oblique plaits on the columella somewhat after the manner of the Volutes and Mitres; and the Tritons, Murices and Ranelle, are distinguished by a system of varicose growth, developed with a regularity which is not to be found in any other genus.

The animals of the different genera referred to this family, so far as they are at present knorn, are, with certain modifications, the same throughout; characterized by a short stout disk, truncated head, and fine pointed tentacles, such as are represented in the Triton tuberosus (Plate G.), the chicf variation consists in the developement of the mantle, which in some genera, and even species, is simple, whilst in others, it is furnished with that variety of filamentary processes which secrete the fronds, spines and tubercles.

It has been remarked by M. Deshayes, that the Cerithia and Cancellurice should not be included in the present family, because they do not strictly come within the category of the flesh-eating tribe; the former have been described to be of phytiphngous habit, and of the latter M. Deshayes observes, that a species inhabiting the shores of the Mediterranean is invariably attached to plants; has it been demonstrated, however, that they are not camivorous? This is a question that remains open to future observers, 
though not very likely, when determined, to evoke any change in the classification; the alimentary system not being so much influenced by the difference between digesting animal and vegetable matter, as is the respiratory system by the difference of inhaling air and water.

Sixteen genera may now be referred to this family, including one which I have found it necessary to propose under the name of Fastigiella.

$\begin{array}{lll}\text { Triton. } & \text { Cancellaria. } & \text { Turbinella. } \\ \text { Ranelia. } & \text { Pleurotoma. } & \text { Fastigiella. } \\ \text { Murex. } & \text { Mangelia. } & \text { Cerithium. } \\ \text { Tyrhis. } & \text { Fusus. } & \text { Cyrtulus. } \\ \text { Pyrula. } & \text { Fasciolaria. } & \text { Triphoris. } \\ \text { Ficus. } & & \end{array}$

Genus 1. TRITON, De Montford.

Inimal; disc oval, short, thick, carrying a smooth oblong operculum, mostly, fitting the aperture of the shell; head stout and rather prominent, somevthat square, with a pair of long slender pointed tentacles, protruling from the front corners, lating the eye placed upon the outer side near the base; at the under part of the head is a small slit, through which a probosc is is evserted for the capture of prey; respiratory siphon varyiny in length according to species.

Shell; oblong or rounded, with the canal sometimes very short, someimes long, and a little recurved, covered in some insiances with a strong bristly, hairy epidermis; whorls crossed with a single solitary varix on each, but very irregularly, and it is occasionally wanting; lip thickened and crenulated, sometines channelled at the upper part.

The genus Triton inclurles a considerable portion of that extensive and much-admired series of Canulifera, whose shells exhibit a peculinity in their mode of formation which is supposed to indicate periods of rest in the calcifying functions of their animal inhabitant. It consists of the deposit of a marginal ridge, with all its varicties of structural embellishment, at intervals, as highly finished, and in as perfect condition, as Nature, in the beauty and harmony of her operations, would lead us to anticipate only at maturity. These varices of fronds, spines, laminæ, or tubercles are secreted by certain filamentary processes, which are exserted, it is assumed, along the edge of the mantle, anterior to a season of rest; that is, the animal has 
the faculty of suspending the function of its calcifying organ at different intervals in the course of its growth, at the same particular periods in each species, in a manner exactly similar to that which induces the formation of claws just described in the mature Pterocera. In that genus there is no appearance of this defensive architectural border until the animal is engaged in the completion of its edifice, a natural effort for the attaimment of that symmetry and finish by which the works of the Invisible are characterized; but in the Tritons, Runelle, and Murices, it occurs at a very early stage of growth, the even tenour of the shell is renewed, and the varix is repeated at successive intervals. In Murex there are three or more in every whorl; in Ranella, one in every half-whorl; whilst in Triton, the periodical developement of a varix occurs less than twice in a whorl, the genus including, not only those having a varix in every whorl, but those in which a varix occurs on the last whorl only. Some species are found occasionally without any varix at all, but this is merely a fortuitous variation of growth.

Such is the arrangement of the varicose Canalifera in popular use; several genera have been proposed for further subdividing them, the most plausible of which is the genus Persona of De Montford, for the Tritones anus, mulus, Se.; whilst Dr. Pfeiffer, on the other hand, unites the Runelles and Tritons into one. All were included by Limnæus under the head of Murex, and there is little or no difference of generic value in the soft parts; it has been observed, however, by M. Deshayes, that the animals of the different species of Triton, excepting the great Trumpet shell * (Triton variegatus), and one or two large allied species, are distinguished by an occellated pattern of colouring as in the $T$. tuberosus here figured.

The Tritons have shells of more solid structurc than the Murices or Ranelle, and of more simple growth. They are not furnished with fronds or spines, nor have they any ramified branches like the Murices; the rude manner in which the whorls are convoluted seems rather to indicate that their animal inlabitant, though possessing abundant power of calcification, is of somewhat sluggish growth. The epidermis of the Tritons is often remarkably thick, hairy, and bristly, and is sometimes accompanied with bristles in small tufts. Another curious peculiarity in these shells is the structure of the apex; it appears in numerous instances to be formed of a horny substance, thinly plated with shelly matter, and it is not an uncomnon thing to find examples in which the calcareous plating is broken off so as to expose the horny cast underneath. The columella of the Tritons is gene-

* In the early ages of Greece, it was customary for the $\mathbf{K} \eta \dot{\rho} \boldsymbol{\xi}$, or common crier, to introduce himself to the notice of the people by lustily blowing through a shell. We learn from tradition, as well as history, that the Triton variegatus or Trumpet-Shell (Murex Tritonis, Limn.) was the one commonly selected for that purpose; but it is more probable that the shells of many other Canalifera were used. Be that as it may, it is certain that the word Kerix was applied by Aristotle from that circumstance to all the canaliculated shells with which he was acquainted, and it appears to have jassed by a strange process of corruption, into that of Herex.-Conch. Syst. vol. ii. p. 191 . 
rally covered with a bright coat of wrinkled cnamel, and the outer lip becomes thickened in a manner somewhat curious; upon arriving at maturity the lip curls under so as to form a deep broad chamnel or gutter, which is then filled up to form the thickened lip. The varices are all constructed in the same manner, each forming for a time the margin of the aperture, and destined, it is conjectured, to protect the lip during a season of rest in the manner already described; as a question for the curious it would be interesting to know what length of time ordinarily elapses between the formation or deposit of a varix, and the renewal of growtl. The elegant margin of the T. femorale is celebrated as having furnished the original model of the gadroon border so frequently used by the silversmith in the decoration of plate; and the common Trumpet of the Mediterranean, T. nodiferns, may be noticed as affording an occasional meal for the Neapolitan fisherman, which, in the absence of more delicate food, is said to be much relished.

The Tritons appear to be widely distributed over the globe: of a hundred species recently illustrated in the 'Conchologia Iconica', the chief portion are from the Molucea and Philippine Islands; some few are from the western coast of America, some from China, several from New Holland, Ceylon, and Mozambique; and there are also one or two from the Mediterranean, the Cape of Good Hope, the West Indies, and the United States.

\section{Species.}

1. acuminata, Reeve.

2. ægrotus, $i d$.

3. amictus, $i d$.

4. angulatus, $i d$.

5. anomalus, Hinds.

6. antiquatus, $i d$.

7. anus, Lam.

8. aquatilis, Reeve.

9. australis, Lam.

10. bacillum, Reeve,

11. bracteatus, Hinds.

12. canaliferus, Lam.

13. cancellinus, Desh.

14. carduus, Reeve.

15. Ceylonensis, Sow.

16. Chemnitzii, Gray.

17. chlorostoma, Lam.

18. cingulatus, Pfeiffer.

19. clandestinus, Lam.

20. clathratus, Sow.

21. clavator, Lam.
22. concinnus, Reeve.

23. constrictus, Brod.

24. convolutus, $i d$.

25. corrugatus, Lam.

26. crispus, Reeve.

27. cutaceus, Lam.

28. cynocephalus, Lam.

29. decapitatus, Reeve.

30. decollatus, Sow.

31. decipiens, Reeve.

32. digitale, $i d$.

33. distortus, Sch. \& Wag. 54. lativaricosus, Reeve.

34. doliarius, Lam. 55. lignarius, Brod.

35. eburneus, Reeve. 56. lineatus, Brod.

36. egregius, $i d$.

37. elongatus, $i d$.

38. encausticus, $i d$.

39. exaratus, $i d$.

40. exilis, $i d$.

41. eximius, $i d$.

42. femorale, Lam.
43. ficoides, Reeve.

44. fictilis, Hinds.

45. fusiformis, Kiener.

46. gallinago, Reeve.

47. gemmatus, $i d$.

48. gibbosa, Brod.

50. grandimaculatus, $i d$.

51. labiosus, $i d$.

52. lampas, Lam.

53. lanceolatus, Kienzer.

57. lotorium, Lam.

58. maculosus, $i d$.

59. Mediterraneus, Sow.

60. moritinctus, Reeve.

61. Nassoides, $i d$.

62. nitidulus, Sow.

63. niveus, Pfeiffer.
49. gracilis, Reeve. 
64. nodiferus, Lam.

65. obscurus, Reeve.

66. olearium, Desh.

67. pagodus, Reeve.

68. Pfeifferianus, $i d$.

69. pictus, $i d$.

70. pilearis, Lam.

71. pygmaus, Pfeiffer.

72. pyrum, Lam.

73. Quoyi, Reeve.

74. Ranelloides, $i d$.

75. reticulatus, Blain.

76. retusus, Lam.

77. ridens, Reeve.
78. rubecula; Lam.

79. rudis, Brod.

80. sarcostoma, Reeve.

81. Saulix, $i d$.

82. scabra, King.

83. Scalariformis, Brod.

84. scrobiculator, Lam.

85. sculptilis, $i d$.

86. Sinensis, $i d$.

87. siphonatus, $i d$.

88. Soverbii, $i d$.

89. Spengleri, Lam.

90. subdistortus, $i d$.
91. tessellatus, Reeve.

92. Thersites, $i d$.

93. triginus, Brod.

94. tortuosus, Reeve.

95. Tranquebaricus, Lam.

96. trilineatus, Reeve.

97. tripus, Lan.

98. truncatus, Hinds.

99. tuberosus, Lain.

100. variegatus, $i d$.

101. verrucosus, Reeve.

102. vespaceus Lam. $_{3}$

103. vestitus, Hinds.

\section{Figures.}

Triton tuberosus. Pl. G.-Shell with animal, showing its short disc, truncated head, pointed tentacles and ocellated painting.-From the ' Voyage de l'Astrolabe.'

Triton tigrinus. Pl. 9. Fig. 43. Shell (diminished two-thirds), showing a strong varix on the left side.-From Mr. Cuming's collection.

\section{Genus 2. RANELLA, Lamarck.}

Animal; similar to that of Triton.

Shell; ovate or oblong-ovate, with the spire more or less acuminated; varices mostly oblique, deposited one on every halfwhorl, forming a longitudinal row on each side; canal sometimes very short, sometimes rather long; aperture ovate, generally canaliculated at both ends.

The genus Ranella was founded by Lamarck upon a peculiarity manifested in the arrangement of the varices, by which the shell acquires a depressed two-edged structure. The animal varies in no respect from Triton, except in the mode in which it forms its shell; the varices or marginal borders, resulting from a periodical function of the mantle, are deposited exactly one on every half-volution, ranging therefore on either side of the shell, like a continuous wing-like appendage from the apex to nearly the base.

Having treated of the mode in which this function is excrcised, under the head of Triton, it may here be noticed that De Blainville assumed them to indicate periods of gestation; but M. Deshayes observes, in reply to this, that, "the varices being deposited from the earliest formation of the shell, it is quite unnatural to suppose, that the animal has the faculty of employing 
that function so soon after its ejection from the ovary". It has been imagined also, that the periodical development of varices indicates the changes of the seasons; but, repeats M. Deshayes, "the canaliferous tribes dwell in a climate where there is scarcely any variation of season, and the temperature of the waters the same all the year round".

Although the genus Ranella has no very high claim to distinction, there is no group in the series whose generic aspect appears more acurately defined to the eye of the common observer; the lateral continuity of the varices imparts a peculiarity to the shell not easily confounded with any other. The species assimilate very much in sculpture; the rarest and most exquisite in form is the well-known 'Fimned Frog' Ranella pulchra.

The monograph of this genus published in the 'Conchologia Iconica" includes fifty species; the greater portion inhabit the eastern seas, the Philippine and Molucea Islands, some are from California and the West Coast of South America, but the largest, singularly enough, exists at the northern limit of the genus, in the Mediterranean.

\section{Species.}

1. affinis, Brod.

2. albifasciata, Sow.

3. albivaricosa, Reeve.

4. anceps, Lam.

5. argus, $i d$.

6. bitubercularis, $i d$.

7. bufonia, $i d$.

8. cælata, Brod.

9. Californica, Hinds.

10. candisata, Lam.

11. caudata, Say.

12. coriacea, Reeve.

13. crassa, Desh.

14. cruentata, Sovo.

15. crumena, Lam.

16. cuspidata, Reeve.

17. elegans, Beck.

18. foliata, Brod.
19. gigantea, Lam.

20. granifera, $i d$.

21. gyrinus, Desh.

22. hastula, Reeve.

23. leucostoma, $i d$.

24. livida, Reeve.

25. lævigata, Lam.

26. margaritula, Desh.

27. Muriciformis, Brod.

28. nana, Sow.

29. neglecta, $i d$.

30. nitida, Brod.

31. nobilis, Reeve.

32. pectinata, Hinds.

33. plicata, Reeve.

34. ponderosa, $i d$.

35. pulchra, Gray.
36. pusilla, Brod.

37. pustulosa, Reeve.

38. pyramidalis, Brod.

39. rhodostoma, Beck.

40. rosea, Reeve.

41. rugosa, Sovv.

42. semigranosa, Lam.

43. siphonata, Reeve.

44. spinosa, Lam.

45. subgranosa, Beck.

46. triquetra, Reeve.

47. tuberculata, Brod.

48. tuberosissima, Reeve.

49. ventricosa, Brod.

50. venustula, Reeve.

51. verrucosa, Sow.

52. vexillum, $i d$.

\section{Figure.}

Ranelda roliata. Plate 9. Fig. 44.-Shell showing the continuous arrangement of the varices from the apex downwards on either side.From Mr. Cuming's collection. 


\section{Genus 3. MUREX, Linnœus.}

Animal; similar to that of Triton.

Shell; ovate or oblong, generally pyriform, or more or less fusiform, spire somewhat angularly turreted; whorls slightly ventricose, varicose, varices three or more on a whorl, variously ornamented with branched foliated or spinous fronds; columella smooth, arched, ending in a canal which is sometimes very short and recurved, sometimes very long and tubulous; aperture nearly orbicular, outer lip generally denticulated or crenated, and sometimes armed with an erect prominent tooth. Operculum hormy.

Though somewhat numerous in species, the genus Murex, in its present limited acceptation, retains few originally referred to it by its founder. After being freely dismembered by Bruguière and Lamarck for the genera Cerithium, Turbinella, Fusus, Fasciolaria, Pleurotoma, Cancellaria and Pyrula, there yet remained an extensive series to be distinguished according to their varieties of varicose growth in the manner described under the genera Triton and Ranella, and of these the largest proportion of species falls to the present genus, because it includes all those whose shell is characterized by the presence of more than two varices on a whorl.

The number of varices displayed, by what may be termed the typical species of the genus is three, imparting a triangular structure to the shell, which has been likened to the calthrop of the ancients; an instrument of war which was scattered on the field of battle for the purpose of wounding the enemies' horse*.

Beyond the number of three, the varices are irregular, following each other in such rapid succession as almost to lose their distinctive character; the genus now merges into Fusus, and it is at this point of contact that many synonymes have arisen, on account of the differences of opinion as to which of the two genera, a species should be referred.

The ITurices are greatly distinguished by the beautiful varieties of structure which are developed on the varices, presenting in some species most elaborate leaf-like fronds, in others a succession of fimbriated laminx, in others a row of long tubular spines: these variations of ormamental growth serve as characters for the subdivision of the genus. The profuse enamelling of the aperture is also striking, exhibiting colours in that purity and brightness which no effort of the pencil can imitate.

* The calthrop was a small three-sided weapon with a row of sharp spikes down each angle, such as is represented in the structure of the threc-varicose Mrurex; discharged over the enemy's quarters, upon whatever side it fell, a row of spikes would be uppermost. 
It is stated in a former page of this work, that the Romans obtained their celebrated dye, from the expressed juice of the MIurex trunculus, inhabiting the Mediterranean and shores of Tyre; the Murex brandaris scems also to have been called into requisition for this purpose, and M. Deshayes attempts to show that remains of this species, in consolidated heaps, are still to be found on the coast, denoting ancient stations for the extraction of purple.*

The genus Murex includes many species of more or less rarity; of these the M. bipinnatus and clavus are distinguished by an elongated peculiarity of growth different from that of any other kind; the $M$. spinicostata is a species of rare occurrence in fine condition; the $M$. monodon remarkable on account of the elegantly prolonged curvature of the fronds. The $M$. alabaster of which only a single specimen has been seen, is a huge curiosity of its kind and forms a striking contrast, in comparison with the refined disposition of sculpture in the M. fenestratus; the M. Stainforthii must not be omitted in this category of rarities, nor the M. crispatus, both of which species are equally distinguished for the peculiar and manifold beauty of the fronds. Among the canaliculated species the $M$. trigonulus, elegans and motacilla are worthy of notice; the $M$. Zelandicus, florifer, muridentatus, territus and eurypteron are of diversified beauty and interest; whilst among the smaller gems of the genus may be enumerated the M. hexagonns, macropteron, Norrisii, gravidus, octogonus, cirrosus, and a few others.

The Murices are very generally distributed throughout the regions of animal life; they are represented on our own shores by the $M$. erinaceus and in the Mediterranean by one or two small species in addition to those just spoken of; in Califormia by the magnificent $M$. erythrostoma, and in Panama by the $M$. regins whose meretricious glow of colours and elaborate structure have long rendered it an object of attraction to the amateur. In the Eastern Seas we find the noble $M$. ramosus and saxatilis in abundance, with numerous other species, among which the well-known 'Venus's comb' $M$. tenuispina, in which all deficiency of beauty in colour is so fully compensated by the delicacy and extraordinary character of its structure.

The following list of species are described and illustrated in the 'Conchologia Iconica’.

* "Numerous dissertations upon the Purple of the ancients have served to show that the colour the most esteemed was obtained from the MIurex brandaris. Rondelet was the first to hold this opinion, and it has been singularly confirmed in recent times by the researches of our learned friend M. Boblaye. Forming part of the scientific expedition to the Morea, he was astonished to find, in places not very remote from the sea, considerable heaps of the remains of this single species, Murex brandaris; he at first regarded them as evidences of some geological phenomenon, but upon a careful examination of the places and accompanying circumstances, he discovered that these depots of fragments of shell were always situated in the vicinity of some ancient ruins, among which sufficient vestiges were to be found of their having been formerly stations for the manufacture of Purple".-Anin. sans, vert. v. ix. p. 550. 
Species.

1. acanthopterus, Lam. 47. crocatus, Reeve.

2. aculeatus, $i d$. 48. cyclostoma, Sow.

3. adunco-spinosus, Beck.49. decussatus, Reeve.

4. adustus, Lam.

5. affinis, Reeve.

6. alabaster, Reeve.

7. alveatus, Kiener.

8. ambiguus, Reeve.

9. angularis, Lam.

10. anguliferus, $i d$.

11. axicornis, $i d$.

12. badius, Reeve.

13. bæticus, $i d$.

14. balteatus, Beck.

15. Banksii, Sow.

16. bellus, Reeve.

17. bicolor, Valen.

18. bipinnatus, Reeve.

19. Blainvillii, Payraud.

20. borealis, Reeve.

21. brandaris, Iinn.

22. brassica, Lam.

23. brevispina, Lam.

24. buxeus, Brod.

25. calcar, Kiener.

26. calcitrapa, Lam.

27. Californicus, Hinds.

28. caliginosus, Reeve.

29. cancellatus, Sow.

30, Capensis, $i d$.

31. Capucinus, Chemn.

32. carduus, Brod.

33. cariniferus (Fusus), So. 79, humilis, id.

34. centrifuga, Hinds.

35. cervicornis, Lam.

36. chrysostoma, Gray.

37. cirrosus, Hinds.

38. clathratus, Reeve.

39. clavus, Kiener.

40. concinnus, Reeve.

41. cornutus, Linn.

42. corrugatus, Sow.

43. crassilabrum, Gray.

44. crassivaricosa, Reeve.

45. crispus, Brod.

46. cristatus, Brocchi.
50. digitatus, Sorv.

51. dipsacus, Brod.

52. distinctus, Christ.

53. dubius, Sovo.

54. Edwardsii, Menke.

55. elegans, Beck.

56. elongatus, Lam.

57. emarginatus; Sov.

58. endivia, Lam.

59. erinaceus, Linn.

60. erosus, Brod.

61. eurypteron, Reeve.

62. falcatus, Sow.

63. fasciatus, $i d$.

64. fenestratus, Chemn.

65. festivus, Hinds.

66. fiscellum, Chemn.

67. florifer, Reeve.

68. foliatus, Gmelin.

69. foveolatus, Hinds.

70. funiculatus, Reeve.

71. Gambiensis, $i d$.

72. gravidus, Hinds.

73. gyratus (Trophon), H. 119. oculatus, Reeve.

74. hamatus, Hinds.

75. haustellum, Linn.

76. hemitripterus, Lam.

77. hexagonus, $i d$.

78. horridus, Brod.

80. imperialis, Sroain.

81. incisus, Brod.

82. inconspicuus, Sow.

83. inermis, $i d$.

84. Kieneri, Reeve.

85. laciniatus, Sow.

86. laminiferus, Reeve.

87. lappa, Brod.

88. laqueatus, Sow.

89. lepidus, Reeve.

90. lingua-vervecina, $C \%$.

91. luculentus, Reeve.

92. lugubris, Brod.
93. macropteron, Dest.

94. maculatus, Reeve.

95. margariticola, Brod.

96. Martinianus, Reeve.

97. maurus, Brod.

98. megacerus, Sow.

99. melanomathos, Gme.

100. messorius, Sow.

101. microphyllus, Lam.

102. Mindanensis, Sow.

103. Monoceros, Sovo.

104. monodon, Sow.

105. motacilla, Chemn. H.

106. mundus, Reeve.

107. muricatus (Trop.).

108. nigrescens, Sow.

109. nigrispinosus, Reeve.

110. nigritus, Plil.

111. nitidus, Brod.

112. nodatus, Reeve.

113. noduliferus, Sow.

114. Norrisii, Reeve.

115. nucula, $i d$.

116. nux, $i d$.

117. occa, Sow.

118. octogonus, Quoy.

120. osseus, $i d$.

121. oxyacantha, Brod.

122. palma-rosæ, Lam.

123. palmiferus, Sorv.

124. pellucidus, Reeve.

125. peritus, Hinds.

126. phyllopterus, Lam.

127. pinnatus, $W$ ood.

128. pinniger, Brod.

129. pistacia, Reeve.

130. planiliratus, $i d$.

131. Pleurotomoides, id.

132. pliciferus, Sow.

133. polygonulus, Lam.

134. pomum, Gmelin.

135. princeps, Brod.

136. pudicus, Reeve.

137. pudoricolor, $i d$.

138. Purpura, Chemn. 
139. purpuratus, Reeve:

140. Purpuroides, Dunk.

141. radicatus, Hinds.

142. radix, Gmetin.

143. ramosus, Limn.

144. rarispina, Lam.

145. rectirostris, Sow.

146. recurvirostris, Brod.

147. regius, $W_{\text {ood }}$.

148. rosarium, Chemn.

149. rota, Sow.

150. rubescens, Brod.

151. rubiginosus, Reeve.

152. rubridentatus, $i d$.

153. rufus, Lam.

154. rusticus, Reeve.

155. salebrosus, King.
156. Saulix, Sow.

157. saxatilis, Limn.

158. scolopax, Dillwyn.

159. scorpio, Linn.

160. secundus, Lam.

161. Senegalensis, Gmelin.178. trilineatus, Reeve

162. similis, Sow.

179. tripterus, Bom.

180. triqueter, $i d$.

164. spectrum, Reeve. 181, trunculus, Linn.

165. spinicostata, Valen. 182. tumulosus, Sow.

166. squamulosus,(Fusus.) 183. turbinatus, Lam.

167. Stainforthii, Reeve. 184. uncinarius, Lam.

168. Steerix, $i d$.

169. tenuispina, Lam. 186. varius, Sow.

170. ternispina, $i d$. 187. vibex, Brod.

171. territus, Reeve. $\quad$ 188. vittatus, $i d$.

172. tetragonus, Brod. 189. Zelandicus, Quay.

\section{Figure.}

Murex florifer. Plate 9. Fig. 42.-A new species, recently collected on the shores of Honduras by Mr. Dyson, in which the varices present a characteristic row of leaf-like fronds.-From Mr. Cuming's collection.

\section{Genus 4. TYPHIS, De Montford.}

Animal ; unknown.

Shell; small, MLurex-shaped, mostly trivaricose, with a hollow spouted tube protruding from the upper part of the whorl, in the centre of the area between the varices; spire rather short, sometimes elongated; columella smooth, aperture small, rounded. Operculum horny.

When treating of this singular group in the 'Conchologia Systematica' I inclined to believe with M. Deshayes that it was sufficient to regard it as a sectional division of the preceding genus; I now, however, appreciate the character by which the Typlictes are distinguished, as one peculiarly generic, inasmuch as it is not the modification of a spine, nor has it an analogous representative in any other genus.

The shell of Typhis is similar in form and general aspect to that of Murex, but uniformly small; its peculiarity consists in having a more or less elongated spouted tube, in the centre of the area between the varices, in 
place of the usual nodule or tubercle. This tube, it will be observed, is not the analogue of a spine; the spines which adorn the varices, so conspicuously developed in the Murex temispina, and others, being always open on one side, are no other than extreme modifications of scales or fronds, but the tube of Typhis, is always closed-the wall of it is entire-and it seems destined for some other purpose than that of ornament. It is a perfectly unique structure; in no other turbinated genus is the least analogy to be found, nor can I trace the gradation which M. Deshayes notices to exist between the tube of the Typhis and the spine of the Murex.

The genus Typhis was founded on a fossil species (Murex tetrapterus, Bronn.; M. fistulosus, Brocc.; M. pungens, Band.) subsequently found living in the Mediterranean, described together with four other recent species by Mr. Broderip in 1832*, of which two were collected by Mr. Cuming at Salango, West Columbia and the Bay of Caraccas, and one by Capt. Sir Edward Belcher at Cape Blanco, West Africa. Three species were then added to the genas, collected by the same illustrious traveller during the voyage of H.M.S. Sulphur, in localities very remote from each other; one was found in from seven to eighteen fathoms water in the Gulf of Nicoya and Bay of Guayaquil, the second was dredged on the l'Agulhas Bank, Cape of Good Hope, at a depth of upwards of fifty fathoms, and the third, the smallest of the series, was found among gravel and coral, in eighteen fathoms water at the straits of Macassar, Indian Archipelago.

\section{Species.}
1. arcuatus, Hinds.
4. Cumingii, Brod.
7. pinnatus, Brod.
2. Belcheri, Brod.
5. Sowerbii, Brod.
8. quadratus, Hinds.
3. coronatus, Brod.
6. nitens, Hinds.

\section{Figure.}

Trphis SowerbII. Plate 12. Fig. 54.-Shell showing the spout-like tubes issuing from between the varices.-From Mr. Cuming's collection.

\footnotetext{
* "De Montfort, after referring to Murex pungens, Bander, as the type of this genus, adds 'La coquille qui nous sert de type pour l'etablissement de ce genre n'est encore bien connue qu'ì l'état fossile ; quoique Bruguière dise très positivement que son analogue marin existoit à Loudres dans le cabinet du Docteur Hunter, fait que malheureusement nous ne pouvons point verifier, mais qui cependant nous devons adopter d'après les profondes connoissances et la perspicacité qui distinguèrent si eminemment ce conchyliologue francois'. In the Dictionnaire des Sciences Naturelles the statement of Braguière is noticed; but M. Blainville observes, that he was not fortunate enough to find the shell. I have examined the Hunterian Collection in London, with the assistance of Mr. Clift and Prof. Owen, with no better success. It may, perhaps, have been in the cabinet of Dr. William Hunter, now at Glasgow; but on consulting Captain Laskey's "General Account of the Hunterian Museum" there, I find no mention of the shell "-W.J.B.
} 


\section{Genus 5. PYRULA, Lamarck.}

\section{Animal ; similar to that of Triton and Murex.}

Shell; somewhat pyriform, spire sometimes exserted, sometimes fatly depressed; columella smooth, canal more or less elongated; lip simple, interior of the aperture sometimes smooth, sometimes radiately ridged or striated. Operculum horny.

The Pyrulc were separated from the genus Fusus of Bruguière, with little to distinguish them beyond their pear-shaped peculiarity of form, which is certainly characteristic in the typical species; there are, however, many inseparable from these which lead to the confines of the group, and so to Fusus by a continuity of character almost imperceptible. The $P$. pugilina and cochlidium so nearly allied, even in respect to species, were referred by Lamarck, one to Pyrula the other to Fusus; the P. carica, canaliculatu and spirata, on the other hand, are very peculiar in form, and ought, without. doubt, to be distinguished from any of the proximate genera; whilst the P.papyracea and Nance form a division of the group allied to Purpure by their very close relation with the $P$. galea and Scalariformis.

One division of the Lamarckian Pyinla, commonly known as the 'Figs', has been distinguished as a genus by Swainson under the name of Ficula, and the propriety of this change has been recently confirmed by the discovery of the living animal, which proves to be allied rather to Harpa and Dolium, and ought properly to have been included in the same family.

The Pyrulce thus restricted are somewhat limited in number; they inhabit chiefly the Fastern Seas, with one or two from Mexico, the West Indies, California and the United States.

\section{Species.}

1. anomala, Reeve. 11. corona (Murex), Gmel. 21. patula, Brod. and Sovo.

2. arauna (Murex), Linn. 12. elongata, Lamarck.

22. perversa, Lamarch.

3. Belcheri(Mur.), Hinds. 13. galeodes, Lamarch.

23. pugilina (Murex), Brn.

4. bezoar (Buc.), Limn. 14, lactea, Reeve.

24. spirata, Lamarck.

5. bispinosa, Plilippi. 15. lignaria, Reeve.

25. spirillus (Murex), Lin.

6. bucephala, Lamarck. 16. lineata, Lam.

7. bulbosa (Murex), Solan. 17. Mawæ, Gray.

26. rapa, (Bulla), Linn.

27. subrostrata, Gray.

8. canaliculata (Murex), L. 18. melongena (Murex), L. 28. Termatana (Murex) Gm.

9. clavella, Reeve. $\quad$ 19. morio (Murex), Limn. 29. tuba (IIurex), Gmelin. 10. cochlidium (Murex), L. 20. Paradisiaca, Reeve. 
Figure.

Pyrula Mawe. Pl. 9. Fig. 41. Shell showing the aperture, smooth columella, and large umbilicus.-From Mr. Cuming's collection.

Genus 6. FICULA, Swainson.

Animal; disk oblong, attenuated posteriorly, rounded in front, with a small acuminated lobe on each side; no operculum; head small, with two small cylindrical tentacles more or less exserted, beneath the base of which on each side is situated the eye, sessile; proboscis capable of considerable elongation; mantle much dilated, expanded throughout the canal, and. over all that portion of the body whorl of the shell forming the boundary of the aperture.

Shell; pyriform or fig-shaped, light and ventricose, widely channelled at the base, channel more or less prolonged, spire very short; columella slight; aperture large, extending posteriorly to the spire; lip thin, entire.

The Lamarckian species of Pyrula, commonly known as 'The Figs', were first distinguished as a genus by Mr. Swainson in his 'Malacology', a volume of 'Lardner's Cyclopedia'; founded, not, however, upon any knowledge of the soft parts, but upon the uniform generic affinity of the shells. Only four species are known, and three have been lately taken alive; the $F$. ficoides and gracitis, were collected by M. Rousseau, a zealous naturalist attached to the Jardin des Plantes, Paris, during a voyage to Madagascar and the Seychelle Islands, and the F. lavigata, was dredged together with the $F$. ficoidles, by Mr. Arthur Adams, Assistant Surgeon, R.N., in the Sooloo Seas, during the recent voyage of H.M.S., Samarang.

The generic importance which Mr. Swainson attached to this limited group has been fully confirmed by the peculiarities of the animal ; although a canaliculated shell, and so closely allied in form to the Pymule carica, spirata and others, as to induce Martini to distinguish them as subdivisions of a particular group, under the titles of the Light Figs, 'Fici tenues', and the Heavy Figs, 'Fici ponderosi', the animal approaches rather to Dolium and Harpa, having an elongated proboscis and the same rounded lobate structure of the front portion of the disc.

The F.gracilis and ficoides lave been beautifully illustrated by $M$. Rousseau under the new generic name Ficus, in M. Chenu's handsome publication, 'Illustrations Conchyliologiques'; the tentacles are partially 
withdrawn, and the dise and mantle somewhat contracted, but the species are represented in an excellent manner *. Mr. $\Lambda$ dams possesses a drawing of the $F$. Tevigata, taken from the living animal, which will probably appear in the 'Zoology of the Voyage of H.M.S., Samarang'; in the mean time he has kindly furmished me with the following from his note-book :-

"The Ficula is a very lively animal when observed in its native element, crawling along with considerable velocity, owing probably to the lightness of its shell, and able to ascend the sides of a glass vessel with facility. The disc is very extensive and not provided with an operculum; it is broad and rounded in front, and acuminated behind, the mantle is thin and expands into two lateral lobes covering a great portion of the sides of the shell, and much more, in the water, than is represented in the handsome ligures of M. Rousseau. The proboscis is rarely exserted when the animal is in motion, but the long tapering tentacles are stretched out to their full extent; the eyes are rather large and black.

"In the species I observed (Ficula lavigata, Reeve,) the mantle was bright pink, mottled with white and lighter pink; the under surface of the disc was of a dark chocolate colour with yellow scattered spots; the head and neck were pink, and also covered with yellow spots. The specimen was dredged from thirty-five fathoms in the Sooloo Sea."

For figures and a critical analysis of the species, I must refer the reader to the Monograph Ficula, in the 'Conchologia Iconica'.

\section{Species.}

1. decussata (Bulla.), Wood.

2. ficoides (Pyrula.), Lamarck.
3. gracilis (Pyrula.), Sowerby.

4. lævigata, Reeve.

\section{Genus 7. CANCELLARIA, Lamarck.}

Animal ; disc oblong, thin, flattened, slightly truncated anteriorly and extending a little beyond the head; head very large and flat forming the segment of a circle at each corner of the extremity of which rises a slim elongated conical tentacle; eyes situated on the outer side of these at the base where they are a little exserted; proboscis none? Operculum none.

* The term Ficus was used by Martini as a common appellative, not in accordance with the prescribed form of nomenclature; it is moreover open to objection in consequence of its being pre-occupied in Botany to distinguish the genus of Figs. 
Shell; oval, diversely ribbed and reticulated on the outside, the last whorl being somewhat ventricose and often forming a large umbilicus; columella more or less strongly plaited, ending in a short, sometimes posteriorly recurved canal; aperture ovate or oblong, with the lip a little capanded and. often reticulated.

This interesting genus so much appreciated by conchologists on account of the many interesting specics added to it within the last few years, has elicited a variety of opinion in the determination of its character, and, consequently, the place which it shonld occupy in the system. The shell is mainly distinguished by its having the columella strongly plaited and in never being more than slightly channelled at the base. Limneus, and even Cuvier, arranged the Cancellariae on this account with the Volutes and Titres; M. Deshayes, on the other hand, inclines to the opinion that they belong to the family Plicuece, consisting of the genera Pyramidella and Tornatella. To the former of these views it is impossible to assent, because the soft parts differ, whilst the plaited columelli less strongly developed, appears throughout, to be rather a modification of the same character in Turbinella; in the latter, it is difficult to understand how such an aflinity cau exist betreen animals, whose shells afford so great a contrast in substance and structure as those of Pyramidella and Cancelleriu, the one vitreous and polished, the other distinguished by great variety of highly relieved sculpture, and which seems to indicate the same carnivorous habits as the rest of the Canalifera. The greatest anomaly in the history of the Cancellariae, is that observed by M. Deshayes, of the $C$. cancellata being a vegetable feeder, and it only remains to be seen whether this is the habit of the genus*.

The shell referred to this genus by Lamarck, under the name $C$. citharella, has no plaits on the columella, and will be found to belong to the little group NIangelia, following next in order after Plenrotoma.

The Cancellarice are not of very common occurrence, and inhabit rather a wide range, they are found at Pananna, Peru, China, Eastern Archipelago, \&c., and their northern limit is in the Mediterranean.

* In order to determine the relation of this genus, it is necessary to become further acquainted with the animal; M. M. Quoy and Gaimard have given a figure of one species, and I have myself had the opportunity of observing another, that which is so abundantly distributed throughout the shores of the Mediterranean. This species differs in some respects from that described by the Zoologists of the 'Astrolabe', but we are unanimous on the subject of there being no operculum. The animal of C.cancellata crawls upon a disc almost as long as the shell, thin and flattened with the edge slightly truneated and passing a little beyond the head. The head is very large, flat, thin and sharp, forming the segment of a circle at each corner of the extremity of which rises a slim elongated conical tentacle; the eyes being situated on the outer side of these at the base, where they are slightly projected. I never observed the animal put forth any trunk; and, having found it invariably oi marine plants, am disposed to think it nourishes itself by bruising them with a pair of horny jaws similar to those of other vegetable-fceding mollusks. It is very 
Species.

1. acuminata, Sow.

2. albida, Hinds.

3. antiquata, $i d$.

4. articularis, Sow.

5. asperella, Lam.

6. asperula, Desho.

7. australis, Sow.

8. bicolor, Hinds.

9. bifasciata, Desh.

10. brevis, Sow.

11. Buccinoides, $i d$.

12. bulbulus, $i d$.

13. bullata, $i d$.

14. cancellata, Lam.

15. candicka, Sow.

16. Cassidiformis, $i d$.

17. chrysostoma, $i d$.

18. clavatula, $i d$.

19. contabulata, $i d$.

20. corrugata, Hinds.

21. costata, Gray.

22. costifera, Sov.

23. Courthouyi, Jay.

24. crenata, Hinds.
25. crenifera, Soro.

26. crispa, $i d$.

27. decussata, Sow.

28. elata, Hinds.

29. funiculata, $i d$.

30. gemmulata, Sow.

31. goniostoma, $i d$.

32. granosa, $i d$.

33. hemastoma, $i d$.

34. imperialis, Mich.

35. indentata, Sow.

36. lactea, Desh.

37. lamellosa, Hinds.

38. lævigata, Sow.

39. Littorinæformis, $i d$.

40. Mitræformis, $i d$.

41. multiplicata, Less.

42. nassa, Roissy.

43. nodulifera, Sow.

44. nodulosa, Lam.

45. obesa, Sow.

46. obliquata, Lam.

47. obtusa, Desh.

48. ovata, Sow.
49. piscatoria, $i d$.

50. pulchra, $i d$.

51. Purpuræformis, Valen.

52. pusilla, Sow.

53. reticulata, Lam.

54. rigida, Sow.

55. rugosa, Lam.

56. Scalariformis, $i d$.

57. scalarina, $i d$.

58. scalata, Sow.

59. similis, $i d$.

60. solida, $i d$.

61. Splengleriana, Desh.

62. spirata, Lam.

63. tessellata, Sow.

64. textilis, Kiener.

65. trigonostoma, Desh.

66. Tritonis, Sow.

67. tuberculosa, id.

68. uniplicata, $i d$.

69. urceolaria, Hinds.

70. ventricosa, $i d$.

71. Verreauxii, Kiener.

\section{Figure.}

Cancellaria Tritonis. Pl. 10. Fig. 47. Shell showing the aperture and strongly plaited columella.-From Mi. Cuming's collection.

timid, and, retiring into its shell upon the least movement, re-appears cautionsly : differing materially in its mode of progression from the Buccina, which exhibit more activity. With these characters the genus Cancellaria cannot be allowed to remain in the vicinity of the Volutes and Mitres; it is known that these are extremely voracious, being provided with a long trunk by the aid of which they attack and suck the juices of the animal selected for prey. Although the absence of an operculum is a negative character of some value, it is not one to be relied on; the Tuns and Harps, for example, are not provided with any operculum, whilst the Helmets and Buccina, to which they are intimately allied, are in no instance without one. Notwitstanding our knowledge of the animal of Cancellaria, therefore, the place which it should occupy in the system is still uncertain, nor can it be determined until we are more fully acquainted with its internal structure, its respiratory and organs of circulation; until, in short, a full comparison of its organization has been instituted. If, as I believe, the Cancellarice feed only on vegetable matter, it is evident they can no longer be arranged with the Fisi and Turbinella; and it is not improbable that the opinion which I deliverd some time since in the 'Encyclopédie' - that the Cancellarice approximate rather to Lamarck's family 'Les Plicacès', will be found nearer the truth than any which has been adopted.-Deshayes, Anim. sans vert. vol. ix. p. 399, 400. 


\section{Genus 8. PLEUROTOMA, Lamarck.}

Animal; "disc short, oval, thin at the margin, at the posterior" extremity of which is placed a rather thick hormy operculum, similar in most respects to that of Buccinum, and consequently not spiral, but terminating behind in a sharp point; head flattened, and from the angles protude two conical pointed tentacles at the base and outer side of which are two eyes; mantle similar to that of Fusus, excepting that it has an incision at the side corresponding to the slit in the shell." ** Shell; turreted, fusiform, spire acuminated; columella smooth, ending in a canal, which is sometimes straiglt and elongated, sometimes short and a little recurved; aperture small, lip simple, emarginated at or below its junction with the body whorl, with a sinus or deep fissure. Operculum horny, acuminated at the lower end.

The genus Pleurotoma includes a very extensive group of mollusks, mostly small, in which the mantle is slit at the side in such a manner as to impart a corresponding character to the shell, and which may be said to be analogous to the slit in Siliquaria, the sinus in Emarginula, the foramen in Haliotis, \&c. It is scarcely necessary to observe that the animal of Pleurotoma has no affinity with these genera, but is, on the other hand, closely allied to Fusus and other Canalifera, in which no indication of this character is to be found. The incision in the mantle, which occurs also in Conus and in some species of Melania, does not therefore seem to be a character of so much generic importance in Pleurotoma, as the turreted fusiform growth of the shell, by which it is allied to the proximate genera.

The shells of Pleurotoma, like those of Turbinella, have the canal sometimes straight and elongated, sometimes short and recurved, and the species exhibit great variety of sculpture. They are very numerous, widely distributed both in the castern and western hemispheres, and dwell in comparatively deep water.

\section{Species.}

1. abbreviata, Reeve.

5. æruginosa, $i d$.

6. affinis, Gray.

9. albicans (Clav.), Hinds.

2. abyssicola, Forbes.

7. alabaster, Reeve.

10. albicostata, Sovv.

3. \#geensis, $i d$.

8. albibalteata, $i d$.

11. albifuniculata, Reeve.

4. xgrota, Reeve.

12. albina, Lam. 
13. albinodata, Reeve.

14. amabilis (Clav), Hinds.

15. angicostata, Reeve.

16. angulifera, $i d$.

17. annulata, $i d$.

18. apicata, Gray.

19. aquatilis, Reeve.

20. arata, $i d$.

21. arctata, $i d$.

22. arcuata, $i d$.

23. argillacea (Clav.), Hds.

24. armillata, Reeve.

25. aspera (Clav.), Hinds.

26. astricta, Reeve.

27. aterrima, Sow.

28. attenuata (Murex), Mo.

29. aureola, Reeve.

30. auriculifera, Lam.

31. australis (Murex), Ch.

32. axis, Reeve.

33. Babylonia, (Murex), L.

34. brtica, Reeve.

35. Beckii, $i d$.

36. bella (Clav.), Hinds.

37. bicanalifera, Sozo.

38. bicolor, $i d$.

39. bijubata, Reeve.

40. bilineata, $i d$.

41. bimarginata, Lam.

42. Boholensis, Reeve.

43. borealis, $i d$.

44. brevicaudata, $i d$.

45. Buccinoides, Lam.

46. cælata (Clav.), Hinds.

47. Cagayanensis, Reeve.

48. callosa, Valenc.

49. canaliculata, Reeve.

50. cancellata, Gray.
61. cedo-nulli, Reeve.

62. cincta, Lam.

63. cinerea (Clav.), H.

64. cingulifera, Lam.

65. clara, Reeve.

66. clathrata, $i d$.

67. clavata, Sowo.

68. clavulus, $i d$.

69. coccinata, Reeve.

70. collaris, Sow.

71. compta, Reeve.

72. concentricostata, $i d$.

73. conica, Enc. Méth.

74. contracta, Reeve.

75. cornea, $i d$.

76. corusca, $i d$.

77. costata, Gray.

78. crassilabrum, Reeve.

79. crebriplicata, $i d$.

80. crenularis, Lam.

81. crispa, $i d$.

82. crispata, Cristof.

83. crocata, Reeve.

84. cryptorraphe, Sow.

85. Cumingii(Buc.), Pow. 133. Garnonsii, $i d$.

86. cuprea, Reeve.

87. Cycladensis, Forbes.

88. dæuala, Reeve.

89. Daphnelloides, $i d$.

90. debilis (Clav.), Hin.

91. decussata, Macgil.

92. delicata, Reeve.

93. Delosensis, id.

94. dentifera (Clav.), H. 142. gravis, Hinds.

95. Deshayesii, Doumet. 143. Greenlandica, Reeve.

96. diadema, Kiener.

97. digitale, Reeve.

98. discors, Sow.

144. Griffithii, Gray.

145. Guildingii, Reeve.

146. Harfordiana, $i d$.

51. candida (Clav.), Hinds. 99. donata(Clav.), Hinds. 147. harpularia, D. Moul.

52. candidula, Reeve.

53. cantharis, $i d$.

54. carbonaria, $i d$.

5. cardinalis, $i d$.

56. carinata, Gray,

100. D'Orbignii, Reeve.

101. Dorvilliæ, Gray.

102. duplicata, Sow.

103. Dysoni, Reeve.

104. ebur, $i d$.

58. castanea, Reeve.

59. catena, $i d$.

60. cavernosa, $i d$.

106. efficta, Reeve.

107. ericea (Clav.), Hinds. 155. imperialis, Lam.
108. exarata, Reeve.

148. hastula, Reeve.

149. hexagona, Sow.

150. hexagonalis, Reeve.

151. Hindsii, $i d$.

152. Hondurasensis, $i d$.

153. hyalina, $i d$.

154. igniflua, $i d$.

109. exasperata, Reeve.

11. eximia, Reeve.

2. fascialis, Lam.

115. fimbriata (Cleove.

H.

16. flammea (Clav.), id.

18. flavida, Lam.

1, Reeve.

122. formosa, Reeve.

12. Forthiensis, $i d$.

125. foveolata, Reeve.

.

28. fulminata, Kiener.

v.), Hinds

av.), $\mathrm{H}$.

. 
157. impressa (Clav.), H. 205. nebula (Murex), Mo. 253. pseudo-carinata, Ree.

158. incisa, Reeve.

159. incrassata, Sow.

160. Indica, Desh.

161. inermis, Hinds.

162. inquinata, Reeve.

163. interrupta. Lain.

164. Javana (Murex), Lin.

165. jubata, Hinds.

166. lactea, Reeve.

167. lanceolata, $i d$.

168. languida, $i d$.

169. laqueata, $i d$.

170. læta (Clav.), Hinds.

171. lævigata, Philippi.

172. leucostoma, Reeve.

173. Leufroyi, Michaud.

174. linearis (Murex), M.

175. lineata, Lam.

176. lineolata, Gray.

177. lirata, Reeve.

178. livida, (Defran.), Mö. 226. opalis, Reeve.

179. Loeviana, Forbes. 227. oxytropis, Sow.

180. luctuosa (Clav.), Hin. 228. pagodus, Reeve.

181. luteo-fasciata, Reeve. 229. palliata, $i d$.

182. lutescens, $i d$.

183. Lyciaca, Forbes.

230. pallida, Sow.

231. papalis, Reeve.

207. nexa, Reeve.

208. nigerrima, Sow.

209. nigrescens, Gray.

210. nitens (Clav.), Hinds 258, puncticincts id.

211. nitida, Kiener.

213. Novæ Zelandiæ, Ree.261. pyramidata; Valen.

214. nux, $i d$.

215. obeliscus, $i d$.

216. obesa, $i d$.

217. obesicostata, $i d$.

(Clav.), Hind 268, ladul Hinds.

22. olivacea, Sow.

223. olyra, Reeve.

224. ornata (Daphn.), H. 272. regularis, Reeve.

225. Owenii, Gray.

184. Lymnææformis, Kie.

185. macrostoma, Reeve.

186. maculosa, Sow.

187. major, Gray.

188. margaritifera, $i d$.

189. marmorata, Lam.

190. maura, Sow.

232. papillaris (Clav.), $\mathrm{H}$

233. Paria, Reeve.

234. pardalis (Clav.), Hi. 282. rubiginosa(Clav.), id. 235. partita (Conopl.), id. 283. rubinicolor, Reeve.

191. merita (Clav.), Hind. 239. pentagonalis, Gray.

192. Metcalfiana, Reeve. 240. pessulata, Reeve.

193. metula (Clav.), Hind. 241. pellis-phocæ, $i d$.

194. micans (Clav.), id. 242. Perronii (Murex), Ch. 290. sacerdos, Reeve.
195. militaris (Clav.), id. 243. Philberti, Michaud. 291. sacra, $i d$.

196. minuta, Forbes.

197. Mitræformis (M.), W. 245. pica, $i d$.

198. Mölleri, Reeve.

199. monile, Valen.

200. mucronata, Reeve.

201. multiplicata, $i d$.

202. muricata, Lam.

203. mystica, Reeve.

204. Nassoides, Gray.
236. patula, Reeve.

237. parvula, $i d$.

238. paxillus, $i d$.

244. Philippinensis, Reeve. 292. saturata, $i d$.

284. rubricata, $i d$.

285. rubrifasciata, $i d$.

286. rudis, Sow.

287. rugifera, $i d$.

288. rugulatus (Def.), Mö.

289. rustica, Sow.

293. scalaris (Clav.), H.

294. scalpta, Recve.

246. picta, Beck.

247. planilabrum, Reeve. 295. scarabæus, $i d$.

248. plumbea (Clav.), H. 296. sculpta (Clav.), H.

249. pluricarinata, Reeve. 297. semen, Reeve.

250. pluteata, $i d$.

298. semicostata, Kiener.

251. polita (Clav.), Hinds. 299. semigranosa, Reeve.

252. Polynesiensis, Reeve. 300. septangularis (M.), M. 
301 . sigillata, Reeve.

322. teres, Forbes.

343. unizonalis, Lam.

302. Sinensis (Clav.), H. 323. tessellata (Clav.), Hi. 344. urnula, Reeve.

303. sinistralis, Petit.

324. Ticanica, Reeve.

345. ustulata, $i d$.

304. simuosa, Gray.

325. tigrina, Lam.

346. Vahlii (Defr.), Möl.

226. tincta, Reeve.

347. varicosa, Reeve.

305. sordida, Reeve.

327. tricarinata, Valen.

348. variculosa, Sow.

328. trifasciata, Gray.

349. variegata, Kiener.

307. spectabilis, $i d$.

329. triticea, Kiener.

350. Vauquelini, Payrau.

309. spicata (Clav.), Hin.

310. spirata, Lam.

330. Tritonoides, Reeve.

351. vexillum, Reeve.

331. tuberculata, Gray. 352. venusta, $i d$.

311. splendidula, Soro.

332. tuberculifera, Brod. 353. vidua, $i d$.

312. spurca (Clav.), Hin.

313. stolida, Hinds.

333. Turbinelloides, Reeve. 354. violacea, Hinds.

314. striata, Kiener.

334. turgida, Forles.

355. virginea, Beck.

315. striolata, Scacchi.

335. turricula (Murex), G. 356. virgo, Lam.

336. turris, Reeve.

357. viridula (Defr.), Möl.

316. Stromboides, Sow.

317. subula, Reeve.

337. umbilicata (Dril.), M. 358. vitrea, Reeve.

338. undaticostata, Reeve. 359. vittata, $i d$.

318. suturalis, Bronn.

339. undosa, Lam.

360. vultuosa, $i d$.

319. symmetrica, Reeve.

340. unedo, Valen.

361. zebra (Buc.), Lau.

320. taxus (AFurex), Chem. 341. unicolor, Sow.

362. zonata, Gray.

321. Tayloriana, Reeve.

342. unimaculata, Sow.

363. zonulata, Reeve.

\section{Figure.}

Pleurotoma cryptorrhaphe. Pl. 11. Fig. 50. Shell showing the aperture and fissure in the lip.-From Mr. Norris's collection.

\section{Genus 9. MANGELIA, Leach.}

Animal ; undescribed.

Shell; Marginella-shaped or fusiform, mostly longitudinally ribbed, spire sometimes short, sometimes acuminately turreted; lip and columella very finely rugosely denticulated, lip thickened, stightly simuated at the upper part; canal very short, more or less truncated.

M. Deshayes passes a severe and somewhat merited reprimand upon M. Kiener, for having, in genus Cancelluvia of his 'Iconographie,' which professes to illustrate the sleells contained in the Lamarckian collection, omitted mention of the $C$. citharella of that illustrious author, notwithstanding the 
authority "mon cabinet" attached to that species in the "Animaux sans vertèbres." * It would certainly have been desirable if $\mathbf{M}$. Kiener had published his reasons for this omission, for they were probably founded on the discovery that the shell in question is not only no Cancellaria at all, but that it is not referable to any genus hitherto established. Mr. Sowerby had already intimated that this shell belongs to anothex genus; and M. Deshayes crroneously thinks, from Martini's figure, that it may be the young of Strombus plicatus.

This "Fusus ad formam cithara compositus" of Martini, Cancellaria citharella of Lamarck, has been collected in various states by $\mathrm{Mr}$. Cuming, at the Philippine Islands, together with upwards of fifty other closely allied species, the whole of which are new, and display a very striking association of character. In addition to these I have a new one from Australia, one from Sicily, some from the West Indies, collected by the Rev. Lansdowne Guilding, and five collected by Sir. E. Belcher, during the surveying expedition of the 'Sulphur,' described and figured by Mr. Hinds in the Zoology of that voyage; all of which have been published in the 'Conchologia Iconica,' under the head of Mangelia, a genus proposed some yenrs since, in manuscript, by the late Dr. Leach of the British Museun, of which I find no published record.

The Mangelice are nearest allied to those aberrant species of Plenotoma in which the pretominant character of that genus, the fissure in the upper extremity of the lip, becomes modified into a somewhat obscure sinus. Their general aspect is that of a more or less fusiform Muiginella without plaits or polished exterior; distinguished, on the other hand, by a row of faint wrinkle-like denticulations on the inner surface of the lip and columella, and a gutter-like sinus in the lip, at its junction with the body-whorl, in a manner similar to that of the Pleurotome above referred to.

It is rarely an author has the pleasure of introducing a whole genus of seventy new species, but such is the opportunity which the indefatigable exertions of Mr. Cuming have afforded me, with the exception of the one included by Lanarck with the Cencellurie, and the five published by Mr.

\footnotetext{
* "Il y a une autre coquille, la Cancellaria citharella de Lamarck, et dont M. Kiener ne parle pas dans sa Monographie. Une telle lacune est fầcheuse dans un ouvrage aussi spècialement consacré à l'illustration de la partie conchyliologique des animaux sans vertèbres. M. Sowerby suppose que cette coquille appartient à un autre genre, et si l'on s'eu rapporte à la figure citée de Martini, elle ne serait en effet qu'un jeune Strombe. Il appartenait done à M. Kiener d'éclairer la science à ce sujet."

And again, "Ml. Kiener nous laisse dans l'ignorance la plus complète à l'égard de cette espèce de Lamarek. Nous avons toujours eru que l'un des buts que se proposait l'auteur du Species des coquilles, était de donner des renseignments positifs sur les espèces de Lamarck, mises à sa disposition. En s'abstenaut, M. Kiener ôte gratuitement à son ouvrage ce qui lui aurait donné le plus d'intérêt, non-senlement aux yeux des simples amateurs, qui tous consultent les travaux de Lamarck, mais aussi ì ceux des personnes qui font de la scicuce d'une manière sérieuse et qui recherchent avec avidité tout ce qui pent les éclairer sur les espèces de Lamarck. Cette Cancel. laria citharella, d'après la figure de Martini, nous semble une jeme Strombus plicatus de Lamarck."-DEshaYes, Aimaux sans vertebres, vol, ix. p. 401 and 407.
} 
Hinds in the 'Zoology of the Sulphur.' They were found by that eminent traveller under various circumstances, some on the reefs, some in concealed situations under stours, and some at depths varying from three to twentyfive fathoms.

\section{Species.}

1. abyssicola, Reeve.

2. angulata, $i d$.

3. Antillarum, $i d$.

1. astricta, $i d$.

5. badia, $i d$.

6. balteata, $i d$.

7. Bertrandi (Pleur.), Pa.31. gibbosa, id.

8. bicolor, Reeve.

9. capillacea, $i d$.

10. casta, $i d$.

11. castanea, $i d$.

12. cavernosa, $i d$.

13. Celebensis, Hinds.

14. cincta, Reeve.

15. cinnamomea, Hinds.

16. citharella (Cancel.), L.40. lyra, $i d$.

17. Columbelloides, Reeve. 41. lyrica, id.

15. Coniformis, Gray.

19. Conohelicoides, Reeve. 43. Marginelloides, id.

20. coronata, Hinds.

21. crassilabrum, Reeve.

22. cylindracea, $i d$.

23. derelicta, $i d$.

24. digitale, $i d$.
42. maculata, $i d$.

25. Dysoni, Reeve.

26. elegans, $i d$.

27. fasciata, $i d$.

28. funebris, $i d$.

29. funiculata, $i d$.

32. Goodallii, Gray.

33. gracilis, Reeve.

3.. Ginnannia, Risso.

35. Hornbeckii, Reere.

36. interrupta, $i d$.

37. lineata, $i d$.

38. Iamellata, $i d$.

39. livida, $i d$.

44. marmorosa, $i d$.

45. nana, $i d$.

46. Novæ-Hollandiæ, $i d$.

47. obeliscus, $i d$.
48. obesa, Reeve.

49. oryza, Hinds.

50. pallida, Reeve.

51. pellucida, $i d$.

52. pessulata, $i d$.

53. planilabrum, $i d$.

54. ponderosa, $i d$.

55. pulchella, $i d$.

56. pura, $i d$.

57. pusilla, $i d$.

58. pyramidalis, $i d$.

59. reticulata, $i d$.

60. rigida, $i d$.

61. Sicula, $i d$.

62. solida, $i d$.

63. Stromboides, $i d$.

64. tæniata, $i d$.

65. tenebrosa, $i d$.

66. turricula, $i d$.

67. vittata, Hinds.

68. vexillum, Reeve.

69. Zebuensis, $i d$.

70. zonata, $i d$.

\section{Figure.}

Mangelia Margineliotdes. Pl. 11. Tig. 52. Shell showing both back and front views.-From Mr. Cuming's collection. 


\section{Genus 10. FUSUS, Lamarck.}

Animal; dish somerhat square and comparatively small, nsmally funished with a hormy operculum acuminated towards the head; head very small, with two tentacles of moderate length in which the eyes are placerl, sometimes at the base, sometimes towards the middle.

Shell; ovately or elongalely fusiform, nerves varicose, canaliculated at the base, canal sometimes very short; columella smooth; lip of the aperture generally denticulated.

It is a feature in the canaliferous tribe of mollusks that a much greater variety of character for the formation of genera is presented in the shell than in the animal, and the same may be observed in regard to species. The soft parts of Fusus differ in no material degree from those of ILrex, Triton, or Pleurotoma, the disk, head, and tentacles having the same general proportions, whilst the operculum of each is acuminated anteriorly in like manner; and in the present genus, though one species may have a long turriculated shell, as in the $F$. longissimus, and another an orate abbreviated shell, like that of $F$. despectus, there is no particular variation in the mimal except in regard to bulk.*

The genus Fusus has, on this account, been considered of somewhat doubtful importance; the knowledge of this similitude in the animal has even elicited a sort of negative argument in favour of its abandonment, that might be applied with equal force to any group in the series. "Take away the columellar plaits from the greater portion of the Turtinella," says M. Deshayes in the work quoted below, "and you make Fusi of them; deprive the Tritons of their varices, and they become Fusi;" it must, however, be remembered, that the genera of this class, though systematically characterised by the presence or arrangement of the columellar plaits, are further distinguished, each by a distinct association of peculiarities. It neecis no examination of the varices to distinguish a Murex from a Triton or Ranella, and still less of the columellar plaits, to discriminate between the solid tuberculated Turinellus and the comparatively delicately nodulous Fusus. The typical difference in the shells of Turbinellus and Fusus, apart from any consideration of the soft parts, must strike every observer; and it

* M. Deshayes inclines to think, from observations he has had an opportunity of making on the living Fusus, that there is a difference in the position of the eyes corresponding to these divisions. "If the animals of a larger number of species were known," says that acute observer, "it is probable that the situation of the eyes would afford a character for the distinction of two natural groups, for it may be remarked that in those species which have a narrow elongated canal the eyes are at the base of the tentacles, but in the ovate short-eanal species they are upon the middle."-Aizim. sans, vert. vol. ix. p. 442. 
seems natural to conclude that the amimal of the former must be of a much more sluggish habit and muscular growth than that of the latter. The Fasciolurie, again, are peculiar in their size and appearance, and may be identified by their style of painting, the stria of the aperture for example, as if there were some curious concordance in the distribution of the colouring matter from the calcifying glands of the mantle.

If any subdivision of the genus Fusus be admitted, it may be made in favour of that group which includes the F. despectus, antiquns, and fornicatus; these do not, however, appear to have that close affinity with the common Whelk of our shores, Buccinum undatum, as observed by Muller, who has brought them together into his genus Tritonium. The $F$. Nifat, buccinatus, and aculeiformis have also a character peculiar to them.

The long Spindle-shaped Fusi are of an exccedingly graceful and delicate structure, and this, it may be presumed, the great Author of their existence intended should compensate for the absence of bright colours or variety of sculpture; all being merely more or less tinged with rust-brown, and strongly or faintly keeled and nodulous. One Spindle-shaped species is nevertheless distinguished as an exception by the pre-eminent beauty of its structure, in having each whorl surmounted by a diadem of erect, compressed scales.*

The elongated Fusi are principally from the Eastern Seas, China, and New Holland; the ovate species are from a colder region, and mostly European.

\section{Species.}

1. acus, Adams \&. Reeve. 17. candelabrum, A.\& R. 33. deformis, Reeve.

2. Afer, Lam. 18. cinereus, Say. 34. despectus, Lam.

3. alternatus, Phil. 19. cinnamomeus, Reere. 35. dilatatus, Quoyf-Gaim.

4. angulatus, Gray. 20. clathratus, id. 36. distans, Lam.

5. antiquus, Lam.

6. aureus, Reeve.

7. australis, Quoy.

8. Bamffius, Brown.

9. Beckii, Reeve.

10. Blainvillii, Marav.

11. Blosvillei, Desh.

12. brevicaudata, $i d$.

13. buxeus, Recve.

14. cælatus, $i d$.

21. clausicaudatus, Hinds. 37. Dupetit-Thouarsii, Kie.

22. colosseus; Lam. 38. exilis, Menke.

23. colus, $i d$.

39. ficula, Reeve.

24. contrarius, $i d$ 40. Fontainei, D'Orb.

25. corallinus (Mur.) Scac. 41. fornicatus, Gray.

26. corneus, Desh. 42. fragosus, Reeve.

27. costatus, Pennant. 43. funiculatus, Lesson.

28. craticulatus, De Blain. 44, Geversianus, Desh.

29. crebricostatus, Lam. 45. gradatus, Reeve.

30. crebriliratus, Reeve. 46. gracillimus, $A . \& R$.

$\begin{array}{lll}\text { 15. Cancellarioides, } i d . & \text { 31. cretaceus, } i d . & \text { 47. heptagonalis, Reeve. } \\ \text { 16. cancellatus, } i d . & \text { 32. Cumingii, Jonas. } & \text { 48. incrassatus, Lam. }\end{array}$

* Fusus pagodus, Lesson, of which a magnificent specimen, collected by Captain Sir Edward Belcher during the voyage of H.M.S. Samarang, in the Straits of Korea, is figured in 'Conch. Iconica,' Fusus, pl. viii. f. 32. 
49. Japonicus, Gray.

50. laciniatus, Desh.

51. lanceola, Reeve.

52. laticostatus, Desh.

53. lignarius, Lam.

54. lineatus, Quoy.

55. lineolatus, Costa.

56. longicauda, Bory.

57. longissimus, Lam.

58. lyratus, Desh.

59. Mandarinus, Ducl.

60. marmoratus, Phil.

61. Mexicanus, Reeve.

62. minutus, Desh.

63. multicarinatus, Lam.

64. multicostatus, Gray.

65. myristicus, Reeve.

66. Nicobaricus, Lam.

67. Nifat, $i d$.
68. nobilis, Reeve.

69. nodosus, Desh.

70. Norvegicus, Reeve.

71. Novæ-Hollandiæ, $i d$.

72. oblitus, $i d$.

73. ocelliferus, Bory.

74. Oregonensis, Reeve.

75. pagoda, Lesson.

76. pallidus, Brod.

77. pastinaca, Reeve.

78. Pleurotomarius, Court.

79. polygonoides, Lam.

80. proboscidiferus, $i d$.

81. pulchellus, Phil.

82. Purpuroides, $D^{\prime} \mathrm{Or} b$.

83. pyrulatus, Reeve.

84. rubens, Lam.

85. rufus, Reeve.
86. Sabini, Gray.

87. sinistralis, Lam.

88. spectrum, $A$.\& $R$.

89. Syracusanus, Lam.

90. tessellatus, Sch. \& $\mathrm{W}$.

91. toreuma, Lam.

92. torulosus, $i d$.

93. tuberculatus, $i d$.

94. tuberosus, Reeve.

95. Turbinelloides, $i d$.

96. tmricula, Kiener.

97. undatus, Desh.

98. ustulatus, Reeve.

99. vaginatus, Desh.

100. ventricosus, Gray.

101. virga, Gray.

102. vittatus, Quoy.

103. vulpinus (Mur.), Bor.

\section{Figure.}

Fusus Nicobaricus. Pl. 11. Fig. 53. Shell showing the aperture, smooth columella, and elongate spindle-like canal._From Mr. Cuming's collection.

\section{Genus 11. FASCIOLARIA, Lamarck.}

Animal; disk oval, truncated in front, and provided at its posterior extremity with a hormy acuminated operculum; head rather large, prolonged into a pair of tentacles, at the outer base of which are situated the eyes.

Shell; fusiform, or pear-shaped, sometimes of very large size, more or less chamelled at the base, whorls most fiequently tuberculated, never varicose; columella more or less plaited at. the base, lower plaits the larger, interior of the aperture very closely rayed with prominent elevated stria.

The Fasciolaria, as observed in treating of Fusus, are closely allied to that genus in their character and habits, and may be scarcely said to differ, except in being of larger size, and in having a more solid fleshy disk, proportioned to the weight and substance of the shell. Though limited in 
species they appear to constitute a very natural genus, distinguished by their large tubercular growth and brilliant display of colours; there is also a character in the style of marking which obtains some importance from the circumstance of its being generally accompanied by numerous transverse lines in a manner peculiar to the genus, whilst the aperture is usually closely radiated with elevaterl lines. The columella of the shell is in this genus distinguished by one or two plaits ranging obliquely at the base.

The Fasciolurive are pretty generally distributed, being found in Ceylon and the Philippine Islands, Australia, Western Africa, Panama, Nexico, and West Columbia, IIonduras and the West Indies, the Mediterranean, Cape de Verd Islands, \&c.

\section{Species.}

1. aurantiaca, Lan.

2. coronata, $i d$.

3. distans, $i d$.

4. filamentosa (Frus.), Mart.

5. fusiformis, Valenc.

6. gigantea, Kiener.
7. granosa, Brod.

12. porphyrostoma, $A . \& R$.

8. lignaria (Mur.), Limn. 13. princeps, Sow.

9. lugubris, $A$. \& $R$.

14. salmo, Gray.

15. trapezium (Mur.), Lin.

16. tulipa, Lam.

11. Persica, Reeve.

16. tulipa, Lan.

\section{Figure.}

Fasciolaria Persica. Pl. 10. Fig. 45. Shell showing the columella with its obliquely descending plaits.-From the collection of $M r$. Cuming.

\section{Genus 12. TURBINELLA, Lamarck.}

Animal; disk rather short, thick, muscular, provided with a small horny acuminated operculum; hearl futtened, terminating with two conical tentucles, which are rather stout at the base, and have the eyes situated at about two-thirds of their length; at the lower part of the head is a slit, through which passes a retractile trunk. The mantle, which lines the interior of the shell in the usual manner, is protonged into a fleshyy siphon, which passes through the sinns at the base of the shell.

Shell; ovate or fusiform, rather solid, often ponderous, spire sometimes short, sometimes slongated, canal now very short and 
recurved, now elongated and straight; whorls generally ridged and tubercled, rarely smooth; columella plaited, plaits compressed, one to five inches in number; epidermis liorny or fibrous.

Apart from any consideration of the animal, the Turbinelle appear at first sight to be a compound of Toluta and Murex, the shell having the columella plaited in a manner resembling the former genus, whilst in general aspect it approaches rather to the latter. Linnæus referred some species to one group, some to the other; but a comparison of the shells with those of Fusus and Fasciolaria will show a remarkable affinity passing into Murex, which is fully confirmed by the similarity in the animals of these genera.

Though comparatively limited in species, the Turtinella are widely dissimilar in general appearance; some are short and pear-shaped, and others elongated and fusiform; all are characterised by a heavy, solid gronth, with considerable depth of colour, and are divisible into five well-defined sections, of which the T. pyrum, cornigera, infundibutum, polygona, and nassatula, may be regarded as types. The columellar plaits are irregular both in number and development, varying from a transverse to the oblique growth noticed in Fasciolaria.

As a rare species of the first group above mentioned, the T. fusus in the British Museum is worthy of notice; of the second, the T. muricata, crestus, and cassidiformis are fine examples; of the third, the T. lanceoluta is an elegant and rare instance; and among the rarities verging upon the fourth and fifth groups may be noticed the T. vexillum and vexillulum, the T. Anstraliensis, the beautiful T. prismatica, which on being immersed in water throws out a delicate iridescent lustre, and two beautifully painted species, collected by Sir Edward Belcher, during the recent voyage of H.M.S. Samarang, T. picta and Belcheri.†

The Turbinelle are pretty widely distributed, but only in very warm climates; none inhabit our own shores, nor do they approach the Mediterramean. The principal localities are the Philippine Islands, the Gallapagos, and other islands of the Pacific, Mauritius, Zanzibar, Panama, Ceylon, Acapulco, Rio Janeiro, and the West Indies.

* The animal of Turbinella connigera is of a deep purple, finely marbled with white, the colours being fainter towards the margin of the foot. The eye is distinct, and well-formed, having a black pupil and iris of a light yellow colour. It crawls with deliberation and apparent diffieulty, seeming to labour under the weight of its heavy shell, as a tortoise does under that of its carapace. It is, moreover, of a very timid disposition, shrinking, also, like the tortoise, quickly within its shell on the slightest alarm. The specimen from which the foregoing observations were taken, was procured in about a fathom water from a weedy bottom on the shores of Billiton, an island in the Java Sea, between Borneo and Sumatra,-Anams, Moll. Voy. Samarang.

$\dagger$ All described and figured in the 'Conehologia Iconica.' 


\section{Species.}

1. acuminata, Kiener.

2. angularis, Reeve.

3. aplustre (Buc.), Mart. 27. fusus, Sow.

4. armata, Brod.

5. attenuata, Reeve.

6. Australiensis, id.

7. Barclavi, $i d$.

8. Belcheri, $i d$.

9. brevicaudata, $i d$.

10. crestus, Brod.

11. candelabrum, Reeve.

12. capitellum ( $V_{o l}$.), Lin. 36. lanceolata, Reeve.

13. carinifera, Lan.

14. Cassidiformis, Valen.

15. castanea, Reeve.

16. Ceramica ( $\left.Y_{0 l}.\right)$, Lin.

17. cerata, Giay.

18. cinerea, Reeve.

19. cingulifera, Lam.

20. concentrica, Reeve.

21. cornigera, Lam.

22. craticulata (MTur.), L.

23. crenulata, Kiener.

24. crocea, Gray.

25. fastigium, Reeve.

26. filosa, Schubert.

28. gemmata, Reere.

31. gracilis, Reeve.

32. imperialis, $i d$.

33. incarnata, Deste.

35. Knorrii, Des/.

37. lauta, $i d$.

39. lyrata, Reeve.

40. maculata, $i d$.

42. nana, Reeve.

43. nassatula, Lam.

44. Nassoides, Reeve.

46. ocellata, Lam.

47. ovoidea, Kiener.

45. Philberti, Recluz.
29. gibbula (MLur.), Gm.

30. globulus ( $V_{0 l}$ ), Chem. 54. rapa, Lam.

34. infundibulum(Mur.), G. 5S. sanguiflua, $i d$.

38. leucozonalis, Lam.

41. muricata (Vol.), Born. 65. Thersites, Reeve.

45. nodata (Buc.), Mart.
66. triserialis, Lam.

49. picta, Reeve.

50. polygona (Mur.), Gm.

51. prismatica (Buc.), M.

52. pulchella, Reeve.

55. recurvirostris, Schub.

56. rhinoceros, Lam.

57. rudis, Reeve.

59. scabrosa, id.

60. scolymos (Mur.), Gm.

61. smaragdulus (Buc.), I.

62. spadicea, Reeve.

63. spinosa (Buc.), Mart.

64. tectum (Buc.), Gray.

67. tuberculata, Brod.

68. turrita $\left(V_{0 l}\right.$.), Gm.

69. ustulata, Reene.

70. varicosa, $i d$.

71. vexillulum, $i d$.

72. violacea, $i d$.

\section{Figure.}

Turbinelata mpeisialis. Pl. 10. Fig. 48. Shell showing its tubercular structure, and columella distinguished by the transverse arrangement and irregularity of the plaits.-From $M r$. Cuming's collection.

\section{Genus 13. CYRTULUS, Hinds.}

Animal; unknown.

Shell ; stontly fusiform, solid and ponderous, with the spire acumimated and plicately noduled, last whort smooth and remarkable for its elevated sustlen grouth around the upper part, contracted towards the lower, the columella being excavated in a manner to correspond; base emarginated, slightly umbiticated; aperture linear, reaching nearly to the base of the spire. 
The rude mis-shapen object for which the present genus was established, partakes of the character of Fusus, with a certain degree of resemblance to the Turbinella pyrum and its congeners, divested of their columellar plaits. It was collected by Capt. Sir Edward Bolcher during the Voyage of H.M.S. Sulphur, at Port Amma Maria, Nukuhiva, Marquesas, dredged at a depth of about nine fathoms, and upon its first appearance seemed rather to be a distorted individual of some unknown species of a more symmetrical plan of convolution; it was, however, described as a new genus by Mr. Hinds, Assistant-Surgeon of that Experition, and, I believe, with correct judgment. Since that period two or three other specimens have presented themselves, each distinguished by the same peculiarity of growth.

It will be observed that the spire of Cyrtulus is characterized by a neat display of sculpture, and suddenly acuminated in the same curiously erect manner as in the Strombus Thersites; the last whorl then assumes a rude swollen growth; almost belonging, as it were, to another species, smooth, very thick, and ponderous, and rising in such a manner around the base of the spire as to give it a sumken half-buried appearance; as if the calcifying organ of the animal which had elaborated the shell with so much beauty and symmetry in its pubescent state, had suddenly been charged to overflowing, and its architectural faculties, so to speak, become nullified. An indication of this sluggish obesity of growth may be often remarkel in specimens of the Buccinum distortum.

The specimens litherto seen are all of one species.

\section{Figure.}

Cyrtulus serotinus. Pl. 11. Fig. 49. Shell showing its sharply acuminated sunken spire, and the ponderous obese growth of the last whorl.-From Sir Edward Belcher's collection.

\section{Genus 14. FASTIGIELLA, Reeve.}

Animal; unknown.

Shell; elongately turreted, contracted and mubiticated at the base, aperture small, canaliculated, canal very short, somewhat twisted.

This shell, for the reception of which I have found it necessary to institute the present genus, is of an entirely new form, differing generically, as well 
as specifically, from any of the class to which it belongs. It is of an elongated, turreted growth, and may be said to partake in almost equal proportions of the characters of two genera somcwhat removed from each other in the system, Turvitellu and Cerithium. As in Turritella, the shell is of a solid, spirally-ribbed structure, without any indication of varices, a condition not to be found in Cerittinu, whilst it possesses a character which excludes it from the family Turlinacea in having a short, umbilicated, twisted canal, different from that of the Cerithium, for the passage of an elevated fold of the mantle. At the base the shell is not much unlike some species of Buccinum, but it is remarkable for its elongated Turritellalike growth. It is, moreover, to all appearance the production of a carnivorous gasteroporl, and more strictly referable to the Camaliferous tribe than the Cerithia, which, according to Deshayes, are vegetable-feeders, and partake in many instances of the fresh-water habits of the Melania.

Unfortumately Mr. Cuming is not in possession of any information respecting the shell, either touching the animal or its place of habitation, and it only remains to observe that I have not as yet found a second species.

\section{Figure.}

Fastigiella carinata. Pl. 10. Fig. 46. Shell showing its umbilicus, short twisted canal and elongated turreted growth.

\section{Genus 15. CERITHIUM, Bruguiére.}

Animal ; rist small, nearly orbicular; head truncated beneath, bordered with a fringe, and furmished with two pointed tentacles bearing the eyes upon a swollen portion of their outer base.

Shell; turveted, prominently chunnelled at the base, mostly rough oi tuberculated, composed of mmmerous vhorls forming a reguspire, often exhibiting an occasional varix, and in freshwater species, frequently eroded or decollated at the apex; columella aiched with sometimes a veflected fold, constituting the edge of the recurved canal.

The genus Cerithium is one of rather anomalous character, from the circumstance of some of the species being of marine habit, others of fluviatile; 
those which dwell in the sea, constituting the more numerous portion, are of a heavy solid growth, exhibiting a certain delicacy of colour and marking, and are, probably carnivorous; but those which inlabit fresh or brackish water at the mouths of estuaries, or live in swamps annong the roots of trees, are of a lighter growth and mostly of a uniform dull brown colour, covered with a horny epidermis. These are herbivorous, and may often be found suspended from the branches of trees by a mass of silken threads, which the animal has the faculty of depositing as a means of attachment. This peculiarity in the habits of Cerithium was first observed some time since in the West Indies, by the Rev. Lansdowne Guilding; it has also been described by Dr. Trail in a Natural History Journal recently published at Singapore, and by $\mathrm{Mr}_{\mathrm{r}}$. Aclauns during his visit to Borneo in the Samarang. *

The shell of the Cerithia is of an elongated lanceolate form, not symmetrically fluted and turbinated like Turritella, but of rather rude growth, frequently presenting here and there a varix, and mostly coronated with tubercles or other coarse sculpture; the clief peculiarity in its structure is the strong twisted, recurved growth of the canal. The species are very numerous, and inhabit all climates within the mean temperature of the Mediterranean; in a fossil state they are still more abundant, and afford much research for the geologist.

The magnificent example selected for illustration is of very large size for a marine species; it is extremely rare, and I cannot learn that it has been named or described.

\footnotetext{
* The characters of the animal recited at the head of this genus are those of Lamarck, the following are of more recent date, and the result of local observation:-

The animal of Cerithium truncatum has a broad, suborbicular, and expanded foot, and ans elongated, subcylinärical, anmulated trunk of a light brown colour, with three rather broad, welldefined, opaque yellow limes extending along its uppers surface, the central one of which reaches from the head to very near the extremity of the proboseis, where it is bifid, the two forks diverging. The two lateral lines are shorter, not bifid at their extremities, and extend forward on the head to within a little distance of the origin of the tentacles. The tentacles are very short, annulated with the eyes, which are small, though with a distinct iris and pupil situated at their tip; wherens in all other Cerithia that have come under my observation, they are placed on tubercles situated on the outer side of the base of the tentacles, or on the tentacles themselves at a little distance from their origin. The foot is of a light pinky brown on its upper surface, mottled with a deep rich brown, and on the under surface is lilac. It is found generally in brackish water in Mangrove swamps, and the mouths of rivers in Singapore and Borneo. Sometimes they crawl on the stones and leaves in the neighbourhood, and sometimes they are found suspended by glutinous threads to boughs and the roots of the Mangroves. The operculum is round, horny, with a central nucleus and concentric elements; it is semi-transparent, and borne upon the posterior part of the foot at its extreme end. When the animal hybernates, it retracts itself iuto the sletl and brings its operculum to fit closely into the aperture, after having previously affixed sixty or seventy glassy, transparent, glutinous thrcads to the place of attachineut, where they occupy the outer or right lip, and extend half-way around the operculum.

There is another very haudsome species, closely allied to the foregoing, which I have frequently found crawling languidly on the leaves of the Pontedera and sedges in the fluviatile marshes on the banks of rivers in several parts of Borneo, and many miles in the interior, where the water is perfectly fresh, which has the eyes likewise terminal, and the proboscis marked with crimson and yellow. The foot is very dark brown, and has a vivid scarlet line extending round the lower margin.-L DAMs, Moll. Voy. Sampraraing.
} 


\section{Species.}

1. Adansoni, Bruy.

2. adustum, Kiener.

3. adversum, Brown.

4. aluco, Bring.

5 , asperum, $i d$.

6. atratum, $i d$.

7. australe, Quoy.

8. breve, $i d$.

9. breviculum, Sovo.

10. Cailliaudi, Pot.\&. ALic. 39. literatum, Brug.

11. clava, Bing.

12. columna, Sow.

13. conicum, Blain.

14. corallinum, Kiener.

15. crissum, Lam.

16. decollatum, Brug.

17. Diemenense, Quoy.

18. dislocatum, Say.

19. ebeninum, Brug.

20. eburneum, $i d$.

21. echinatum, Lam.

22. elegans, Blain.

23. Emersonii, Adans.

24. erythræonense, Lam.

25. fasciatum, Brug.

26. ferrugineum, Say.

27. fluviatile, Pot.\&. IFich.

28. giganteum, Lam.

29. granarium, Kiener.
30. gramulatum, Kiener.

31. Guarianum, D'Orb.

32. heteroclites, Lam.

33. inflatum, Quoy.

34. læve, $i d$.

35. Lafondi, Michaud.

36. lemniscatum, Quoy.

37. lima, Brug.

38. lineatum, Lam.

40. Iutulentum, Kiener.

41. maculosum, $i d$.

42. Madagascariense, $B l$.

43. Mediterraneum, Desh.

44. microptera, Kiener.

45. minutum, Nuttall.

46. moniliferum, Kiener.

47. Montagnei, D'Orb.

48. morus, Lam.

49. muricatum, Brug.

50. muscarum, Say.

51. mutatum, Sow.

52. nobile, Reeve.

53. nerinea, Blain.

54. nodulosa, Brug.

55. obeliscus, Brug.

56. obtusum, Lan.

57. ocellatum, Brug.

58. Pacificum, Sow.
59. palustre, Brug.

60. perversum, Lam.

61. Peruvianum, $D^{\prime} \mathrm{Or} t$.

62. pictum (Mur.), Wood.

63. punctatum, Brug.

64. pusillum, Nuttall.

65. radix, Dufo.

66. radula, Brug.

67. reticulatum, Totten.

68. rubus, Desh.

69. rugosum, Kiener.

70. semiferrugineum, Lam.

71. semigranosum, $i d$.

72. septemstriatum, Say.

73. Sowerbyi, Kiener.

74. subulatum, Lam.

75. sulcatum, Brug.

76. telescopium, $i d$.

77. treniatum, Quoy.

78. torulosum, Brug.

79. tristoma, Blain.

80. tuberculatum, Lam.

81. turritella, Quoy.

8.2. uncinatum, Desh.

83. varicosum, Sow.

84. variegatum, Quoy.

85. vertagus, Brug.

86. vulgatum, $i d$.

87. zonale, $i d$.

\section{Figure.}

Cenztrifum nobile. Pl. 12. Fig. 59. Shell shoming its elongated growth, small aperture, and spouted canal.-From MLr. Cuming's collection.

Genus 16. TRIPHORIS, Deshayes.

Animal ; unknown.

Shell; small, sometimes cylindrically, sometimes pyramidally elongated. sinistral, terminuting at the base in a tubular spouted canal, recurved backwards, aperture small and round. 
The genus Triphoris was instituted by M. Deshayes for the reception of a small fossil Cerithium, of which the C.perversum of the Mediterranean appears to have been the first-described recent species; it is, however, to the zeal of Capt. Sir Edward Belcher and the ability of his assistant, Mr. Hinds, luring the voyage of H.M.S. Sulphur, that we are mainly indebted for bringing this interesting group into notice. On the occasion of that Expedition visiting the Straits of Malacca, New Guinea, and New Ireland, several important species were obtained, all distinctly characterised in manner following.*

The Triphores are small spirally attenuated shells, the species figured being magnified and one of very large size, and nearly all are reversed; coupled with this peculiarity is that of the canal being prolonged backwards, in the form of a spouted tube, whilst the aperture is extremely small, and closes near the body-whorl in such a mamer as to form another minute tube or the rudiment of one. This third aperture, whence the name Triphoris, is rarely more than indicated by a sinus or slight fold, and it is probably in consequence of the living species of the Mediterranean and the fossil type of the genus representing the extremes of this character, that M. Deshayes has considered the Lamarckian Cerithium perversum inadmissible. The species are distinguished by a remarkable variety of sculpture, developed in most of them with peculiar force and neatness.

In addition to the localities mentioned above, two or three species were collected in the West Indies by the Rev. Lansdowne Guilding; "on the west of America," sitys Mr. Hinds, "though much attention was bestowed on small shells during the voyage of the Sulphur, not a single specimen was found."

\section{Species.}

1. adversus, Deshayes. 12. concinnus, Hinds.

2. æmulans, Hinds.

3. affinis, $i d$.

4. asperrimus, $i d$.

5. bilix, $i d$.

6. cancellatus, $i d$.

7. candidus, $i d$.

8. Carteretensis, $i d$.

9. castus, $i d$.

10. clemens, $i d$.

11. colebs, $i d$.
13. concors, id.

14. corrugatus, $i d$.

15. elegans, $i d$.

16. gigas, $i d$.

17. Grayii, $i d$.

18. hilaris, $i d$.

19. marmoratus, $i d$.

20. maxillaris, $i d$.

21. Metcalfei, $i d$.
22. micans, Hinds.

23. monilifer, $i d$.

24. perversus, Deshayes.

25. roseus, Hinds.

26. ruber, $i d$.

27. sculptus, $i d$.

28. tristis, $i d$.

29. vitreus, $i d$.

30. vittatus, $i d$.

31. vulpinus, $i d$.

* A few species will be described by Mr. Adams and myself, in addition to these, in the fortheoming "Mollusea of the Voyage of H.MI S. Samarang. 
Figure.

Tripioris gravis. Pl. 12. Fig. 55. Shell magnified to twice the matural size, showing its reversed growth, rounded aperture, and recurved tubular canal.

\section{Family 6. PARASI'ICA.}

Animal ; marine, parasitic, living imbedded in the soft parts of the Star Fish, and producing a thin liyatine turbinated shell.

The family Parasitica is one which I had occasion to propose about five years since, in my 'Conchologia Systematica,' for the introduction of a genus, well known to English conchologists but ill-understood on the continent, named Stilifer, representing a small pectinibranchiate mollusk, so peculiar in its habits that it could not be referred with propriety to any of the existing groups. Mr. Gray includes the genus in his family Naticida, but as the shell is very different in its structure and turbinate growth from any of the Natica tribe, and the character and aftinities of the animal do not appear to be fully comprehended, I shall not at present venture upon any removal.

Of the species known, all appear to belong to one genus though materially differing in the form of the shell, and they are remarkably distinguished by their parasitic habit of growth, living imbedded in the soft parts of the Star Fish, from the juices of which it is believed they obtain nourishment.

\section{Genus 1. STILIFER, Broderip.}

Animal; dist narrow, slender, very much mroduced beyond the head in front and but little extended belind; head small, rounded, with two elongate subulate tentacles having the eyps on the onter side of their base; mantle wholly contained within the shell.

Shell ; extremely thin, hyaline, transparent, either globose consisting of few whorls, or elongated composed of many; apex elevated, obtuse, and mostly bent or rudely twisted; aperture entire below, stightly simated at the upper part with the lip extremely thin and delicate.

The interesting little parasite which forms the subject of this genus was 
collected by Mr. Cuming at Isord IJood's Island, one of the Ciallapagos, imbedded in the soft parts of a Star Fish, and a species has been recently obtained by Mr. Adams, under precisely similar circumstances, on the coast of Borneo. The Stilifer, though known for more than half a century by a figure of Chemnitz, * was not described by Lamarck, nor is it mentioned by M. Deshayes in his new edition of that author; it was, however, known by the name of Phasianella stylifera to Turton, who found a dozen attached to the spines of an Echinus in Torbay; and Fleming describes it under the head of Telutina, whilst recording his opinion that it might be elevated to the rank of a genus with the appellation of Stylina. This name being already in use for a genus of polyps, Mr. Broderip, to whose skilful care Mr. Cuming intrusted the Star Fish collected by him with the mollusk in situ, adopted the title of Stitifer. The description of the animal given by this accomplished naturalist from the dissections of Professor Owen, $\dagger$ varies materially from that of Mr. Adams published in the Proceedings of the Zoological Society; the former describes the mantle as being thick, flesliy, and cup-shaped, completely enveloping the last two or three whorls of the shell ;f the latter conceives this external organ to be the foot, and the mantle to be very small, conccaled within the shell, as described at the head of this genus in his own words. $\|$

As a solitary instance of a mollusk dwelling and propagating within the fleshy substance of another animal, the Stilifer is an object of great interest; $\$$ the shell is as delicate and transparent as a glass bubble, and it is curious that whilst one species, $S$. Astericola, should be almost as

* Helix corallina, Chemn. Conch. Cab. vol. xi. p. 286. pl. 210. f. 1284-5.

† Conch. Syst. vol. ii. p. 175. pl. 225. f. 8 to 12.

+ This mantle (which in Stil. Astericola is of a green hue, is thick, fleshy, and cup-shaped, with a small aperture at its base and a free posterior margin, enveloping the soft parts and the last whorls of the shell, which has thus somewhat the appearance of a small acorn set in its cup. On the ventral aspect of this mantle is the rudiment of a foot; and from the small basal aperture a retractile proboscis (which when exserted is as long as the whole animal) is protruded. At the base of this proboscis are two thick, round, somewhat pointed tentacula; and at the base of them are the eyes or rather ocular specks without pedicles. The branchia is placed on a single stem. At the base of the proboscis is a spherical muscular stomach, and the intestine ascends into the spire of the shell, where it becomes attached to the liver, which, in the present species, is of an orange colour.-Pro. Zool. Soc.

II Mr. Gray noticed in his 'Synopsis' that "what has been called the enlarged mantle appears like the foot," and as Mr. Adams' observations are drawn from the living individual, whilst Mr. Broderip's were from a contracted specimen in spirits, it is highly probable that he is right.

$\S$ Mr. Cuming found this elegant little parasite burrowed in different parts of the rays of the oral disk of Asterias solaris, Gray, where it is almost hidden from sight, so deeply does the animal penetrate into the substance of the Star Fish, in which it makes a comfortable cyst for itself, wherein it most probably turns by the aid of its rudimentary foot. All the specimens infested with Stiliferi appeared to be in the best health, though there is reason to believe that these Mollusca feed upon the juices of the Star Fish. With that instinct of self-preservation imparted to all parasites whose existence depends upon that of their nidus, the Stilifer, like the Ichneumon among insects, appears to avoid the vital parts; for, in no instance did Mr. Cuming find it imbedded anyshere save in the rays, though some had penetrated at their base and very near the pelvis. When extracted, the older shells have much the appearance of a milky-clouded glass bubble: the younger shells are of an unclouded transparency.-Pro. Zool. Soc. 1832. 
round as a pea, another, S. sulutata, should be long and tuberculated; both forms, however, exhibit the peculiar elevation of the apex after the manner of a rude mammillary style or column.

\section{Species.}

$\begin{array}{ll}\text { 1. Astericola, Broderip. } & \text { 3. pyramidalis, Reeve. } \\ \text { 2. corallina (Helix), Chemn. } & \text { 4. subulata, Sowerby. }\end{array}$

5. stylifera (Phasianella), Turton.

\section{Figure.}

Stylifer pyramidalis. Pl. 12. Fig. 56. Shell, showing the aperture and transparent glassy structure.-From Mr. Cuming's collection.

\section{Family 7. TURBINACEA.}

Shell ; tuberculated, eitler conical or elongately turriculated, sometimes closely sometimes loosely convoluted; aperture entire at the base, with no indication of any simus.

We now pass to a division of the pectinibranchiate order of Gastropods distinguished by their less voracious habits, and the more tubularly convoluted structure of their shell. They are rarely provided with any proboscis like the carnivorous tribes of this order, and exist chiefly, if not altogether, on vegetable matter; hence, as a general rule, their shell is less solid, though rarely fragile.

The genera of this family, amounting to twenty in number, correspond in a manner to the Linnæan Trochus and Turbo, and the shell is mostly lined with an iridescent pearly nacre. The varieties of coloured beaded sculpture are most diversified in Trochus, whilst in Phasianella and Banlivia a bright array of colours is exhibited on a plane surface, without the aid of sculpture. The resources of architectural ornament are perhaps nowhere more besutifully represented than in Delphinula, in one species of which genus the tubercles are prolonged into a lofty diadem of vaulted spines. In Scalaria a singular effect is produced by a periodical deposit of the reflected margin of the aperture, leaving the whorl encircled by so many rings. In Phorus the animal exercises the remarkable property of agglutinating to the surface of its shell the various debris of corals, shells, or stones it may be in contact with; and each species shows a different modification of this habit.

By far the larger portion of the Turbinacea are inhabitants of the Eastern World. 
The following is a list of the genera, to which all the species of Turbinacea at present known may be referred:-

$\begin{array}{lll}\text { Turritella. } & \text { Trochus. } & \text { Delphinula. } \\ \text { Pifasianella. } & \text { Trochiscus. } & \text { Scalaria. } \\ \text { Elenchus. } & \text { Monodonta. } & \text { Monoptigma. } \\ \text { Bankivia. } & \text { Morulus. } & \text { Eulima. } \\ \text { Litrorina. } & \text { Rotella. } & \text { Bonellia. } \\ \text { Margarita. } & \text { Phorus. } & \text { Rissoa. } \\ \text { Turbo. } & \text { Solatium. } & \end{array}$

\section{Genus 1. TURRITELLA, Lamarck.}

Animal; disk short, oval, sumnounted by a stout pedicle which serves as a support for the head and enters the shell; head prolonged into a cylindival vallier flattened trunk, broad at the base and cleft at its anterior extremity; tentacles elongated, with the cyes at the outer base; mantle forming a finged rimg or collar, variously ormanemed according to the species, through which the head passes in and out of the shell. Operculum horny, multispiral.

Shell; very long, narrow, turreted; whorls mumerous, generally tiansversely, never longitudinally, ribbed, devoid of spines or tubercles, convoluted into a spival screw; aperture small, somewhat round, with the margins disjoined, lip sharp, never reflected, broadly simuated towards the upper part.

In speaking of the genus Terebra (ante p. 55), I observed that " the shell of Turritella has very much the form of Terebra, but the aperture is round and entire; so that Terebra may be likened to a very long drawn-out Buccimem, and Turitellu to a similarly clongated Turbo." The comparison camnot, however, be continued with the sime foree, for the shell of Turbo is of a solid pearly composition, whilst that of Turitelle is not, and the animals are somewhat dissimilar, though the shell of both is alike distinguished by its rounded aperture and by the absence of any basal canal or sinus. It is, indeed, a matter of doubt whether so much importance can be attached, as hitherto, to the canaliculated structure of shells. According to the observations of M. Deshayes and MM. Quoy and Gaimard, there must be a closer relitionship than has been yet acknowledged between the Turilellee and the Cerithice and Meleniee, although the shell of one genus is 
simple and cntire, whilst that of the other is characterized by a strongly recurved canal.*

The Turitella are apparently a strong muscular group of mollusks, the disk being surmounted by a stout pedicle, by the strength of which the shell is borne up at an angle, and not allowed to trail upon the ground, as in the Cerithicu and other elongated forms. MM. Quoy and Gaimard also notice a peculiarity in the mantle, which is prolonged into a fringed ring or collar, through which the head passes in and out of the shell.

'The genus is somewhat limited in species compared with Cerithium or' Terebra, and the shells exhibit little variation of colour. They are all of a more or less sombre lue, though none are very dark, but may be admired on account of the beatiful symmetry of their graduated screw-like proportions.

The Turvitelle inhabit both the East and West Indies, and one or two species occur on the coast of Senegal and New Holland.

\section{Species.}

1. acutangula, Deshayes. 11. duplicata, Lanarck. 20. nodulosa, King.

2. alternata, Say. 12. erosa, Courthouy.

21. replicata, Lamarck.

3. australis, Lamarck. 13. exoleta, Lamarck.

22. rosea, Quoy.

4. bicingulata, Lamarck. 14. fuscata, Lamarck.

23. spirata, Sowerby.

5. bisuturalis, Say.

15. granosa, Quoy.

24. terebra, Lanarck.

6. brevialis, Lamarck.

16. imbricata, Lamarck.

7. Broderipiann, D'Orb. 17. impressa, Say.

25. tricarinata, King.

8. carinifera, Lamarck.

18. ligar, Deshayes.

9. cingulata, Sowerby. 19. mesal, Deshayes.

26. trisulcata, Lamarck.

27. ungulina, Deshayes.

28. virginiana, Lamarck.

10. comea, Lamarck.

\section{Fignte.}

Turritela picta. Plate 11. Fig.5l. Shell, showing the symmetrical screw-like convolution of the whorls and rounded aperture, with its margin entire.-From Mr. Cuming's collection.

* If we make an actual comparison of the animal of Turritella with that of Turbo and Trochus, we find the differences between them to be too great to allow of their being any longer maintained in the same family. By extending the comparison to the Cerithia, we immediately recognise a much closer analogy between Turritella and that genus, than could be at first imagined. The Cerithia are not zoophagous, as Lamarek believed; their mode of living and organization prove it. The comparison may be further extended to the Irelanice and Jelanopsides which inhabit fresh water. I have already indicated (Encyclopédie Méthodique) the relation which may be traced between the Melanice and the Turritelle and Cerithia, and the observations of MM. Quoy and Gaimard are confirmative of this opinion. To explain in a word what I mean by a comparison, which is not, however, altogether exact, I may say that the Melanice are to the Turritellce what the Neritina are to the Nerite, and the Melanopsides to the Cerithia.-DesuaYes, Anim. sans vert. vol ix. p. 250. 


\section{Genus 2. PHASIANELLA, Lamarck.}

Animal ; disk narrow, heud somewhat prolonged, tentacles long and narrow, with the eyes situated on pedicles at the outer base; mantle omamented with three pairs of digitated processes, and produced above the head into a conspicuous fringed collar. Operculum calcareous, ear-shaped.

Shell; ovately oblong, smooth, polished, spire regular, columella rounded, aperture oval, lip entire, acute, never reflected.

The genus Phasianella includes a small group of mollusks, comprising a few species only, mainly characterized by the peculiar texture and aspect of their shell. The soft parts are not unlike those of the preceding genus of Turbinuced, excepting that the distinguishing features of the family are more prominently developed. The fringed collar, described in Turritella, forms a striking object in the animal of Phasicuella, and its narrowed disk is further distinguished by three pairs of digitated processes. The shell is of a very different structure, and has long excited the admiration of collectors, by its highly polished porcelain surface and beautifully variegated painting. The operculum is moreover ear-shaped and calcareous.

The Phusianelle live most abundantly in the situations they inhabit, and all the langer species with which we are familiar are from the continent of New Holland; there is a small species, P. pulla, found on our own coast, one, I believe, in the West Indies, and one in the Mediterranean.

\section{Species.}

1. ambigua, Nuttall.

2. angulifera, Lister.

3. brevis, Menke.

4. clegans, Lamarck.

5. inflexa, Blainville.

6. Lehmanni, Menke.

7. lineata, Lamarck.

8. marmorata, Dufo.
9. Mauritiana, Lamarck. 17. sulcosa, Mighels.

10. nebulosa, Lamarck. 18. tenuis, Michand.

11. perdix, Gray. 19. varia, Sowerby.

12. Preissii, Menke. 20. variegata, Lamarck.

13. pulchella, Récluz. 21. venusta, Reeve.

14. pulla, Sonerby.

15. rubens, Lamarck.

16. solida, Deshayes.
22. Vieuxii, Payraudeau.

23. vinctus, Brown.

\section{Figure.}

Pinasianelua venusta. Plate 12. Fig. 59. Shell, showing the aperture and variegated porcelain surface.-From Mr. Cuming's collection. 


\section{Genus 3. ELENCHUS, Humphrey.}

Animal ;

Shell; conical, pyramidal, but not flattened at the base, whorts comex, margins disjoined. Substance of the shell a stout. hormy periostracum, lined with a thin bright iridescent nacre.

The term Elenchus has been applied for some years past to a group of shells somewhat limited in number, but very deserving of generic honour. Though uniform in shape, the species are perhaps most distinguished for the peculiarity of their composition, being little calcarcous and richly iridescent. The trpical character of the genus may be recognised in the well-known Trochus iris, so remarkable for the brilliant irilescence of its pearly nacre; the species here selected for illustration is another equally distinguished in this respect, and there are several interesting small species, composing Mr. Gray's genus Thalotia, from New Holland.

For list of species of this and other imperfectly named genera, which the anthor proposes to work out in the Conchotogu Lconica, see Appendix.

\section{Figure.}

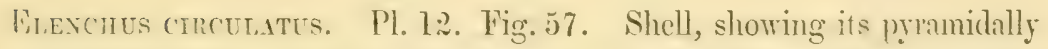
ovate form and iridescent interior.-From $M L$. Cuming's collection.

\section{Genus 4. BANKIVIA, Deshayes.}

Animal ; - - ?

Shell; clongated, subulate, with the surfuce potished, somenthat porcellanous, colwinclla thiclicued, rolled orer, turisted, truncated at the base; aperture rather small, lip thin.

Such is the generic description of a shell of which there are several differently coloured varieties, but only one species, which has been mixed up along with the Trochus inis in the genus Elenchus. It appears to have been first distinguished by M. Deshayes in Pl. 70. Fig. S, of' his "Truiti" Elémentaire de Conchyliologie' ambl, as I learn, was miended as the tyge 
of a new genus, for which he proposed the name Bankivia. To the great loss of Conchology that important work remains still incomplete, the text never reached so far as to include the present genus, and I am not aware that any publicity has yet been given to it.

The shell of Buntivia, it will be observed, has few characters in common with Elenchus ; it has apparently no epidermis, and is of the same porcellanous structure as Phasianella, sometimes banded with deep red and purple, sometimes, as in the variety selected for illustration, painted with fine zigzag lines. The columella presents, however, the most important gemeric feature, in being thickly rolled and twisted, truncated at its junction with the lip, which is thin and not reflected. The interior of the shell is faintly iridescent.

Figure.

Bankivia purpurascens. Pl. 2. Fig. 61. Shell, showing the truncated columella.

Genus 5. LITTORINA, Férussac.

Animal; diste smath, thin at the edtye and nearly circular, atmost conceated by the shell, furnished behind with a hormy blackish operculnm; head somewhat thickened, prolonged into a conical snont, which is transversety wrinkled and cleft at the catremity by the month; tentacies conical, broad at the base, at the outer sides of which are situated the eyes.

Shell; turtinated, not pearly, small, mostly rather solid, columella somewhat flattened, arched; aperture rotundately ovate, margins disjoined, lip sharp, sometimes shightly expanded.

The common Periwinkle of our shores, Littorina vulgaris, may be referred to as a familiar type of this very natural group, including a multitude of species of which many remain to be described. Lamarck confounded some with the Turbines, some with the Phasianella, and even De Férussac, after founding the genus, left it not a little confused through the introduction of several Paludine, which have for the most part thimmer shells, and are not of the same marine habits.

The general aspect and composition of the shells of the Littorince seem to indicate sufficiently that they belong to an animal dissimilar from Phasianella, and so it proves to be; it is comparatively smaller, with a 
more proboscis-like head, and has no fringed collar or digitated processes. The shell differs from Phasianella in not possessing the same beantiful porcelain surface, but on the contrary numerous varieties of sculpture, and from Turbo in being of uniformly smaller size, and never pearly.

The Littorina appear to be very generally distributed in both hemispheres, but it will not be possible to notify their localities, or form an estimate of their number, until the species have becn collected and named. "They dwell," says M. Deshayes, "as their title indicates, on the rocks along shore, and are almost always out of the water, placing themselves within reach of the spray."

The miscellaneous assemblage of genera comprehended in the family Littorinice of Mr. Gray's Synopsis, have but a remote affinity with the group represented by the present genus.

For List of Species see Appendix.

\section{Figure.}

Littorina pulchin. Pl. 12. Fig. 60. Shell, showing its rounded-ovate aperture and slightly expanded lip.-From Mr. Cuming's collection.

\section{Genus 6. MARGARITA, Leach.}

Animal; simitar to that of Trochus.*

Shell; turbinated, sometimes rather depressed, sometimes largely umbilicated, onter surface smooth, polished, with, in many instances, a stining hormy epidermis, inner surfuce delicately pearly, iridescent; margins disjoined, lip simple, acute. Operculum horny, spiral.

The animal of this genus, according to the testimony of M. Deshiayes, differ's in no respect from that of T'rochus, yet the shell presents a singular peculiarity of character, constant alike in all the species. They are, however, susceptible of being divided into two very distinct groups, one of rather light spiral structure, largely umbilicated, of very much the form of Cyclostoma, the other, to which the species selected for illustration belongs,

* Fide Deshayes. "Grîce à l'extrême obligeance de M. Janelle, nous avons de Spitzberg l'animal d' une espèce qui pourrait entrer dans le genre MIargarite, et cet animal ne diffère en rien de celui de Trochus." - Anim. sans vert. vol ix. p. 185. 
of more solid growth, having a porcellanous surface with the umbilicus filled up by a callous deposit. The first of these affect a northeru latitude, and are amongst the most conspicuous of the molluscous fauna of Greenland and Spitzbergen; they exhibit little variety of colouring and no pattern, being mostly of a uniform yellowish olive or pale brown. The last are apparently inhabitants of a warmer region, of more striking colours and prettily striped; the M. teniata, for example, is encircled by fillets of bright red, and the $M$. pulchelle by alternate bands and lines of dark violet blue.

\section{Species.}

1. acuminata, Sowerby.

2. arctica, Leach.

3. carnea, Sovoerby.

4. costellata, $i d$.

5. expansa, $i d$.

6. Gronlandica, Beck.
7. minutissima, Mighels.

8. pulchella, Reeve.

9. sigaretina, Sowerby.

10. Solariformis, $i d$.

11. striata, Brod. \& Sow.

12. sulcata, Sowerby.
13. tæniata, Sowerby.

14. umbilicalis, Br.\& Sow.

15. undulata, Sowerby.

16. violacea, King.

17. vulgaris, Leach.

\section{Figure.}

Margarita pulcielda. Pl. 14. Fig. 69 and 70. Shell, showing the base and callous deposit at the umbilicus.-From Mr. Cuminor's collection.

\section{Genus 7. TURBO, Linnaus.}

Animal; dish stort, thick, bearing at its linder extremity sometimes a hormy, mostly a calcareous operculum; head cylindiaceous, proboscis-shaped and truncated in front, tentacles situated. a little in arrear, with the eyes elevated on short pedicles at the outer base.

Shell; turbinated, rather thick, sometimes umbilicated, interior silver-, rarely golden-, pearly, whorls more or less rounded, rough or smooth, mostly spirally ribbed, with the margins disjoined.

The animals of Turbo, Troctues, Delphinula, Margarita, and Monodonta are so nearly similar that much difference of opinion has prevailed amongst author's as to the propriety of separating them. The head has a blunt proboseis-like form, with the tentacles a little behind, bearing the eyes on 
short pedicles at the outer base, and the disk is short and thick, with mostly a calcareous, sometimes a horny operculum. The number of species is, however, very extensive, and the shells of these genera afford sufficient characters to entitle them to be generically distinguished in the manner commonly arlopted. Much undue value has been set upon the composition of the operculum, and a new division of the Lamarckian Trocti and TurZines has been attempted, by throwing the species of these genera together, and re-arranging then according to the operculum, referring those in which it is horny to Trochus, and those in which it is calcareous to Turto. Observation tends, however, to show that the opcrculum is a very subordinate part of the species, and that in Trochus and Turbo, as in Natica, it is sometimes horny, sometimes calcareous, without any corresponding differences in the shell or its animal inhabitant, to support the notion of its indicating a difference of genus.

The opercula of the Turbinacea furnish no characters for generic arrangement, but are well worth observing on account of their variation in dificrent species. It is mostly of a solid testaceous substance, sometimes smooth, sometines granulous; in some species it is deeply circularly grooved, the ridges being granulated or serrated, whilst in others it is composed of a crowded tuft of club-shaped particles. In all these, the imner surface is coated with a horny layer, and in the $T$. pica and one or two other species the operculum consists of a horny lamina only, without any calcareous deposit. Considerable variation will thus be found to occur in the opercula of shells without any corresponding variation in the shell, and shells of very different character have very often the same operculum; the same heavy, stony operculum which is common to Turlo is frequent in Trochus, and the horny operculum of Trochus is to be met with in Turto.

It results from these observations that there can be no true generic distinction between the genera of which we have been treating; the Trochi are to the Turlines among marine shells, what the Carocolle are to the Helices among land shells, the animal in neither case presenting any apparent difference; but for the convenience of reference, and in order not to subvert the names by which the species of this group have been so long familiarly known, the Lamarckian genera may be adopted without prejudice to the laws of classification.

The Turbines are sometimes smooth, almost porcellanous, but mostly spirally ribbed or grooved, ornamented with scales or laminæ. The interior layer and chief substance of the shell consists of mother of pearl, often very iridescent and sometimes of a golden hue. The shells are remarkable for their symmetry of form and vivid admixture of colours, they are distinguished by their bold tubular growth, and will not stand pyramidally on their base like the Trochi. A complete monograph of the genus published in the 'Conchologia Iconica' comprises sixty species, and shows their 
range of liabitation to be limited to warm climates, chiefly the islands of the Lastern Archipelago, Australia, and New Zealand, two species being found in the Mediterranean, and one or two in the West Indies, Mexico, and California.

\section{Species.}

1. argyrostoma, Linn.

2. articulatus, Reeve.

3. canaliculatus, Gmel.

4. Chemnitzianus, Reeve.

5. chrysostoma, Limn.

6. cidaris, Gmel.

7. circularis, Reeve.

8. corallinus, $i d$.

9. cornutus, Gmel.

10. coronatus, $i d$.

11. crassus, Gray.

12. crenulatus, Gmel.

13. fluctuatus, Reeve.

14. gemmatus, $i d$.

15. histrio, $i d$.

16. imperialis, Gmel.

17. Japonicus, Reeve.

18. Jourdani, Kiener.

19. Lajonkairii(Delph.),D.

20. laminiferus, Reeve.
21. lugubris, Reeve.

22. magnificus, Jonas.

23. margaritaceus, Linn.

24. marginatus, Nuttal.

25. marmoratus, Linn.

26. militaris, Reeve.

27. murreus, $i d$.

28. Natalensis, $i d$.

29. Nicobaricus, Gmel.

30. niger, Gray.

31. nivosus, Reeve.

32. petholatus, Linn.

33. pica, $i d$.

34. porcatus, Reeve.

35. porphyrites, Gmel.

36. pulcher, Reeve.

37. pustulatus, $i d$.

38. pyropus, $i d$.

39. radiatus, Gmel.

40. rubicundus, Reeve.
41. rugosus, Linn.

42. sanguineus, $i d$.

43. sarmaticus, $i d$.

44. saxosus, Reeve.

45. setosus, Gmel.

46. smaragdus, $i d$.

47. sparverius, $i d$.

48. speciosus, Reeve.

49. Spenglerianus, Ginel.

50. spinosus, Reeve.

51. squamiger, $i d$.

52. tessellatus, Kiener.

53. Ticaonicus, Reeve.

54. torquatus, Gmel.

55. Trochoides, Reeve.

56. Tursicus, $i d$.

57. undulatus, Chemn.

58. variabilis, Reeve.

59. versicolor, $i d$.

\section{Figure.}

Turbo petholatus. Pl. 13. Fig. 65. Shell, showing its bold tubular structure and rounded aperture.

\section{Genus 8. TROCHUS, Linnaus.}

Animal; similar to that of Turbo.

Shell ; conical, pyramidal, more or less flattened beneath; whorls rather depressed, mostly angled at the periphery; columella arched, margins disjoined, lip simple.

Having spoken freely of this genus and its affinities under the head of Turbo, it only remains to notice the great variety and detail of sculpture 
developed in the different species. The shell of Trochus seems to exhibit an exubcrance of design in this respect, which accompanies its pyramidal form, and offers a generality of character by which to distinguish it from Turbo. In every species of Turbo, which is not absolutely smooth, the sculpture, be it ribs, or tubercles, or scales, is arranged transversely, but in Troctus it is mostly carved longitudinally or obliquely, in patterns more varied and more fanciful. In T. calcar the whorls are armed with prominent tufted tubercles, in $T$. unguis with vaulted scales, in T. undosus they are bordered with a waving rib, like a twisted cable, in T. olivacens carved with oblique slightly waved ridges, whilst the T. gemmosus, annulatus, and others, are studded with various designs of beading.

The Trocki are numerous in species, and widely and abundantly distributed; they occur on our own coast, also in the Mediterranean, and in all tropical latitudes.

For List of Species see Appendix.

Figure.

'Trochus modestus. Pl. 13. Fig. 67. Shell, showing its pyramidal form.-From Mr. Cuming's collection.

\section{Genus 9. TROCHISCUS, Sowerby.}

Animal ;

Shell ; depressly orbicular, somewhat discoid, largely and deeply umbiticated, rather solid, smooth, pearly within, margins disjoined, lip simple. Operculum horny, internally very sinooth. and shining, externally set with circular rows of fibrous flaties curled over towards the centre.

The solitary species which has been erected into a genus under the name of Trochiscus is certainly a shell of very anomalous character. It may be described as a compound of Turbo, Trochus, Solarinm, and Rotella, partaking most of the typical structure of the first of these genera, but scarcely comprehended within the limits assigned to it by Lamarck. The sholl is of a heavy Rotella-like substance, smooth on the outer surface, and, as in Solarim, the umbilicus penetrates inwardly to the apex. The opereulum, on the other hand, is more like that of Delplimula, with the addition of the prominent circular rows of curled flakes noticed above.

It is a native of New Holland. 
Figure.

'T'rochiscus Normisu. Pl.14. Fig. 68. Shell, showing its smooth solid growth, large deep umbilicus and operculum.-From Mr. Cuming's collection.

\section{Genus 10. MONODONTA, Lamarck.}

Animal; similar to that of Turbo.

Shell; rather small, ovate or conoidal, rather solid, columella excavated, truncated and toothed at the base, lip sometimes dentately ridged within, margins disjoined.

The genus Monodonta was introduced by Lanarck for the sake of distinguishing a numerous group of Trocki, from the typical forms of that genus, on account of the colunella being suddenly truncated in a manner so as to present a tooth. It has not, however, been generally adopted on account of the gradual development of this peculiarity commencing in Trockus, and rendering it difficult to say exactly where the genus under consideration should commence. In treating of the Turlinacea generically in a former work, I came to the same conclusion as M. Deshayes, that the genus Ilonedonla is unnecessary; but upon coming to an examination of the species, so extensive and characteristic a serics being conveniently separated under this head, I have not hesitated to follow Lamarck's arrangement of the series for facility of reference.

For List of Species see Appendix.

\section{Figure.}

Monodonta Labeo. Pl. 13. Fig. 64. Shell, showing a characteristic development of the tooth upon the columella_-From Mr. Cuming's collection.

\section{Genus 11. MORULUS.}

Animal ; - ?

Shell; extremely variable in form, sometimes ovately turbinated with the apex depressed, sometimes Trochi-form, raised towards the apex into a sharp pyramid, of a peculiar opake white substance more or less stained with brown; columella distinguished by a depressed Tamelliform tooth. 
It is rarely that colour presents any character of sufficient constancy to be recorded as one of the distinguishing features of a genus. In the present instance the shell is most inconstant in form, for whilst in one instance it is of an ovately turbinated growth like a Nerita or Delphimula, in another it is of a sharp pyramidal form according to the true type of Trochus. In all cases the shell is of a peculiar opake cream-white substance, more or less stained with dark brown, and it is a permanent character of the columella to be furnished with a sharp lamelliform or shelf-like tooth. One of these forms was collected by Mr. Cuming at the Philippine Islands, the other at Panama.

For List of Species see Appendix.

Figure.

Morulus cidaris, Pl. 13. Fig. 63. Shell, showing its dull opake substance and lamellated tooth upon the columella.-From Mr. Cuming's collection.

\section{Genus 12. ROTELLA, Lamarck.}

Animal ; - ?

Shell ; orbicular, smooth, polished, spire very short, base callous, about equally convex with the spire, aperture semicircular.

The Rotelle form another interesting section of the Trochus tribe, of small size, and easily recognised by their lenticular shape and polished surface. The species selected for illustration is one of extreme rarity and extraordinary large size; few excecding a half to three quarters of an inch in diameter. It is curious to observe that the Rotella, with their polished exterior, are never found with any foreign matter attached to them, and M. Deshayes thinks that this indicates a peculiar organization of the animal, in which the mantle is extended over the shell.

\section{Species.}

1. costata, Valenciennes.

4. gigantea, Lesson.

7. rosea, Lamarck.

2. elegans, Beck.

5. Javanica, Lamarck.

8. suturalis, $i d$.

3. Guamensis, Quoy.

6. monilifera, $i d$.

9. vestiaria, Sowerby. 


\section{Genus 13. PHORUS, De Montford.}

Animal; - - ?

Shell; orbicular, rather conical, sometimes largely umbiticated, spire short, obtuse, whorls regular, more or less covered with agglutinated fragments of stones, shells, Scc., sometimes furmished at the periphery with spouted tubes; under surface rather concave, gramular, striated or lamellated; aperture somewhat depressed, not pearly, margins disjoined, lip simple and acute. Operculum thin, horny, oval.

The Carrier Troclus shell has always been an object of interest on account of the singular manner in which it is loaded with fragments of stones, shells, corals, or any marine débris with which it may chance to have been in contact. It would appear as though its animal occupant were furnished with a powerful kind of cement, which it exudes during the formation of the shell in such a manner that whatever immediate substances it is able to remove, become firmly agglutinated to it, and cannot afterwards be dislodged without violence; the mollusk seems moreover to mould its shell in a manner to receive them.

For the purpose of distinguishing the Lamarckian Trochus agglutinans, long known to amateurs by its soubriquets of 'Mineralogist' and 'Conchologist,' according to whether its burden was composed of stones or shells, De Montford proposed the name of Phorus, and several species are now known, in each of which the agglutinating property is differently exercised. The shell varies materially from the Truchus type, being almost colourless, not pearly, and of a more fragile texture; one or two species present a somewhat Calyptrcea-like aspect, but they belong evidently to an animal of locomotive habits, and the whorls are more completely convoluted than in that genus.

The distinction of species, independent of the usual characters of sculpture, itc., is represented in the method of agglutinating as follows :-In the $P$. onustus (T.agglutinans, Lamarek) the entire surface is covered indiscriminately with stones, shells, or corals; in the $P$. calculiferus the agglutinating property is limited to the outer edge of the whorls, collecting only very small stones, intermixed with shells, generally valves of Nuculu or Pectunculus. The P. corvugatus attaches flat fragments of shell, the P. Indicus and solaris small pebbles on the first one or two whorls only, and in the $P$.exutus rarely more than the mark of some pebbles having been at one time agglutinated is discernible.

The P.onustus is an inhabitant of the West Indies, but all the other species are from the castern world, Japan, Chini, and the Plilippines. 
The beautiful spouted-tubed P. solaris, known to Jimmæus, but still of great rarity in fine condition, is from Malacca.

\section{Species.}

1. calculiferus, Reeve.

2. cereus, $i d$.

3. corrugatus, $i d$.
4. exutus, Reeve.

5. Indicus (Troclus), W.

6. onustus, Reeve.
7. pallidulus, Reeve.

8. solaris (Trochus), Limn.

9. Solarioides, Reeve.

\section{Figure.}

Phorus onustus. Pl. 14. Fig. 71. Shell, showing the aperture, with three valves of Cardium, one of Pectunculus, one of Arca, and a piece of coral agglutinated to the periphery of the last whorl, which in each instance is moulded to receive them.

\section{Genus 14. SOLARIUM, Lamarck.}

Animal; dist small, oval, eleveted on a short pedicle, and furmished at its linder extremity with a small hormy spiral opriculum, head flattened, and prolonged into two tentacles, at the base of each of which is a short pecticle, supporting the eyes; the mantle is reflected into a collar around the aperture.

Shell; circular, depressely conoid, consisting of a number of whorls closely comvoluted together, but in such an anmilar arrangement as to form a vide perspective umbiticus, outer edge of the whorls sharply angled, imparting a trapesiform shape to the aperture, of which the tip is simple and acute.

'The Stair-case Trochus, another shell equally well known to collectors with the last, also constitutes the type of a genus to which several interesting species may be referred, and the importance of which has been confirmed by observations on the amimal mate by MM. Quoy and Gaimard, the eminent naturalists of the Voyage de l'Astrolabe. Elevated on a short pedicle, like the Turlines and Trochi, and bearing a modified resemblance to those genera in the reflected collar of the mantle, the head is not shaped like a proboscis, but prolonged, somewhat after the manner of Buccinum and Purpura, into two elongated tentacles. 


\section{Species.}
1. areola, Deshayes.
9. fragile, Hinds.
18. perdix, Hinds.
2. asperum, Hinds.
10. fulvum, $i d$.
19. perspectivum, Lam.
3. cælatum, $i d$.
11. granulatum, Lamarck.
12. hybridum, $i d$.
20. placentale, Hinds.
4. Chemnitzii, Kiener.
13. quadriceps, Hinds.
21. purpuratum, $i d$.
5. cingulum, id.
14. levigatum, Lanarck.
22. stramineum, Lamarck.
6. cylindraceum, Deshayes.
15. luteum, $i d$.
7. dealbatum, Hinds
16. maculatum, Reeve.
23. Trochoides, Deshayes.
24. variegatum, Lamarck.
25. virgatum, Hinds.

17. magnum, Lesueur.

\section{Figure.}

Solartum maculatum. Pl. 13. Fig. 62. Shell, showing its vory depressed lenticular convolution.-From Mr. Cuming's collection.

\section{Genus 15. DELPHINULA, Lamarck.}

Animal; similar to that of Turbo.

Shell; turbinated, almost discoid, Inbular and somewhat loosely comvoluted, mostly ornamented with scales, spines, or tubercles, frequently largely umbilicated; aperture rounded, margins contimuous, interior pearly, lip sometimes frilled.

The Delphinule, first distinguished as a genus by Lamarck, are chiefly rcmarkable on account of their loosely convoluted growth and, so far as regarits the typical species, their luxuriant display of scales and tubercles or spines. The shell has consequently a rounded aperture, with no columellar axis, and bears much the same relation to Turbo as Cyclostoma does to Helix, the animal being in erther case, with trifling modification, the same. There are, however, two very distinct sections of the genus, one above referred to as comprising the typical species, in which the shell is of larger size, richer in colour, and of more luxuriant growth; and the other in which the shells, extremely delicate and curious in their detail of sculpture, are somewhat stout, whilst others are of comparatively thin texture, and in some of which the interior is not pearly. Allied to these are one or two rather fragile species, partaking in their general aspect of the character of Cyclostoma and Sigarelus, and belonging probably to a different generic type of which our knowledge is at present insufficient.*

* An interesting example of this group has just been sent me by Mr. Robert Swift, of St. Thomas's, West Indies, described as having been picked up on the sea-beach by the Pastor of the Duteh Reformed Church of that place. 
All the Delplinula, excepting those just spoken of, are inhabitants of the eastern world, principally in the vicinity of the Philippine Islands, China, and Malacca; the D. Tyria, incisa, and Peronii, three most characteristic species, are from New Holland.*

\section{Species.}

1. aculeata, Reeve.

2. atrata, $i d$.

3. australis, Kiener.

4. cancellata, $i d$.

5. cidaris, Reeve.

6. clathrata, $i d$.

7. Cobijensis, $i d$.

8. crenata, Kiener.

9. depressa, $i d$.
10. discoidea, Kiener.

11. distorta (Turbo), Linn. 20. Peronii, Kiener.

12. evoluta, Reeve.

13. formosa, $i d$.

14. imperialis, $i d$.

15. incisa, $i d$.

16. laciniata (Turbo), L.

17. muricata, Reeve.

18. nivea (Turbo), Chemn. 27. varicosa, $i d$.
21. radiata, $i d$.

22. Reeviana, Hinds.

23. Scalarioides, Reeve.

24. sphærula, Kiener.

25. syderea, Reeve.

26. Tyria, $i d$.

\section{Figure.}

Delpinnula muperialis. Pl. 15. Fig. 77. Shell, showing its rounded aperture, loosely convoluted tubular structure and luxuriant ramified growth.-From Mr. Cuming's collection.

\section{Genus 16. SCALARIA, Lamarck.}

Animal; cylindrical, disk short and nearly square; head short, obtuse, flattened, with a pair of small sessile eyes, situated at. the outer base of the tentacles. Operculum horny, spirat. Shell; tubularly turreted, the whorls being rarely contignons and encircled thronghout with a greater or less number of elevated ribs; aperture round, margin continuous and reflected.

There are few mollusks which produce a more delicate and beautifully symmetrical shell than the Scaluria; no shell has been more highly prized by the amateur than the Wentle-Trap, and none in which the absence of colour is so lavishly compensated by delicacy and variety of sculpture. Although a species inhabits the seas of Europe in tolerable abundance, the soft parts have not been very fully described; sufficient is known of the animal to show that it is closely allied to Delphinula, and, as in most

* The small white Delphinulce are so far removed from the typical species of the genus, that it would be as well to adopt the genus Liotia under which they have been separated by Mr. Gray. 
of the genera of this extensive series of regetable feeders, the foot is limited in size and its operculum is horny.

It is somewhat curious that in a genus numbering nearly a hundred species, of which most are inhabitants of equatorial seas, there is so little indication of colour. Where such exists it is extremely effective, the ground colouring of the whorl being of a rich semitransparent brown, whilst the rings are white, as in the S. Pallasii; and it is equally worthy of remark that the most highly coloured species, the $S$. communis of our own shores, is that which inhabits the coldest region.

The species are chiefly characterized by the difference in the number and developement of the rings, which it may be remarked are formed at intervals by the reflected margin of the aperture, and are always alike in individuals of the same. Unlike other shells of this family in which the lip is rarely reflected until the animal arrives at maturity, the formation of rings commences after this manner from a very early period of growth, and these, less complicated in structure, are analogous to the varices of the canaliferous tribes. In the well-known Scalaria pretiosa of the China Seas, the rings or varices are situated at moderate intervals, increasing in area in exact geometrical proportion with the size of the shell; in S. imperialis they are of the same comparative substance, but developed at much more frequent intervals; in $S$. lyra they are extremely fine, having almost the appearance of silken threads; in $S$. raricostata they are only deposited at remote intervals, and with considerable irregularity; and in S.alata they are characterized at the upper part by the addition of a curious wing-like process, of which there are various indications more or less strongly exhibited in many species. The most aberrant form of the genus is the S. magnifica, in which the whorls are contiguous, and the typical peculiarity of the genus seems scarcely to enter into its plan of growth, there being only a few slight rings at irregular intervals on the last two whorls. In composition and texture this shell is, nevertheless, a Scalaria, and affords an important link with Turritella.

Among the localities noted by Mr. Sowerby in his beautiful monograph of this genus lately published in the 'Thesaurus Conchyliorum,' are the following:-Eastern Seas principally, West Indies, Pacific Islands, California, and New Holland.

\section{Species.}

1. aciculina, Hinds.

2. aculeata, Sow.

3. acuminata, $i d$.

4. alata, $i d$.
5. albilineata, Sow.

6. angulata, Say.

7. aurita, Sow.

8. australis, Lam.
9. bicarinata, Sow

10. bulbulus, $i d$.

11. bullata, $i d$.

12. Catanauanensis, $i d$. 
13. clathratulus, Montagı. 40. granulosa, Q. \& $G$.

67. polita, $i d$.

14. clathrus, Kiener.

41. Grœnlandica, Kiener.

68. porrecta, Hinds.

15. cochlea, Sow.

42. hexagona, Sow.

43. hyalina, $i d$.

69. pretiosa, Lam.

16. communis, Lam.

44. immaculata, $i d$.

70. principalis, Pallas.

17. concinna, Soro.

18. connexa, $i d$.

45. imperialis, $i d$.

71. pulcherrima, Sow.

19. coronata, Lam.

20. crassa, Sowo.

21. crassicostata, $i d$.

22. crassilabrum, $i d$.

46. inconspicua, $i d$.

72. pyramidalis, Sow.

73. raricostata, Lam.

47. indistincta, $i d$.

74. replicata, Sow.

48. irregularis, $i d$.

49. laxata, $i d$.

75. rubrolineata, $i d$.

50. lineata, Say.

76. similis, $i d$.

23. creberrima, Hinds.

24. crenata, Linn.

51. lineolata, Kiener.

77. statuminata, $i d$.

25. curvilineata, Sovv.

26. decussata, Lan.

27. denticulata, Soro.

28. diadema, $i d$.

29. Dianæ, Hinds.

30. dubia, Sow.

31. Elenensis, $i d$.

32. fasciata, Soro.

33. fragilis, Hanley.

34. friabilis, Sow.

35. fusca, $i d$.

52. lyra, Sozo.

78. subtilis, $i d$.

53. magnifica, $i d$.

79. sulcata, $i d$.

54. marmorata, $i d$.

55. Martinii, Wood.

56. Mindoroensis, Sow.

57. Mitræformis, $i d$.

58. multicostata, $i d$.

80. suturalis, Hinds.

81. tenuicostata, Sow.

82. tenuis, $i d$.

83. Trevelyana, Leach.

84. trifasciata, Sow.

85. turricula, $i d$.

59. muricata, Kiener.

86. Turtonis, $i d$.

60. Novangliæ, Courthouy. 87. undulata, $i d$.

61. obesa, Sow.

88. unifasciata, $i d$.

62. obliqua, $i d$.

89. varicosa, Lam.

63. obtusa, $i d$.

90. venosa, Sow.

36. Georgettina, Kienier.

37. glabrata, Hinds.

38. gracilis, Sow.

39. gradata, Hinds.

64. ovalis, $i d$.

91. vestalis, Hinds.

65. Pallasii, Kiener.

66. Philippinarum, Sow.

92. vulpina, $i d$.

\section{Figure.}

Scalaria mperialis. Pl. 15. Fig. 74. Shell, exhibiting its tubular structure and periodical deposit of annular varices. - From IIr.Cuming's collection.

\section{Genus 17. MONOPTYGMA, Lea.}

Animal; unknown.

Shell; sulfusiform or elongately subulate, rounded and imperforated at the base, columella distingnished by an obscure winding plait, aperture small, entire.

For this genus we are indebted to Mr. Lea of Philadelphia, by whom it was founded, upon at fossil species, in his 'Contributions to Geology,' 
p. 185. It has a small oblong aperture, no umbilicus, and the columella is furnished at the upper part with a small wiuding plait, more or less obscurely developed.

Although Mr. Lea notices a recent species, which he proposes to call Monoptygna Melanoides, he does not accompany the name with any description. The species here figured, is a sharp subulate shell, rounded at the base, composed of about ten whorls of a convexly flattened growth, each encircled by six fine equidistant linear grooves. The sutures are somewhat deeply impressed, and there is no indication of any umbilicus. It is of rather solid structure and evidently of marine habits.

\section{Figure.}

Monoptygma cinerea. Pl. 15. Sp.76. Shell, showing its small entire aperture.-From Mr. Cuming's collection.

\section{Genus 18. EULIMA, Risso.}

Animal; unknown.

Shell; subulate, frequently ver'y peculiarly obliquely distorted, not umbilicated, polished ivory white, shining, whorts genevally distinguished by a flattened or channelled varix; columella arched, aperture small, entire, lip simple, obtuse.

The genus Eulima, established by Risso, includes a limited, but extremely natural group of sinall subulate shells, distinguished by their solid structure and white enamelled surface, shining like porcelain. Many of the species have likewise a curious distorted obliquity of growth, occasioned in some measure by the formation of a row of channelled varices, consisting of one in each whorl deposited a little in advance of that which precedes it.

The typical species of this genus is the Turbo politus of Linnæus, Dillwyn, and Montagu; Turbo subulatus of Donovan and Dillwyn is also one of the group, and M. Deshayes refers Melania nitide of Lamarck to Eulima. Of the species figned under this hear in Sowcrby's 'Conchological Illustrations,' a portion of them have been separated by M. Deshayes for ample reasons under the title of Bonellia, properly Niso.

The Enlima are very distinct in their generic character, having little aflinity with Scalaria and less with Melania; there are one or two species on the southem shores of Europe, one from New Holland, and two or three species inhabit the Pacific Islands. 
Species.
1. articulata, Sowerby.
5. labiosa, Sowerby.
8. pusilla, Soverby.
2. brevis, $i d$.
6. major, $i d$.
9. subangulata, $i d$.
3. distorta, Deshayes.
7. polita (Turbo), Linm.
10. subulata (Turbo), Don.
4. hastata, Sowerby.

\section{Fignure.}

Eulmi major. Pl. 15. Fig. 78. Shell, of polished porcelain white, showing the aperture and oblique distortion of the spire.-From $M r$. Cuming's collection.

\section{Genus 19. NISO, Risso.}

Animal; unknown.

Shell; turriculated, rather solid, polished, apex rather sharply acuminated, whorls turned upon a more or less wide axis, producing a deep umbilicus, columella simple, aperture rather small, angular and slightly channelled at the base; variously painted.

The genus Niso was founded by M. Risso in his 'Histoire Naturelle de l'Europe Méridionale,' p. 218, for the purpose of distinguishing a fossil shell agreeing in general character with Lamarck's Bulinus terebellatus, allied to the genus Eulina, but differing in having a deep umbilicus, occasioned by the broad axis of volution of the whorls, penetrating nearly to the apex.

Among the shells collected by Mr. Cuming on the shores of Westerm Anerica, and figured by Mr. Sowerby in his 'Conchological Illustrations,' are three, referred to the genus Eulima, which present the same remarkable character as that above noted, accompanied by a variegated style of painting and a sinuated inclination of the aperture. M. Deshayes, perceiving the character by which these are distinguished from Eulina to be of importance, arranged them in his edition of Lamarck, together with the fossil $B$. terelellatus, as a new genus under the title of Bonellia. Had the genus, however, not been anticipated by M. Risso, the name Bonellia could not have been maintained, it being already given to a genus of Echinoderms by M. Rolando, and published in the same work, vol. iii. p. 470 .

No observations have been made on the animal of this genus. Of the species collected by Mr. ('uming, the $N$. splendiduta and imbricatu were 
obtained at St. Elena, West Columbia, and the $N$. interrupta was dredged in the Gulf of Nicoiya. The $N$. Urmnea is reported to be from China.

\section{Species.}

1. brunnea (Eul.), Sow. 2. imbricata, Sow. 3. interrupta (Eul.), Sow. 4. marmorata, Soro. $\quad$ 5. splendidula (Eul.), Sow.

\section{Figure.}

Niso splendidula. Pl. 15. Fig. 79. Shell, showing its sinuated aperture and very deep umbilicus.-From Mr. Cuming's collection.

Genus 20. RISSOA, Fréminville.

Animal ; disk elongated, somewhat triangular, truncated in front, pointed behind, and furnished with a horny operculum; head cylindrical and proboscis-shaped, having a long pointed tentacle on each side, at the outer base of which are situated the eyes.

Shell; turriculated, enlarged at the base, rarely umbilicated; sometimes short; aperture oval, semihnar, slightly channelled, lip generally thickened and more or less produced.

The species composing this genus being for the most part extremely small, they have been much neglected by conchologists. M. Risso appears to have been the first to observe their claim to rank as a particular genus, when M. Fréminville paid him the compliment of associating them under a new generic type with his name. Lamarck included the few species known to him under the head of Melania, but various specics have been described since that period by MM. Desmarest, Michaud, and Philippi, including the animal as above described.

Several of these inhabit the Mediterranean, between twenty and thirty have been now observed on the shores of the British Isles, and it is not impossible that the number will be greatly increased, as the same powers of observation become extended to more distant localities.

The shell may be chiefly recognised from its being enlarged at the base, whilst the upper part of the aperture is slightly channelled; the lip is mostly thickened and more or less produced or expanded. The following 
list of the species is from the last edition of Lamarck. A monograph of the genus is much needed.

\section{Species.}

1. acicula, Soro.

2. acuta, Desm.

3. alba, Forbes.

4. arata, Récluz.

5. Bruguierei, Payraud.

6. Bryerea, Macgill.

7. Buccinoides, Desh.

8. cancellata, Récluz.

9. Chesnetii, Michaud.

10. cingillata, Macgill.

11. cingulus, Michaud.

12. costata, Récluz.

13. crenulata, Michaud.

14. cyclostomata, Récluz.

15. deformis, Sow.

16. Deshayesiana, Récluz.

17. Desmarestii, $i d$.

18. elongata, Phil.

19. excavata, $i d$.

20. fragilis, Michaud.

21. fulva, $i d$.

22. Gougeti, $i d$.
23. gracilis, Macgill.

24. grossa, Michaud.

25. Guerinii, Récluz.

26. hyalina, Desm.

27. Inca (Rissoina), D'Or.

28. interrupta, Jolenston.

29. labiata, Phil.

30. lactea, Michaud.

31. lilacina, Récluz.

32. lineolata, Michaud.

33. marginata, $i d$.

34. Matoniana, Récluz.

35. minutissima, Nich.

36. monodonta, Phil.

37. Montagui, Payraud.

38. muriatica, Macgill.

39. oblonga, Desm.

40. parva, Récluz.

41. præusta, $i d$.

42. pulchella, Phil.

43. punctulum, $i d$.

44. puncturata, Macgill.
45. pusilla, Des\%.

46. pygmæa, Michaud.

47. radiata, $P h i l$.

48. reticulata, Sow.

49. rubra, Macgill.

50. scalaris, Michaud.

51. semistriata, Jolnnston.

52. spirata, Sow.

53. Souleyetana, Récluz.

54. striata, Quoy.

55. striata, Macgill.

56. striatula, Récluz.

57. subumbilicata, Mac.

58. tridentata, Michaud.

59. tristriata, Thompson.

60. truncata, Macgill.

61. ulvæ, $i d$.

62. unifasciata, Récluz.

63. ventricosa, Desm.

64. ventricosa, Macgill.

65. violacea, Desm.

66. vittata, Récluz.

\section{Figure.}

Risson Cuningit. Pl. 15. Fig. 75. Shell, showing the aperture with its thickened lip and sinuated formation at the upper part.

\section{Family 8. PLICACEA.}

Shell ; distinguished by having the columella strongly plaited and the base entire without indication of any sinus, the animal. being of marine habits, and furnished with a horny operculum.

Little is known of the soft parts of this family beyond the external form of Pyranizidella described by M. Quoy in the 'Voyage de l'Astrolabe*.'

\footnotetext{
* Comme on le voit, rien n'est encore connu sur l'organisation intéricure des Pyramidelles ;
} 
The observations of this eminent naturalist are sufficient to show that the animal of that genus is the type of a distinct group, and there is little doubt, from the corresponding structure of the shell, of the immediate affinity of the Tomatelle. Prior to the introduction of the family Plicacea by Lamarck, the species of which it is composed were referred to the genera Voluta, Bulimus, and Auricula; the shell will, however, be found to differ in an important degree from the first of these, in wanting the notch at the base which indicates the passage of an uplifted fold of the mantle, used for the conveyance of water to the breathing organs, and from the last by its inhabiting the sea; and even were we unacquainted with the marine habits of the Plicacea, it might be presumed from the hard porcelain texture of the shells, that their fabricators are not denizens of the air or of fresh-water.

The genera above mentioned, both very limited in species, are all that can at present be referred to this family; $M$. Deshayes proposes to include his marine genus Bonellia (Niso, ante p. 149) with them, but the remarkable umbilicated growth of that shell, and absence of plaits on the columella, are characters of too much importance to be lightly regarded.

\section{Pyramimella. Tornatella.}

\section{Genus 1. PYRAMIDELLA, Lamarck.}

Animal; disk short, thick, triangular, furnished at the hinder extremity with a small operculum; head triangular, rather deeply bilobed, bearing at the two lateral points of the angle a rather long tentacle, similar to that of Aplysia; eyes small, situated at the inner base of the tentacles.

Shell ; pyramidally turreted, composed of mumerous whorls forming a sharply acuminated spire; columella mostly three-plaited, sometimes with only two plaits; aperture rather small, rounded at the base, lip stightly expanded.

The genus Pyramidella contains those Plicacea whose shells are pyramidally turreted, composed of many whorls, forming an acuminated spire, and having a small semi-rounded aperture with the plaits of the columella more than usually transverse. The branchial cavity of this mollusk

il faut encore rechercher si ce genre, ainsi que les Tornatelles, appartient aux mollusques dioiques, ou s'il est monoique comme la plupart de ceux qui ont l'ouverture entière.-Deshayes, Anim. sans vert, vol. ix. p. 54. 
according to the observations of M. Quoy, is widely open in front; no basal notch or channel is therefore needed in the shell for the passage of that organ, which leads in most of the carnivorous tribes to the respiratory cavity in a more concealed situation.

Among the few species known of this genus, the $P$. maculosa is the largest and most elongated; the P.dolabrata is common in the Eastern Seas; the P.ventricosa is a fine species from New Holland, and the P.plicata, chiefly remarkable for its longitudinally plicated ribs, of which there is no indication in the before-mentioned species, is, according to Lamarck, from Mauritius.

\section{Species.}

1. cincta, Reeve.

2. corrugata, Lam.

3. dolabrata, $i d$.

4. glans, Reeve.
5. gracilis, Brocchi.

6. maculosa, Lam.

7. plicata, $i d$.

8. solida, Sow.
9. sulcata, Nutt.

10. terebellum, Lam.

11. ventricosa, Guerin.

\section{Figure.}

Pyramidella maculosa. Pl. 14. Fig. 73. Shell, showing its elongately pyramidal growth, plaited columella, and small aperture.

\section{Genus 2. TORNATELLA, Lamarck.}

Animal ; wnknown.

Shell; cylindrically oval, with a very short spire, mostly transversely striated, never ribbed, columella strongly two-plaited, sometimes with one plait only, aperture oblong, reaching nearly to the top of the body-whorl.

Although shells of this grenus are by no means of rare occurrence, it does not appear that the animal has been yet described. Their typical form is the reverse of that of Pyramidella; instead of having a small aperture and long dramn out spire, the shell is of an oval Bulla form, has a very short spire, and an oblong aperture reaching nearly to the summit of the body whorl. The plait or plaits of the columella range obliquely, and are strongly developed.

Linnæus placed the Tomatelle among his Volutes; Bruguiére observing the absence of any notch at the base, transferred them to the genus Bulimus, where they became associated with a numerous tribe of uncongenial habits, which the sagacity of Lamarck readily detected. They constitute 
a very natural family with the Pyramidelle, and, so far as the shell is concerned, agree in character, though differing materially in their plan of convolution. Among the few species known, the T. coccinata of the Philippine Islands is the rarest and at the same time the prettiest; the T. flammea, solidula, virgata, glabra, nitidula, insculpta and oryza are all from the same locality. To these may be added T. Siebaldii from Japan, T. venusta from Peru, T.tessellata from the Red Sea, and the T.fasciata of our own southern shores.

\section{Species.}
1. auricula, Lam.
7. insculpta, Reeve.
12. Siebaldii, Reeve.
2. bullata, Kiener.
8. nitidula, Lam.
13. solidula, Lam.
3. coccinata, Reeve.
9. oryza, Reeve.
14. tessellata, Reeve.
4. fasciata, Lam.
10. pedipes, Lam.
5. flammea, $i d$.
11. punctata, Férussac.
15. venusta, D'Orbigny.
6. glabra, Reeve.
16. virgata, Reeve.

Figure.

Tornatella coccinata. Pl. 14. Fig. 72. Shell, shoming its compressly convoluted growth, strongly plaited columella, and oblong aperture.From Mr. Cuming's collection.

\section{Family 9. IANTHINEA.}

\section{Genus IAN'THINA, Lamarck.}

Animal; head large, prolonged into a short swollen proboscis, having a perpendicular mouth, the lips of which are thickened and furnished with prickly hooks or plates; above the neck on each side is a pair of tentacles of unequal length, the front one being the shorter, at the outer base of which is situated a very small indistinct eye; foot short, having attached to its under surface a broad fin-like appendage with a float of vesicles.

Shell; globose, turbiniform, thin and brittle, with the whorls either rounded or inclined to angular at the periplery; columella long and straight, margin of the aperture thin, never reflected.

The Ianthina or Sea-Snail constitutes a type of which there is little approximation in any of the pectinibranchiate genera, though possessing the essential characters of the order. It might be treated rather as the 
analogue of an arboreal suail, whose organs and functions are fitted, by an extreme modification of nature, to inhabit the sea. The beautifully reticulated lung of the air-breathing mollusk is transformed into a pectinate gill for the respiration of water, the mouth is furnished with an armature for the comminution of hard flesh-food of marine origin, less easily digested, and to the foot is attached a broad dilated fin and vesicular float, contrived for the purpose of sustaining the animal on the surface of the water. The shell presents also the change that might be expected to result from its difference of habit, being of a thin brittle calcined substance, and not enveloped by any of those hairy, or horny, or hydrophanous kinds of epidermis which are peculiar to the plant-eating snail.

The float of bubbles or vesicles, by which the Ianthince are more particularly distinguished, has been said to serve a mechanical purpose, by which the animal is enabled to sink or swim at pleasure; there does not, however, appear to be any sufficient testimony to this effect, and it is difficult to imagine that such a use could be nade of them; but it has been noticed that the Ianthince are rarely seen except in calm weather. According to the observations of the eminent naturalists of the 'Voyage de l'Astrolabe,' the Ianthince deposit their ovaries, filled with minute eggs, in great plenty about the vesicles, which the animal has the faculty of detaching. Notwithstanding that few species are known, they are extremely prolific in the equatorial seas, and, without doubt, as in the case of the surface-swimming Pteropods, the predacious inhabiters of the deep allow them but a limited existence.

One remarkable peculiarity in Ianthina is, that in all the species, and I believe six or eight will be found when they come to be examined, the shell is of a uniform colour, a clear intense violet, and it is distinguished more strongly, according to the species, by a close succession of extremely delicate concentric lines of growth. The animal has been observed to eject a violet fluid when alarmed or irritated.

A considerable number of Ianthina were collected by Capt. Sir Edward Belcher in the South Atlantic Ocean during the voyage of the Samarang,*

* Mr. Arthur Adams, R.N., F.L.S., Assistant-Surgeon of the Samarang, has kindly favoured me with the following interesting observations made by him on this occasion.

"In our passage from the Cape to St. Helena we experienced several days calm, the surface of the South Atlantic being like a sheet of glass, and covered over with innumerable Ianthina, Physalice, and Felellce, with parties of Flying-fish and solitary Skip-jacks, emerging suddenly from its depths and disturbing the stillness by their flights and splashings. In the act of swimming, the dilated natatory appendages of Ianthina, are kept fully extended, while the vesicular float precedes the shell, and keeps it in a reversed position on the surface" of the water. The female evidently has the power of voluntarily detaching certain portions of the float to which any nidimental sacks are fixed, for among the thousands obtained in the trawls, were several specimens with hardly a remnant left, while isolated floats were also numerous. The high seas appear to be the natural home of these beautiful mollusks, and I have seen a fleet of many hundreds wrecked on the coral reefs of the Meia-co-shima Islands, making the shore quite blue at the waterline. I have taken them up adhering in masses by means of the sucker-like fore-part of the foot; for although alive and uninjured, I never observed them make the slightest effort to crawl, which mode of progression appears to be denied them. They have a habit, when nearly dead, of 
some of large size and very deeply coloured, others of smaller size, having a delicate silken appearance from the prominent and very neat succession of concentric striæ.

\section{Species.}
1. bifida, Nutt.
3. fragilis, Bory.
5. prolongata, Blain.
2. exigua, Lam.
4. globosa, Swainson.
6. umbilicata, D'Orbigny.

\section{Figure.}

Ianthina globosa. Pl. 15. Fig. 80. Shell, showing its light inflated form and violet colour.

\section{Family 10. NERITACEA.}

\section{Shell; abruptly transversely convoluted and more or less globose, with the spire short and the last whorl much enlarged.}

The Neritacea present two very distinct groups, which, but for the similarity in the typical structure of their shells, exhibiting a peculiar transverse form of convolution, might be regarded as separate families. The first, comprising the genera Navicella, Neritina, and Nerita, is an extensive series, not varying materially in size, inhabiting seas and rivers, of which the animal is small, and the shell remarkable for its beautiful varieties of painting. The second group, consisting of the genera Natica and Sigarelus, the latter of which was until lately associated with Haliotis, is characterized by an animal of much larger proportions, generally more or less enveloping the shell by a thickened ridge and dilated extension of the foot. All the species of this division are of marine habits.*

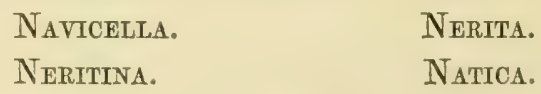

\section{Sigaretus.}

exserting the end of the long proboscis, which is then seen to be armed with numerous curved hooks; their eyes are very small and indistinct, and are placed on a short peduncle on the outside of the conical tentacles. If injured or irritated in the water, they cject a very pretty violet-coloured fluid, which appears to be evanescent like iodine. These "schools of sen-snails" comprised about four distinct species sailing among themselves in an indiscriminate manner, becoming more numerous towards the evening, and entirely disappearing when the breeze sprang up and ruffled the surface of the sea."

* The genus Neritopsis, hitherto referred to this family, is removed, together with the genus Narica, to the family of the Velutinide. 


\section{Genus 1. NAVICELLA, Lamarck.}

Animal; ovately oblong, rather slight, the disk occupying the wide aperture of the shell, with a peculiar quadrangular slightly radiated operculum, insinuated between it and the visceral mass; head flattened and auriculated, with two large subulate tentacles, at the outer base of which are two other short truncated tentacles, bearing the eyes.

Shell; transversely elliptic or oblong, Limpet-shaped, spire very short, columella depressly flattened, forming a transverse shelf, last whorl extremely patent, and marked with two muscular impressions.

A small genus of fresh-water mollusks, whose shells are remarkably depressly convoluted, and very similar in appearance to those of the Crepidula or Slipper-Limpet, the columella being transformed into a flattened septum, forming a shelf, as it were, across one side of the aperture. The Navicella are, however, very distinct from the Crepidula, and have little affinity with any of the Limpet tribe; they are not of the same parasitical habits, and live free in flowing streams. Their shells are of regular symmetrical formation, and not subject to the distorted irregularities of growth which is the common lot of those living attached to the roughthewn surface of the rocks.

The painting of the Navicella shells is generally of a mottled character, in lines or subtriangular patches radiating from the apex, covered with a thin fibrous olive epidermis, and the interior is mostly of a bluish tinge. The operculum is composed of two parts, one of which is internal, imbedded between the middle of the disk and the viscera, occupying the spiral chamber of the shell, the other is of stouter substance and appears to radiate at a right angle with the former.

The Navicella are unknown to Europe and the western Hemisphere; they inhabit the streams of the Philippine and Feejee Islands, and are found in New Guinea, New Ireland, New Holland, and in Mauritius and the neighbouring Isles, where they are said to be eaten by the poorer natives for food. The largest species, selected for illustration, is prettily variegated with yellow upon a dark olive-black ground; for delicacy of form and colouring the $N$. lineata and Recluiii are perhaps the most interesting species. These two last mentioned are of a compressly oblong form, resembling a fragile boat, of which the septum forms the poop. 


\section{Species.}

1. apiata, Guillou.

7. Freycineti, Récluz.

13. porcellana, Desh.

2. atra, Reeve.

8. Janelli, $i d$.

14. radiata, Reeve.

3. Bourgainvillei, Récluz.

9. La Perousei, $i d$.

15. Recluzii, $i d$.

4. depressa, Lesson.

10. lineata, Lam.

16. suborbiculata, Sow.

5. D’Urvillei, Récluz.

11. Luzonica, Soul.

17. Suffreni, Récluz.

6. Entrecastauxi, $i d$.

12. macrocephala, Guill.

18. tessellata, Lam.

\section{Figures.}

Navicella porcellana. Pl. 16. Fig. 82. Shell, showing at Fig. $a$ its videly dilated aperture, lateral muscular impressions, transverse septum and inconspicuous spire, and at Fig. $b$ its external variegated painting covered with a dark olive epidermis.-From Mr. Cuming's collection.

\section{Genus 2. NERITINA, Lamarck.}

Animal; disk triangularly ovate, truncated and thicker towards the front, bearing about the middle a peculiar semilunar calcareous operculum; head large, but little projected, furnished with a dilated labial appenduge and having four tentacles, two long and subulate, two short and truncated, on which are situated the eyes.

Shell; ovately globose, with the spire very short and indistinct, and the whorls sometimes armed with hollow spines; columella depressly flattened into a transverse septum, aperture semicircular, lip simple, sometimes dilated on either side; outer surface mostly covered with a dark epidermis.

The Neritina or Fresh-water Nerites are more stoutly convoluted than the Navicelle, and form an interesting link between them and the Neritce of still more solid growth, inhabiting the sea. There is little difference in the animal beyond that resulting from their different circumstances of habitation. The Neritince dwell principally on the banks of rivers, and are not unfrequently found upon palms and other fluviatile plants.

Ferr species of this extensive genus present any variation of sculpture beyond a slightly plicated or granulated surface, with the exception of some which are coronated with a row of hollow spouted spines, short as in 
$N$. brevispinosa, or remarkably long as in $N$. corona. Some of the species are curiously winged on each side, as in the $N$. dilatata and latissima.

There is scarcely any limit to the geographical distribution of the Neritince, save in the frigid and cold temperate zones. The genus is represented in an humble, but very prettily painted condition on our own coast, it is plentiful in the West Indies, and is found throughout the great continent of North, South, and Central America. It is not less abundant in the Eastern world. Magnificent specimens were collected by Mr. Cuming in the Philippines, among which the $N$. labiosa, selected for illustration is perhaps the largest. In Sumatra and other Islands of the Oriental Archipelago, in India, and in South Africa, the Neritince are also more or less plentiful.
1. afra, Sono.
2. alata, Brod \& Sow.
27. intermedia, Sow.
52. rara, Dufo.
3. atra, Nutt.
28. Jordani, Butler.
29. labiosa, Sow.
53. reclivata, Say.
4. auriculata, Lam.
30. Lamarekii, Desh.
54. reticularis, Sowo.
5. bætica, $i d$.
31. latissima, Brod.
55. reticulata, $i d$.
6. brevispina, $i d$.
32. lineolata, Lam.
56. rivalis, Parreys.
7. caffra, Gray.
8. callosa, Desh.
9. canalis, Sow.
33. lugubris, $i d$.
57. Sandwichensis, Desh.
34. lutescens, Muhlfeld.
35. meleagris, Lain.
58. semiconica, Lam.
59. serratilinea, Ziegler.
10. cariosa, Gray.
36. microptera, Nutt.
60. Smithii, Gray.
11. cassiculum, Sow.
37. Mittreana, Récluz.
12. chlorostoma, $i d$.
38. morio, Sow.
61. spinosa, Sow.
62. strangulata, Muhlf.
13. convexa, Nutt.
39. nux, Brod.
63. strigilata, Lam.
14. Coromandeliana, Sow.
15. corona, Lam.
16. crepidularia, $i d$.
40. obtusa, Benson.
41. Oweniana, Gray.
64. subgranosa, Sow.
65. subsulcata, Sow.
66. Sumatrensis, $i d$.
17. Dalmatica, Partsch.
18. Danubialis, Ziegler.
19. dilatata, Brod.
42. perversa, Lam.
43. Philippinarum, Sow.
44. picta, $i d$.
67. tranversalis, Ziegler.
68. triserialis, Soro.
69. venosa, Menke.
20. Domingensis, Lam.
21. dubia, $i d$.
45. piperina (Nerita), Ch.
46. pisiformis, Récluz.
70. vespertina, $N u t$.
47. Prevostiana, Fér.
71. violacea, Lami.
48. pulchra, Sow.
72. virginea, $i d$.
22. faba, Sow.
23. fasciata, Lam.
24. fluviatilis, $i d$.
25. gagates, $i d$.
49. pulligera, Lam.
50. punctulata, $i d$.
51. pupa, $i d$.
73. viridis, $i d$.
74. Waigion, Less.
75. zebra, Lam.
76. ziczac, $i d$.

\section{Species.}

26. granosa, Sow.

\section{Figure.}

Neritisa labiosa. Pl. 16. Fig. 83. Shell, showing its solid dilated growth, and curious operculum. From AIr. Cuming's collection. 
Genus 3. NERITA, Linnaus.

Animal; very similar to that of Neritina, the disk being rather stouter.

Shell ; semiglobose, solid, smooth, sometimes ribbed, spire small and. indistinct, columella transversely flattened, sometimes crenulated or toothed, aperture semicircular, frequently grooved within,

The animal of Nerita differs so little from Neritina, that naturalists have been somewhat divided as to the propriety of separating these genera. The genus Cerithium presents an instance in which the changes are considerable in the composition and substance of the shell, arising out of differences of habit, some being marine, others dwelling in estuaries and situations where the water is only brackish, and others again living in the vicinity of springs or stagnant marshes, quite beyond the influence of the tide. So it is with the Nerite and Neritina, and were it not that collectors are in the habit of distinguishing them, agreeably with the views of Lamarck, since whose time no new facts have been elicited in their natural history, they would have been here fused into one.

The Sea-Nerites construct shells of very solid growth, and paint them with extremely vivid colours; the colours are, moreover, so variable in the same species that it is only by a close observation of form and general design, that their specific relation is understood. With this robust structure and display of colour, the shells of this genus are also characterized by variations of sculpture which are not found in the fresh-water genus. Many of the species are strongly ribbed, the interior of the shell being marked with corresponding grooves, and the edge of the lip more or less strongly crenulated, others have the flat columellar septum granulated, and in some species, such as in that selected for illustration, $N$. ornata, and the well-known Bleeding-tooth, $N$.peloronta, it is dentated.

The Nerita, like the Neritince, are very generally distributed throughout the globe; but are rather more confined to the equatorial regions. Few species, if any, remain undescribed; the entire family of the Neritacea has been investigated with minute accuracy by M. Récluz of Paris, to whom Mr. Cuming, with a proper international spirit, forwarded the new species resulting from his researches in the Philippine Islands.

\section{Species.}

1. Adansonia, Récluz.

2. albicella, Linn.

3. Anatolica, Récluz.
4. Antillarum, Gmelin.

5. antiquata, Récluz.

6. apiata, $i d$.
7. argus, Récluz.

8. atrata, Chemn.

9. atropurpurea, Récluz. 
10. aurantia, Recluz.

11. balteata, Reeve.

12. Beaniana, Recluz.

13. Bernhardi, $i d$.

14. bisecta, Reeve.

15. bullula, $i d$.

16. chlorostoma, Lamk.

17. chrysostoma, Recluz.

18. comma-notata, Reeve.

19. costata, Chemnitz.

20. Deshayesii, Recluz.

21. Dombeyi, $i d$.

22. electrina, Reeve.

23. erubescens, $i d$.

24. Essingtoni, Recluz.

25. exuvia, Linnaus.

26. filosa, Reeve.

27. fragum, $i d$.

28. fulgurans, Gmelin.

29. fuliginata, Reeve.

30. funiculata, $i d$.

31. gemmulata, $i d$.

32. genuana, $i d$.

33. Georgina, Recluz.
34. granulata, Reeve.

35. Grayana, Recluz.

36. grisea, Reeve.

37. grossa, Linnœus.

38. haustrum, Reeve.

39. Helicinoides, Reeve.

40. Hindsii, Recluz.

41. histrio, Linnceus.

42. Le Guillouana, Recl.

43. lineata, Chemnitz.

44. Listeri, Recluz.

45. Longii, $i d$.

46. marmorata, Reeve.

47. Maura, Recluz.

48. maxima, Chemnitz.

49. Neritinoides, Reeve.

50. Neritopsoides, $i d$.

51. nigerrima, Chemnitz.

52. nivosa, Reeve.

53. Novæ-Guineæ, Less.

54. oleagina, Reeve.

55. Orbignyana, Recluz.

56. ornata, Sowerby.

57. oryzarum, Recluz.
58. patula, Recluz.

59. pellis-serpentis, Reeve.

60. peloronta, Limneus.

61. picea, Recluz.

62. plexa, Chemnitz.

63. plicata, Linnceus.

64. polita, $i d$.

65. præcognita, C. B. Ads.

66. quadricolor, Gmelin.

67. ringens, Reeve.

68. Rumphii, Recluz.

69. Savieana, $i d$.

70. scalpta, Reeve.

71. semirugosa, Recluz.

72. Senegalensis, Gmelin.

73. signata, Macleay.

74. Spengleriana, Recluz.

75. squamulata, Le Guillou.

76. stella, Chemnitz.

77. tessellata, Gmelin.

78. versicolor, Lamarck.

79. vexillum, Reeve.

80. Yoldii, Recluz.

\section{Figure.}

Nerita costata. Pl. 16. Fig. 86. Shell, showing its solid, globose growth, and toothed columella.

\section{Genus 4. NATICA, Adanson.}

Animal; oval, very large and expanded, rounded at each end; mantle largely developed, enclosing a thick circular vidye, holding the shell. Head furnished with a long trunk and surrounded by a tentacular veil, from which are caserted two widely separated lanceolate tentacles. Hind lobe of the disk carrying the operculum partially spread over the shell.

Shell; globose or Neritoid, sometimes openly inflated; spire short, very often scarcely exserted; whorls few, forming a large umbilicns, which is sometimes filled with a dense callosity, sometimes will a columnar callosity entering spirally; aperture 
generally more or less lunar. Operculum sometimes testaceous, generally hormy, spiral.

The comparatively recent discovery that the soft parts of Natica are similar to those of Sigaretus, required that these genera, which in Lamarck's time were arranged at some distance from each other in the system, should be brought into more inmediate relationship. By malacologists, indifferent to the characters of the shell, the Natice have been removed to the Sigaretus family; but conchologists, unwilling to lose sight of their obvious and long-acknowledged affinity in this respect with the Nerites, have caused the Sigareti to be removed to this family. It was by the French navigators, MMI. Quoy and Gaimard, during the voyage of the 'Astrolabe,' that the minal portion of Natica was first fully observed, thongh figured a century before by $\Lambda$ danson. Differing essentially from that of Nerita, it proved to be of very much larger dimensions in proportion to the size of the shell, distinguished by a broad mantle-like expansion of the foot, and characterized by a more or less thickened circular ridge, holding the shell, and sometimes almost concenling it from view. The Natica has, moreover, a retractile proboscis, which the Nerite has not, and it is of more predaceous habits. The lobe which carries the operculum is also largely developed and reflected over the shell. The animal of Sigaretus is of similar structure; and looking only to the distinctive features of organization of the soft parts, there is little family relationship between it and the Nerites.

The shells of Natica are not particularly variable in form. They are nearly all of the same peculiar scuiglobose, lunar-apertured plan of convolution, which is charncteristic of the Nerites, more largely umbilicated, but having the umbilicus sometimes filled up with callous enamel, and sometimes partially filled with a peculiar spiral columnar callosity. Little, however, as this variation is, the Natica have been divided into seven genera:-Natica proper (N. canrena), Lunatia, Lamarck ( $N$. monilifera), Neverita, Risso (N. albumen), Ampullina, Lamarck (N. fluctuata), Ruma, Chemnitz (N. MLurra), Mamma, Klein (N. mamilla), and Naticina, Gray (N. papilla). The chief conchological distinction between the genera Nerita and Natica is, that whilst the Nerites are mostly strongly grooved and otherwise sculptured, and richly painted, the Natica are smooth and polished, as is almost invariably the case with shells more or less enveloped by the soft parts of the animal, and are painted, generally with light colours.

The Natica live mostly in sandy and muddy beaches, at about lowwater mark, and are strictly carnivorous.*

* Speaking of a large species, $N$. heros, jnhabiting the shores of Massachusetts, Dr. Gould says, in his history of the Invertebrata of that State:- "This, in common with other suecies of Natica, is very voracious, and plays a conspicuous part in devouriug the dead fish and other 


\section{Species.}

1. Adansoni, Reeve.

2. albula, Recluz.

3. albumen, Lamarck.

4. ala-papilionis, Chemn. 38. florida, Reeve.

5. asellus, Reeve.

6. aurantia, Lamarck.

7. Baconi, Reeve.

8. bifasciata, Gray.

9. borealis, Sowerby.

10. Broderipiana, Recluz.

11. bulbosa, Reeve.

12. Buriasensis, Recluz.

13. Campeachiensis, $i d$.

14. caudidissima, Le Guill.

15. canrena, Linnceus.

16. Caribbæa, Philippi.

17. catenata, $i d$.

18. Chemnitzii, Recluz.

19. Chinensis, Lamarck.

20. clausa, Brod. and Sow.

21. collaria, Lamarck.

22. Colliei, Recluz.

23. columnaris, $i d$.

24. conica, Lamarck.

25. cornea, Möller.

26. cora, D'Orbigny .

27. Cumingiana, Rechuz.

28. deiodosa, Reeve.

29. Draparnaudi, Recluz.

30. dubia, $i d$.

31. duplicata, Say.

32. effusa, Swainson.

33. Elenæ, Recluz.

34. fibula, Reeve.

36. Hava, Gould.

40. forata, Reeve.

46. Gambix, $i d$.

48. glabella, $i d$.

55. heros, Say.
35. filosa, Soverby.

37. Flemingiana, Recluz.

39. fluctuata, Sowerby.

41. Forskalii, Chemnitz.

42. Fortunei, Reeve.

43. fulgurans, Recluz.

44. fulminea, Gmelin.

45. Gallapagosa, Recluz.

47. genuanus, Reeve.

49. glauca, Humboldt.

50. glaucina, Lamarck.

51. globosa, Chemnitz.

52. Grœulandica, Beck.

53. Gualteriana, Petit.

54. Helicoides, Johnston.

56. iunthostoma, Desh.

57. immaculata, Totten.

58. imperforata, Sowerby.

59. Incii, Philippi.

60. intemerata, $i d$.

61. intricata, Donovan.

62. Jamaicensis, C. B. Ad. 96. porcellanea, D'Orbigny.

63. Jukesii, Reeve.

64. Lamarckiana, Recluz. 98. Priamus, $i d$.

65. leucophra, Reeve.

66. lineata, Lanarck.

67. locellus, Reeve.

68. macilenta, Philippi.
69. maculata, Deshayes.

70. maculosa, Lamarck.

71. Maheense, Recluz.

72. mamilla, Lamarck.

73. mamillaris, $i d$.

74. Marochiensis, id.

75. Maura, Bruguière.

76. melanostoma, Lamarck.

77. melanostomoides, Quoy.

78. melastoma, Swainson.

79. millepunctata, Lam.

80. monilifera, $i d$.

81. Montagui, Forbes.

82. nitida, Dorovan.

83. nucula, Reeve.

84. orientalis, Gmetin.

85. Panamaensis, Recluz.

86. pavimentum, $i d$.

87. pellis-tigrina, Chemenitz.

88. perspicua, Recluz.

89. Petiveriana, $i d$.

90. Philippiana, $i d$.

91. phytelephas, Reeve.

92. picta, Recluz.

93. pisiformis, $i d$.

94. plicatula, Nuttall.

95. plumbea, Lamarck.

97. Powisiana, Recluz.

99. problematica, Reeve.

100. proxima, C. B. Adans.

101. pulicaris, Philippi.

102. pusilla, Say.

animals which are thrown up by the tide. Many of the shells thrown upon the shore are found to be perforated with a small round hole: this is done principally by the different species of Natica. They have the power of perforating shells, it is generally supposed, by discharging an acid which decomposes the shell, and through the aperture they extract the juices, and destroy the lives of the otherwise secure inhabitants. 'Their foot is very large, so as to completely envelope the objects on which they prey. In moving, they burrow in the sand, so as to be almost entirely concealed by it, and their place is generally indicated by a small heap of sand. The singular nidus in which the animal of Natica deposits its eggs has been an object of much curiosity and speculation. It is a mass of sand glued together into the shape of a broad buwl, open at the bottom, and broken at one side. Its thickness is about that of an orange-peel, ensily bent without breaking when damp, and when held up to the light will be found to be tilled with little cells, arranged in quincunx order. Each of these cells contains a gelatinous egg, having a yellow nucleus, which is the embryo shell." 
103. pyramis, Reeve.

104. pyriformis, Recluz.

105. rapulum, Reeve.

106. ravida, Souleyet.

107. Raynaudiana, Recluz. 119. Succinioides, $i d$. 108. Recluziana, Desh.

109. rufa, Born.

110. rufilabris, Reeve.

111. Sagraina, D'Orbigny. 123. Traillii, $i d$.

112. Sebæ, Souleyet.

113. semisulcata, Gray.

114. Simiæ, Chemnitz.

126. umbilicata, Quoy.
115. septentrionalis, Beck. 127. unifasciata, Lamarck. 116. solida, Blainville. 128. unimaculata, Reeve.

117. spadicen, Gmelin. 129. variabilis, Recluz.

130. Vavaosi, Le Guillou.

131. venustula, Philippi.

132. vestalis, $i d$.

133. violacea, Sowerby.

134. vitellus, Lamarck.

135. Zanzibarica, Recluz.

136. zebra, Lamarck.

137. Zelandica, Quoy.

125. uber, Valenciennes.

\section{Figure.}

Natica Cumingrana. Pl. 16. Fig. 84. Shell, showing its solid, polished, sculptureless surface, and large, open umbilicus, with in-growing callosity.

\section{Genus 5. SIGARETUS, Adanson.}

Animal; oval-oblong, acuminated in front, rounded belind, furnished at both ends with a capacious lobe which envelopes a large portion of the shell; head very large, depressed, furnished with two long conical tentacles; operculum small, oblong, hormy, concealed within a fold of the posterior lobe.

Shell; suborbicular, somewhat ear-shaped, globose or depressly globose, striated, never umbilicated; spire short, but little raised; aperture dilated, disjoined; lip simple.

The soft parts of Sigaretus, though closely allied to Natica, are larger, and they are furnished with more capacious lobes, both in front and behind more largely enveloping the shell. In most of the Natice the animal is able to draw itself entirely within the shell and cover itsclf in by a tight-fitting operculum, mostly calcareous. In Sigaretus the animal is more bulky than can be contained in the shell, and the operculum is merely rudimentary, a small, useless, horny appendage concealed within a fold of the hind lobe.

The shell is of a brownish-white, famn, or sand colour, never highly painted or marked with any pattern. The outer surface is striated and mostly linearly grooved, the spire small, the aperture large and shining. The Sigareti are not very numerous. They inhabit the westem coast 
of South America, West Indies, India, and China, and are of sluggish habits, crawling and burrowing into beds of wet sand and mud.

\section{Species.}

1. agriensis, Recluz.

2. Antillarum, $i d$.

3. apertus, Anton.

4. bifasciatus, Recluz.

5. Carolius, Chenu.

6. clathratus, Bosc.

7. concavus, Lam.

8. Cuvierianus, Recluz.

9. Delessertii, Chenu.

10. depressus, Pliil.

11. Deshayesianus, Recluz.
12. haliotoideus, Linn

13. insculptus, $A d . \& \cdot R v$. 23. neritoideus, Lim.

14. Italicus, Chenu.

15. Javanicus, $i d$.

16. lacteus, Klein.

17. lævigatus, Lam.

18. latifasciatus, $A d$. \& $R v$. 29. striatellus, $i d$.

19. Leachii, Blainville.

20. Levesquei, Recluz.

21. Listeri, Recluz.
22. maculatus, Say.

24. perspectivus, Say.

25. Petitianus, Recluz.

26. planulatus, Chenu.

27. sinuatus, Recluz.

29. striatus, De Serr.

30. 'Turonicus, Recluz.

31. zonalis, Quoy.

\section{Figure.}

Sigaretus concavus. Pl. 1. Shell, with animal, showing its capacious hooded hinder lobe, and acuminately folded front lobe, from which protrudes one of the tentacles belonging to the head concealed beneath.-From M. d'Orbigny's 'Toyage dans l' Amérique Méridionale.' Sigaretus concavus. Pl. 23. Fig. 137. Shell of the same species divested of the soft parts, showing its thin, arched columella and inflated aperture.

\section{Family 11. PERISTOMATA.}

Shell; globose or turbinated, sometimes discoid, with little scul])ture beyond a malleated or indented surface or an occasional keel, mostly of a sombre olive or greenish colour.

This small family includes the freshwater pectinate-gilled gastropods, in which the shell is mostly of a round or roundly-turbinated snail-like form. The largest are the Ampullaria, whose shells are stoutly globose and inflated. They inhabit chiefly the banks of rivers, in parts liable to be dried up for a season, and to meet the exigences of this change of condition are furnished with a double system of respiration, a waterbreathing and an air-breathing apparatus. The next group in the family are the Paludina, which are smaller and more numerous, but still of the same dark, sombre character, enveloped in a horny epidermis. Lastly 
come the Falvate, few in species and minute, with shells of elegantly spiral or discoid growth.

Ampullaria. Paludina. Valvata.

\section{Genus 1. AMPULLARIA, Lamarck.}

Animal; globutar or subdiscoid, with the disti mostly large and thin, oblong-square or triangular, broadly truncated in front. Itead flattened, terminating with a pair of tentacles, below which is another pair longer and more slender, and below these a pair of eyes sometimes sessile, sometimes mounted on peecticles. On the left sicle of the body is a conspicuous respiratory canal, formed by a fold of the mantle, leading to a pair of pectinate gills; in front is an open pulmonary cavity.

Shell; globose or ovate, more or less umbilicated, rarely imperforated, covered with a ralher thick olive epidermis; suture of the spire sometimes simple, sometimes channelled; whoits more or less ventricose, smooth; aperture rather large, lip simple. Operculum sometimes horny, sometimes calcrireous, closing the aperture.

The sombre hue and obvious similarity of form, destitute of any indication of sculpture, of the shells of Ampullaria, have led to this genus being very much neglected by the collector; and their unattractive range of habitation, in swampy marshes, ponds, and rivers, has not been very inviting to the traveller. A few ardent naturalists, including among the foremost M. d'Orbigny and Mr. Bridges on the banks of the great rivers of Bolivin, Dr. Spix in Brazil, M. Caillaud in Africa, Mr. Yates and Mr. Wallace at the rivers Marañon and Amazon, MIM. Sallé and Ghiesbrecht in Mexico, Mr. Dyson in Honduras, Mr. Benson in India, and Mr. Layard and Mr. Tompleman in Ceylon, have directed their energies since Lamarck's time to Ampullaria-lunting; and the result of their labours cnabled me to describe in the 'Conchologia Iconica' a hundred and thirty species, of which scarcely a dozen were known to Lamarck.

The species of Ampulluria are exceedingly well defined, though bearing great general resemblance, and, what is not usual with mollusks affecting such habitats, many of them are stained at the aperture with brilliant colour. The animal is of an amphibious nature, possessing a double system of respiration, which adapts it to breathe either air or water, according to the reçuirements of the place of its habitation, which may be 
at one time flooded and at another dry. In addition to a pair of pectinate gills to which the water passes through a lateral tubular fold of the mantle, there is also a pulmonary sac or lung for breathing air. This peculiarity, observed originally by Mr. Guilding at the Caribbee Islands, was noticed first in detail by M. Caillaud on his return from his expedition to the Nile. It is related by him, that when unpacking in Paris a box of Ampullarice which he had collected four months before in one of the tributaries of the Nile, he threw the specimens into a basin of water to get rid of their oflensive smell; when great was his surprise to sce some of them crawl forth alive. The Ampullarice are, however, water-animals rather than land, the power of respiring through a lung being only a temporary faculty sufficient for the mollusk to survive the occasional drying-up of its more natural element. In 1827, when M. d'Orbigny had collected together at Buenos Ayres some Ampullaria found near the mouth of the river Plata, he tried an experiment with the view of testing the observations which had been made on this subject some few years before in the West Indies by Mr. Guilding. Some of the specimens which he kept alive out of water lived eight months and others thirteen months. Many of the Ampullaria inhabit rivers, but not in parts where there is any rapid flow. Although the shells are mostly of a sombre olive-green colour, the soft parts are often prettily striped and dotted.

The genus furnishes half-a-dozen well-marked subdivisions: A. fasciutu (Ampullaria proper); A. scalaris (Pomus, Humphrey); A. connu-arietis (Ceratodes, Guilding); A. megastoma (Pomella, Gray); A. Botteniana (Lrunistes, De Montford); A. Platce (Ampulloidea, D'Orbigny), the last not having the respiratory tube.

So many new species of Ampullaria have been collected by recent travellers in comparatively few localities, that it is nore than probable the genus abounds to a much larger extent than we have at present any idea of. It does not, however, exist in the great rivers of North America or of north-temperate Europe, ant is peculiar to warm and tropical latitudes.

\section{Species.}

1. adusta, Reeve.

10. Bridgesii, Reeve.

2. Arazonica, $i d$.

11. buxea, $i d$.

19. Columbiensis, Sowerby.

3. ampullacea (Helix) Lin.12. caliginosa, $i d$. 20. compacta, Reeve.

4. aperta, Philippi.

13. canaliculata, Lanarck, 22. conica, Wood.

5. auriformis, Reeve.

14. carinata, Swainson.

21. complicata, id.

6. aurostoma, Lea.

15. Cassidiformis, Reeve.

7. balanoidea, Gould.

16. cerasum, Hanley.

8. bilineata, Reeve.

17. cinerea, Reeve.

9. bulla, $i d$.

18. citreum, $i d$.

23. cornucopia, Reeve.

24. crassa, Swainson.

25. Cubensis, Reeve.

26. Cumingii, King.

27. cuprina, Reeve. 
28. decussata, Moricand. 59. Lattrei, Reeve.

29. depressa, Say.

30. dira, Reeve.

31. Dolioides, $i d$.

32. Dysoni, Hantey.

33. electrina, Reeve.

34. elegans, D'Orbigny.

35. encaustica, Reeve.

36. erythrostoma, $i d$.

37. fasciata, $i d$.

38. figulina, Spix.

39. filosa, Reeve.

40. flatilis, $i d$.

41. fumata, $i d$.

42. Ghiesbrechtii, id.

43. gigas, Spix.

44. glauca (Helix), Linn.

45. globosa, Swainson.

46. Gossei, Reeve.

47. hæemastoma, $i d$.

48. Hanleyi, $i d$.

49. haustrum, $i d$.

50. hepataria, $i d$.

51. Hondurasensis, id.

52. Hopetonensis, Lea.

53. immersa, Reeve.
60. Layardi, $i d$.

61. Linnei, Plitippi.

62. livescens, Reeve.

63. lubrica, $i d$.

64. luteostoma, Swainson.

65. Luzonica, Reeve.

66. Lymnææiormis, $i d$.

67. mosta, $i d$.

68. Malabarica, Philippi.

69. malleata, Jonas.

70. maura, Reeve.

71. megastoma, Sowerby.

72. melanocheila, Reeve.

73. Metcalfei, $i d$.

74. miltocheilus, $i d$.

75. nobilis, $i d$.

76. notabilis, $i d$.

77. nubila, $i d$.

78. nux, $i d$.

79. oblonga, Swainson.

80. olea, Reeve.

81. olivacea, Spix.

82. Oronocensis, Ziegler.

83. ovata, Olivier.

54. insularum, D'Orbigny. 85. papyracea, Spix.

55. intropicta, Reeve.

56. Javanica, $i d$.

57. labiosa, Koch.

86. patula, Reeve.

87. Pernambucensis, $i d$.

88. Physoides, $i d$.

58. Largillierti, Philippi. 89. picta, $i d$.

90. pilula, Reeve.

91. planorbula, Philippi.

92. Platæ (Helix), Maton.

93. polita, Deshayes.

94. porphyrostoma, Reeve.

95. producta, $i d$.

96. prunulum, $i d$.

97. puncticulata, Swains.

98. reflexa, $i d$.

99. Roissyi, D'Orbigny.

100. rufilineata, Reeve.

101. saxea, $i d$.

102. scalaris, D'Orbigny.

103. simplex, Reeve.

104. sordida, Swainson.

105. speciosa, Philippi.

106. Spixii, D'Orbigny.

107. Sprucei, Reeve.

108. Swainsoni, Philippi.

109. teres, $i d$.

110. testudinea, Reeve.

111. trochulus, $i d$.

112. Turbinoides, $i d$.

113. urceus (Nerita), Müll.

114. venetus, Reeve.

115. vermiformis, $i d$.

116. vexillum, $i d$.

117. vittata, $i d$.

118. vitrea (Helix), Born.

119. Yatesii, Reeve.

120. zonata, Spix.

\section{Figure.}

Ampuliarta Oronocensis. Pl. 17. Fig. 90. Shell, showing its globose form, and sombre, olive, horny covering, tinged with blood-red about the aperture.

\section{Genus 2. PALUDINA, Lamarck.}

Animal; with a large mantle and oblong triangular disk, having a hormy operculum, sometimes spiral, sometimes concentric, on a rounded posterior lobe. Head produced into a lengthened 
muzzle, at the base of which are two slencler tentacles, with the eyes sometimes sessile, sometimes on short pedicles.

Shell; wate or conoidal, covered with a sombre-olive epidermis; spire somewhat turreted, often croded; whorts round, smooth or keeled; aperture round or ovate, the margin being mostly continuous, and the lip simple.

The Palutina are smaller and more numerous than the Ampullaria, and more decidedly aquatic. There are few fresh-water streams in any part of the world without them, and in the great river countries of India and America they are especially abundant. The shells are of a similar dull-greenish lhe, and the soft parts, presenting the same contrast of colour and pattern as in the preceding genus, are variously spotted on a coppery or golden ground, while a few are dark blue-black, encircled by a white line.

Some of the Paludince are viviparous, and some are oviparous, and the shells of the young fry are covered more or less with bands of hairs. A small oviparous species, inhabiting our own ditches and canals, was made a genus by Dr. Leach, with the name of Bythinia, and an interesting group dwelling in the brooks and rivers of South America, having their eyes sessile and operculum formed in a spiral, have been arranged in a separate genus by D'Orbigny, under the title of Paludestrina.

\section{Species.}

1. abbreviata, Michaud. 19. contorta, Shuttleworth. 37. Georgiana, Lea.

2. achatina, Lamarck.

20. Coosaensis, Lea.

38. gibba, Michand.

3. acuta, Deshayes.

21. costata, Quoy.

39. gigantea, Busch.

4. altalis, Ravenal.

22. crassa, Nuttall.

40. gigas, Lesson.

5. anatinum, Desh.

23. Cumingii, D'Orbigny.

41. grana, Say.

6. andecola, D'Orbigny.

7. angularis, Miiller.

24. culminea, $i d$.

42. granum, Menke.

8. angulata, Lea.

25. Cyclostomatiformis.

26. cylindrica, Parreys.

43. Haleiana, Lea.

9. atra, Villa.

27. decisa, Say.

44. Hamiltoni, Metcalfe.

10. australis, D'Orbigny. 28. decollata, Sewasch.

45. imperialis, Lea.

11. Bengalensis, Bowdich. 29. diaphana, Michaud.

12. bicarinata, Desm.

30. dissimilis, Say.

46. impura, Lamarck.

13. bicolor, Sowb.

31. doliaris, Gould.

47. incrassata, Lea.

48. inflata, Benson.

14. Boissieri, Charpen.

32. erosa, Ziegler.

49. integra, Say.

33. Ferussacina, Desm.

50. intertexta, $i d$.

15. brevis, Michaud.

34. fontinalis, Phitippi.

16. Bulimoidea, $i d$.

51. Isabelliana, $D^{\prime} \mathrm{Or} b$.

52. Javanica, Busch.

17. Bulimoides, Lamarck. 35. fusca, D'Orbigny.

53. lacustris, Beck.

18. charrana, D'Orbigny. 36. genicula, Conrad.

54. lapidum, D'Orbigny. 
55. lecythoides, Benson. 70. Parreyssii, Pfeiffer.

56. limosa, Say.

57. lustrica, $i d$.

58. magnifica, Conrad.

59. marginata, Michaud.

60. melanostoma, Benson.

61. miliaris, Parreys.

62. multicarinata, Caill.

63. Naticoides, Férussac.

64. nigra, D'Orbigny.

65. nucleus, Thompson.

66. obesa, Philippi.

67. obtusa, Troschel.

68. olivacea, Sowerby.

69. Parchappii, D'Orb.
71. parvula, Guilding.

72. patula, Brumati.

73. peristomata, $D^{\prime} O r b$.

74. Petitiana, $i d$.

75. petrosa, Gould.

76. ponderosa, Say.

77. piscium, D'Orbigny.

78. porata, Say.

79. pulchella, Benson.

80. pyramidata, Busch.

81. radiata, Benson.

82. Remossii, $i d$.

83. rubens, Menke.

84. scalaris, Jay.
85. similis, Michaud.

86. semistriata, D'Orb.

87. striata, $i d$.

88. subcarinata, Say.

89. subpurpurea, $i d$.

90. Swainsoni, Morcle.

91. thermalis, Draparn.

92. tricarinata, Anton.

93. Troostiana, Lea.

94. unicarinata, Sowerby.

95. unicolor, Lamarck.

96. viridis, $i d$.

97. vivipara, $i d$.

98. Warreni, Shuttleworth.

\section{Figure.}

Paludina oxytroris. Pl. 17. Fig. 93. Shell, a fine keeled species, covered with a dark horny epidermis.

\section{Genus 3. VALVATA, Müller.}

Animal; with a short disk, bilobed or forked in front. Head with long slender tentacles, at the outer base of which are situated the eyes, sessile; gill long, plumose, pectinated, partially exserted.

Shell; discoid or turbinated, umbilicated, rather thin; whorls symmetrically tubular, sometimes smooth, sometimes kiceled or striated; aperture circular, with the margin continuous.

In this genus is comprehended a small group of fresh-water mollusks, living on aquatic plants or under stones, in gentle rivers, lakes, and ditches, comparatively minute in size, and having a spiral cyclostomoid shell. Only eleven species are known, and they are all inhabitants of the temperate and north temperate regions of the globe,-chiefly in Europe, and in North America. The animal, of a dusky-grey colour, is not much unlike that of Paludina, except that its eyes are not raised on pedicles, and the shell, without sculpture, is of the same sombre greenish hue, sometimes inclining to yellow. 
Species.

1. alpestris, Shuttleworth. 5. obtusa, Pfeiffer.

9. spirorbis, Draparnand.

2. cristata, Alder.

6. Pupoidea, Gould.

10. tricarinata, Say.

3. Cumingii, Reeve.

7. pygmea, C. B. Adans. 11. trochlea, Dunker.

4. depressa, C. Pfeiffer.

8. sincera, Say.

\section{Figure.}

Valvata Cunirngit. Pl. 17. Fig. 88. Shell, showing a rather more depressed form than is usual in this genus.

\section{Genus 4. LACUNA, T'urton.}

Animal; having a muzale-shaped head, with two long tentacula, bearing eyes or bulgings at the external bases. No neck-lobes; operculigerous lobe expanded or winged laterally, and furnished behind with two filamentary processes, more or less developed, but sometimes nearly obsolete. Foot rounded at both extremities, contracted at the sides, centrally grooved. Branclial plume single.-Forbes.

Shell; subglobosely or elongately turbinated; spire sometimes very short, sometimes prolonged, smooth, covered with an epidermis; columella peculiarly grooved and umbilicated. Operculum semicircular, horny, spiral.

Under this head is comprised a small genus of mollusks, well represented on our own shores, where they live attached to seaweed. The species are few in number, but extremely variable in form; they are however always characterized by the presence of a peculiar grooved umbilicus. In Lacunce pallidula and puteolus the shell is of a globose, wide-mouthed form, with a very small spire, whilst in $L$. cressior and vincta it is oblong and turbinated. The peculiarities of the animal, first noted by Philippi, have becn more fully observed and described by the Swedish conchologist Lovén, and by Edward Forbes. The above-named four species, having various synonyms, inhabit the European coasts, and Dr. Gould describes one as being peculiar to Massachusetts at Chelsea Beach. 


\section{Species.}
1. albella, Lovén.
5. labiosa, Lovén.
8. puteolus, Turton.
2. carinata, Adams.
6. neritoidea, Gould.
9. unifasciata, Carpenter.
3. crassior, Montagu.
7. pallidula, Da Costa.
10. vincta, Montagu.
4. fragilis, Menke.

\section{Figure.}

Lacuna pallidula. Pl. 17. Fig. 89. Shell, of the subglobose form of the genus, showing the characteristic umbilical groove.

\section{Family 12. MELANIANA.}

Shell ; turriculated or glabose, covered with an olive or black epidermis, variously sculptured. Aperture sometimes entive, sometimes notched at the base. Animal fuviatile, furnished with a horny epidermis.

Univalve river mollusks, affecting rapid streams in contiguity with the sea, are numerous in species, but all may be included under this family in three genera. Their shells are for the most part of solid structure, covered with an olive or black horny epidermis, differing essentially in this respect from those of the family Lymnaana, which inhabit more stagnant water; and they have frequent indications of rough usage in being more or less eroded or decollated.

\section{Genus 1. MELANOPSIS, Férussac.}

Animal; similar to that of Melania.

Shell; fusiform or conically cylindrical, generally covered with a black horny epidernis; apex sharp, but often decorticated; columella smooth, often callous at the upper part, and more or less truncated at the lower; aperture rather small, sometimes notched above, conspicuonsly notched below; lip scarcely reflected. Operculum horny, spiral, small.

The shells colleeted under the head of MLelanopsis are distinguished from the Alelenire proper by much the same character as Achatina anong land sholls is distinguished from Bulimus, namely, in being notched at the base, 
and having the columella truncated. The columella is moreover overlaid with enamel, forming a callosity at the upper part. Those species which, like our figured example $M I$. atra, have the aperture notched above as well as below, were separated by Lamarck to form his genus Pirena, but the difference is not material.

The animal of Melanopsis, according to the observations of M. Quoy, is the same cxternally as that of Melunia, and not very far removed from its marine analogue Cerithium.

\section{Species.}
1. atra, Férussac.
8. Dufourii, Férussac.
15. labiata, Sowerby.
2. acicularis, $i d$.
9. erosa, Roth.
16. Neritæformis, Desh.
3. Brasiliensis, Moric.
10. Esperi, Férussac.
17. nodosa, Férussac.
4. Buccinoides, Férussac.
11. Ferussacii, Roth.
19. semigranulosa, Desh.
5. cariosa, Deshayes.
12. fusiformis, Sowerby.
19. spinosa, Deshayes.
6. cornea, Férussac.
13. granulosa (Pirena),Lk. 20. Wagneri, Roth.
7. costata, $i d$.
14. Jordanica, Roth.

Figure.

Melanopeis atra. Pl. 18. Fig. 99. Shell of a remarkably lengthened acicular species, of the Pirena section, showing a notch at the upper part of the aperture as well as at the lower.

\section{Genus 2. MELANIA, Lamarck.}

Animal ; disk short and slight; head proboscis-shaped, subconical, truncated, with the tentacles distant and subulate, having the eyes on the outer side sometimes at the base, sometimes more advanced; mantle fringed. Operculum hormy.

Shell ; more or less turreted, generally wrinkled or nodulous, mostly covered with a black or olive epidermis; spire clongated, generally more or less eroded towards the apex; columella smooth, arched; aperture ovate, entire, sometimes attcmately channelled at the base; lip simple.

In this genus are brought together the very numerous series of elongately convoluted univalve shells which inhabit the great tropical rivers, chiefiy of India, of the islands of the Eastern seas, and of the southern States of North America. Although of that uniform dull olive-colour 
throughout, which is characteristic of their habits, they present a great variety of form and sculpture. Some, as in $M$. subulata, are merely spirally striated, and very sharply acicular; others, like $M I$. amarula, are conspicuously coronated, and the modifications of growth between these extremes are exceedingly numerous and well-defined. Two sections may be noticed as having a stronger title to be distinguished as subgenera than the rest. Those of a dwarfed, solid, globose form (Anculotus, Say), and those in which the aperture is attenuated into a short canal (Io, Lea), as represented at Fig. 98.

As this genus has never been monographed, the list of species which follows is unavoidably very far from complete. Many more are known than have been as yet described.

\section{Species.}

1. acutocarinata, Lea.

2. altilis, $i d$.

3. amarula, Lamarck.

4. annulifera, Conrad.

5. armigera, Say.

6. asperata, Lamarck.

7. aspirans, Hinds.

8. aurita, Rang.

9. Babylonica, Lea.

10. batana, Gould.

11. bellicosa, Hinds.

12. blanda, Lea.

13. Boykiniana, $i d$.

14. caliginosa, $i d$.

15. canaliculata, Say.

16. carinifera, Lamarck.

17. castanea, Lea.

18. catenaria, Say.

19. catenoidea, Lea.

20. Celebensis, Quoy.

21. Cincinnatiensis, Lea.

22. circinata, $i d$.

23. clavæformis, $i d$.

24. coarctata, Lamarck.

25. columella, Lea.

26. comma, Conrad.

27. concinna, Lea.

28. conica, Say.

29. coronata, Philippi.
30. corrugata, Lamarck.

31. costata, Quoy.

32. costulata, Lea.

33. crassa, Philippi.

34. crebristriata, Lea.

35. crenulata, Deshayes.

36. Curreyana, Lea.

37. decollata, Lamarck.

38. decora, Lea.

39. depygis, Say.

40. dubiosa, Lea.

41. Duttoniana, $i d$.

42. ebenum, $i d$.

43. Edgariana, id.

44. elevata, Say.

45. erythrostoma, Quoy.

46. exarata, Lea.

47. fasciolata, Olivier.

48. figurata, Hinds.

49. flammulata, Plitippi.

50. florata, Hinds.

51. Florentiana, Lea.

52. fulgurans, Hinds.

53. fuliginosa, Lea.

54. fumosa, Hinds.

55. funiculus, Quoy.

56. fuscata, Deshayes.

57. fusiformis, Lea.

58. gaudiosa, Hinds.
59. glans, Phitippi.

60. globula, Lea.

61. gracilis, $i d$.

62. granifera, Lamarck.

63. granum, Philippi.

64. Helvetica, Michaud.

65. Hildrethiana, Lea.

66. Holstonia, $i d$.

67. Hydii, Conrad.

68. inermis, Sowerby.

69. inquinata, Defrance.

70. isogonia, Say.

71. Kirtlandiana, Lea.

72. læta, Jay.

73. lævigata, Lea.

74. levissima, Sonverby.

75. laqueata, Say.

76. latebrosa, Hinds.

77. Lecontiana, Lea.

78. lima, Conrad.

79. lineata, Say.

80. lirata, Menke.

81. luctuosa, Hinds.

82. mosta, $i d$.

83. mitra (Helix), Meusch.

84. Moluccensis, Quoy.

85. monozonalis, Lea.

86. multilineata, Say.

87. mutilata, $i d$. 
88. nassula, Conrad.

89. Niagarensis, Lea.

90. Nickliniana, $i d$.

91. nitens, $i d$.

92. nodulosa, $i d$.

93. obovata, Say.

94. obtusa, Lea.

95. occata, Hinds.

96. occidentalis, Lea.

97. Ocoöensis, $i d$.

98. olivata, Conrad.

99. ornata, Plilippi.

100. Papuensis, Quoy.

101. perpinguis, Hinds.

102. picta, Hinds.

103. pilula, Lea.

104. plicatula, $i d$.

105. Plutonis, Hinds.

106. Potosiensis, Lea.

107. prasinata, Conrad.

108. prærosa, Say.

109. pugilis, Hinds.

110. pyramidata, $i d$.

111. Rangii, Deshayes.
112. regularis, Lea.

113. rufa, $i d$.

114. rugosa, $i d$.

115. salebrosa, Conrad.

116. Sayii, Deshayes.

117. scabra, Férussac.

118. scalaris, Wagner.

119. semicarinata, Say.

120. semigranosa, Phil.

121. setosa, Swainson.

122. sordida, Lea.

123. spinosa, $i d$.

124. striatula, id.

125. strigosa, $i d$.

126. subcylindracea, $i d$.

127. subglobosa, Say.

128. subsolida, Lea.

129. subulata, Deshayes.

130. sulcosa, Lea.

131. Taitiana, $i d$.

132. tenebrosa, $i d$.

133. terebra, Philippi.

134. terebralis, Lea.

135. teres, $i d$.
136. testudinaria, Plil.

13\%. tirouri, Férussac.

138. torquata, Plilippi.

139. trilineata, Say.

140. Troostiana, Lea.

141. truncata, Lamarck.

142. truncatula, $i d$.

143. tubereulata, W Wagner.

144. tuberculata, Lea.

145. tympanorum, Desh.

146. undulata, Say.

147. uniformis, Quoy.

148. variabilis, Benson.

149. varicosa, $T$ ard.

150. venusta, Lea.

151. verucosa, Hinds.

152. virgata, Lea.

153. Virginica, Say.

154. virgulata, Férussac.

155. viridis, Lea.

156. Warderiana, $i d$.

157. Winterii, Plitippi.

158. zonata, $i d$.

\section{Figures.}

Melania asperata. Pl. 18. Fig. 97. Shell, illustrating the typical form of the genus, with aperture entire.

Melania spinosa. PI. 18. Fig. 98. Shell, illustrative of the To section of the genus, in which the aperture is attenuated at the base into a canal.

\section{Genus 3. PALUDOMUS, Swainson.}

Animal ; similar to that of Melania.

Shell; ovate, somewhat ventricose; spire short, sometimes depressed, sometimes exserted; columella a little excavated, rather broad, flat, entire at the base, rounded; aperture large, somewhat semicircular, slightly channelled at the upper part; lip simple. Epidermis olive, brown, or black. 
The genus Paludomus was founded by Mr. Swainson in his "Treatise of Malacology,' forming vol. 123 of Lardner's Cabinet Cyclopædia, for the sake of distinguishing an ovate-oblong form of Melania brought from Ceylon by Dr. Sibbald, and of which three species were figured by MIr. Griffith in his edition of Cuvier's 'Animal Kingdom.' The genus has however remained in comparative obscurity from the want of any species being known of sufficiently typical character to make it appreciated. That desideratum has been now supplied by the zeal of Mr. George Gardner (now unfortunately deceased), of the Royal Botanic Gardens of Ceylon, a gentleman much attached to Natural History, and already known to the scientific world by his interesting botanical rescarches and 'Travels in the Interior of Brazil.'

As only one or two species approaching Melania were known, it has been satisfactory to receive such an important typical addition to the group as that afforded by the present series, more especially by the $P$. loricatus, Gardneri, Tenuntii, undatus, pictus, and funiculatus, all of which are characterized by an oval Nerite-like form, which fully entitles them to the generic distinction less significantly arvarded by Mr. Swainson to the Melania-like species.

Like all fresh-water shells, the Patudomi are of a dark sombre colour, always more or less eroded at the apex; the Nerite-shaped species exhibit however a very characteristic waved pattern interiorly in an incipient stage of growth, which in a more advanced state is entirely overlaid by a deposit of colourless matter, when they are further distinguished by a rich chocolatebrown tint of colouring on the columella and edge of the aperture. The animal is probably little more than a modified condition of the Melania, being similar in habit, and having the same black horny operculum of a more triangular form.

Of the following species, thirteen are from Ceylon, two from the Himalayan district of India, and one from Point Palmas, Sumatra.

I am not aware that the genus exists in any of the streams of North America, but it may be said to be represented by Mr. Say's Anculotus, which appears to be as peculiar to the Transatlantic district as Paludomus is to the Ceylonese.

\section{Species.}
1. Chilinoides, Reeve.
6. loricatus, Reeve.
11. spiralis, Reeve.
2. conicus $\left(M e l_{0}\right)$, Gray.
7. Neritoides, $i d$.
3. funiculatus, Reeve.
8. nigricans, $i d$.
12. Stephanus (Mel.), Ben.
4. Gardneri, $i d$.
9. olivaceus, $i d$.
13. sulcatus, Reeve.
5. globulosus (Mel.), Gr. 10. pictus, $i d$.
14. Tennentii, $i d$.
15. undatus, $i d$. 
Figure.

Paludonus undatus. Pl. 18. Fig. 100. Shell, showing its globose Natica-like form.

\section{Family 13. LYMNAANA.}

Shell; thin, mostly transparent, smooth; aperture sometimes very large, sometimes very small, with the lip simple.

The well-known pond and ditch Snails which constitute this family dwell in fresh-water as their proper element, but have the capacity of breathing air, to provide against the emergency of their places of habitation becoming dried up. They are accustomed to rise to the surface of the water to breathe and to take in a supply of air, and are furnished with the means of retaining it for some considerable time.*

In aquaria they have been observed to lower themselves from plants at the water level, by a mucous thread, and to re-ascend by it. The genera are :-

Ancylus. Lymatea. Physa. Planorbis.

Genus 1. ANCYLUS, Geoffroy.

Animal; with a broad head, tentacles triangular, with eyes at their base; mantle simple; disk ovate, large.

Shell; thin, Limpet-shaped, with the vertex rather sharp, incurved posteriorly; aperture oval, very large, simple at the maryin.

The Limpet form of the little Ancylus led to many errors among conchologists before the discovery of its true place in the system. So unlike Lymna a and Planorbis in the absence of convoluted whorls, no one could have supposed the shell to have any immediate relationship with those genera. But. the animal, observed by Guilding and De F'érussac, was found, notwithstanding the difference of its conchological characters, to be nearly the same, and to be affected by the same peculiarities as regards its habits and mode

* Professor Edward Forbes describes that when ascending in sunny weather, the Lymnacance creep, as it were, reversed on the surface, as if the film of water in immediate contact with the air was in a different condition from the fluid beneath, and served as a floor or ceiling on which these mollusks progress. They lay their eggs, he continues, in consistent, transparent, gelatinous masses, on the leaves and stems of water-plants or on stones. 
of breathing. Of our two British species one has been separated as a new genus, Felletia, on account of some minute difference in the tongue. teeth.

\section{Species.}

1. capuloides, Jan.

6. irroratus, Lamarck. 10. oblongus, Lightfoot.

2. concentricus, $D^{\prime} \mathrm{Or} b$.

7. Jacustris, Müller.

11. radiatus, Lamarck.

3. culicoides, $i d$.

8. Moricandi, D'Orbigny. 12. rivularis, Say.

4. fluviatilis, Müller.

9. obliquus, Broderip.

13. spina-rosa, Drapnd.

5. Gayanus, D'Orbigny.

\section{Figure.}

Ancrlus fluviatilis. Pl. 18. Fig. 94. Shell, slıwing its open, Limpetlike form, and sharply incurved top.

\section{Genus 2. LYMN EA, Draparnaud.}

Animal; having a broad head, the tentacles being also broad, with the eyes placed at their inner bases; mantle sometimes reflected over the shell, foot broad, often oblong.

Shell; oblong or ovate, sometimes turriculated, smooth, horny, spire sharp, aperture mostly large, lip simple.

In this genus are included two very fairly defined groups, known respectively as Lymnaa proper, and Amphipeplea. Of the first, our common British $L$. stagnalis is a good typical species, the shells being mostly. light and largely inflated, though some have a narrow turriculated growth, and are thicker in substance. The second group, of which there are many foreign species not as yet described, is distinguished by an inflated shell of a shorter Bulla-like form, over which the animal, as in that genus, more or less reflects the mantle.

The Lymnce inhabit ponds, lakes, and quiet streams, in all parts of the world, being of a dull uniform horny substance, with little or no variation of colour.

\section{Species.}
1. acuminata, Lamarck.
6. Burnettii, Alder.
11. elongata, $i d$.
2. impla, Mighels.
7. catascopium, Say.
12. emarginata, $i d$.
3. ampullacea, Rossm.
8. columellus, $i d$.
13. fragilis, Pulteney.
4. appressa, Say.
9. desidiosa, $i d$.
14. fusca, Pfeiffer.
5. auricularia, Drapnd.
10. clodes, $i d$.
15. gingivata, Goupil. 
16. glaber, Miüler.

17. glutinosa, $i d$.

18. gracilis, Jay.

19. humilis, Say.

20. intermedia, Férussac.

21. invòluta, Harvey.

22. Lessoni, Deshayes.

23. lnteola, Lamarck.

24. macrostoma, Say.

25. marginata, Michaud.

26. megastoma, Say.

27. membranacea, Porro.
28. minuta, Drapnd.

29. Moravica, Parreys.

30. ovalis, Gray.

31. ovata, Drapnd.

32. palustris, $i d$.

33. papyracea, Spix.

34. peregra, Draparnaud. 45. turrita, $i d$.

35. reflexa, Say.

36. rufescens, Gray.

37. rugata, Ziegler.

38. Sicula, Parreys.
39. stagnalis, Draparnaud. 40. strigata, Parreys.

41. subglobosa, Sowerby.

42. succinea, Deshayes.

43. Timorensis, Sowerby.

44. truncatula, Mïller.

46. umbrosa, Say.

47. Virginiana, Lamarck.

48. viridis, Quoy.

4. Z. Ziegleri, Pfeiffer.

\section{Figure.}

Lymnæa STAGNalis. Pl. 17. Fig. 92. Shell, showing its light horny substance and inflated growth.

\section{Genus 3. PHYSA, Draparnaud.}

Animal ; having a broad head, with the tentacles subulate or setaceous, with the eyes placed at their inner bases; foot lanceolate; mantle lobed or simple.

Shell; oblong or ovate, mostly sinistral and polished; spire sharp; aperture frequently oblong-triangular, lip simple.

The animal of Physa varies from the typical form of that of Lymnea, in lhaving the foot lanceolate and the tentacles more slender. The shell may be best distinguished by its being mostly sinistral, and in liaving a polished porcellanous surface. The species are of a darker horn-like colour, and affect the same habitats.

A British species, in which the mantle of the animal is not lobed, has been made genus Aplexus, and a few in which there is an inclination in the columella of the shell to be truncated, after the manner of Achatina, have been separated under the generic title of Physopsis.

Speaking of the Pliysa fontinalis, Professor Forbes says :- "The animal is of a pale yellowish-grey, darkening in individuals to a decp-fuscous hue. Its tentacles are long and slender, with conspicuous black eyes at their inner basis. The mantle is highly contractile, and, when expanded, envelopes a great part of the shell (indicated by its polished surface), and is divided at the edge into finger-like processes. It is bilobed, th ceolu- 
mellar division having more digitations, usually five, than that which is projected over the spire. The foot is obtusely angled in front and pointed behind. It does not appear that there are any essential differences distinguishing the animals of the different varieties. They all advance with a jerking motion."

\section{Species.}
1. acuta, Draparnaud.
8. fontinalis, Drapnd.
15. Mangeriæ, Gray.
2. alba, Turton.
9. Georgiana, Quoy.
16. Novæ-Hollandiæ, Blvl.
3. aurea, Lea.
10. Guerinii, Mittre.
17. Peruviana, Gray.
4. castanea, Lamarck.
11. gyrina, Say.
18. rivalis, Soxerby.
5. contorta, Michaud.
12. heterostropha, $i d$.
19. subopaca, Lamarck.
6. elliptica, Lea.
7. elongata, Say.
13. hypnorum, Linnæus.
20. Tongana, Quoy.
14. Ludoviciana, Mittre.
21. truncata, Férussac.

Figure.

Physa Mangerie. Pl. 17. Fig. 91. Shell, showing its triangularly ovate form, and dark porcellanous shining surface.

\section{Genus 4. PLANORBIS, Guettard.}

Animal; having a stout broad proboscis-like head, with two slender tentacles, with eyes at their inner bases; foot short and obtuse. Shell; discoid, with a depressed spire, with the apex more or less sunk in a concavity; whorls rounded, sometimes keeled, with the aperture mostly semilunar; lip simple.

We have seen how puzzled conchologists were as to the affinities of Ancylus, owing to the Limpet-like form of its shell. Similar difficulty occurred originally with Planorlis; the shell being distinguished by the same peculiarity of the whorls coiling upon each other in a discoidal plane as in the fossil Ammonites. Cuvier was the first to determine anatomically the affinity of Planorlis with Lymnaa and Physa, as suggested by their similarity of habit; and so uniform in character are its numerous species, that no subgenus has been proposed worth recording.

The animal of Plannrlis is rather variable in colour, black or slate, or chestnut or yellowish, or yellow dotted on a dark-fuscous ground. The shell is mostly of a livid-slate or greenish-horny colour, inclining to yellow. 
It dwells abundantly in the rivulets and pools of Europe and North and South America, and also of China and Hindostan.

\section{Species.}

1. albus, Miüler. 18. elevatus, Adams.

2. Alexandrinus, Ehrenb. 19. exacutus, Say.

3. anatinus, D'Orbigny. 20. exustus, Deshayes.

4. Andecolus, $i d$.

5. armigerus, Say.

6. bicarinatus, $i d$.

7. campanulatus, $i d$.

8. carinatus, Aiüller.

9. complanatus, Lam.

10. contortus, Müller.

11. coretus, Adanson.

12. corneus, Draparnand.

13. cristatus, $i d$.

14. deflectus, Say.

15. deformis, Lamarck.

16. devians, Porro.

17. dilatatus, Pfeiffer.
21. ferrugineus, Spix.

22. glaber, Jeffreys.

23. Guadaloupensis, Sow. 40. olivaceus, Wagner.

24. heliciformis, Roth. 41. orientalis, Lamarck.

25. heloicus, D'Orbigny. 42. parallelus, Say.

26. heliophilus, $i d$.

27. hirsutus, Gould.

28. hispidus, Draparnand. 45. peregrinus, D'Orb.

29. imbricatus, Miiller. 46. Peruvianus, Broderip.

30. Kermatoides, D'Orb. 47. spirorbis, Miuller.

31. lacustris, Lightfoot. 48. tenagophilus, D'Orb.

32. lentus, Say.

33. leucostoma, Millet. 50. trivolvis, Say.

34. lugubris, Wagner. 51. vortex, Müller.

\section{Figure.}

Planoris corneus. Pl. 17. Fig. 57. Shell, showing its horny substance, discoid convolution of the whorls, and semilunar aperture.

\section{Family 14. AURICULACEA.}

Shell; ovate, with the columella toothed or strongly plaited; aperture oval, with the lip mostly thickened and toothed or warted within.

The Auriculacea, like the family Lymnceana, live in stagnant water and yet breathe air, but they live much more out of water, in damp and moist places, in swampy vegetation, among the roots of marsh trees; and they mostly affect places bordering on the sea and within range of brackish water. Their shells are consequently of more solid growth, and present more brightness and variety of colour. The genera are

Chilina.

Scarabus.

Auricula. 


\section{Genus 1. CHILINA, Gray.}

Animal; rather large, depressed; head flattened, with two angular tentacles, having the eyes situated about the middle; foot broad, with a fold of the mantle projecting beyond it.

Shell; ovate, inflated, with the spire sometimes turriculated; columella sharply plaited; aperture entire at the base, lip thin.

The Chitina are a group of mollusks peculiar to South America, dwelling, not in stagnant water, but in running, limpid streams, not attached to plants, but to fragments of rock and stones below the surface. They present an interesting link between the Auricula and Lymncee, and are regarded by some authors as merely a subgenus of the latter. Both shell and animal are, however, peculiar. The shells are of a uniform greenisholive colour, with bands of markings, having the columella sharply plaited; and the animal presents a difference in the tentacles and in the development of the mantle.

\section{Species.}

1. ampullacea, Sowerby.

2. bulloides, D'Orbigny.

3. Dombeyana, Sowerby.

4. fluctuosa, Gray.

5. Huminea, $i d$.
6. fluviatilis, Gray.
11. Puelcha, D'Orbigny.
7. gibbosa, Sowerby.
12. robustior, Soverby.
8. major, $i d$.
9. ovalis, $i d$.
13. Tehuelcha, D'Orbigny.
14. tenuis, Gray.
10. Parchappii, D'Orbigny.

\section{Figure.}

Cinlina antpullacea. Pl. 19. Fig. 105. Shell, with olive-green-spotted epidermis, showing its thin columellar plait.

\section{Genus 2. SCARABUS, De Montford.}

Animal; simitar to Auricula.

Shell; ovate, with the spire obtusely pyramidal, and the whorls peculiarly depressed, each forming a varix on either side, anid the last being sometimes abruptly turned at the base to form an angle; aperture oval, expanded, prominently wart-toothed on both sides. 
De Montford, though a bit of a charlatan in the literature of conchology, founded some very excellent genera, with this among the number. The Scarati, of which many more species are known than are named, are all of the same pyramidally ovate solid growth, and agree to a considerable extent in painting, but the character which entitles them cliefly to rank as a genus, is the presence of a row of varices on either side, coupled with a striking uniformity in the construction and dentition of the aperture.

According to the observations of Mr. Arthur Adams in Borneo and Celebes during the voyage of the 'Samarang;' the Scarali are wholly terrestrial, inhabiting moist spots in woods, and feeding on decayed vegetable matter among the tree-roots or under dry stones.

\section{Species.}

1. castaneus, Lesson.

2. Cumingianus, Petit.

3. imbrium, IIontford.

4. lekithostoma, Reeve.
5. Lessoni, Blainville.

6. Petiverianus, Férussac.

7. plicatus, $i d$.

8. pyramidatus, Reeve.
9. striatus, Reeve.

10. trigonus, Troshel.

11. undatus, Lesson.

\section{Figure.}

Scarabus imbrium. Pl. 19. Fig. 104. Shell, showing its solid obtusely pyramidal growth, with the lateral varices, and peculiar warttoothed aperture.

\section{Genus 3. AURICULA.}

Animal; head broad and short, having two tentacles, with eyes at their imner bases; mantle thickened at the edge; foot oblong. Shell; ovate, or ovate-oblong, rather solid, covered with a brown epidermis; columella either toothed or strongly plaited; aperture longitudinally ovate, rounded and entire at the base, with. the lip sometimes simple, sometimes thickly reflected.

The Auricula, which have been long known to naturalists by the only two species even now discorered of any material size, the Midas' and Judas' Ears, may be said to be the land or marsh representatives of the marine Volutes. They comprise the few shells among the pulmo-branchiate, or air-breathing mollusks, that have strong plaits winding round the columella, and they are never chamnelled at the base, as is the case with the 
genera of carnivorous proboscis-armed sea mollusks in which the columella is plaited.

Externally the shell of Auricula is usually dark chestnut-brown, occasionally banded, and often wrinkled; internally the teeth and plaits, which are essentially conspicuous, are sometimes brightly coloured.

The Auricule abound chiefly in the swampy islands of the Eastern seas. Only two small species have been found in England.

The best-established subgenera of the group are Melampus, Pellipes, and Carychium.

\section{Species.}

1. acuta, D'Orbigny. 16. felis, Lamarck.

31. monile, Lamarck.

2. alba, Gray.

17. Firmini, Payraudeau.

32. mustelina, Deshayes.

3. angulifera, Petit.

18. frumentum, Guillou.

33. myosotis, Draparnaud.

4. angistoma, Deshayes.

19. fuscagula, Lea.

34. myotis, Nuttall.

5. auricella, Férussac.

20. globulus, D’Orbigny.

21. Judæ, Lamarck.

35. nitens, Lamarck.

6. australis, Quoy.

22. labrella, Deshayes.

36. nucleus, Férussac.

7. avena, Guillou.

23. lineata, Draparnaud.

37. pallida, Gray.

8. bidentata, Montagu.

24. livida, Deshayes.

9. biplicata, Deshayes.

25. lutea, Quoy.

38. Pepita, Pfeiffer.

10. borealis, Conrad.

26. Malchi, Mïller.

39. personata, Michaud.

11. coniformis, Lamarck.

12. cornea, Deshayes.

27. marginata, Deshayes.

40. reflexilabris, $D^{\prime}$ Orb.

41. rugata, Menke.

13. costata, Quoy.

28. Micheli, Mitire.

14. denticulata, Montagu. 29. Midæ, Lamarck.

42. Sileni, Lamarck.

15. fasciata, Deshayes.

30. minima, Draparnaud.

43. stagnalis, D'Orbigny.

44. subula, Quoy.

45. uniplicata, Mittre.

\section{Figure.}

Auricula Midæ. Pl. 19. Fig. 103. Shell, with its solid growth and chestnut-brown epidermis, showing the strongly plaited columella and rounded base.

\section{Family 15. CYCLOSTOMACEA.}

Shell ; depressed, globose, turreted, smouth, wilh the lip mostly reflected, sometimes notched or figured at the maryin; operculum horny or calcareous. 
In the families Cyclostonacea and Colinacea are included the extensive series of Land Snails, which, since Lamarck's time, has increased from about two hundred and fifty species to upwards of five thousand. The conchologists of Germany, more especially Dr. Pfeiffer of Cassel, owing perhaps to their inland position, have worked almost exclusively during the past ten years upon land shells; and encouragement lias been given far and wide to travellers, particularly to plant-collectors, in all comntries to look well after Suails. The researches of Mr. Cuming, both in the arid plains of Chili and in the rich woods of the Philippine Islands, have added to our stores of land shells to an extent almost unprecedented in any branch of natural history; and many scarcely less zealous collectors have contributed to enrich our cabinets from the vast territories of Brazil, Bolivia, and Venezuela, and from India, Australia, and the Western Isles. It may seem strange that natural history should have occupied, more or less, the attention of men's minds since the tiane of Lristotle, and that the land snails, the most readily accessible of all shells, should have so long dwelt in obscurity; but the philosopher might ask, with nearly as much show of reason, how comes it to pass that the world has existed for more than six thousand years, - according to Baron Bunsen, twenty thousand,and it is only now that we have discovered the use of steam-engines, electric telegraphs, and lucifer matches. Snails, of one sort or another, inhabit all lands, and being of sluggish habit the types of form are very local. Who then shall say that even the number of species known up to the present time is not very far short of the actual existence of mollusks on land, seeing that they scarcely amount to the average proportion of a single species to every area of 2000 square miles?

The Cyclostomacea, numbering, according to the latest conchological census, about 1150 species, differ from the great bulk of the land shells included under the head of Colinaceu, in being opereulated and inclining to amphibious habits. They affect damper situations, and some live partially in water. Dr. Pfeifier distributes the Cycloslomacea into forty-three genera, indicated in our lists of species as subgeneric divisions of tie fullowing :-
Helicina.
Cyclostoma.
Truncatelila.
Stonstoma.
Pupina.
Geomelania.

\section{Genus 1. HELICINA, Lamarck.}

Animal; similar to that of Cyclostoma.

Shell; depressly globose, with the spire mostly rather sharp, generally smooth; aperture semiorbicular; lip reftected, sometimes 
indented with a stit or fissure near the columella, which is callous at the base; operculum horny, sometimes a little calcareous, not spiral.

A series of prettily painted, bright-coloured little shells, including, besides Helicina proper, the subgenera Alcadia, Schasicheila, Lucidella, and Trochatella of authors, are classed under this head. Only four species were known to Lamarck. Now we have more than 270. By far the greater number are inhabitants of the West Indies and Central America; a few are from the Pacific, Feejee, and Philippine Islands.

A character to be noted in this genus is that the operculum is never spiral. It is mostly horny, sometimes a little calcareous. A few of the Helicina are characterized by a slit in the margin, which, as in Pupina, is not unfrequently filled up with enamel.

\section{Species.**}

1. acuminata, Velasq. 24. Blandiana, Gundl.

2. acuta, $P f r$.

3. acutissima, Soro.

4. Adamsiana, Pfr.

5. adspersa, $i d$.

6. agglutinans, Sorv.

7. albocincta, Jacq.

8. albolabris, $i d$.

9. amœna, Pfr.

10. ampliata, $A d$.

11. angulata, Sow.

12. Antillarum, $i d$.

13. Antoni, Pfr.

14. arenicola, Mor.

15. articulata, Pfr.

16. aurantia, Gray.

17. Barbadensis, Pfr.

18. Bastidana, Poey.

19. Bayamensis, id.

20. beryllina, Gould.

21. Besckei, Pfr.

22. biangulata, $i d$.

23. bicolor, $i d$.
25. Brasiliensis, Gray.

26. brevilabris, $P f r$.

27. Briarea, Poey.

28. bulla, Pfr.

29. Candeana, D'Orb.

30. caracolla, Moric.

31. carinata, $D^{3} \mathrm{O} \cdot \mathrm{b}$.

32. Catalinensis, Pfr.

33. Chiapensis, id.

34. chrysochasma, Poey.

35. chrysocheila, Binn.

36. chrysocheila, Shutt.

37. ciliata, Poey.

38. cinctella, Shutt.

39. cingulata, $P f r$.

40. citrina, Grat.

41. Columbiana, Phil.

42. columellaris, Gundl.

43. concentrica, $P f r$.

44. concinna, Gundl.

45. conoidea, $P f r$.

46. convexa, $i d$.
47. Cordilleræ, sallé.

48. cornea, Sow.

49. costata, Gray.

50. crassilibris, Phil.

51. Cumingiana, $P f r$ 。

52. delicatula, Shutt.

53. denticulata, Pfr.

54. depressa, Gray.

55. diaphana, Pfr.

56. Dominicensis, $i d$.

57. Draytonensis, $i d$.

58. Dysoni, $i d$.

59. egregia, $i d$.

60. elata, Shutt.

61. elongata, D'Orb.

62. exigua, Pfr.

63. exigua, Jacq.

64. fasciata, Lam.

65. festiva, Sow.

66. flammea, Quoy.

67. flavida, Menke.

68. foveata, Pfr.

69. fragilis, Mor.

* The Land Shells having been recently described by Dr. Pfeiffer, it is intended to give the list of species from his mouographs, regarding his genera as subgenera. 
70. fulgora, Gould.

71. fulva, $D^{\prime} O r b$.

72. Funcki, Pfr.

73. Ghiesbreghti, $i d$.

74. glabra, Gould.

75. globosa, Gray.

76. globulosa, D'Orb.

77. goniostoma, Sow.

78. gonochila, $P f r$.

79. Gouldiana, Forb.

80. granum, $P f r$.

81. gratiosa, $i d$.

82. Guadaloupensis, Sow.128. Norfolkensis, Pfr.

83. hæmastoma, Moric. 199. notata, Sallé.

84. Hanleyana, Pfr.

85. Heatei, $i d$.

86. Heloisæ, Sallé。

87. Hjalmarsoni, Pfr.

88. humilis, Jacq.

89. Idæ, Pfr.

90. inconspicua, $i d$.

91. intusplicata, $i d$.

92. Jamaicensis, Sow.

93. jugulata, Poey.

94. Kieneri, Pfr.

95. Küsteriana, $i d$.

96. laciniosa, Migh.

97. Lazarus, Sow.

98. Lambeyana, Poey.

99. lens, Lea.

100. lenticularis, Sox.

101. Lindeni, $P f r$.

102. lineata, $A d$.

103. lirata, $P f r$.

104. livida, Jac.

105. Louisiadensis, Forb.

106. Lundi, Beck.

107. lutea, Less.

108. Macgillivrayi, $P f r$.

109. maculata, Soro.

110. margaritacea, Less.

111. Mangeriæ, Gray.

112. maxima, Sow.

113. Mayarina, Poey.

114. merdigera, Shutt.

115. Merguiensis, $P f r$.
116. microdina, Mor.

117. miniata, Less.

118. minuta, Sow.

119. modesta, $P f r$.

120. Moquiniana, Recl.

121. Moreletiana, Pfr.

122. multicolor, Gould.

123. musiva, $i d$.

124. neritella, Lam.

125. Nicobarica, Phil.

126. nitida, $P f r$.

127. nobilis, $A d$.

130. occidentalis, Guild.

131. oculata, Say.

132. oleosa, $P f r$.

133. orbiculata, Say.

134. Orbignii, Pfr.

135. oresigena, $D^{\prime} O r b$.

136. Oweniana, Pfr.

137. oxytropis, Gray.

138. pallida, Gould.

139. parva, Sow.

140. pellucida, $i d$.

141. phasianella, $i d$.

142. pictella, Pfr.

143. pisum, Phil.

144. pisum, Jacq.

145. platychila, Muhlf.

146. plicatula, $P f r$.

147. pulcherrima, Lea.

148. pygmæa, Pot.

149. pyramidalis, Sow.

150. Reeveana, Pfr.

151. repanda, $i d$.

152. retracta, Poey.

153. rhodostoma, Gray.

154. riparia, Pfi.

155. Rohri, $i d$.

156. rostrata, Mor.

157. rotella, Sow.

158. rotelloidea, Migh.

159. rotundata, $D^{\prime} O r b$

160. rubromarginata, Gdl. 206. Sumbonata, Shutt.

161. rudis, Pfi.
162. rufa, $P f r$.

163. rugosa, $i d$.

164. rustica, $i d$.

165. Sagraiana, D'Orb.

166. Salleana, $P f r$.

167. Sandozi, Shutt.

168. Sandwichiensis, Sorb.

169. sanguinea, $P f r$.

170. scopulorum, Mor.

171. Shanghaiensis, Pfr.

172. silacea, Mor.

173. similis, Sowo.

174. sinuosa, $P f r$.

175. solidula, Gray.

176. sordida, King.

177. Sowerbyana, Pfr.

178. sphæroidea, $i d$.

179. spinifera, $i d$.

180. Sprucei, $i d$.

181. Stanleyi, Forb.

182. straminea, Mor.

183. striata, Lan.

184. striatula, Pot.

185. striatula, Sow.

186. suavis, $P f r$.

187. subdepressa, Poey.

188. subfusca, Menke.

189. subglobulosa, Poey.

190. sublævigata, $P f r$.

191. submarginata, Gray.

192. substriata, $i d$.

193. sylvatica, $D^{\prime} O r b$.

194. tæniata, Quoy.

195. Tamsiana, Pfo.

196. tenuis, $i d$.

197. Tilei, $i d$.

198. Titanica, Poey.

199. trochiformis, Sovo.

200. trochlea, Gould.

201. trochulina, $D^{\prime} O r b$.

202. tropica, Jan.

203. turbinata, IVieg.

204. turbinella, Pfr.

205. uberta, Gould.

207. unidentata, Pfr. 
209. unifasciata, Gray. 209. variabilis, $\mathrm{T} \mathrm{Vag}$. 210. vernalis, Mor. 211. versicolor, Pfr.

\section{Brownei, Gray.}

221. capax, Gundl. 222. citrino-labris, $A d$. 22. consanguinea, $i d$. 224. dissimulans, Poey. 225. dubiosa, $A d$. 226. Grossei, $P f r$. 227. Gundlachi, $i d$.

213. aureola, Féruss.
212. vestita, Guild.

213. velosa, Ant.

214. vinosa, Sluutt.

215. virens, $P f r$.
216. viridis, Lam.

217. zebriolata, $P f r$. 218. zephyrina, Ducl. 219. zonata, Less.

Subgenus Alcadia, Gray.

228. hirsuta, $A d$.

229. hispida, Pfr.

230. Hollandi, $A d$.

231. macilenta, $i d$.

232. major, Gray.

233. megastoma, $A d$.

234. micrastoma, $i d$.

235. minima, $D^{\prime} O r b$.
236. palliata, $A d$. 237. pusilla, $i d$.

238. rhamphostyla, $P f$. 239. rubella, $i d$. 240. solitaria, $A d$. 241. succinea, $P f r$. 242. velutina, Poey.

\section{Subgenus Lucidelia, Swainson.}

\section{Subgenus Schasicheila, Shuttleworth.}

245. alata, Menke.

246. Nicoleti, Shutt. 247. pannucea, Mor.

Subgenus Trochatella, Swainson.

248. callosa, Poey. 2.49. capillacen, $P f r$. 250. Chittyana, $i d$. 251. chrysostoma, Shutt. 252. conica, Pfr. 253. constellata, Mor. 25. dilatata, Poey. 25ั. elegantula, Pfr. 256. excavata, $i d$. 257. Gouldiana, id.

258. Grayana, $i d$.
259. hians, Poey.
260. Josephinæ, Ad.
261. luteo-apicata, Poey.
262. opima, Shutt.
263. Petitiana, D'Orש.
264. petrosa, Gundl.
265. politula, Poey.
266. pulchella, Gray.
267. regina, Mor.

268. rubicunda, Gundl. 269. rupestris, $P f r$. 270. semilirata, $i d$. 271. Sloanei, D'Orb. 272. stellata, $V e l$. 273. subunguiculata, Poey. 274. Tankervillei, Gray. 275. tenuis, $A d$. 276. virginen, Lea.

\section{Figure.}

Helicina agglutinans. Pl. 19. Fig. $101 a$, $b$. Shell, showing at Fig. 1016 a peculiarity in the animal of agglutinating small pebbles to the periphery of the whorls after the manner of the Carrier Trochus. Fig. 101 a. Shell, denuded of the pebbles, showing the form of the aperture.

\section{Genus 2. StOAstoma; C. B. Adams.}

Animal; disc oblon!, rather acmminately produced at the linder extremity; head forming a truncated snout, and furmished with 
two small tentacles; colour dark bottle-yreen, inclining to black. Shell; globose or conic, sometimes a little depressed, spirally variously sculptured, the whorls being mostly rounded, in a few instances slightly angled, last whorl sometimes very much produced; umbilicus sometimes concealed; aperture small, somewhat semicircular.

The genus Stoastoma was founded by the late Professor C. B. Adams, about ten years since, for the reception of a few exceedingly minute shells inhabiting Jamaica, Porto Rico, and probably some other of the West India Islands. As the name of the first discovered type, Stoastoma pisum, implies, they are like microscopic peas, globose and subdiscoidal in form, with a small semicircular aperture, presenting good subgeneric differences, and soine marvellous varieties of sculpture. About twenty species, named in honour of various conchological friends, were defined by Professor Adams, but that number has been increased to eighty by Mr. Edward Chitty, formerly of Jamaica, who has described his specimens in the Proceedings of the Zoological Society, and liberally deposited them, together with the rest of his West Indian collection, in the British Museum. Mr. Chitty's attention being specially called to the little Stoastoma Wilkinsonianum, by Professor Adams, whilst on a visit to Jamaica, he found it to agree with a minutc shell picked up by him in his garden some time previously, and determined to search for more. "I ransacked my garden," snys Mr. Chitty, "and all round in vain; for, as I now conclude, it had been brought there accidentally, perhaps by a bird; till at last I crossed a deep ravine, a streamlet at the bottom of it, and got to one side of what we call 'Little Yallahs Hill,' which stands a good half-mile crowfly from my garden. There I found a spot, a slope on the hillside, with crumbling fine dirt running, or sifting as it were, down it." In this dirt, he goes on to relate that he found plenty of $S$. Willininsonianum and other new species, and continues:- "The formation of Jamaica being mostly tertiary limestone, out of about a quart of such dirt as this I have taken dozens and dozens of minute specimens of no less than thirty-one species, besides larger ones which the naked eye could well see,-probably upwards of fifty species from one quart of dirt altogether!"

Mr. Chitty means, doubtless, a quart of dirt made up from different localities; for in describing the geographical distribution of the Stoastomata, lie states that five or six species may be found to inhabit a certain spot, and that you may search in vain for them outside a circumference of about three-fourths of a mile:

We give the species grouped according to Mr. Chitty, adopting his genera as subgenera. 
Species.

1. Livesayanum, $C h$. 3. pisum, $A d$. 4. succineum, Sow.

2. Pfeifferianum, $A d$.

Subgenus Blandia, Chitty.

5. Bairdianum, $\mathrm{Cl}$.

8. Jeffreysianum, $C h$. 11. Macgillivrayi, $C h$.

6. Blandianum, $i d$.

9. Loweanum, $i d$.

12. Traillianum, $i d$.

7. Hillianum, $i d$.

10. Lukisianum, $i d$.

13. Troschelianum, $i d$.

Subgenus Fadyenia, Chitty.

14. Bowerbankianum. Cl. 15. Fadyenianum, $A d$. 16. Grayanum, $C h$.

Subgenus Lewisia, Chitty.

17. Agassizianum, $C h$. 19. Philippianum, $A d$. 20. Woodwardianum, $C h$.

18. Macandrewianum, $i d$.

\section{Subgenus Lindleya, Chitty.}

21. Albersianum, $\mathrm{Cl}$.

22. Alderianum, $i d$.

23. Arthurianum, $i d$.

24. Boisserianum, $i d$.

25. Bridgesianum, $i d$.

26. Dennisonianum, $i d$.

27. Fischerianum, $i d$.

28. Gaskoinianum, $i d$.

29. Gutierezianum, id.
30. Henryanum, $C h$.

31. Jayanum, $A d$.

32. Leanum, $i d$.

33. Lindleyanum, $i d$.

34. Moricandianum, $i d$.

35. Newcombianum, $C l$.

36. Orvenianum, $i d$.

37. Pickeringianum, $i d$.
38. Poeyanum, $\mathrm{Ch}$.

39. Polyblankianum, $i d$.

40. Redfieldianum, $A d$.

41. Reeveanum, $\mathrm{Ch}$.

42. Ruesseanum, $i d$.

43. Salleanum, $i d$.

44. Shuttleworthianum, id.

45. Wollastonianum, $i d$.

Subgenus Metcalfeia, Chitty.

46. Bacquieanum, Ch.

47. Chittyanum, id.

48. Dorhnianum, $i d$.

49. Layardianum, $i d$.

ธ7. Adamsianum, $C h$.

58. Anthonianum, $i d$.

59. Barronianum, $i d$.

60. Carpenterianum, $i d$.
50. Metcalfeianum, $C h$.

51. Mitchellianum, $i d$.

52. Morchianum, $i d$.

53. Sinclairianum, $i d$.

\section{Subgenus Petritia, Chitty.}

61. Cumingianum, $A d$. 65. Stevensianum, $C h$.

62. Fortuneanum, Ch. 66. Stokesianum, $i d$.

63. Grevilleanum, $i d . \quad 67$. Stricklandianum, $i d$.

64. Petitianum, $A d$. 68. Taylorianum, $i d$.

\section{Subgenus Wrlkinsonea, Chitty.}

69. Abbottianum, $C h$.

74. Hanleyanum, $\mathrm{Ch}$. 78. Moussonianum, $\mathrm{Ch}$.

70. Bensonianum, $i d$.

75. Hollandianum, $A d$. 79. Schomburgkianum, $i d$.

71. Dysonianum, $i d$.

76. Jardineianum, $\mathrm{Cl}$.

80. Tappanianum, $A d$.

72. Gouldianum, $A d$.

77. Laidlawianum, $i d$.

81. Wilkinsonianum, id.

73. Greenwoodianum, $C h$. 
Figure.

For an illustration of this genus see woodcut in Mr. Chitty's paper in the Proceedings of the Zoological Society for 1857, p. 166.*

\section{Genus 3. CYCLOSTOMA, Lamarck.}

Animal; with a proboscis-shaped musale, and two subulate tentacles, with the eyes at their external bases; foot ovate, furnished with an operculum sometimes hormy, sometimes calcareous, fitting close to the aperture, in some instances formed of several whorls.

Shell; globosely turbinated, sometimes cylindrically turreted, forming, not unfrequently, an open perspective umbilicus; whorts round, mostly spirally sculptured, with the lip expanded and reflected, rarely simple.

Of all the genera of land shells this is the most comprehensive in respect of form and variety of structure. It contains shells globose and widely umbilicated, and shells cylindrical convoluted so closely as to show scarcely a trace of an umbilicus ; and there are peculiarities of character attaching to the lip in many of the species which present good distinguishing characters for subgeneric division. The species known to this date are 720 in number, distributed into as many as forty natural groups; and we only regret that the limits of this elementary work will not admit of their being separately characterized. All are operculated, and in some species the operculum consists of several distinct whorls.

Owing to the roundly turbinated form of the shell, and to the presence of an operculum, the Cyclostomata known to Linuæus were not placed by him in his genus Helix, but in Turbo; and notwithstanding the difference of habits, the animal has an evident relationship, not yet fully understood, with Littorina, and some other of the pectinate-gilled mollusks. Their geographical range is mainly tropical, only one small species being found in Britain.

* The gushing enthusiasm with which Mr. Chitty has complimented his "bosom friends" in the foregoing harlequinade of proper names, identifying their memory not only with the titles of species but of geuera, renders the list of Stoastomata rather grotesque. However much Mrs. Metealfe may be delighted at hearing Mr. Metcalfe dilate upon the beauty of his Metcalfein Metcalfeiana, we can fancy the astonishment of Mr. Wilkinson at being presented by Mrs. Wilkinson with two lovely Wilkinsonee Wilkinsoniane; and the familiarity with which Mrs. Wilkinson is brought into generic association with Sir Robert Schomburgk, Dr. Gould, and Mr. Hanley in the names Wilkinsonaa Schomburgkiana, Gouldiana, and Hanleyana, is suggestive of flirtations that can scarcely be tolerated with propriety in the conchological nomenclature. 


\section{Species.}

1. Abeillei, Grat.

2. album, Sow.

3. articulatum, Gray.

4. asperum, Potiez.

5. Banksianum, Sow.

6. Barclayanum, Pfi.

7. Belairi, Petit.

8. bicarinatum, Sow.

9. Boivini, Pfi.

10. Bronni, $A d$.

11. buccimulum, Bolt.

12. calcareum, Pfi。

13. campanulatum, $i d$.

14. carinatum, Born.

15. cariniferum, Sow.

16. Carolinense, $P f r$.

17. castaneum, $i d$.

18. castum, $i d$.

19. Chevalieri, $A d$.

20. chloroticum, Pfr.

21. concinnum, Sow.

22. citrinum, $A d$.

23. costulatum, Ziegl.

24. crenulosum, $A d$.

25. Creplini, Dunk.

26. Cuvierianum, Petit.

27. deliciosum, Féruss.
68. pulchellum, Sovv.

69. pulchrum, Gray.

70. pyrostoma, Sow.

71. Rangelinum, Poey.

72. Redfieldianum, $A d$.

73. reticulatum, $A d$. $\&$. .

74. retrorsum, $A d$.

75. rugosum, Lam.

76. saccatum, $P f r$.

77. sarcodes, $i d$.

78. sericinum, $A d$.

79. sinuatum, $P f r$.

80. solidum, Menke.

81. Sowerbyi, Pfr.

82. striatulum, $i d$.

83. subliratum, $i d$.

s. sulcatum, Lam.

\$. . tectilabris, $A d$.

31i. tenue, Sow.

87. thysanoraphe, Sow.

s.s. tricarinatum, Müll.

89. trochlea, Bens.
57. Madagascariense, Gray. 90. undulatum, Sow.

58. Michaudi, Grat.

59. microchasma, Pfi.

60. modestum, Petit.

61. Moulinsi, Grat.

62. multifasciatum, $i d$.

63. Novæ-Hiberniæ, Quoy.

64. obsoletum, Lam.

65. occlusum, Morch.

66. Olivieri, Sow.

67. parvipirum, $P f r$.
91. unicarinatum, Lam.

92. unicolore, $P f r$.

93. virgatum, Sow.

9. virgo, Pfr.

9.5. vittatum, Sow.

96. xanthochilum, $i d$.

97. Yallahense, $A d$. 95. Zanguebarium, Petit.

99. zonatum, $i d$.

100. zonulatum, Féruss.

33. fascicularis, $i d$.

34. formosum, Sow.

\section{Subgenus Adamstella, Pfeiffer.}

101. chlorostoma, Sow. 106. mirabile, Wood. 111. pingue, Pfr.

102. cinnamomeum, Pfr. 107. mirandum, $A d$. 112. pulchrior, $A d$.

103. Grayanum, $i d$. 108. monstrosum, $i d$. 113. variabile, $i d$.

104. ignilabris, $A d$. 109. moribundum, $i d$. 114. xanthostoma, Sov.

105. intermedium, $i d$. 110. Pearmaneanum, $C h$.

\section{Subgenus Alycexus, Gray.}

115. amphora, Bens. 117. constrictum, $i d$. 119. gibbum, Féruss.

116. armillatum, $i d$. 118. distortum, Hain. 120. hebes, Bens. 
121. prosectum, Bens. 122. pyramidale, $i d$. 123. sculptile, $i d$.

129. grande, $P f r$. 130. helicinum, $C h$ 。

124. spiracellum, Ad.\&.R. 127. umbonale, Bens. 125. strangulatum, Hutt. 128. urnula, $i d$. 126. stylifer, Bens.

Subgenus Aulopora, Troschel.

131. Itieri, Guérin. 132. sphæroideum, Dsturn.

Subgenus Bourciera, Pfeiffer.

133. helicinæforme, $\mathbb{P f r}$.

\section{Subgenus Cataulus, Pfeiffer.}

134. aureum, Pfr. 139. eurytrema, $P f r$.

143. pyramidatum, $P f r$.

135. Austenianum, Bens. 140. hæmastoma, $i d$. 144. Templemani, $i d$. 136. Cumingii, $P f r$. 137. decorum, Bens. 141. Layardi, Gray. 145. Thwaitesi, $i d$. 142. marginatum, $P f:$ 146. tortuosum, $C h$. 138. duplicatum, Pfr.

\section{Subgenus Choanopoma, Pfeiffer.}

147. Adolfi, Pfr.

157. Hillianum, $A d$.

166. Pretrei, D'Orb.

148. alatum, $i d$. 158. interruptum, Lam. 167. pudicum, id. 149. anomalum, $A d$. 159. labeo, $A d$.

150. Arangianum, Gundl. 160. lima, $i d$. 151. bilabiatum, Gray. 161. Incina, Limn. 168. pulchrum, Wood. 169. scabriculum, Soro. 152. Chittyi, $A d$. 162. lincinellum, Lam. 170. scuticosum, Shutt. 153. decussatum, Lann. 154. evolutum, $A d$. 155. fimbriatulum, Sow. 163. majusculum, Mor. 172. spinulosum, $A d$. 164. mite, $P f r$. 173. sulculosum, Fêruss. 165. perplicatum, Gundl. 174. tentorium, Pfr. 156. granosum, $A d$.

\section{Subgenus Chondropoma, Pfeiffer.}

175. angustatum, $P f r$.

176. argutum; $i d$.

177. blandum, $i d$. 178. Blauneri, Shutt. 179. Candeanum, D'Orb. 180. claudicans, Poey. 181. Cordovanum, Pfr. 182. crenulatum, Féruss. 183. Cumanense, Pfi. 184. decurrens, Poey. 186. dentatum, Say. 187. diaphanum, Pfr. 188. dissolutum, $i d$. 189. egregium, Gundl. 190. elongatum, $P f$ r 191. eusarcum, $i d$. 192. harpa, $i d$.
193. hemiotum, $P f r$. 194. integrum, $i d$. 195. irradians, Shutt. 196. jucundum, $P f r$. 197. lætum, Guttier. 198. latilabre, $D^{\prime} O r b$. 199: litturatum, $P f r$. 200. Loweanum, $i d$. 201. magnificum, Sallé. 202. mœstum, Shutt. 203. Newcombianum, 205. obesum, Menke. 206. Ottonis, Pfr. 207. perlatum, Gundl. 208. Petitianum, $P f r$. 209. Pfeifferianum, Poey. 210. pictum, Pfir.
211. plicatulum, $P f r$. 212. Poeyanum, D'Orb. 213. puneticulatum, $P f i$. 214. revinctum, Poey. 215. revocatum, Gundl. 216. rubicundum, Mor. 217. Sagebieni, Poey. 218. Salleanum, Pfr. 219. Santacrusense, $i d$. 220. semicanum, Mor. 221. semilabre, Lam. 222. sericatum, Mor. 223. Shuttleworthi, $P f r$. 224. simplex, $i d$. 225. Swifti, Shutt. 226. tencbrosum, Mor. 227. tenuiliratum, $P f r$. 228. Tortolense, $i d$. 
229. truncatum, Wigm.

230. turritum, Pfr.

233. acerbulum, Mor.

234. Agassizi, Chp.

235. ambiguum, Lam.

236. Antiguense, Shutt.

237. catenatum, Gould.

238. cinclidodes, $P f i$.

239. confusum, $i d$.

240. dislocatum, Buird.

241. Grateloupi, Pfi。

24. Gruneri, $i d$.

243. illustre, Poey.

244. incultum, $i d$.
231. vesperinum, Mor. 232. violaceum, $P f r$.

Subgenus Cistula, Gray.

245. Küsteri, Pfr.

256. rigidulum, Mor.

246. Largillierti, $i d$.

257. Riisei, $P f r$.

247. lineolatum, Lam.

258. rostratum, $i d$.

248. lugulve, $P f r$.

249. mordax, $A d$.

250. pallidum, $P f r$.

251. platychilum, $i d$.

252. pleurophorum, $i d$.

253. procax, Poey.

254. radiosum, Nor.

255. radula, $P f r$.
259. rufilabre, Beck.

260. sagittiferum, $A d$.

261. Sauliæ, Sow.

262. scabrosum, Humpler.

263. Shephirardianum, $A d$.

264. 'Tamsianum, Pfr.

265. Thoreyanum, Phil.

266. trochleare, Pfr.

\section{Subgemus Craspedopoua, Pfeiffer.}

267. costatum, Shutt. 268. Iucidum, Lowe.

269. Lyonnetianum, Lowe.

\section{Subgenus Ctenopona, Stuttleworth.}

270. bilabiatum, D'Orb. 275. echinatum, Gundl.

271. Campbelli, $A d$.

272. coronatum, Poey.

273. deficiens, Gundl.

274. Dominicense, $P f r$.
276. honestum, Poey.

277. immersum, Gundl.

278. pisum, $A d$.

279. rotundatum, Poey.
280. rugulosum, Pfr.

281. sculptum, Gundl.

282. sordidum, $i d$.

283. torquatum, Guttier. 284. Wilkinsoni, $A d$.

\section{Subgenus Cyclophorus, Montford.}

285. æquivocum, $P f i$. 286. alabastrinum, $i d$. 287. albidum, Jacq. 2S8. alternans, $P f r$. 289. altivagum, Benson. 290. Amboinense, Pfr. 291. amœnum, $i d$. 292. annulatum, Trosch. 293. Apiæ, Recluz. 294. appendiculatum, Pfr. 313. Charpentieri, Mouss. 295. aquila, Soro. 296. atramentarium, $i d$. 297. aurantiacum, Schum. 295. Aurora, Benson. 299. Bairdi, Pfr. 300. balteatum, Benson. 301. Beauianum, Pet. 302. Bensoni, Pfi. 314. coeloconus, Benson. 315. convexiusculum, $P f r$. 334. floridum, $P f \circ$. 316. cornu-venatorium, Siv.335. Forbesianum, $i d$. 317. Couderti, Fis.et Bem. 336. fornicatum, $i d$. 318. cratera, Benson. $\quad 337$. fulguratum, $i d$. 319. cryptomphalum, id. 338. Gayi, Hupé. 320. cucullatum, Gould. 339. Guayaquilense, Pfr. 321. Cumingii, Sow. 340. Guimarisense, Sorv. 303. Borncense, Meclulfe. 322. cuspidatum, Benson. 341. guttatum, Pfi. 
342. Himalayense, $P f r$. 343. Ibyatense, $i d$. 344. incisum, Jacq. 345. Indicum, Desh. 346. involvulum, Mïll. 347. Jerdoni, Benson. 34. labiosum, Pfi. 349. leucostomum, $i d$. 350. lignarium, $i d$. 351. linguiferum, Sow. 352. lingulatum, $i d$. 353. liricinctum, Benson. 354. loxostomum, $P f r$. 355. luridum, $i d$. 356. lutescens, $i d$. 357. maculosum, Soro. 358. Malayanum, Benson. 359. margarita, $P f r$. 360. marmoratum, Fér. 361. Menkeanum, Phil. 362. Mexicanum, Mente. 363. Moricandi, Pfr. 364. Nilagiricum, Benson. 365. obligatum, Gould. 391. Siamense, Soro. 366. oculus-capri, Wood. 392. speciosum, Phil. 367. orbiculatum, Benson.

369. parma, id.

370. parvum, Sow. 352. purum, Forb. 388. scurra, Benson.
368. Parapse, Benson.

371. Pearsoni, Benson. 372. perdix, Brod. et Sono.397. treniatum, Pfi. 373. Phænotopicum, Bens. 398. texturatum, Soro. 374. Philippinarum, Sow. 399. Theobaldiantm, Bens. 375. picturatum, Pfr. $\quad 400$. Thersites, Shutt. 376. pinnulifer, Benson. 401. Thwaitesi, Pfr. 377. polynema, Pfr. 402. tiara, Gould. 378. ponderosum, $i d$. 403. tigrinum, Sow. 379. porphyriticum, Bens, 404. tomotrema, Benson. 380. psilomitum, Pfr. $\quad 405$. trochoides, Mörch. 381. punctatum, Grat. 406. Tryblium, Benson.

383. pyrotrema, Benson. 408. turbinatum, Pfr. 3S4. ravidum, $i d$ 409. turbo, Chen. 385. rufescens, Soro. 410 . turgidum, Pfr. 386. Schrammi, Stuutt. \$11. validum, Sow. 387. scissimargo, Benson. 412. volvulum, Müll. 389. semisulcatum, Soro. 413. Wahilbergi, Benson. 414. Woodianum, Lea. 415. Zebra, Grat. 416. Zebrinum, Bensoir. 417. Zollingeri, Mouss.

\section{Subgenus Cyclotus, Guilding.}

418. asperulum, Soro. 419. Bogotense, Pfr. 420. Chinense, $i d$. 421. cingulatum, Soro. 422. conoideum, Pfr. 423. corniculum, Mouss. 424. corrugatum, Sow. 425. crassum, $A d$. 426. daucinum, $P f$ : 427. diatretum; Gould. 428: discoideum, Sow. 429. distinctum, $i d$. 430. distomella, $i d$. 431. dubiosum, $A d$. 432. Duffianum, $i d$. 433. Dunkeri, Pfr. 434. Dysoni, $i d$. 435. exiguum, Sow.
436. filocinctum, Benson. 454. opalinum, Mouss. 437. floccosum, Shutt. 455, orbellus, Lam. 438. Fortunei, $P \int r$. 439. giganteum, Gray. 440. glaucostoma, $P f r$. 441. Granadense, Shutt. 442. Hebraicum, Less. 443. Inca, $D^{\prime} O r b$. 44. incomptum, Sow: 445. irregulare, $P f r$. 456. pallescens, $A d$. 4.57. perpallidum, $i d$. 458. planorbulus, Lam. 459. plebejum, Sow. 460. Popayanum, Lea. 461. prominulum, Fér. 462. pusillum, Sow. 463. Quitense, Pfr. 446. Jamaicense, Chemn. 46\%. Recluzianum, $i d$. 44.7. jugosum, $A d$. $\quad 465$. scalare, $i d$. 448. laxatum, Sow. 466. semistriatum, Sow. 449. Lindstedti, $P f r . \quad$ 467. sordidum, $P_{f}$. 450. Macgillivrayi, $i d$. 468. spurcum, Grat. 451. Martinicense, Shutt. 469. stramineum, Reeve. 452. montanum, Pfr. 470. subdiscoideum, Sow. 453. mucronatum, Sow. 471. subrugosum, $i d$. 
472. substriatum, Soro. 475. translucidum, Sow. 478. variegatum, Srons. 473. suturale, $i d$. 476. triliratum, Pfr. 479. volvuloides, Soro. 474. Tourannense, Soul. 477. varians, $A d$.

Subgenus Dermatocera, Adams.

480. maculosum, Soul. 481. vitreum, Less.

Subgenus Diplomimatina, Benson.

482. Australix, Benson. 487. costulatum, Hutt. 492. minor, A. Adans. 483. Bensoni, Adams. 488. diplocheilus, Benson. 493. pachycheilus, Benson. 484. Cantori, $P f r$. 489. folliculus, $P f r$. 494. polypleuris, $i d$. 485. capillaceum, $i d$. 4.86. chordatum, id. 490. Huttoni, id. 495. Sowerbyi, Pfr.

491. Macgillinrayi, $i d$.

\section{Subgenus Hydrocena, Parreys.}

496. acutiliratum, $P f r$. 497. albescens, $i d$. 498. Annatonense, $i d$. 499. aurantiacum, Desh. 500. breviculum, $P f$. 501. Bridgesi, $i d$. 502. bulimoides, Jacq. 503. Cattaroense, $P f r$. 504 . cereum, $i d$. 505. Clinense, $i d$. 506. corneum, $i d$. 507. dubium, $i d$. 508. erosum, Qroy. 509. exiğtum, Jacq. 510 . expansilabre, $P f r$. 511. exquisitum, $i d$.
512. exsertum, Pfr.

513. glabratum, $i d$. 514. globosum, Benson.

515. granum, $P f \%$.

516. Guamense, Pfi.

517. gutta, Sluntt.

518. hieroglyphicum, Fér.

519. Huahcinense, Pfr. 520. illex, Bens.

521. malleatum, Pfr. 522. milium, Bens. 523. minutissimum, Soro. 524. multiliratum, Pfr. 525. Navigatorum, $i d$. 526. noticolum, Benson. 527. oblongum, $P f r$.
528. obtusum, Pfi. 529. occanicum, Jacq. 530. plicosum, Pfr. 531. pupoides, $A n t$. 532. pyrami, $P f i$. 533. Pyxis, Benson. 534. radiatum, Pfi. 535. roseum, Gould. 536. rubeum, Quoy. 537. sarritum, Benson. 538. scitulum, Gould. 539. solidulum, Pfr. 540. terebrale, Gould. 541. tersum, Benson. 542. vallatum, Gould. 543. vestitum, $P f r$.

\section{Subgenus Jamaicra, C. B. Adams.}

541. anomalum, $A d$.

545. Moussonianum, $A d$.

$$
\text { Subgenus Leonia, Gray. }
$$

546. mammillare, Lam.

\section{Subgenus Leptopoma, Pfeiffer.}

547 . acuminatum, Sow. 556 . ciligerum, Mouss. a48. acutimarginatum, $i d$. $55 \%$. conulus, $P \int r$. 549. apicatum, Benson. 550 . aspirans, $i d$. 551. atricapillum, Sov. 552. barbatum, $P f i$. 5รั3. bicolor, $i d$. 5 5.4. Birmanum, $i d$. ร็ร5. ciliatum, Sow. อ5 8. Cybeus, Benson. 559. duplicatum, Pfi. 560. elatum, $i d$.

565. halophilum, Benson. 566. Hanleyanum, Pfr. 567. heloicoides, Grat. 568. ignescens, $P f r$. 569. immaculatum, $C 7$. 570. insigne, Sow. 571. Jacquinoti, Pfi. 572. latelimbatum, $i d$. 563. Garreli, Soul. 564. goniostomum, Sow. 573. Lowi, id. 
574. luteostomum, Sovo. 575. Massenæ, Less. 576. melanostomum, Pet. 577. oraphilum, Benson. 578. Panagense, Sow. 579. pellucidum, Grat.

591. dubium, Gm. 592. evolutum, Reeve.

595. depressum, Sono. 596. desciscens, Pfr.
580. perplexum, Sow.

581. pileus, Sow.

582. pœcilum, $P f r$.

583. regulare, $i d$.

584. Sechellarum, Pfr.

585. semiclausum, $i d$.

Subgenus Licina, Gray.

593. labeo, Mïll.

594. Reeveanum, Pfr.
586. sericatum, Pfr. 587. signatum, $i d$. 588. tenebricosum, $A$ d.et $R$. 589. undatum, Metcalfe. 590. Wallacei, $P f r$.

\section{Subgenus Lithidion, Gray.}

597. niveum, Pet.

599. sulcatum, Gray.

598. Souleyetianum, Pet.

\section{Subgenus Megalomastoma, Guilding.}

600. altum, Sow.

610. cylindraceum, Chemn. 620. Orbignyi, Pfr.

601. alutaceum, Menke.

611. digitale, Gundl.

621. pauperculum, Sow.

602. Anostoma, Bens.

612. funiculatum, Bens.

613. gravidum, Bens.

622. procer, Poey.

603. Antillarum, Sorv.

604. apertum, Poey.

614. Guatemalense, Pfr.

623. sectilabrum, Gould.

605. auriculatum, $D^{\prime} O{ }^{\prime} \%$.

606. bifasciatum, Sow.

607. bituberculatum, $i d$.

608. complanatum, $i d$.

609. croceum, Sow.

615. Guildingianum, $i d$.

616. Gundlachi, $i d$.

624. seminudum, Poey.

625. simulacrum, Mor.

626. tortum, Wood.

617. leoninum, Pfr.

618. Mani, Poey.

627. ungula, Poey.

619. Myersi, Haines.

628. ventricosum, $D^{\prime} O r \cdot 6$.

629. verruculosum, Shutt.

Subgenus Opisthoponus, Benson.

630. biciliatum, Mouss. $\quad$ 633. euryomphalum, Pfr. 635. rostellatum, Pfr. 631. birostre, Pfr.

634. pterocycloides, $i d$. 636. tubuliferum, $i d$.

632. Cochinchinense, Pfr.

\section{Subgenus Оторома, Gray.}

637. albicans, Sow.

643. Coquandianum, Pot. 649. Philippianum, Pfr.

638. auriculare, Gray.

639. blumus, Bens.

644. Guillaini, id.

650. politum, Sovv.

645. hæmastoma, Ant.

651. pygmæum, $i d$.

640. clathratulum, Recl.

641. clausum, Sozo.

642. Comorense, Pfr.

646. Listeri, Gray.

652. unifasciatum, $i d$.

647. multilineatum, Jay. 653. vitellinum, Pfr.

648. naticoides, Recl.

Subgenus Pomatias, studer.

654. auritum, Zieg.

659. gracile, Küist.

664. patulum, Dunk.

655. Barthelemianum, Shu.660. maculatum, Dunk. 665. Porrio, Strob.

656. Carthusianum, Dup. 661. Nouleti, Dupuy.

657. cinerascens, $R m$.

662. obscurum; Dunk.

666. scalarinum, Villa.

658. crassilabrum, Dup.

663. Partioti, Moquin.

668. tessellatum, Wiegm. 
Subgenus P'́terocyclos, Benson.

669. Álbersi, Pfr.

670. anguliferum, Soul.

671. bifrons, Pfr.

672. bilabiatum, Bens.

673. Blandi, id.

674. cetra, $i d$.

686. Egea, Gray.

687. rubellum, Pfr.

690. Adamsi, Pfr.

691. armatum, $A d$.

692. Augustæ, $i d$.

693. avena, $i d$.

694. Barclayanum, $C h$.

695. canescens, $P f i$.

696. Chemnitzii, $W_{\text {ood. }}$

697. columna, $i d$.

698. costatum, Menke.
675. Cingalense, Bens.

676. Cumingii, Pfr.

677. hispidum, Pear's.

678. Hansei, Haines.

679. nanum, Bens.

680. parvum, Pears.

Subgenus Realia, Gray.

688. turriculatum, Pfr. 689. ventricosum, Jacq.

Subgenus Tudora, Gray.

699. fascia, Wood. 708. papyraceum, $\Lambda d$.

700. focundum, $A d . \quad$ 709. pauperatum, $i d$.

701. ferrugineum, Lam. 710. planospira, Pfr.

702. Griffithianum, $A d$. 711. pupæformis, Sow.

703. maritimum, $A d$.

704. megachila, Pot.

705. Moreletianum, Pet.

706. muticum, $A d$.

707. uobile, $P f r$.
681. pullatum, Bens.

682. rupestre, $i d$.

683. tenerum, Menke.

684. tenuilabiatum, Metc.

685. Troscheli, Bens.

712. pupoides, Mor.

713. quaternatum, Lam.

714. simulans, $A d$.

715. Tappianum, $i d$.

716. versicolor, $\mathrm{Pfr}$.

\section{Genus 4. PUPINA, Vignard.}

Animal; partaking of the characters of Cyclostoma and IIelicina. Shell; cylindrical, mostly polished; spire more or less obtuse at the apex; last whorl rather contracted; aperture circular, with the lip thickened, sometimes duplex, frequently cut near the columella with a small fumnel-shaped canal or fissure. Sometimes a distinct tube is formed against the body-whorl. Operculum horny.

The trenty-seven species associnted under this head, though affording good generic distinctions, partake much of the characters of Cyclostoma and Helicina. The very characteristic division of the former, known as Cataulus, presents an indication of the tubular appendage of the lip so curiously developed in the Pupina, subgenus Raphlantus; and the more polished and gaily-painted Pupince, with a simple fissure in the lip, exhibit a link with the Helicince.

No Pupina has been found in the Western Hemisphere. The habitats of the species are well known, and range chiefly among the Philippine and North Australian groups of islands. 


\section{Species.}

1. artata, Bens.

2. Arula, id.

3. aurea, Hind.

4. bicanaliculata, Sov.

5. bilinguis, Pfr.

15. lubrica, Soto.

16. pupiniformis, Sow.

Subgenus Registoma, Hasselt.

17. Cumingiana, $P f i^{\circ}$

18. exigua, Sow.

19. fusca, Gray.

24. bombycina, $P f r$.

(1)

6. grandis, Forb.

7. humilis, Jacq.

8. imbricifera, Bens.

9. Kerandreni, $V i g n$.

10. Mindorensis, $A d$.

Subgenus Callia, Gray.
Subgenus Pupinella, Gray.

21. Nicobarica, Pfr.

22. pellucida, Sow.

Subgenus Rinaphanlus, Pfeiffer.
11. Moulinsiana, Fisch.

12. Strangei, Pfr.

13. superba, $i d$.

14. Thomsoni, Forb.

20. grandis, Groy. 23. similis, Sow.
25. chrysalis, $P f r$.
26. Lorraini, $P f r$.

Subgenus Streptaulus, Benson.

27. Blandfordi, Bens.

\section{Figure.}

Pupina (Registoma) grandis. Pl. 20. Fig. 109. Shell, showing the funnel-shaped fissure in the lip.

\section{Genus 5. TRUNCATELLA, Risso.}

Animal; Foot short, rounded at both ends; head bilobed, more or less muswle-shaped; tentacula short, triangular, diverying, with the eyes placed centrally at their upper bases.

Shell; cylindrically turreted, decollated or obtusely truncated at the apra; whorts rather narrou, sometimes smooth, somelimes transversely finely-ribbed; aperture ovate; lip simple, contimoous. Operculum hormy, simple.

The little shells which constitute this genus are rather isolated from the rest of the family. The animal has the faculty of looping itself like the geounetric caterpillar, so as to accuire a leap, and when found in numbers on the sea-shore, which is its natural habitat, the sand appears alive in 
a manner with the skippings of the Truncatellide. Although, strictly speaking, a water mollusk, for which reason it is placed by many authors with the Rissoce, the Truncatella is able to subsist for a long time on land. Mr. Lowe relates having preserved specimens taken on the shores of Madeira for five weeks in a dry box, which, on being placed in a glass of sea-water, crawled forth alive.

Only one species, T. Montagui, has been found in Britain. The remainder are from the Mediterranean, West Indies, California, Madeira, and Teneriffe, Philippine Islands, Mauritius, Australia, Pacific Islands, Rio Janeiro, etc.

\section{Species.}
1. Adamsi, Pfr.
10. elongata, Poey.
19. rostrata, Gould.
2. aurantia, Gould.
11. Guerini, Villa.
20. scalariformis, Reeve.
3. Bairdiana, $A d$.
12. lirata, Poey.
21. scalaris, Mich.
4. Barbadensis, Pfr.
13. Lowei, Shutt.
22. striatula, Menke.
5. bilabiata, $i d$.
14. marginata, Kust.
6. Californica, $i d$.
15. modesta, $A d$.
23. subcylindrica, Gray.
7. Caribbrensis, Soro.
16. Montagui, Lowe.
24. teres, Pfr.
8. Ceylanica, $P f r$.
17. porrecta, Gould.
25. truncatula, Dunk.
9. clathrus, Lozee.
18. pulchella, $P f r$.
26. valida, $P f r$.
27. Vitiana, Gould.

\section{Figure.}

Ihuncatella Caribbizensis. Pl. 20. Fig. 107. Shell, considerably magnified, showing the peculiarity of the truncated apex.

\section{Genus 6. GEOMELANIA, Pfeiffer.}

Animal; similar to Truncatella.

Shell ; imperforated, turreted, whitish, often glossy, densely sculptured with longitudinal ribs; apew truncuted; aperture somewhat squarely ovate, effused, produced at the base into a tongue-like appendage; lip mostly thickened and reflected.

Allied to the Truncutelle, with the apex similarly truncated, and with an animal in no respect differing, * are the Geomelania, a group of shells almost as numerous in species, of more slender form, in which the aperture is curiously effused at the base into a sort of tongue-like appen-

* Arthur Adams, Pro. Zool. Soc. 1850, p. 169. 
dage. They are rather sharply ribbed longitudinally, and are mostly of glossy whiteness.

So far as is at present known, the genus is peculiar to the Island of Jamaica.

\section{Species.}

1. affinis, C. B. Adams. 9. gracilis, C. B. Adams. 17. pauperata, C.B.Adams.

2. Beardsleana, $i d$. 10. Hilliana, $i d . \quad$ 18. procera, $i d$.

3. conica, $i d$. 11. inornata, Chitty. 19. pygmæa, $i d$.

4. costulosa, $i d$. 12. Jamaicensis, Pfr. 20. pyramidata, $i d$.

5. elegans, $i d$. 13. magna, C. B. Adams. 21. sinuosa, Chitty.

6. exilis, $i d$. 14. media, id. 22. striosa, C. B. Adams.

7. expansa, $i d$. 15. minor, $i d$. 23. typica, $i d$.

8. fortis, $i d$ 16. parva, Chitty. 24. vicina, $i d$.

\section{Figure.}

Geomelania Jamaicensis. Pl. 18. Tig. 95. Shell of white, glassy substance, showing its fine longitudinal ribs, and tongue-like production of the aperture.

\section{Family 16. COLIMACEA.}

Shell; multiform, not tubercled, nor spined, nor varicose, rarely ribbed; aperture occusionally toothed; lip sometimes simple, mostly reflected. No operculum.

In the great family of land shells included under this head, the animal is more of the slug type, and has no operculum. The shell is mostly of light structure, varying in substance and colour according to temperature and to the nature of the vegetation on which its inhabitant feeds. As there is no country without its snail, its geographical range is universal. Some forms, such as Helix and Butimus, have the widest possible distribution, but others, such as Anostoma, Achatina, and Achatinella, are extremely local. The species, numbering upwards of four thousand, are divided into twelve genera, as follow :-

Clausilia.

Cylindrella.

Pupa.

Achatina.
Achatinella.

Partula.

Bulinus.

Helix.
Anostoma.

Proserpina.

Succinea.

Vitrina. 


\section{Genus 1. CLAUSILIA, Draparnand.}

Animal; short, usually broad, obtuse behind, with stout clavate upper tentacula, and very small lover ones.-Forbes.

Shell; elongately turreted, sinistral, contracted at the last whorl, aperture pyriformly ovate, furnished with tooth-like plaits, and a small elastic shelly bone attached to the columella.

The Clansilice are a numerous tribe, of limited range, inhabiting old walls and trunks of trecs, or under stones among dead leaves, chiefly in the south-eastern parts of Europe, and all producing a horny, turriculated shell, some of whch are finely ribbed throughout. The chief peculiarity of the genus, as its name denotes, consists in the animal having the faculty of closing itself in the shell by means of an elastic bony appendage attached to the columella, and this appendage is not present, like an operculum, during the growth of the animal, but is formed only at maturity. Another peculiarity is that the shells are reversed, the whorls being convoluted to the left, and a little contracted towards the aperture. The margin of the aperture is continuous, and often conspicnously reflected, and within, on the columella side, are usually two tooth-like plaits with often smaller internal ones.

In the list of species which follows are included thirteen, supposed to be destitute of the bony appendage, and separated, for this reason, under the name of Balea.

\section{Species.}

1. abrupta, Küst. 18. Bergeri, Mayer.

2. acridula, Zieg.

3. aculus, Benson.

4. aguata, Partsch.

5. albescens, Menke.

6. albida, Parr.

7. albocincta, $P f r$.

8. alboguttulata, Wagn.

9. Almissana, Küst.

10. Anatolica, Roth.

11. Antigua, Schübl.

12. aquila, Parr.

13. armata, Kutsch.

14. australis, Forbes.

15. badia, Zieg.

16. Balsamoi, Strob.

17. Belcheri, Pfr.
19. bicarinata, Zieg.

20. bicolor, Pfr.

21. bicristata, Friv.

22. bidens, Linn.

23. Bielzii, Parr.

24. bigibbosa, Chp .

25. bilabiata, Wagn.

26. binotata, Zieg.

27. biplicata, Mont.

28. blanda, Zieg.

29. Boissieri, Chp.

30. Bourcieri, Pfi.

31. Brauni, Chp.

32. Brembina, Strob.

33. brevicollis, Pfr.

34. brunnea, Zieg.
35. bulimoides, Braun.

36. Buschii, Kïst.

37. cærulea, Fér.

38. Calcaræ, Phil.

39. Campanica, Mich.

40. canaliculata, $P f r$.

41. canalifera, Rossm.

42. candida, Pfr.

43. candidescens, Zieg.

44. Cantrainei, Desh.

45. capillacea, Rossm.

46. carissima, Zieg.

47. Cattaroensis, $i d$.

48. Cecillei, Phil.

49. Charpentieri, Pfr.

50. Chinensis, $i d$.

51. chondriformis, Jan. 
52. cincta, Brum.

53. cinerascens, Kïst.

54. cinerea, Phil.

55. circumdata, Friv.

56. claviformis, $P f r$.

57. Cochinchinensis, $i d$.

58. Comensis, Shut.

59. commutata, $R m$.

60. compressa, $P f r$.

61. consocia, Zieg.

62. conspersa, Parr.

63. conspurcata, Jan.

64. contaminata, Zieg.

65. cornea, Pliil.

66. corpulenta, Friv.

67. corrugata, $C h$.

68. corticina, $V$.d. Busch.

69. corynodes, Held.

70. costata, Zieg.

71. costulata, Jan.

72. crenulata, Riss.

73. Cretensis, Muihlf.

74. crispa, Lowe.

75. Cumingiana, Pfr.

76. curta, Rossm.

77. cyclostoma, $P f \circ$.

78. cylindrica, Gray.

79. Dacica, Friv.

80. Dalmatina, Ptsch.

81. Deenia, Cantr.

82. deltostoma, Lowe.

83. densistriata, Zieg.

84. denticulata, Oliv.

85. Deshayesii, $P$. et $I I$.

86. detersa, Zieg.

87. diminuta, Parr.

88. diodon, Stud.

89. discolor, Pfr.

90. Dominicensis; $i d$.

91. Draparnaudi, Beck.

92. Dunkeri, $P \int r$.

93. Eichwaldi, Siem.

94. elata, Gould.

95. elata, Zieg.

96. elatior, Spix.

97. elegans, Bielz.
98. elongata, Cantr.

144. isabellina, $P f r$.

99. epistomium, Kiist.

100. exarata, Zieg.

101. exigua, Lowe.

102. fallax, Rossm.

103. filograna, Zieg.

104. fimbriata, Miihlf.

105. flammulata, $P f r$.

106. Forbesiana, $i d$.

107. formosa, Zieg.

108. Fortunei, Pfr.

109. frondigera, Parr.

110. Freyeri, Kïst.

111. fritillaria, Friv.

113. fulcrata, Zieg.

114. Funcki, Pfr.

115. fusca, De Betta.

116. Fussiana, Bielz.

117. galeata, Parr.

118. gastrolepta, Zieg.

119. gibbula, $i d$.

120. glorifica, Parr.

121. gracilicosta, $i d$.

122. gracilis, Rossm.

123. Græca, $P f i$.

124. grandis, Klein.

125. Grayana, Pfr.

126. Grimmeri, Par\%.

127. grisea, Desh.

128. Grohmanuiana, Part. 174. maculata, Zieg.

129. Hanleyana, Pfr.

130. Hedenborgi, id.

175. maculosa, Desh.

176. mœsta, Fér.

177. Marcelia, Risso.

178. imarginata, Zieg.

132. hetæra, Friv.

133. heterostropha, Riss.

134. homalorhaphe, Pfr.

135. Hübneri, Rossm.

136. Idæa, Pfr?

137. inflata, Oliv.

138. inserta, Porro.

139. insignis, Gould.

179. Massenæ, P.etMich.

180. Meisneriana, $S h$.

181. Michaudiana, $P f r$.

182. microstoma, Kïst.

183. Milleri, Pfr.

184. Moniziana, Loxe.

185. montana, Steutz.

140. intermedia, F. Schm. 186. Montenegrina, Küsl

141. intempta, Zieg. 187. Moritzii, Monss.

142. invalida, $P f r$ 188. Moussoni, Chp.

143. inuncta, Parr. 189. mundi, Zieg. 
190. nævosa, Fér.

191. nectarina, Friv.

192. Negropontina, Pfr. 193. Neumeyeri, Küst.

194. Newcombi, Pfi. 195. nigricans, $P$ ult. 196. nobilis, $P f r$. 197. oleata, Rossm. 198. olivacea, Cantr. 199. Olivieri, Roth. 200. Olympica, Friv. 201. orientalis, $V . d$. Busc. 202. orthostoma, Mike. 203. oxystoma, Rossm. 204. pachygastris, Ptsch. 205. pachystoma, Kïst. 206. Prestana, Phil. 207. pagana, Zieg. 208. Parreyssi, $i d$. 209. parvula, Stud. 210. patula, Chp. 211. pellucida, $P$ ef . 212. peregrina, Gould. 213. Peruana, Trosch. 214. perversa, Linn. 215. petrosa, Parr. 216. Pfeifferi, Kïst. 217. Philippiana, Pfr. 218. piceata, Zieg. 219. picta, $P f i$. 220. plicata, Drap. 221. plicatula, $i d$. 222. plumbea, Rossm. 223. pluviatilis, Benson. 224. Porroi, Pfr. 225. proboscidea, Kïst. 226. puella, $P f r$. 227. pulchella, $i d$.
228. pumila, Zieg. 229. punctulata, Kiist. 230. Reeveana, Pfr. 231. retusa, Oliv. 232. robusta, Kïst. 233. Rossmassleri, Pfr. 234. rubicunda, Kïst. 235. rugicollis, Zieg. 236. rugosa, Drap. 237. Sandrii, Kiist. 238. Sarda, Villa. 239. Sarsi, Phil.

240. satura, Zieg. 241. saxatilis, Parr.

242. saxicolor, $i d$. 243. scalaris, $P f r$. 24. Schmidti, $i d$. 245. chuchi, Voith. 246. semidenticulata, $P f r$. 284. torticollis, $O l$. 247. semirugata, Zieg. 245. senilis, $i d$. 249. septemplicata, Phil. 250. sericata, $P f r$. 251. serrulata, Mus. Petrp. 289. turgida, Zieg. 252. Shanghiensis, Pfi. 290. turrita, $P f r$. 253. Sieboldti, $i d$. 254. socialis, Friv. 255. Somchetica, Pfr. 256. Sowerbyana, $i d$. 257. Spratti, $i d$. 258. Stabilei, Chp. 259. stabilis, Zieg. 260. Stentzii, Rossm. 261. stigmatica, Zieg. 262. strangulata, Fér. 263. striata, Pfr. 264. strigata, $i d$. 265. strigillata, Müllf.
266. Strobeli, Porro. 267. strumosa, Friv. 268. Sturmi, Küst. 269. subcristata, $i d$. 270. subcylindrica, Zieg. 271. subulata, $P f r$. 272. succineata, Zieg. 273. sulcosa, Wagn. 274. Syracusana, Phil. 275. Taurica, Kryn. 276. tenuilabris, Rossm. 27\%. teres, Oliv.

278. tetragonostoma, Pfr. 279. Tettelbachiana, $R s s m$. 280. Thermopylarum, $P f r$. 281. Thessalonica, Friv. 282. Thomasiana, Chp. 283. torquata, Held. 285. translucida, Zieg. 286. tridens, Chemn. 287. Tristensis, Leach. 288. tuba-paradisi, Ehr. 291. valida, $i d$. 292. varians, Zieg. 293. Vamensis, Pfr. 294. ventricosa, Dray. 295. ventricosa, Leach. 296. vetusta, Zieg. 297. vibex, Rossm. 298. Vidovichii, Parr. 299. virginea, $P f r$. 300. viridana, Zeig. 301. Voithii, Rossm. 302. Whateliana, Chp. 303. Ziegleri, Kiist.

\section{Figure.}

Clausilia ixvalida. A new species from Shanghai, showing the internal tooth-like plaits. 


\section{Genus 2. CYLINDRELLA, Pfeiffer.}

Animal ; similar to that of Clausilia.

Shell; elongately cylindrical, many-whorled, sometimes truncated. at the apex; last whorl fiequently unrolled and curiously protiuding; aperture small, rounded, with the lip generally continuous and expanding.

The genus Cylindrella was founded by Guilding under the name of Siphonostoma, * for the reception of one or two peculiarly many-whorled cylindrical land shells, then known as Pupe, which have been remarkably added to within the last few years. Upwards of a hundred species, of the most exquisite variety of form and sculpture, have been discovered, and all, so far as their habitats are known, are, with one single exception $(C$. Cumingiana, from the Philippine Islands), inhabitants of the West Indies or Central America.

Of all land shells the Cylindrella are the most rapidly convoluted, many of the species turning twenty whorls and more before reaching maturity; and some of them, such as $C$. seminudu, are quite fantastic in their form and sculpture. The most striking feature in the genus is a certain tendency, in many species, of the last whorl to strike off from its axis of convolutiou and end like a jutting spout.

\section{Species.}

1. abbreviata, Desh.

2. acus, $P f r$.

3. Adamsiana, $i d$.

4. Aqnesiana, $A d$.

5. alabastrina, $P f r$.

6. alba, $A d$.

7. aspersa, $i d$.

8. Augustæ, id.

9. Blandiana, Pfr.

10. brevis, $i d$.

11. carinata, $i d$.

12. cinerea, $i d$.

13. collaris, Fér.

14. columna, $A d$.

15. costata, Guild.

16. costulata, $A d$.

17. crispula, Pfr.
18. Cumingiana, $i d$.

19. cylindrus, Chenin.

20. decollata, Nyst.

21. denticulata, $P f r$.

22. Dominicensis, $i d$.

23. Dunkeriana, $i d$.

24. elatior, $A d$.

25. elegans, $P f r$.

26. elongata, Chemn.

27. fasciata, $i d$.

28. filicosta, Shutt.

29. fistularis, Mor.

30. flammulata, Pfr.

31. Goldfussi, Mke.

32. Gossei, Pfr.

33. Gouldiana, $i d$.

34. gracilicollis, Fér.
35. gracilis, Wood.

36. gracillima, Poey.

37. Gravesii, Adlams.

38. Greyana, $i d$.

39. Gruneri, Dunk.

40. Hanleyana, Pfi.

41. Hollandi, Adams.

42. Humboldtiana, Pfr.

43. humilis, Adanzs.

44. hyalina, Pfr.

45. inornata, Adams.

46. jejuna, Gould.

47. lata, Adums.

48. Laterradei, Grat.

49. Lavalleana, Orb.

50. leucopleura, Mke.

51. Liebmanni, $P f r$.

* The name Siphonostoma having been already used in zoology by Otto, was changed in 1840 by Dr. Pfeifler to Cylindrella. 
52. mallenta, Pfro.

53. marmorata, Shutt.

54. Maugeri, Gray.

55. Menkeana, $P f r$.

56. monilifera, $i d$.

57. Moreleti, $i d$.

58. Morini, Mor.

59. nobilior, Adams.

60. ovata, Desh.

61. Oviedoiana, Orb.

62. pallida, Guild.

63. perplicata, Fér.

64. Petiveriana, $i d$.

65. Pfeifferi, Mke.

66. Philippiana, Pfr.

67. Pilocerii, $i d$.

68. Poeyana, Orb.
69. porrecta, Gould.

70. Portoricensis, $P f r$.

71. princeps, Adams.

72. pruinosa, Mor.

73. puncturata, Pfr.

74. pupæermis, Adams.

75. pusilla, $i d$.

76. recticosta, Pfr.

77. Rüsei, $i d$.

74. Robertsi, Adans.

79. Romeri, Pfr.

8). rosea, $i d$.

81. Rugeli, Shult.

82. Sagraiana, Pfr.

43. Salleana, $i d$.

84. sanguinea, $i d$.

85. scalarina, Shult.
86. seminuda, Adams.

87. sericea, $P f r$.

88. similis, Adams.

89. simplex, $i d$.

90. Sowerbyana, Pfr.

91. speluncæ, $i d$.

92. subtilis, Mor.

93. subula, Fér.

94. tenella, Adams.

95. teres, Mhe.

96. tomacella, Mor.

97. torquata, $i d$.

98. tricolor, Pfr.

99. variegata, $i d$.

100. volubilis, Mor.

101. zebrina, Pfr.

102. zonata, Adams.

\section{Genus 3. PUPA, Draparnaud.}

Animal ; short, stout, acute belind, its upper tentacles developed, its lower ones short, or almost obsolete.

Shell ; oblong-cylindrical, many-whorled, often rather thick, mostly ribbed, sometimes deeply umbilicated, generally rather obtuse at the apex; aperture somewhat squarely ovate, generally more or less toothed; lip thickly reflected.

The Pupce are a cylindrical form of land shell, composed of numerous whorls, the species very much resembling each other in substance and colour, and characterized generally by a very similar plan of sculpture. They are mostly fawn-white or brownish, sometimes covered with an olive epidermis, and generally densely striated or ribbed in an oblique direction, with the margin of the aperture thickly reflected.

The genus is largely represented in southern Europe and in the islands of the Mediterranean, and also in the Mauritius, and in the W'est Indies and North America.

\section{Species.}
1. admodesta, Migh.
5. anconostoma, Lowe.
9. antivertigo, Drap.
2. affinis, Arad.
6. Anglica, Fér.
10. Antonii, Kiist.
3. alpicola, Chem.
7. angustior, Jeff?
11. A pennina, Chp.
4. alvearia, Dillu.
8. antiquissima, Eiclew.
12. aridula, Held. 
13. armifera, Say.

14. Ascaniensis, A. Schm.

15. atomus, Shutt.

16. avenacea, Brug.

17. Barbadensis, Pfr.

18. Bergomensis, $C h p$.

19. bicolor, Hutt.

20. bigranata, $R m$.

21. biplicata, Mich.

22. Boileausiana, Chp.

23. Brauni, $R m$.

24. brevicostis, Bens.

25. Büttneri, Siem.

26. calathiscus, Lowe.

27. calcarea, Pfr.

28. Callicratis, Scacchi.

29. Capensis, Kurr.

30. capitata, Gould.

31. carinata, $i d$.

32. cassida, Lowe.

33. cassidula, $i d$.

34. castanea, Schult.

35. cerea, Dınk.

36. cereana, Miüllf.

37. Charpentieri, Shutt.

38. cheilogona, Lowe.

39. clausilioides, Boub.

40. clavulata, Lam.

41. columella, Benz.

42. concinna, Lowe.

43. conica, $R m$.

44. conoidea, Newc.

45. contorta, Calc.

46. contracta, Say.

47. corticaria, $i d$.

48. costulata, Nilss.

49. crystallum, Mor.

50. Cumingiana, Pfr.

51. cupa, Jan.

52. curta, Ant.

53. cyclostoma, Kïst.

54. cylindracea, Zieg.

55. cylindrica, Mich.

56. dealbata, $W_{e b b}$.

57. decora, Gould.

58. decumana, Fér.
59. dilucida, Zieg.

60. dimidiata, Pfr.

61. doliolum, Brug.

62. dolium, Drap.

63. duplicata, Küst.

64. edentula, Drap.

65. elegantula, $P f r$.

66. exilis, Adams.

67. fallax, Say.

68. Farinesii, Desm.

69. farinosa, Trosch.

70. Ferrari, Porro.

71. ferraria, Lowe.

72. fontana, Krauss.

73. Freyeri, F. Schm.

74. frumentum, Drap.

75. funicula, $\mathrm{Val}$.

76. fusca, Lowe.

77. fusiformis, Küst.

78. fusulus, Miüll.

79. fusus, Lam.

80. gibba, Love.

81. glans, Küst.

82. goniostoma, id.

83. Gouldi, Binn.

84. granum, Drap.

85. Gruneri, $P f r$.

86. gularis, $R m$.

87. Gundlachi, Pfr.

88. Hassiaca, $i d$.

89. heptodonta, Risso.

90. hexodon, Adams.

91. Hoppii, Moll.

92. Huttoniana, Bens.

93. infundibuliformis, Ob.139. mumiola, $P f r$.

94. inornata, Mich. 140. muscorum, Linn.

95. intermedia, Mor. 141. nana, Mich.

96. irrigua, Lowe.

97. jamaicensis, $A d$.

99. Kokeilii, $R m$.

100. Kusteri, Pfr.

101. Kurri, Krauss.

102. lævigata, Lowe.

103. Lamarckii, And.

104. lamellosa, Lowe.
105. lapidaria, Hutt.

106. lata, Adams.

107. laurinea, Love.

108. leucodon, Mol.

109. Lymnæana, Lowe.

110. lucida, Jan.

111. Lusitanica, Rossm.

112. lyrata, Gould.

113. maculosa, Lam.

114. marginalba, Pfr.

115. maritima, $i d$.

116. marmorata, $i d$.

117. Martiniana, Küst.

118. megacheilos, Jan.

119. mellita, Gould.

120. Menkeana, Pfr.

121. Michaudi, Terv.

122. Micheli, $i d$.

123. microspora, Lowe.

124. miliola, Orb.

125. milium, Gould.

126. millegrana, Lowe.

127. minor, Mor.

128. minuta, Say.

129. minutissima, Hartm.

130. modica, Gould.

131. modiolus, Féruss.

132. monodon, Held.

133. monticola, Lowe.

134. Moquiniana, Küst.

135. Mühlfeldtii, $i d$.

136. multicostata, $i d$.

137. multidentata, Risso.

142. Neumeycri, Küst.

143. Newcombi, Pfr.

145. nodosaria, Orb.

146. Noroseelandica, Pfr.

147. obliterata, Charp.

148. oblonga, Pfr.

149. occulta, Parr.

150. ovata, Say. 
151. ovularis, Otiv.

152. pachygastra, Zieg.

153. pacifica, Pfr.

154. pagoda, Féruss.

155. pagodula, Desm.

156. pallida, Phil.

157. Paredesii, Orb.

158. Parreysii, Friv.

159. Partioti, Moq.

160. pediculus, Shutt.

161. pellucida, Pfr.

162. pentodon, Say.

163. Pfeifferi, Krauss.

164. Philippii, Cantr.

165. pleurophora, Shutt.

166. plicidens, Bens.

167. polyodon, Dunker.
177. regia, Bens.

178. Rhodia, Roth.

179. Rüsei, $P f r$.

180. ringens, Mich.

181. Rossmassleri, Schm.

182. rupestris, Pliil.

183. rupicola, Say.

184. Sagraiana, Pfr.

185. Sardoa, Cantr.

186. saxicola, Lowe.

187. Schmidti, Kust.

188. Schultzi, Phil.

189. scyphus, Friv.

190. secale, Dunker.

191. seminulum, Loree.

192. Sempronii, Charp.

193. Senegalensis, Mor.
203. striatella, Féruss.

204. Sturmii, Kïst.

205. substriata, Jeffr.

206. subulata, Bivon.

207. sulcata, Miill.

208. sulculata, Risso.

209. tæniata, Shutt.

210. tantilla, Gould.

211. tenuidens, Adans.

212. trilamellata, Risso.

213. triplicata, Studer.

214. Truncatella, Pfr.

215. tumidula, Desh.

216. tutula, Bens.

217. umbilicata, Dunker.

218. umbilicus, Roth.

219. utriculus, Menke.

168. Pottebergensis, Krau. 194. septemdentata, Risso. 220. uva, Linn.

169. pumilio, Gould. 195. servilis, Gould. 221. variabilis, Dunker.

170. pusilla, Muiller. 196. Shuttleworthiana, Chp.222. variolosa, Gould.

171. putilla, Shutt. $\quad$ 197. simplex, Gould. 223. Vergniesiana, Charp.

172. pygmæa, Dunker. 198. sorghum, Mor. 224. versipolis, Féruss.

173. Pyrenæaria, Mich. $\quad$ 199. sphinctostoma, Lowe. 225. Villæ, Charp.

174. quinquedentata, Born.200. squalina, Rossm. 226. vineta, Lowe.

175. quinquelamellata, Ris.201. Sterrii, Voith. 227. vulcanica, Küst.

176. recta, Lowe. 202. Strangei, $P f r$ 228. Wahlbergi, Krauss.

\section{Figure.}

Pupa maritura. Pl. 21. Fig. 118. Shell of solid, chalky substance, showing its pupa or chrysalis form, and the oblique sculpture and light-grey colouring characteristic of the genus.

\section{Genus 4. ACHATINA, Lamarck.}

Animal ; similar to that of Bulimus.

Shell; ovate or fusiformly oblong, sometimes polished, sometimes covered with an epidermis; whorls mostly striated or grained; columella rolled inwards, conspicuously truncated at the base; lip of the aperture simple, never thickened or reflected. No operculum. 
It will be seen on reference to Plate $H$. that the animal of Achatina is similar in all respects to that of Bulimus. M. Deshayes says, such is the resemblance, that for him Aclatina is an artificial genus. The generic characters of the shells run also successively into one another, but they are divisible into more distinctly typical groups. The animals of Bulinus ollongus and Achatina regina are very like, but the shells of these two species are essentially different. One is characterized by a massive, callous columella, and thickened, reflected lip; whilst in the other the lip is not reflected, and the columella is thinly rolled over, and truncated at the end. And so many species partake respectively of these particular characters, in connection with others, extending even to features of geographical distribution, that the shell in this instance is a more important aid to classification than the animal; or, to speak correctly, there are better distinguishing characteristics in the hard parts of the animal, than in the soft.

The Achatince are not of the same arboreal habits as the Butimi, but dwell in places where there is more moisture, in swamps or in the vicinity of lakes and rivers. They are divided by Pfeiffer into five sections, the first, Achatina proper, being by far the most numerous, including the fine series represented by the large $A$. variegata, zelra, and others, which are peculiar to West Africa, and take the place of the Bulimi in that district.

Another subgenus is that named Spiraxis, in which the shell is small, and of a highly polished, horny texture. It includes many extremely beautiful and delicate forms, chiefly inhabitants of the Central American continent and archipelago. A group of still smaller species, distinguished by the subgeneric name of Tomatellina, have the columella twisted; and there remain two other very distinct types, one represented by the well-known British Azeca tridens, and the other by the large and singularly long-convoluted shell, A. columina (Columna flammea).

\section{Species.}
1. accincta, Migh.
13. aperta, Guild.
14. arcuata, Pfr.
25. Blandiana, $A d$.
2. acicula, Müll.
15. assimilis, Reeve.
3. aciculoides, Jan.
16. attenuata, Pfi。
4. acuminata, $P f r$.
17. aurata, Mor.
18. Azorica, Alb.
19. bacilliformis, Jonas.
20. balanus, Bens.
21. balteata, Reeve.
26. bullata, Gould.
5. acuta, Lam.
6. alabastra, Rang.
7. albicans, $P f r$.
8. algira, Brug.
9. allica, Reeve.
10. anentum, $i d$.
22. Bensoniana, Pfi.
23. bicolor, Jay.
27. Californica, Pfi.
28. candida, Shutt.
29. carinata, Pfr.
30. Carminensis, Mor.
11. angiostoma, $A d$.
12. Antoniana, $P f \%$.
24. Blainiana, Poey.
31. carnen, Pfr.
32. Cassiaca, Bens.
33. cerea, Pfir.
34. Ceylanica, $i d$.
35. clarata, Gray.
36. clavus, $P f r$. 
37. cochlea, Reeve.

38. confusa, $P f r$.

39. conifera, Reeve.

40. consobrina, $\mathrm{Or} b$.

41. conspersa, Pfi.

42. coronata, $i d$.

43. corusca, Reeve.

44. costulata, $A d$.

45. costulosa, $i d$.

46. crassilabris, Bens.

47. crassula, $i d$.

48. crenulata, Ant.

49. Cumingii, Sleutt.

50. curvilabris, $P f r$.

51. cyanostoma, Rupp.

ธ2. cylindrella, Mor.

53. Daudebarti, Desh.

54. decussata, $i d$.

55. delibuta, Mror.

56. delicatula, Stutt.

57. Dennisoni, Reeve.

58. Deshayesi, Pfi.

59. diaphana, King.

60. dilatata, Zieg.

61. Dominicensis, Gm.

62. Donelli, King.

63. Dunkeri, Pfi.

64. emarginata, $S w$.

65. erecta, Bens.

66. exilis, $P f r$.

67. fasciata, Miill.

68. flammigera, Fér.

69. follicularis, Mor.

70. follieulis, Gron.

71. fulgurata, $P f r$.

72. fulica, Fér.

73. fuliginea, $P f r$.

74. fulminea, Fér.

75. fulva, Brug.

76. fusca, $P f r$.

77. fusiformis, $i d$.

78. Gayana, $A d$.

79. gemma, Bens.

80. glabra, $P f r$.

81. glutinosa, $i d$.

82. Gossei, id.
83. Gouldii, Reeve.

84. gracilior, $A d$.

85. gracilis, Lowe.

86. granulata, $P f r$.

87. Griffithsi, $A d$.

88. Gundlachi, Pfr.

89. Hohenwarti, Rossm. 90. Hügeli, $P f r$.

91. hyalina, Rang.

92. immaculata, Lam.

93. impressa, $P f r$.

94. incerta, Reeve.

95. indotata, $i d$.

96. Ingallsiana, $\Lambda d$.

97. inornata, Pfor

98. interstincta, Gould.

99. involuta, $i d$.

100. iostoma, $P f r$.

101. iota, $A d$.

102. isabellina, Pfi.

103. Jamaicensis, $i d$.

104. Javanica, Reeve.

105. Jerdoni, Bens.

106. Kercadonis, Grat.

107. Knorri, Jon.

108. Kraussi, Reeve.

109. Iabica, Mor.

110. lactea, Reeve.

111. Lamarckiana, Pfr.

112. Largillierta, $i d$.

113. Leacociana, Lowe.

114. leucozonias, $\mathrm{W}$ ulch.

115. levis, $A d$.

116. Liebmanni, $P f r$.

117. ligata, $A d$.

118. lignaria, Reeve.

119. Lindoni, Pfr.

120. lirifera, MIor.

121. longispira, $A d$.

122. lotophaga, ACor.

123. lubrica, Mïll.

124. Maderensis, Lowe.

125. magnifica, Pfr.

126. Malaguettana, Rang. 172. puella, $i d$.

127. marginata, Swain.

128. Marminii, Desh.
129. marmorea, Reeve.

130. melampoides, Lowe.

131. micans, $A d$.

]32. miliaris, Jon.

133. minima, Siem.

134. monilifera, $P f r$.

135. Moreletiana, Dest.

136. mucida, Reeve.

137. nana, Stutt.

138. nemorensis, $A d$.

139. nitens, Gray.

140. nitida, $A d$.

141. nitidissima, Forb.

142. obtusa, Pfr.

143. octona, $C h$.

144. oleacea, Fér.

145. onychina, Mror.

146. Oreas, Bens.

147. ornata, Pfr.

148. oryza, Lowe.

149. osculans, $A d$.

150. Ottonis, Pfr.

151. panthera, Fér.

152. papyracea, $P f i$.

153. paritura, Gould.

154. paxilus, Reeve.

155. pellucens, $A d$.

156. perplexa, $i d$.

157. Perrotteti, Pfr.

158. Peruviana, Lam.

159. Petiti, Desh.

160. Pfeifferi, $D k r$.

161. Philippiana, Pfr.

162. Phillipsii, $A d$.

163. picta, Reeve.

164. plicatula, Pfr.

165. porphyrostoma, Shtt.

166. Portoricensis, Pfr.

167. procera, $A d$.

168. procerula, Mor.

169. producta, Lowe.

170. propinqua, $A d$.

171. proxima, $i d$.

173. Punctogallana, Pfr.

174. purpurea, Chem. 
175. pusilla, Pfi.

176. pygmæa, $i d$.

177. Rangiana, $i d$.

178. Reeveana, $i d$.

179. legina, Fér.

180. reticulata, Pfr.

191. rhodostoma, Phil.

182. Riisei, Pfi.

183. Rodatzi, Dlor.

184. rosea, Fér.

185. rubella, Mor.

186. Sauleydi, Joann.

187. Sayea, Riss.

188. Sellovii, King.

159. semidecussata, Mke.

190. semisculpta, Pfr.

191. semisulcata, Desh.

192. semitarum, Rang.

193. sericina, Jon.

194. sicilis, Mor.

195. siderata, Reeve.

196. similis, $A d$.

240. flammea, Martyn.

Subgenus Spiraxis, C. B. Adams.

241. aberrans, S7utt.

242. acus, $i d$.

243. Adamsiana, $P f r$.

244. anomala, $i d$.

245. brevis, $A d$.

246. bulimoides, $P f r$.

247. coniformis, Shutt.

248. consimilis, Reeve.

249. costulosa, $A d$. 250. Cubaniana, $D^{\prime} O{ }^{\circ} \cdot$. 251. cylindracea, $P f r$. 252. Dysoni, id.

277. mitræformis, Lowe. 278. pupæformis, Cantr.
198. sinistrosa, Chem.

199. solidula, Pfr.

200. solitaria, $A d$.

201. sordida, King.

202. Sowerbyana, Pfr.

203. stigmatica, Shutt.

204 . straminea, Desh.

205. striata, Lea.

206. striata; Miill.

207. striatella, Rang.

208. strigata, King.

209. striosa, $A d$.

210. subemarginata, Desh.

211. subulata, Pfr.

212. subulatoides, Orb.

213. sulcata, Gray.

214. suturalis, Pfi.

215. Tandoniana, Shutt.

216. tenera, $A d$.

217. tenuis, Gray.

218. tenuispira, Bens.

Subgenus Columa, Perry.
197. simpularia, Mor.

\section{3. episcopalis, Mor.}

254. eximia, s/utt.

255. flavescens, $i d$.

256. inusitata, $A d$.

257. irrigua, Shutt.

258. Lattrei, Pfr.

259. ligulata, Mor.

260. lurida, Shutt.

261. lymneiformis, $i d$.

262. Meridana, Mor.

263. mirabilis, $A d$.

264. mitræformis, Shutt.

Subgenus Azeca, Leach.

279. tridens, Pult.

280. triticea, Lowe.
219. terebella, Lowe. 220. tincta, Reeve.

221. Tortillana, Pfr.

222. trochlea, Pfr.

223. truncata, Gmelin.

224. turris, $i d$.

225. turritellata, Desh.

226. undulata, Guild.

227. unicolor, $A d$.

225. unizonata, Jan.

229. ustulata, Lam.

230. Vanuxemensis, Lea.

231. variegata, $\mathrm{Col}$.

232. venusta, Pfr.

233. vicina, $A d$.

234. virginea, Linn.

235. vitrea, Webb et Berth.

236. vivipara, Sow.

237. voluta, Chem.

238. Yucatanensis, Pfr.

239. Zebra, Chem.
265. Newcombi, Pfi. 266. Nicoleti, Shutt.

267. nigricans, $P f r$.

268. obeliscus, Reeve.

269. paludinoides, $D^{\prime} O{ }^{\circ} b$.

270. physodes, Shutt.

271. Richardi, Pfr.

272. Salleana, $i d$.

273. splendida, Ant.

274. streptostyla, $P f r$.

275. turricula, Migh.

276. ventricosula, Mor.

281. tornatellina, $i d$.

282. tuberculata, $i d$.

\section{Subgenus Tornatelina, Beck.}

283. achatinoides, $P f r$.

284. bilamellata, Ant.
285. castanea, Pfr.

286. Cornica, Bens.
287. Cubensis, Pfr.

288. Cumingiana, $i d$. 
289. Ferussaci, $P f r$.

290. Fraseri, Bens.

291. Funcki, Pfr.

292. globosa, Pet.

293. lamellata, Pot. el $M$.

294. lamellifera, Mur.

295. lamellosa, Reeve.
296. minuta, Ant.

297. Novoseelandica, $P f r$. 304. Reclusiana, Pet.

298. ovata, Ant.

299. ovuliformis, Love.

I. 300. Paroliana, ITebb.

301. peponum, Gould.

302. Petitiana, Pfi.
303. Philippii, Pfr.

305. sinistrorsa, Cham.

306. trochiformis, Beck.

307. trochlearis, $i d$.

308. turrita, Ant.

\section{Figures.}

Achativa regixa. Pl. $/ 1$. Fig. 3. Showing the resemblance of its animal to that of Bulimus oblongus figured above, notwithstanding the generic difference in the shells.

Achatina zebra. Pl. 20. Fig. 110. A small example of the West African type of the grenus, showing the truncated columella of the shell, and thin, unreflected lip.

Achatina (Spiraxis) nigricays. Pl. 20. Fig. 111. Shell illustrative of the section of polished horny texture, chicfly inhabiting Central America.

\section{Genus 5. ACHA'IINELLA, Swainson.}

Animal; with four tentacles, the upper ones clubbed at the end, elongated and eyed, the lover ones short and slightly clavate; surface of the body covered with numerous gianulations; foot long, narrow, tapering belind. (Newcomb.)

Shell; rather small, conical, sometimes turreted, dextral or simistral, imperforate, or only very slightly umbilicated; whorls sia to seven in mumber, very rarely sculptured; columella short, mostly callously twisted; lip rather thickened, rarely reflected.

The numerous scries of gaily painted shells, which constitute this genus, are rather similar in character, and they are mostly of an uniform small size. The most striking feature of the group is their very restricted range of habitation. The whole are natives of one isolated locality, the Sandwich Islands, where they take the place of the Bulimi and Achatince of the Continent. None of the Achatinelle appear in the 'Systema Nature.' The same year in which Capt. Cook discovered the Sandwich Islands, Linnæus died. Twenty years afterwards, a straggler found its way into the last plate of Chemnitz's 'Conchylien Cabinet,' but where it came from, nobody kncw, and it was described as a sea shell,-Turbo lugubris sinistrorsus. 
Nearly half a century passed away, and M. Deshayes's edition of Lamarck's great work appeared without any tidings of this abundant Sandwich Island Snail. Some species had, ir the meantime, reached M. de Férussac in France, Mr. Swainson in England, and Professor Green in the United States. So recently as 1550 , I felt proud of a monograph of five-and-forty species, fifteen of which were new; but the especial researches, amid the hamnts of the Aclatinelle, of Mr. Frick and Dr. Newcomb, have since then increased the number to nearly two hundred.

\section{Species.}

1. abbreviata, Reeve.

2. acuta, Newc.

3. Adansoni, id.

4. adusta, Reeve.

5. aftinis, Neroc.

6. albida, $P f r$.

7. albolabris, Newc.

8. amœna, $P f i$.

9. ampla, Neroc.

10. apicata, $i d$.

11. aplustre, $i d$.

12. aptycha, $P f r$.

13. assimilis, Newc.

14. attenuata, $P f r$.

15. bacca, Reeve.

16. Baldwinii, Newc.

17. bella, Reeve.

18. bilinenta, $i d$.

19. Buddii, Newc.

20. bulimoides, Swain.

21. candida, Pfi:

22. castanea, Reeve.

23. cerea, $P \int r$.

24. cestus, Nexc.

25. Chamissoi, Pfr.

26. chlorotica, $i d$.

27. cinnamomia, $i d$.

28. cinerosa, $i d$.

29. citrina, Migh.

30. clara, $P f r$.

31. Clementina, id.

32. colorata, Reeve.

33. concinna, Nercc.
34. conspersa, $P f r$.

35. comea, Nenc.

36. corneola, Pfr.

37. crassa, Nevoc.

38. crassidentata, $P f r$.

39. crassilabrum, Neroc.

40. Cumingii, Newc.

41. cuneus, Pfr.

42. curta, Newe.

43. cylindrica, $i d$.

44. decipiens, $i d$.

45. decora, Fériss.

46. dentata, $P f r$.

47. dimidiata, $i d$.

48. dolium, id.

49. dubia, Nerec.

50. Dunkeri, Cum.

51. duplicata, Newc.

52. Dwighti, $i d$.

53. elegans, $i d$.

5 t. elevata, $i d$.

55. Enmersonii, $i d$.

56. extincta, Pfr.

57. Ferussaci, $i d$.

58. flavescens, Newc.

59. Forbesiana, Pfr.

60. Fricki, $i d$.

61. fulgens, Newc.

62. fulva, $i d$.

63. fumosa, $i d$.

64. fusca, $i d$.

65. fusiformis, $P f r$.

66. gemma, $i d$.
67. Germana, Newc.

68. gigantea, $i d$.

64. glabea, $i d$.

70. globosa, Pfir.

71. glutinosa, $P f r$.

72. goniostoma, $i d$.

73. Gouldi, Newo.

74. gracilis, $P f r$.

75. gुrana, Newc.

76. Grayana, $P f i$.

77. grisea, Newc.

78. glossa, Pfi.

79. Hanleyana, $i d$.

80. Helena, Newc.

81. humilis, $i d$.

82. hybrida, $i d$.

83. inflata, Pfr.

84. intermedia, Newc.

85. irregularis, $P f r$.

86. Johnsonii, Newc.

87. labiata, $i d$.

88. lanceolata, $i d$.

89. lorata, Féruss.

90. luctuosa, $P f r$.

91. lugubris, Chemn.

92. lurida, Pfi.

93. macrostoma, $i d$.

94. Maniensis, Newc.

95. Mastersi, $i d$.

96. margarita, $P f r$.

97. melanostoma, Newc.

98. melanotis, $i d$.

99. Mighelsiana, Pfr. 
100. minuscula, $i d$.

101. mœsta, Newc.

102. monacha, $P f r$.

103. mucronata, Nexce.

104. multicolor, Pfr.

105. multilineata, Neroc.

106. mustelina, Migh.

107. napus, $P f r$.

108. nigra, Newc.

109. nitida, $i d$.

110. nivosa, $i d$.

111. nobilis, Pfr.

112. nubilosa, Migh.

113. nucleola, Gould.

114. obclavata, $P f r$.

115. obeliscus, $i d$.

116. obesa, Neroc.

117. obscura, $i d$.

118. obtusa, $i d$.

119. olivacea, Reeve.

120. ornata, Newc.

121. oryza, $P f r$.

122. ovata, Nezoc.

123. oviformis, $i d$.

124. pallida, Nutt.

125. perdix, Reeve.

126. perversa, Swain.

127. petricola, Newc.

128. Pfeifferi, $i d$.

129. physa, $i d$.

130. picta, Migh.

131. planospira, $P f r$.

132. plicata, Migh.
133. polita, Nevo.

134. porcellana, $i d$.

135. porphyrea, $i d$.

136. prasinus, Reeve.

137. producta, $i d$.

139. pulchella, $P f r$.

139. pulcherrima, Swain.

140. pulla, Neve.

1.1. pupoidea, $i d$.

142. pyramis, $P f r$.

143. radiatus, $P f r$.

14. recta, Newc.

145. Redfieldi, id.

146. Remyi, $i d$.

14.7. reticulata, $i d$.

149. rosea, Swain.

119. rubens, Gould.

150. rubiginosa, Neroc.

151. rudis, Pfr.

152. rufa, Newc.

153. rugosa, $i d$.

154. rutila, $i d$.

155. sanguinea, $i d$.

156. semicarinata, $i d$.

157. semicostata, $P f r$.

159. simulans, Reeve.

159. solitaria, Newc.

160. sordida, $i d$.

161. soror, $i d$.

162. Sowerbyana, Pfr.

163. spirizona, Féruss.

16 t. splendida, Newc.

165. Stewarti, Green.
166. straminea, Reeve.

167. subvirens, Newc.

168. succincta, Pfr.

169. suffusai, Reeve.

170. sulcuta, Pfr.

171. Swainson, $i d$.

172. Swiftii, Newc.

173. teniolata, Pfr.

174. terebra, Neroc.

175. teres, Pfr.

176. tessellata, Newc.

177. Tetrao, $i d$.

178. transversalis, $P f r$.

179. tristis, Féruss.

180. turgida, Newo.

181. turritella, Féruss.

182. umbilicata, $P f r$.

183. undulata, Newc.

184. valida, $P f r$.

185. variabilis, Newc.

186. ventulus, Féruss.

187. ventrosa, $P f r$.

188. venulata, Newc.

189. venusta, Migh.

190. vidua, $P f r$.

191. violacea, Neroc.

192. virgulata, Migh.

193. viridans, $i d$.

194. vitrea, Nexc.

195. vittata, Reeve.

196. vulpina, Féruss.

197. Zebrina, Pfr.

\section{Figure.}

Achatinella decora. Pl. 20. Fig. 113. A reversed species; a strong, callously twisted columella, and thickened, but not reflected, lip.

Genus 6. PARTULA, Férussac.

Animal; similar to that of Bulimus.

Shell ; acuminately ovate or oblong, generally obliquely produced 
tonards the base, dextral or sinistral, but litlle umbilicated; uhorls five to sia, more or less smooth or mimutely line-engraved; columella thickened, fatly appiessed ; aperture somewhat squarely ovate; lip broadly flatly reflected, sometimes callous.

Partula is another genus peculiar to Polynesia, but not restricted, like Achatinella, to a particular group of islands. It inhabits equally the Sandwich Islands, the Society Islands, the Friendly Islands, the Navigators', and the Ladrones. It is a dwarf representative of the Continental genus Bulinus, and follows in this respect the general law of geographical distribution affecting the animals and plants of islands of comparatively recent submergence remote from the mainland.

The species are not so numerous as those of the preceding genus, but are tolerably abundant, and form an equally natural group. They are much alike in form and substance, and are all more or less conspicuously engraved with fine spirally impressed lines; whilst the aperture is peculiar in being produced somewhat obliquely, and in having mostly an ear-like aspect, owing to the callous thickening of the lip being invariably broadly flatly reflected.

\section{Species.}

1. amabilis, Less.

2. auricula, Féruss.

3. brumalis, Reeve.

4. Carteretensis, Quoy.

5. compressa, $P f r$.

6. decussatula, $i d$.

7. denselineata, Reeve.

8. dentifera, Pfr.

9. faba, Martyn.

10. filosa, $P f r$.

11. Ganymedes, $P f r$.

12. gibba, Quoy.

13. glutinosa, Pfr.

14. gonocheila, $i d$.
15. Guamensis, id.

16. Hebe, $i d$.

17. hyalina, Brod.

18. inflata, Reeve.

19. Isabelina, $P f r$.

20. lineata, Less.

21. Macgillivrayi, Pfr.

22. micans, $i d$.

23. Mastersi, $i d$.

24. mucida, $i d$.

25. Navigatoria, $i d$.

26. nitens, $i d$.

27. nodosa, $i d$.
25. Otaheitapa, $P f r$.

29. Pacifica, $i d$.

30. radiolata, $i d$.

31. repanda, $i d$.

32. Reeveana, $i d$.

33. rosea, Brod.

34. rubescens, Reeve.

35. Salomonis, $P f r$.

36. solidula, Reeve.

37. spadicea, $i d$.

38. stenostoma, $P f i$.

39. suturalis, $i d$.

40. varia, Brod.

\section{Figure.}

Palztula faba. Pl. 21. Fig. 115. Shell, showing the square, ear-like aperture, with its flattened, broadly reflected lip. 


\section{Genus 7. BULIMUS, Scopoti.}

Animal; moderately large, having a well-developed head, furnished with four cylindrical retractile tentacles, of rhich the two upper. ones are the more prominent, bearing the eyes at their extremities; shin mostly gramulaterl; mantle not reflected on the shell; disk large, lanceolate belind.

Shell; ovate, oblong, or turreted, whorls sometimes few and ventricose, sometimes numerous and contracted, fragile, and often transparent; mostly firm, covered not unfiequently with a double hydrophanous epidermis; columella straight, sometimes one-plaited, never truncated at the ent; aperture with the margins disjoined; lip either simple or reflected.

Under the head of Bulimus are included all the oblong and elongated forms of Snails, distributed almost universally throughoont the mainland and adjacent islands of both hemispheres, of which the rounded and more numerous forms belong to Ilelix. The Achulince being separated, as we have seen, from the Bulimi by reason of the truncature of the columella; the number of Bulimi proper, compared with the IIelices, are as one to two. In both these genera the number of species known was comparatively limited, until an expedition was made some thirty years ago by Mr. Cuming to westem South America, and another subsequently to the Philippine Islands. "It was in 1536," relates Mr. Broderip, "that Mr. Cuming proceeded to the Philippine Islands, by permission of the Queen Regent of Spain, and aided by powerful recommendations from her government, which opened to him the interior of the islands, and caused him to be received with a noble hospitality, equalled only by the warm interest which facilitated his pursuits wherever he arrived and made himself known." Species of which we had but an imperfect knowledge, owing to the imperfect condition in which a stray specimen chanced to reach the cabinet of the comnoisseur, were found in luxuriant plenty, and many new species were discovered in their airy solitude on the tree branches, or concealed among the fallen leaves, in equal abundance. Other travellers were stimulated to the same degree of enthusiasm, and the richly-rrooded forests of Bolivia and Venezucla, combining the snail-producing elements of food and temperature in similar luxuriance in the opposite hemisphere, have been ransacked, chiefly by plant-collectors, with similar success.

Upon the completion of my monograph of this genus in the "Conchologia Iconica,' I was tempted to draw up a summary of the views which had presented themselves to me on the general geographical distribution of the 
Bulimi, and on the modification of their shell to the local physical conditions in which the species live.* It ran as follows:-

The Bulimi are distributed over the equatorial, tropical, and warm temperate regions of the globe in assemblages of species, limited in their range, and of very distinct typical character; and being of sluggish habits with few means of transport, little migration occurs even where there are no such natural boundaries as seas, deserts, or mountain chains. Of the Butimi known from all parts of the world, the localities of nearly 600 species are now well authenticated. Their area of geographical distribution lies between $40^{\circ} \mathrm{S}$. and $35^{\circ} \mathrm{N}$. in the new world, and between $42^{\circ} \mathrm{S}$. and $52^{\circ}$ to $55^{\circ} \mathrm{N}$. in the old world; - that is, between the southern borders of Chili and Texas in the former, and between Van Diemen's Land and Germany, if not Sweden, in the latter. And there is no country within this area of which the genus of snails under consideration does not form part of the zoology. There is one abnormal species, B. lubricus, removed from the genus by British authors (Zua lubricu), which obtains a more northerly range and a greater elevation in both hemispheres.

Regarding the differences of form, composition, and disposition of colour in the shell, the Bulimi are distributed over this area in seven provinces, comprising about forty typical assemblages of species. Of these threefifths inhabit the western hemisphere, principally Central America, and two-fifths have a wider range and greater local variety of character, in conformity with the more varied arrangement of the land, in the eastern. Taking the size and substance of the shell at different clevations and in different degrees of temperature, it may be remarked that the calcifying energies of the Bulimi are most strongly exerted in thickly wooder districts, in the midst of plenty of decaying vegetable matter, close and humid, with a mean heat of from $80^{\circ}$ to $85^{\circ}$, among shady thickets or in ravines. Near the sea-level in thin calcareous soil, and in sandy plains, where the vegetation is scanty and parched, and in grassy savamnahs, the shell is thin and often vividly coloured. In those species whose habit it is to burrow in the ground, the shell is mostly small, patternless, and of glassy tenuity, even in localities remote from each other and differing materially in physical character.

The Westery Heuispinere comprises four grand provinces of distribution, the Venezuelan, the Brazilian, the Chilian, and the Bolivian, and from these may be further distinguished the districts of the Galapagos Islands and of the Great Antilles. The first province includes the countries of New Granada and Venezuela; the second comprises the empire of Brazil and Buenos Ayres; the third comprises Chili and West Peru; and the fourth province includes Bolivia and the Argentine liepublic. About three hundred and fifty species have been described fom this hemisplere.

\footnotetext{
* Read before the Royal Society in 1851 .
} 


\section{The Venezuelan Province.}

The highest condition of the genus is in intertropical America, which yields nearly one-half of the number of species known from all parts of the world. In the luxuriant districts of New Granada and Venezuela, watered by the tributaries of the Magdalena and Orinoco rivers, with a temperature varying from $70^{\circ}$ to $100^{\circ}$ in the shade, about sixty species have been collected at different altitudes. On the mountain-sides near the sea, away from the land breezes, with little vegretation, where the thermometer never falls below $80^{\circ}$, are a few species, B. erectus, Cacticolus, etc., of which the shell is extremely thin and sombre from the want of moisture for the animal, which is curiously spotted and painted, and attaches in clusters to the parched Cacti, eating into their fleshy substance. The animals of the beautifully variegated shells of the Philippine Bulimi are of a uniform dull grey colour. These contrasts between animal and shell are worth noting. Higher up on the mountains of Venezuela for the space of about 2,000 feet, the country being still of a sandy and stony nature, with little vegetation except Cacti and other dry prickly plants, and a few trees in the ravines, the Bulimi are still comparatively small, but the shell is more brilliant in colour. B. Curianensis, Knorri, and Studeri are beautiful examples of this type, of which the darker varicties inhabit the higher and woodier situations. They are rarely found at a greater elevation, or in a lower temperature than about $76^{\circ}$ within doors. Proceeding upwards on the mountains of Tenezuela, the plants become thicker, and give place to lirge trees, with underwood of broad green leaves, enveloped in clouds and mists which occasion considerable humidity. In these situations at an elevation of from 4,000 to 6,000 feet are the richly-coloured $B$. fulminans and Blaimilleunus, and at a still greater altitude reaching to 8,000 feet, with a proportionately lower temperature of from $65^{\circ}$ to $70^{\circ}$, under decayed leaves in thick moist woods, in ravines and in crevices of the mountains, are the large stout dark-painted B. Moritianus, astrapoides, pardalis, Funckii, etc., representing the most highly calcified condition of the genus hitherto discovered.

\section{The Brazilian Province.}

Passing in a south-casterly direction into the great territory of Brazil, we have no information of the presence of any typical assemblages of Bulimi until reaching the countries of Bahia and Minas Geräes. It can hardly be doubted, however, that in Guayana, Pará, and all that country constituting the great basin of the Amazon, many fine species occur, in addition to $B$. Bensoni, which belongs to the widely spread $B$. zebra type, as well as in Piauliy, Goyaz, and the more sterile parts of Pernambuco. From Bahia southwards to Rio Janeiro, the genus is represented by about sixty species, in six characteristic typical groups, extremely local, and of 
which the shell differs remarkably in its plan of convolution. In no part of the American continent is the theory of specific centres of creation, advocated by Professor E. Forbes, so distinctly recognized as in this area of ten degrees. On the Corcovado and other lofty mountains in the vicinity of Rio, in dense woods at an elevation of 1,000 to 1,500 feet, is a singular group, B. Pantagruelinus, exesus, ortontostoma, Pupoides, etc., of which the shell differs from all other types of the New World, in having a number of tooth-like processes developed within the aperture of the last whorl on arriving at maturity. The only country in which this character again appears is in the centre of the Old World, among the smaller and more temperate species of Syria and Hindoostan. In this part of Brazil we have also another type, peculiar to the locality, in which the last whorl is produced in front into a longitudinally angled channel, as in B. goniostoma, egregius, angulatus, fusiformis, etc. Upon the leaves of damp underwood, at an elevation of about 2,000 feet, is another distinct and brilliantly coloured group, B. multicolor, Miersii, and the large B. ovatus, which inhabits also the neighbouring island of St. Catharina. In the lower grounds upon orange-trees and in the coffee plantations about Tejuca at 1,000 feet above the sea-level, the Bulimi, as in the lower parts of Venezuela, have their shells characteristic of less moisture and ferrer opportunities of retirement. B. papyraceus may be quoted as an example. The more lofty and thickly wooded parts of Minas Gerïes produce a type with shells of solid growth and intertropical brilliancy of colour, represented by B. Milleri, bilabiatus, planidens, melanostomu, etc. In the vicinity of Bahia is a group with shells of totally different construction and of lighter substance, B. navicula, auris-leporis, etc., in which the last whorl is convoluted transversely, at a right angle with the axis of the spire. Lastly, at Caravelhas, below Bahia, and at the little island of Coxaprego, at the mouth of the Iguaripe river, is a remarkable type, represented by B. calcareus, obeliscus, sylvaticus, ete., of which the shell, presenting a singular contrast with the preceding group, is composed of a large number of whorls, drawn out into the elongated form of a Turritella. This partial grouping of opposite forms, within a comparatively limited area having ferw natural boundaries, will doubtless become broken up to a certain extent with the spread of human population. Already have the climate and natural vegetation of Rio been modified by the clearing away of the neighbouring forests of the Corcovado range of hills, which tends to reduce the humidity and other circumstances that combine to favour the growth and calcification of the terrestrial mollusca.

Owing probably to the recent geological disturbances that are supposed by Lyell, Darwin, and others to have taken place in the southern extremity of the American continent, there are no typical provinces of Bulimi below Rio. The genus is represented by one or two scattered species in 
Buenos Ayres, extending in the widely-distributed B. sporalicus to the banks of the Rio Negro, but none are recorded from the sterile, riverless plains of Patagonia. That the genus should be suddenly arrested at this point in a tropical condition, without any of the graduated forms which abound in the north temperate countries of both hemispheres, is doubtless owing to the upraising of the land in this part of South America, which Mr. Darwin considers to have occurred within the period of the now-existing sea-shells. Mr. Cuming collected worn shells of Tolutu Brasiliana (a species liring on the shores of Bucnos Ayres) in a bank of other dead sea-shells fifty miles inland. The climate is many degrees warmer in Patagonia and Tierra del Fuego than in the same latitude of the northern hemisphere. "Evergreen trees," says Mr. Dirwin, "flourish luxuriantly under it, humming-birds may be seen sucking the flowers, and parrots feeding on the secels." Snails being of less fugitive character than birds, and having fewer means of transport than plants, appear not to have inigrated thither. The sea which washes the shores of Patagonia is peopled with a fauna of more tropical character than the land, owing to the warmth of the great equatorial current, which flows southward along the Eastern coast of South America, and causes a bend in the system of isothermal lines laid down by Humboldt of nearly ten degrees. A fine lirge richly painted Volute, $r$. Mugellunica, in common use among the Patagonians as a drinking-cup, inhabits their shore abundantly. Yet the northem limit of this genus does not approach the Mediteriancan nor any part of Europe. It is right howerer to add, that a species of Cymba, to which genus $T$. Hagellanica is the nearest allied form of Tolute, has been very recently dredged off Lisbon by Mr. M'Andrew.

\section{The Chitian Province.}

Crossing to the west side of the American continent and returning northward, we are impressed with the marked difference between the Bulimi on the west and those on the east side of the chain of the Andes. In the sindy plains of Chili, where there is little moisture beyond that arising from the dews, the Bulimi, about thirty-five in number, are mostly sunll, with thin, often transparent shells, having little of colour or marking. Towards the mountains at the roots of shrubs, on dead trunks of trees or under Cacti, are several species distributed somewhat miscellaneonsly in respect of form, as B. granulosus, erythrostoma, Pupiformis, etc., Nent the sea-shore they assume a more distinct typical character, of which the shell, Succinea-like, is widely inflated, and owing to the dry calcareous nature of the soil and absence of vegetation is extremely thin, brittle, and simply dark-speckled. The B. Broderipii, punctulifer, rupicolus, and reflexus are characteristic examples. Surrounded with few of the conditions which serve for the formation of shell, the calcifying functions of 
this group are but feebly exercised. They exist for many months together in the crevices of rocks in a state of torpidity, and are only roused during the excessive dews. "Wait till the dews come," said a Chilian one day to Mr. Cuming, "and they will all come to life again."

In the warmer, but still comparatively rainless district of Peru, the Bulimi have more brightly-coloured shells, with more variety of pattern. They are about as numerous in species as those of Chili, under as many types. In the more arid parts of Peru, upon the mountains, the shell is thin, as in B. varians, tigris, lemniscatus, and tumidulus, compared with those inhabiting more woody districts on the eastern side of the Andes. They have, moreover, a colder aspect than those of the same latitude in Brazil, on account of the more scanty nature of the vegetation, the lesser humidity of the atmosphere, and the cold precipitated from the antarctic drift current which flows in a northerly direction along the western shores of South America nearly to the equator. The effect of moisture and consequent amount of decaying vegetable matter in promoting the formation of shell is curiously illustrated by the presence of a stout richly-coloured species of large size, B. phasianellus, on the rainy border of Peru, where they crawl up the stripped trees in great abundance; and by the B. Tupacii, dwelling on bushes and garden walls on the Bolivian side of the Andes at an elevation of 9,000 feet, which has a robust darkpainted shell similar to those of the equally lofty Venezuelan type. $B$. rosacens, which inhabits a wide range of country, extending from the environs of Valparaiso, near the sea, to Cocapata in Bolivia, crouches under stones in the sand in the first-named locality, and has a pale, smooth, calcareous shell. But in the woods of Cocapata, where it lives in more humid situations among the trunks of trees, the shell is larger, stouter, more richly coloured, and with more of epidermis. Thus we have the change which characterizes different species, presented in the same species under different couditions. Another remarkable instance is presented in B. zebra. This species inhabits an area of Central America enclosing Honduras, Nicaragua, the West Indies, and Pernambuco, reaching to the shores of Peru, and produces a shell varying so much in character according to the physical conditions under which it is formed, that it has been described as several species. The same thing has occurred with B. regina, which in its range from New Granada and Guayana to Bolivia and the interior of Peru, affects a condition partaking in each instance of the local conchological character of the country.

\section{The Bolivian Province.}

From Bolivia and the Argentine Republic about forty Bulimi are described, illustrative of six types. The large Brazilian B. oratus, living near the coast, is here represented in the heart of the continent, at Santa Cruz, 
by the gigantic B. maximus and Valenciennesii inhabiting the dense forests of the Cordilleras with B. lacunosus and a few other allied forms. Another type with shells of stout growth is represented by B. T'upacii, thamnoicus, and inca; and an extremely interesting form is presented in $B$. onca, found by M. D'Orbigny at the bottom of a deep ravine near Tutulima. A few species with delicately painted shells, constituting another group, inhabit the woods in the vicinity of Cochabamba, B. linostoma, xunthostoma, fusoides, etc.; and a characteristic group with shells of light structure, freely marked but not highly coloured, is typified by B. poecilus, hygrohylceus, marmarinas, oreades, etc. The ground-burrowing species, with extremely thin shells devoid of colour or pattern, consist of $B$. bacterionides, lichnorum, turritella, etc. Two or three species have been collected on the mountains surrounding the Lake of Titicaca, which is itself 14,000 feet above the level of the sea. Of these B. Pentlandi and Hamiltoni may be quoted as examples. In the high lands of the Cordillera range, commencing at the Lake of Titicaca, passing along the region of medicinal barks, as laid down by Weddell, to Cuzco, Chachapoyas, and the Andes of Caxamarca, and extending across the equator by Quito, Bogotá, and Merida, nearly to Caraccas, many fine species have been collected, but of too miscellaneous a variety of form to show any typical assemblages. From this extensive and little-explored region we have B. labeo, Adlamsoni, Thompsoni, rhodolarynx, Hurtwegii, Alto-Peruvianus, alutacens, Taylorianus, murrinus, Lobbii, Clansilioides, and columellaris, singularly different from each other, and differing altogether from the Bulimi of Bolivia and La Plata. There is, however, one well-defined group inhabiting the southern extremity of the Cordillera range at Merida and Bogotá, of which B. Cathcartia, Teranyi, Succinoides, and quadricolor are characteristic examples. They have peculiarly inflated richly coloured shells, and are covered with a delicate hydrophanous epidermis disposed in hieroglyphic patterns after the manner of the Philippine Bulimi.

\section{Central America.}

Of the remaining Bulimi of the American continent, about ten species inhabit the central neck of land which comprises the countries Veragua, Panama, Costa Rica, Nicaragua, Honduras, and Guatemala. Fourteen species have been collected in the hilly parts of Mexico; and two or three species scattered in California, Texas, and Alabama, constitute the northern limit of the genus in the new world. The Bulimi of Central America are very distinct from those of which we have been speaking hitherto. $B$. Panamensis, vexillum, translucens, and unicolor from Panama, $B$. corneus from Real Llejo, B. discrepans from Conchagua, and B. Hondurasanus, and Dysoni from Honduras, are all characterized by a thin transparent horny shell of the same type. They have little pattern or variety of colour, and 
live upon the trunks of trees or under fallen leaves. None of the South American types have any representatives in Central America. There is, however, a single species in Honduras, $B$. Kieneri, belonging to a singular Cyclostoma-like type, which belongs evidently to Jamaica, where it is represented by B. Gossei, turricula, unicarinatus, cylindricus, and Guildingii. In Mexico the Bulimi are more varied. Five species, B. Mexicanus, serperastrus, livescens, Humboldtii, and nitelinus, in which the shell is of a light, brittle structure, oblong form, and simply dark-banded, belong to a type quite peculiar to this locality, extending in B. Californicus to the opposite peninsula. At Vera Cruz, on the eastern side of Mexico, a Bolivian type appears in B. Lattrei, Jonasi, and fenestratus. A very remarkable type is presented in the Mexican B. Dombeyanus, which is at present unique. B. labiatus and Schierlianus, which are almost colourless, partake of the typical character of $B$. confinis and liquabilis inhabiting Texas, and of $B$. dealbutus inhabiting Alabama, which is the most northern species of the genus in this hemisphere.

\section{Islands of the Western Hemisphere.}

The terrestrial conchology of the islands of the western hemisphere is for the most part typically distinct from that of the continent, and the more so in each particular group of islands in proportion to their distance from the main-land. This receding gradation of types is distinctly shown in the Bulimi of the Great and Little Antilles. In the first group of islands this genus has but a meagre share in the conchology, which conprises more of Cyclostomata. In the latter group the Bulimi, passing southward, are gradually larger and more painted, and exhibit a relationship with those of the neighbouring continent. Jamaica, Cuba, and Tortola yield a fer species of the Cyclostoma type, B. Gossei, turricula, etc., just spoken of as appearing at Honduras in B. Kieneri; but there are more of the ground-burrowing glassy type, such as $B$. subula, octonoiles, Goodhalli, and pauperculus inhabiting the savannahs. B. immaculatus is a rather large species, and B. mirabilis, remarkable for its squamate growth, is quite unique as a type. In Guadaloupe and Martinique, connecting the leeward and windward of the West India Islands, $a_{\omega}$ few species occur with shells of darker and more solid growth, as B. Guadaloupensis, Martinicensis, and clirysalis. In the principal islands of the Little Antilles approximating to the South American continent, the Bulimi increase in size and colouring, gliding distinctly into the types of the Venezuelan province. The richly painted B. fulminans and Blainvilleanus of Merida are represented in the island of St. Vineent by B. auris-Sileni; the delicate B. rosealus and runlhostoma of Bogotá by B. stramineus and Fincentimus in the same island; and $B$. glaber, a robust species of Trinidad, is represented in the nearest main-land of Venezucla by B. distortus and euryomphalus, and in New Granada by B.perdix. 
The Galapagos Islands contribnte about ten species of Bulimus, small in size and of a dusky hue, agreeing in this respect with what has been observed by Mr. Darwin in reference to the dusky colour of the birds and insects. B. eschariferns and mugulosus from Chatham Island, B. ustulatus, nux, and unifusciatus from Charles Island, B. Jucoli and miferus from Jacob Island, B. calvus from James Island, and B. Darwinii and sculpturatus, of which the particular jsland has not been noted, are all typically distinct from the Bulimi of the neighbouring continent. A species has however been very recently discovered, $B$. achatellinus, partaking of the character of Achatinella, an allied genus of snails singularly confined to the Sandwich Islands. The Bulimi of the Galapagos Islands seem, nevertheless, to be purely aboriginal, living among dried tufts of grass, upon comparatively leafless bushes, or under detached picces of lava, and presenting obvious indications of the voleanic nature of the soil and desert character of the vegetation.

The Polynesian Islands have no Bulimi except one or two small transparent ground-burrowing specics, $B$. Antoni and Oparanus from the island of Opara, B. Tuclievi from IIardy's Island, and B. Sandwicensis from the Sandwich Islands. Their absence is, however, compensated by the presence of two other genera of land-snails which are not found anywhere else. In the Society, Marquesas, Friendly, and Navigators' Islands the Butimi are represented by the Partula; in the Sandwich Islands by the Achatinelle.

The Bulimi of the Eastenn Hemispinene are more partial in their character and distribution than those of the western, owing to there being less explored land within the parallels of latitude enclosing the conditions most favourable to their existence. In West $A$ frica they are replaced by a tribe of large Achatine. But in the localities which they inhabit within this intertropical area, comprising chiefly the islands of the Indian Archipelago, they are more numerous in species in proportion to the extent of land. The Bulimi of the old world have a wider range in the warm temperate regions, and the geographical position of the genus is more insular than continental. As many species have been collected in the Philippine Islands alone as in the whole extent of continent between Sweden and Cochin China. The eastern Bulimi, comprising about two hundred and fifty species, present three grand typical provinces of distribution, which may be termed the Caucasian, the Malayan, and the African. The limits of these provinces are well marked, and they possess no species in common. The species are all distinct from those of the western hemisphere.

\section{The Cancasian Province.}

The Caucasian province has its centre in Asia Minor, and occupies an area extending west and east over the sonthern countries of Europe and 
Asia to the opposite shores of North Africa. At the eastern limit of this province in the British Isles and at the western limit in the Meia-co-shinalı Isles, the shell is of the same form, substance, and colour. The shell of the Caucasinn Bulimus is small, mostly white or dusky brown, sometimes convoluted sinistrally, and partakes very much of the character of $P$ upa, which is the predominant genus of this district. At the north-זrestern extremity of the Caucasian province the grenus is represented in the British Isles, Germany, France, Spain, and Portugal by the small B. obscums, montanus, and acutus. The first of these extends to South Sweden, fifteen to twenty degrees nearer the Arctic Circle than in the new world, agreeably with the curve of Humboldt's isothermal lines in that direction, illustrative of the warmer comparative temperature of this portion of the eastern hemisphere. In B. ventrosus and decollatus the genus obtains a more southern range, extending into Sicily and the Canary Islands. The Butimi of the Canary Islanls are, however, for the most part indigenous. Of the following specirs inluabiting this group, B. variatus, Moquinianus, obesatus, baticatus, Bertheloti, subliuphanus, only the last is foumd in any other locality, the Cape de Verd Islands. No Canary Island Bulimus has been collected in Portugal, Spain, or Sicily, but a species has been found to range along with B. barlbarus, rupestris, and Bergeri over Greece and the eastern islands of the Mediterranean to Algeria and the borders of Egypt. $B$. detritus, subtitis, and quinquententatus may be noted as belonging more especially to Austria and Central Europe, and B. Farnensis, Frivaldstiyi, and Chersonesicus to Turkey and the Crimea. Towards the vicinity of the Caucasus the Bulimi are more numerous, of larger and more solid growth, and more divided into groups. Owing to the dry juiceless thorny character of the vegetation, their habits difler from those of the humid and woody countries of intertropical America. Their shells are comparatively small, with little colouring matter or epidermis, and they live under stones or blocks of rood, or suspended for a long season in a state of torpidity from the shrubs. The difference between the shell of the Caucasian and that of the Malayan or Venezuelan Bulimi is very characteristic of the physical conditions with which the animal is surrounded in each instance. B. labrosus, labiosus, Alepi, Syriacus, and Ehrenbergi are true Caucasian types. In B. Sprattii and Lycicus the shell has a light and ventricose growth, but in B. spotiatus, zebriolus, and Tournefortianus it has an elongated Pupa-like form.

Passing the south-western countries of Asia we find no species of Bulimus recorded from any locality between Syria and Afghanistan. Of the terrestrial conchology of Persia, Tartary, and Beloochistan, nothing is at present known, and very little of that of China. South of Syria a natural boundary is imposed to the range of the genus in that direction by the rainless and riverless deserts of Arabia. A few species make their appear- 
ance in the more fertile parts near the Gulf of Bab-el-mandeb and the Indian Ocean. B. Tatireflerus, a fine species inhabiting the vicinity of Mriskat on the Gulf of Oman, has a polished shell of solid, stony composition, withont colour or marking, of precisely the same type as B. labiosus and labrosus of Asia Minor. B. firagosus and Forslialii inhabiting Yemen, also patternless, assimilate to the tumid tribe of Pupce of $\Lambda$ sia Minor. Abysinia and the neighbouring island of Socotrn, marking the eastem boundary of the Cancasian province, contribute two species from each locality, one of which species in both instances belongs to an Indian type, the other being remote from it. B. Olivicri of Abyssinia has an inflated shell, with a dark fibrous epidemis rery distinct in character from any Asiatic or Luropean species, while $B$. Abyssinicus from the same locality has been collected also in Central India, north of the river Nerbudda. It is allied in form with B. Jerloni from the hilly districts of the Decean peninsula, and both species agree in typical character with B. frugosus of Arabia. B. Sucotrensis, inhabiting the island of Socotra, off Cape Guardiatui, has a peculiar little solid pea-shaped shell unique as a type; but as sectated with it in the same locality is an oblong cylindrical form, $B$. couligmus, belonging to a type of Hindoostan, represented by B. pullus, inhabiting the environs of Delli and Bundelkhund and cxtending into the Gangetic plains.

In the south-western countries of Asia the genus is very meagrely represented, but the species are peculiar in their circumstances of habitation. Two of comparatively large size occur on the hills of $A$ fghanistan, B. Griffithisi and eremitu, with opaque colourless shells partaking of the Syrian type. From the whole of Hindoostan, including the Ilimalaya range, the Punjab, Scinde, Nepaul, Bhotan, Assan, the Deccan, and Carnatic, only tive-and-twenty species have been collected, limited apparently in number of individuals. In the plains watered by the numerous branches of the Ganges, with a temperature varying in the season of the hot winds from $85^{\circ}$ to $90^{\circ}$ at night, to $130^{\circ}$ or $140^{\circ}$ in the sun, the Bulimi are scattered and of miscellaneous character. On the wooded hills ri-ing into a moist and cooler atmosphere they are more abundant. B. rmfistrifulus at an elevation of 4,000 feet has a fulvous, horny, oblong shell. B. conopictus and tutulus, inhabiting a lower level, are minute delicate brown species, the latter being convoluted in the form of a rounded Cyclostoma. B. pullus is a light cylindrical form, B. cereus and gracilis are thin, horny species, and B. punctutus, Bontice, and Bengalensis have light inflated shells of a type altogether different. The most characteristic Bullimi inhabiting this part of $A$ sia are those of the Ilimalaya range, $B$. Kunavurensis, pretiosus, vibex, nivicola, celebs, and arcuatus. Their shells are of a fulvous brown colour, mostly streaked with opacue white marks, all uf one type, distinct from the Syrian, but suficiently allied to come into 
the same province of distribution. Occupying a loftier situation than the species before mentioned, they have, as in Venezuelis, stouter shells, but are still comparatively small and sombre. On the mountain slopes, where the Flora, represented by the rhododendron and juniper, is of a subarctic character, the genus inhabits a much colder temperature in elevation than it reaches in either hemisplere in latitude. Two species, B. arcuatus and nivicola, are found in the Liti Pass at an elevation of 14,000 feet on juniper bushes among patches of snow at the hottest period of the year. This is the only locality in which the genus approaches the snow-line. The plysical conditions of India below the Emodic or Alpine region of vegetation are not calculated to favour the growth of Butimi. In the plains there is a scarcity of wood and forest, such as we liave noticed to serve so materially for the production of these snails in South America; and the burning of the thickets in the hill countries for the pasturage of cattle, offers the same obstacles to their growth and increase as the clearing aray of the virgin forests in Brazil.

\section{The Malayan Province.}

The Malayan province of the genus, which comprises the islands of the Indian Archipelago, commences on the south-western corner of the Asiatic continent, where it is represented at Burmah by $B$. Sylheticns and in Siam by $B$. atricallosus. These species are of a totally different type from any of the Butimi of Hindoostan, and agree precisely with that characteristic Malayan type which appears at Java, Timor, Celebes, and Amboyua in $B$. citrinus, lavus, contusus, chloris, and sinistralis, at Borneo in B. Adansii, at Ceylon in B. Ceylanicus, and at Mindanao, the most southern of the Philippine Tslands, in B. maculiferus. B. fulyuratus and malleatus, having an inflated shell with a winding plait upon the columella, represent a type peculiar to the Feejee Islands. B. mittocheilus, with a wax-like fusiform shell and brilliant vermilion lip, from Christoval Island, one of the Solomon's Group, is unique as a type. B. filurutus and Caledonicus, with large robust shells of dark chestnut-brown colour, red internally, represent another very distinct type in the island of New Caledonia, but this appears agrain twelve degrees further south at Auckland, North Island of New Zealand, in the only species inhabiting that group, B. Shongii. It is worthy of notice, that this large, stout, tropical-looking Butinus is under the same latiturle of the eastern hemisphere, which is characterized in the western hemisphere by the delicate species of the dry, sandy countries of Chili and Buenos Ayres.

The Bulimi of the Philippine Islands, which are very numerous and of large size, belong chielly to one type, represented by $B$. pyythoy:ste', bicoloratus, lignarius, fulgetrum, nimbosus, and others. The shell of this type is not so much distinguished by colour, as by the presence of a double 
membranous epidermis, to which the different species are indebted for their characteristic patterus. B. Cumingii, Leaii, and a few others, belong to another type of which the shell is inflated, and mostly shining white, with only a very slight single epidermis. About eighty species of Bulimus have been collected in the twenty-two islands of the Philippine group, all extremely local in their range of habitation. With the exception of about half-a-dozen of the eighty, each species is confined to its particular island. The equable climate of these islands, the excessive rains, and woody character of the regetation, combine materially to favour the growth of snails. They live some on the branches of the trees and in shady recesses, and others among light thickets on the outskirts of the woods. The large species are strictly arboreal, and deposit their eggs standing on end in parallel rows upon a leaf. 'The transparent, horny, ground-burrowing type which appears at Hindoostan in $B$. cerens and gracilis, and at Java in $B$. Achatinucens, is here represented by B. elongutulus and Panayensis.

The only species collected in China are B. decorticatus, belonging to the ground type, which is universal, and B. Cantori, from the environs of Nanking. They belong to the Caucasian type, which reaches the islands of 'Ty-pin-san and Koo-kien-san of the Neia-co-shimal group of the Ycllow Sea in B. Anglicoilles found under decayed leaves among the loose stones which surround the tombs.

Of the Bulimi of Australia little is at present known. One species, $B$. utomatus, with a large, dark-coloured inflated shell, has been collected at Port Macquarric, one small species, B. trilineutus, at Port King George, and two, B. Kingii and influtus, of which the precise locality is unknown. Two species with thin, dusky shells, $B$. melo and Dufiesniz, inhabiting Tan Diemen's Land, constitute the southern limit of the genus in the eastern hemisphere.

\section{The African Province.}

The African province includes all that explored portion of the continent below Senegal on the west side, and Zanzibar, including the islands of Mauritius and Madagascar, on the east. In the intertropical area along the west const of Africa, extending from latitude $15^{\circ} \mathrm{S}$. to $15^{\circ} \mathrm{N}$, the Butimi are replaced in great measure by a group of large Achatine, which inhabit principally the hot and swampy districts on the banks of the Gambia, Num, Gaboon, and Niger rivers, and reach in a modified form to the sandy plains of Loanda. The shells are large, inflated, and richly dark-painted, and the shells of the few Bulimi that are associated with them belong to the same characteristic type. The two genera meet at this point. Bulimus corrilus of Liberia and Achatina Sulcycti belong to the same natural type, notwithstanding that they are referred to different genera. B. Adansoni, diricanus, tenebricus, turtinatus, flammeus, Numidicus, and interstinctus 
belong also to the Achatina type. B. neuricus, Guineensis, and vivipara are three fragile species of different habits from the same country, and another type is presented in B. tumefuctus and pemplligodes with peculiarly globose inflated shells. As an instance of the mingling of types on the confines of the great provinces of distribution which meet in North Africa, it may be remarked that $B$. Ruppellianus inhabiting the eastern confines belongs to this Achatina type, and B. reticulutus inhabiting the western belongs to the Syrian Bulimus type, which is exactly the reverse of the general typical character of the Bulimi in these localities. B. Downsii, found abundantly at Princes Island off the coast of Guinea, inhabits also the nearest mainland. At St. Ifelena a small brown species is found, $B$. Helena; and in the more elevated parts of the island, in an apparently semifossil state, the remains of an extinct type, $B$. auris-vulpina, are found. Mr. Darwin, who observed this well-known species at St. Helena imbedded in the soil, attributes the extinction of it to some recent geological disturbances, which caused the entire destruction of the woods and consequent loss of food and shelter to the snails.

Nothing is known of the Bulimi of Africa, south of the tropics, excepting those described by Dr. Krauss from the neighbourhood of Natal. Eight species collected in this part are of very miscellaneous character, but typically distinct from those of the west coast. B. Natalensis, conulus, and spadiceus are thin and globosely convoluted, B. Burchellii and meridionalis are of light ovate form, and B. linearis and turreformis are elongated. They are all small. A very remarkable species has, however, been discovered in this locality, $B$. Kranssii, nearly equal in size to the largest Butimus of tropical America, and as brilliant in colour. F'rom Mozambique we have but one small light species, $B$. Mozambicensis. In Madagascar are two species of large size and elongated form, B. clavator and obtusatus, differing essentially from any of the continental types; and in the Seychelle Islands are tro, B. fulvicans and velutinus, partaking in some measure of the smaller Natal species. In Mauritius there is only one small ground species, $B$. clavulinus.

\section{Species.}

1. Abyssinicus, Rupp.

2. abyssolum, $D^{\prime}$ Orb.

3. Achatinaceus, $P f r$.

4. acuminatus, Sow.

5. acutus, Miüll.

6. Adamsii, Reeve.

7. Adamsoni, Gray.

8. Adansoni, $P f r$.
9. adoptus, Reeve.

10. Egle, Brod.

11. affinis, $i d$.

12. Africanus, Reeve.

13. albatus, Fér.

14. albicans, Brod.

15. albizonatus, Reeve.

16. Alepi, Fér.
17. Alto- Peruvianus, Rve.

18. alternans, Beck.

19. alutaceus, Reeve.

20. ambustus, $i d$.

21. Andicola, Pfr.

22. angiostoma, Wagner.

23. angulatus, $i d$.

24. Antoni, Pfr. 
25. aplomorphus, Jonas. 26. apodemetes, $D^{\prime} O r \cdot 6$.

27. aquilus, Reeve.

28. arcuatus, $P f r$.

29. astrapoides, Jonas.

30. atomatus, Gray.

31. atricallosus, Gould.

32. auratus, $P f r$.

33. auripigmentum, Reeve.

34. auris-bovina, Lam.

35. auris-leporis, $i d$.

36. auris-Midæ, Chemn.

37. auris muris, Mor.

38. auris-Sileni, Born.

39. auris-vulpina, Chemn.

40. bacterionides, $D^{\prime} O r b$.

41. badiosa, Fér.

42. badius, Sow.

43. bæticatus, Fér.

44. Bahiensis, Moric.

45. Bairdii, Reeve.

46. balanoides, Jonas.

47. barbarus, Linn.

48. Bengalensis, Lam.

49. Benguelensis, $P f r$.

50. Bensoni, Reeve.

51. Bergeri, Pfr.

52. Bertheloti, $i d$.

53. bicolor, Sono.

54. bidens, Krynicki.

55 . bicoloratus, Lea.
71. Burchellii, Gray.

72. Cacticolus, Reeve.

73. calcareus, Born.

74. Caledonicus, Petit.

75. Californicus, Reeve.

76. caliginosus, $i d$.

77. Calista, Brod.

78. calvus, Soro.

79. Calypso, Brod.

80. camelopardalis, $i d$.

81. canaliculatus, $P f r$.

82. candelaris, $i d$.

83. cantatus, Reeve.

84. Cantorii, Plitippi.

85. Caraccasensis, Reeve

86. carneus, $P f r$.

87. castaneus, $i d$.

88. castrensis, $i d$.

89. castus, $i d$.

90. ceratinus, Benson.

91. cereus, Reeve.

92. cerussatus, $i d$.

93. Ceylanicus, $P f r$.

94. Chersonesicus, Sono.

95. Chilensis, Lesson.

96 . Chimborasensis, $R$

97. chloris, $i d$.

98. chrysalidiformis, Sow.144. Curianensis, $i d$.

99. chrysalis, Pfr.

100. cincinniformis, Sow.

101. cincinnus, $i d$.

120. concinnus, Sowo.

121. confinis, Reeve.

122. confusus, $i d$.

123. coniformis, Pfr.

126. constrictus, Pfr.

129. conulus, $i d$.

corneus, $i d$.

132. corouatus, $P f r$.

133. Cosensis, Reeve.

134. costatus, Pfr.

135. coturnix, Sow.

138. Cretensis, $P f r$.

139. Crichtoni, Brod.
117. columellaris, Reeve.

118. compactus, Friv.

119. concentricus, Reeve.

124. connivens, Reeve.

125. conspersus, Sow.

127. contiguus, Reeve.

128. contortuplicatus, $i d$.

130. Coquimbensis, Sow.

136. crassilabris, Gray.

137. crepundia, D'Orb.

140. crystallinus, Reeve.

141. culmineus, D'Orb.

56. bilabiatus, Brod.et Soro. 102. cinereus, Reeve.
57. bifulguratus, Reeve.

58. bilineatus, Sovo.

59. bivittatus, $i d$.

60. Blainvilleanus, $P f r$.

61. Boholensis, Brod.

62. Boissieri, Moric.

63. Bolivianus, Pfr.

64. Bolivianus, $i d$.

65. Bontiæ, Chemn.

66. Boysianus, Benson.

67. breviculus, Pfr.

65. Bridgesii, $i d$.

69. Broderipii, Sow.

70. bullula, Brod.
108. cinnamomeo-lineatus, 148 . c.

148. cylindricus, Gray.

104. citrino-vitreus, Moric. 150. dactylus, Brod.

105. citrinus, Brug. 151. Daphnis, $i d$.

106. Clausilioides, Reeve. 152. Dardanus, Friv.

107. clava, $i d$.

108. clavator, Petit.

153. Darwinii, Pfr.

154. dealbatus, Say.

109. clavulinus, Potiez. 155. deceptus, Reeve.

110. coagulatus, Reeve. 156. decollatus, Linn.

111. coarctatus, Pfr. $\quad$ 157. decoloratus, Sow.

112. cochleades, $i d$. 158. decorticatus, Reeve.

113. cuelebs, Benson. 159. decussatus, $i d$.

114. ccenopictus, Hutton. 160. delumbis, $i d$.

115. coloratus, Nyst. 161. demotus, $i d$.

116. columella, Philippi. 162. Denisoni, id. 
163. dentatus, King.

164. depstus, Reeve.

165. depictus, $i d$.

166. derelictus, Brod.

167. Deshayesii, Pfi.

168. detritus, Miill.

169. Diana, Brod.

170. digitale, Reeve.

171. dilatatus, $P f r$.

172, discrepans, Sow.

173. distortus, Brug.

174. Dombeyanus, Fér.

175. Dominicus, Reeve.

176. Downesii, Gray.

177. Draparnaudi, Pfr.

178. Dryas, Brod.

179. Dufresnii, Leach.

180. Dunkeri, Pfr.

181. durus, Spix.

182. Dussumieri, —?

183. Dysoni, Pfr.

184. eburneus, $i d$.

185. effeminatus, Reeve.

186. effusus, $P f r$.

187. egregius, $i d$.

188. Ehrenbergi, $i d$.

189. electricus, Reeve.

190. electrum, $i d$.

191. elegans, Pfr.

192. elongatulus, $i d$.

193. eous, Reeve.

194. erectus, $i d$.

195. eremita, Benson.

196. erosus, Brod.

197. erubescens, Pfr.

198. erythrostoma, Sow.

199. eschariferus, $i d$.

190. Euboicus, Reeve.

201. euryomphalus, Jona

202. evanescens, Brod.

203. exesus, Spix.

204. exiguus, Reeve.

205. exilis, Gmelin.

206. exornatus, Reeve.

20\%. fabrifactus, $i d$.

208. fasciolatus, Oliv.
209. Faunus, Brod.

210. Favanii, Lam.

211. fenestratus, $P f i$.

212. feriatus, Reeve.

213. ferrugineus, $i d$.

214. Ferussaci, Dunker.

215. fictilis, Brod.

216. fidustus, Reeve.

217. flammeus, Miill.

218. folliculus, Pfr.

219. formosus, Gray.

220. Forskalii, Beck.

221. foveolatus, Reeve.

222. fragosus, Fér.

223. frater, $i d$.

224. fraterculus, $i d$.

225. Frivaldskyi, $P f r$.

226. fucatus, Reeve.

227. fulgetrum, Brod.

228. fulguratus, Jay.

229. fulminans, Nyst.

230. fulvicans, Pfi.

231. Funckii, Nyst.

232. fuscagula, $D^{\prime}$ Orb.

233. fusiformis, Rang.

234. fusoides, $D^{\prime}$ Orb.

235. gallina-sultana, Fav. 281. hygrohylæus, D'Orb.

236. gastrum, Ehrenberg. 282. ignavus, Reeve.

237. gelidus, Reeve.

238. geometricus, Pfr.

239. gibber, Krynicki.

240. Gibbonius, Lea.

241. gilvus, Sow.

242. glaber, Gmetin.

243. glandiformis, Lea.

244. glomeratus, Reeve.

245. goniostoma, Fér.

246. Goodallii, Miller.

247. Gossei, Pfr.

248. Goudoti, Petit.

249. gracilis, Hutton.

250. gracillimus, $P f i$.

251. Granadensis, $i d$.

252. granulosus, Rang.

253. Grateloupi, Pfr.

254. Grayanus, $i d$.
255. gregarius, Adms.\& $R$.

256. Griffithsii, Benson.

257. Gruneri, $P f r$.

258. Guadaloupensis, Brug.

259. Guerini, $P f$ 。

260. Guildingii, $i d$.

261. Guimarasensis, Brod.

262. Guineensis, Jonas.

263. guttatus, Brod.

264. Hachensis, Reeve.

265. Hamiltoni, $i d$.

266. Hanleyi, $P f r$.

267. harpa, $i d$.

268. harpa, $i d$.

269. Harrisii, Reeve.

270. Hartwegii, Pfr.

271. Hegewischi, $i d$.

272. Helena, Quoy.

273. Hennahi, Gray.

274. heterotrichus, Mor.

275. Hindsii, $P f r$.

276. Hohenackeri, Kryn.

277. holostoma, Pfr.

278. Hondurasanus, $i d$.

279. Huascensis, Reeve.

280. Humboldtii, $i d$.

283. immaculatus, Adans.

284. imperator, Pfr.

285. impressus, Reeve.

286. Inca, D'Orb.

287. incomptus, Sow.

288. inflatus, Lamarck.

289. inglorius, Reeve.

290. interstinctus, Gould.

291. inutilis, Reeve.

292. irregularis, $P f r$.

293. irroratus, Reeve.

294. Jacobi, Sow.

295. Jamaicensis, Reeve.

296. Janeirensis, Sow.

297. Jayanus, Lea.

298. Jerdoni, Benson.

299. Jonasi, Pfr.

300. juglans, $i d$. 
301. Jussieui, $V a l$.

302. Kellettii, Reeve.

303. Kieneri, Pfr.

304. Kingii, Gray.

305. Knorri, Pfr.

306. Kraussi, $i d$.

307. Kunawurensis, Hutt.

308. labeo, Brod.

309. labiosus, Miüll.

310 . labrosus, Oliv.

311. lactarius, Menke.

312. lacunosus, $D^{\prime} \mathrm{Or}$.

313. lætus, Reeve.

314. lievus, Miill.
347. Lycicus, $P f r$.

393. multifasciatus, Lam.

348. Lymnoides, Lamarck.394. murrinus, Reeve.

349. Lyonnetianus, Pallas.395. mus, Brod.

350. macilentus, Reeve. 396. mutilatus, Reeve.

351. macrostoma, Pfr.

352. maculatus, Lea.

397. myristicus, $i d$.

398. nanus, $i d$.

399. Natalensis, Krauss. 400. navicula, IV agn.

35 t. malleatus, Jay.

355. Manoelii, Mor.

356. manupictus, Reeve.

401. neglectus, Pfr.

402. neuricus, Reeve.

357. marmarinus, $D^{\prime} \mathrm{Or} b$. 403. nigrofasciatus, $P f r$.

358. Martinicensis, Pfr. 404. nigropileatus, Reeve.

359. mavortius, Reeve. 405. nigrilineatus, $i d$.

360. maximus, Sow. $\quad 406$. Nilagaricus, $P f i$.

315. Lamarckianus, $P f i$. 361. Meiacoshimensis, $A d$. 407. nimbosus, Brod. 316. Largilliertii, Philippi.362. melanocheilus, Nyst. 408. nitelinus, Reeve.

317. latebricola, Benson. 363. melanostoma, Swain. 409. nitidulus, Pfr.

318. latireflexus, Reeve. 364. melo, Qroy. 410. nitidus, Brod.

319. Lattrei, Pfr.

320. Laurentii, Soro.

321. Leai, $P f i$.

322. lemniscatus, Desh. 323. leopardus, $P f r$.

324. leucodon, id.

325. lencophrus, Sow.

326. Liberianus, Reeve.

327. lichenorum, $D^{\prime} \mathrm{Or}$.

328. lignarius, $P f$.

329. lilacinus, Reeve.

330. liliaceus, Guilding.

331. Limensis, Reeve.

332. limonoicus, $D^{\prime} O r b$.

333. linearis, Krauss.

334. lineatus, Spix.

335. linostoma, D'Orb.

336. liquabilis, Reeve.

337. lithoicus, $D^{\prime} O r b$.

338. litus, Fér.

339. livescens, $\mathrm{Br}$.

340. lividus, Reeve.

341. Lobbii, $i d$.

342. Loewii, Philippi.

343. Loxensis, Pfr.

34.4. lucidus, Reeve.

345. lubricus, Miüll.

346. Luzonicus, Sow.
365. membranaceus, Phil. 411. nivicola, Benson.

366. Merduenianus, Kryn. 412. nobilis, Reeve.

367. Meridanus, $P f i$. 413. nucinus, $i d$.

368. meridionalis, $i d$. 414. nucleus, Sow.

369. Mexicanus, Lam. 415. Numidicus, Reeve.

370. micra, D'Orb. 416. nux, Brod.

371. micra, $i d$.

372. Miersii, Sow.

373. Milleri, $i d$.

374. miltocheilus, Reeve. 420. obliquus, Reeve.

375. Mịnosarum, D'Ort. 421. oblongus, Mïll.

376. Mindoroensis, Brod. 422. obscurus, $i d$.

377. minimus, Adams. 423. obtusatus, Gmel.

378. mirabilis, $i d$. 424. obtusus, Drap.

379. modestus, Brod. 425. occultus, Reeve.

380. mollicellus, Reeve. 426. octonoides, Adans.

381. monilifer, Pfr. 427. odontostoma, Gray.

382. moniliferus, Gould. 428. olivaceus, Pfi.

383. monozonus, $P f r$. $\quad 429$. Olivieri, $i d$.

384. Montagnei, $D^{\prime} \mathrm{Or} b$. 430. onager, Beck.

385. montanus, Drap. $\quad$ 431. onça, D'Orb.

386. Monte-Vidensis, Pfr.432. opalinus, Sow.

387. montivagus, $D^{\prime}$ Orb. 433. Oparanus, $P f r$.

388. Moricandi, Pfr. 434. Orbignii, $i d$.

389. Moritzianus, $i d$ 4 435. Oreades, D'Orb.

390. Mozambicensis, id. 436. oryza, Brug.

391. muliebris, Reeve. 437. ovatus, Miüll.

392. multicolor, Rang. 438. ovoideus, Brug. 
439. ovulum, Reeve.

440. pallens, Jonas.

441. pallidior, Sozo.

442. Panamensis, Brod.

443. Panayensis, Pfr.

4. Pantagruelinus,

445. papyraceus, Maroe

446. pardalis, Fér.

447. Partuloides, Brod.

448. patricius, Reeve.

449. pauperculus, Adans.

450. Pazianus, $D^{\prime} O{ }^{\prime} 6$.

451. pellucidus, $P f r$.

452. pemphigodes, Jonas.

453. Pentlandi, Reeve.

454. perdix, Pfr.

455. perspectivus, $P f r$.

456. Peruvianus, Brug.

457. pessulatus, Reeve.

458. Petiti, Pfr.

459. Pfeifferianus, Reeve.

460. phasianellus, $V a l$.

461. Philippinensis, $P f r$.

462. Philippii, Pfr.

463. pictor, Brod.

464. Physoides, Menke.

465. pintadinus, D'Orb.

466. piperatus, Sozo.

467. planidens, Mich.

468. plectostylus, Pfr.

469. pocilus, $D^{\prime}$ Or.b.

470. politus, Reeve.

471. polygyratus, $i d$.

472. Popelairianus, Nyst.

473. porphyrius, Pfr.

474. Powisianus, Petit.

475. prætextus, Reeve.

476. pretiosus, Cantor.

477. primula, Reeve.

478. primularis, $i d$.

479. proximus, Sow.

480. pruinosus, $i d$.

481. pseudo-Succinea,Mor.527. rugulosus, $i d$.

482. pubescens, Mor.

483. pudicus, Linn.

484. puellaris, Reeve.

486. pullus, Gray.

491. pupa, Linn.

501. Quitensis, $i d$.

504 . redditus, $i d$.

505. Reevii, Brod.

506. reflezus, $P f r$.

507. regina, Fér.

513. rimatus, $P f r$.

521. rudis, Anton.
485. pulicarius, Recve.

487. pulverulentus, $P f r$.

488. punctatus, Anton.

489. punctulatissimus, Less.535. Satyrus, Brod.

490. punctulifer, Sow.

492. Pupiformis, Broa?.

493. Pupoicles, Spix.

494. purpuratus, Reeve.

495. pustulosus, Brod.

496. pyramidalis, Sow.

497. pythogaster, Fér.

498. quadricolor, $P f r$.

499. quadridens, Miill.

502. Recluzianus, $i d$.

503. reconditus, Reeve.

508. reticulatus, Reeve.

509. rhodacme, Pfr.

510. rhodocheilus, Reeve.

511. rhodolarynx, $i d$.

512. rhodostoma, Gray.

414. ringers, Dunker.

515. Rivasii, $D^{\prime} O r b$.

516. Romblonensis, Pfr.

517. rosaceus, King.

518. roseatus, Reeve.

519. Rossmässleri, Pfr.

520. rubrifasciatus, Reeve. 566. spadiceus, Menke.

522. mufistrigatus, Benson. 568. spectralis, $i d$.

5:3. rufogaster, Lesson.

524. rufo-niger, $F e ́ r$.

525. rugatus, Reeve.

526. rugiferus, Sov.

528. rupestris, Phil.

529. rupicolus, Reeve.

530. Ruppellianus, $P f r$.
567. spectatus, Reeve.

536. Sayi, Pfr.

537. scabiosus, Sont.

538. Scalariformis, Brod.

539. Scalarioides, Reeve.

540. Schiedeanus, Pfr.

541. scitulus, Reeve.

54\%. sculpturatus, $P f r$.

54.3. scutulatus, Brod.

544. seductilis, $P$ fr.

545. segregatus, Benson.

547. sex-dentatus, Spix.

548. Shongi, Lesson.

549. Sidoniensis, Fér.

550 . signatus, W Tagn.

551. signatus, Sow.

552. Sikkimensis, Reeve.

553. simplex, Jonas.

554. Sindicus, Benson.

555 . sinistralis, Reeve.

556. Siquijorensis, $P f r$.

557. smaragdinus, Reeve.

558. Socotrensis, Pfr.

559. solidus, $i d$.

560. solitarius, Poiret.

561. solivagus, Reeve.

562. solutus, Troschel.

563. sordidus, Lesson.

564 . sordidus, $i d$.

565. Sowerbyi $P f$

569. Spixii, Wagn.

570. spoliatus, Parreyss.

571. sporadicus, $D^{\prime} O r b$.

572. Sprattii, Pfr.

573. spretus, Reeve.

574. stabilis, Sow.

575. stramincus, Guild.

576. striatus, King. 
577. strigatus, Sow.

578. Studeri, $P f r$.

579. subearinatus, $i d$.

580. subdiaphanus King.

581. subsemiclausus, Pet.

582. subtilis, Rossmïster.

583. subula, Pfi:

5S4. subuliformis, DLoric.

585. succinctus, Reeve.

586. Succinoides, Petit.

587. suffusus, Reeve.

588. sulcosus, $P f r$.

589. Sylheticus, Reeve.

590. Sylvanus, Brod.

591. sylvaticus, $\mathbb{W}$ agner.

592. Syriacus, $1 P f r$.

593. treniolus, Nyst.

594. Taunaysii, Fér.

595. Tauricus, Lang.

596. Taylorianus, Reeve.

597. tenebricus, $i d$.

598. tenuissimus, Fér.

599. tepidulus, Reeve.

600. terebella, Adans.

601. terebralis, $P f r$.

602. terebraster, F'́r.

603. thamnoicus, $D^{\prime} O i \cdot$.

604. Thompsoni, $P f$ r.

605. Ticaonicus, Brod.

606. tigris, Brod.
607. torridus, Gould.

609. Tournefortianus, Fér. 638. ustulatus, $i d$.

6019. translucens, Brod.

610. transparens, Reeve.

611. tribalteatus, Reeve.

612. trichodes, $D^{\prime} \mathrm{O} \cdot \mathrm{r}$.

613. tricinctus, Reeve.

614. tridens, Brug.

61.). trifasciatus, Chemn.

6]6. trilineatus, Quoy.

617. trilineatus, $i d$.

618. truncatus, $P f r$.

619. Tuckeri, Pfr.

6:20. tumefactus, Reeve.

6:21. tunidulus, $P f r$.

62:. Tunetanus, Reeve.

623. Tupacii, D'Orb.

$6: .1$ turbinatus, Lea.

62.5. turricula, $P f r$.

626. turriformis, Kranss.

6::7. turritella, $D^{2} \mathrm{Or} b$.

6:28. turritus, Brod.

629. tutulus, Benson.

6:30. uber, $P f \%$.

631. umbilicaris, Soul.

63:. umbraticus, Reeve.

6i3. undulatus, Guild.

6:31. unicarinatus, Lam.

(53.). unicolor, Sow.

636. unidentatus, $i d$.
637. unifasciatus, Soro.

639. variatus, Webl \& Ber.

640. varians, Brod.

641. Varmensis, Friv.

642. velatus, Brod.

643. velutinus, $P f r$.

644. venosus, Reeve.

645. ventricosus, Drap.

646. ventrosus, Fúr.

647. Veranyi, Pfr.

648. verecundus, Reeve.

649. versicolor, Brod.

650. vibex, Hutton.

651. vimineus, Mror.

652. Vincentinus, Pfi。

653. virens, $i d$.

654. virgulatus, Fér.

655. vittatus, Spix.

656. Voithianus, Pfi.

657. Wagneri, id.

658. Woodianus, Lea.

659. xanthostoma, $D^{\prime} O r b$.

660. Yungasensis, $i d$.

661. zebra, Miill.

662. zebriolus, F'́r.

663. Ziebmanni, $P \int r$.

664. Ziegleri, $i d$.

665. zonulatus, idl.

666. zoographicus, D'Orb.

\section{Figures.}

Bulmuds rosaceus. Pl. H. Fig. 1. Shell, with animal, showing its specific characteristic of red granulations, and two pairs of tentacles, the lower being always the shorter.

Bulmids oblongus. Pl. H. Fig. 2. Shell, with animal, showing the skin to be still granulated, but of the same uniform colour.

Bulnudus onca. Pl. 21. Fig. 116. A fine Bolivian species, discovered by M. D’Orbigny in a deep ravine near Tutulima, on the north-easi side of the Eastern Cordilleras. 


\section{Genus 8. HELIX, Linncus.}

\section{Animal; similar to that of Bulimus.}

Shell; globose or orbicularly depressed, mostly smoolli, generully covered with an epidermis; spire ralher obtuse, but little raised; aperture transverse; lip mostly reflected.

Little can be said of this genus that has not been said already in speaking of Bulimus. The animal is the same. The form of shell which it includes, namely, all that are globose or orbicularly depressed, cmbraces about twice as many species in number, but a much larger proportion that are small. Dr. Pfeiffer enumerates 1,674 species, including thirty-one of the type Streptaxis and four of Tomigerns, and some additions lave since been made to this number in the Proceedings of the Zoological Society. But his list comprises many that have not been verified by observation, and I shall therefore content mysclf by quoting the 1,500 species which I have examined, described, and figured in the 'Conchologia Iconica.'

The remarks on the geographical distribution of the Butimi apply very generally to the Ilelices, except that they liave a more extended range to the north. The proportion of Helices to Bulini in the United States and adjacent territorics of North America is as 79 to 11, while in the particular State of Massachusetts, whose isothcrmal parallel of temperature is that of Scotland, there are sixteen Helices and no Bulimus but the B. lutrieus, which is an abnormal form of the genus, separated, with reason, by British authors under the name of Zna.

\section{Species.}

1. abjecta, Love. $\quad$ 17. æruginosa, $P f r$.

2. abnormis, $P f r$.

3. acies, Parts.

4. actinophora, Lowe.

5. acuducta, Bens.

6. aculeata, Miïl.

7. acuminata, $P f r$.

8. acuta, Lam.

9. acutimargo, $P f$.

10. Adansoni, Webb.

11. adusta, Sow.

12. adusta, Hinds.

13. advena, Tebb.

14. xgrotus, Reeve.

15. æmula, Rossm.

16. ænea, Krauss.
18. afficta, Fér.

19. Africana, $P f r$.

20. Aglaja, $i d$.

21. agreabilis, Zieg.

22. alabastrites, Mich.

23. alauda, Fér.

24. Albaiensis, Sow.

25. Albanica, Zieg.

26. Albersi, Pfr.

27. albicans, $i d$.

28. albidens, Bens.

29. albolabris, Say.

30. Alexandri, Gray.

31. algira, Lim.

32. alliaria, Mill.
33. alligans, Adams.

34. Alonensis, Fér.

35. alpina, Bign.

36. alternata, Say.

37. alveus, Adans.

38. Amazonica, Pfr.

39. ambigua, Adans.

40. amicta, Reeve.

41. ammoniformis, $D^{\prime} O r \cdot b$.

42. Ammonitoides, Reeve.

43. ammonoceras, $P f r$.

44. ampulla, Bens.

45. ampullarioides, Reere.

46. anaglyptica, $i d$.

47. anceps, Gould.

4.8. Andicola, $P f$. 
49. angigyra, Zieg.

50. angistoma, F'ér.

51. anguiculus, Reeve.

52. angulata, Fúr.

53. angustata, $i d$.

54. angustispira, Adams.

55. Annatonensis, $P f r$.

56. annulata, Sow.

57. annulifera, $P f r$.

58. anomala, Adans.

59. Anthoniana, id.

60. antiqua, $A d$. and Rve.

61. antiquorum, Leach.

62. aperta, Born.

63. apex, Adans.

64. apia, Homb.

65. appendiculata, $P \int r$.

66. appressa, Say.

67. apicina, Lam.

68. approximata, Le Guill.

69. aprica, Kranss.

70. Arabica, Terv.

71. arata, Sow.

72. arboreoides, Adams.

73. arborea, Suy.

74. arbustorum, Limn.

75. arcta, Loxe.

76. arctispira, Pfi:

77. arcuata, $i d$.

78. areolata, Soro.

79. argentea, Reeve.

80. argillacea, Fér.

S1. argonautula, Webb.

82. arietina, Rossm.

83. Armeniaca, Pfr.

84. Armida, $i d$.

S5. armillata, Lowe.

86. Armitageana, Lowe.

87. arridens, Lowe.

88. aspera, Fér.

89. asperella, $P f f^{\circ}$.

90. aspersa, Mïll.

91. atrata, $P f r$.

92. atrolabiata, Kryn.

93. Atropos, Fér.

94. attrita, Lowe.
95. Auberi, D'Orb.

96. Audebardi, Pfr.

97. Audouinii, $D^{\prime} O{ }^{\prime} b$.

98. aulacospira, $P f r$.

99. aulica, $i d$.

100. aurata, Sow.

101. auricoma, Fér.

102. auriculata, Say.

103. auriculina, Petit.

104. auridens, Rang.

105. auris, $P f r$.

106. australis, Menke.

107. avara, Say.

108. avellana, Fér.

109. avus, $P f r$.

110. Baconi, Bens.

111. Bactriana, Hutt.

112. badia, Fér.

113. Bahamensis, Pfi。

114. Bainbridgii, $i d$.

115. Bajadera, $i d$.

116. Balmei, Potiez.

117. balteata, Sorv.

113. Banatica, Parts.

119. barbatula, Reeve.

120. barbula, Charp.

122. Easkcrvillei, $i d$.

123. Bataviana, Busch.

124. Beckiana, Pfi:

125. Belangeri, Desh.

126. Belcheri, Pfr.

127. bella, $i d$.

128. Berlanderiana, Mor.

129. Bermudensis, Pfr.

130. Berytensis, Fér.

131. Besckei, Dunk.

132. Bethencourtiana, Sht.178. buccinella, Pfr.

133. biangulata, Pfr.

134. bicallosa, Friv.

135. bicarinata, Sorv.

136. biconcava, Pfr.

137. bicostata, $i d$.

138. bidens, Chemn.

139. bidenticulata, Bens.

140. bifasciata, Bur\%.
141. bifrons, Lowe.

142. bifurcata, Desh.

143. bigonia, Fér.

144. bilamellata, $P f r$.

145. bilineata, $i d$.

146. Binneyana, $i d$.

147. bipartita, Fér.

148. bisculpta, Bens.

14.9. bistrialis, Beck.

150. bisulcata, $P f r$.

151. bituberculata, $i d$.

152. Blandiana, Adams.

153. Bogotensis, Pfr.

154. Boholensis, $i d$.

155. Boissieri, Charp.

156. Boivini, Petit.

157. Bombayana, Grat.

15\&. bombycina, $P f r$.

159. Bonplandi, Lam.

160. Boothiana, Pfr.

161. Borneensis, $i d$.

162. Bomii, Chemn.

163. Bourcieri, Pfi.

164. bracliyodon, Sozo.

165. Brardiana, Pfr.

166. Brasiliana, Desh.

168. brevior, Adams.

169. brevipila, $P f r$.

170. brevis, Adams.

171. Bridwilli, Pfr.

172. Broderipii, $i d$.

173. Bronni, $i d$.

174. Brookei, Ad. \& Rve.

175. Bruguieriana, Pfr.

176. Brumeriensis, Forbes.

177. brunnea, Anton.

179. Buchi, Dubois.

180. Buddiana, Adams.

181. Buffoniana, Pfr.

182. bulla, id.

183. bullacea, $i d$.

184. bullula, Hutton.

185. Bulweriana, Lowe.

186. buonobæua, D'Orb. 
197. bursatella, Gould. 188. Busbyi, Gray.

189. Buschi, Pfi。

190. Butleri, $i d$.

191. cacuminifera, Bens.

192. caduca, Pfr.

193. caducior, Reeve.

194. cxrulans, Miihlf.

195. czlatura, Fér.

196. Caffra, $i d$.

197. Cailliaudi, Desh.

198. calamechroa, Jonas.

199. calcarea, $P f r$.

200. calculus, id.

201. Californiensis, Lea.

202. caliginosa, $A d$. \& $R$. 248. cespitum, Drap.

203. callifera, $P f$.

204. calva, Lowe.

205. campanula, Pfr.

206. Campbelli, Gray.

207. campecina, Ezq.

208. Candaharica, Pfr.

209. candicans, Zieg.

210. candidissima, Drap.

211. candidula, Stud.

212. canescens, $A d$. \& $R$.

213. Cantiana, Mont.

214. Capensis, Pfr.

215. caperata, Mont.

216. capitanea, Pfr.

217. capitium, Bens.

218. caput-spinulæ, Reeve.

219. cara, Adams.

220. Carascalensis, Fér.

221. carbonaria, Sow.

222. Carica, Roth.

223. cariosa, Oliv.

224. cariosula, Mich.

225. Carmelita, Tér.

226. carneola, Pfr.

227. carnicolor, Fér.

228. carocolla, Limn.

229. Caroni, Desh.

230. Carseolana, Fér.

231. Carthusiana, Muill.

232. Cassiquiensis, Newc. 278. circumdata, Fér.

250. Ceylanica, $P f r$.

252. Charpentieri, Pfr.

253. Chastellii, Fér.

256. Chenui, $i d$.

257. Chiliensis, Mïhl.

274. cingulella, Zieg.

276. Circe, Pfr.

277. circulus, $i d$.
279. circumfirmata, Red.

280. circumlineata, Kust.

281. circumornata, Fér.

282. circumsessa, Shuttl.

283. citrina, Linn.

284. Clairvillia, Fér.

285. clathratula, Pfr.

286. clausa, Rafin.

287. Cleryi, Recl.

288. climacterica, Bens.

289. Clymene, Shuttl.

290. coactiliata, Fér.

291. Cobresiana, Aten.

292. codonodes, $\mathrm{Pfr}$.

293. Codringtoni, Gray.

294. cognata, Fér.

295. collodes, Sow.

296. collyrula, Reeve.

251. chalicophila, D'Orb. 297. coluber, Beck.

298. columbaria, Sow.

299. Columbiana, Lea.

254. cheiranthicola, Lowe. 300 . columellata, Adams.

255. Chemnitziana, Pfr. 301. coma, Gray.

302. compacta, Lowe.

303. compar, $i d$.

304. complanata, Desh.

305. compressa, Zieg.

306. compressivoluta, Rve.

307. concavospira, $P f r$.

308. concisa, Fér.

309. concolor, $i d$.

310. conformis, $i d$.

311. conicoides, Metc.

312. coniformis, Fér.

313. connectens, Adams.

314. connivens, Pfr.

315. conoidalis, $A d$. \& $R$.

316. conomphala, Pfr.

317. consanguinea, $A d$.

318. consolvina, Fér.

319. consona, Zieg.

320. consors, Lowe.

275. cinnamomea, Valenc. 321. conspersula, Pfr.

322. conspurcata, Drap.

323. Constantina, Forbes.

324. constricta, $P f r$. 
325. consul, $P f r$.

326. contermina, Sluttl.

327. continua, $P f r$.

328. contorta, Fér.

329. conus, Phil.

330. convexa, Rafin.

331. Cookiana, Gmel.

332. Coreyrensis, Part.

333. Coreanica, $A d$. \& $R$

334. Coresia, Gray.

335. coriaria, $P f r$.

336. cornea, Diap.

337. corneo-virens, Pfr.

338. corniculum, $i d$.

339. cornu-giganteum, Ch.385. deflexa, Pfr.

340. cornu-militaris, Limn. 386. delibrata, Gould.

34. 1. coronata, Desh.

342. corylus, Reeve.

4.43. cosmia, Pfro

344. costata, Miill.

345. costellata, $D^{\prime} \mathrm{Or} \cdot$.

346. costulata, Zieg.

34\%. costulifera, $P f \%$.

348. cotyledonis, Bens.

349. crassicostata, $i d$.

350 . crassidens, $P f r$.

351. crassilabris, $i d$.

352. crebriflammea, $i d$.

353. cretata, Brod.

354. Cretica, Fér.

355. crinigera, Bens.

356. crispata, Fér.

357. Croatica, Part.

358. cromyodes, $P f r$.

359. cruentata, Guild.

360. cryptica, Brod.

361. Cubensis, Pfr.

371. cyathellus, $P f r$.

372. cyathus, $i d$.

373. cyclodon, TVebb.

374. cyclopax, Bens.

375. cygnea, $i d$.

376. Cyparissias, Parr.

377. Cypria, Pfr.

378. cysis, Bens.

Tealbata, Lovee.

380 . decipiens, Sow.

381. decora, Ad. and Rve. 382. decorata, Pfr.

383. decussata, Bens.

384. Dehnei, Rossm.

387. delphinula, Lowe.

338. demissa, Binn.

389. Dennisoni, Pfr.

390. densa, $\Lambda d$. and $R$.

391. dentiens, Fér.

392. denudata, Rossm.

393. depauperata, Lowe.

394. depilata, C. Pfr.

395. depressula, Parr.

396. dermatina, Shuttl.

397. desertorum, Forsk.

398. despecta, Gray.

399. Despreauxii, D'Orb.

400. destituta, Charp.

401. detecta, Fér.

402. diaphana, Lam.

403. dichroa, Pfr.

404. dictyodes, $i d$.

405. difficilis, $i d$.

406. dilatata, $i d$.

407. Dillwymiana, $i d$.

362. Cumberlandiana, Lea.408. diluta, Pfr.

363. Cumingii, $P f r$.

364. cumulus, $i d$.

365. Cunninghami, Gray.

366. curta, Sow.

409. dimera, Jonas.

410. diminuta, Adams.

367. curvidens, $P f r$.

368. curvilabrum, Ad.\& R. 414. discina, Love.

369. cuticula, Shuttl.

370. Cuvieriana, Lea.
415. discolor, Fér.

416. dissimilis, $D^{\prime} O r 6$.
417. distincta, Pfro

418. divisa, Forbes.

419. doliolum, Pfro

420. Dominicensis, id.

421. Dorfeuilliana, Lea.

422. Dringi, Pfr.

423. Dryope, Brod.

424. dubiosa, Pfi.

425. Duclosiana, Fér.

426. dumeticola, Bens.

427. Dumonti, Pfr.

428. Dunkeri, $i d$.

429. Dunkiensis, Forbes.

430. Dunnix, Gray.

431. Dupetithouarsii, Desh.

432. Dupotetiana, Terv.

433. Dupuyana, Pfr.

434. Duvalii, Petit.

435. cchinulata, Lowe.

436. Eddystonensis, Rve.

437. Edgariana, Lea.

438. egena, Say.

439. egenula, Mor.

440. Egesta, Gray.

441. Ehrenbergi, Roth.

442. Eichwaldi, Pfr.

443. elata, Bign.

444. elegantissima, $P f r$.

445. elevata, Say.

446. ellipsostoma, $P f r$.

447. Emiliana, $i d$.

448. engonata, Shuttl.

449. epidermia, Anton.

450. epistyliulum, Adans.

451. epistylium, Müll.

452. epistyloides, Fér.

453. epixantha, Pfr.

454. eremophila, Boiss.

45. ericetorum, Mïll.

456. Erigone, Gray.

457. erronea, Pfr.

458. erubescens, Lowe.

4.59. Estella, D'Orb.

460. Eucharis, Desh.

461. euchroes, $P f r$.

462. euclasta, Shuttl. 
463. curyomphala, $P f r$. 509. fragilis, $P f r$.

464. euspira, $i d$.

465. Eva, $i d$.

466. exæquata, Gould.

467. excavata, Bean.

468. excellens, $P f r$.

469. excentrica, $i d$.

470. exceptiuncula, Fér.

471. excisa, $P f r$.

472. exclusa, Fér.

473. exilis, Miill.

474. eximia, Pfr.

475. explanata, Miill.

476. extensa, $i d$.

477. Fabricii, Beck.

478. Falconari, Reeve.

479. fallaciosa, Fér.

480. fallax, Say.

481. fastigiata, Hutt.

482. fausta, Lowe.

483. faustina, Zieg.

484. fenestrata, Soro.

485. festiva, Dorov.

486. fibula, Brod.

487. fictilis, Lowe.

488. fidelis, Gray.

459. figulina, Parr.

490. filaris, Valenc.

491. filicina, Schmidt.

492. filicosta, Pfr.

493. filimargo, Zieg.

494. filocincta, $P f r$.

495. flavida, Zieg.

496. Flora, Pfr.

497. floridus, Sow.

498. florulifern, Pfr.

499. fodiens, $i d$.

500. fœetens, Stud.

501. Fontinelli, Micr.

502. Foremaniana, $A d$.

503. formosa, Fér.

504. Forsteriana, Pfr.

505. fortis, Adams.

506. fortunata, S/uuttl.

507. Fortunei, Pfi.

s08, foveata, $i d$.
510. Fraseri, Gray.

511. fricata, Gould.

512. fruticola, Kryn.

513. fruticum, Miull.

514. fucata, Pfr.

515. fulgens, Soro.

516. fulgurata, $i d$.

517. fuliginosa, Griff.

518. fulva, Miill.

519. fulvida, Pfr.

520. funiculata, $i d$.

521. furva, Loroe.

522. fusca, Mont.

523. fusco-cincta, Adams. 569. grisea, Limn.

524. fuscosa, Zieg.

525. fuscula, Adams.

526. gabata, Gould.

527. Gaberti, Less.

528. Gaertneriana, $P f r$.

529. galactostoma, $i d$.

530. gallinula, $i d$.

531. gallo-pavonis, $V a l$.

532. ganoma, Pfr.

533. Gardneri, Pfr.

534. Gaskoini, $i d$.

535. Gaudryi, $D^{\prime} O{ }^{2}$.

536. gemina, Busch.

537. gemma, Pfr.

538. Gemonensis, Fér.

539. generalis, Pfr.

540. germanus, Reeve.

541. Ghiesbrighti, Nyst.

54.2. Gibboni, Pfr.

54.3. gilva, Fér.

544. glabella, Drap.

545. glaberrima, $P f r$.

546. glabriuscula, $i d$.

547. glacialis, Thomas.

548. glaphyra, Jay.

549. glauca, Benson.

550. globularis, Zieg.

551. globuloidea, Terv.

552. globulus, Miill.

553. glutinosa, Metc.

554. Gmeliniana, $P f r$.
555. goniomphala, $i d$.

556. Gossei, $i d$.

55\%. Goudotiana, Fér.

558. Gouldi, Pfr.

559. gradata, $i d$.

560. Grællsiana, $i d$.

561. graminicola, Adams.

562. grandis, $P f r$.

563. granifera, Gray.

564. granulata, Quoy.

565. grata, Mich.

566. Grayi, Pfr.

567. Greenwoodii, Gray.

568. Griffithi, $P f$.

570. griseola, $P f r$.

571. Grohmanni, Phit.

572. Gruneri, Pfr.

573. Gualteriana, Linn.

574. Guayaquilensis, Pfr.

575. Guerini, $i d$.

576. Gueriniana, Loxe.

577. Guillarmadi, Shuttl.

578. gularis, Say.

579. gummata, Soro.

580. Gundlachi, Pfr.

581. Gussoniana, Shuttl.

582. guttata, Oliv.

583. guttula, $P f r$.

584. gyria, Roth.

585. gyrostoma, Fér.

586. hæmastoma, Linn.

587. halata, Mousson.

588. Harfordii, Brod.

589. Hartmanni, Pfr.

590. Hartungi, Albers.

591. Hartweigi, $P f r$.

592. Helenensis, Forbes.

593. heliaca, D'Orb.

594. Helicinoides, Homb.

595. Helicoides, $P f r$.

596. helicophantoides, $i d$.

597. helicycloides, D'Orb.

598. heligmoidea, $i d$.

599. hepatica, Reeve.

600. hians, Pfr. 
601. hieroglyphicula, Mch. 647. inconspicua, Adams. 693. Knysnaensis, Pfr.

602. Himalayana, Lea. 603. Hindsii, $P f r$.

604. hippocrepis, $i d$.

605. hirsuta, Say.

606. hirta, Menke.

607. Hispana, Linn.

608. Hispanica, Part.

609. hispida, Linn.

610. hispidula, Lam.

611. Hoffmanni, Part.

612. Hollandi, Adans.

613. holoserica, Stud.

614. Hondana, Pfr.

615. honesta, Gould.

616. Hookeri, Reeve.

17. Hopetonensis, Shuttl. 663. instabilis,

617. Hopetonensis, Shuttl. 663. instabilis, $i d$.

618. horiomphala, Pfr. 664. intermedia, Fér.

619. horizontalis, $i d$.

620. Huaheinensis, $i d$.

621. Hugeli, $i d$.

622. Humboldtiana, $\overline{V a l}$.

623. humilis, Hutton.

624. Humphreysiana, Lea.670. inversicolor, Fér.

625. Huttoni, Pfi:

626. hyalina, Fér.

627. hydatina, Rossm.

628. hydrophana, Sow.

629. hylephila, D'Orb.

630. hyphasma, $P f r$.

631. hypopolea, $i d$.

632. hystrix, Migh.

633. Ibuensis, $P f r$.

634. Ide, Gray.

635. igniflua, Reeve.

636. ignobilis, Soro.

637. Iloconensis, $i d$.

648. incrassata, Poey.

649. indentata, Say.

650. Indica, $P f r$.

651. indistincta, Fér.

652. induta, $P f r$.

653. infans, $i d$.

654. infecta, Reeve.

655. infrendens, Gould.

656. infula, Bens.

657. ingens, Adams.

658. inornata, Say.

659. inquinata, Busch.

660. insculpta, $P f r$.

661. insignis, $D^{\prime} 0 \cdot 6$.

665. interna, Say.

666. interrupta, Benson.

667. intertexta, Binn.

668. intorta, Soro.

669. invalida, Adams.

671. Isabella, Fér.

672. Isabellina, Pfr.

673. isodon, $i d$.

674. Jacksoniensis, Gray.

675. Jacquinoti, $P f r$.

676. Jamaicensis, Chemn.

677. Janus, $i d$.

678. Japonica, $P f r$.

679. Javanica, Lam.

680. Jeffreysiana, $\boldsymbol{P} f$.

681. Jenynsi, $i d$.

682. Jervisensis, Quoy.

683. Jonasi, Pfr.

638. immaculata, Ad.\& R. 684. Josephinæ, Fér.

639. immunda, Adams. 685. Juilleti, Terver.

640. imperator, De MTontf. 686. Juliana, Gray.

641. impexa, Reeve.

642. inæqualis, $P f r$.

643. Incei, $i d$.

644. incarnata, Miill.

645. incerta, Drap.

646. inchoata, Mor.
687. juloidea, $i d$.

688. Juno, Pfr.

689. Kawaiensis, $i d$.

690. Kellettii, Forbes.

691. Keppelli, Pfr.

692. Kivi, Gray.
694. Kochi, id.

695. Krausi, $i d$.

696. Krynickii, Andr.

697. Kurri, $P f r$.

698. Kusteri, id.

699. labiata, $i d$.

700. labium, Férussac.

701 . labyrinthica, Say.

702. labyrinthus, Chemn.

703. lacera, Pfr.

704. laciniosa, Lowe.

705. lactea, Miill.

706. læsa, Reeve.

707. læta, Pfr.

708. lævigata, Rafin.

709. lævipes, Müll.

710. Lais, Pfi。

711. Lamarckiana, Lea.

712. lamellata, Jeffr.

713. lamellifera, Adams.

714. lamellosa, Fér.

715. lampas, Mïll.

716. lampra, Pfr.

717. Lancerottensis, $W_{e} b \mathrm{~b}$.

718. lancula, Fér.

719. languida, Pfr.

720. lanuginosa, Boiss.

721. lanx, Fér.

722. lapicida, Linn.

723. Lasallii, Eyd.

724. latens, Lowe.

725. latitans, Brod.

726. Launcestonensis, Rve.

727. lauta, Lowe.

728. laxata, Fér.

729. Layardi, Pfr.

730. Leachii, Fer.

731. lecta, $i d$.

732. lecythis, Bens.

733. Lefebriana, Fér.

734. Leimonias, Gray.

735. lemniscata, $I V e b b$.

736. lenis, Shutll.

737. lens, Fér.

738. lenticula, $i d$. 
739. lentiginosa, Lowe. 740. leporina, Gould.

741. Leprieurii, Petit.

742. leptogramma, Pfr.

743. leptosticta, Lowe.

744. Lessoni, Pfi.

745. leucodon, $i d$.

746. leucoraphe, $i d$.

747. leucostoma, $A d$. \& R.793. Macmurrayi, Adanes. 839. Mindanaensis, Sow.

748. leucozona, Zieg.

749. levis, Pfr.

750. Leytensis, $i d$.

751. libata, Reeve.

752. Liebetruli, Albers.

753. ligata, Mïll.

754. ligera, Say.

755. Lightfooti, Pfr.

756. lignaria, $i d$.

757. ligulata, Fér.

758. lima, $i d$.

759. limbata, Drap.

760. Lindeni, Pfi.

761. lineata, Say.

762. lingulata, Desh.

763. Linnæana, Pfr.

764. litturata, $i d$.

765. lituus, Less.

766. livida, Guild.

707. Iovisiadensis,

767. Louisiadensis,
768. Loveni, Krauss. 769. Lowii, Fér.

770. loxotropis, Pfr.

771. loxodon, $i d$.

772. lubrica, Bens.

773. lucana, Mïll.

774. Iucerna, $i d$.

775. lucida, Drap.

776. lucidella, Pfr.

777. lucorum, Linn.

778. luctuosa, Beck.

779. Ludovici, Albers.

780. Luhuana, Sow.

781. Luquillensis, Shuttl.

782. lurida, Lowe.

783. Lusitanica, Pfr.

784. luteo-cornea, id.
785. lutescens, Zieg.

786. Luzonica, Sow.

787. lychnia, Bens.

788. lychnuchus, Miïl.

789. Lyelliana, Lowe.

790. Macandrewiana, Pfr. 836. microspira, Pfr.

791. Macgillivrai, Forbes. 837. Mighelsiana, id.

792. Mackensii, Valene. 838. mina, $i d$.
795. macrostoma, Mühlf. 841. Minoricensis, Mittre.

796. Madagascariensis, Lm.842. minuscula, Binn.

797. Maderensis, Wood. 843. mirabilis, Fér.

798. Maderaspatana, Gray.844. misella, $i d$.

799. magister, $P f r . \quad$ 845. modesta, $i d$.

800. magnifica, Fér. $\quad$ 846. monile, Brod.

801. Malaccanus, Pfi: $\quad$ 847. monilifera, $\mathbb{W} e b b$.

802. malleata, Fér. 848. monochroa, Sow.

803. mamilla, $i d$. 849. monodonta, Lea.

804. mandarina, Gray. $\quad 850$. mononema, Bens.

805. mansueta, $P f r$. 851 . Montfortiana, $P f r$.

806. marginata, Müll. $\quad 852$. monticola, Sow.

807. maritima, Drap. 853. monozonalis, Lam.

808. Mariæ, Gray. 854. morbida, Mor.

809. Marmatensis, Pfr. $\quad$ 855. Moretonensis, Pfr.

810. marmorata, Fér. 856. Moricandi, Sow.

811. marmorella, Pfr. $\quad$ 857. Moussoni, Pfr.

812. Martini, $i d$ 858. mucronata, $i d$.

859. Mülleri, $P f r$.

860. multidentata, Gould.

861. multilineata, Say.

862. multistriata, Des.

863. munda, Adams.

817. Meda, Porro.

818. mediocris, $P f$.

864. muralis, Miiller.

819. melanocheila, Valenc. 865. muscarum, Lea. 820. melanostoma, Drap. 866. mustelina, Lowe.

821. melanotragus, Born. 867. musicola, Shuttl.

822. Melitensis, Fér. $\quad$ 868. Najas, Pfr.

823. membranacea, Lowe. 869. Naninoides, Bens.

824. membranicosta, Pfr. 870. nasuta, Metc.
825. Menkeana, $i d$.

826. mera, Reeve.

827. mercatoria, Gray.

828. Merguiensis, Phil.

829. Merziana, $P f r$.

830. metaformis, Fér.
871. Natalensis, $P f r$.

872. Navigatorum, $i d$.

873. Nautiliformis, Cantr.

874. Naxiana, Fér.

875. neglecta, Drap.

876. nematophora, $P f r$. 
877. nemoralina, Petit. 923. omalomorpha, D'Ort. 969. Paraguayana, $P f r$. 878. nemoralis, Limn. 924. omphalodes, Pfr. 970. parilis, Fér. 879. nemornloides, Adams.925. oomorpha, Sow. 880. nemorensis, Mïll. 926. opalina, $i d$. 881. Neogranadensis, Pfr. 927. Oparica, Anton. 882. Newcombi, id. 92S. Ophelia, Pfr. 883. Niciensis, Fér. $\quad$ 929. orbicula, D’Orb. 884. Nicobarica, Chemn. 930. orbiculata, Fér. 885. nigrescens, Trood. 931. Orbignii, Webb. 886. nigritella, Plit. $\quad 932$. orbis, Beck. 887. Nilagirica, $P f r$. 858. nitens, Mich. 933. orbitula, Soro. 889. nitida, Miill. 934. Oreas, Koch. 935. orcula, Benson. 890. nitidiuscula, Sow. 936. orientalis, Gray. 891. nitidula, Drap. $\quad 937$. ornatella, $P f$. 892. Nivariensis, Shuttl. 938. orobia, Bens. 593. nivosa, Soro. 939. Orsinii, Porro. 894. nobilis, $P f r$. 896. Norrisii, Sorv. 940. orthostoma, $P f i$. 895. Nouleti, Le Guill. 942. otostoma, Pfr. 597. Novæ-Hibernix, Qy. 943. Otthiana, Forbes. 898. noverca, Friv. 944. oviformis, Grat. 899. novella, Pfi: 945. ovi-vitellus, Reeve. 900. nucleola, Rang. 901. nuda, Pfr. 946. ovum, Valen. 902. nummus, Ehrenb. 903. nympla, $P f r$. 904. obesa, Beck. 905. obliquata, Reeve. 906. oblita, Pfr. 907. obliterata, Fér. 908. oblonga, Sow. 909. obnubila, Reeve. 910. obscurata, Porro. 911. obserata, Lowe. 912. obstricta, Say. 913. obtecta, Lowe. 914. obtusa, $P f r$. 915. obvoluta, Miill. 916. occidentalis, Recl. 917. ochroleuca, Fér. 918. Okeniana, Pfr. 919. oleacea, Shuttl. 920. oleosa, Pfr. 947. ovum-reguli, Lea. 948. Owenii, Pfr. 949. oxytes, Bens. 950 . oxytropis, Lowe. 951. pachygastra, Gray. 952. pachystyla, Pfr. 953. Pacifica, $i d$. 954. Paciniana, Phil. 955. paleata, Reeve. 956. Pallasiana, Pfr. 957. palliata, Say. 958. pallidula, $P f r$. 959. paludicola, Bens. 960. paludosa, $P f r$. 961. Pan, Brod. 962. Pandoræ, Forbes. 963. pagodula, Pfr. 964. papilio, Love. 965. papilla, MFüll. 966. papillata, $P f r$. 971. Parlatoris, Bivon. 972. parmula, Brod. 973. Parraiana, $D^{\prime} O r b$. 974. partita, $P f r$. 975. parva, Parr. 976. patina, Adams. 977. paupercula, Love. 978. pellis-lacerti, Reeve. 979. pellis-serpentis, Clım. 980. pellita, Fér. 981. pellucens, S7uttl. 982. pellucida, Gould. 983. pemphigodes, $P f r$. 984. Pennantiana, $i d$. 985. Pennsylvanica, Gm. 986. peracutissima, $A d$. 987. peraffinis, $i d$. 988. perdepressa, $i d$. 989. perdita, Reeve. 990. perplicata, Bens. 991. Perotteti, Pfr. 992. personata, Lam. 993. persimilis, Shuttl. 994. perspectiva, Say. 995. petrobia, Bens. 996. Petronella, Charp. 997. Pfeifferi, Phil. 998. Phæedra, Pfr. 999. phæogramma, $i d$. 1000. Phillipi, Gray. 1001. phlogophora, Pfr. 1002. phloides, $i d$. 1003. picta, Bom. 1004. picturata, Adans. 1005. pila, $i d$. 1006. pileiformis, Moric. 1007. pileus, Miïll. 1008. pilula, Reeve. 1009. pinguis, Krauss. 1010. Pinicola, Pfi. 1011. Pincieana, $i d$. 1012. Pisana, Miill. 921. olivetorum, Gmelin. 967. papyracea, Brod. 922. Olivieri, Fér. 968. paradoxa, Pfr.

1013. pisiformis, Desh. 1014. Pityonesica, $P f i$. 
1017. placida, Shuttl. 1016. plaguptycha, $i d$. 1017. planata, Chemn. 1018. Planorboides, Fér. 1019. Planti, Pfr. 1020. platychela, Menke. 1021. platyodon, $P f r$. 1022. platystypla, $i d$. 1023. plectilis, Bens. 1024. plectostoma, $i d$. 1025. plicaria, Lam. 1026. plicata, Born. 1027. plurizonata, Ad \& R 1073 . pyrrozona Phil. 1028. pœcilosticta, Pfr. 1029. Poeyi, Petit. 1030. Poiretiana, Pfr. 1031. politissima, $i d$. 1032. pollodonta, $D^{\prime}$ Orb. 1033. polychroa, Sow. 1034. polygyrata, Born. 1035. polymorpha, Lowe. 1036. pomatia, Linn. 1037. Pompylia, Shuttl. 1038. pomum, Pfr. 1039. ponderosa, $i d$. 1040. Pondicherriensis, id.1086. Rangiana, Fér. 104l. porphyria, $i d$. 1042. Portia, Gray. 1087. rapa, DIüll. 1088. rapida, Pfr.

1043. Porto-Sanctana,Sow.1089. rariplicata, Bens 1044. Powisiana, Pfr. 1045. præstans, $i d$. 1046. pratensis, $i d$. 1047. princeps, Reeve. 1048. problematica, Pfr. 1059. procera, $i d$. 1050. profunda, Say. 1051. Proserpinula, Pfr. 1052. protea, Zieg. 1053. proxima, Fér. 1054. pruinosa, $P f r$. 1055. prunum, Fér. 1056. ptychodes, Pfr. 1057. ptychomphala, id. 1058. pubescens, $i d$. 1069. puella, Brod. 1060. pulchella, Müll. 1064. Punica, Mor. 1065. pura, Alder. 1068. puteolus, Bens. 1069. pygmæa, Drap. 1070. pyramidata, $i d$. 1071. Pyrenaica, id. 1072. pyrostoma, Fér. 1075. quadrata, Fér. 1077. quæsita, Desh. 1081. radians, $i d$. 1082. radiaria, $i d$. 1094. Rawsonis, Pfr. 1095. recedens, $i d$. 1096. rectangula, $i d$. 1097. Redfieldii, $i d$. 1098. refuga, Gould. 1099. regalis, Bens. 1100. Reginæ, Brod. 1101. regularis, Pfr. 1102. Rehbeini, $i d$. 1103. Reinga, Gray. 1104. remota, Bens. 1106. retifera, Pfr.
1061. pulcherrima, Sow. 1107. retrorsa, Gould. 1062. punctata, Born. 1108. retusa, Pfr. 1063. punctulata, Sow. 1109. revelata, Fer. 1110. rhombostoma, Pfr. 1111. Richmondiana, $i d$. 1066. purpurascens, Pfr. 1112. Rissoana, $i d$. 1067. pustula, Fér. 1113. Rivolii, Desh. 1114. Roemeri, Pfr. 1115. Roissyana, Fér. 1116. rosarium, Pfr. 1117. Roseti, Mich. 1118. rota, Brod. 1119. rotabilis, Reeve. 1120. Rothi, Pfr. 1121. rotula, Lowe. 1076. quadridentata, Brod.1122. rotundata, Müll.

1123. ruderata, Stud. 1124. rudiuscula, $P f r$. 1079. Quimperiana, Fér. 1125. rufa, Lesson. 1080. Quitensis, Pfr. 1126. rufescens, Pennant. 1127. rufula, $P f r$.

1128. ruginosa, Fér.

1129. rugosiuscula, Nich. 1130. rugosa, Chemn. 1131. Rumphii, Busch.

1132. sabuletorum, Bens. 1133. saccharata, Lowe.

1134. saccata, Pfr.

1135. Sadleriana, Zieg. 1090. rariguttata, Mouss. 1136. sagemon, Beck. 1091. Raspaillii, Payr. 1137. sagittifera, $P f r$. 1092. Ravergiensis, Fér. 1138. Sagraiana, D’Orb. 1093. ravida, Bens. $\quad$ 1139. Salleana, Pfr. 1105. resplendens, Phil. 11t0. Sandvicensis, $i d$.

1141. sannio, $i d$.

1142. Santanaensis, $i d$.

1143. sarcinosa, Fér.

1144. sarcodes, Pfr.

1145. sarcostoma, IV ebb.

1146. Saulcyi, D'Orb.

1147. Sauliæ, Pfr.

1148. saxicola, $i d$.

1149. Sayi, Binn.

1150. scabriuscula, Desh.

1151. scelerostoma, $P f r$.

1152. scepasma, $i d$. 
1153. Schmidtii, Zieg. $\quad$ 1199. Siquijorensis, Brod. 1245. streptaxon, Pfr. 1154. Schombrii, Scac. 1200. Sirena, Beck. 1246. striatella, Anth. 1155. Schroeteriana, Pfr. 1201. skiaphila, D'Orb. 1247. strigata, Miill. 1156. Schrenkii, Midd. 1202. Skinneri, Reeve. 1248. strigella, Drap. 115\%. Schumacheriana, Pfr.1203. Smyrnensis, Roth. 1249. strigilis, Pfr. 1158. scrobiculata, $i d$. 1204. sobrina, Fér. 1250. strobilis Fér. 1159. sculpturata, Gray. 1205. solaria, Menke. 1251. strongylodes, Pfr. 1160. scytodes, Pfr. 1161. Seetzeni, Koch. 1206. Solarioides, Reeve. 1]62. segestana, Phil. 1207. Solarium, Quoy. 1252. strumosa, $i d$. 1163. selenina, Gould. 1209. solidula, Pfr. 1164. semen-lini, Moric. 1210. solitaria, Jay. 1165. semicastanea, Pfr. 1211. soluta, Zieg. 1166. semiconvexa, $i d$. 1212. Sophiæ, Gask. 1167. semicostulata, Beck. 1213. soror, F'er. 1253. Stuartix, Sorv. 1254. Studeriana, Fér. 1255. Sturmiana, $P f$. 1256. stylodon, $i d$. 1257. subangulata, $i d$. 1258. subaquila, Shutt. 1259. subeallifera, Lowe. 1168. semidecussata, $P f r$. 1214. Souleyetana, Petit. 1260. subcastanea, Pfr. 1169. semiglobosa, $i d$. 1170. semigranosa, Soro. 1171. semirugata, Beck. 1172. sepulchralis, Fér. 1173. sericatula, $P f r$. 1174. sericea, Drap. 1175. serpens, Spix. 1176. serpentina, Fér. 1177. serrula, Benson. 1179. serrulata, Beck. 1179. serrilis, Sluuttl. 1180. setigera, Sow. 1181. setipila, Zieg.

1182. setosa, $i d$.

1183. Setubalensis, Pfr. 1184. sexlamellata, $i d$. 1185. Shanghaiensis, $i d$. 1186. Shuttleworthi, $i d$. 1187. Sicana, Fér.

1188. Sieboldiana, Pfi. 1189. similaris, Fér.

1190. similis, Adams.

1191. simplicula, Mor.

1192. simulans, Adams. 1193. simulata, Fér.

1194. Sinaitensis, $P f r$. 1195. sincern, Adams. 1196. Sinclairi, Gray. 1197. singularis, Pfr. 1198 . sinnata, Mïll.
1215. Sowerbyana, Pfr.

1216. speciosa, Jay.

1217. spectabilis, $P f r$.

1218. spectrum, Reeve.

1219. Spengleriana, $P f r$. 1220. sphærica, Sow.

1221. sphærion, $i d$.

1222. sphæroidea, Le Guil.1268. subrudis, Pfi.

1223. spinosa, Lea. 1269. subrugata, $i d$.

1224. spiralis, Le Guill. 1270. subtesta, Bens.

1225. spiriplana, Oliv. 1271. subtilis, Anton.

1226. spirulata, $P f r$. 1272. subvitren, $P f r$.

1227. splendida, Drap. 1273. succinea, $i d$.

1228. splendidula, Pfr. $\quad$ 1274. Sudensis, $i d$.

1229. Spratti, $i d$.

1230. spreta, Adams.

1231. squalida, Lowe.

1232. squalus, Hinds.

1233. squamosa, Fér.

1234. stellaris, Love.

1235. stenomphala, Mke.

1236. stenostoma, $P f$. 1237. stephanophora, Des. 1283. Swainsoni, $i d$.

1238. stigmatica, $P f r . \quad$ 1284. sylvatica, Drap.

1239. Stimpsoni, id. 1285. Syrensis, $P f r$.

1240. stipulata, Reeve. 1286. Syriaca, Ehrenb.

1241. Stoddarti, Gruy. 1287. systropha, Albers.

1242. stolephora, Valenc. 1288. tabellata, Lowe. 1243. Strangei, $P f r . \quad$ 1289. tæniata, $W e b b$. 1244. strangulata, Adams. 1290. Tamsiana, Dunk. 
1291. tapeina, Bens. 1292. Taranaki, Gray. 1293. Taurica, Kryn. 1294. Tayloriana, $A d$. \& $R$. 1295. tectiformis, Sow. 1296. tenera, $i d$. 1297. tenerrima, Adams. 1298. tenuicostata, Dunk. 1299. tenuis, Pfr. 1300. tephrodes, $i d$. 1301. terrestris, Chemn. 1302. tescorum, Bens. 1303. tessellata, Mühlf. 1304. Testæ, Pliil. 1305. Texasiana, Moric. 1306. textilis, Shuttl. 1307. Thais, Jacq. 1308. Theodori, Phil. 1309. Thersites, Brod. 1310. thiarella, $W e b b$. 1311. Thomasi, Pfr. 1312. Thwaitesii, $i d$. 1313. thyreus, Bens. 1314. thyroides, Say. 1315. tiara, Mighels. 1316. tichostoma, Pfr. 1317. tigrina, Crist. 1318. tomentosa, Pfr. 1319. Tongana, Quoy. 1320. torrefacta, Adans. 1321. tortilabia, Less. 136\%. uncigera, Petit. 1322. Tourannensis, Soul. 1368. undata, Lowe. 1323. Townsendiana, Lea. 1369. undulata, Fér. 1324. tradita, Reeve. 1370. unica, Pfr. 1325. Tranquebarica, Fab. 1371. unicolor, id. 1326. Trenquelleonis, Gra.1372. unidentata, Chemn. 1327. triaria, Friv. 1373. unguicula, Fér. 1328. trichotropis, Pfr. 1329. tricolor, $i d$. 1330. tridentata, Say. 1331. tridentina, Fér. 1331. tridentina, Fer. 1374. ungulina, Linn. 1375. urnula, Pfr. 1375. urnula, Pfr. 1421. xanthodon, Anton. 1376. Valenciennesii, Eyd.1422. xanthotricha, Pfi. 1377. valida, Adans. 1423. Xystera, Talenc. 1332. trigonostoma, $P f r$. 1378. vallicola, $P f r . \quad$ 1424. Yorkensis, $P f r$. 1333. trigrammephora, O. 1379. Vancouverensis, Lea.1425. Yulei, Forbes. 1334. triodonta, $D^{\prime}$ Orb. 1380. varicosa, Pfr. 1335. tristis, Pfr. 1381. variolosa, $i d$. 1336. triumphalis, Reeve. 1382. vellicata, Forbes.

1383. velutina, Lam. 1384. ventrosula, $P f r$. 1385. vermiculata, Mïll.
O. 1386. vermis, Reeve. 1387. vernicosa, Krauss. 1388. Veronica, Pfr. 1389. verrucula, $i d$. 1390. versicolor, Born. 1391. verticillus, Fér. 1392. vesicula, Bens. 1393. vestalis, Parr. 1394. vilis, Pfr. 1395. Villiersii, D’Orb. 1396. villaris, $P f r$. 1397. villosa, Drap. 1398. vincta, Valenc. 1399. Vindobonensis, Fér. 1354. tumulorum, WV.\& B.1400. virgata, Mont. 1355. Tunetana, Pfr. 1401. virginalis, Jan. 1402. virgo, Brod. 1403. virgulata, Sow. 1404. viridis, Des\%. 1405. vitellina, $P f r$. 1406. Vitrina, Wagn.

1407. Vitrinoides, Desh. 1362. Typinsana, Ad.\& R.1408. vittata, Mïll. 1363. Uitenhagensis, Kra. 1409. vittosa, Drap. 1410. volubilis, Reeve. 1411. volvoxis, Parr. 1412. vortex, $P f$. 1413. vorticialis, Bens. 1414. Vulcania, Lowe. 1415. vultuosa, Gould. 1416. Waltoni, Reeve. 1417. Webbiana, Lowe. 1418. Winteriana, Pfr. 1419. Wollastoni, Love. 1420. Woodiana, Pfr. 1426. zaleta, Say. 1427. zebra, Pfr. 1428. Zebuensis, Brod. 
1429. Zelandix, Gray.

1430. Zelobori, $P f r$.

1431. Zeus, Jonas.

1432. Ziegleri, Schmidt.

1433. zodiaca, Fér.
1434. Zollingeri, Pfr. 1435. zonalis, Fér.

1436. zonaria, Limn.

1437. zonata, Studer.
1438. zonifera, Sow. 1439. Zonites, $P f r$. 1440. zonulata, Fér. 1441. zosterophora, $P f \%$.

\section{Figures.}

1leurx Listeri. Pl. 21. Fig. 119. Shell, showing the orbicularly depressed form, separated by Lamarck as Carocolla.

Hewix Lezonica. 1'l. 21. Fig. 122. Shell, showing its globose form and reflected lip.

\section{Genus 9. ANASTOMA, Fischer.}

Animal ; simitar to that of Helix.

Shell ; orlivelur, globosely lens-shaped ; the last urhorl surtdrnly turned upwards on a plane with the spire; aperture semicirculne, furmished with five strong plait-like teeth, of which lwo are on the body whorl; outer lip thickened and reflected.

In Brazil there exists a curious form of snail, of which two species appoared fifty years ago in the works of Férussac and Lamarck, one being already known to Linnacus; yet, notwithstanding the researches of recent traveller's, no other species has been discovered. The peculiarity of this form consists in the singular manner in which the latter half of the last whorl is suddenly turned uprards, so as to bring the aperture on a plane with the spire. Up to this period, the position of the shell on the living suail would be, as in all other genera, with the apex uppermost; but in Anostoma the animal, on approaching maturity, so abruptly alters the coil of the last whorl, as to turn the shell completely over, with the apex downwards. Botl species are constant in their mamner of growth, and are not uncommon.

\section{Species.}

1. ringens (Helix), Linn. 2. globulosum, Linn。

)

Figure.

Anastoma ringens. Pl. 21. Fig. 117. Shell, showing its semilunar 
aperture, turned up on a plane with the spire, by which it may be seen that the living animal protruding from it would crawl with the apex downwards.

\section{Genus 10. PROSERPINA, Gray.}

Animal ; undescribed.

Shell ; depressty orbicular, polished, shining; aperture furnished on either side with strong, winding, tooth-like plaits; lip simple, never reflected.

The few species that have been associated under this head differ from the ordinary IIelix type in being of a polished, shining substance, generally bright-yellow or greenish, characterized by having the interior furnished on either side with strongly-developed winding plaits. The shell is never umbilicated, nor is the lip ever reflected. It does not appear that the animal has been observed.

One species, $P$. colina, is from Mexico; the remainder are from Jamaica and Cuba.

\section{Species.}
1. bidentata, $A d$.
4. globulosa, Orb.
7. opalina, $A d$.
2. depressa, $\mathrm{Or} b$.
5. linguifera, Jonas.
8. pisum, $i d$.
3. eolina, Dud.
6. nitida, Gray.

Figure.

Proserpina nitmda. Pl. 21. Fig. 121. Shell, showing the aperture with its tooth-like plaits and simple lip.

\section{Genus 11. SUCCINEA, Draparnaud.}

Animal ; of large subgelatinous bulk; head with four stout influted tentacles, of which the lower pair are very short.

Shell; ovate, thin, fragile; spive small; aperture large, with the margins disjoined; columella narrow and thinly edged; lip simple.

The well-known transparent Amber suail, Succinea putris, of our mudbanks and damp incadow's, gives but an inadequate notion of the genus in 
its more tropical range. Among the foreign species are several, like our figured specimen $S$. patula, which better illustrate the character of the animal, and show it to be more nearly allied to Bulimus and Helix than to the Limnere, near which the Succinece mostly dwell. But though dwelling in the vicinity of rivers, ponds, and marshes, and being to some extent amphibious, their habit is to live on land. The faculty of living under water is only extended apparently in instances of rare occurrence, to provide for the chances of occasional submergence by tides and floods. The Succinea are widely distributed in both hemispheres, including especially the oceanic islands of the Pacific.

\section{Species.}

1. abbreviata, Mor.

2. acuta, $P f r$.

3. Egyptiaca, Ehr.

4. æquinoxialis, $\mathrm{Or} \cdot \mathrm{b}$.

5. angustior, $A d$.

6. aperta, Lea.

7. appendiculata, $P f r$.

8. areuaria, Busch.

9. aurea, Lea.

10. australis, Fér.

11. avara, Say.

12. Barbadensis, Guild.

13. Bensoni, Pfr.

14. Borneensis, id.

15. brevis; Dunk.

16. bullina, Fér.

17. caduca, Migh.

18. campestris, Say.

19. Candeana, Lea.

20. cancella, Gould.

21. cepulla, $i d$.

22. Chiloensis, Phil.

23. cingulata, Forbes.

24. concisa, Mor.

25. concordialis, Gould.

26. contorta, $A d$.

27. crassiuscula, Bens.

28. crocata, Gould.

29. Cumingii, Pfr.

30. Cuvieri, Guild.

31. Delalandei, $P f r$.
32. depressa, Rang.

33. Dominicensis, Pfr.

34. Donnetti, $i d$.

35. effusa, Shuttl.

36. exarata, Krauss.

37. explanata, Gould.

38. fragilis, King.

39. Gayana, Orb.

40. Gouldiana, $P f i$.

41. gracilis, Lea.

42. Grœnlandica, Beck.

43. Guatemalensis, Mor.

44. Gundlachi, Pfr.

45. haliotidea, Mitt.

46. helicoidea, Gould.

47. hortulana, Mor.

48. humerosa, Gould.

49. Indica, Pfr.

50. inflata, Lea.

51. infundibuliformis, $G d$. 82. retusa, Lea.

52. latior, $A d$.

53. longiscata, Mor.

54. lumbalis, Gould.

55. luteola, $i d$.

56. Magellanica, $i d$.

57. mamillata, Beck.

58. Mannana, Gould.

59. margarita, Pfr.

60. Menkeana, $i d$.

61. modesta, Gould.

62. Nuttalliana, Lea.
63. obliqua, Say.

64. oblonga, Dunk.

65. ochracea, Betta.

66. Oregonensis, Lea.

67. orientalis, Bens.

68. ovalis, Say.

69. pallida, $P f r$.

70. papillata, $i d$.

71. patentissima, Mke.

72. patula, Bens.

73. Pfeifferi, Rossm.

74. picta, Pfr.

75. pinguis, $i d$.

76. procera, Gould.

77. pudorina, $i d$.

78. pusilla, Pfr.

79. putamen, Gould.

80. putris, Linn.

81. recisa, Mor.

83. Rüsei, Pfr.

84. rotundata, Gould.

85. rubescens, Desh.

86. rubicunda, $P f r$.

87. rugosa, $i d$.

88. rusticana, Gould.

89. Sagra, Orb.

90. Salleana, $P f r$.

91. St.-Helenæ, Less.

92. semiglobosa, Pfr.

93. semiserica, Pfr. 
94. solidula, $P f r$.

95. spurca, Gould.

96. striata, Krauss.

97. subgranosa, $P f r$.

98. subrugata, $i d$.

99. Tahitensis, $i d$.
100. Tamsiana, $P f r$.

101. Taylori, id.

102. Texasiana, $i d$.

103. tigrina, Less.

104. Totteniana, Lea.

105. undulata, Say.
106. unguis, Fér.

107. venusta, Gould.

108. vesicalis, $i d$.

109. virescens, $\mathrm{M}$ or .

110. Wardiana, Lea.

\section{Figure.}

Succinea patula. Pl. 20. Fig. 112. Shell, showing its inflated, fragile substance and broad aperture.

\section{Genus 12. VITRINA, Draparnaud.}

Animal; bulky, large for the shell; lanceolate; head with four tentacles, the lower pair short; mantle ample, thick, reflected upon the shell; furnished with a lobe on the right side under the spire; tail obliquely truncated; edge-teeth of tongne aculeate. (Forbes.)

Shell; rotundately ovate, sometimes depressed, imperforate, thin, vesicular, glassy or horny green; spive short; last whorl large and inflated; lip and columella simple.

The extensive family of the Colimacea is brought to a close with a genus of which the shell is of a slight, vesicular, horny or greenish-glassy substance, coiled into no more than three whorls, and offering a transition to the family of the Limacinea, in which the shell ceases to be convoluted. The appearance of Vitrina when in motion is that of a Limax, with a IIelix shell upon its back. The mantle is prolonged into a lobe, such as in Limax is developed for the protection of the gills, but here the shell intervenes for their protection. is many as eighty species are known. Twelve, including three abnormal forms described by Hartmann as a separate genus, Daudebardia, inhabit Europe, but only one, $V \cdot$ pellucida, has been found in Britain, common in all parts of the country, chiefly among moss and under stones. The remainder, with two exceptions, are about evenly distributed over the islands and continents of the Old World, as far south as New Holland, from whence several very interesting species have been received. The only species known to the western hemisphere is one inhabiting the vicinity of Portland and eastern part of Maine, in the United States, $V$. Anericana,* and one inhabiting Greenland, $V$. Angelica.

* Dr. Binuey remarks on this species, that "when kept in confinement the animal has been 


\section{Species.}

I. Abyssinica, Rupp.

2. Americana, $P f r^{\circ}$.

3. Angelicx, Beck.

4. angularis, Fér.

5. annularis, Stud.

6. aperta, Beck.

7. atrovirens, Moric.

8. baccata, Hutt.

9. Beckiana, Pfr.

10. Bensoni, id.

11. bicolor, Beck.

12. Birmanica, Plil.

13. Blauneri, Shuttl.

14. brevipes, Drap.

15. caperata, Gould.

16. cassida, IIutt.

17. castanea, $P f r$.

18. Ceylanica, Beck.

19. cornea, Pfr.

20. crenularis, Beck:

21. Cumingii, idl.

22. Curieri, Fér.

23. diaphana, Drap.

24. dimidiata, $P f i$.

25. Draparnaldi, Cuv.

26. elongata, Dunk.

27. fasciolata, Fer.
28. Freycineti, Fér.

29. fumosa, Pfr.

30. fusco-succinea, Beck.

31. gigas, Bens.

32. glacialis, Forbes.

33. grandis, Beck.

34. Gruncri, $P f r$.

3.). Guimarasensis, $i d$.

36. gutta, $i d$.

37. hians, Rupp.

35. irradians, $P f r$.

39. Keppellii, $i d$.

40. Lamarckii, Fér.

41. Langi, Pfi.

42. Leytensis, Beck.

43. Luzonica, $P f r$.

44. Naravigna, Mandr.

45. marcicla, Gould.

16. margarita, Beck.

47. Milligani, $P f r$.

45. monticola, Bens.

49. Musignani, Mandr.

50. Natalensis, Kranss.

51. nigra, Quoy.

52. nitida, Gould.

53. obtusa, Sowo.

5. 4. papillata, $P f r$.
55. pellicula, Fér.

56. pellucida, Müll.

57. planospira, $P f r$.

58. planulata, $i d$.

59. Pœppigii, Mke.

60. politissima, Beck.

61. præstans, Gould.

62. progastor, Orb.

63. Pyrenaica, Fér.

64. resilicus, Beck.

65. robusta, Gould.

66. Rüppelliana, $P f r$.

67. rufa, Drap.

68. rufescens, $i d$.

69. rufo-virens, Moric.

70. Ruivensis, Couth.

71. Salomonia, Pfr.

72. sigaretina, Red.

73. smaragdulus, Beck.

74. Sowerbyana, $P f r$.

75. Strangei, id.

76. sulculosa, Fér.

77. tenclla, Gould.

78. Verreanxii, $P f r$.

79. virens, $i d$.

80. zebra, Guill.

\section{Figure.}

Virrixi moxtrol.1. Pl. 21. Fig. 120). Shell, inhabiting the neighbourhood of Calcutta, showing its inflated, few-whorled form, and thin, vesicular substance.

\section{Family 17. LIMACINEA.}

Shell; small, not comoluted beyond a small spiral mucleus, sometimes caternal, sometimes internal.

noticed to feed upon vegetable matter placed within its reach, and it has been detected, in several instances, preying upon dead and even living earth-ivorms. It is hence inferred, with some probability, that its habits are carnivorous."

Edward Forbes remarks of the Limax tribe, that they "are herbivorous by preference, but carnivorous when taste or necessity prompts them." 
The mollusks which come under the common apjeliation of Siugs have no shell beyond a small ear-shaped shicld, commencing in its development from an obtuse subspiral nucleus; serving for the protection of the pulmonary cavity of the animal, which is situated sometimes, as in Limax, near the liead, sometimes, as in Pamacella, in the middle, and sometimes, as in Testacellu, near the tail; and it is only in the last instance that the shell is external and cxposed to view. In addition to these, there are one or two genera having either no shell at all, or the merest rudimentary fragment in the shape of a few calcarcous grains. The Limacinea, so far as they have been observed, imhabit chicfly the temperate regions, and are more carnivorous than vegretable feeders. Divested of any shelly encumbrance, or having it only moderately developed on the tail, they are able to burrow into the ground to the depth of nearly two feet; sometimes, however, they suspend themselves from trees by means of a gelatinous thread.* The shell-secreting genera are-

Testacella. Limax. Parmacella.

\section{Genus 1. TESTACELLA.}

Animal; clongated, scmicylindrical; alisc covering and combined with the entire upper surface of the borly, which berrs an eaternal shell at the hinder extremity of the back; head with four tentacles, the upper ones bearing the eyes. (Forbes.)

Shell; ear-shaped, rather compiessed, covered with a brownish epidermis; spire very small, obtuse.

The Testacella is a small carnivorous slug, feeding chiefly on worms, and having the habit during the winter of burrowing in the ground to the depth of one to two feet. As if for providing, under these circumstances, a place of security for the more delicate organs, the pulmonary cavity of the animal is situated in the rear under the protection of a rather strong, compressly auriform shell. The whole of the shell is exposed, and its spiral nucleus is a little beaked and reaches nearly to the posterior edge

* "All the species," says Dr. Binney, of the United States, "that have come under my notice possess the power of suspending themselves in the air by a gelatinous thread. This they effect by accumulating a quantity of tenacious mucus at the posterior extremity of the foot, which they attach to the object from which they are to commence their descent; then, loosing their own hold, they hang suspended by this point. Continuing the secretion, their own weight attenuates the mucous attachment, and draws it out into a thread. As this dries and bardens a fresh supply is afforded, the thread is lengthened, and the animal lets itself down any desirable distance. At this time also the margin of the foot pours out mucous freely, and during the whole operation the locomotive dise is in active undulatory motion." Terr. MIoll. U. S. v. 2, p. 4 . 
or tail of the soft parts. Only two species are known, one inhabiting Britain and the Channel Islands, ${ }^{*}$ and the other the Canary Islands.

\section{Species.}

1. haliotoidea, Draparnand. 2. Maugei, De Férussac.

Genus 2. LIMAX.

Animal; elongated or oblong, semicylindrical, rounded or carinated posteriorly, anteriorly furmished with an oblong disc, in which is imbedded an ungniform shell; head with four tentacles, the two upper ones furnished with eyes. (Forbes.)

Shell; subquadrate, irregular, subcrystalline, with an umbonal nucleus, covered with an epidermis more or less reflected over the sides.

Most of the known species of slugs are of this genus. The small, voracious Limax agrestis, the pest of our gardens, or the larger $L$. cinereus, taken as types, may be observed to have a kind of fleshy shield over the back of the neck, and in this is concealed a small crystalline shell of oblong-square form, not convoluted, but secreted in concentric layers from a kind of umbonal nucleus. So little attention has been paid to these almost shell-less mollusks, that few observations have been made of their existence in foreign lands. Lamarck only described four species of his own country. M. Deshayes, in his edition of Lamarck's work, increased the number to nineteen, including four from New Zealand, Ascension Island, and Mauritius, observed by MM. Quoy and Gaimard, and one or two from Carolina, Madeira, and Teneriffe. We have in Britain eight species, two of which are found in the Eastern United States, near the sea, probably transported thither. Tro aboriginal species, distinct from the British, have been described from the Western States.

\section{Species.}
1. agrestis, $\operatorname{Linn}$.
3. Alpinus, Lam.
5. Ascensionis, Quoy.
2. albus, $i d$.
4. arborum. Bouch.
6. bitentaculatus, $i d$.

* Testacella haliotoidea has been collected in the neighbourhood west of London; Mr. Sowerby found it in a garden at Lambeth, and I once captured a specimen crawling into a conservatory at Wandsworth. 
7. campestris, Binney. 13. hortensis, Fér. 18, rufus, Linn.

8. Caroliniensis, Bosc. 14. nebulosus, Blainv. 19. Sowerbyi, Fér.

9. cinereus, Miiller. 15. noctilucus, Fér. 20. subfuscus, Drap.

10. fuscatus, Férussac. 16. oxyurus, Blainv. 21. sylvaticus, $i d$.

11. flavus, Lam. 17. perlucidus, Quoy. 22. tenellus, Mïller.

12. gagates, Drap.

\section{Genus 3. PARMACELLA, Cuvier.}

Animal; oblong, with a somewhat gibbous, fleshy shield on the middle of the back, enclosing a shell; head, with four tentacles, of which the upper pair are the larger.

Shell; rudely ear-shaped, covered with a horny epidermis; spire short, sometimes irregularly papillary.

In this genus the pulmonary cavity and fleshy shield, enclosing a shell for its protection, is situated about the middle of the animal. The shell is of much more uncouth growth than that of Testacella, the spire being irregular and rudely papillary. We have no Parmacella in Britain, nor is it-nor is Testacella - known in North America. The first specimen, $P$. Olivieri, was discovered by M. Olivier in Mesopotamia ; another species, $P$. palliolum, was received from Brazil ; a third, $P$. calyculata, was discovered by MM. Webb and Berthelot in the Canary Islands, and Cuvier speaks of "some others from India." We only know of the following.

\section{Species.}

1. calyculatn, Soro.

3. palliolum, Férus.

4. Taunaisii, Férus.

2. Olivieri, Cuvier. 



\section{INDEX TO PLATES OF SHELLS.}

\begin{tabular}{|c|c|c|c|}
\hline$g$. & Page & & Page \\
\hline 1. Marginella nubeculata ... & 53 & 33. Trichotropis bicarinata .... & 72 \\
\hline 2. Ringicula auriculata ..... & 53 & 34 $a$. Columbella hæmastoma .. & 80 \\
\hline 3. Erato lrevis $\ldots \ldots \ldots \ldots$ & 43 & $34 b$. Columbella elegans ...... & 80 \\
\hline 4. Oliva angulata .... & 59 & 35. Oniscia Dennisoni ....... & 84 \\
\hline 5. Ovulum volva $\ldots \ldots \ldots$ & 36 & 36. Rostellaria fusus & 91 \\
\hline 6. Terebellum subulatum .... & 35 & 37. Strombus Novæ-Zelandiæ .. & 94 \\
\hline 7. Voluta volvacea $\quad . . . .$. & 47 & 38. Struthiolaria straminea .... & 88 \\
\hline 8. Cymbium Linnæi ... & 46 & 39. Priamus stercus-pulicum .. & 87 \\
\hline 9. Cymbium Broderipii ...... & 46 & 40. Pterocera multipes....... & 92 \\
\hline 10. Cypræa leucostoma & 43 & 41. Pyrula Mawæ & 106 \\
\hline uteostoma ....... & 64 & 42. Murex florifer & 103 \\
\hline 12. Cyllene Grayi & 65 & 43. Triton tigrinus ... & 98 \\
\hline orthii ... & 51 & 44. Ranella foliata .. & 99 \\
\hline 14. Conus Victoriæ ..... & 34 & Persica........ & 119 \\
\hline ra pretiosa.... & 56 & nata. . . . . . . & 123 \\
\hline 16. Phos Cumingii ........ & 67 & 47. Cancellaria Tritonis ..... & 109 \\
\hline is planicostatus .... & 62 & Ila imperialis ...... & 121 \\
\hline 18. Quoyia decollata & 63 & rotinus ........ & 122 \\
\hline 19 a. Eburna papillaris & 61 & ptorrhaphe.. & 113 \\
\hline 19 b. Eburna Japonica ........ & 61 & 51. Tu & 131 \\
\hline nchus striatus & 69 & ginelloides .. & 115 \\
\hline 21. Ancillaria Mauritiana..... & 60 & 53. Fusus Nicobaricus....... & 118 \\
\hline 22. Buccinum melanostoma... & 68 & rbii........ & 104 \\
\hline 23. Fossarus clathratus .... & app. & 55. Triphoris grandis ....... & 127 \\
\hline 24. Dolium fimbriatum & 73 & 56. Stylifer pyramidalis ..... & 129 \\
\hline 25. Magilus antiquus ... & 71 & 57. Elenchus circulatus ..... & 133 \\
\hline 26. Harpa imperialis ... & 74 & 58. Phasianella venusta ..... & 132 \\
\hline 27. Concholepas Peruvianus. . & 75 & 59. Cerithium nobile..... & 125 \\
\hline 28. Cassis areola & 83 & 60. Littorina pulchra ..... & 135 \\
\hline 29. Monoceros grande.... & 76 & 61. Bankivia purpurascens .... & 134 \\
\hline 30. Purpura aperta & 78 & 62. Solarium maculatum ..... & 144 \\
\hline 31. Cassidaria Tyrrhena ...... & 85 & 63. Morulus cidaris . ........ & $1+1$ \\
\hline 32. Ricinula iodostoma $\ldots$. & 82 & 64. Monodonta labeo .... & 140 \\
\hline
\end{tabular}


65. Turho petholatus . . . . . 138

66. Rotella gigantea $\ldots \ldots \ldots, 141$

67. Trochus modestus ...... 139

68. Trochiscus Norrisii $\ldots . . .140$

70. $\}$ Margarita pulchella $\ldots . . .136$

71. Phorus onustus ........ 143

72. Tornatella coccinata ..... 154

73. Pyramidella maculosa..... 153

74. Scalaria imperialis ....... 147

75. Rissoa Cumingii ....... 151

76. Monoptygma cinerea ..... 148

77. Delphinula imperialis..... 145

78. Eulima major......... 149

79. Niso splendidula $\ldots \ldots \ldots 150$

80. Ianthina globosa $\ldots \ldots \ldots 156$

81. Narica cancellata (see vol. 2.)

82. Navicella porcellana ..... 158

83. Neritina labiosa ........ 159

84. Natica Cumingiana ..... 164

85. Neritopsis radula (see vol. 2.)

86. Nerita costata......... 161

87. Planorbis comens ....... IS1

88. Valvaía Cumingii ....... 171

89. Lacuna pallidula ....... 172

90. Ampullaria Oronocensis .. 168

91. Physa Maugeriæ ....... 180

92. Lymnæa stagnalis ....... 179

93. Paludina oxytropis....... 170
Fig. Page

94. Ancylus fluviatilis $\ldots \ldots .178$

95. Geomelania Jamaicensis .. 201

96. Assiminea .......... app.

97. Melania asperata...... 175

98. Melania (Io) spinosa . . . 175

99. Melanopsis atra ...... 173

100. Paludomus undatus ..... 177

101. Helicina agglutinans ... 188

102. Separitista Chemnitzii .... app.

103. Auricula Midæ........ 184

104. Scarabus imbrium ...... 183

105. Chilina ampullacea ..... 182

106. Cyclostoma volvulum .... 198

107. Truncatella Caribbæensis.. 200

108. Nematura Deltæ ........ app.

109. Pupina grandis........ 199

110. Achatina zebra........ 212

111. Achatina(Spiraxis) nigricans 212

112. Succinea patula ...... 249

113. Achatinella decora ..... 214

114. Clausilia invalida ....... 204

115. Partula faba......... 215

116. Bulimus onça ....... 232

117. Anastoma ringens ..... 246

118. Pupa maritima....... 208

119. Helix Listeri ......... 246

120. Vitrina monticola...... 250

121. Proserpina nitida ....... 247

122. Helix Luzonica ....... 246 


\section{INDEX TOO PLATES OF ANIMALS.}

VOL. I.

Plate Page $\mid$ Plate Page

A. 1. Spirula Peronii ....... 18 F. 1. Oliva maura ........ 59

2. Argonauta Argo....... $15 \quad$ 2. Ovulum ovum ....... 36

B. Argonauta Argo...... ib. 3. Conus textile ...... 34

C. Nautilus Pompilius .... 23 G. 1. Dolium pomum ..... 73

D. 1. Voluta angulata...... 47 2. Dolium olearium ..... ib.

2. Cassis glauca....... 83 3. Triton tuberosum..... 98

3. Cypræa tigris....... 43 H. 1. Bulimus rosaceus..... 234

E. 1. Dolium perdix ...... $73 \quad$ 2. Bulimus oblongus ... 234

2. Harpa ventricosa $\ldots \ldots .74 \quad$ 3. Achatina regina $\ldots . .212$ 

INDEX TO VOL. I.

\begin{tabular}{|c|c|c|c|c|c|}
\hline & Page & & Irage & & Page \\
\hline Ach & 208 & Carychium ...... & 184 & Delphinula & \\
\hline chatinella ..... & 212 & Cassidaria & 85 & Dermatocera & 96 \\
\hline Adamsiella ...... & 192 & Cassis......... & 82 & Diplomatina..... & 196 \\
\hline$\ldots \ldots \ldots$ & 86 & Cataulus....... & 193 & Dolium ...... & 72 \\
\hline Alcadia & 186 & Cephalopoda .... & 9 & Eburna ....... & 61 \\
\hline Alycæus & 192 & Ceratodes ... & 167 & Elenchus ....... & 133 \\
\hline Ampliipeplea .... & 178 & Cerithium .... & 123 & to $\ldots \ldots \ldots$ & 43 \\
\hline Ampullaria ..... & 166 & Chenopus ..... & 89 & Eulima ....... & 148 \\
\hline$\ldots$ & 162 & Chilina & 182 & nia ........ & 190 \\
\hline oidea...... & 167 & Choanopoma .... & 193 & laria.... & 118 \\
\hline ria ...... & 60 & Iropoma.... & 193 & Fastigiella ..... & 122 \\
\hline$\ldots \ldots$ & 174 & Cist & 194 & ıla ......... & 106 \\
\hline$\ldots \ldots$ & 177 & ia....... & 202 & as ......... & 116 \\
\hline Anastoma & 246 & acea .... & 200 & opoda...... & 24 \\
\hline Aple & 179 & bella .. & 78 & mia ..... & 200 \\
\hline lais. . . . . . . & 89 & Columellata .... & 44 & $\ldots \ldots \ldots$ & 73 \\
\hline$\ldots \ldots$ & 12 & ana...... & 209 & nа $\ldots . .$. & 185 \\
\hline Aulopoma ..... & 193 & Concholepas .. & 75 & $\ldots \ldots \ldots$ & 235 \\
\hline$\ldots \ldots$ & 183 & $\ldots \ldots \ldots$ & 31 & ocena ...... & 196 \\
\hline cea ...... & 181 & oluta ...... & 31 & na ... & 154 \\
\hline Azeca & 209 & edopoma... & 194 & $\ldots \ldots$ & 174 \\
\hline Baled & 202 & oma.... & 194 & cia ........ & 196 \\
\hline ivia .. & 133 & Cyclophorus & 194 & $\ldots \ldots$ & 171 \\
\hline Bithynia. & 169 & stoma . . & $19 \mathrm{l}$ & Lanistes ....... & 167 \\
\hline Blandia & 190 & stomacea & 184 & Leonia.......... & 196 \\
\hline Bonellia ....... & 149 & Cyc & 195 & Leptoconchus .... & 69 \\
\hline Bourciera....... & 193 & drella . & 205 & Leptopoma ...... & 196 \\
\hline Buccinum & 67 & Cyllene & 65 & Lewisea ....... & 190 \\
\hline Buli & 216 & $C y_{m} b a$ & 45 & Licina . . . . . . . & 197 \\
\hline Bullia & 65 & Cymbium ... & 45 & Limacinea $\ldots$. & 250 \\
\hline Callia & 199 & ea ....... & 37 & $\operatorname{Limax} \ldots .$. & 252 \\
\hline Canalifera ... & 94 & Cyrtulus...... & 121 & Lindleya ... & 190 \\
\hline Cancellaria & 107 & Daudebardia & 249 & Liotia & 145 \\
\hline
\end{tabular}




\begin{tabular}{|c|c|c|c|c|c|}
\hline & Page & & & & \\
\hline Lithidion & 197 & Parmacella . & 253 & Ruma & \\
\hline Littorina & 134 & Partula & 214 & Scalaria & \\
\hline Lucidella....... & 186 & Pectinibranchiata & 30 & Scarabus & \\
\hline Lunatia & 162 & Pedipes & 184 & Schasicheila..... & \\
\hline Lymnæa & 178 & Peristomata & 165 & Sigaretus & \\
\hline Lymnæana & 177 & Persona & 96 & Siphonostoma & \\
\hline Magilus & 70 & Petitia & 190 & Solar & \\
\hline Mamma & 162 & nella. . & 132 & Spin & \\
\hline Mangelia ....... . & 113 & Pho & 142 & Spi & \\
\hline rita & 135 & $\mathrm{Ph}$ & 66 & Stil & \\
\hline Marginella ...... & 51 & ( & 179 & Sto & \\
\hline Megalomastoma .. & 197 & Phy & 179 & elus ..... & \\
\hline Melampus & 184 & Pir & 173 & Strep & \\
\hline ia ...... & 173 & & 62 & & \\
\hline ana $\ldots .$. & 172 & & 180 & ria & \\
\hline opsis ..... & 172 & a.... & 110 & 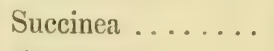 & 24 \\
\hline$\ldots \ldots \ldots$ & 4 & 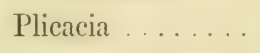 & 151 & & \\
\hline Metcalfeia & 190 & Pol & 68 & $T h c$ & 13 \\
\hline$\ldots \ldots \ldots$ & 48 & Por & 197 & 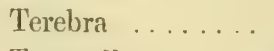 & \\
\hline eros ..... & 75 & Pol & 167 & lla. . . . . . . & 25 \\
\hline lonta ...... & 140 & $P o r$ & 16 & «s $\ldots .$. & \\
\hline igma ... & 147 & & 86 & la $\ldots . .$. & 1 \\
\hline us $\ldots . .$. & 140 & $a \ldots \ldots$ & 247 & $i n a . . .$. & 20 \\
\hline$\ldots \ldots \ldots$ & 100 & $\ldots \ldots$ & 91 & pis $\quad . .$. & \\
\hline Niassa & 6 & os...... & 198 & s....... & \\
\hline$\ldots \ldots \ldots$ & 161 & $\ldots \ldots$ & $\cdot 206$ & $\ldots \ldots \ldots$ & \\
\hline$n a \ldots$ & 16 & $\ldots \ldots$ & 19 & $i u m \quad \ldots .$. & \\
\hline la....... & 157 & $a \ldots \ldots$ & 199 & $l l a \ldots \ldots$ & 18 \\
\hline us .. & 19 & & 7 & is $\ldots .$. & 1 \\
\hline$\ldots \ldots \ldots$ & 160 & $\ldots . .$. & 5 & $\operatorname{Tr}$ & 13 \\
\hline$a \ldots \ldots$ & 15 & & 15 & ella ...... & 19 \\
\hline na ...... & 158 & & 10 & $\ldots \ldots$ & 13 \\
\hline Neverita & 162 & & 6 & cea ...... & 12 \\
\hline Niso .. & 149 & $\ldots \ldots$ & 98 & Turbinella ...... & 11 \\
\hline Oliva & 57 & Rap & 19 & Tudora. . & 19 \\
\hline Oniscia .. & 84 & Rea & 198 & ella $\ldots . .$. & 13 \\
\hline Opisthoporus & 197 & Registon & 199 & Typhis... . .... & 10 \\
\hline Otop & 197 & & 8 & Valvata $\ldots . . .$. & 17 \\
\hline Ovulum & 35 & cula & 53 & Vitrina......... & 24 \\
\hline Paludestrina & 169 & & 150 & Voluta & 4 \\
\hline Palt & 16 & aria..... & 90 & Wilkinsonaa .... & 19 \\
\hline mus & 17 & Rotella ..... & 141 & $Z u a$ & 23 \\
\hline ica & 列 & & & & \\
\hline
\end{tabular}




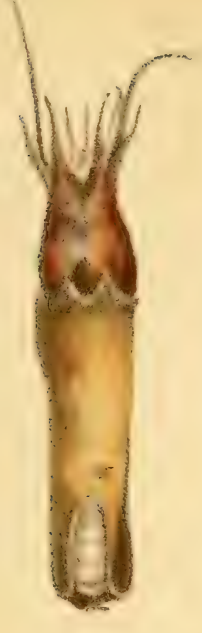

(x

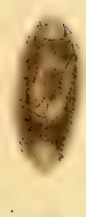

2
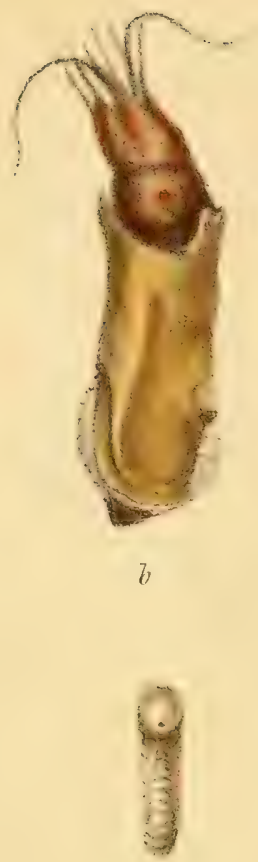

e
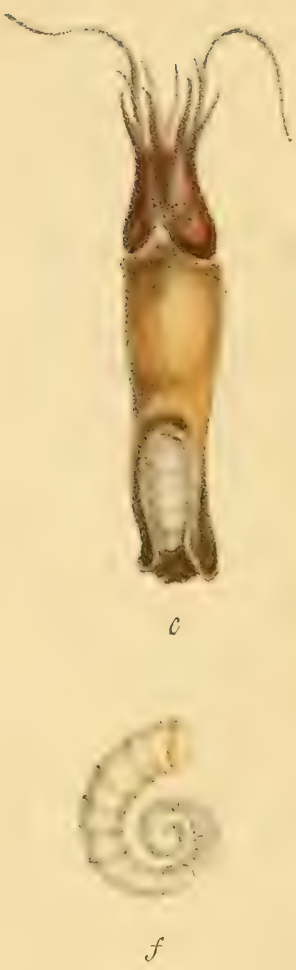

Spirula Peronii. Iamarck.

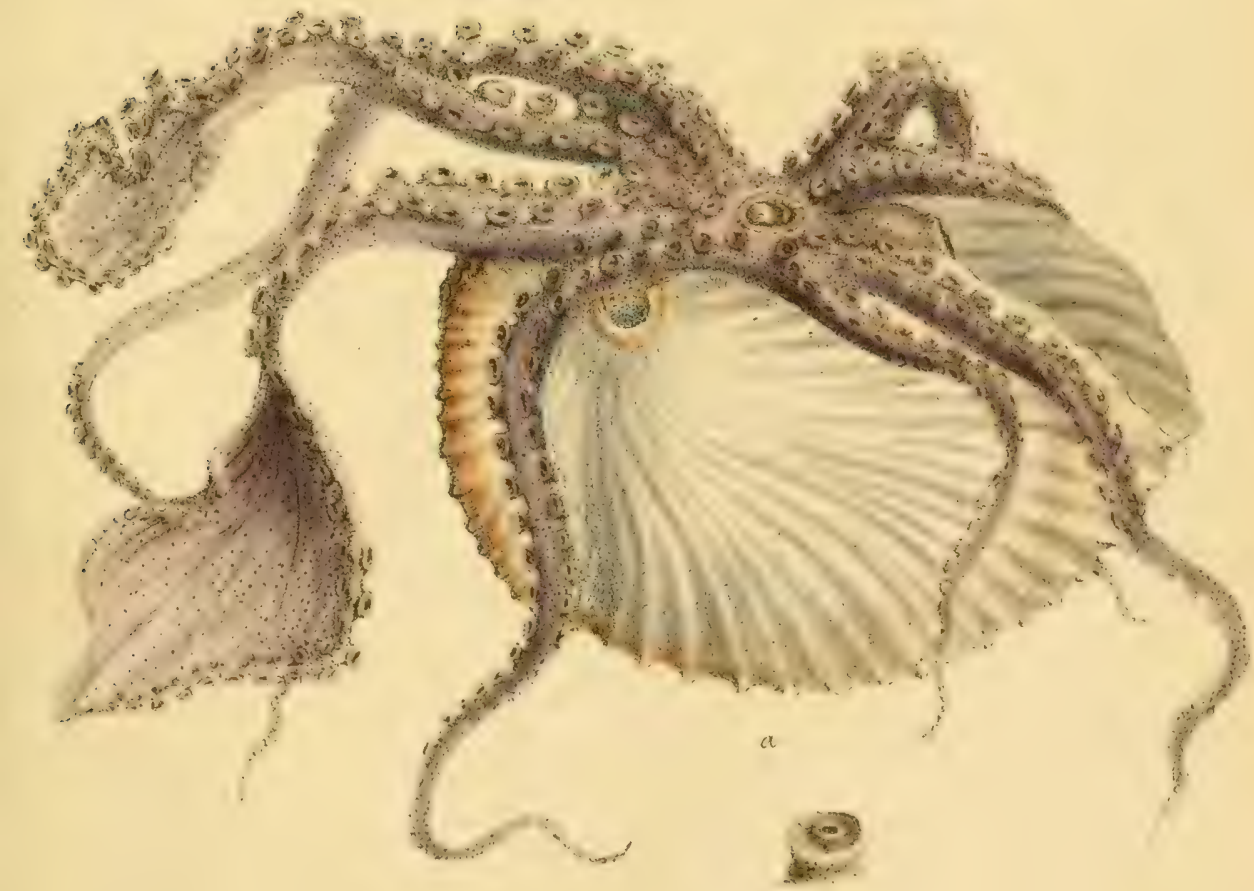

Miller del etlith 



$$
b
$$




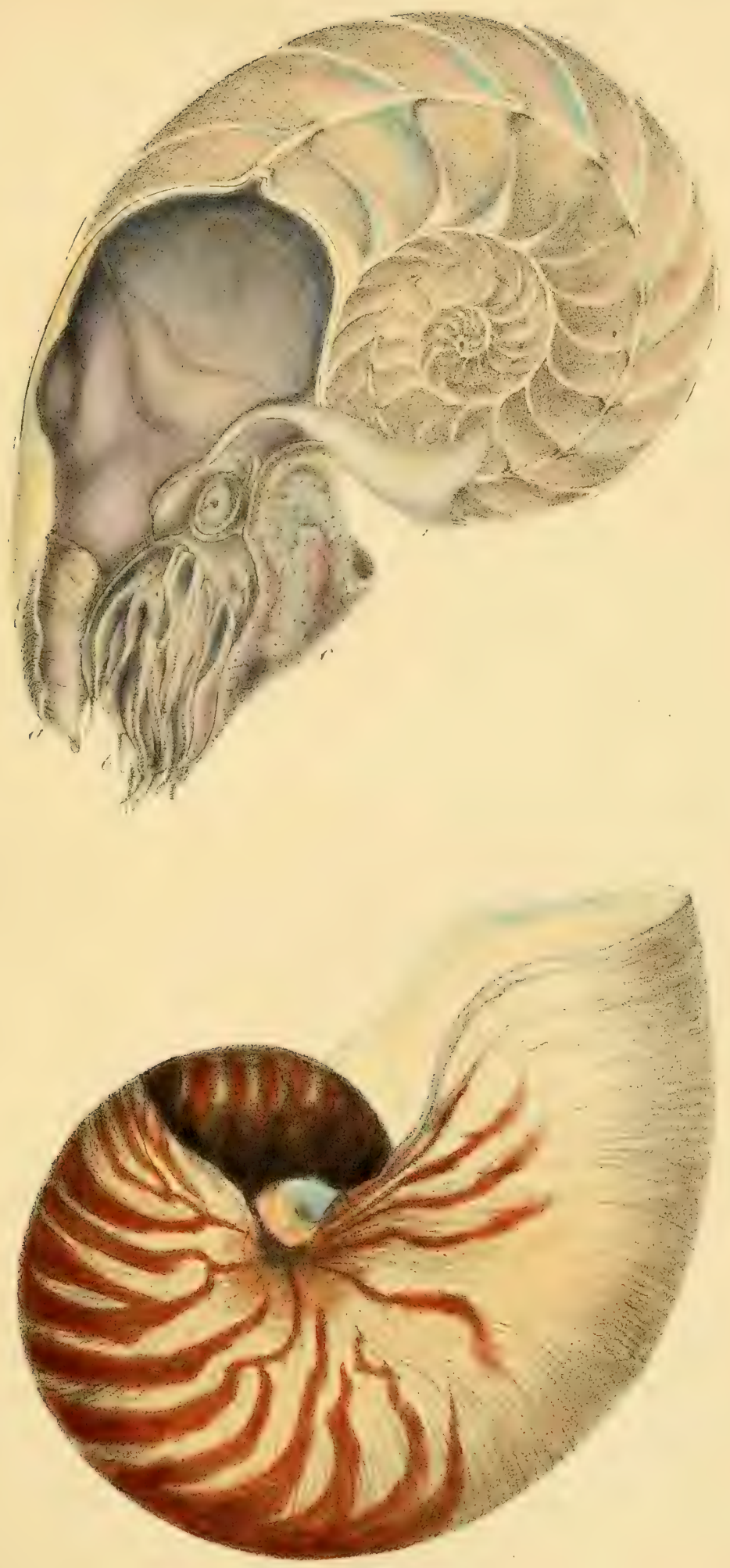



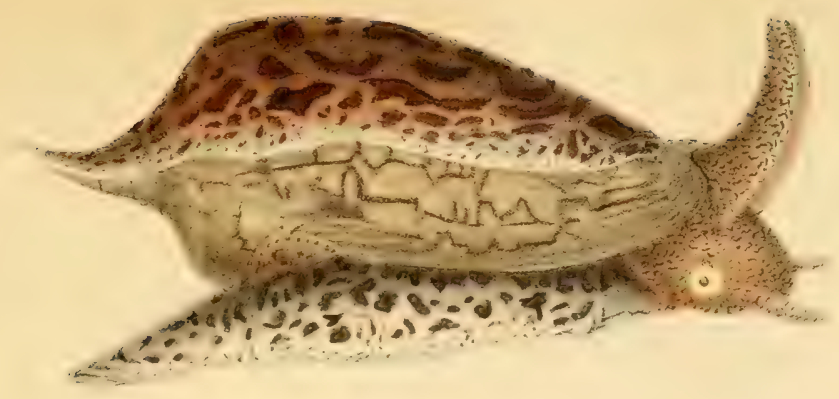

Plate D.

Voluta arènlata, D.v

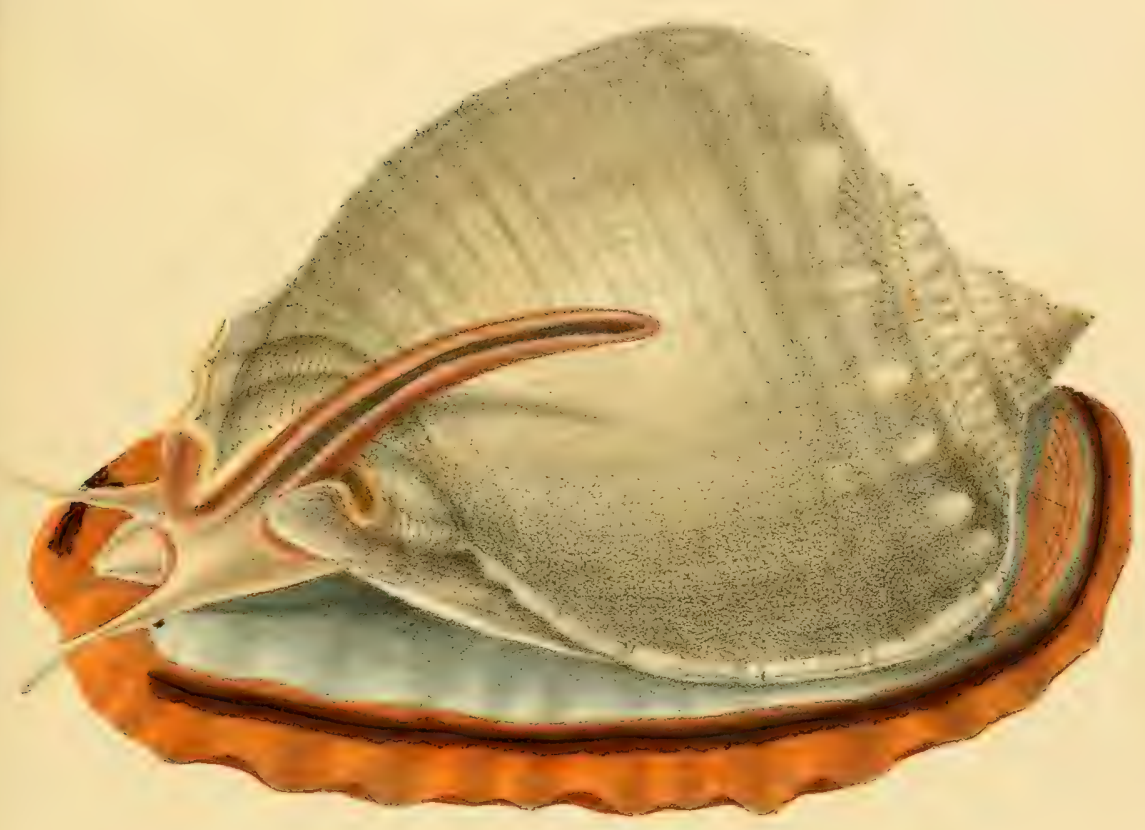

vassis flarca, Lam.

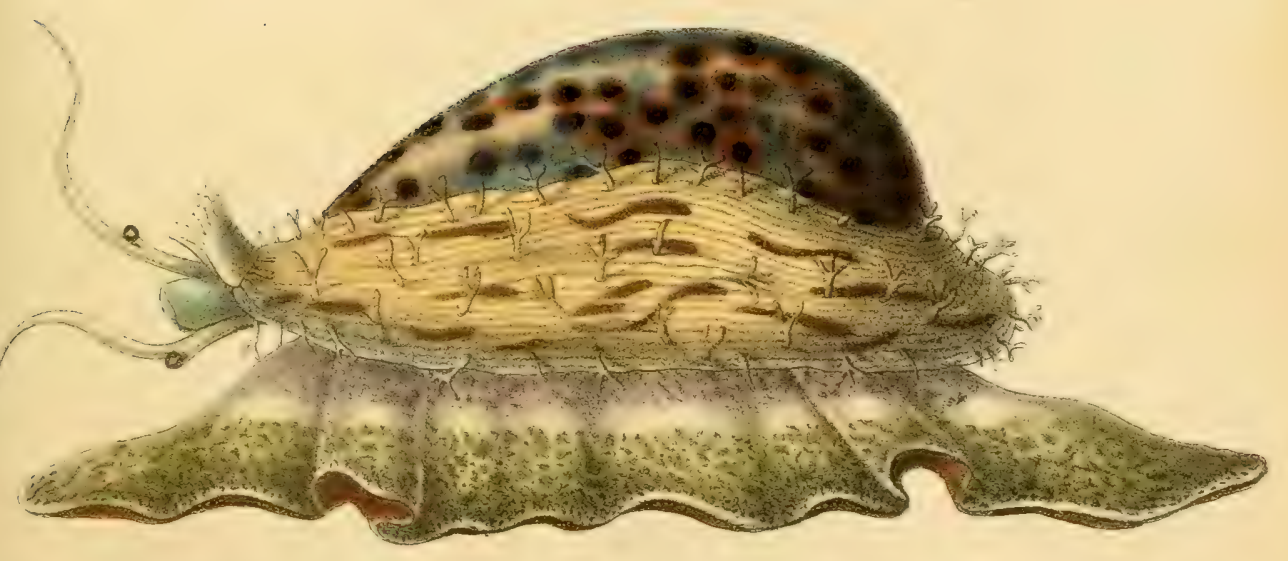





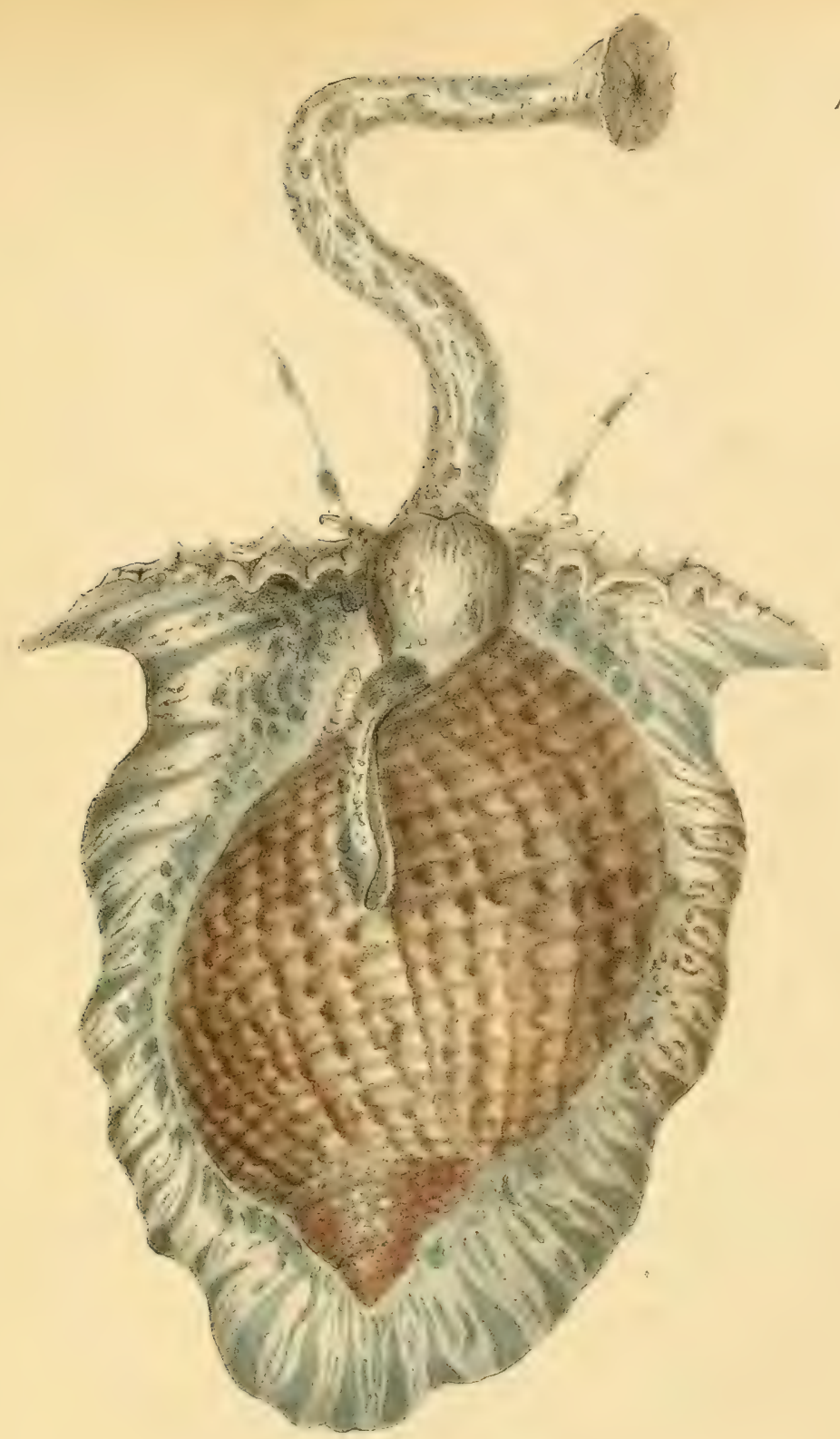

Put E.

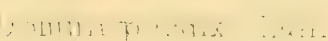

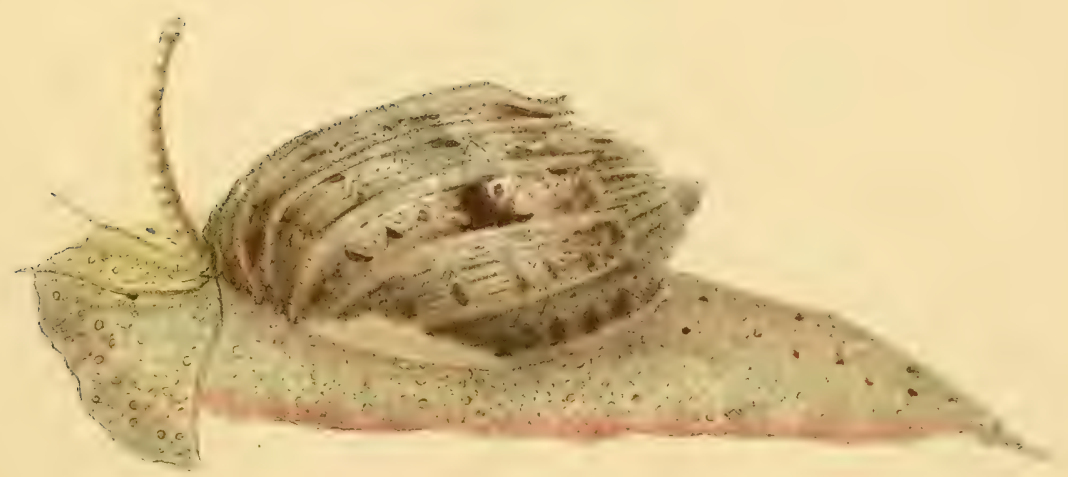





\section{Plate F}

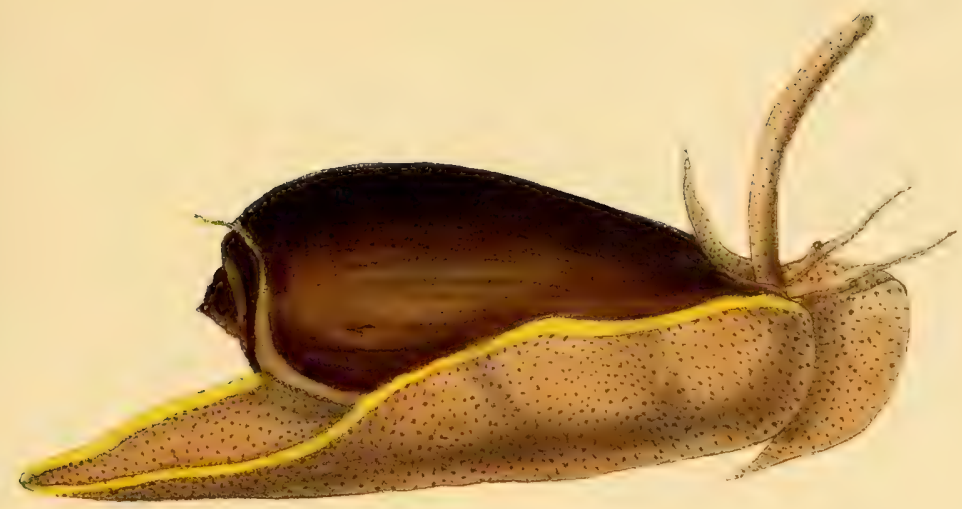

Oliva maura: Lam

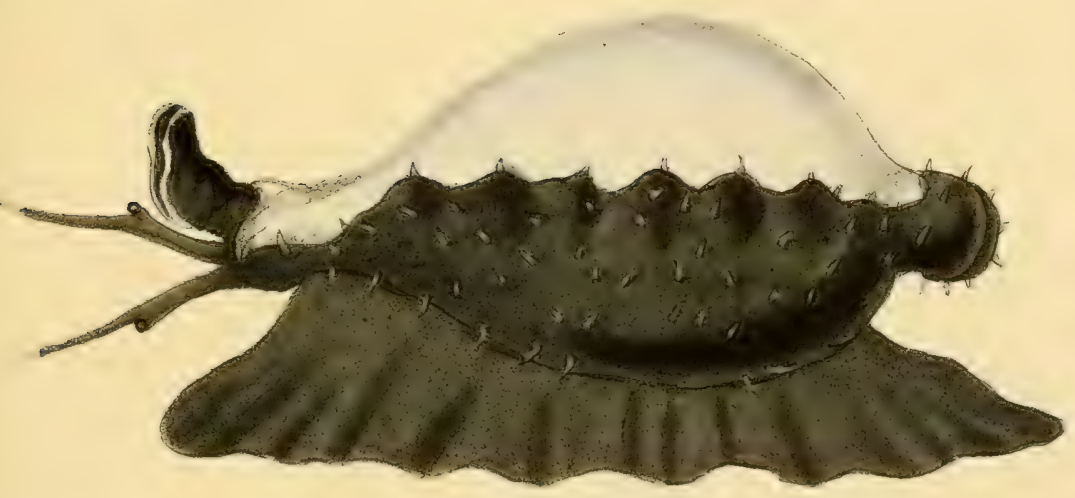

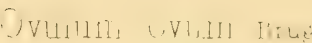

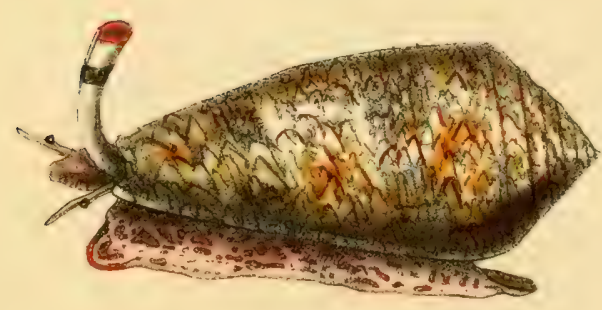

Miller lith

Conus textile. Linn 

Plate G.

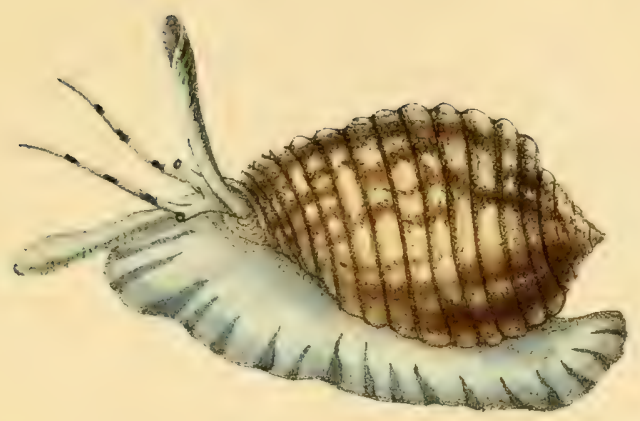

Dolium pomum-Lam

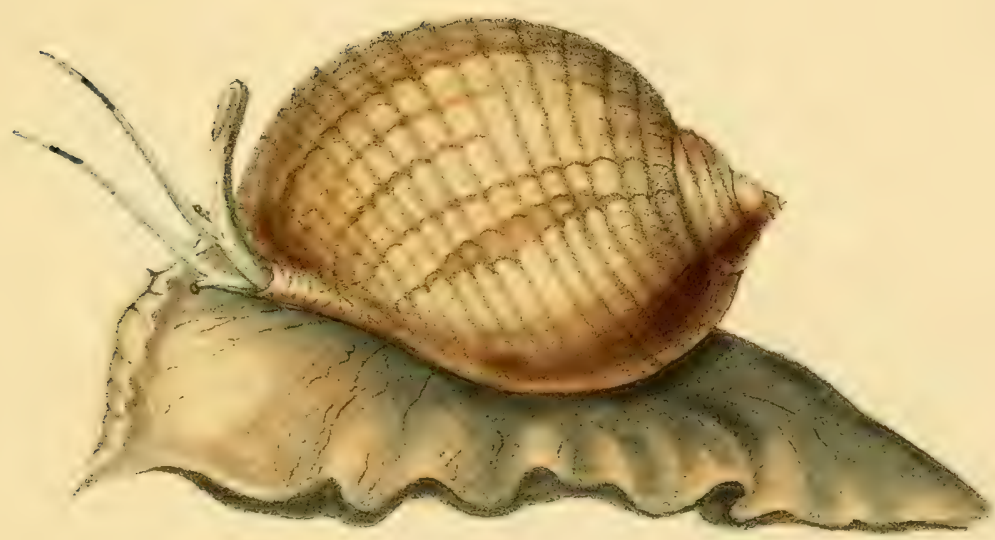

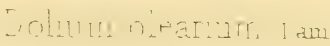

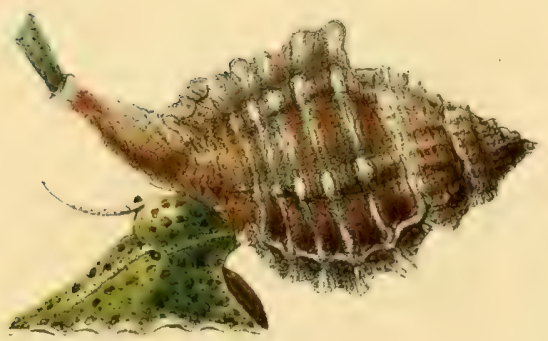

Miller lith.

Triton trib erosum: Lam 



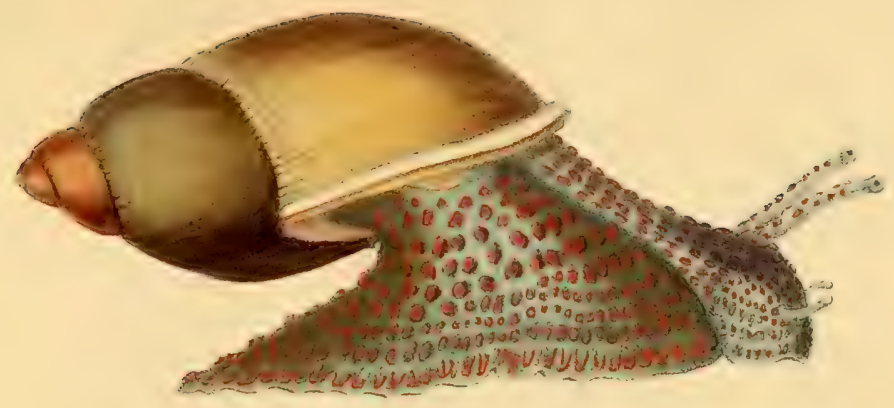

Dulim is rosaceus King

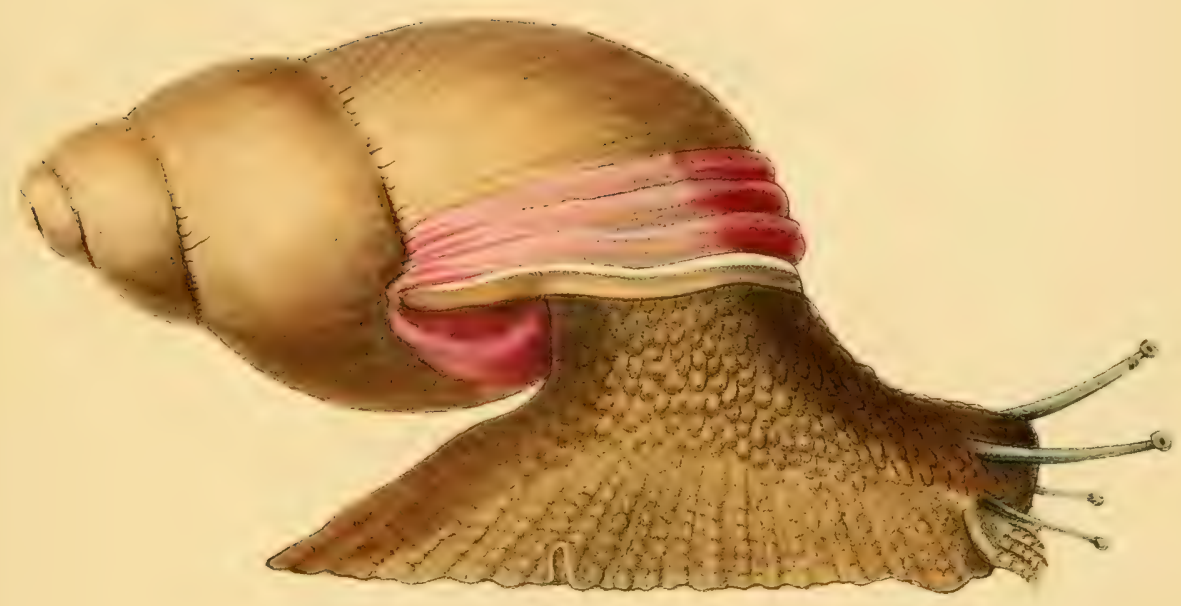

Bulimus riblonga. Miller.

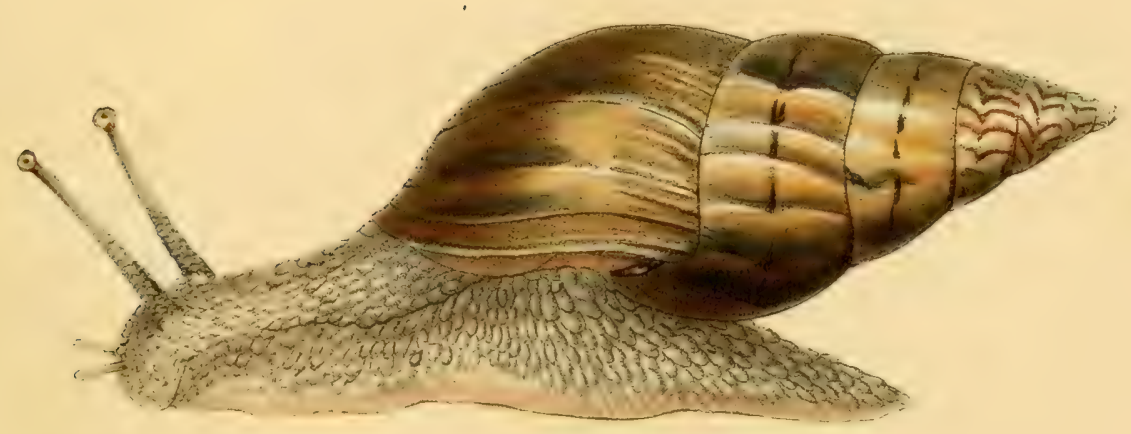





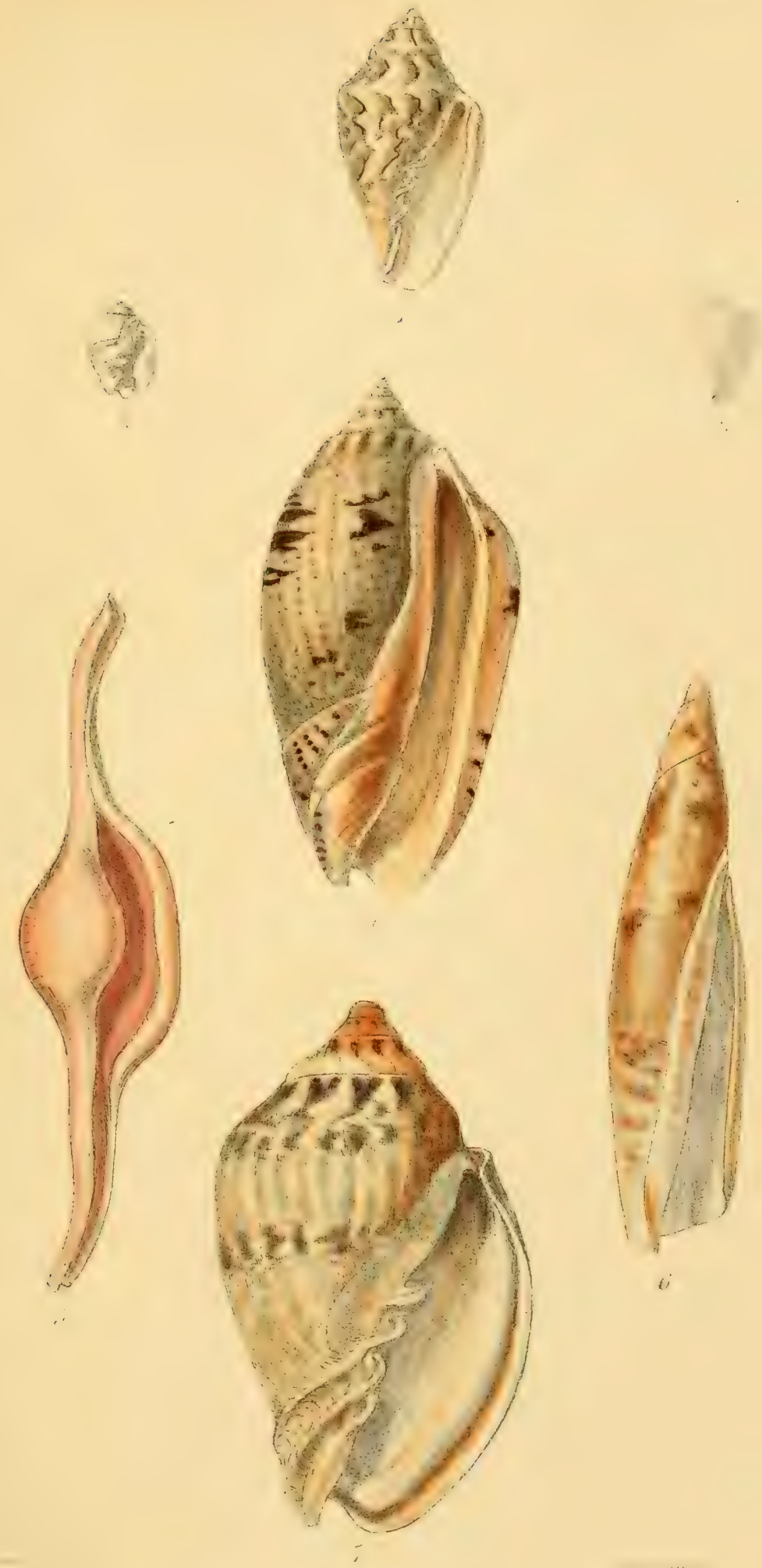





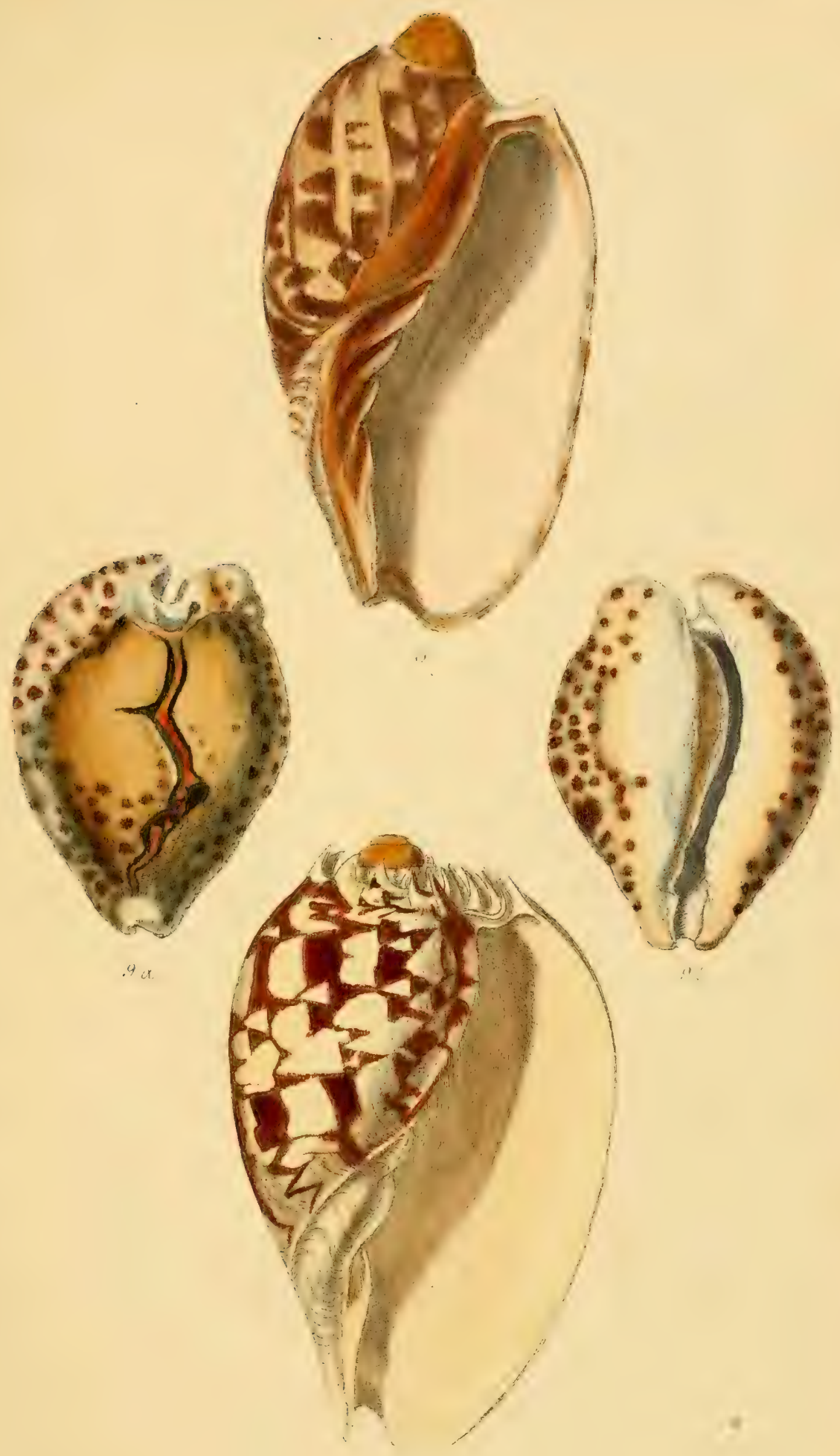





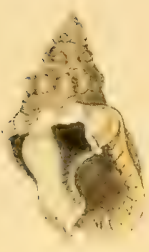

$7 i$

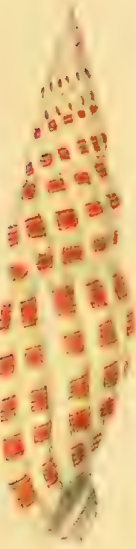

1."

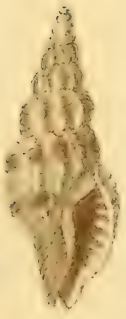

16
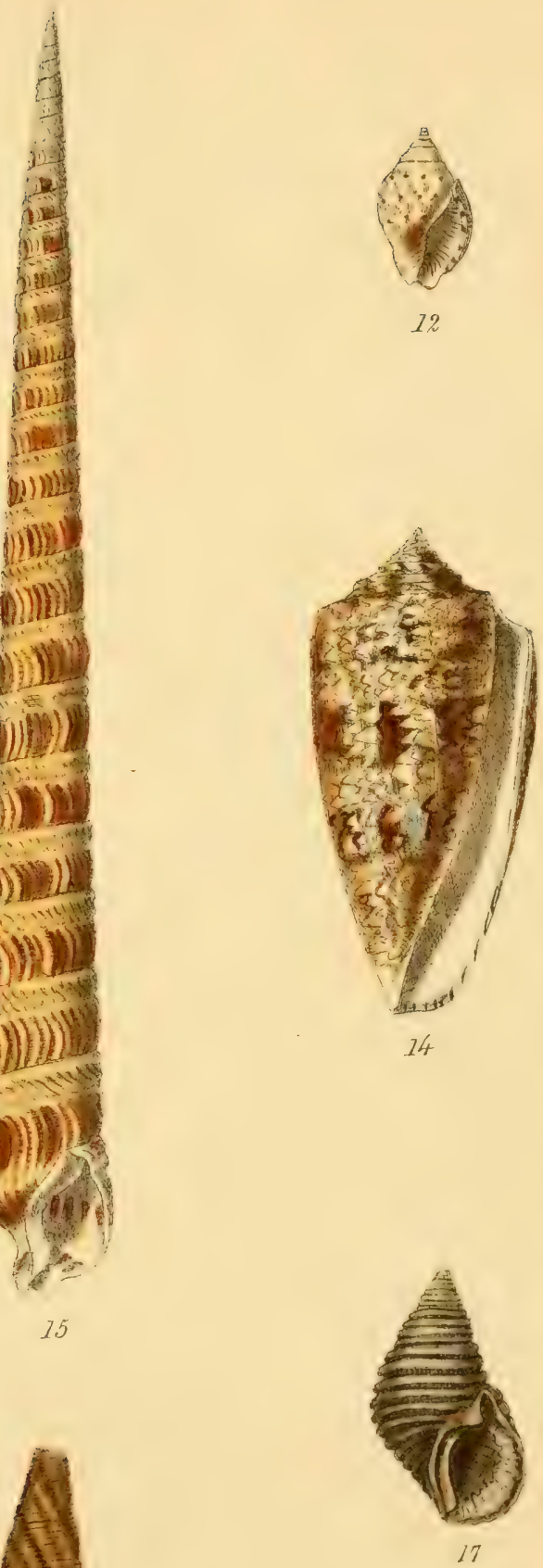

Sowerby del

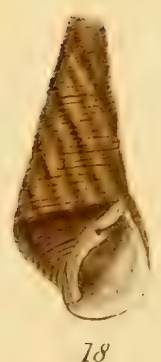



Plate \&.

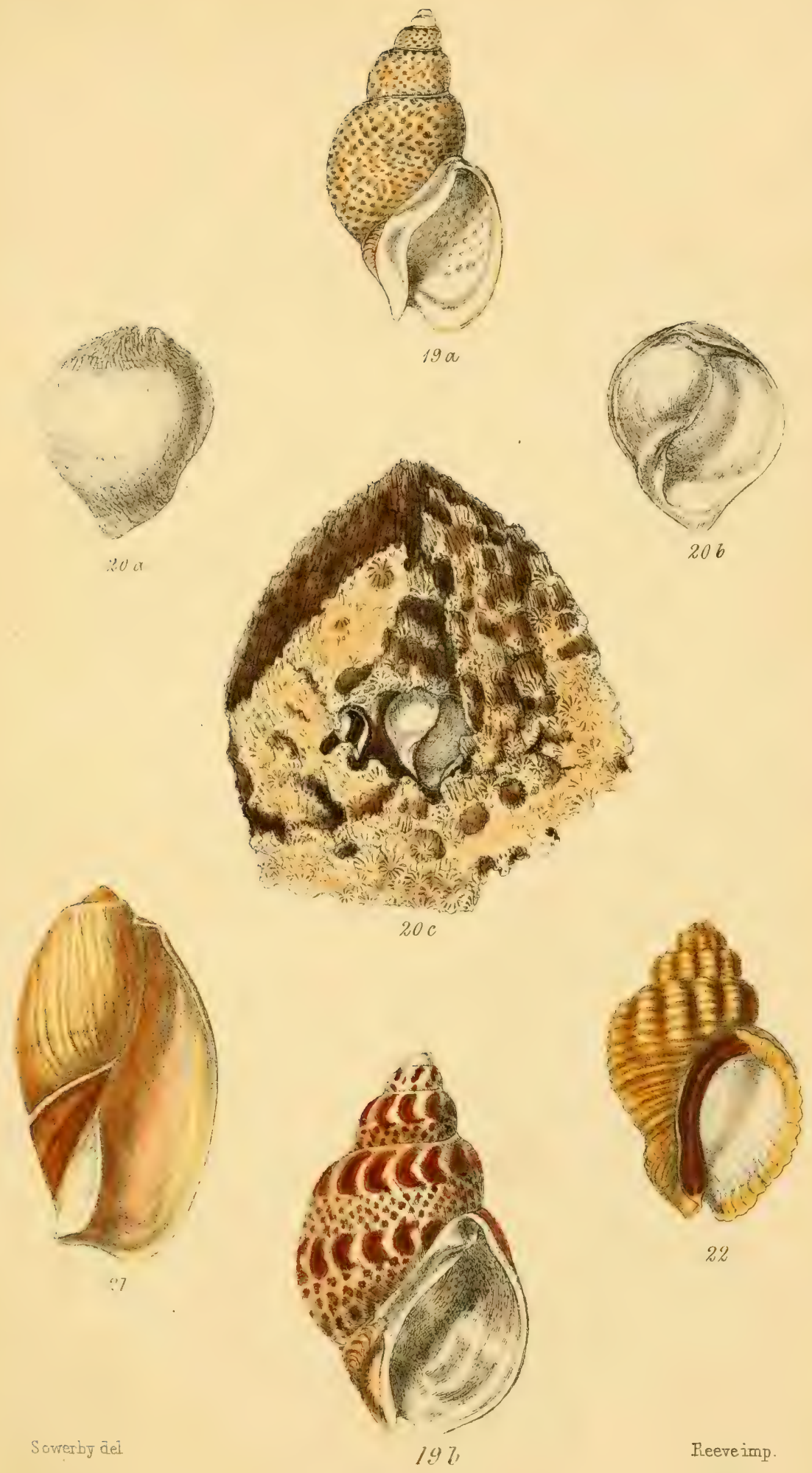




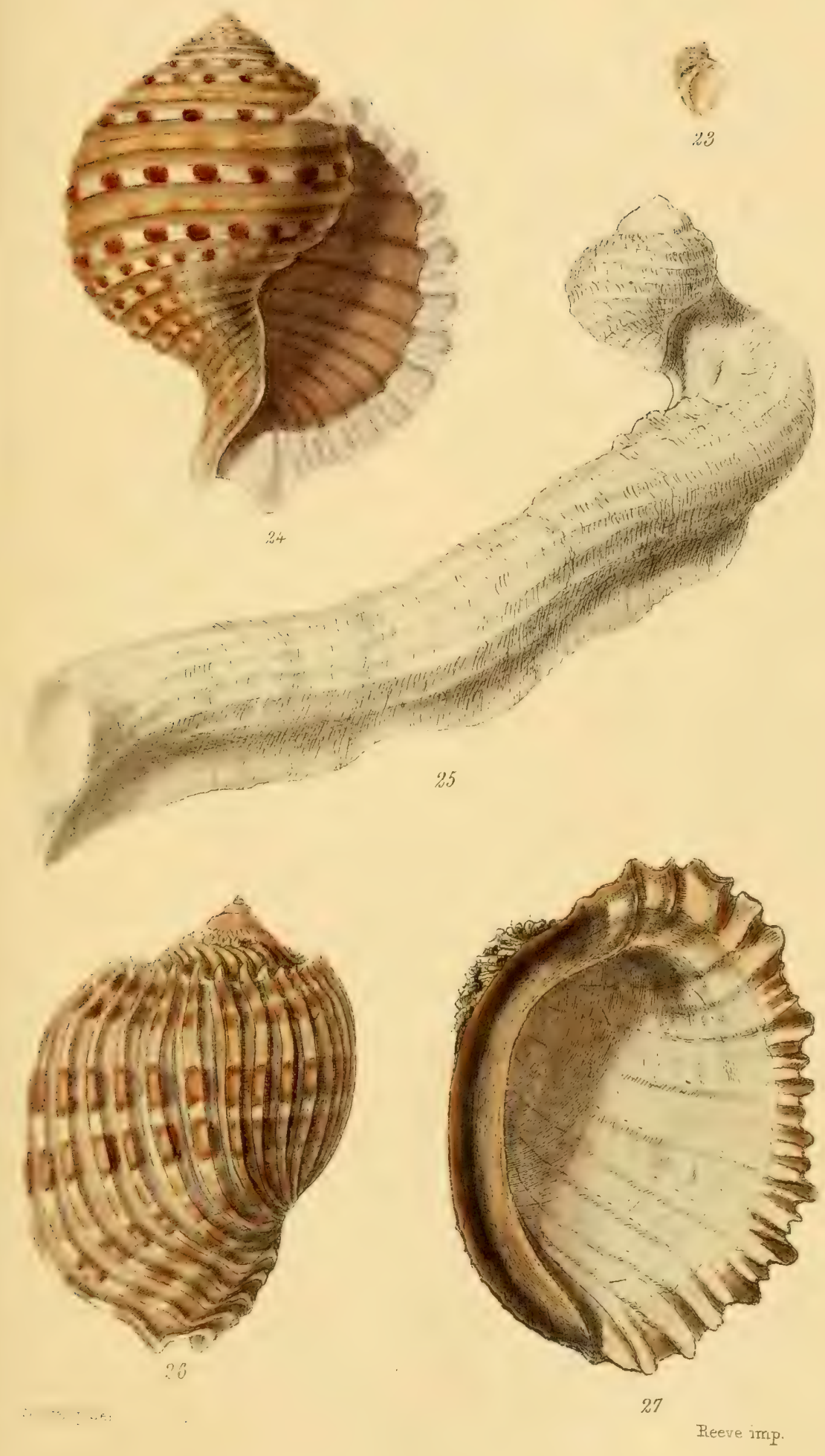

Plate 6

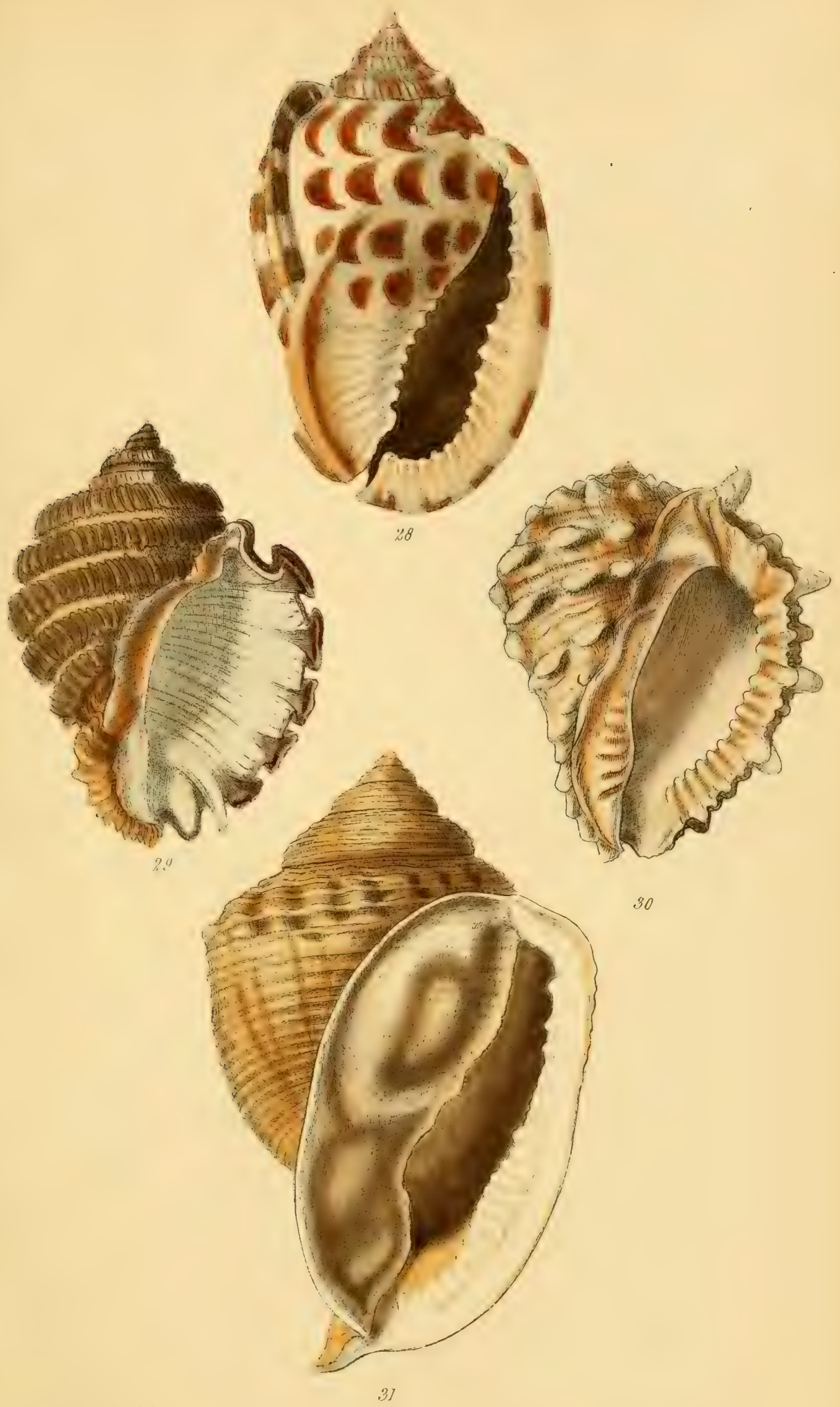




Plate?
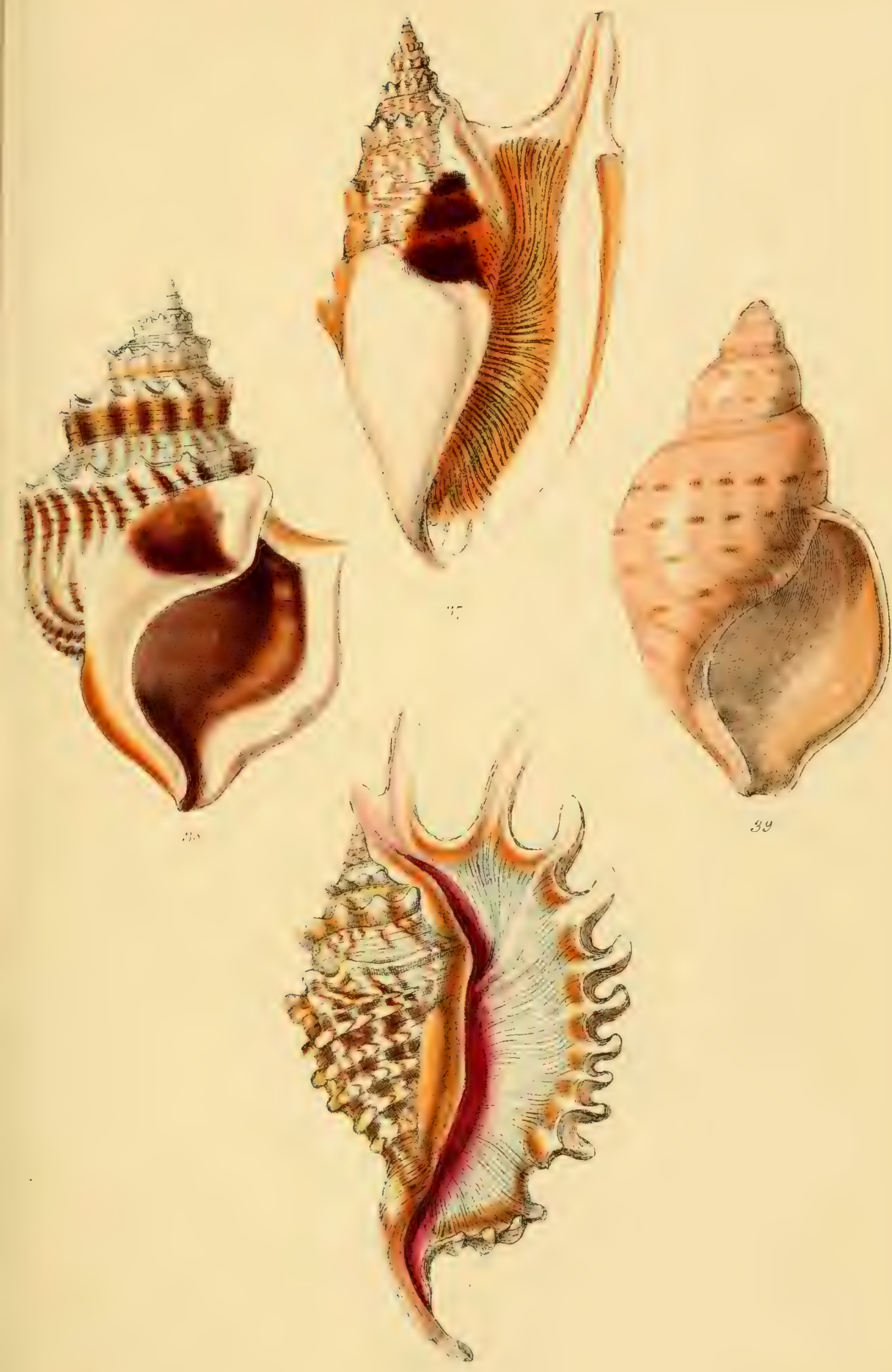

$3 y$

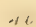



Plate 9.
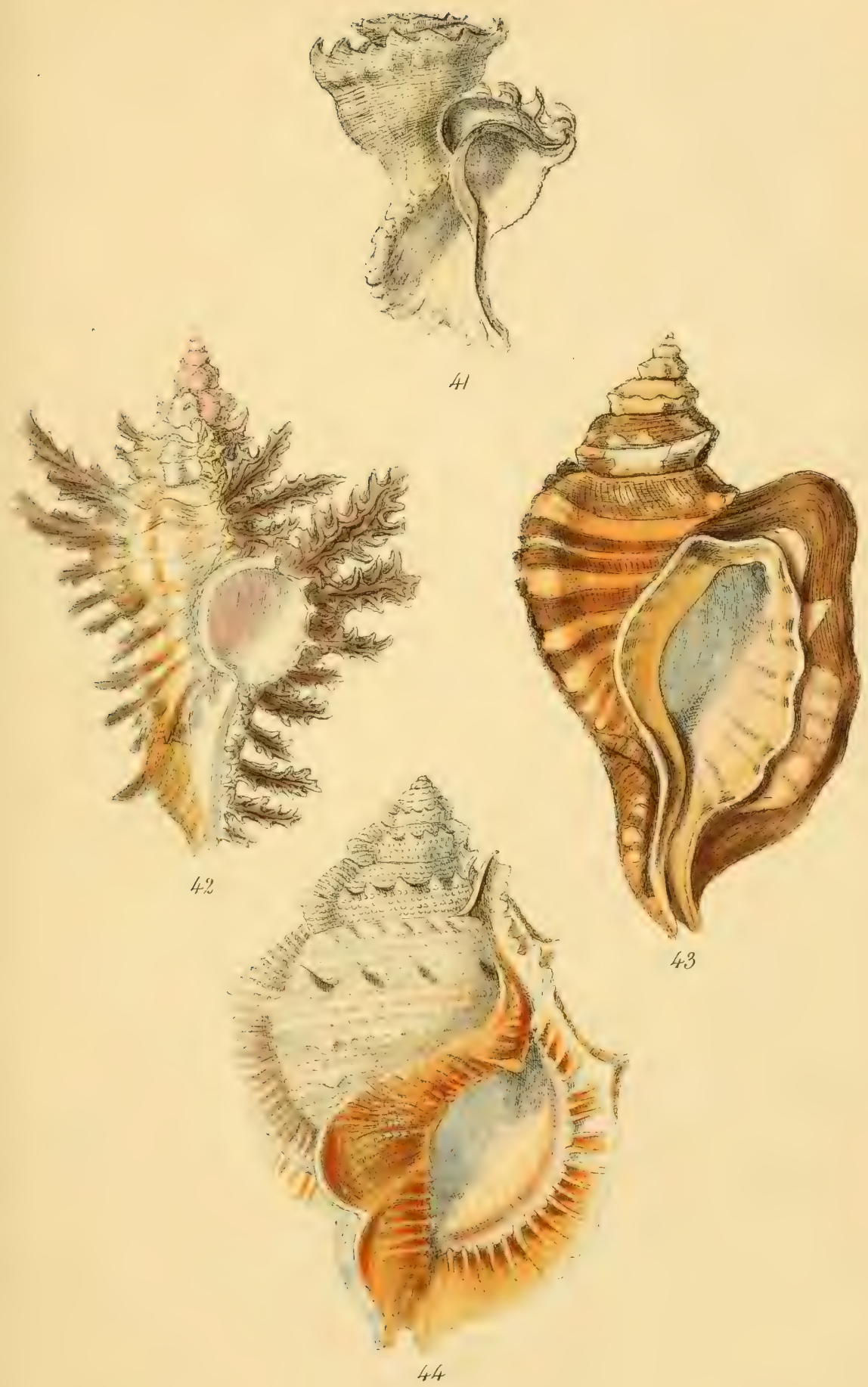


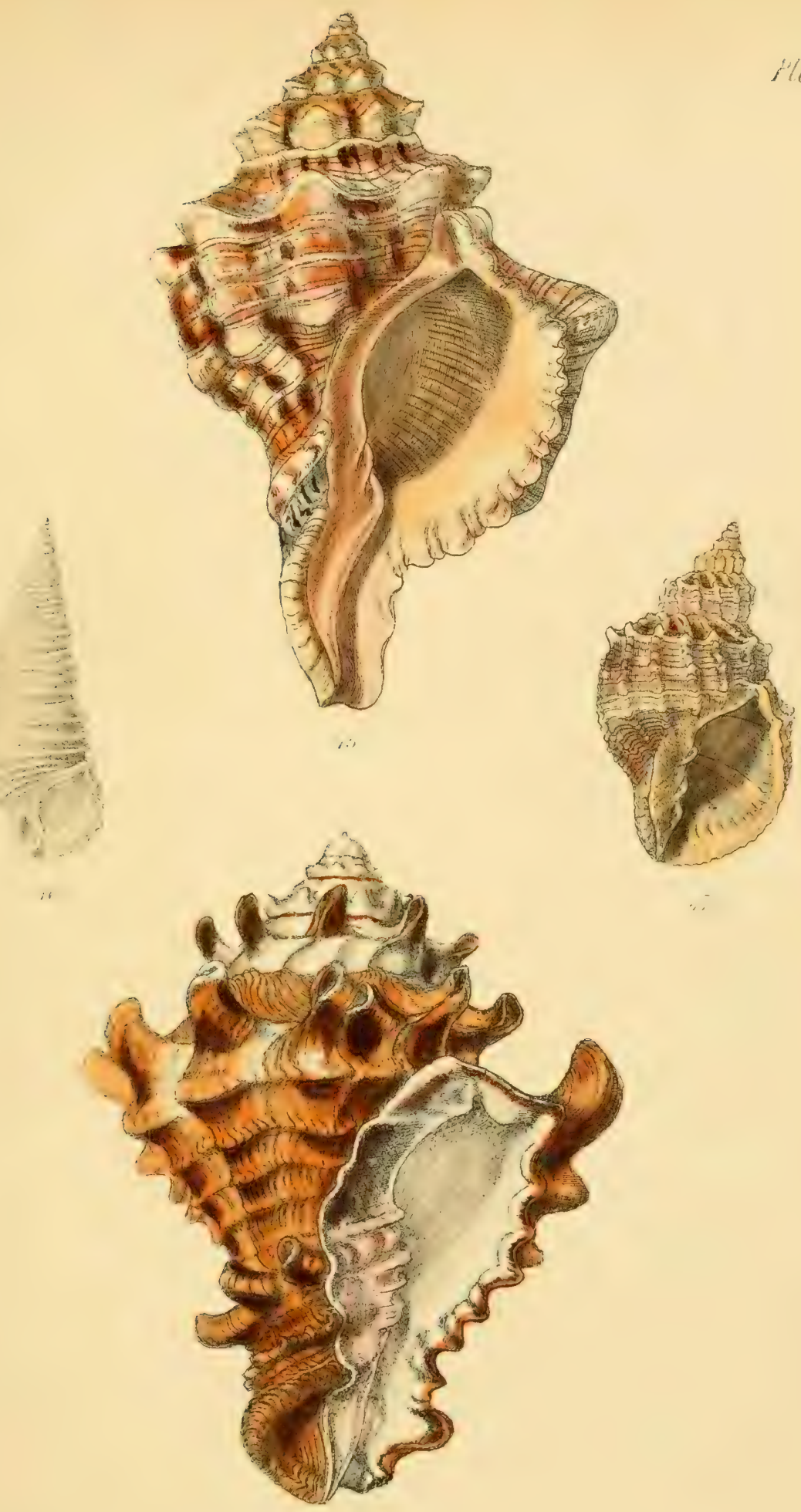


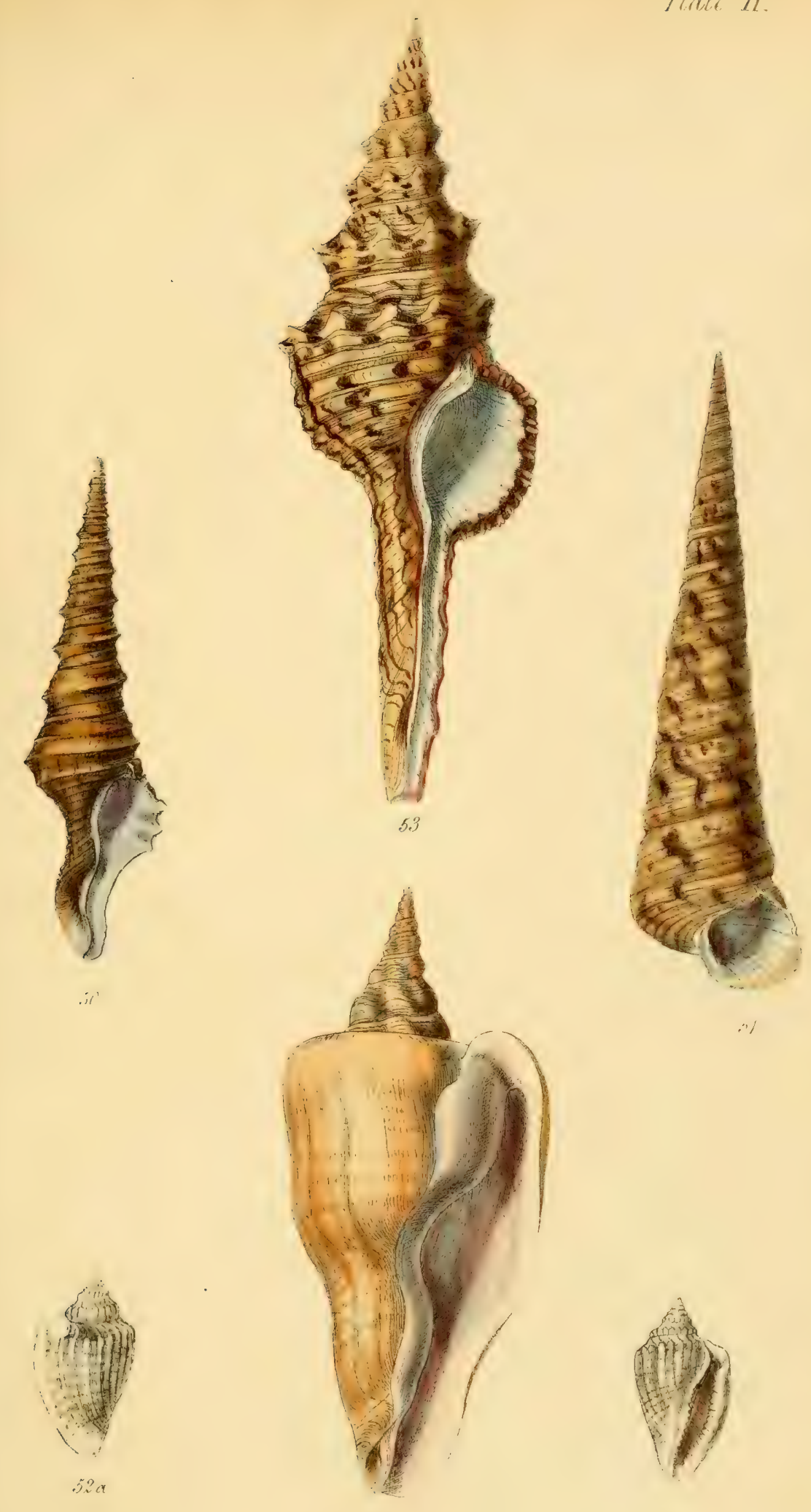



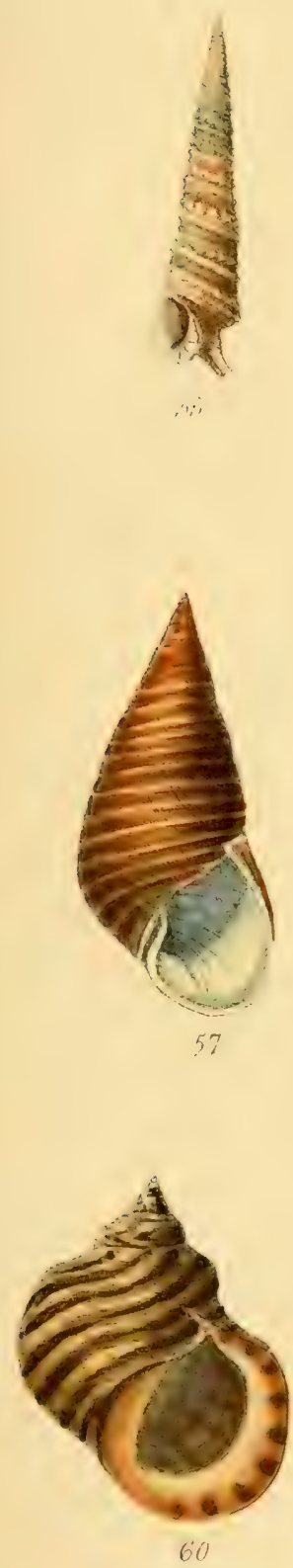

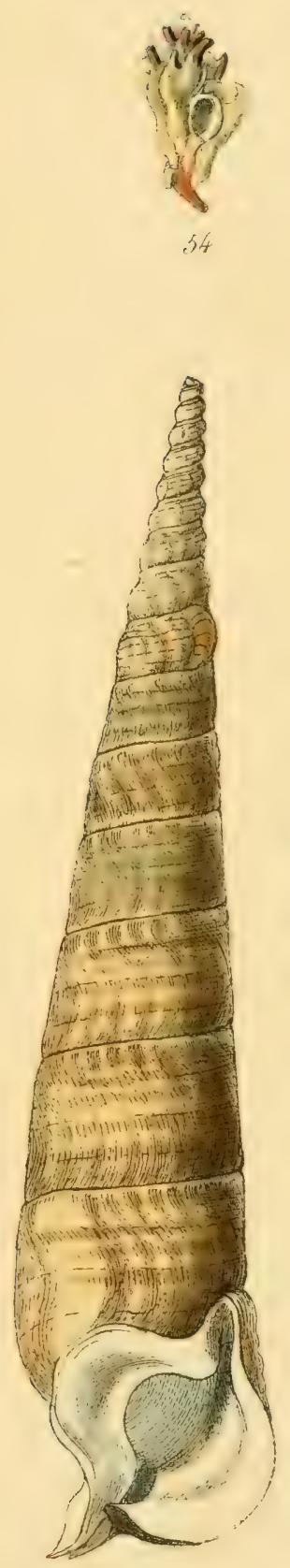

59

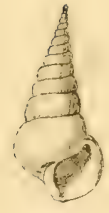

56
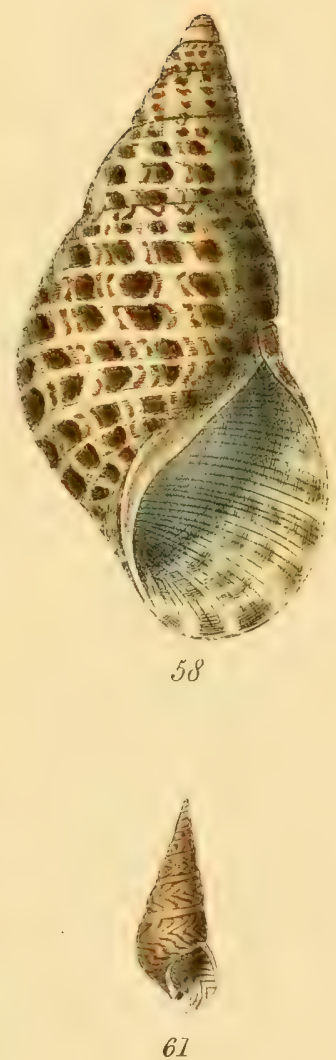

Plate 13
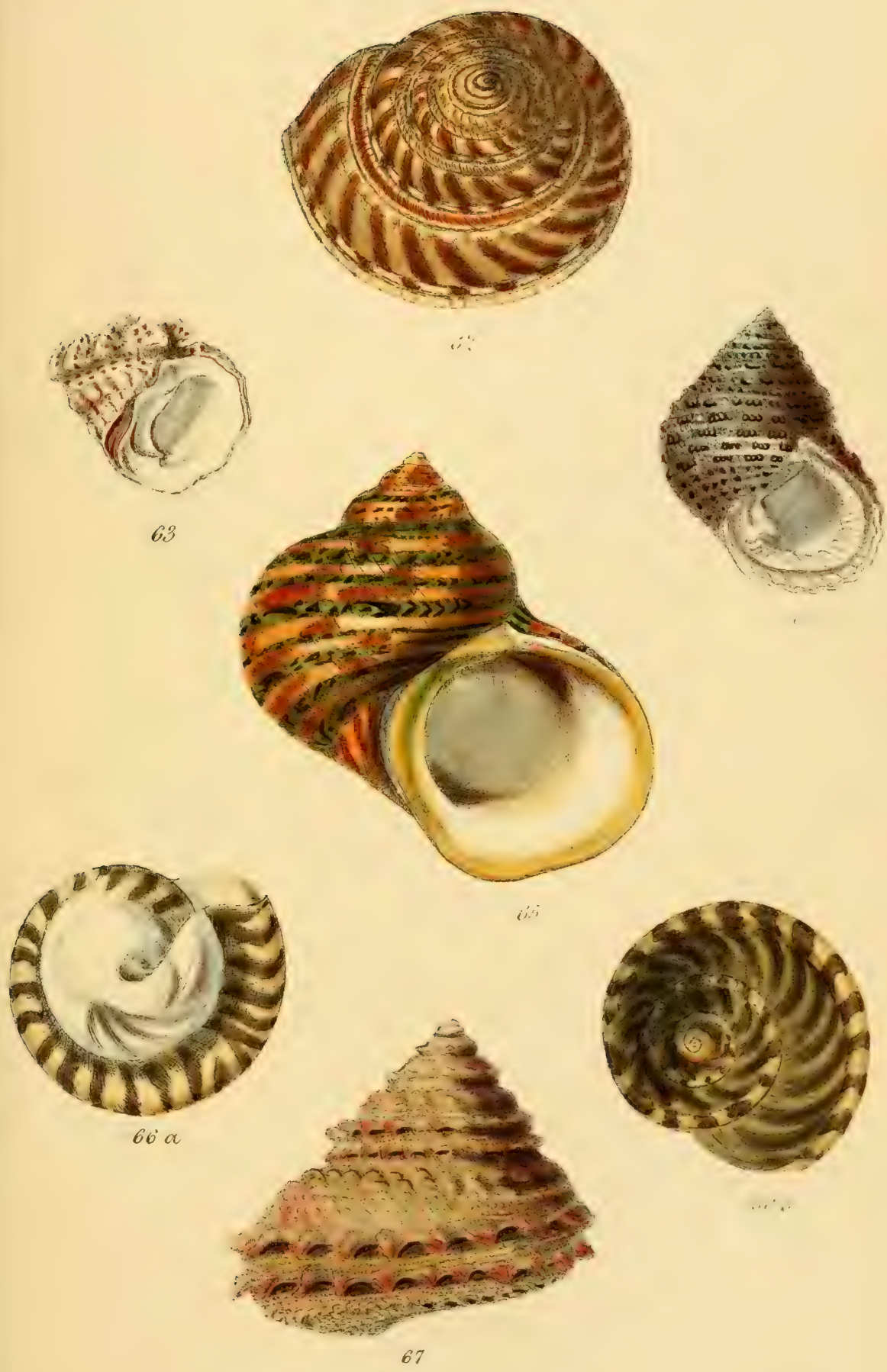

Plate It
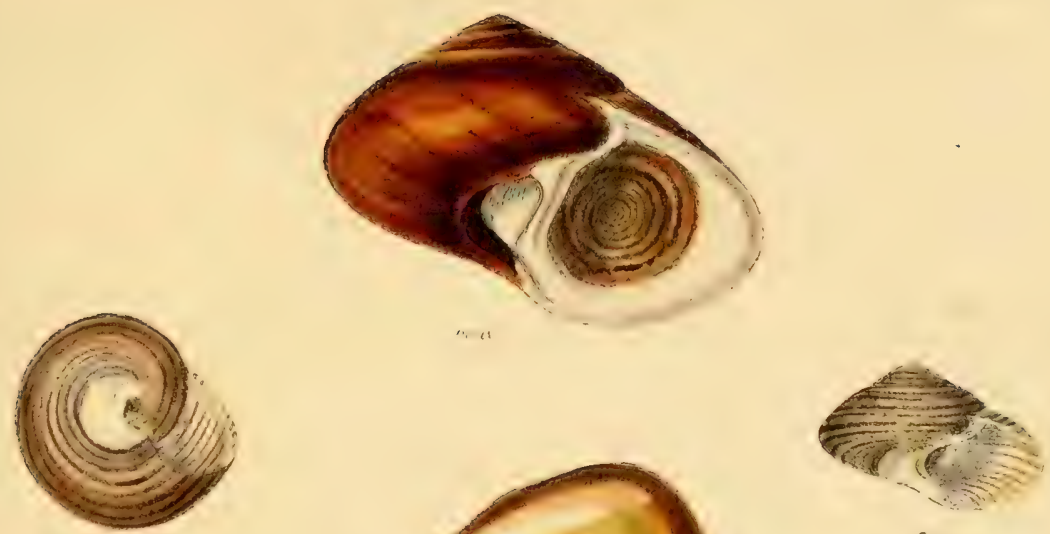

$\therefore y$

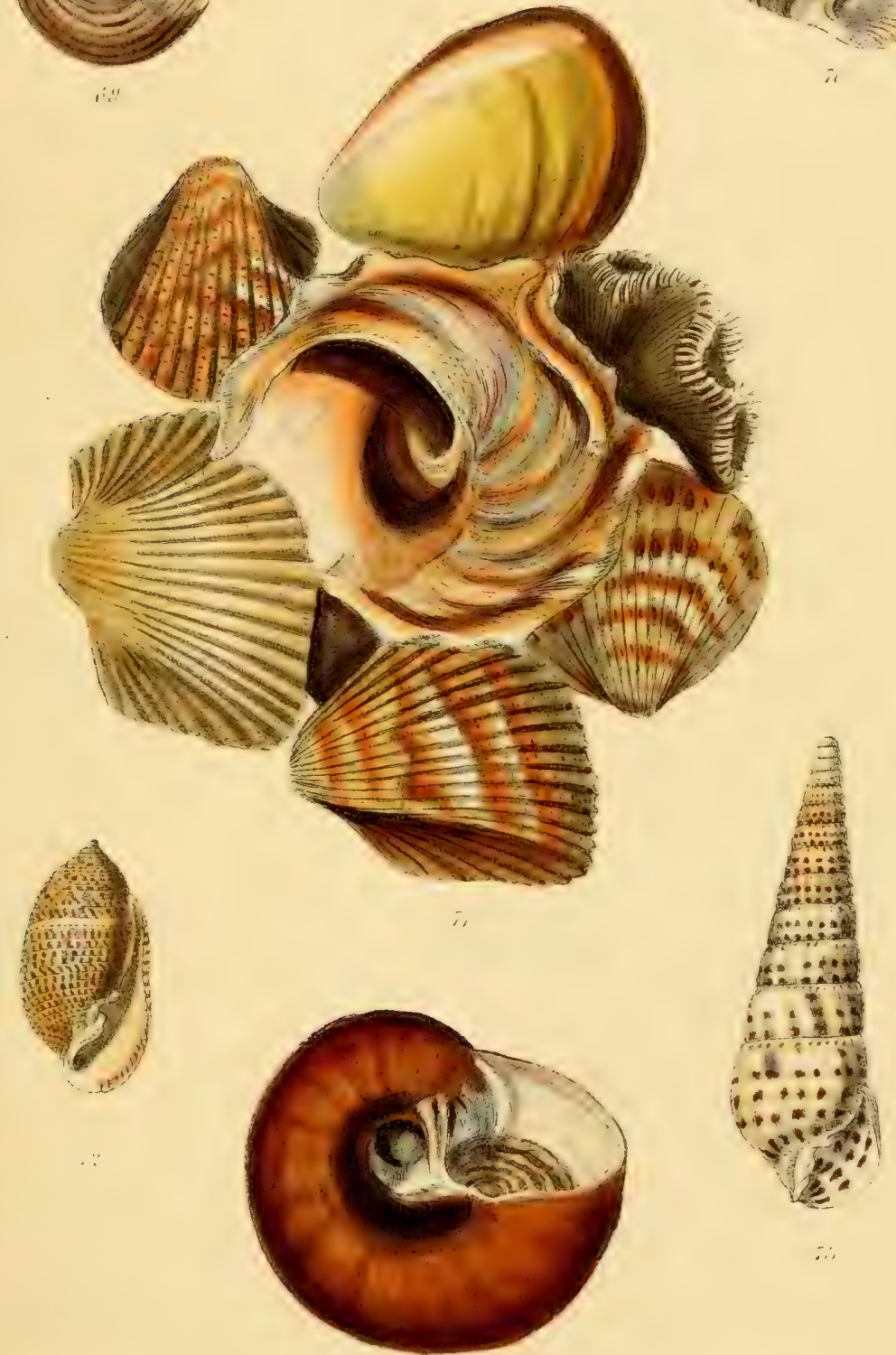



Plate 15
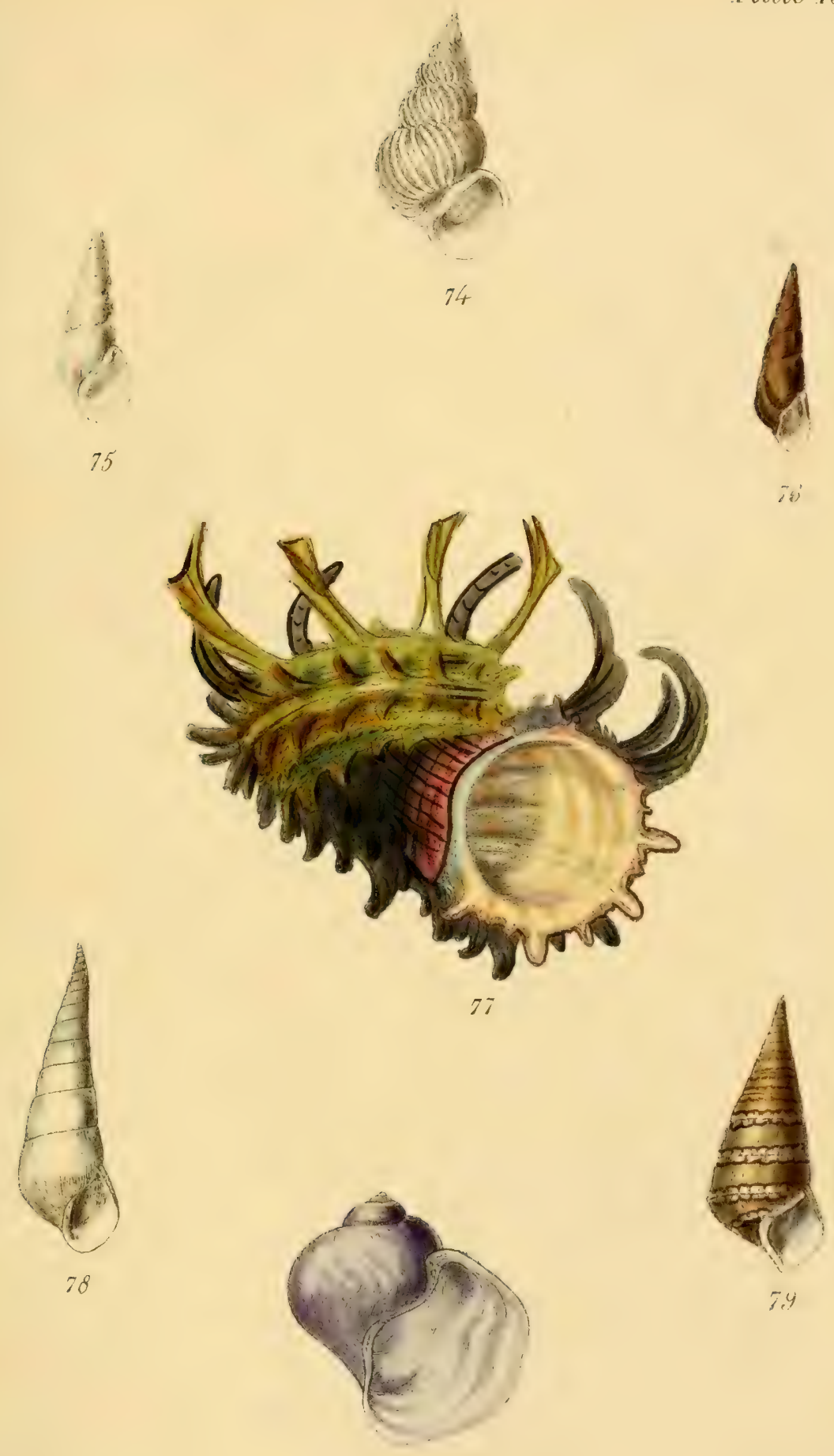

7i

78 



\section{Plak 16.}
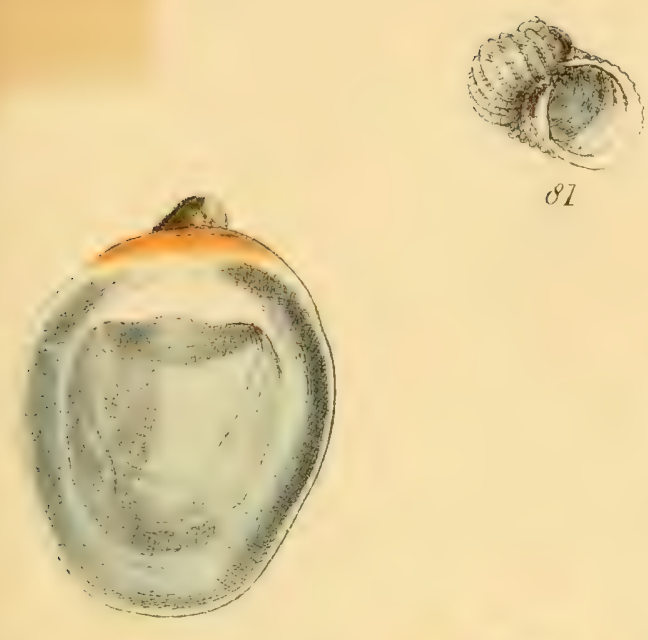

$42 x$
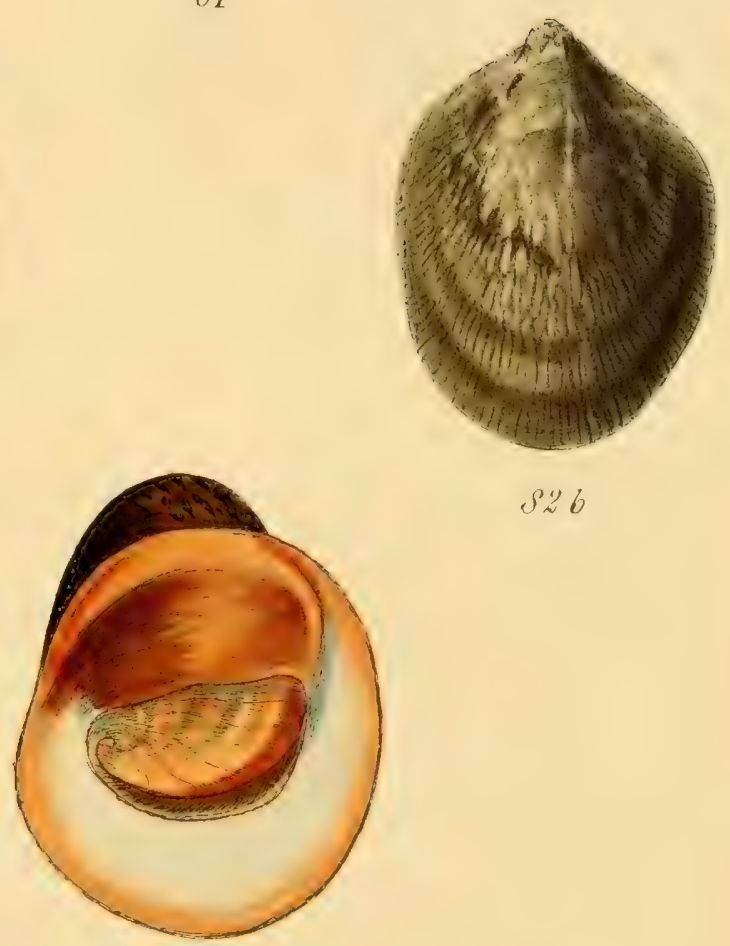

s. 6

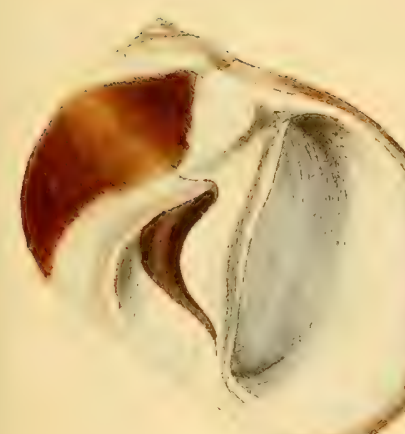

(8.3

Ste
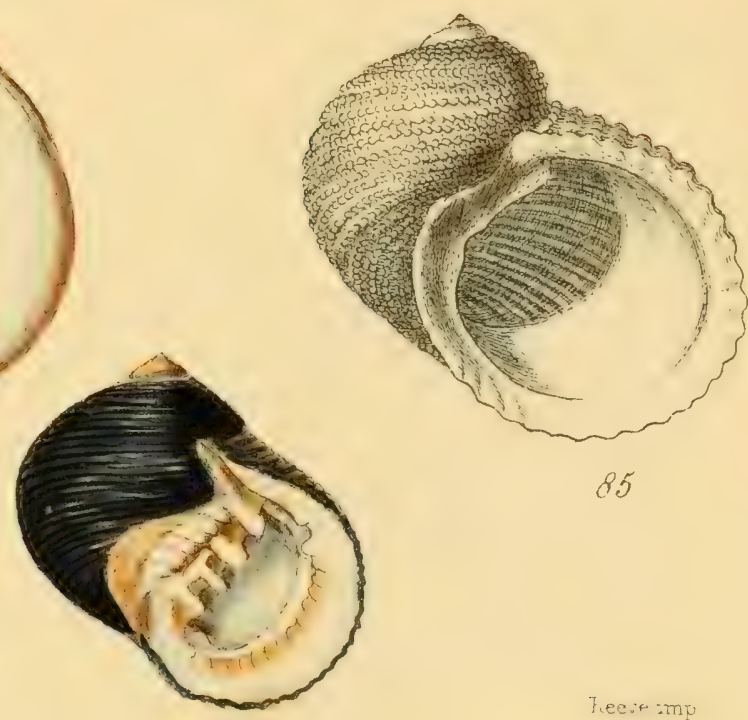

Plate $1 \%$

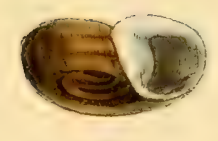

$i 7$

C
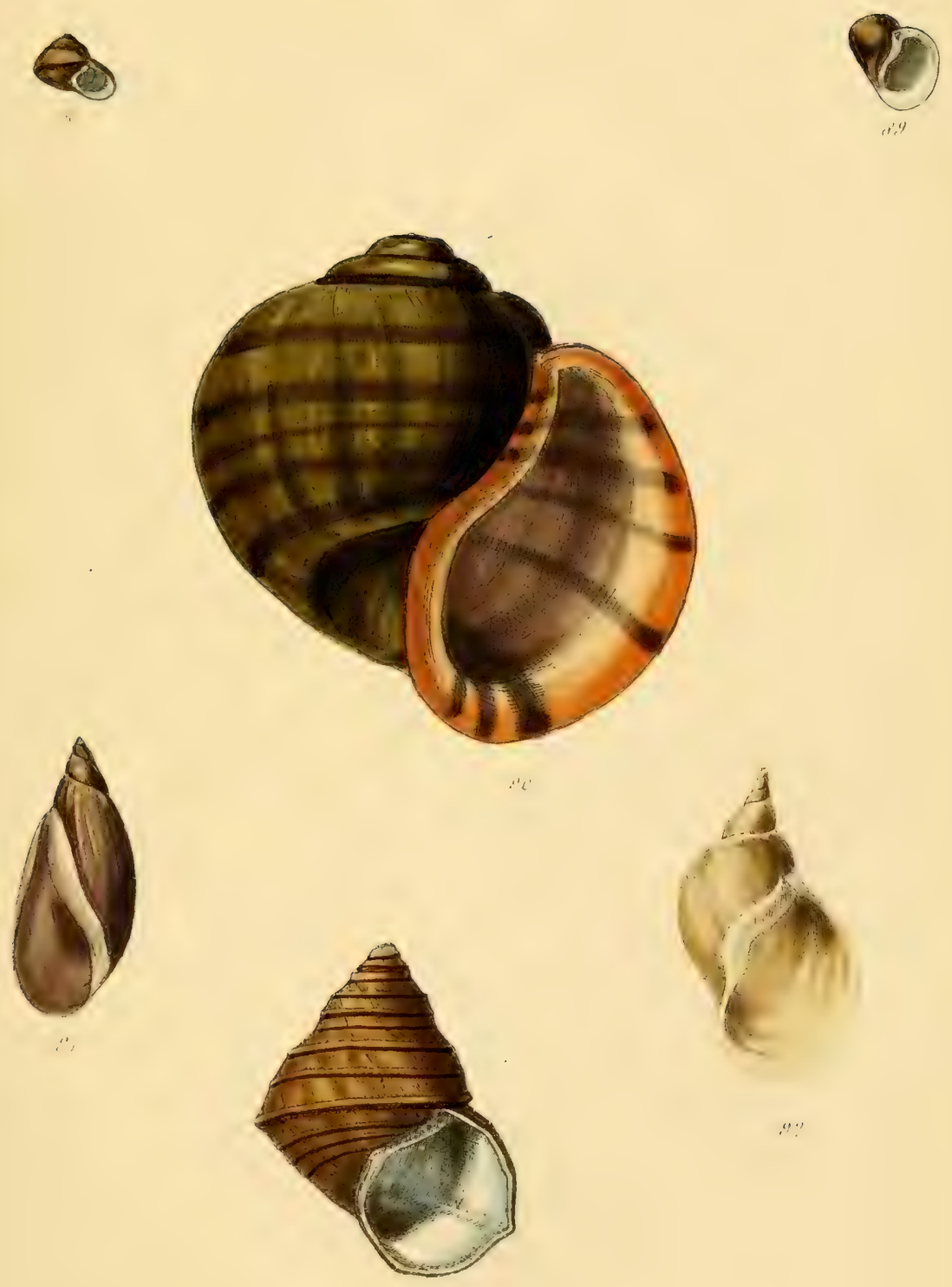


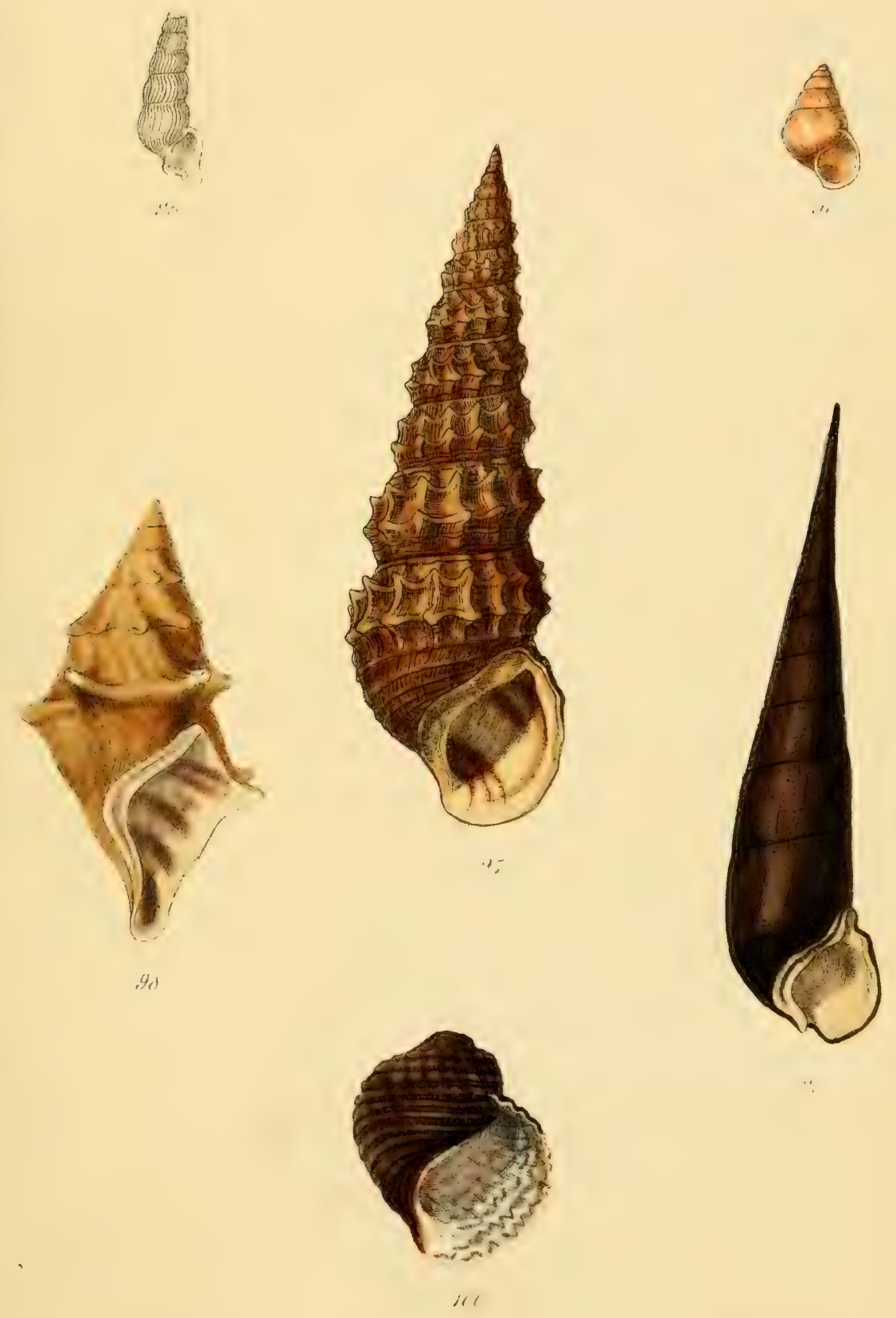

Sowerby del 



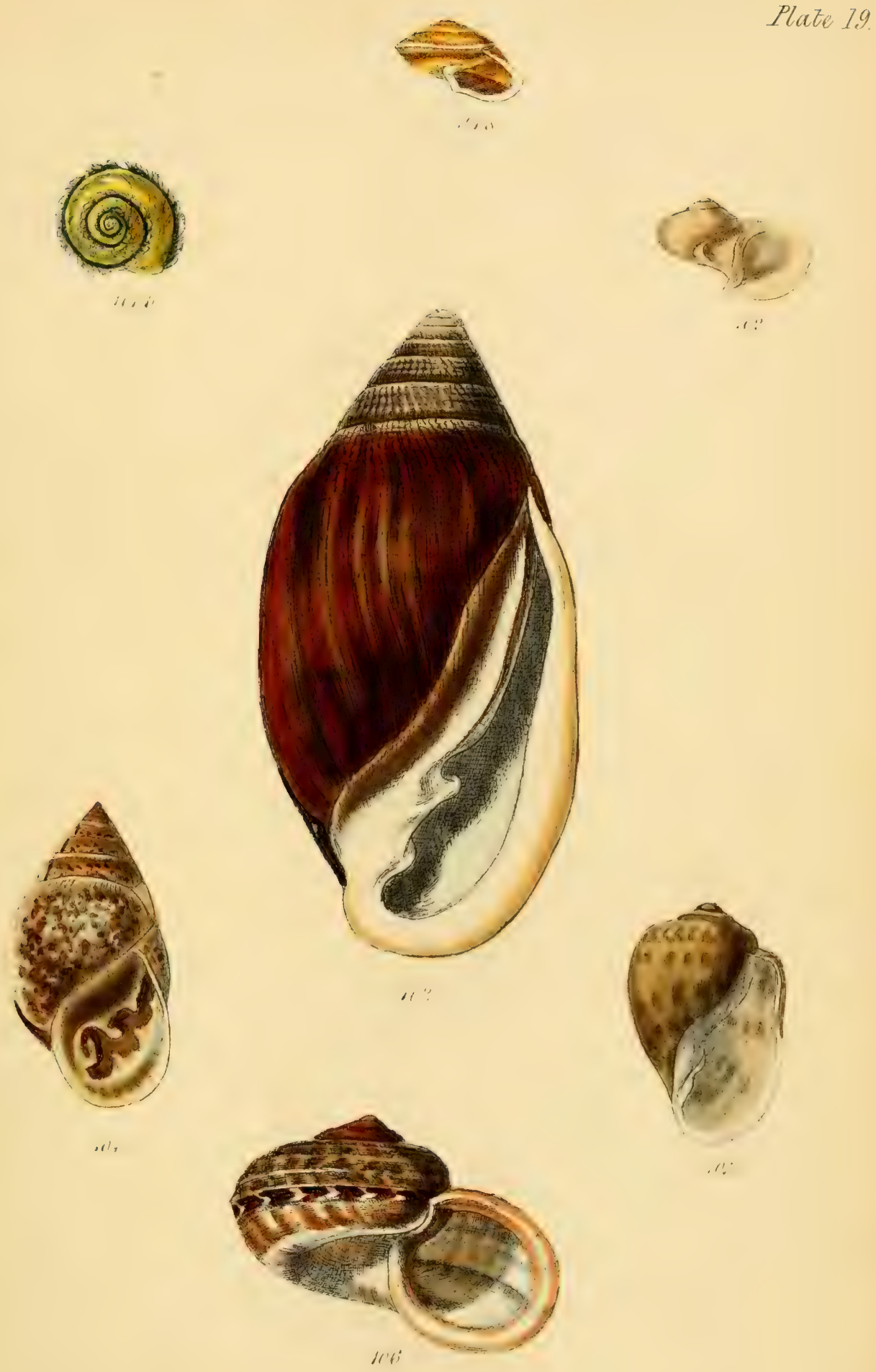




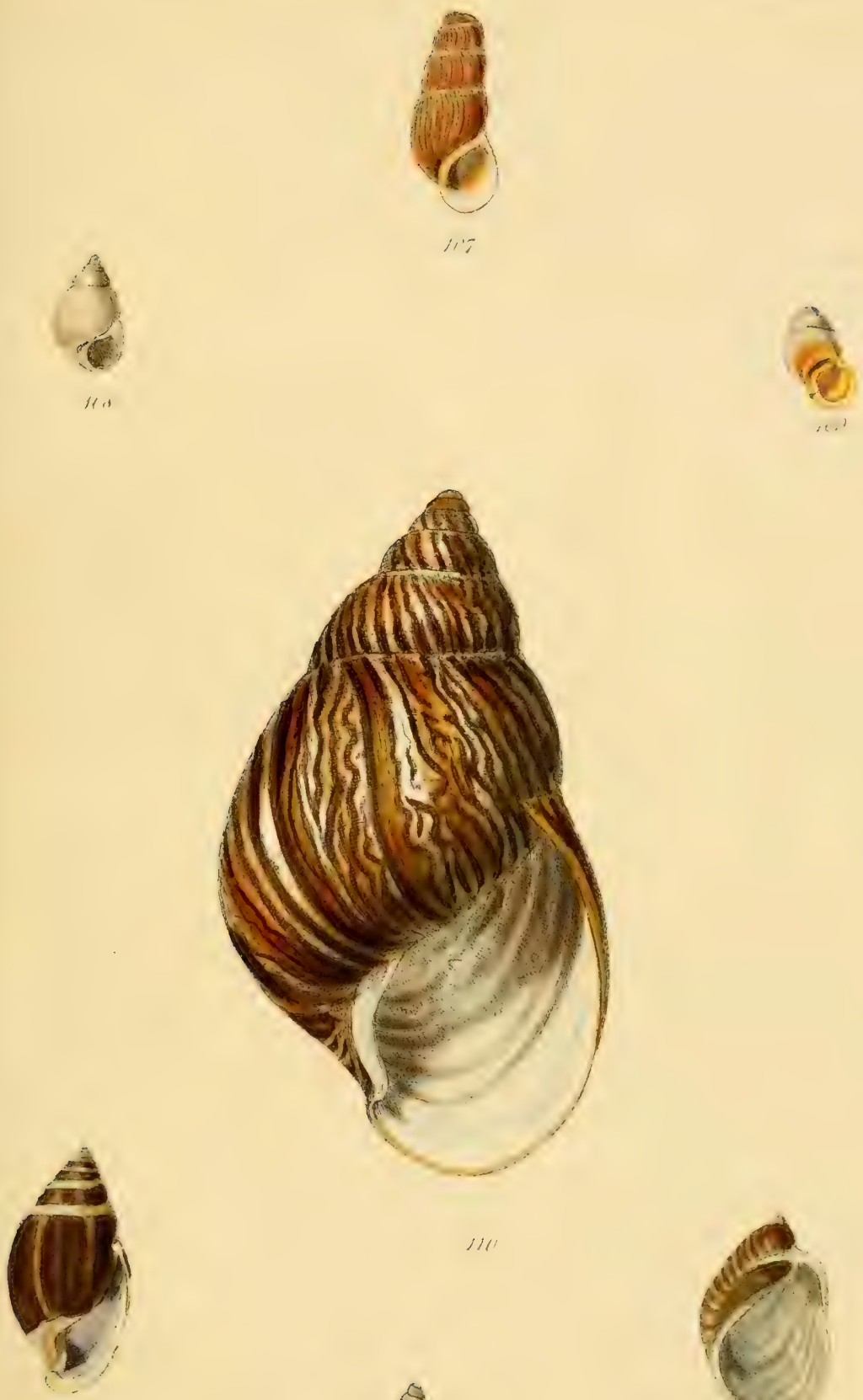

III
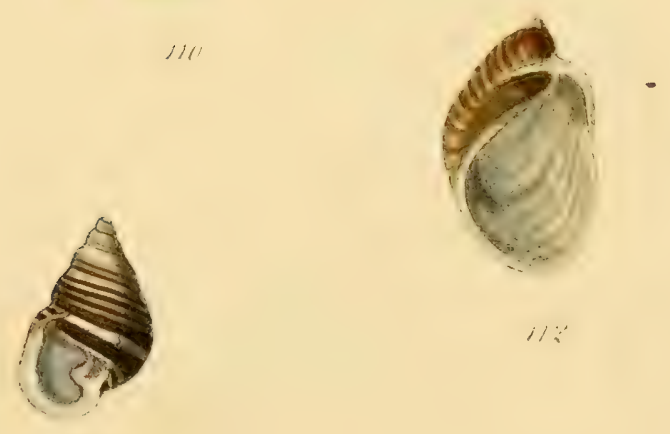


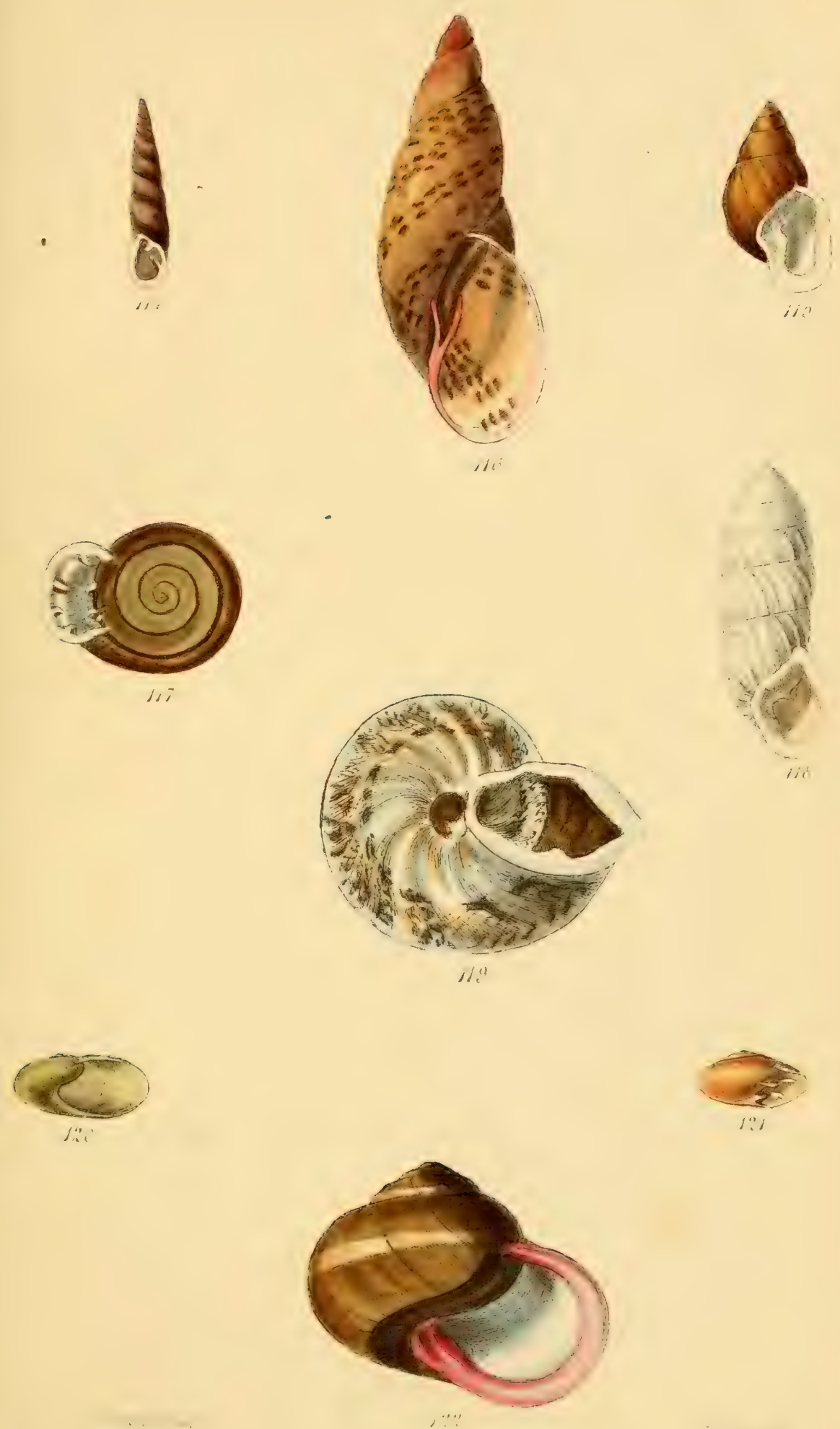



\section{ELEMENTS OF CONCHOLOGY;}

AN INTRODUCTION TO

THE NATURAL HIST'ORY OF SHELLS

AND OF

THE ANIMALS WHICH FORM THEM.

BY

\section{LOVELL REEVE, F.L.S., F.G.S.}

CORRESPONDING MEMBER OF TIE LYCEUM OF NATURAL IISTORY OF NEW YORK AND OY THE NATURAL HISTORY SOCIETY OF WURTEMBERG.

IN 'TWO VOLUMES.

VOL. II.

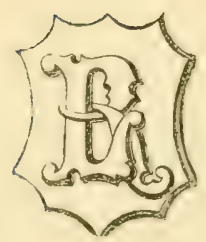

PUBLISHED BY THE AUTHOR, LONDON; 5, HENRIETTA STREET, COVENT GARDEN. 1860. 



\section{CONTENTS OF VOL. II.}

Order 3. Pleurobranchitata . . . . . . . . . . . . . . 1

Family 1. Bullacea . . . . . . . . . . . . . ib.

2. Aplystana . . . . . . . . . . . . . . . .

3. Semphyliddana . . . . . . . . . . . . . . . 6

Order 4. Cervicobranchiath . . . . . . . . . . . . . . . 5

Famili 1. Tubispiracea . . . . . . . . . . . . ib.

2. Macrostomata . . . . . . . . . . . . 10

3. CApUlacei . . . . . . . . . . . . . . . . 17

4. Fissuracti. . . . . . . . . . . . . . . . 23

Order 5. Cyclobranchiata . . . . . . . . . . . . . 31

Family 1. Patellacea . . . . . . . . . . . . . 32

2. Chitonacea . . . . . . . . . . . . . . . . . 3 .

Order 6. Cirrhobranchitata . . . . . . . . . . . 4.

7. Nucleobranchitata . . . . . . . . . . . . . . .

Class 3. Pteropoda . . . . . . . . . . . . . . . 43

4. Lamelimbranchita . . . . . . . . . . . 4.

Order 1. Unimusculosa . . . . . . . . . . . . . 46

Family 1. Ostracea . . . . . . . . . . . . . . . ib. 
Page

Family 2. Pectinacea . . . . . . . . . . . . . 52

3. Aviculacea. . . . . . . . . . . . . . 62

4. Mytilacea . . . . . . . . . . . . . 67

5. Tridacnacea . . . . . . . . . . . . . . . 74

Order 2. Brmusculosa . . . . . . . . . . . . . . 76

Family 1. Chamacea . . . . . . . . . . . . . ib.

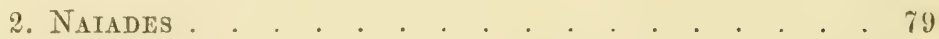

3. TrigonaceA . . . . . . . . . . . . . . . 90

4. Arcacea. . . . . . . . . . . . . . 91

5. Cardiacea . . . . . . . . . . . . . . 98

6. Conchacea . . . . . . . . . . . . . 105

7. NymphaceA. . . . . . . . . . . . . 118

8. Lithophaga . . . . . . . . . . . . . . . 133

9. Mactracea. . . . . . . . . . . . . 136

10. Myaria . . . . . . . . . . . . . 146

11. Solenacea . . . . . . . . . . . . . . 162

12. Pholadarta . . . . . . . . . . . . . 167

13. Tubicola . . . . . . . . . . . . . . 171

Class 5. Brachiopoda . . . . . . . . . . . . 180

ILLUSTRATIONS.

Animals, Plates $I$ to $Q$.

Sirells, Plates 22 to 46 ; Fig. 123 to 248. 


\section{ELEMENTS}

OF

\section{CONCHOLOGY.}

\section{Order 3. PLEUROBRANCHIATA.}

Branchix; placed on the right side of the animal, either beneath the edge of the mantle or in a special cavity.

In the Order of Pleurolranchiata, or right-gilled Gastropods, the shell is more subordinate in value to the soft parts than in either of the preceding orders. It includes a number of complicated, curiously formed, and brilliantly coloured, but, alas! horribly smelling, mollusks, which have no shell whatever; some have only a rudimentary or membranaccous shell, and in none is the shell absolutely external or of solid structure. The families are :-

Bullacea. Aplysiana. Semiphyllidiana.

\section{Family 1. BULLACEA.}

\section{Genus 1. BULLA, Klein.}

Animal; head generally broad and truncated, with the eycs indistinct or wanting; disc large and bulliy, furnished with ample lobes which serve as swimming-organs, and are used for more or less investing the shell; tentacles sometimes modificd into an anterior reflected lobe, mostly furnished with a gizzurd.

Shell; hormy or shelly, lightly convoluted, more or less envelopert by the animal.

Bulla shells, of which as many as a hundred and fifty species are known, from different parts of the world, are of light inflatedly-convoluted growth, 
belonging to mollusks having their fleshy parts much developed in folds. The foot is lobed behind and reflected over the spire of the shell; the sides are lobed in a manner sufficient to envelope doubly the shell, the lobes acting sometimes as fins, and in some instances even the tentacles are modified into an anteriorly-reflected lobe, the eyes being either indistinct or wanting.* All these variations afford good distinctive characters for the determination of groups. For the conchologist it will suffice to follow the Lamarckian plan of including them in a single family and genus.

The Bulle dwell mostly in depths of from one to thirty fathoms, seldom appearing above low water-mark, and a few, such as B. hyclatis, live in brackish water. Their sliells are mostly of a delicate hyaline substance; but some of the larger and firmer species, frecuenting our own shores, and a few among the exotic forms, are brilliantly painted.

Forbes and Inanley include the operculated genus Tomatella in this fanily; but a consileration of the foreign species of that genus would seem to argue that the alleged affiuity is more fanciful than real.

\section{Species.}

1. acuminata, Bing. 20. brevis, Quoy.

2. alba, Brovon.

3. albocincta, Huev.

4. Algin, Adans.

5. alicula, Ehren.

6. Adansoni, Phil.

7. ambigua, Adams.

8. ampullạ, Linn.

9. amygdalus, List.

10. arachis, Quoy.

11. aspersa, Adams.

12. angustata, $i d$.

13. australis, Quoy.

14. bicincta, $i d$.

15. biplex, Adams.

16. biplicata, $i d$.

17. bizonia, id.

18. Borneensis, $i d$.

19. brevissima, $i d$.
21. Bruguieri, Adams.

22. bullata, Miüll.

23. canaliculata, Say.

24. castanea, Adams.

25. catena, Mont.

26. Cecillii, Phil.

27. cinctella, Adams.

28. coarctata, $i d$.

29. concinna, $i d$.

30. concentrica, $i d$.

31. constricta, $i d$.

32. Coreanica, $i d$.

33. corticata, Miill.

34. Cranchii, Leach.

35. cruentata, Adams.

36. Cumingii. $i d$.

37. curta, $i d$.

38. cylindracea, Tenn.
39. cylindrica, IIell.

40. cymbalum, Quoy.

41. dobilis, Gould.

42. decussata, Adams.

43. dentifera, $i d$.

44. eburnea, $i d$.

45. elegans, Gray.

46. elongata, Adans.

47. exigua, $i d$.

45. ferruginosa, Chemn.

49. flavescens, Adams.

50. fusca, $i d$.

51. fusiformis, $i d$.

52. glabra, $i d$.

53. glauca, Quoy.

54. Gouldii, Courth.

55. gracilis, Adanzs.

56. Guildingii, Swains.

57. Hanleyi, Adams.

* Mr. Arthur Adams, speaking of the Bulla Corecnica, says, "There are no visible cyes or tentacles, and its elongated head probes with its extremity the mud-flats on which the species abounds, for the small bivalves which constitute its food. Some of the large mud-flats among the Corean Islands were covered with these shapeless mollusks, and afford tempting morsels to the grallatorial birds seen striding over the mud. 'I'he Bulla soluta appears to be blind, while the head is very elongated, and the side lobes of the foot well developed for swimming, which faculty this form enjoys in great perfection." - Moll. Toy. Samarang, p. 65. 
58. hiemalis, Courth.

59. hirundanina, Quoy.

60. hordacea, Adams.

61. hydatis, Linn.

62. insculpta, Totten.

63. involuta, Adams.

64. lignaria, Linn.

65. lineata, Wood.

66. lineolata, Courth.

67. lutea, Quoy.

68. mamillata, Phil.

69. marmorata, $A d$.

70. media, Phil.

71. minor, Adans.

72. monodonta, $i d$.

73. Natalensis, Krauss.

74. naucum, $\operatorname{Linn}$.

75. nebulosa, Gould.

76. nitida, Adams.

77. nitidula, List.

78. nonscripta, $A d$.

79. oblonga, $i d$.

80. obstructa, Gould.

81. obtusa, Turton.

82. occidentalis, $A d$.

S3. occulta, Migh.

54. olivacea, Ehren.

85. olivula, Adans.

S6. oryza, Tott.
87. ovoidea, Quoy.
115. scutulum, Lovén.
88. ovulata, Broch.
116. simplex, Adams.
89. papyrus, Adams.
90. parvula, $i d$.
117. Sinensis, $i d$.
91. pectinata, Mï̈ll.
118. solida, Bing.
92. pellucida, Brown.
119. soluta, Chemn.
93. pemphis, Phil.
120. speciosa, Adams.
121. striatella, $i d$.
94. pertenuis, Migh.
122. strigella, Lovén.
95. Philippii, Kroten.
123. subangulata, Mïll.
96. physis, Limn.
124. succinea, Conrad.
97. planospira, $A d$.
98. polita, $i d$.
125. succisa, Ehren.
126. tenella, Adams.
99. pruinosa, Clark:
100. punctulata, $A d$.
101. punctata, $i d$.
127. tenera, $i d$.
12S. tenuis, id.
129. thalassiarehi, Mart.
102. puncto-striata, $M I i g h$. 130. tortuosa, $A d$.
103. pusilla, Pfeiff: $\quad$ 131. triticea, Courth.
104. pygmæa, Adams. 132. truncata, $A d$.
105. pyramidata, $i d$. 133. truncatula, Bruy.
106. pyriformis, $i d$. 134. tumida, Adans.
107. quadripartita, Asc: 135 . turrita, Niüll.
108. Quoyii, Gray. 136. umbilicata, Mont.
109. rostrata, Adans. 137. vestita, Plil.
110. rotundata, $i d$.
111. rufolabris, $i d$.
112. Sarsii, Pliil.
113. scabra, Chemn.
114. Schroteri, Pliil.
138. vexillum, Chemn.
139. virescens, Sow.
140. viridis, Rang.
141. vitræa, Adams.
142. voluta, Quoy.

\section{Figures.}

Bulla pHysis. Pl. M. Fig. 3. Animal, showing the shell partially invested by the lateral lobes proceeding from the very ample disc. From the Voyage de l'Astrolabe.

Bjulla albocincta. Pl. 2:. Hig. 123. Shell of a large tropical species of richly banded inflated growth.

\section{Family 2. APLYSTANA.}

\section{Shell ; horny or shelly, not convoluted, internal.}

In this family the branchio or gills are contained within a cavity, and the only development of shell procecting from the amimal, which is of 
comparatively large size, is an irregularly concave shield, mostly of rather horny substance, secreted for their protection. The animal presents a singular variety of form and colour, and there are many species without any trace of a shell ; they have, however, always a distinct head and tentacles, and may be at once distinguished in this respect from the Bulle. The shelled genera are-

Aplysia.

Dolabelia.

\section{Genus 1. APLYSIA, Linnars.}

Animal; head distinct, having four well-developed tentacles, with Iuo small sessile eyes at the lateral basis of the npper ones; branchial cavity closed by an opercular lobe, containing in some instances a horny shell; mantle variously extended into over. lapping lobes.

Shell; rather comex, thin, hormy, a little acminated and beaked inward behind, rounded in front.

Among the fer mollusks described by the writers of ancient Greece, the Aplysia occupies no inconspicuous place. The front pair of tentacles in this genus are mostly largely developed, partaking of the same disposition to amplitude and folding as other parts of the animal, and from the fancied resemblance of the Mediterranean $A$. depilans, with its ear-like tentacles,

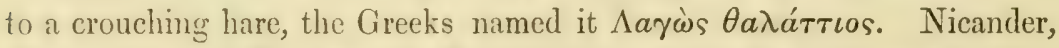
Dioscorides, and Pliny speak of superstitious and of poisonous qualities attaching to it, and the Sea-hares are not regarded with affection even by fishermen of the present day.*

The $A_{1}$ tysice are very generally distributed, and exhibit many fantastic

* "Few mollusks have had greater popular fame, or a worse character than the Aplysice. From very ancient times they have been regarded with horror and suspicion, and many writers on Natural History, conversant with them only through the silly stories of ignorant fishermen, have combined, in ancient and modern times, to hold them up to censure for their poisonous qualities. To touch them, according to Europeans, was sufficient to generate disease in the foolhardy experimenter; whilst Asiatics, reversing the consequences, maintained that they met with instantaneons death when handled by man. Physicians wrote treatises on the effects of their poison, and discussed the remedies best adapted to neutralize it. Conspirators brewed nauseous beverages from their slimy bodies, and administered the potion, confident of its deadly powers. Every nation in the world, on whose shores the poor Sea-hares crawled, accorded to them the attribute of ferocity and danger. Yet, strange to say, there does not appear to have been the slightest foundation for a belief in their crimes. The Aplysia is a perfectly harmless, gentle, timid, and, if observed in its native element, beautiful animal. Its odour is sometimes, it is true, not over-pleasant, and when irritated, it ejects a fluid, the vivid purple hue of which may have excited alarm. Its shape, in which it resembles more than most mollusks the body of some little quadruped, attracted the attention of the curious; but why it should have excited their fears, and filled with terror the muscular hearts of sturdy fishermen, is a problem to be solved only when the predisposing causes of groundless superstitions shall have been sifted and traced to their minutest roots." - Forbes and Hanley, Hist. Brit. Moll., vol, iii. p. 553. 
varieties of form and colour. The shell, where it exists, is a horny, slightly concave shield, attenuated and a little beaked at the hinder extremity. In colour it is mostly of a reddish-fawn, passing into brown. In the following list of species there are probably many in which there is no rudiment of a shell, but I have not sufficient data for separating them.

Species.

1. alba, Cur.

2. Brasiliana, Rang.

3. Brongniarti, $B l$.

4. Brugnatelli, Vanb.

5. camelus, Cuv.

6. concava, Sow.

7. dactylomella, Rang.

8. depilans, Linn.

9. fasciata, Poir.

10. Ferussaci, Rang.

11. fimbriata, $A d$.

12. fusca, Til.

13. gelatinosa, Rang.

14. Inca, D'Orb.
15. Keraudrenii, Rang. 28. Poliana, $\mathrm{Ch}$.

16. Lessonii, id.

17. lineolata, $A d$.

18. livida, D'Orb.

19. longicornis, Rang.

20. maculata, $i d$.

21. marginata, $B l$.

22. marmorata, $i d$.

23. Neapolitana, $C \%$.

24. nigra, D'Orb.

25. nodifera, $A d$.

26. oculifera, $i d$.

27. Petersoni, Sow.
29. proten, Rang.

30. punctata, $C u v$.

31. quadrata, Sow.

32. Rangiana, D'Orb.

33. rosea, Rathke.

34. sorex, Rang.

35. tigrina, $i d$.

36. unicolor, $B l$.

37. virescens, Risso.

38. viridis, Bose.

39. vulgaris, $B l$.

40. Webbii, Vaub.

\section{Genus 2. DOLABELLA.}

Animal; similar to that of Aplysia, with the branchial cavity more in the rear.

Shell; calcareous or inclined to horny, hatchet-shaped, posteriorly somewhat thicker and a little reflected at the edge.

The Dolabella is very like Aplysia in general aspect, and has its foremost tentacles developed in a similar manner, like expanded ears; the branchial cavity is, however, situated more towards the hinder part of the animal, and the shell is larger, stouter, and more calcareous.

The drawing of $D$. Rumplhii, with its numerous filamentary processes, given in our Plate $L$, was made by Mr. Arthur Adams from a number which he observed at the Mauritius, feeding in groups of eight or nine in a small muddy inlet of the sea.

\section{Species.}

1. ascifera, Fér.

2. rolabrifera, $C u v$.

3. ccaudata, liang. 

4. fragilis, Lam.
7. petalifera, Rang.
10. truncata, Rang.
5. gigas, Rang.
8. Rumphii, Cuv.
11. unguifera, $i d$.
6. Hassettii, $i d$.
9. 'Teremidi, Rang.

Figures.

Plate L. Animal, showing its front ear-like pair of tentacles and its structure of overlapping folds, concealing the branchial lid which contains the shell.

Pl. 22. Fig. 1:27. Shell, showing the thickened incurved margin of the hinder extremity.

\section{Family 3. SEMIPHYLLIDIANA.}

Shall ; hormy or stelly, morer or less imbelded in the uppers surface of the animal for the protection of the viscera.

The genera embraced in this family are not very closely allied, but they agree in having an intermal shell scereted, not over a branchial cavity, for the branchire are free, but over the viscera.

Pleurobranchus.

UMBRELLA.

\section{Genus 1. PLEUROBRANCHUS, Cwier.}

Animal; head with two grooved tentacles, the eyes at their caternal bases; mouth covered with a more or less broad veil; body equally overlapped by the mantle and by the foot; mantle sometimes enclosing a delicate membranaceous shell; branchia feather-litie, free.

Sholl; an internal, flexible, membranaccous shield, oblong-square, rather convex towards the margin, where a lind of subspiral apex is formed.

Pleurobranchus is only known to the conchologist by a thin membranaceous concavely-flattened shield, secreted within the hinder portion of the mantle. The mollusk from which this is extracted is a broadly-ovate, fleshy mass, presenting great variety of character in different species, but having the branchix projecting from the right side in the form of an claborately-branched plume. Of the following species, two, P. plunula and membranaceus, are found at low water on our own shores. 


\section{Species.}

1. citrinus, Rupp.

2. cornutus, Quoy.

3. Forskalii, D. Cle

4. luniceps, $A d$. \& $R$.
5. mamillatus, Quoy.

6. membranaceus, Mont.

7. Patagonicus, Orb.

8. Peronii, Cuv.
9. plumula, Mont.

10. punctatus, Quoy.

11. reticulatus, Rang.

12. tuberculatus, $D$. Ch.

\section{Figure.}

Peeurobiancilus ameabranaceus. Pl. 22. Fig. 129. Shell, of thin semitransparent inembranaccous substance, with its slight marginal apex.

\section{UMBRELLA, Lamarck.}

Animal ; disc very large and swollen; tentacles enr-shaped, having a pair of small sessile eyes between them; mouth covered with a small, lobed veil; mantle more or less enclosing a capacious, oval, flat, shelly shield.

Shell; orbicular, flat, rather convex at the upper part, with a very small nearly central verten, rather concave beneath, impressed with a central, callous, yellow deposit, being surrounded by a regular continuous muscular impression.

Umbrella is very unlike Pleurobranchus, whether as regards animal or shell; but in both the branchix take the form of a plume or row of plumes attached to the right side, while the head is furnished with a veil, and the shell in both genera is invested, or partially invested, by the mantle. Here the resemblance ends. Umbrella is a stout, swollen, warty mollusk, having a large shcll, often of rather solid, calcareous substance, planted flat upon the back, and the inner surface is characterized by a callous deposit of a peculiar yolk-yellow colour. It was known to the older naturalists by the name of 'The Chinese Parasol.'

Three species are known, varying so little in specific character, so far as the shell is concerned, as to be scarcely distinguishable, but from widely distant localities. One is a native of the tropical Eastern seas, another of the Mediterranean, and the third of the Bay of Panama.

\section{Species.}
1. Indica, Lam.
2. Mediterranea, Lam.
3. ovalis, Carp. 


\section{Figure.}

Umbrella Indica. Pl. 22. Fig. 126. Shell, showing the callous deposit of the inner surface.

\section{Order 4. CERVICOBRANCHIATA.}

\section{Branchiæ; placed within a cavity in the neck.}

The neck-gilled Gastropods present a remarkable contrast of form, but are allied by obvious zoological characters. No two mollusks of a class are more unlike each other in external appearance, whether as regards the animal or the shell, than Siliquaria and Haliotis; yet it will be seen that the affinity between them is curious, and the transition of structure easy and natural. The Slipper and Cup-and-Saucer Limpets come into this order, but they are physiologically distinct from the Patella, or Limpets proper, whose relationship is with the Chitons. The families into which the Gasteropoda Cervicobranchiata are divided are-

$$
\text { Tubispiracea. Macrostomata. Capulacea. }
$$

\section{Family 1. TUBISPIRACEA.}

Shell; an irregular loosely convoluted spiral tube, with the whorls detached.

The shell of this family, though of spiral growth, resembles that of Sermula, a genus of Annelides. It is, however, convoluted like the rest of the spiral gastropods, but with this difference, the whorls are wholly detached, and they are drawn out into a winding tube, like a corkscrew, withont forming any columellar axis. Every spiral univalve, it may be here remarked, is a modification of an enlarging tube. It is not difficult to conceive that a plastic enlarging tube might be moulded into any kind of spiral univalve, with all the appliances necessary for expansion or dilatation and for the addition of external ornament in the form of such devices as varices, tubercles, spines, scales, rings, etc. The two genera of this family represent the first stage in this ideal plan of conchological architecture. The genera, one of which is characterized by having a branchial fissure throughout, are-

Vermetus.

Siliquaria. 


\section{Genus 1. VERMETUS, Adanson.}

Animal ; allied to that of Scalaria.

Shell; tubular, irregularly convoluted into a loose spire, divided internally at irregular intervals by sepla; operculume horny.

The history of this genus presents an instructive example of the value of original observation. Naturalists living at home at ease are very apt to perpetuate error; and even Limnæus, while luxuriating in his professorial chair at Upsal, fell into the belief that the Termetus shell belonged to the same natural order as the Serpula. Adanson, a veteran member of the Academy of Sciences of Paris and contemporary of Limneus, investigated with much original research the zoology of the coast of Senegal, and discovered, amongst other equally interesting facts, that the animal of Vermetus was no annelide, but a mollusk. It is, in fact, a kind of unrolled Scalaria or Delphinula, and, like them, is furnished with a horny operculum. Owing to their loose manner of convolution, several specimens often become twisted among each other.

We have no Termetus on our own shores. Its southern limit is in the Lusitanian portion of the Mediterranean, and it reaches to Anstralia, but of its geographical range little is at present known. D’Orbigny describes a species from South America; and Dr. Gould includes the Senegal $V$. lumbricalis among the molluscan fauna of Massachusetts.*

\section{Species.}

1. annulus, Rous.

7. glomeratus, Bivon.

13. subcancellatus, Biv.

2. arenarius, Quoy.

8. Knorri, Desh.

14. tenuis, Rons.

3. bicarinatus, Desh.

9. lumbricalis, Lam.

15. triqueter, Biv.

4. dentifera, Quoy.

10. Novæ-Hollandiæ,Rous.16. tulipa, Rous.

5. eburneus, Reeve.

11. pellucidus, Brod.

17. varians, D'Orb.

6. gigas, Bivon.

12. semisurrectus, Biv.

\section{Figure.}

Vernetus eburneus. Pl. 22. Fig. 130. Shell, showing its loose, detached mode of convolution.

* "A very fine group was hooked up by a friend in New Bedford Harbour, containing not less than fifty individuals inseparably intertwined. The living animals then occupied them." - Invert. Mrass., p. 247.

VOL. II. 


\section{Genus 2. SILIQUARIA.}

Animal; hearl distinct, having two small tentacles with oyes at. lleir lases; branclice consisting of simple filaments placed beneath the left lobe of the mantle, uthich is slit thronghout. Shell ; tubular, irregulurly loosely convoluted, having a slit throughout, which is sometimes a little articulated.

It was some time after the discovery of the molluscan character of $V e r-$ metus that the Lamarckian Siliquarice (Seryula anguina, Linn., and Sermula muricuta, Born) were found to be similarly organized. The shell of Siliquaria, cspecially $S$. muricatu, as may be seen by our figure, is of more irregular, Serpula-like growth; yet it has the molluscan type of a predetermined maturity, and the slit, which constitutes its principal generic feature, as distinguished from Fermetus, is the homologue of the slit in Fissurella and Limarginule and of the row of holes in Haliotis. It in fact corers a corresponding fissure in the left lobe of the mantle, adapted to the passage of the branchice, which in this mollusk take the form of protruding filaments.

Siliqueriu ranges with Termelus in the eastern hemisphere, but is more limited in specics. None have as yet been found on the American shores.

\section{Species.}
1. anguina, Lamarck.
4. lævigata, Lam.
6. papillosa, Rees.
2. australis, Quoy.
5. muricata, Bing.
7. squamata, Blainv.

3. lactea, Lam.

\section{Figure.}

Siliquaria muricata. Pl. 23. Fig. 136. Shell, shoming the slit, which passes through its entire length, and may be observed towards the apex to be partially articulated.

\section{Family 2. MACROSTOMATA.}

Shell; only slighlly convoluted, sometimes perforated with a row of holes.

The Lamarckian system of classification does not apply with accuracy to this part of the series. The family Mucrostomata, even with the changes 
we have felt necessary to make, not only includes genera differing so materially from each other that they might be regarded as types of separate families, but species which should constitute separate genera. Neither Dr. Gray, Professor Forbes, nor the Messrs. Adams agrce as to the natural affinities of the Lamarckian Macrostomata, and the discrepancy of these authors' views leads me to the conviction that the time is not yet ripe for deciding their exact place in the system. The genera are-

Haliotis. Neritopsis. Velutina.

Stomatella. Narica.

Genus 1. HALIOTIS, Linnæus.

Animal; shaped like the shell, its head terminating in a short muz le, and bearing two subulate tentacles and two stout eye peduncles at their external bases; a fimbriated lobe between the tentacles, apparently contimuous with the fimbriated and cirrlated lateral lobes of the body; lateral cirrhi muerous; foot very large, oblong, rounded at the extremities, bearing on its upper extremity a rudimentary operculigerous lobe, but no operculum; branchial plumes, two. (Forbes.)

Shell; ovate, ear-shaped, flat, with a small, lateral, depressed spire, pearly and richly prismatic within, roughly ribbed or wrinkled withont, rarely smooth; left side more or less angulated, perforated along the angle by a row of holes; left lip inflexed, flattened; right lip simple; aperture very laige, wide open.

Haliotis is curiously intermediate in its characters betreen the Turbinacea, or Trochus family, and the tribe of fissured Limpets. On referring to our figure of $H$. tuberculata in Plate $I$, it will be seen that the animal is encompassed by a cirrhated lobe, and it also possesses, as in Trochus, a head-veil; but on the other liand, the branchiæ are as plumes in connection with filaments passing through a slit in the mantle, over which the shell is slit as in Fissurella and Emarginula, and, as we have just seen, in Siliquaria. The number of pallial filanents being alike in any individual of the same species through all its stages of growth, the shell has only so many of its holes open at one time; as the filaments advance with the growth of the animal, new holes are formed in the additions made to the shell, and the old ones are filled up.

The interior of the 'Ear Shells' is lined with a pearly nacre of peculiar 
brilliancy and iridescence, glorring with all the colours of the rainbow. Attention must, however, be given to the outer crust of the shell for the discrimination of species. The varieties of situation and tubular excrescence are often very characteristic. The number of perforations varies in different species, but, as we have just stated, they are alike in individuals of the same species; where an exception occurs, it is that there are sometimes one, or at most two, less in the adult than in the young sliell. When the animal is growing it has one or two holes open in arrear of the number required, and on reaching maturity the holes are filled up.

It is a curious circumstance in the geographical description of the $I I a$ liotides, that few, if any, are to be found where Chitons abound, as if they exchange places to a certain extent in the two hemispheres. There are a few species of Italivi is in California ; but along the western coast of South America, where Chitons are most abundant, not a single species has been observed; and only one small species, II. pulcherrima, has been collected at any of the islands of the Pacific. They inhabit the shores of China, Japan, Ceylon, Mozambique, the Cape Colony, Bomeo, and the Philippine Islands; but the grenter number, and inost striking, of the species are from New Zealand and Lustralia, displaying all that speciality and strangeness of design which is so characteristic of the general natural history of those colonies. The nearest approach of the genus to our own shores is in the II. tuberculuta of Guernsey, which is sold in the fish-market as an article of fuorl.* They are found at low water attached to the under-surface of frigments of rock, and on the least alurm they fix themselves by suction with the force of a Limpet.

Species.

1. albicans, Quoy.

2. ancile, Reeve.

3. aquatilis, $i d$.

4. asinina, Lin.

5. astricta, Reeve.

6. bistriata, Gmel.

7. Californiensis, Swain.

8. clathatra, Reeve.

9. coccinea, $i d$.

10. coccoradiata, $i d$.

11. concinna, $i d$.
12. corrugata, Gray.

13. Cracherodii, Leach.

14. cruenta, Reeve.

15. Cunninghami, Gray.

16. discus, Reeve.

17. diversicolor, $i d$.

18. Dringii, $i d$.

19. elegans, Koch.

20. Emmæ, Gray.

21. excavata, Lam.

22. funebris, Reeve.
23. gemma, Reeve.

24. gibba, Phil.

25. gigantea, Chem.

26. glabra, $i d$.

27. incisa, Reeve.

28. iris, Gmel.

29. Jacnensis, Recve.

30. Janus, $i d$.

31. Japonica, id.

32. Kamtschatkana, Jonas.

33. lamellosa, Lam.

* While dining one day with a well-known naturalist and antiquary of Gucrnsey, Mr. F. C. Lukis, an entremet of Haliotis tulerculata was served. I had understood they possessed the delicacy of a veal cutlet, but on endeavouring vainly to masticate oue, they reminded me more of what might be the taste of a dish of little duodecimo Latin grammars. 
34. lauta, Reeve.

35. Mariæ, Gray.

36. marmorata, $i d$.

37. Midx, Lin.

38. multiperforata, Reeve.

39. nævosa, Martyn.

40. nebulata, Reeve.

41. ovina, Chem.

42. papulata, Reeve.

43. parva, Lin.

44. pertusa, Reeve.

45. planilirata, $i d$.

46. pulcherrima, Marlyn.

47. pustulata, Reeve.
48. reticulata, Reeve.

49. Roei, Gray.

50. rosacea, Reeve.

51. rubicunda, Gray.

52. rubiginosa, Reeve.

53. rufescens, Swain.

54. rugosa, Reeve.

55. rugoso-plicata, Chem.

56. sanguinea, Hanl.

57. scutulum, Reeve.

58. semistriata, $i d$.

59. sepiculata, $i d$.

60. Sieboldii, $i d$.
61. speciosa, Reeve.

62. splendens, $i d$.

63. squamata, $i d$.

64. squamosa, Gray.

65. Stomatiæformis, Reeve.

66. striata, Lin.

67. Tayloriana, Reeve.

68. tuberculata, Lin.

69. varia, $i d$.

70. virginea, Cleem.

71. viridis, Reeve.

72. Zelandica, $i d$.

73. ziczac, $i d$.

\section{Figures.}

Haltotis tuberculata. Pl. $I$. Fig. 4. Animal, showing its encircling cirrhated lobe and tentacles.

Haliotis Emme. Pl. 23. Fig. 131. Shell, of a species from Australia, named by Dr. Gray after his accomplished lady, showing the iridescent pearly lining of the interior.

\section{Genus 2. STOMATELLA, Lamarck.}

Animal ; head broad, proboscidiform; tentacles subulate, with a fimbriated lobe at their inner bases; eyes on peduncles at the outer bases of the tentacles; mantle with the fiont calge entive; muscle of attachment crescentic, open in front; foot, with a fringed lateral membrane. (Adams.)

Shell ; more or less ear-shaped, imperforate, externally smooth or sculptured, and mostly bright-coloured, internally pearly; aperture very large, wide open.

A brilliantly-coloured group of small species, partaking of the character of Trochus and Haliotis, but considerably removed from the typical form of either genus. The animal resembles that of Trochus in having a fimbriated lobe or veil in front, while the shell is that of Huliotis withont the holes, the mantle of the animal not being slit in front. Some of the species are operculated and some not. Those without an operculum constitute Dr. Gray's genus Gena. The species separated by Lamarck under the name Stomatid present no apparent diflerence beyond a wrinkling of 
the shell. Australia and the Philippine Islands are the chief recorded habitats.*

Species.

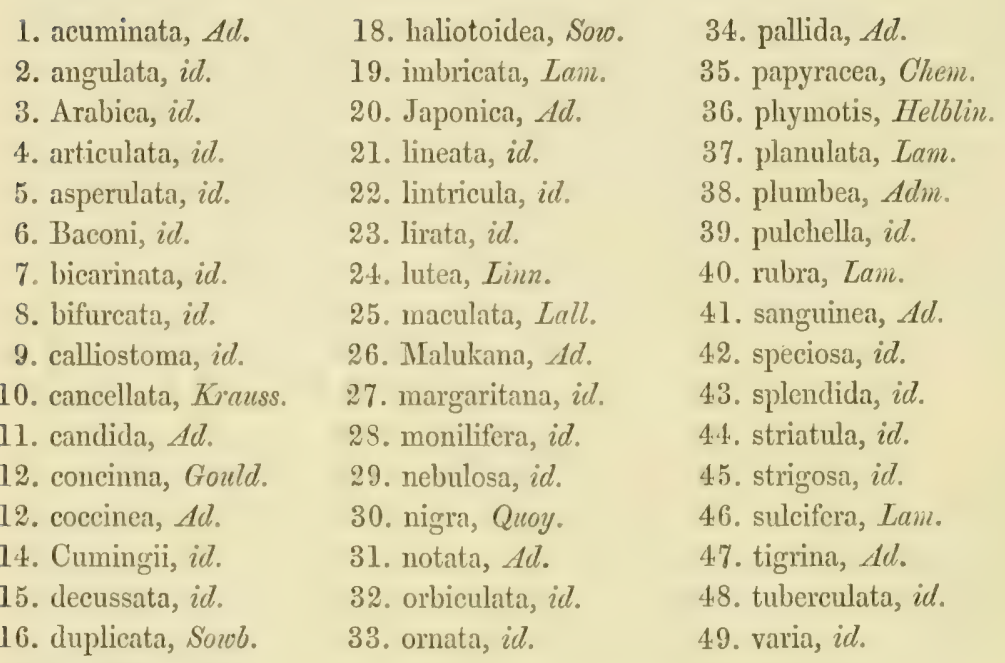

17. fulgurans, $A d$.

\section{Figure.}

Stomatella (Stomatia) phymotis. Pl. 22. Fig. 125. Shell, showing its imperforate ear-shape and pearly interior.

\section{Genus 3. NERITOPSIS, Sowerby.}

\section{Animal; unknown.}

Shell; Nerite-shaped, with the columella curiously broadly notched near the middle, white; operculum thin, horny.

The animal of this genus is not as yet known; but naturalists are pretty well agreed on the place it should occupy in the system. Formerly it was regarded as a member of the $N$ erite family, but now it is pronounced to be intermediate between Stomatella and Narica. 'The old Nerita ractula of Linnæus is still the only recent species. The most striking

* "In their habits these mollusks are littoral, living on coral reefs and among stones between tide-marks; the finest species prefer coral reefs exposed to the action of the waves. Some of the genera, as Gena and Stomatia, have considerable locomotive powers and glide (especially Gena) with some degree of celerity. The latter genus and Stomatia possess the faculty, common to some other kinds of mollusea, of spontaneously detaching a considerable portion of the hind part of the foot when disturbed or irritated."-A. Adams, in Thes. Conch., part xv. p. 828. 
peculiarity of the shell is a broad notch in the columella, which has all the appearance of being broken.

Mr. Cuming collected several of the only species known (Nerita radula, Limmeus) at the Philippine Islands, but never met with any but dead specimens.

\section{Figure.}

Neritopsis radula. Pl. 16. Fig. 85. Shell, showing its granuled sculpture and peculiar notch in the columella.

\section{Genus 4. NARICA, Recluz.}

Animal; head with the tentacles subulate, having eyes sessile on their outer bases; foot smatl, circular, with a dilated wing-like expansion on each side, produced in front into a lobe.

Shell; subglobose, slightly umbilicated, white; spire short; last whorl rather inflated; aperture rounded; lip simple, with the margins nearly entire.

The original type of this genus is a shell figured by Chemnitz with the name Nerita cancellata. Lamarck, observing it to be of light, latticed, chalk-white substance, slightly umbilicated, included it in Sigaretus. MM. Quoy and Gaimard met with living specimens during the voyage of the 'Astrolabe,' and referred it to Telutina. They, however, expressed their opinion that it might be set apart for the formation of a new genus, and suggested Tanitioro, the name of one of the islands of the Pacific. The rules of our nomenclature will not allow of the use of this term,- - as well might a genus be named Great Britain or Ireland,-and I therefore adopt the name of Narica, subsequently proposed for it by M. Recluz. In the 'Revue de la Société Cuviérienne' for 1844, that naturalist, who has paid particular attention to the families of the Nerita, Sigareti, and their allies, published a monograph of the Narica, and we have now a very natural assemblage of twenty-six species.

\section{Species.}

1. acuta, Recluz.

2. Blainvilleana, $i d$.

3. cancellata, Chemn
4. cidaris, Recluz.

5. clathrata, $i d$.

6. Cumingiana, id.
7. Cuvieriana, Recluz.

8. Deshayesiana, $i d$.

9. distans, $i d$. 
10. Gaimardi, Adans.

11. granulosa, Recluz.

12. Gueriniana, $i d$.

13. helicoidea, Le Guill.

14. Iamellosa, $D^{\prime} O r^{\circ}$.

15. ligata, Recluz.
16. Mauritiana, Recluz.

17. Orbignyana, $i d$.

18. Petitiana, $i d$.

19. plicata, $i d$.

20. Quoyi, id.

21. rosea, $i d$.
22. rugata, Adams.

23. Sigaretiformis, Pot.

24. Souleyetiana, Recluz.

25. striata, $D^{\prime} O{ }^{\circ} 6$.

26. sulcata, $i d$.

\section{Figure.}

Narica canceldata. Pl. 16. Fig. S1. Shell, showing its white, cancellated substance and light umbilicated growth.

\section{Genus 5. VELUTINA, Fleming.}

Animal; butlin! head short, broad, bearing two rather obtuse, subulate tentactes, separated at their bases by the bieadth of the lieat; on bulgings at their origins erternally ave the eyes; proboscis retractile; mantle ample, thict, more or less reflected on the shell all rourid; foot laige, obtusely quadrate in front, rounded behind; branchial plumes two. (Forbes.)

Shell; subglobose, thin, more or less coriaccous, stightly umbiticated, covered with a thin epidermis; whorls fewo; spire short; last whorl ventricose; aperture large, rounded, entire; lip simple.

A genus of light, inflated, rosy-mouth shells, of northern habitation, dwelling at low-water mark, and often far out at sea at considerable depth, chiefly in the Arctic and boreal provinces of Europe and North America. Linnæus, uninformed of the strictly marine nature of this mollusk, included the species known to him in his genus Ilelix; but his contemporary, Müller, referred it, more naturally, to Bulla. The shell is of rather fragile substance, with mostly only a very slight secretion of calcareous matter beneath the epidermis. We include two nearly allied forms described by British authors in the genera Lamellaria and Otina.

\section{Species.}
1. antarctica, Couth.
3. Caspiensis, Adams.
5. cryptospira, Midd.
2. capuloidea, Blainv.
4. conacea, Pallas.
6. glacialis, Couth. 
7. lævigata, Linin.

8. perspicua, $i d$.

9. plicatilis, Miill.
10. prætenuis, Conth.

11. Sitkensis, Adams.
12. tuberculosa, Adams.

13. zonata, Gould.

\section{Figure.}

Velutina levigata. Pl. 22. Fig. 124. Shell, showing its light, inflated, coriaceous structure.

\section{Family 3. CAPULACEA.}

Shell ; conoid or cap-shaped, sometimes resting on a slielly plate, and mostly furnished with an internal shelly appendage.

Two very natural groups of Limpets are associated in this family, connected, nevertheless, by a character in the animal of secreting from the foot a shelly basal plate in its place of attachment. The first comprehends two genera, Pileopsis and Hipponyx, whose shells have more the form of a cap. They have no internal appendage, and are mostly parasites upon other shells. The second group, which comprehends the interesting series of Cup-and-Saucer and Slipper Limpets, known as the Calyptrailce, have all an internal shelly appendage, varying from a slender half-funnel, and largely developed cup, to a laterally compressed fold, and spirally chambered trochiform septum, or a cross deck. The genera are-

$\begin{array}{lll}\text { Pileopsis. } & \text { Calyptra. } & \text { Trochita. } \\ \text { Hipponyx. } & \text { Crucibuldi. } & \text { Crepidula. }\end{array}$

\section{Genus 1. PILEOPSIS, Lamarck.}

Animal; with a lecad produced into a proboscidiform mante; tentacles two, long, subulate, unconnected, with the eyes or bulgings at their external bases; mantle fringed at the margin; branchial plume single; foot strong, suborbicular, its sides plain.

Shell; cap-shaped, oblignely conical, covered with a snft wetroty epidermis, with the vertex incurved; aperture laryely dilated.

The well-known Hungarian Cap Limpet, which is an inhabitant of our shores, and ranges throughout the European seas from Norway to the Mediterranean, represents a genus numbering many forcign species which 
have not yet been described. They are distinguished by their conical form rising into an incurved apex, and by the first indication of a faculty possessed by some of this family of secreting a shelly plate or filmy approximation to one on their place of attachment. Of this we shall find a full derelopment in Mippony.r, and a still more perfect one in Culyplraa. The British Pileopsis is mostly found attached to Oysters and Scallops.

\section{Species.}

1. astericola, $A d$. \& $R$.

2. crystallinus, Gould.

3. militaris, Limn.
4. paleaceus, Menke.

5. pilosus, Deslı.

6. radiatus, Sars.
7. sagittiferus, Gould.

8. Ungaricus, Linn.

\section{Figure.}

Prleopsis Uxgaricus. Pl. 23. Fig. 135. Shell, showing its widely. conical, cap-like form rising into an oblique incurved apex.

\section{Genus 2. HIPPONYX.}

Animal ; similar to that of Pileopsis.

Shell ; obliquely cap-shaped, mostly supported on a shelly plate,

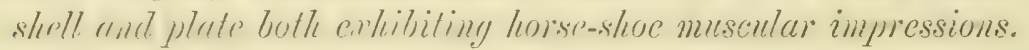

To any one accustomed to examine dead and broken shells for the sake of the parasites to be found on them, Hipponyx will be a familiar genus. The species both from the Eastern and Western scas of the tropical and subtropical zones are numerous, but few of them have been described, and the genus is much in want of the services of a monographer. There are none in the European seas, and so little is the apparent zoological difference between this and the preceding group, so far as their characters are known, that Himpony.r might fairly be merged into Pileryssis. The shells are smaller, and mainly distinguished by the presence of a strong horseshoe muscular impression, which is repeated on the surface of the basal plate.*

* "Of this remarlable genus Mr. Cuming brought honne three species, in such perfect condition as respects the shell, as to possess both valves in situe. The two specimens which exhibit these three species appear to me so interesting that I shall venture upon a particular description of them. The first, of the species which I have named Hipp. Alitrula, is a group of abont twenty individuals, of various sizes, from $\frac{r}{3} \frac{2}{0}$ to $\frac{1}{2}$ an inch in diameter, adhering by their lower or flat valves to an irregular piece of stone; the attached valves, as usual, are conformed to the irregu. larities of the surface of the stone, and when they have been at first attached to a cavity, they 


\section{Species.}

1. acuta, Quoy.

2. antiquata, Linn.

3. australis, Quoy.

4. barbata, Sow.

5. conica, Schum.

\section{6. foliacea, Quoy.}

7. granulosa, Adams.

8. imbricata, Gould.

9. Mitrula, Sow.

10. orientalis, Dufo.
11. Panamensis, C. B. Ad.

12. radiata, Quoy.

13. subrufa, Mart.

14. Ticaonica, Sow.

15. trigona, Gmel.

\section{Genus 3. CALYPTRAA, Lamarck.}

Animal; with a broad and slightly produced mus 7 ; tentacles two, rather short, lanceolate, unconnected, with the eyes on bulgings at their external bases; mantle with a simple edge; branchial plume single; foot suborldicular, stigletly angled in front; its sides plain, sometimes secreting a basal plate. Shell; globosely conical, thin, irregular, generally beaked at the top, transparent-white, radiately densely very mimutely striated, with an internal, oblique, semifunnel-shaped appendage.

The Cup-and-Saucer Limpets associated by Lamarck under this head require to be separated into three genera. Calyptraa, in its restricted sense, includes thirty-three species, all having a shell of peculiarly fine, semitransparent, thread-like tissue, with a slender, erect internal appendage, like the half-section of a funnel, and some of the species secrete a well-formed basal plate. The larger Lamarckian Culyptrace, having an internal appendage in the form of a distinct cup, are included under genus Crucibulum; and those in which the internal appendage forms a trochoid septum, under genus Trochita.

The circumstances which led to the necessity of making this change are

are hollow : the upper valves are also somewhat modified in form by the same cause, so as to be more or less regular according as the lower valve has adhered to a more or less smooth and even part of the stone. The attached valves have not attained a great degree of thickness, consequently I do not suppose any one of the individuals to be of advanced age; there are, however, sereral which can only just have occupied their positions on the stone: these are not above $\frac{1}{40}$ part of an inch in diameter, and they show the perfect point of the upper valve, somewhat convoluted and inclined toward the anterior edge. Other individuals, which are placed in a cavity of the stone, are very regular in shape, but have their ridges slightly curved upwards in conformity with the nearly regular vesicular shape of the cavity. The edges of the lamelle near the outer margin in most of the specimens are furnished with a thin fringe of epidermis, but the very young shells are destitute of this. An individual of Hipp. subrufa is observable among the group of Hipp. Mitrula : its apex is distinctly spiral and its epidermis hairy.

"The second specimen belongs to the species which $I$ have named Hipp. barbata. This is a very complete specimen, and reminds me of the beautiful fossil species Hipp. Cornucopice; it is a small individual, having its attached valve very much thickened and adhering to a much larger one of the same species; its edge is much elevated, and it is deeply concare; the free valve is rather smaller, and conical, and its edge is surrounded by the elevated edre of the attached valve."- Sowerby, Pro. Zool. Soc., 1835, p. 4. 
of interest. When Mr. Cuming visited the Island of Zebu, one of the Philippine group, about twenty years since, he observed on some coral reefs a number of dead shells of Calyptrac equestris. Supposing that living specimens could not be far off, he was induced, after much search, to turn over a mass of coral that lay sunk about two feet in the sand just below low-water mark. To his surprise he found the living $C$. equestris attached by the foot to a separate calcareous plate. Upon further search he discovered specimens of other species similarly attrched, and some also at the Island of Bohol; and having secured the animal, he submitted it to P'rofessor Owen for dissection. The phenomenon was observed about the same time at Mahé, one of the Seychelle Islands, by a distinguished French conchologist, M. Dufo; but no dissection appears to have been made by lim of the amimal. Professor Owen found it to difter from other forms of Calyptrainte "in the smaller development of its locomotive and respiratory organs, and the greater development of the organs for the prehension and assimilation of food." "The foot," continues the Professor, "may well oller diminished proportions when the animal has chosen a site for the deposition of its ventral plate and has taken up a fixed abode. Muscular action being thenceforward much restricted, the necessity for extensive respiration is in the same degree abolished."

\section{Species.}

1. aculeata, Reeve. $\quad$ 12. diaphana, Reeve.

2. $\Lambda$ damsii, $i d$.

3. alveolata, $A$. $A d$.

4. Balanoides, Reeve.

5. bulla, $i d$.

6. cancellata, $A d$. \& $R$.

7. cepacea, Brod.

8. cicatricosa, Reeve.

9. comea, Brod.

10. corrugata, id.

11. cyathella, Reeve.
13. dormitoria, $i d$.

14. equestris, Linn.

15. fibulata, Reeve.

16. Hipponiciformis, $i d$.

17. Layardi, $i d$.

18. Martiniana, $i d$.

19. ossea, $i d$.

20. papyracea, $A$. $A d$.

21. porosa, Reeve.

22. Roissyi, Dufo.
23. sacchari-meta, Reeve.

24. scabris, $i d$.

25. scutulum, $i d$.

26. stella, $i d$.

27. stultorum, $i d$.

28. tectum-Sinense, $C l$.

29. tortilis, Reeve.

30. umbo, id.

31. uncinata, $i d$.

32. Vanikorensis, Quoy.

33. varia, Brod.

\section{Figure.}

Calyptran veuestris. Pl. 24. Fig. 139. Shell, in its place of attachment on the rock, lifted to show the basal plate.-From Mr. Cuming's Collection. 


\section{Genus 4. CRUCIBULUM, Schumacher.}

Animal; simitar to that of Calyptræa, but with the foot laryer and rounded.

Shell; ovate or orbicular, sometimes depressed, somelimes conoid, radiately ribbed or vidge-striated, sometimes spined, with the top mostly near the centre; internal appendage cup-shaped, sometimes laterally compressed.

This genus, founded in 1817 by the eminent astronomer and naturalist Schumacher, is retained for that section of the Lamarckian Calyptrece in which the internal appendage takes the form of a cup; and it is sometimes free and sometimes laterally compressed and attached. Concomitant with this there is a marked generic difference in the shell compared with the Calyptrae proper, being of more solid growth, and having no trace of transparent thread-like tissue. It differs, nevertheless, remarkably according to locality, mode of attachment, and situation of habitat. A few of the species have been described several times over, especially $C$. spinosum. Sometimes the shell of this species is largely spined, sometimes only furnished with fine prickles; sometimes it is stout and convex, sometimes almost flat, and the colour is equally variable. Without an extended series of individuals from all parts of its geographical range it is impossible to determine the limits of such a species satisfactorily.

The Crucibula eminently belong to the New World. One or two small species have been collected in the Eastern seas, but all those of mark are from California and the western shores of South and Central America.

\section{Species.}

1. auriculatum, Chem.

2. auritum, Reeve.

3. concameratum, $i d$.

4. corrugatum, Carp.

5. extinctorum, Lam.

6. ferrugineum, Reeve.

7. imbricatum, Brod.

8. lividum, Reeve.
9. morbidum, Reeve.

10. pectinatum, Carp .

11. radiatum, Brod.

12. rugosum, Desh.

13. scutellatum, Gray.

14. serratum, Brod.

15. sordidum, $i d$.

16. spectrum, Reeve.
17. spinosum, Sow.

18. striatum, Say.

19. tenue, Brod.

20. trigonale, $A d$. \& $R$.

21. umbrella, Desh.

22. verrucosum, Reeve.

23. violaceum, Carp.

\section{Figure.}

Crucibulum rugosum. Pl. 23. Fig. 134. Shell of an unusually deep bonnet-shaped species, showing a large, well-dedined, internal cup. 


\section{Genus 5. TROCHITA, Schumacher.}

Animal; similar to that of Calyptræa.

Shell ; conical, sometines inclining to spiral ; internat appendage somewhet lateral and effused, sometimes trochoid, reaching to the margin.

In this genus the intermal appendage takes the form of a spiral septum of trochoid growth. In some species, as in T. radians, spirata, and clypeollnin the appendage reaches to the margin; in others, as in T. conica, sutpeflere, and Sineinsis, the appendage is comparatively small, lateral, and effused. 'The last constitute Dr. Gray's genus Galerus.

The western consts of South and Central America and Australia are the principal habitats of this genus. One species, T. Sinensis, is found in Britain, but only as a straggler on the southern shores.

\section{Species.}
1. aspersa, C. B. Ailans.
6. lichen, Brod.
11. radians, Lam.
2. Calyptreformis, Lam.
7. maculata, Quoy.
12. Sinensis, Limn.
3. clypeolum, Reeve.
8. mamillaris, Brod.
13. solida, Reeve.
t. conica, Brod.
9. pellucida, Reeve.
14. spirata, Forbes.
5. corrugata, Reeve.
10. poculum, $i d$.
15. subreflexa, Carp.

\section{Genus 6. CREPIDULUM, Lamarck.}

Animal; similar to that of Calyptræa.

Shell; ovate or oblong, gradually oblique, smooth exteriorly, rarely ribbed, with the apen mostly marginal and nore or less beaked, interiorly hollow, with a horizontal deck-litie lamina, sometimes notched at the side.

The Slipper Limpets are of a more oblong form than the Cup-and-Saucer Limpets, and the internal appendage takes the form of a transverse deck. The species are prettily marked, and mostly smooth, but there are one or two very beautiful exceptions; $C$. costata and aculeata are ribbed and densely beset with prickles, whilst in $C$. Lessonii the shell is disposed in a series of delicately fringed laminæ.

They are chiefly inhabitants of the New World. 


\section{Species.}

1. aculeata, Gmel.

2. adunca, Sow.

3. Aplysioides, Reeve.

4. arcuata, Brod.

5. bilobata, Gray.

6. convexa, Say.

7. costata, Desh.

8. dilatata, Lam.

9. excavata, Brod.

10. exuviata, Nutt.
11. fimbriata, Reeve.

12. foliacea, Brod.

13. fornicata, Linn.

14. glauca, Say.

15. hepatica, Desh.

16. incurva, Brod.

17. Lessonii, $i d$.

18. lirata, Reeve.

19. marginalis, Brod.

20. Nautiloides, Less.
21. onyx, Sow.

22. pallida, Brod.

23. porcellana, Linn.

24. rostrata, C. B. Adams.

25. rugosa, Nutt.

26. scabies, Reeve.

27. squama, Brod.

28. unguiformis, Lam.

29. Walshi, Herm.

\section{Figures.}

Crepidula costata. Pl. 23. Fig. 135. Shell of a finely-developed ribbed species, showing the internal appendage modified into a cross deck.

\section{Family 4. FISSURACEA.}

Shell; dish-shaped or conical, not spiral, perforated or notched or siphonated.

In dividing the class of Gastropods into Orders according to the structure and position of the branchix, the arrangement up to this point is natural enough; but now the systematist finds limself a little perplexed. "It would seem," says Prof. Forbes, "to be a law, in both animal and vegetable kingdoms, that no character, whether of structure or form, preserves an equal value in every tribe, but varies in its importance; in one group characterizing a class, in another scarcely determining a species." The several kinds of Limpets which come into our present Order, CervicoUranchiata, on account of the branchire being contained within a cavity of the neck, include a somewhat miscellaneous assemblage of genera, as much distinguished from one another in many important particulars as they are from the Patella, or true Limpets, which are included, after the method of Cuvier, in a separate Order along with the Chitons, on account of the branchia being placed around the body beneath the edge of the mantle.

The Fissuracea, so named after the principal characteristic of the group, have their shells either perforated at the apex or in front, or at the front margin; and to the fissured Limpets must be temporarily referred the genus Siphonaria, of which the shells exhibit the mark of a siphon, as well as Acmoa and Gadinia, of which the shells camnot well be distinguished 
from Patella without a knowledge of the soft parts of each individual species. The fissure mainly answers the purpose of a vent; but it is stated by some writers to aid also in the conveyance of water to the branchial cavity.

The genera are-

$\begin{array}{lll}\text { Fissurella. } & \text { Parmophorus. } & \text { Acmea. } \\ \text { Emarginula. } & \text { Siphonaria. } & \text { Gadinia. }\end{array}$

\section{Genus 1. FISSURELLA, Bruguière.}

Animal; with a short muz le terminating a tumid head, bearing two subulate tentacles, at the external bases of which are the eyes placed on rudimentary peclicles; a range of mumerons cirrli around the sides at the base of the very large foot; mantle proaluced in front, with a fringe of cirrli above its margin; anat sipition in the form of a short, truncated, membranous canal, projecting from the apical aperture of the shell: branchial plumes two.

Shell ; depressly conical, ovate or oblong-ovate, slield-shaped, generally attenuated anteriorly, radiately striated or ribbed, perforated at the summit; orifice oblong or nearly orbicular, sometimes contracted, sometimes excavated at the sides, most frequently inclined anteriorly.

The Fissurellae, or Key-Hole Limpets, form a very attractive group for the conchologist. Their shells are for the most part large and gaily painted, and in the smaller species the deficiency of painting is often compensated by an elaborate lattice of sculpture. The orifice at the summit of the shell, which inclines more or less towards the front, and has a fold passing out of it in connection with the vent of the animal, varies materially in form in different species, but is always the same in the different individuals of a species. It is mostly oblong, sometimes a little excavated at the sides, but more frequently contracted in the middle in such a manner as to give a somerwat toothed character to the margin.

On reference to our figures in Plate I. of $F$. maxima and megatrema, it will be seen that the comparative size between the animal and its shell is variable in the extreme. The shell in most cases forms a complete covering to the animal, and while the disk is furnished with warts and papillæ, the mantle is more or less elaborately fringed at the edge. Whereas in M. D'Orbigny's subgenus Fissurellidea, the soft parts are immensely en- 
larged, the shell, imbedded in the thickened mantle, has (juite a rudimentary appearance. The orifice of the shell is in such instances enlarged according to the proportions of the animal. In another form of Fissurella, allied to this, genus Macrochisma of Swainson, the fecal orifice is stretched, so to speak, nearly to the anterior basal margin. Some of the Fissurella, more especially those of conical form, have the vertex subspiral and a little inflected, and in all there is an indication of this structure in an early stage of growth. With the advance of growth the orifice becomes enlarged, and the subspiral vertex disappears.

The geographical range of the Fissurelle is considerable, but the genus, commencing with a single species on our own shores, $F$. reticulata, is but poorly represented in the eastern hemisphere. The large gaily-painted species inhabit the western coast of South America, and are found in comparative abundance from California down to Patagonia and the Falkland Isles.

\section{Species.}

1. aculeata, Reeve.

2. Agis, $i d$.

3. æqualis, Soro.

4. alabastrites, Reeve.

5. alternata, Soy.

6. aperta, Sow.

7. aspera, $i d$.

8. asperella, $i d$.

9. atrata, Reeve.

10. australis, Krauss.

11. Balanoides, Reeve.

12. Barbadensis, Sol.

13. candida, Soro.

14. catillus, Reeve.

15. Cayennensis, Lam.

16. Chemnitzii, Sow.

17. clathrata, Reeve.

18. clypeus, Sow.

19. coarctata, King.

20. compressa, Reeve.

21. concinna, Phil.

22. Conoides, Reeve.

23. costata, Less.

24. crassa, Lam.

25. crenigera, Sovo.

26. crenulata, $i d$.

VOL. II.
27. cruciata, Krauss.

28. Cumingii, Reeve.

29. cyathulum, $i d$.

30. dactylosa, id.

31. Darwinii, $i d$.

32. densiclathrata, $i d$.

33. digitale, $i d$.

34. dubia, $i d$.

35. Dysoni, id.

36. edititia, $i d$.

37. elongata, Pliil.

38. excelsa, Reeve.

39. exquisita, $i d$.

40. fascicularis, Lam.

41. fimbriata, Reeve.

42. fulvescens, Sow.

43. fumata, Reeve.

44. funiculata, $i d$.

45. galericulum, $i d$.

46. gemmulata, $i d$.

47. gibberula, Lam.

48. glaucopis, Reeve.

49. grisea, $i d$.

50. hiantula, Lam.

51. Hondurasensis, Reeve. 77. nigrita, Sow.

ว2. Humphreyi, $i d$.
53. inæqualis, Soro.

54. Incii, Reeve.

55. Indusica, $i d$.

56. Jukesii, $i d$.

57. larva, $i d$.

58. lata, Sow.

59. lati-marginata, $i d$.

60. lentiginosa, Reeve.

61. limatula, $i d$.

62. limbata, Sow.

63. Lincolni, Gray.

64. Listeri, D'Orb.

65. macrotrema, Soro.

66. maxima, $i d$.

67. Metcalfii, Reeve.

68. Mexicana, Sow.

69. microtrema, $i d$.

70. muricata, Reeve.

71. mutabilis, Sou.

72. mus, Reeve.

73. Natalensis, Krauss.

74. neglecta, Desh.

75. nigra, Less.

76. nimriradiata, Regve.

78. nigro-ocellata, Reeve. 
79. nigro-punctata, Sow.

80. nimbosa, Lin.

81. nodosa, Borm.

82. obscura, Sow.

83. obtusa, $i d$.

84. octagona, Reeve.

85. olivacea, Gray.

86. oriens, Sow.

87. ostrina, Reeve.

88. Panamensis, Sow.

89. Peruviana, Lam.

90. Philippiana, Reeve.
91. picn, Soro.

92. picta, Gmel.

93. Pileopsoides, Reeve.

94. pulchra, Sow.

95. pustula, Lin.

97. reticulata, Don.

98. rota, Reeve.

99. rugosa, Sow.

100. Rupellii, $i d$.

101. sagittata, Reeve.

102. salebrosa, $i d$.
103. scutella, Gray.

104. Sieboldii, Reene.

105. Singaporensis, $i d$.

106. stellata, $i d$.

107. suffusa, $i d$.

109. Ticaonica, $i d$.

110. venusta, $i d$.

111. viminea, $i d$.

112. virescens, Sow.

113. viridula, Lam.

114. volcano, Reeve.

\section{Figures.}

Fissurelifa maxima. Pl. I. Fig. 1. Shell, with animal, showing the warts and papillo of the basal disc or foot, and fringed border of the margin extending over the shell's edge.-From the 'Toyage de l'Astrolabe.'

Fissurella (Fissurellidea) megatrema. Pl. I. Fig. 2. Animal of very enlarged proportions, with the shell of small size imbedded in the mantle.-From the 'Toyage dans l'Amér. Mérid.'

Fissurella Bridgesit. Pl. 24. Fig. 145. Shell, showing from the interior its dish-like form and key-hole orifice.

\section{Genus 2. EMARGINULA.}

Animal; with a short mazle, teminating a tumid head bearing two subulate tentacles, with subjectunculated eyes at their external bases; a range of cirrtii around the sicles at the base of the foot; mantle simple-edlyed: anal siphon with its angulated membranous sides projecting from the edges of the fissure; branchial plumes two. (Forbes.)

Shell; conical or depressly conical, rayed or latticed without; vertex incurved posteriorly; front side or margin fissured.

Under this head may be included all the fissured Limpets not referable to the preceding genus. We have secn that in Fissurella the orifice of the shell is central, and that, in its enlargenent, the subspiral nucleus of the vertex becomes absorbed. In Enarginula the incurved vertex is preserved, and the orifice is at the front basal edge of the shell, and takes the 
form of a marginal slit, or of a mere sinus; the shells, too, are uniformly smaller. Two very small forms may be added, possessing good distinctive characters, Cemoria (Patella Noachina, Limn.), with an inner shelly chamber, inhabiting our northern seas, in which the slit is diamond-shaped, and situated, as it were, in the neck of the subspiral vertex; and Rimula, inhabiting the seas of the Philippine islands, in which the slit is situated inidway between the vertex and the margin. Both were known to geologists in a fossil state before living specimens were collected.

The coloured Emarginule are chiefly from Australia and the Philippine Islands. On our own shore the genus is well represented, in addition to the Cemoria, * by three elaborately cancellated species conspicuously fissured at the margin.

\section{Species.}

1. acuminata, Adanes. 18. cuvirostris, Desh.

2. alveolata, $i d$.

19. denticulata, $A d$.

3. annulata, $i d$.

4. Arabica, $i d$.

5. aspera, Gould.

20. depressa, Blainv.

21. exquisita, $A d$.

22. fastigiata, $i d$.

23. fissura, Linn.

6. Blainvillei, Defr.

24. fissurata, Chemn.

7. cancellata, Phil.

25. fungina, Gould.

26. galeata, Adams.

27. galeata, Gould.

9. carinata, $i d$.

10. catillus, $i d$.

11. clathrata, $A d . \& \cdot R$.

28. Huzardii, Payr.

29. imbricata, $A d$.

30. lata, Quoy.

31. Noachina, Linn.

32. nodulosa, Adans.

35. parmophoroidea, Quoy.

12. cognata, Gould

13. conica, D'Orb.

14. crassa, Sow.

15. crassilabrum, $A d$.

33. notata, Linn.

34. octoradiata, Gmel.

36. polygonalis, $A d$.

37. princeps, Gould.

38. propinqua, $A d$.

39. pumila, $i d$.

40. reticulata, Chemn.

41. rosea, Bell.

42. rubra, Lam.

43. rudis, Adans.

44. sculptilis, $i d$.

45. scutellaris, $i d$.

46. stellata, $i d$.

47. striatula, Quoy.

48. sulcifera, Adams.

49. tricarinata, Born.

50. Vanicorensis, Quoy.

17. cucullata, Gould.

* "This very curious shell was first observed as a fossil by Linuæus himself, in the pleistocene beds of Sweden. Not until of late years has it been taken alive, and British cabinets were for a long time supplied with specimens from the pleistocene beds of the Clyde. Mr. Smith, of Jordan Hill, was the first to maintain its existence in the living state in the British seas. Except on the Northumberland coast, where it has beea taken at Cullereoats by Mr. Alder, and in fifty fathoms sixty miles to the east of the north coast of Durham by Mr. King, its localities are all Scottish. It ranges in depth from twenty to one hundred fathoms, and occurs at intervals throughout the Hebrides and off the coast of Zetland. It is a species essentially of northern origin, and has now its chief habitats in arctic and boreal seas, exteuding along the coast of Greenland, and down those of boreal America to Cape Cod. It dates its origin from the pleistocene epoch, and can only be regarded as a lingerer in our existing seas." - Forbes and Hanley, Brit. Moll., vol. ii. p. 4.76 . 


\section{Figures}

Eriarginula fissurata. Pl. 23. Fig. 132. Shell, showing externally a small fissure at the upper front margin.

Euarginula (Cemoria) Noncmina. Pl. 23. Fig. 133. Shell, showing the diamond-shaped fissure behind the incurved vertex.

\section{Genus 3. PARMOPHORUS, De Blainville.}

Animal; body thick and flesthy, liaving a white oblong sticld-litie shell "pon. its back, partially covered by a fold of the mantle; herad with an clonyaled muzic, and a pair of thicti prominent tentacles, with eyes at their outer bases.

Shell; oblong, converly depressed, shichl-lilie, faintly enarminated. in front, white, vertex minutely recurved.

Paimenthoins, both animal and shell, thongh much larger, is closcly allied to Emarginula, but the soft parts are more fleshy in comparison, and the shell is partially covered in by a fold of the mantle. All the Parmophoms shells are of an oblong shield shape, and of a peculiar white composition. As in Enarginnlu, they are sinuated at the front edge, but the sinus is very superficial; it never amounts to a fissure, and in some specimens is scarcely discernible. The animal, so far as may be gathered by MM. Quoy and Gaimard's figure of $P$. unstralis, is jet-black, presenting a striking contrast with the shell. It inhabits shallow water where collected by Mr. Cuming at the Philippine Islands, and is found also on the shores of Australia and New Zealand.

\section{Species.}

1. angustatus, Adams.

7. decussatus, Adams.

12. intermedius, Reeve.

2. Australis, Blainv.

8. elegans, Gray.

13. osseus, Gould.

3. carinatus, Adams.

9. elongatus, Lam.

14. radiatus, Adams.

4. cicatricosus, $i d$.

5. cinereus, Gould.

10. granulatus, Blainv.

15. tumidus, Quoy.

6. corrugatus, Reeve.

11. imbricatus, Quoy.

16. unguis, Lim.

\section{Figures.}

Parmophorus Australis. Pl. M. Fig. 2. Animal, with the shell enclosed within a fold of the mantle.-From the 'Toyage de l'Astrolabe.' 
Parmophorus granulatus. Pl. 25. Fig. 150. Shell, showing its mlnutely recurved vertex and faint marginal sinus.

\section{Genus 4. SIPHONARIA, Sowerby.}

Animal; body oval, rather depressed; head subdivided into turo equal lobes without tentacles or apparent eyes; edges of the mantle crenulated; bianchia in the form of a square membrane in the sims formed on the right, between the foot and the mantle. Shell; ovate, sometimes elevately conical, uncinate at the top, sometimes depressed, radiately ribbed or striated, denticulated at the margin; interior exhibiting a siphonal impression.

$\Lambda$ very natural group of Limpets, in which the special characteristic of the animal, a branchial sinus on the right side, between the foot and the mantle, is accompanied by a corresponding siphonal impression on the imer surface of the shell. The conchologist, therefore, is enabled readily to distinguish them, and the species exhibit peculiarities of form and general aspect which strike the eye, independently of their leading generic character. The genus, of which nearly forty species have been described, is very generally distributed within the tropical and subtropical zones of both hemispheres.

\section{Species.}

1. æquilorata, Reeve.

2. amara, Nuttall.

3. atra, Quoy.

4. Baconi, Reeve.

5 . bifurcata, $i d$.

6. Brasiliana, $i d$.

7. cancer, $i d$.

8. characteristica, $i d$.

9 . cochleariformis, $i d$.

10. concinna, Soro.

11. corrugata, Reeve.

12. costata, Sow.
13. denticulata, Quoy.

14. Diemensis, $i d$.

15. ferruginea, Reeve.

16. fuliginata, $i d$.

17. funiculata, $i d$.

18. lirata, $i d$.

19. gigas, Sow.

20. Kurracheensis, Reeve.

21. læviuscula, Blainv.

22. lineolata, Sow.

23. Luzonica, Reeve.

24. Macgillivrayi, $i d$.
25. mora, Sow.

26. obliquata, $i d$.

27. palpebrum, Reeve.

28. pica, Sorv.

29. redimiculum, Reeve.

30. scabra, $i d$.

31. sipho, Sow.

32. Siquijorensis, Reeve.

33. spinosa, $i d$.

34. Tristensis, Soro.

35. venosa, Reeve.

36. zebra, $i d$.

\section{Figure.}

Sipmonaria sipio. Pl. 24. Fig. 144. Shell, shoming on the left side the internal siphonal impression. 
Genus 5. ACMAA, Eschscholtz.

Animal; with two subulate tentacles bearing eyes on the outer sides of their swollen bases; mantle-margins fringed; branclice forming a pectinated plume, lodged in a cervical cavity; foot large, ovate, with plain sides. (Forbes.)

Shcll; ovate, depressly conoid; apex approaching the anterior nargin, smooth or radiatety striated.

The shells of Acmea (Tecturu, Audouin; Patelloidea, Quoy and Gaimard; Lottia, Gray) are so like those of Patella, that it is not possible to separate them entirely without an examination of the animal. $\Lambda$ few of the typical forms of the genus are known, but it is not improbable that the list of Patella includes many species belonging to the genus Acmea. The only point in which the animals differ is the arrangement of the branchix. In Patella they form an encircling cord of minute close-set plates, whilst in Acmea they form a plume lodged in a cavity of the neck.

The Acmece inhabit Australia and the western coast of South America, and two species, A. testudinalis and virginea, frequent our own shores and the seas of northern Europe, to which may be added two small British species, described as genera by Forbes and Hanley, Pilidium and Propilictium, of which the animals are without eyes, and their shells have more the appearance of minute Emarginula, without the slit.

\section{Species.}

1. æruginosa, Midd. 16. fragilis, Quoy.

2. alveus, Couth.

3. Ancyloides, Forbes.

4. ancylus, Esch.

5. araneosa, Gould.

6. Asmi, Midd.

7. cassis, Esch.

8. conica, Gould.

9. conoidea, Quoy.

10. conspicua, Pliil.

11. cymbiola, Gould.

12. digitalis, Esch.

13. discors, Phil.

14. elongata, Quoy.

15. flammea, $i d$.
17. fulva, Mïller.

18. fungus, Meusch.

19. leucopleura, Gmel.

20. limbata, Phil.

21. melanoleuca, Gmel.

22. melanosticta, $i d$.

23. mitella, Menke.

24. orbicularis, Quoy.

25. parasitica, D'Orb.

26. patina, Esch.

27. persona, $i d$.

28. personoides, Midd.

29. pileolus, $i d$.

30. pileopsis, Quoy.
31. pintadina, Gmel.

32. pustula, Helb.

33. rugosa, Quoy.

34. scabra, Gould.

35. scurra, Lesson.

36. septiformis, Quoy.

37. squamosa, $i d$.

38. stellaris, $i d$.

39. striata, $i d$.

40. subrugosa, D'Orb.

41. testudinalis, Müll.

42. textilis, Gould.

43. variabilis, Sow.

44. virginea, Miill.

45. viridula, Lam. 


\section{Figure.}

Aсmæa gigantea. Pl. 24. Fig. 142. Shell, showing the interior of an unusually large species.

\section{Genus 6. GADINIA, Gray.}

Animal; Tead distinct, flattened; tentacles expanded, funnelshaped; eyes sessile; foot flat, thin, simple. (Adams.)

Shell; rotundately conical, smooth or rayed, sometimes rather solid, whitish.

This genus, more generally known to collectors by Mr. Sorrerby's name Mouretia, has a peculiar whitish roundly conical shell, while the animal differs from that of Acmea in having the tentacles expanded and funnelshaped. The species are as yet but imperfectly known, and only the following have been described.

\section{Species.}
1. Afra, Gray.
3. Garnotii, Payr.
5. reticulata, Sow.
2. costata, Krauss.
4. Peruviana, Sow.
6. stellata, $i d$.

\section{Figure.}

Gadinia Peruvina. Pl. 24. Fig. 143. Shell of a solid, broadly conical form, showing the interior, with its horse-shoe muscular impression.

\section{Order 5. CYCLOBRANCHIA'TA.}

Branchiæ; placed round the body in a circle, between the mantle and the foot or disc.

In this Order are brought together, after the method of Cuvier, two families possessing very liffering kinds of shell, but in the animal of each there is a similarity in the arrangement of the branchix. The branchial plume, which in the preceding family is lodged within a cavity of the neck, is in the Patellacen modified into an elongated cord of plates cxtending round the body between the mantle and the foot; and the same arrangement obtains in the Chitonacea. There is, liowever, something 
problematical about the relationship, which further researches are needed to elucidate.

Patellacea. Chitonacea.

\section{Family 1. PATELLACEA.}

Shell; dish-shaped, of one more or less depressly conoid piece; margin entire.

In addition to the genus of true Limpets, Patella, we include in this family a group of which $\mathrm{Mr}$. Cuming possesses an interesting series of species, but of which few are as jet described, Scutella. The shells have rather the appearance of Emarginule without the slit.

Patella.

Scutella.

Genus 1. PATELLA, Linnœus.

Animal; with tuo subulate tentacles, bearing eyes on the outer sides of their suollen bases; mantle-maryin fringed; branchial plume forming a fixed cordon of minute close-set plates, placed between the mantle and base of foot, and ranging nearly round the body; foot a large ovute or round disc, with plain sides. (Forbes.)

Shell; ovate or rounded, more or less convex, dish-shaped, not spiral; apex sometimes central, generally more or less inclined anteriorly, mostly ractiately ribbed or ridged, sometimes scaled, generally crenulated at the margin.

The Patelle are so named from a resemblance in the form of their shell to the patella, or dish, formerly used by the Latins for carrying meat in their sacrifices. In structure it is the most simple of shells, being a plain, unconvoluted shicld, without perforation or notch, more or less raised in convexity, inclining to an apex, rarely more than superficially developed, sometimes bent anteriorly into an incurved hook. From this apex, radiate ridges or ribs which are sometimes scaled, and have the interstices not unfrequently wrought into lattice-work by concentric ridges. The radiating sculpture is, however, mostly smooth, though presenting most diversified patterns in detail. The painting of the Patelle is also much varied; rays of different colour mostly predominate, and they are so modified by external causes in different individuals of the same species, that many have been described several times over. 
The Patelle inhabit all seas, and are most abundant in individuals. Some of the finest are from the shores of the Cape Colony. We have three species in Britain, $P$. vulgata, ${ }^{*}$ athletica, and pellucida; the first two of these are rock-dwelling species, the last inhabits seaweeds and is the type of a separate genus, Patina.

\section{Species.}

1. achates, Reeve.

2. aculeata, $i d$.

3. affinis, $i d$.

4. ænea, Martyn.

5. albicostata, C. B. Ad.

6. amussitata, Reeve.

7. araneosa, $i d$.

8. Araucana, $D^{\prime} O \cdot b$.

9. argentata, Sow.

10. Argenvillei, Krauss.

11. articulata, Reeve.

12. aspera, Lam.

13. aster, Reeve.

14. atramentosa, $i d$.

15. Balanoides, id.

16. biradiata, $i d$.

17. Bonnardi, Payr.

18. Borneensis, Reeve.

19. cærulea, Lam.

20. Candei, D'Ort.

21. canescens, Reeve.

22. cantharus, $i d$.

23. Chiloensis, id.

24. Chitonoides, $i d$.

25. cimeliata, $i d$.

26. cinis, $i d$.

27. clathratula, $i d$.

28. clypeater, Less.
29. cochlear, Gmel.

30. coffea, Reeve.

31. compressa, Lim.

32. corrugata, Reeve.

33. costoso-plicata, Mart.

34. cretacea, Reeve.

35. Cubensis, $i d$.

36. Cumingii, id.

37. decora, Phil.

38. depsta, Reeve.

39. diaphana, Nutt.

40. dira, Reeve.

41. Dunkeri, Phil.

42. Earlii, Reeve.

43. electrina, $i d$.

44. elegans, Phil.

45. enneagona, Reeve.

46. exarata, $N u t t$.

47. exusta, Reeve.

48. fenestrata, Nutt.

49. ferruginea, Sow.

50. floccata, Reeve.

51. Fuegiensis, id.

52. funebris, $i d$.

53. granatina, Linn.

54. grano-striata, Reeve.

55. granularis, Limn.

56. guttata, $D^{\prime} \mathrm{O} \cdot 6$.
57. imbricata, Reeve.

58. inradiata, $i d$.

59. Jacksoniensis, $i d$.

60. laciniata, $i d$.

61. lacunosa, $i d$.

62. lanx, $i d$.

63. lentiginosa, $i d$.

64. leucophæa, Nutt.

65. leucopleura, Gmel.

66. lima, Reeve

67. lineata (Lottia), Gray.

68. livescens, Reeve.

69. longicosta, Lam.

70. lugubris, Dunk.

71. Luzonica, Reeve.

72. Magellanica, Mart.

73. mamillata, Nutt.

74. margaritaria, Chem.

75. Mexicana, Brod.\&. Sow.

76. mixta, Reeve.

77. morbida, $i d$.

78. navicula, $i d$.

79. nigrisquamata, $i d$.

80. nigro-lineata, $i d$.

81. nigro-punctata, $i d$.

82. nigro-sulcata, $i d$.

83. nimbus, $i d$.

84. Nuttalliana, id.

* "The common Limpet is universally distributed around our coasts, living on the surface of rocks and stones between tide-marks. Although capable of moving about with facility, when well-grown it appears to become lazy and sedentary, often living in crevices, where, having once lodged, it remains till it becomes too large to come out. When it moves about, it makes upon the rock a curious fucoid-like track of some breadth, probably caused by the edges of the shell. On calcareous rocks, and especially upon chalk, it frequently, as it were, excavates a cavity for itself, apparently by the action of the carbonic acid set free during respiration, since the marks of the action of the ciliary currents from the gills are distinctly visible. This animal is sometimes used for food, though much too leathery to become a delicacy." - Forbes and Hanley, Brit. Jloll., vol. ii. p. 425 . 
85. occidentalis, Reeve. 86. oculus, Born.

87. opea, Nutt.

88. Oregona, $i d$.

89. pencillata, Reeve.

90. pentagona, Born.

91. petulata, Reeve.

92. pica, $i d$.

93. plana, Phil.

94. plicata, Born.

95. plumbea, Lam.

96. pruinosa, Krauss.

97. puncturata, Lam.

98. radians, Gmel.

99. rota, Chem.
100. rustica, Linn.

101. saccharina, $i d$.

102. sanguinalis, Reeve.

103. sanguinans, $i d$.

104. scabra, Nutt.

105. scalata, Reeve.

106. scutellaris, Lam.

107. spectrum, Nutt.

108. squamifera, Reeve.

109. stellularia, Quoy.

110. stipulata, Reeve.

111. tenera, $A \bar{d}$.

112. testudinaria, Linn.

113. toreuma, Reeve.

114. tramoserica, Martyn. 129. zebrina, Less.
115. umbella, Gmel.

116. umbonata, Nutt.

117. uncinata, Reeve.

118. undato-lirata, $i d$.

119. ustulata, $i d$.

120. variabilis, Sow.

121. varicosa, Reeve.

122. variegata, $i d$.

123. venosa, $i d$.

124. verriculata, $i d$.

125. vespertina, $i d$.

126. vidua, $i d$.

127. vulgata, Limn.

128. zebra, Reeve.

\section{Figure.}

Patella lovgicusta. Pl. 25. Fig. 146. Shell of a strongly-ribbed species, in which the ribs extend more than usually beyond the margin.

\section{Genus 2. SCUTELLA, Broderip.*}

Animal; like that of Patella.

Shell; ovate, more or less depressly conoid, mostly cancellated by the crossing of concentric and radiating ribs or stria.

In the Cumingian collection is a series of shells chiefly from Central America and the Philippine Islands, only a few of which have been described, offering good distinguishing characteristics apart from Patella. They are uniformly smaller and more delicate, and are mostly finely sculptured. When fully monographed, their generic features will be better understood and explained.

\section{Species.}
1. Arabica, Rüpp.
5. crenulata, Brod.
8. Galathea, Lam.
2. asperulata, Adams.
6. elongata, Adams.
9. granulosa, Adams.
3. cinnamomea, Gould.
7. ferruginea, $i d$.
10. lævicostalis, id.

4. costata, Adams.

* The word Scutella is also used for a genus of Radiata, but there is not much chance of confounding a Limpet with a Sea-Egg. 


\section{Figure.}

Scutella crenulata. Pl. 24. Fig. 140 and 141. Shell, showing its external cancellated sculpture and internal muscular impression.

\section{Family 2. CHITONACEA.}

Shell; oblong-dish-shaped, of eight separate pieces, either set in a cartilaginous frame, or in the mantle separately.

Of all mollusks the Chitons are they which naturalists have been most puzzled to know what to do with. Milne-Edwards doubted if they were Mollusca at all; and De Blainville showed that he was much of the same opinion by classing them, like Linnæus, with the Barnacles. Cuvier brought them into relationship with the Patelle, after the manner of Adanson, on account of the similarity of the breathing-system, and naturalists are now pretty well agreed upon this arrangement. The genera are-

Chiton.

Chitroneluus.

\section{Genus 1. CHITON, Linnaus.}

Animal ; head obscurely defined, formed of a proboscis covered by a flesly semicirculur hood; no tentacles nor eyes; branchia forming a series of lamella between the mantle and foot on each side; foot an oblong disk, rounded at each extremity.

Shell; oblong or elongately ovate, eight-valved, valves moving one upon another, convex, umbonated in the middle, somewhat winged on each side, fixed in a cartilaginous frame, which is cither smooth, squamate, hairy, spinous, or fasciculate, sometimes widely expanded, sometimes covering the valves entircly.

Unlike Patella, the animal of Chiton is a blind oblong mass, without tentacles, and with scarcely a definable head, yet the branchiæ are similar, and the shell may be likened ideally to a Limpet divided into eight pieces. Dr. Gray considers the posterior terminal valve to be the homologue of the shell of Patella. 'The eight separate pieces, or valves, are sustained in their place by a cartilaginous frame, a horny extension of the mantle, and they move one upon another, like plate-armour, by the aid of three flexible muscles, attaching crosswise to each valve. This horny frame or ligament is distinguished by the following varieties of character. In 
C. elegans it appears in its simplest form, thin and transparent; in $C$. alatus it is covered with a rough sandy deposit, in $C$. Blainvillei with a few scattered bristles, in $C$. Permianus with a dense growth of hair, in $C$. setiger with straggling bristle-like hairs, in $C$. Coquimbensis with oblong beads, in $C$. aculeatus with short cylindrical spines, in $C$. spinosus with sharp curved spines, in $C$. magnificus with close-set calcareous grains, in C. squamosus with close-set scales, in $C$. fuscicularis with tufts of little bristly spiculx, and in $C$. Sitkensis, in which the mantle entirely covers the valves, with minute stars of glassy spiculæ.

The imbedded portion of each valve is more or less produced posteriorly into two processes, according to the oblong tendency of their structure, and the comparative force necessary to keep them in order. In most species where the valves are narrow across, these processes, termed apophyses, from their analogy with the apophysis of the vertebrate skeleton, are but slightly developed, and the sinus between them is finely serried. In valves of a more oblong form, as in $C$. incisus, the apophyses become more prominent, until in Chitonellus, where the valves are longer than wide, and isolated from each other, the apophyses are developed to an extent that enables the valves to be sustained each by itself in the substance of the mantle. The exposed portion of each valve, the only part that is characterized by any sculpture or design of colouring, has the appearance of a convex shield, supported on either side by a raised, triangular, winged growth, forming, as it were, the radii of a circular plate, which meet together in the anterior terminal valie; so that the sculpture and colouring of the front valve is almost invariably the same as in the lateral areas of the rest; and the sculpture and colouring of the central areas of the valves is as invariably different.

The Chitons live attached to stones and fragments of shells in deep water, sometimes on exposed rocks, but most frequently under stones at about low-water mark. They exist in abundance on the shores of southwestern America, of Australia, and New Zealand, the Eastern Archipelago, the Pacific Islands, Cape of Good Hope, West Indies, Sitka, and the shores of Europe and Asia, six species inhabiting our own shores.

'The genus has been subdivided chiefly according to characters of the encircling cuticle.

\section{Species.}
1. aculeatus, Linn.
6. alatus, Sow.
11. arbutum, Reeve.
2. acutiliratus, Reeve.
7. albilineatus, $i d$.
12. articulatus, Sow.
3. acutirostratus, Ad. Rie.
8. amiculatus, Pallas.
13. assimilis, Reeve.
4. Adelaidensis, Reere.
9. antiquus, Reeve.
14. astriger, $i d$.
ค. æreus, id.
10. aquatilis, $i d$.
I. at atratus, Sow. 
16. australis, Soro.

17. Barnesii, Gray.

18. Blainvillii, Brod.

19. Bowenii, King.

20. brevispinosus, Sow.

21. cælatus, Reeve.

22. Cajetanus, Poli.

23. Californicus, Nutt.

24. caliginosus, Reeve.

25. cancellatus, Leach.

26. Capensis, Gray.

27. carinulatus, Reeve.

28. castaneus, Wood.

29. castus, Reeve.

30. catenulatus, Soro.

31. catillus, Reeve.

32. cerasinus, Chem.

33. Chilensis, Frembly.

34. Chiloensis, Sovo.

35. chlamys, Reeve.

36. ciliatus, Sow.

37. cimolius, Reeve.

39. cinereus, Linn.

39. cingillatus, Reeve.

40. circellatus, Ad.\&. Rve.

41. circumvallatus, Reeve.

42. clathratus, $i d$.

43. coarctatus, Sow.

44. Colliei, Gray.

45. colubrifer, Reeve.

46. Columbiensis, Soro.

47. concentricus, Reeve.

48. contractus, $i d$.

49. Coreanicus, Ad. \&. Rie.

50. corrugatus, Reeve.

51. Coquimbensis, Frembly.

52. crenulatus, Brod.

53. crinitus, Pen.

54. crispus, Reeve.

55. crocinus, $i d$.

56. Cumingii, Frembly.

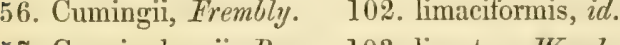

57. Cunninghamii, Reeve. 103. lineatus, $W_{\text {ood }}$.

58. decussatus, $i d$.

104. lineolatus, Fremb.

59. Dieffenbachii, Reeve. 105. linter, Chem.

60. disjunctus, Fremb.

61. dissimilis, Reeve.

62. dispar, Sono.

63. divergens, Reeve.

64. elegans, Fremb.

76. fulvus, Wood.

77. gigas, Chemn.

78. Goodallii, Brod.

79. granatus, Reeve.

80. graniferus, Soro.

81. granosus, Fremb.

82. Grayi, Sowo.

83. Guildingii, Reeve.

84. Hanleyi, Bean.

85. hastatus, Sow.

86. Hennahii, Gray.

87. Hindsii, Sow.

89. illuminatus, Reeve.

90. incarnatus, $i d$.

91. Incii, $i d$.

92. incisus, Soro.

93. inquinatus, Reeve.

94. insignis, $i d$.

96. labeculatus, Reeve.

98.

99. lævis, Pen.

100. laqueatus, Reeve.

101. lentiginosus, Sow.

107. luridus, Sow.
108. Luzonicus, Sow.

109. Lyellii, $i d$.

.110. lyratus, id.

111. Magdalenensis, Hinds.

66. Emersonianus, Couth.112. magnificus, Desh.

67. exiguus, Sow. $\quad$ 113. marginatus, $P$ en.

68. fascicularis, Lin. 114. marmoratus, Gmel.

69. fastigiatus, Gray. 115. marmoreus, Chem.

70. floccatus, Sow. $\quad$ 116. Mediterraneus, Gray.

71. fortiliratus, Reeve. 117. metallicus, Reeve.

72. formosus, Ad. \& Rve.118. Milleri, Gray.

73. foveolatus, Sow. 119. monticularis, Quoy.

74. fulgetrum, Reeve. 120. muscarius, Reeve.

75. fuliginatus, $A d . \& \cdot R$. 121. nobilis, Gray.

88. hirundiniformis, $i d$.

122. Novæ-Hollandiæ, id.

123. occidentalis, Reeve.

124. pallidulus, $i d$.

125. pallidus, $i d$.

126. patulus, Soro.

127. pectinatus, $i d$.

128. pellis-serpentis, Quoy.

129. pertusus, Reeve.

130. Peruvianus, Lam.

131. petasus, Ad.\& Reeve.

132. petholatus, Soro.

133. piceus, Gmsl.

134. pictus, Reeve.

135. picus, $i d$.

136. porphyreticus, $i d$.

137. productus, $i d$.

138. proprius, $i d$.

139. Proteus, $i d$.

140. pulchellus, Gray.

141. pulcherrimus, Solo.

142. puncticulatus, Reeve.

143. punctulatissimus, Sow.

144. pusillus, $i d$.

145. Quoyii, Des/.

146. reticulatus, Reeve.

147. retusus, Sow.

148. roseus, $i d$.

149. ruber, Lowe.

150. rugosus, Gray.

151. rugulatus, Sow.

106. longicymba, De Blain.152. sanguineus, Reeve.

153. scaber, $i d$. 
154. scabriculus, Sov.

155. scarabeus, Reeve.

156. sculptus, Sow.

157. scutiger, $A d . \&$ Reeve.169. squamosus, Linn.
158. segmentatus, Reeve. 170. Stangeri, Reeve.

159. setiger, King.

160. setosus, Sow.

161. Siculus, Gray.

162. Sinclairi, $i d$.

163. Sitkensis, Reeve.

164. Sowerbyanus.

165. spiculosa.
166. spiniger, Soro.

167. spinosus, Brug.

168. spinulosus, Sow.

171. Stokesii, Brod.

172. striatus, Barnes.

173. striolatus, Gray.

174. Sueziensis, Reeve.

175. sulcatus, $\mathbb{W}$ ood.

176. Swainsoni, Sow.

177. textilis, Gray.
178. truncatus, Sorv.

179. tulipa, Quoy.

180. tunicatus, $\mathbb{W}_{\text {ood. }}$.

181. undulatus, Quoy.

182. ustulatus, Reeve.

183. violaceus, Quoy.

184. virescens, Reeve.

185. virgatus, $i d$.

186. virgulatus, Sow.

187. volvox, Reeve.

188. Watsoni, Sow.

189. Zelandicus, Quoy.

\section{Figure.}

Chiton spiviger. Pl. 25. Fig. 147. Shell, showing the eight valves in a broad cartilaginous frame beset with calcareous bristles.

\section{Genus 2. CHITONELLUS.}

Animal; similar to that of Chiton.

Shell; of eight isolated pieces, longitudinally oblong valves, of which the apophyses are much produced, partially imbedded in the substance of the mantle, which is thick and elongated; valves approximating towards the head.

The Chitonelli resemble the Chitons in their internal organization, but in connection with a difference in the condition of the mantle and its shell, there is a marked difference in their habits and geographical distribution. The mantle is very thick and fleshy, peculiarly elongated, sometimes covered with a harsh down, but mostly tough and leathery; it is invariably destitute of any horny, cartilaginous part, and is never furnished with spines, bristles, or any sort of calcareous armature. The valves of the shell are of a longitudinally oblong form, with the inner posteriorly projecting plates or apophyses very much produced and firmly imbedded in the substance of the mantle. Sustained by the apophyses alone, the valves are perfectly isolated from one another, far remcved, in the more typical species, posteriorly, but approximating towards the head, where they are sometimes much worn by the friction arising from the animal's propensity of thrusting itself into holes and crevices of rocks.

The Chitonelli are not found in company with Chitons. On the south- 
western shores of America, where the Clitons, some fifty or sixty species, are more abundant than in any other part of the world, not a single Chis tonellus has been taken. At the Philippine Islands, on the other hand, where Chitons are scarce, the largest species of Chitonellus known was found by Mr. Cuming in plenty, and of extraordinary dimensions. They were found dwelling in holes and cavities, either of natural formation or bored by other mollusks, into which they force themselves by attenuating their bodies in a manner truly surprising. At the Island of Zebu, where Mr. Cuming met with a number of C.fasciatus, he found them partially or entirely imbedded in holes and circuitous crevices of the coral reefs, sometimes turned completely at a right angle, and at an angle again. Many that were only partially imbedded, from having thrust themselves into holes not deep enough to contain them, hung down with the posterior end of the body fat and swollen, and whenever any force was used to withdraw them, it invariably broke off. Mr. Cuming did not find the Chitonellus fasciatus under any other circumstances, and could only obtain specimens entire by splitting the coral and taking them from their hiding places, in which they would be attenuated to the length of a foot and more. Higher up among the islands of the Corean Archipelago, C. fasciatus was found by Sir E. Belcher and Mr. Adams under stones; and, unlike the Chiton, it would crawl away, on turning up the stone, at about the pace of our common garden snail. Some interesting species have been collected in Australia of smaller size, with the valves less isolated.

The Australian and Tasmanian species are smaller, and the valves, characterized by a more elaborate variety of sculpture and colour, are broader and less removed from each other.

\section{Species.}
1. fasciatus, Quoy.
4. larviformis, Blainv.
6. rostratus, Reeve.
2. Gunnii, Reeve.
5. oculatus, Quoy.
7. striatus, Lam.

3. lævis, Lam.

\section{Figure.}

Chitonellus fasciatus. Pl. 25. Fig. 149. Animal, much contracted from being dried, head downwards, showing the shell imbedded in the substance of the mantle; the valves isolated from one another, approximate towards the head, and are become worn from the friction arising from the habit of the mollusk of thrusting itself into holes and crevices of rocks. 


\section{Order 6. CIRRHOBRANCHIATA.}

Branchix; two equal tufts of soft, flexible, club-shaped cirrhi.

According to the observations of two most eminent French naturalists, M. De Blainville and M. Deshayes, the branchiæ of a very anomalous genus of mollusks known as the Dentaliada, or Tootl-shells, are a couple of tufts of soft, flexible, club-shaped, cirrhus-like filaments, one on each side of the animal's head. An English naturalist, Mr. Clark, who has devoted a life to the anatomy of the mollusca of our southern shores, has declared that these tufts are not branchix, but salivary glands, and that what M. Deshayes calls the lobes of the liver are the branchix. Should this observation be confirmed, the name of our Order must be changed. We have only one genus to record-

\section{Dentalium.}

\section{Genus 1. DENTALIUM, Limnaus.}

Animal; clongated, attached to the shell near its hinder extremity; head rudimentary, eyeless and without tentacles, cirrhated on the lip; mantle circular, thick and fleshy in front, thin posteriorly, capable of investing the entire frontal part of the body; foot placed centrally and anteriorly, consisting of a pointed cone, flanked by two symmetrical side-lobes mounted on a long pedicle. (Forbes.)

Shell; tubular, regular and symmetrical, smooth or futed, and more or less curved, attenuated posteriorly, open at both ends, anterior aperture, which is the larger, simple and generally oblique; posterior also simple, sometimes slit on the convex side.

The Dentalium embraces a curious compound of affinities. It is a gastropod partaking of the characters of the Limpet; its shell may be likened to that of a smooth or fluted Fissurella pushed out, by a stretch of the imagination, telescope-fashion, into a curved tube. It has the conical foot of some of the bivalves; and as if presenting a passage to those headless mollusks, the head of Dentalium exists only in a rudimentary form, without tentacles or eyes. Again, there are traces of affnity with the Annelides. Apart from the consideration of the tubular form of the shell, which induced buth Cuvier and Lamarck to class Dentalium with the 
shell-worms, the animal, like them, is of worm-like configuration, and redblooded.

The Dentatium shells are mostly white, but there are some brilliant cxceptions from the Eastern Seas in D. elephantinum, aprinum, and formosum. The last, collected by Sir Edward Belcher outside a coral reef, near the city of Sooloo, at a depth of sixteen to trenty fathoms, is especially beautiful in colour. It is of large fluted growth, richly variegated with rose and olive-green.

We have two Dentalia in the British Seas, one $D$. entalis, a northern species, the other, D. Tarentinum, a southern species passing into the Mediterranean.

\section{Species.}

1. abbreviatum, Desh. $\quad$ 13. formosum, $A d$. \& $R$. 24. pseudo-sexagonum, $D e$.

2. acuminatum, $i d$.

14. Indicum, Chemn.

25. quadrangulare, Sow.

3. ambiguum, Chemn.

15. inversum, Desh.

26. rubescens, Desh.

4. aprinum, Linn.

16. lacteum, $i d$.

27. sectum, $i d$.

17. Lessoni, $i d$.

28. splendidum, Sow.

6. bicarinatum, Desh.

18. longitrorsum, Reeve.

29. strangulatum, Desh.

7. dentalis, Linn.

8. eburneum, $i d$.

19. nebulosum, Linn.

30. striatum, Lam.

20. novem-costatum, Lam. 31. subulatum, Desh.

9. elephantinum, $i d$.

21. octogonum, $i d$.

32. tesseragonum, Sow.

22. perpusillum, Sow.

23. politum, Linn.

33. translucidum, Desh.

34. variabile, $i d$.

11. entalis, Linn.

12. fissura, Lam.

\section{Figure.}

Dentalium elepmantinum. Pl. 25. Fig. 14.8. Shell of an exotic fluted species, the largest of the genus, showing that it is open at the apex, as well as at the base.*

* Since the publication, in 1852, of the Family Turbinacea, attention has been given to a group of minute mollusks, the Cecida, with tooth-like shells, classed hitherto under Dentalium, but shown, through the anatomical researches of Mr. Clark, to have the nearest relationship with Turritella. Prior to the elucidation, by Forbes and Hanley, of the two British species of Cacum, embodying the results of Mr. Clark's dissection, the phenomenon of an unconvoluted Gastropod, without any indication of the spiral which commences in Vermetus, was a kind of zoolo. gical puzzle to naturalists; one referred it to the Cephalopods, another to the Petropods, and another to the Annelides. Among the shells from Mazatlan, described by Mr. Philip Carpenter, and deposited in the British Museum, a great many Caca were found, and in a monograph of the genus published in the 'Proceedings of the Zoological Society' for 1858, he gives characters of as many as forty-three species. 


\section{Order 7. NUCLEOBRANCHIATA.}

Branchix; phumose, forming, in connection with the visceral organs, an extemal nucleus, capped with a delicate glassy shell.

The gelatinous swimmer, represented in Plate $K$, appears to have little of the character typical of the class Gasteropoda, but the natatory fin of Carinaria is supposed to be the equiralent or homologue of the Snail's locomotive disc. The branchie form part of a nucleus which, it may be observed, is quite external to the body, and they communicate with the head and mouth by means of a long connecting gut.

\section{Carinaria.}

\section{Genus 1. CARINARIA, Lamarck.}

Animal; body gelatinous, swollen, prickly, a little compressed at the sides, attenuately acuminated posteriorly; head prolonged into a trunk armed with symmetrical hormy processes; tentacles turo, having at the base of euch a conspicuous eye; visceral mass and branchia contained in an outer nuclens communicating by a gut with the mouth; covered by a transparent ylassy shell; below the body is a vertical fin.

Shell ; cap-shaped, very thin, liyaline, corrugate, attemuted into a hooked rertex, funished along the back with a keel, which is either simple or toothed.

The 'Glassy Nautilus,' as the delicate transparent shell of Carinaria has been long erroneously called, is, perhaps, the most remarkable production in the whole conchological series. The Carinaria is a swollen transparent mass of gelatine, having a well-developed head, with tentacles and eyes and a powerfully-armed proboscis for the seizure and elimination of food; but the viscera and branchire are gathered into a nucleus outside the upper dorsal part of the body, communicating with the proboscis by a long attenuated kind of gut; and attached to this nucleus, like a cap, is the wellknown delicate little glassy shell. Beneath the gelatinous body is a vertical natatory fin, and the animals congregate and swim about rapidly at night, with Firola and other shell-less mollusks of similar character, resting occasionally by the aid of a sucker, which may be observed on the hinder part of the fin.*

* "The Carinaria tribe," writes Dr. Johnston, in his own delightful style, "need occasional repose and cessation from activity - and how admirably is the foreseen want provided against! 
The largest species, $C$. vitrea (C. gracilis, milhi), has been captured in the vicinity of the Moluccas, and a small species, $C$. Atlantica, was taken by Sir Edward Belcher at twilight, in the trawl, in the North Atlantic Ocean. M. D'Orbigny describes a third species in his South American Voyage, and there is the well-known species, C. fiagilis, of the Mediterranean.

\section{Species.}

1. Atlantica, $A d$. \& $R$. 3. punctata, D'Orb. 4. vitrea, Lan.

2. fragilis, Bory.

\section{Figure.}

Carinaria fragilis. Pl. $K$. Animal, showing its thick gelatinous substance; head with eyes and tentacles; proboscis and narrow gut leading to the dorsal nucleus covered by the shell, from which extend in feathery plumes the branchix. Beneath the body is the natatory fin. From a specimen in my possession, cast ashore after a storm at Messina, and brought from thence by the Rev. L. B. Larking.

\section{Class 3. PTEROPODA.}

Animal; pelaric, subgelatinous; abdominal portion of the body sometimes enclosed within a shell; head, where there is a shell, indistinct, with or without tentacles; mantle large and thin, attached on either side like a vinged membiane; natatory disk also wing-like; branchia pectinate, lodged in a cavity.

Shell; thin, horny or glassy, sometimes cartilaginous, variously shaped, globose, triangular, cylindrical or needle-like, sometimes cuspidate or sharply long-spined.

The Pteropods are a class of oceanic swimmers allied zoologically and in habit to Carinaria. They are very small, limiterl in kind, but abundantly prolific in individuals, and obtain motion by the aid of a pair of wing-like natatory fins. Only part of them are furnished with a shell, which is extremely thin and glassy. "In warmer seas than those which encircle our

where are they to rest-where fix their anchor in the world of unstable water around them? They are created to live and are born amidst the fields of seaweed which voyagers describe with amazement as covering leagues of sea within the Tropics; and to enable them to attach themselves to the narrow leaves of the sargassum, they are furnished by their Creator with a small sucker, which like a cupping-ylass applied against the surface of the leaf, suspends them there without exertion."-Introduction to Conchology, p. 119. 
islands," writes Professor Edward Forbes, * who had frequent opportunities of observing the Pteropods of the Mediterranean and Egean Seas, "the surface of the water, when the weather is calm and the sun is shining, glistens with glassy needles or shelly bubbles. These, upon closer examination, prove to belong to curious mollusks, which instead of creeping over submarine rocks and weeds, or burying in the soft mud and sand of the sea-bed, aspire to a garer and more sportive life, and play the part of Neptune's bees and butterlies." According to the observations of M. D'Orbigny, the Pteropods begin to appear at twilight, and particular species rise to the surface at successive hours of the night. He considers that they inhabit particular zones at different depths, and occupy as many periods of time in making their way to the surface, disappearing again at the approach of day. It would appear from the remarks of Edward Forbes and D'Orbigny that their observations are at rariance; but it is more than probable there are day Pteropods as well as night Pteropods, and that, like the travellers who differed on the colour of the chamcleon, both are equally right. $\dagger$

The Pteropods are only known to the conchologist by a few little glassy slells, of which it is scarcely necessary to particularize the species. The largest are those of Myaliea and Cleotluin, with shells of a globose form, armed with cusps or elongated spines. Curieriu has a small cylindrical shell; in Creseis it is needle-like; and in Atlanta it has the discoidal form of a Nautilus.

\section{Class 4. LAMELLIBRANCHIATA.}

Animal ; bodly a mass of viscera furnished on each side with turo lamella-litie branchice, and cmeloped by a sac or mantle, which secretes on either side a shelly valve, connected at the dorsal margin by an elastic horny ligament; no distinct head or eyes; mouth represented by a simple opening in the front part of the mantie; hind part of the mantle opened, with the edges some-

* Brit. Moll. vol. ii. p. 377 .

$\dagger$ Dr. Johnston gires a most picturesque account of the upward flight of the Cleodores, "when the garish eye of day begins to dawn," and of the gradual appearance of the Hyales, "who do not leare the abyss and mingle in the crowd until night lends them her friendly veil." Mr. Godwin-Austen's humour is of a rougher hind. In his coutinuation of Forbes' 'Natural History of the European Seas, 'the Pteropods are described as leading a life of dissipation. The sundelighting bees and buttertlies of the Agean, whose characters have been hitherto irreproachable, are likened to gnats and moths who "shun the light, and if the sun is bright you may look in rain for them during the live-long day. Hyalae tridentata, though it does not venture out till dusk, retires early, whilst some species, such as Cleodora pyramidata, are to be met with only during the midnight hours and the darkest nights. This tribe, like a higher one, has its feir irregular spirits who manage to keep it up the whole night through. All, however, are back to their homes before dawn surprises them." 
times prolonged into two tubes, from one of which water is inhaled, throngh, the other ejected; internal muscles adliering to the shells, sometimes two to each valve, sometimes only one; a muscular oryan or foot developed on the ventral side of the viscera in some of the two-muscled linds, and more or less exserted. Shell; alworys bivalve, the valves hinging together by the aid of an elastic ligament, and by interlocking teeth.

In descending the series of univalve mollusks through the classes of Cephalopods, Gastropods, and Pteropods, we have advanced by tolerably natural gradations, designating the respective groups by the peculiarities of the organ of locomotion. In the bivalve mollusks the fort is at first absent, or only rudimentary, and the animal is of widely different organization, and of widely different habits. Lamarck distinguished them as a separate class of invertebrate animals, adopting the name Conchifera, to signify that all are shell-bearing; Cuvier introduced the negative appellation of Acepluta, or headless, because they have either no head, or only a very indistinct representative of one. De Blainville, and subsequently Owen, selecting a character which is present, and at the same time peculiar, throughout, the lamellar structure of the branchire, designated the class Lamellibranchiata.

The Lamellibranchiate Mollusca are then, as any one ahout to partake of an oyster may observe, a mass of viscera lying in the bed of a pair of shells, furnished on each side with two elaborate gills in the form of vascular lamelle, commonly known as the beard, and over these is a sac or mantle, in two lobes, the calcifying organs of the animal, each secreting a shell. The shells, or valves, are joined at the dorsal margin by interlocking tecth, and by the aid of an elastic ligament, which has a tendency to open the shell, in opposition to the artion of a pair of internal muscles, or of two pairs, by which the animal closes it. The Lamellibranchiates, or Bivalves, as they are more commonly called, are all water animals, and have for the most part a sort of tadpole existence in early life. All are oviparous, and when escaped from the eggr, commence life with a more or less perfect metamorphosis. Many swim freely about by the help of ribratile cilia, and are provided with eyes which become obsolete when no longer needed. The mouth is simply an opening in the front part of the animal leading to the stomach. It has none of the claracteristics of the mouth in the higher mollusks, but is nevertheless furni-hed with a pair of ielicate labial palps, which are supposed to be organs of taste. The formt, unlike that of the higher mollusks, is narrow and keel-like, and is not so much an organ of locomotion as an organ of general usefulness; its chief employment is digging and burrowing in the sand. The mantle consists sometimes of two disconnected lobes; generally the lobes are united, 
having a ventral opening for the passage of the foot, and a double opening behind for the purposes of inlaling and cxcretion, of which the margins are in many genera prolonged into siphons.

The shells of the Lamellibranchiates, present forms and varieties of the highest interest to the conchologist, aud, as in other genera of mollusks, there are often curious differences of sculpture and colour where there is little apparent specific difference in the animal. The most striking modifications of character are those of the ligament and the hinge. Changes in the development of these are for the most part accompanied by corresponding changes in the objects generally, and they have been universally sclected for the determination of genera. The class may be divided into orders according to the number of the internal adductor muscles :-

Unimusculosa.

Bimusculosa.

\section{Order 1. UNIMUSCULOSA.}

Shell; attactied to the animal by a single central muscle.

In this division, comprising the Oysters, Scallops, Mussels, and Clams, the shell is attached to the animal by a strong central muscle, accompanied in some instances by one or more small collateral muscles. Any one who has watched the oyster-vendor at his stall may have observed the force which is required to detach the animal from its shell, when cutting at the muscle. MLany a Lamellibranchiate of small size and of comparatively frail texture possesses a massive shell, and nothing short of great strength in the adductor muscle would serve for closing it. The Order includes five families, as follows :-

Ostracea. Mytilacea. Aviculacea.

Pectinacea. Tridachacea.

\section{Family 1. OS'TRACEA.}

Shell; mostly attached to foreign substances, irregular, foliated or laminated; right valve generally larger than the left valve.

In this family the shells are of an irregular growth, with only a faintlydeveloped linge, and the species are not very readily definable. 'There is considerable apparent difference in the extreme forms of the group, the Anomice and the Ostrece, but they are connected by two intermediate links', Placunanomia and Placuna, in which their peculiarities are very naturally blended. The shell of Anomia is toothless, and the animal attaches itself 
to foreign bodies by a bony plug which passes through the substance of the lower or left valve. In Placunanomia the animal attaches itself also by a bony plug, but the orifice through which it passes is protected by a rude divaricate tooth, or rather double-tooth, which appears in a more symmetrical form in Placuna, where the orifice and plug of adhesion are wanting. Ostrea has neither plug nor hinge.
Anomia.
Placunanomia.
Placuna.
Ostrea.

\section{Genus 1. ANOMIA, Linnaus.}

Animal; body massive, shaped like the shell, with the mantle freely open, having pendent margins bearing a double fringe of short cirrhii; no siphonal tubes; foot very small, often nearly obsolete; adductor muscle divided into three portions, the longest of which attached to a shelly plug passes through an orifice in the lower valve; branchial leaftets doubled on themselves; month surrounded by membranous borders and two pairs of long labial tentacles; sexes distinct.

Shell; generally orbicular, inequivalve, irregular, affixed, sometimes rather solid, mostly very thin, hyatine; lower valve flat, orbicularly perforated and notched near the hinge, perforation filled with a subcalcareous pluy of adhesion; upper valve convex, squamately laminated, striated or ribbed, with three subcentral muscular impressions; linge toothless, with the liganent. short, attached to a callosity.

The Anomice are chiefly remarkable for the manner in which they affix themselves to foreign bodies. The adductor muscle divides into three portions, and the central portion passes out through an orifice in the substance of the shell for the purpose of anchorage, and secretes a bony plug, which serves as an operculum. As in all mollusks of parasitic habits, the shell varies exceedingly in the same species, becoming more or less shaped to the irregularities of its place of attachment. If growing upon a ribbed surface, the shell assumes a ribbed structure; but the ribs formed under these circumstances are not characterized by the definition which belongs to a species that has a natural ribbing of its own.

There is, perhaps, more difficulty in discriminating between the different states of a species incident to age and habitat. The well-known $A$. ephippium of the European Seas has been described twenty times over. Even of the nine recent dnomice described by Lamarck, eight are supposed to 
be different states of A. eplippium. Suppressing all these, the genus is now rich in species of fine size and brilliant colour from Australia, California, Peru, and the Galapagos, Sandwich, and Philippine Islands.* The following have been recently described and figured in the 'Conchologia.'

\section{Species.}

1. Achrus, Gray.

2. Acontes, $i d$.

3. aculeata, Miïl.

4. adamas, Gray.

5. xnigmatica, $\mathrm{C} /$.

6. Alectus, Gray.

7. amabxus, $i d$.

8. argyritis, Reeve.

9. cælata, $i d$.

10. costata, id.

11. cytæum, Gray.
12. Dryas, $i d$.

13. elyros, $i d$.

14. ephippium, Linn.

15. fidenas, Gray.

16. hamillus, $i d$.

17. Humphreysiana, $R$.

18. lampe, Gray.

19. laqueata, Reeve.

20. larbas, Gray.

2L. lucerna, Reeve.

22. malleata, $i d$.
23. metallica, Reeve.

24. nobilis, $i d$.

25. pacilus, Gray.

26. placentella, Reeve.

27. plenilunium, $i d$.

28. ramosa, $i d$.

29. scabra, $i d$.

30. sol, $i d$.

31. spinosa, $i d$.

32. strigilis, $i d$.

33. Tyria, id.

\section{Figure.}

A vomia ADAmas. Pl. 26. Fig. 156. Shell, showing the perforated under valve of a bright transparent reddish-orange species, found by $\mathrm{Mr}$. Cuming at Lord Hood's Island in the Pacific, affixed to a shell of the large Avicula margaritifera.

\section{Genus 2. PLACUNANOMIA, Broderip.}

Animal; similar to that of Anomia.

Shell; nearly equivalie, irregular, thin, sometimes rather solid, generally smooth; hinge internal, composed in the lower valve of two converging teeth, in the upper of two ligamentary grooves; lower valve fissured, or triangularly perforated near the linge, perforation descending from the linge, admitting a partially bomy muscle of adhesion which sometimes insinuates itself between the lamine of the shell.

In this genus, as in Anomia, a portion of the adductor muscle passes

* The Anomia anigmatica was found abundantly by Mr. Cuming at the Philippine Islands attached to Mango-trees and Nipa Palms, growing between tides on the sea-shore. 
out for the purpose of anchorage, through a perforation in the lomer valve, but the orifice, instead of being open to the hinge, is soldered across the top by a rude triangular ridge, or pair of converging tecth, of which a more symmetrical development appears in the hinge of Plucuna. In the curious species from central America, Placunanomia Cuningii, upon which the genus is founded, the orifice is very contracted, and the calcifying muscle insinuates itself between the laminx of the shell depositing a plate there; but this is only a peculiarity of the species. Taking the soldering triangular ridge as the distinguishing characteristic of the genus, a series of fourteen species become associaterl together, all of which may be recognized at a glance from the true Anomia.

The greater part of the Placunanomia are from the Central American continent and the West Indies, but there are some fine species from Australia and New Zealand, and the old Limman Anomia putelliformis of our own shores comes into the group.

\section{Species.}

1. abnormalis, Gray.

2. alope, $i d$.

3. Australica, Reeve.

4. cepio, Gray.

5. Cumingii, Brod.
6. echinata, Brod.

7. foliata, id.

8. Gouldi, Reeve.

9. Harfordi, $i d$.

10. ione, Gray.
11. macrochisma, Desh.

12. patelliformis, Linn.

13. rudis, Brod.

14. Zealandica, Gray.

\section{Figure.}

Placunanomia ione. Pl. 26. Fig. 157. Shell, turned over to show that the orifice compared with that of Anomia, in the adjoining figure, is soldered across the top. The orifice is partially filled up by the plug of adhesion. The converging hinge-teeth being internal, are not seen in the figure, but some idea of them may be gathered from the tooth of Placuna shown in Fig. 158.

\section{Genus 3. PLACUNA, Bruguière.}

Animal; unknown.

Shell; nearly equivalve, thin, semitiansparent but firm, comparatively smooth; linge consisting of two slender vidges in the lower valve, converging at the ligamentary margin.

In this genus are comprised the few large semitransparent shells comvOL. II. 
monly known as Saldle Ojsters, from their peculiar saddle-shaped bend, and Chinese 1 indow Oysters, from the circumstance of their being used by the poorer inhabitants of the Celestial Empire for glazing windows. The valves press so closely one upon the other that it would scem scarcely possible for the animal to be able to close its shell, and until a living specimen falls into the hands of a malacologist skilful enough to observe it, the habits of Placuna in this respect must remain a mystery.

The converging tooth-like ridges of the hinge are a conspicuous feature of the genus; and the ligament rests partly on these and partly along the hinge margin on either side of the umboes.

\section{Species.}
1. Lincolnii, Gray.
3. placenta, Linn.
4. sella, Gmelin.

2. papyracea, Lam.

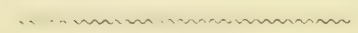

Figure.

Placuna placenta. Pl. 27. Fig. 15S. Shell, of a small specimen, with the upper valve removed, to show the converging ridges of the linge.

\section{Genus 4. OSTREA, Limnaus.}

Animal; edlyes of the mantle double, and each bordered by short tentacular fringes; branchial leaflets not doubled on themselves; labial appenduges triangular, comnected around the mouth by a plain membrane; no foot.

Shell; afficed, inequivalve, irregular, with the umboes mostly very unequal and divaricate, receating fiom each other with the growth of the shell; lower valve the larger, convex; upper valve generally rather flat; linge toothless, with the ligament, either internal or semi-internal, atfached to the umbonal area.

The renowned mollusks of this genus produce shells of such irregular growth that nothing short of a baronetcy, it has been said, will ever induce a conchological commoner to monograph them. Their habit of getting into nooks and crevices when young, though in their metamorphic destiny denied the power of escape, obliges them to build their shell in all sorts of improbable places, and the result is a dislocation of forms and characters 
which make the species extremely difficult to recognize. If they cannot "add colours to the chameleon," they can, at lenst, "change shapes with Proteus." They cluster one upon another, vary the development of the shell according to the situation of their place of attachment, and when affixed to sticks and stems, throw out shelly protuberances to cling by. As if to compensate, however, for these deformities, there is a species dear to Europeans, the only one inhabiting Britain, which has been cultivated from the earliest dawn of epicureanism for its delicacy of taste, and it is not improbable that some of the exotic species may be equally delicious.*

Among the more constant specific forms of Ostrea may be mentioned O. carinata and crista-galli, in which the margins interlock in deep zigzag undulations, and a Philippine species, regarded as the living representative of Lamarck's fossil genus Gryphea. In this the umbonal area of the lower valve, which in most species more or less recedes by successive layers of growth from the umbo of the upper valve, curves over, like an inverted Roman lamp.

\section{Species.}

\section{Adriatica, Lam.}

2. bicolor, Hanley.

3. borealis, Lam.

4. callochroa, Hanley.

5. Chemnitzii, $i d$.

6. circumsuta, Gould.

7. cochlear, Poli.

8. Columbiensis, Hanley.

9. conchaphila, Carp.
10. cornucopiæ, Lan.

11. crista-galli, Linn.

12. cristata, Born.

13. cucullata, $i d$.

14. Cumingiana, Dunk.

15. Cyrnusii, Payr.

16. deformis, Lam.

17. denticulata, Born.

18. discoidea, Gould.
19. edulis, Limn. 20. elliptica, Lam.

21. excavata, Zid.

22. frons, Linn.

23. fucorum, Lam.

24. gallina, $i d$.

25. gibbosa, $i d$.

26. glomerata, Gould.

27. guineensis, $D z n k$.

* "The Ostrea edulis may be said to have its capital in Britain, for though found elsewhere on the coasts of Europe, both northwards and southwards, in no part of them does it attain such perfection as in our seas, through which it is generally distributed, sparingly in some places, abundantly and in gregarious assemblages in others, chiefly inhabiting the laminarian and coralline zones. The ancient Romans valued our native oysters even as we do now, and must have held them in higher estimation than those of Italian shores, or they would not have brought them so far for their luxurious feasts. Juvenal records the exquisite taste of the epicure :-

$$
\text { " "Who }
$$

At the first bite each oyster's birth-place knew ;

Whether a Lucrine or Circæan he 'd bitten,

Or one from Rutupinian decps in Britain." "

Although Juvenal sang the praises of the British oyster in the foregoing passage, (Satires iv. 140,) so wittily translated by Professor Forbes (History of the British Mollusca and their Shells, vol. ii. p. 310), it has often excited the wonder of philosophers how any one should have had courage to make the first gulp of so repulsive an object. Byron, we believe, among others, says :-

"That man had sure a palate covered o'er

With brass or steel, that, on the rocky shore,

First broke the oozy oyster's coat,

And risked the living morsel down his throat." 
28. haliotidea, Lam.

29. hippopus, $i d$.

30. hyotis, Chemn.

31. imbricata, Lam.

32. iridescens, Gray.

33. labrella, Lam.

34. lacerata, Hanley.

35. margaritacea, Lam.

36. megadon, Hantey.

37. Mytiloides, Lam.

38. mordax, Gould.
39. multistriata, Hanley. 49. Sinensis, Gmel.

40. numisma, Lam. 50. sinuata, Lam.

41. pes-tigris, Hanley. 51. spathulata, $i d$.

42. plicata, Chemn. 52. spinosa, Quoy.

43. pyxidata, $A d$. \& $R$. 53. stentina, Payr.

44. rosacea, Desh.

45. rostralis, Lam.

46. ruscuriana, $i d$.

47. scabra, $i d$.

48. Senegalensis, Gmel.
54. trapezina, Lam.

55. tuberculata, $i d$.

56. turbinata, $i d$.

57. Virginica, Gmel.

58. Webbii, Recluz.

\section{Figure.}

Ostrea bicolor. P1. 26. Fig. 159. Shell, with the upper valve lifted on one side to show the hinge.

\section{Family 2. PEC'IINACEA.}

Shall; either fiee or affired, mostly inequivalve, generally auriculated on cither side of the umbo; ligament internal or semiinternal, within a central triangular pit.

The Pectinacen are numerous in species, and have shells remarkable for their elaborate sculpture and brilliant varieties of painting. The Spondyli, in which the umbonal area noticed in Ostrea has its maximum development, thrors out spines and fronds more profuse and sharply attenuated than in any other genus of lamellibranchiates; and the Pectens, distinguished by a beautiful regularity of growth and vivid colouring, present the first indication of the byssus which is so conspicuous a characteristic in the trro succeeding families Aviculacea and MIytilacea. Linked with these are two or three rather abnormal though intermediate forms of striking interest. The genera are-

\begin{tabular}{|c|c|}
\hline Spondylus. & Hinnites. \\
\hline
\end{tabular}

\section{Genus 1. SPONDYLUS, Linnaus.}

Animal; orat or oblong; edges of the mantle disunited, thick, furnished with numerous rows of tentacular cirrli, of which 
several are truncated, terminated by a smooth convex surface; mouth oval, furnished with large divided lips, having on each side a pair of oblong-pointed labial palps; branchice doubled over, formed of detuched filaments; foot ructimentary, with a club-like pedicle at its disc. (Deslunyes.)

Shell; afficed, inequivalve, irregular, more or less auriculated, radiately striated and ridged, rarely ribbed, variously prickled and spined; umboes equal, separated by a very large fat area, more and more produced with age; linge, with two solid recurved teeth in each valve, strongly interlocking and receiving the ligament between them.

One of the first shells that attracted the attention of the Father of $\mathrm{Na}$ tural History on the shores of the Mediterranean was the beautifully spined Thorny Oyster, Spondylus gataropus. There it still lives in all its royal panoply of purple and white; and the name which Aristotle gave to it more than two thousand years ago remains to this day. Nearly seventy species from different parts of the globe are now associated with it in the genus, and all have their peculiar type of form and sculpture. The growth of the Spondyli varies, like that of the Ostrea, according to the irregularities of their place of attachment, but the shell is of firmer substance, and the larger concave valve being the lower, the upper valve is left free for the development of the variously ramified fronds, spines, and prickly scales by which the species are so profusely ornamented.

It is curious to observe how in many Spondyli the upper valve advances with the animal in its progress of growth without change, while the lower valve, being affixed, is added to by successive layers upon layers. An umbonal area is often thus formed of very considerable extent, the hinge and ligamentary pit being pushed forward with the advancing growth; and water sometimes becomes hermetically sealed betreen the layers, moving as freely between them as in a spirit-level. The following is a list of the Spondyli described and figured in the 'Conchologia.'

Species.

1. aculeatus, Chemn.

2. affinis, Reeve.

3. albibarbatus, $i d$.

4. Americanus, Lam.

5. asperrimus, Sow.

6. aurantius, Lam.
7. barbatus, Reeve.

8. basilicus, $i d$.

9. Butleri, $i d$.

10. camurus, $i d$.

11. candidus, Lam.

12. castus, Reeve.
13. ciliatus, Brod.

14. coccineus, Lam.

15. croceus, Chemn.

16. Cumingii, Sow.

17. cuneus, Reeve.

18. digitatus, Sow. 
19. ducalis, Chemn.

20. electrum, Reeve.

21. erinaceus, $i d$.

22. flabellum, $i d$.

23. foliaceus, Chemn.

24. fragilis, Sow.

25. fragum, Reeve.

26. gilvus, $i d$.

27. Gussoni, Costa.

28. gædaropus, Linn.

29. histrix, Reeve.

30. ictericus, $i d$.

31. imbutus, $i d$.

32. imperialis, Chemn.

33. Lamarckii, $i d$.

34. Layardi, Reeve.

35. leucacantha, Brod.
36. limbatus, Sow.

37. lingua-felis, $i d$.

38. lougitudinalis, Lam.

39. microlepos, $i d$.

40. multimuricatus, $R$.

41. multisetosus, $i d$.

42. mus, Chemn.

43. Nicobaricus, $i d$.

44. nudus, $i d$.

45. nux, Reeve.

46. ocellatus, $i d$.

47. Pacificus, $i d$.

48. pictorum, Chemn.

49. plurispinosus, $R$.

50. princeps, Brod.

51. radula, Reeve.

52. ramosus, $i d$.
53. regius, Limn.

54. rubicundus, $R$.

55 . setiger, $i d$.

56. Sinensis, Sow.

57. spectrum, Reeve.

58. tenebrosus, $i d$.

59. tenellus, $i d$.

60. tenuispinosus, Sow.

61. unicolor, $i d$.

62. ustulatus, Reeve.

63. varians, Sow.

64. variegatus, Chemn.

65. vexillum, Reeve.

66. violaceus, $i d$.

67. virgineus, $i d$.

68. zonalis, Chemn.

\section{Figure.}

Spondylus croceus. Pl. 27. Fig. 160. Shell, illustrative of the vividcolouring and branching sculpture of the genus, but showing only a small development of the umbonal area.

\section{Genus 2. PLICATULA.}

Animal; supposed to be simitar to that of Spondylus.

Shell; afficed, irregular, inequivalie, attemated towards the linge, not auriculated; margins mostly plicated; unboes unequal; no unbonal area; hinge composed of two strong teeth in each valve closely interlocking.

The genus Plicatula comprises only a few recent species, but it holds an important place in fossil conchology, and the species are distinguished by a marked uniformity of character. Like Spondylus, the hinge consists of two pairs of closely-interlocking tecth; no umbonal area is, however, formed as in that genus, and the shells are uniformly small, characterized by a speciality both of sculpture and colour. There is no indication of fronds or prolonged spines, and the shell is always of a dull reddish-brown, unrelieved by any variety of painting.

The species are from Western America, Australia, and the Philippine Islands. 
Species.

1. australis, Lam.

2. cristata, $i d$.

3. deltoidea, Dunk.
4. depressa, Lam.

5. lineata, Recluz.

6. penicillata, Carp.
7. plicata, Forsk.

8. regularis, Phil.

9. reniformis, Lam.

\section{Figure.}

Plicatula Philippinardar. Pl. 27. Fig. 161. Shell, with the upper valve dropped to show the strongly-toothed hinge, and the absence of umbonal area.

\section{Genus 3. HINNITES, Defrance.}

Animal; supposed to be similar to that of Spondylus.

Shell ; afficed, inequivalve, thick, ponderons, slightly auriculated; hinge and umbonal area in both valves broad and toothless, with a central, rather deep, oblong-triangular pit containing the ligament.

We have seen that Plicatula has the tecth of the Spondylus, but no umbonal area. Hinnites has the umbonal area of that genus, but no teeth; it moreover resembles Spondylus in the size and massiveness of its growth. The genus was founded originally from two fossil species. The two recent species referred to it are shells of great rarity in the collection of the British Museum,- -one described by Dr. Gray, in the 'Annals of Philosophy,' the other by Mr. Sowerby, in the 'Zoological Journal.' Both are figured in vol. viii. of the 'Conchologia.' An attaching species of Pecten (Ostrea pusio, Limn.) has been referred to this genus, but it has little or no participation in its characters.

\section{Species.}

1. corallinus, Sow.

2. giganteus, Gray.

\section{Genus 4. PECTEN, Bruguière.}

Animal; shaped as the shell; mantle freely open, with pendent margins, bearing, usually two, fringes of tentacular filaments, the one series at their fixed, the other at their free border. 
Among the former are ranged globular, stining ocelli; no siphonal tubes; foot small, cylindrical, with a byssal groove from which a weak byssus is spun, mostly when the animal is young; mouth surrounded by foliaceons leaflets and two pairs of labial tentacles, which are smooth externally, pectinated internally; branchial leaftets equal, each pair partially doubled on itself. (Forbes.)

Shell ; ravely affired, more or less orbicular, regular, inequivalve, nearly equilateral, unequally auriculated on cither side of the linge, sometimes a little gaping, mostly symmetrically rayed with ribs or vidlyes; unboes approximated, without any intervening area; linge toothless, with a marginal ligament, and a central internal solid ligament in a deep triangular pit; a more or less distinct byssal sinus in one valve.

In all collections of British shells the Pectens occupy a conspicuous place as the most gaily painted of bivalves; but the British species, with their attractive varieties of colour and pattem, are but as the bramble beside the rose when compared with the Harlequins, Ducal Mantles, and other elaborately scaled and intensely brilliant species of exotic climes. Lamarck, while enumerating as many as fifty-nine species of Pecten, described it, in the plenitude of his enthusiasm, as "le beau et immense genre." Now we have even finer species, and three times as many; and so nicely balanced are the general affinities between them, that conchologists have failed to establish more than two received subdivisions, - the sections Vola and Amusium.

The Pectens live at various depths, and move, either alone or in groups, with a jerking motion by the rapid opening and shutting of their valves.* When at rest they spin a slight byssus from the foot. The shell, which is of lighter substance than in the preceding genera, is developed in radiations, like a pleated fan, with the utmost symmetry and order, and the painting of the lower valve is oftentimes little less brilliant than that of the upper. By the older writers Pectens were called indifferently Scallops, and sometimes Cockles; and the Pecten Jacobcaus, named in honour of St. James, was worn as an emblem by the pilgrim journeying to the Holy

* Dr. Landsborough, the well-known Scottish naturalist, writes :- "We observed on a sunny September day in a pool of sea-water, left on Stevenston Strand by the ebbing tide, what we at first thought some of the scaly brood at play. On close investigation, however, we found that it was the fry of Pecten opercularis skipping quite nimbly through the pool. Their motion was rapid and zigzag, very like ducks in a sunny blink rejoicing in the prospect of rain. They seemed, by the sudden closing and opening of their valves, to have the power of darting like an arrow through the water. One jerk carricd them some yards, and then by another sudden jerk they were off in a moment in a different tack."-Scottish Christian Herald, vol. ii. p. 165. 
City, and is still conspicuous in the heraldry of those whose ancestors are said to have been pilgrims.*

\section{Species.}

1. albo-lineatus, Sow.

2. altus, Reeve.

3. argenteus, $i d$.

4. asper, Sow.

5. asperrimus, Lam.

6. asperulatus, $A d$. \& $R$. 40. Fabricii, Phil.

7 . aurantiacus, $i d$.

8. Australis, Sow.

9. arthriticus, Reeve.

10. bifrons, Lam.

11. blandus, Reeve.

12. Bruei, Payr.

13. circularis, Sow.

14. clavatus, Poli.

15. cloacatus, Reeve.

16. concinnus, $i d$.

17. corallinoides, $D^{\prime} O r^{\prime} b$.

18. corneus, Soro.

19. coluscans, Hind.

20. crassicostatus, Sow.

21. cretatus, Reeve.

22. cristularis, $A d . \& \cdot R$.

23. crotilus, Reeve.

24. cruentatus, $i d$.

25. cuneatus, $i d$.

26. cuneolus, $i d$.

27. Cumingii, $i d$.

28. daucus, $i d$.

29. Danicus, Chemn.

30. Darwinii, Reeve.

31. denticulatus, $A d$. \& $R$.

32. dentatus, Sow.

33. Dieffenbachi, Gray.

34. digitatus, Reeve.
35. distans, Lam.

36. Dringi, Reeve.

37. effulgens, $i d$.

38. erubescens, $i d$.

39. exasperatus, Sow.

41. fasciculatus, Reeve.

42. filosus, $i d$.

43. flabelloides, $i d$.

44. flexuosus, Poli.

45. floridus, Hinds.

46. fricatus, Reeve.

47. fucatus, $i d$.

48. fulvicostatus, $A d$. \&. $R$.

49. funebris, Reeve.

50 . fumatus, $i d$.

51. fuscus, Klein.

52. gemmeus, Reeve.

53. gemmulatus, $i d$.

54. gibbus, $\operatorname{Lin}$.

55. glaber, $i d$.

56. gloriosus, Reeve.

57. hastatus, Sow.

58. histrionicus, Gmel.

59. hyalina, Poli.

60. Idæus, Reeve.

61. imbricatus, Gmel.

62. inæquivalvis, Sow.

63. irradians, Lam.

64. irregularis, Sow.

65. Islandicus, Müll.

66. Jacobæus, Lin.

67. Japonicus, Gmel.

68. laqueatus, Sow.
69. larvatus, Reeve.

70. latiauritus, Conrad.

71. Laurentii, Gmel.

72. Layardi, Reeve.

73. lemniscatus, $i d$.

74. lentiginosus, $i d$.

75. leopardus, $i d$.

76. leucophæus, $i d$.

77. limatula, $i d$.

78. lividus, Lam.

79. luculenta, Reeve.

80. Madreporarum, Petit.

81. Magellanicus, Gmel.

82. magnificus, Sow.

83. maximus, Lin.

84. medius, Lam.

85. miles, Reeve.

86. miniaceus, Lam.

87. mirificus, Reeve.

88. modestus, $i d$.

89. mollitus, $i d$.

90. multicostatus, $i d$.

91. mundus, $i d$.

92. muscosus, Wood.

93. nasans, Phil.

94. nobilis, Reeve.

95. nodosus, Lin.

96. Novæ-Zelandiæ, Rve.

97. nucleus, Born.

98. nux, Reeve.

99. obliteratus, Lin.

100. opercularis, $i d$.

101. ornatus, Lam.

102. pallium, Lin.

* Ophelia sings :-

"How should I your true love know

From another one?

By his cockle-hat and staff,

And his sandal shoon."

And Scott, describing the Palmer in Marmion,-

"The scallop shell his hat did deck."

VOL. II. 
103. parvus, Sow.

104. Patagonicus, King.

105. pes-anatis, Reeve.

106. pes-felis, Lin.

107. pica, Reeve.

108. pictus, Sow.

109. pleuronectes, Lin.

110. plica, $i d$.

111. proteus, Solander.

112. prunum, Reeve.

113. pseudanusium, Klein.136. solidulus, Reeve.

114. pseudo-lima, Sow.

115. pulchella, Reeve.

116. purpuratus, Lam.

117. pusio, Lin.

118. pyxidatus, Born.

119. radula, Lin.

120. Reevei, Adans.

121. reticulatus, Reeve.

122. roseo-punctatus, $i d$.

123. rubidus, Hinds.

124. rufiradiatus, Reeve.

125. rugosus, Solo.

126. russatus, Reeve.

128. saniosus, Reeve.

130. sentio, Reeve.

131. sericeus, Hinds.

132. serratus, Sow.

133. Sinensis, $i d$.

135. solaris, Born.

137. Sowerbyi, $i d$.

138. speciosus, $i d$.

139. spectabilis, $i d$.

140. spectrum, $i d$.

141. spiniferus, Sow.

142. splendidulus, $i d$.

144. squamosus, $i d$.

145. stellatus, Reeve.

146. Strangei, $i d$.

147. subnosus, Sonv.

148. subplicatus, $i d$.
149. subrufus, Turton.

127. sanguinolentus, Gmel. 150. sugillatus, Reeve.

129. senatorius, Gmel.

134. Singaporinus, $i d$.

143. squamatus, Ginel.
151. sulcatus, Bom.

152. superbus, Sow.

153. tegula, Wood.

154. tenellus, Reeve.

155. tenuigranosus, $i d$.

156. testudineus, $i d$.

157. textilis, $i d$.

158. tigrinus, Miill.

159. tigris, Lam.

160. tinctus, Reeve.

161. Tranquebaricus, Gmel.

162. triradiatus, Reeve.

163. undulatus, Sow.

164. unicolor, Lam.

165. ustulatus, Reeve.

166. varius, $\operatorname{Lin}$.

167. velutinus, Sow.

168. ventricosus, $i d$.

169. vestalis, Reeve.

170. vexillum, $i d$.

171. ziczac, Lin.

\section{Figure.}

Pecten bifroxs. Pl. 27. Fig. 162. Shell, of an exotic species, showing its auriculated hinge and symmetrically rayed growth.

\section{Genus 5. HEMIPEC'TEN, Adams and Reeve.}

Animal ; unknown.

Shell ; orbicular, very thin, lyaline, concentrically lineated; lover valve flat, auriculated posteriorly, with a cieep byssal sims, having the opposite margin finely denticled; npper valve convex, scarcely aniculated; linge toothless, with a marginal ligament, and a sma?l central internal ligament in a somewhat superficial pit.

During the cruise of the 'Samarang' among the islands of the Eastern Archipelagoes in 1843-6, under the commant of Capt. Sir Edward Belcher, two semitransparent hyaline shells, about an inch and a quarter in diameter, were dredged off the Island of Sooloo, partaking curiously of the 
characters of two genera not hitherto reckoned very closely allied, Pecten and Anomia. They appeared to be varieties of one and the same species, although on being submitted to Dr. Carpenter for microscopic examination, he detected a rudimental sculpturing over the whole of the visible external surface of one of them which is wanting in the other. In form and general outline, and in the structure of the hinge, Hemipecten, as the name given to this shell denotes, resembles the preceding genus; but in substance, and in its habit of being affixed to its place of attachment by the Aat valve, it resembles Anomia; and a consideration of this affinity has led to the observance by Professor Forbes of relations of more physiological import.* From the circumstance of the lorer valve being perforated by a deep sinus, of which there is no corresponding growth in the upper, it might be compared with Pedum; but in that genus, which lives imbedded in madrepore, the habits of the animal are different, and the shell has an umbonal area, like that of Spondylus.

The two specimens (now in the collection of T. Lombe Taylor, Esq.) were obtained from a coral and stony bottom at the depth of about fourteen fathoms. The under valve of each is smooth, showing it to have been affixed, the upper valve, covered, in part, in both specimens with particles of coral and parasitic shells, is in one smooth and colourless, in the other decussately wrinkled and delicately rayed with orange-red.

\section{Species.}

1. Forbesianus, Adams \& Reeve.

(Figured in the Mollusca of the Voyage of the Samarang, Pl. 20.)

\section{Genus 6. LIMA, Bruguière.}

Animal; oval; mantle fieely open, its margins pendent and fringed with long tentacular filanents; ocelli absent or inconspicuous; no siphlons; body produced, in part linguiform; foot small, lingulate, furnished with a byssul groove; labial palps subtriangular, small, pectinuted; mouth surrounded by tenta-

* "Anomia has really very close relations with Pecten, and is connected to the latter by the curious genus Hemipecten of Reeve. The perforation in one of the valves of Anomia is chiefly a greater extension of the auricular sinus in Pecten, and when the young fry of this genus shall have been carefully observed, we believe they will be found spinning a byssus which, passing throngh this sinus, fixes the shell in the first instance, before a portion of it becoming attached, eventually becomes detached with a part of the adductor muscle, and forms the opercular process." - Forbes and Hanley, Brit. Holl., vol. ii. p. 323. 
cular filaments; anal tube cylindric, externally visible; branchial leaflets equal on each side. (Forbes.)

Shell; nearly equivalve, inequilateral, auriculated, gaping on one side; umboes divaricate, their internal areas being inclined outwards; liinge toothless, but sometimes indistinctly crenulated on either side; ligament partially external, contained in a central triangular pit.

One of the most obvious peculiarities of the Limce is that their shell is of a pure transparent-white substance, sometimes, however, covered with a brown epidermis; and the animal is peculiar in having the mantle fringed with a multitude of long tentacular filaments, which are sometimes of a beautiful scarlet-tinged orange-colour. In form the shell has a close resemblance to Pecten, but the umboes have a tendency to project outwards, and to form, in both valves, an inner area. The species are mostly characterized by a scaly sculpture, and gape, more or less, on the anterior side for the passage of a byssus, by the aid of which it weaves together fragments of coral, and builds a kind of nest for itself.* Three species are British.

\section{Species.}
1. angulata, Sow.
9. fasciata, Linn.
17. rotundata, $i d$.
2. arcuata, $i d$.
10. fragilis, Chemn.
18. Sarsii, Loven.
3. Basilanica, $A d$. \& $R$.
11. hians, Gmel.
19. scabra, Born.
4. bullata, Bom.
12. inflata, Chemn.
20. squamosa, Lam.
5. Caribbæa, $D^{\prime}$ Orb.
13. Loscombii, Leach.
21. subauriculata, Mont.
6. Cumingii, Sow.
14. multicostata, Sow.
22. tenera, Chemn.
7. dentata, $i d$.
15. orientalis, $A d$ \& $R$.
23. ventricosa, Soro.
8. excavata, Chemn.
16. paucicostata, Sow.
24. vulgaris, Link.

\footnotetext{
* Speaking of the Lima hians, Dr. Landsborough says :- "The coral nest is curiously constructed, and remarkably well fitted to be a safe residence for this beautiful animal. The fragile shell does not nearly cover the mollusk, the most delicate part of it, a beautiful orange fringework, being altogether outside of the shell. It is not contented with hiding itself among the loose coral, for the first rude wave might lay it naked and bare. It becomes a marine mason, and builds a house or nest. It chooses to dwell in a coral grotto ; but in constructing this grotto it shows that it is not only a mason but a rope-spinner, and a tapestry-weaver, and a plasterer. When the Lima is taken out of its nest, and put into a jar of sea-water, it is one of the most beautiful marine animals you can look upon. The shell is beautiful; the body of the animal within is beautiful; and the orange fringe-work outside the shell is highly ornamental. Instead of being sluggish, it swims about with great vigour. Its mode of swimming is the same as that of the scallop. It opens its valve, and suddenly shutting them expels the water, so that it is impelled onwards or upivards; and when the impulse thus given is spent, it repeats the operation, and thus moves on by a succession of jumps. When moving through the water in this way the reddish fringe-work is like the tail of a fiery comet."-Excursions to Arran, p. 319.
} 


\section{Figures.}

Lima inflata. Pl. $N$. Fig. 1. Shell, containing the animal with its tentacular fringe and byssus-spinning foot.

Lrma squamosa. P1. 28. Fig. 163. Shell, showing its white substance and scaly sculpture, with the byssus protruding from the anterior gape.

\section{Genus 7. PEDUM, Bruguière.}

Animal; oval-oblong, flat, lobes of the manile free, thickened at the edge, and furnished with several rows of tentacular cirrhi and equidistant smooth tubercles; a pair of large branchice descending on each side; foot worm-shaped, furnished with a large silky byssus; mouth oval, having on each side a pair of labial palps. (Quoy and Gaimard.)

Shell; inequivalve, thin, compressed, slightly anviculated, lower valve rather convex, reflected at the sides, deeply simuated near the linge, lower valve flat; hinge toothless, with the ligament partially external, contained within a channelled pit running across a produced umbonal area of the lower valve.

The earliest publication of the very remarkable shell which constitutes this genus was the mention of "a rare oyster from the Indies" more than a century ago in the 'Catalogue Raisonné' of Davila; and no other species has been met with. From having a largely-developed umbonal area, it was then called the 'Spondylus-like Oyster ;' but, unlike that genus, it has a very conspicuous sinus for the passage of a stout silken byssus, and according to the observations of MM. Quoy and Gaimard, partakes much of the character of the Pectens.

Until lately the Pedum, reported to be an inhabitant of the Mauritius, has been a shell of great rarity; but it has been found in comparative abundance in the Red Sea imbedded chiefly in masses of madrepore, and the accomplished naturalists of the Astrolabe have gone so far as to express their belief that the animal has the power of boring and enlarging its place of habitation.

\section{Figure.}

Pedum Spondyoldeum. P1. 2S. Fig. 164. Shell, showing its refiected sides and umbonal area. Pl. N. Fig. 3 : showing a mass of madrepore with four specimens imbedded therein. 


\section{Family 3. AVICULACEA.}

Shell; irregular, rather thin, fibro-laminar; linge toothless; ligament marginal, either linear or cnclosed in pits or grooves; lower valve notched or simuated for the passage of a byssus.

The Aviculacea, of which the large Pearl Oyster is the type, have shells of a fibrous laminar structure, partaking of the foliated structure of the Oysters proper; but the animal has a well-developed foot, such as appears only occasionally in the preceding family in a rudimentary form, and it is furnished with a gland which secretes a byssus of considerable strength. Bivalves that are provided with the means of mooring themselves to foreign bodics, have no interlocking terth, except in the ponderous Clams. The hinge of the Ariculucee is only a ligament hinge, the liganent being more that usually developed, and either linear or contained in variously arranged pits or grooves according to the genus.

The shells of this family have, of all bivalves, the least proportion of lime in their composition, and the largest, therefore, of membranous tissue; and the testaceons fluid used for the internal lining is that beautifully iridescent silvery substance called nacre, or mother-o'-pearl. The genera are-

AvtCula.

Pelina.
VuLSELLA.

Crenatula.
Malleus.

\section{Genus 1. AVICULA, Klein.}

Animal; oval, fatlened, with the lobes of the mantle free throughout, frilled at their edtges; foot sometimes small, sometimes vather long, furmished wille a byssal groove; mouth and labial palps vather large, obliquely truncated, adductor muscle strenythened by smaller auxiliary muscles.

Shell; incquivalve, sometimes orlicular, sometimes obliquely triangular, with the anterior side more or less elongately winged; hinge toothless, but furnished in most instances, beneath the umboes, with an obscure tubercle; ligament linear, more or less dilated in the middle.

The obliquely triangular winged Aricule, or Swallows, and the round Aviculce, or Pearl Oysters (the Meleagrince of Lamarck), are associated together in this gemus. 'Though differing materially in shape, the animal is the same, and even the roundest form of Mleleagrina possesses in a rudimentary shape the winged process which is developed in so extraordinary 
a manner in some of the Avicula proper. The orbicular species are remarkable also for their very elihorately scaled or foliated structure, those that are least winged being generally the most scaled; and the colours are in some few kinds as brilliant as can well be imagined. Both varieties of Avicula produce pearls, but it is to the large round $A$. margaritifera of the tropical and subtropical seas in both hemispheres that we are indebted for the pearls of commerce. The choicest pearls are formed within the fleshy part of the mantle, owing to some disorganization of the secreting gland which causes the pearly nacre, used for the lining of the shell, to accumulate in little pea-like balls; and great is the eagerness with which they have been procured in all ages for ornamenting the person.*

The Avicule are abundant in the tropical and subtropical seas, and are handsomely, but with rarity, represented on our own shores by the $A$. Tarentina, whose home is in the Mediterranean. The smaller species, some of which are extremely fragile, attach themselves chiefly to bunches of zoophytes.

\section{Species.}

1. ærata, Reeve.

2. ala-corvi, Chemn .

3. ala-perdicis, Reeve.

4. Anomioides, $i d$.

5. aquatilis, $i d$.

6. argentea, $i d$.

7. assula, $i d$.

8. Atlantica, Lam.

9. barbata, Reeve.

10. castanea, $i d$.

11. cetra, $i d$.

12. Chamoides, $i d$.

13. cornea, $i d$.

14. crocea, Chemn.
15. Cumingii, Reeve.

16. electrina, $i d$.

17. eximia, $i d$.

18. fibrosa, $i d$.

19. fimbriata, $i d$.

20. flabellum, $i d$.

21. flammata, $i d$.

22. flexuosa, $i d$.

23. formosa, $i d$.

24. fucata, Gould.

25. gregata, Reeve.

26. heteroptera, Lam.

27. hystrix, Reeve.

28. imbricata, $i d$.
29. inquinata, Reeve.

30 . iridescens, $i d$.

31. irradians, $i d$.

32. irrasa, $i d$.

33. lacunata, $i d$.

34. lata, Gray.

35. lentiginosa, Reeve.

36. libella, $i d$.

37. lotorium, Lam.

38. macroptera, $i d$.

39. Malleoides, Reeve.

40. marmorata, $i d$.

41. maura, $i d$.

42. muricata, $i d$.

* "During the continuance of the pearl-fishery, there is no spectacle which Ceylon affords more striking to the European than the Bay of Condeatchy. "This desert and barren spot is at that time,' says an eye-witness, 'converted into a scene which exceeds in novelty and variety almost anything I ever witnessed. Several thousands of people, of different colours, countries, castes, and occupations, continually passing and repassing in a busy crowd; the vast numbers of small tents and huts erected on the shore, with the bazaar or market-place before each; the multitude of boats returning in the afternoon from the pearl-banks, some of them laden with riches; the anxious expecting countenances of the boat-owners, while the boats are approaching the shore, and the eagerness and avidity with which they run to them when arrived, in hopes of a rich cargo ; the vast numbers of jewellers, brokers, merchants, of all colours and all descriptions, both natives and foreiguers, who are occupied in some way or other with the pearls, some separating and assorting them, others weighing and ascertaining their number and value, while others are hawking them about, or drilling and boring them for future use ;-all these circumstances tend to impress the mind with the value and importance of that object which can of itself create this scene." "-Johnston, Introd., p. 53. 
43. nebulosa, Conrad.

44. occa, Reeve.

45. perviridis, $i d$.

46. Pernoides, $i d$.

47. Peruviana, $i d$.

48. pica, Gould.

49. Placunoides, Reeve.

50. prætexta, $i d$.

51. producta, $i d$.

52. pulchella, $i d$.
53. punctulata, Reeve.

54. radula, $i d$.

55. reticulata, $i d$.

56. rutila, $i d$.

57. Savignyi, Desh.

58. scabriuscula, Reeve.

59. scalpta, $i d$.

60. semisagitta, Lam.

61. signata, Reeve.
62. smaragdina, $i d$.

63. spectrum, $i d$.

64. sugillata, $i d$.

65. Tarentina, Lam.

66. tegulata, Reeve.

67. trochilus, $i d$.

68. vexillum, $i d$.

69. vitrea, $i d$.

70. zebra, $i d$.

\section{Figure.}

Avicula LATA. PI. 2S. Fig. 165. Shell, of a species intermediate in form between the two Lamarckinn divisions, Avicula and Meleagrina, showing the linear position of the ligament.

\section{Genus 2. VULSELLA, Lamarck.}

Animal ; unknown.

Shell; longitudinal, equivalve, somewhat irregular, umboes equal ; hinge-callosity in cach valve prominent, depressed at the upper part, and having an obliquely arched conical pit containing the ligament.

The Fulsella, of which the soft parts have not yet been observed, have an extended tongue-like shell, like the lobeless Mallei, and they have a similar hinge, the ligament being contained in a central spoon-shaped pit. The umboes are, however, attenuated, and recede from each other so as to form a kind of hooked area. Of sixteen species at present known the shells present a great similarity of sculpture, all being more or less beset with laminæ of minute crenulated scales. There is very little indication of a byssus, and, like Crenatula, their habit is to live imbedded in sponge. They chiefly inhabit the Red Sea.

\section{Species.}
1. attenuata, Reeve.
5. Isocardia, Reeve.
9. Mytilina, Lam.
2. corollata, $i d$ :
6. Limæformis, $i d$.
3. crenulata, Lam.
7. lingua-felis, $i d$.
10. phasianoptera, $i d$.
4. hians, $i d$.
8. lingulata, Lam.
11. Pholadiformis, $i d$.
12. rudis, $i d$. 
13. rugosa, Lam.

14. spongiarum, $i d$.

15. Tasmanica, Lam. 16. trita.

\section{Figure.}

Vulsella attenuata. Pl. 2S. Fig. 166. Shell, showing its elongated tongue-like growth.

\section{Genus 3. MALLEUS, Lamarck.}

Animal ; undescribed.

Shell; irregular, nearly equivalie, elongated, sometimes lobed on each side; umboes tivaricate; hinge toothless, with the ligament partly external, on a sloping area, partly internal within a central pit, with a small passage for the byssus.

The genus Malleus was founded for the reception of two oyster-like shells of very remarkable longitudinal growth, of which the hinge portion is prolonged on either side, at a right angle, into an extended narrow lobe. The term mallens, a mallet or hammer, aptly designates this form. But in none of the species since discovered, with the same natural affinities, is the hinge portion lobed. The Hammer Oysters have as many as eleven species associated with them in this genus in which there is no hammer structure, and in at least half of them, which are very small, the laminated growth soon terminates, forming a kind of nucleus, and the remaining portion of the shell is an independent transparent deposit of brittle calcareous matter, characterized in most instances apart from the body of the shell by a different speciality of colouring.

The large Mallei are from the islands of the Eastern Seas, the small brittle species are from West Columbia and the islands of the Pacific.

\section{Species.}

1. albus, $\operatorname{Lam}$.

2. anatinus, $i d$.

3. aquatilis, Reeve.

4. dæmoniacus, $i d$.

5. decurtatus, Lam
6. legumen, Reeve.

7. maculosus, $i d$.

8. regula, Forsk.

9. rufipunctatus, Reeve.
10. solitarius, Reeve.

11. tigrinus, $i d$.

12. vesiculatus, $i d$.

13. vulgaris, Lam.

\section{Figure.}

Malleus anatinus. Pl. 28. Fig. 167. Shell, showing the hinge ligaVOL. IL. 
mentary pit, and the utmost inclination that any species has to become lobed, excepting the two well-knowu cross-lobed species known as the Hammer Oysters.

Genus 4. PERNA, Lamarck.

Animal; mantle prolonged belind, with the lobes free throughout; foot conical, carrying at its base a rough large byssus. (Deshayes.)

Shell; flat, nearly equivalve; umboes small, often terminal and hooked; hinge broad, marginal, deeply cut with parallel grooves containing the ligament; posterior opening for the passage of the byssus conspicuous.

The Pernce are variously shaped, round, pectinate, or winged, but the genus may be at once recognized by the peculiarities of the hinge. It takes the form of a broad marginal plate cut across with great regularity by parallel grooves, and the intermediate ridges of the valves do not interlock with each other, like teeth, but press in contact, leaving the cavities between them for the reception of the ligament.

The shells of Perna have a strong affinity with those of Malleus in respect of growth, but the hinge is of quite a different structure. They are chiefly from the Eastern Seas. A few are from the West Indies and from the Islands of the Pacific.

\section{Species.}

1. Anomioides, Reeve. 11. isognomum, Linn.

2. attenuata, $i d$.

3. Australica, $i d$.

4. Californica, Conrad.

5. caudata, Reeve.

6. costellata, Conrad.

7. Cumingii, Reeve.

8. ephippium, Linn.

9. fimbriata, Reeve.

10. imbricata, $i d$.
12. laticostata, Reeve.

13. legumen, Gme?

14. lentiginosa, Reeve.

15. Limoides, $i d$.

16. linguiformis, $i d$.

17. lobata, $i d$.

18. marsupium, Lam.

19. nucleus, Lam.

20. patibulum, Reeve.
21. pectinata, Reeve.

22. quadrangularis, id.

23. rudis, $i d$.

24. seminuda, Lam.

25. serratula, Reeve.

26. spathulata, $i d$.

27. vespertilio, $i d$.

28. vitrea, $i d$.

29. Vulsella, Lam.

\section{Figure.}

Pekva Australica. P1. 29. Fig. 168. Shell, with the upper valve 
dropped to show the hinge of parallel grooves containing the ligament.

\section{Genus 5. CRENATULA, Lamarck.}

Animal; undescribed.

Shell ; thin, nearly equivalve, smooth, mostly concentrically striated, oblique; hinge lateral, linear, crenulated, crenules set in a row along the margin, callous, rather hollow, receiving the ligament.

The Crenatula, of which cight species are now known, are distinguished by a marked speciality of character. They cannot be said to run into any of the proximate genera. Their shells are of a delicate horny substance, and of a curiously oblique-quadrate or obliquely-ovate growth, the hinge being set on a prolonged lateral margin in a row of jutting hollow crenules. All the species are from the Red Sea, excepting one of very distinct typical character, C. flammea, from New California. Like the Tulsella, they live imbedded in sponge.

\section{Species.}

1. avicularis, Lam.

4. folium, Gray.

7. picta, Gmel.

2. bicostalis, $i d$.

5. Mytiloides, Lam.

8. viridis, Lam.

3. flammea, Reeve.

6. nigrina, $i d$.

Figure.

Crenatula avicularis. Pl. 29. Fig. 169. Shell, with the upper valve dropped to show the jutting ligamentary crenules.

\section{Family 4. MYTILACEA.}

Shell; more or less narrovly elongated, equicalve, but very unequal-sided, of homy fibro-laminar substance, sometimes smooth, sometimes prickly scaled; animal afficed by a byssus.

The byssus-spinning Mussels are distinguished from the byssus-spinning Oysters by having a narrower more elongated shell, of lighter more horny substance; and the animal commences to show the lobes of its mantle united, with a development of siphonal orifices in front for the transmission 
of water to and from the branchix. They include the gigantic Pinna of the Mediterranean, and more than fifty others of more exotic range, most of them elaborately scaled and some brilliantly coloured; the beautiful assemblage of which the edible and tulip Nussels are the types; and a group of borers which, notwithstanding their confined habits, have shells with a most delicately sculptured and silken surface. With a few very limited exceptions, they are inhabitants of the sea. The genera are-

Pinna. Mytilus. Modiola. Lithodomus.

\section{Genus 1. PINNA, Linnæeus.}

Animal ; triangulur; mantle frecly open; no siphons; mantle margins with serrated edlyes; mouth with foliaceons lips and short palps; arms furnished with a long ligulate valve; foot small, with a byssal groove; adductor muscles very unequal. (Forbes.)

Shetl; equivalve, oblique, longitudinally wedtge-shaped, fibro-laminar, generally scaled; linge laterul, toothless, with the liganent rather internal, continued throughout its whole length.

Authors are somewhat divided as to whether the genus Pinna should be included in this or in the preceding family. Like the Aviculacea, the animal has its mantle-lobes disunited, and there are no siphons; but in the structure of its shell and in liabitat, it partakes more of the character of the true Mussels, in which the lobes of the mantle begin to be united and to form siphous in front. The single species inhabiting our own southwestern shores, $P$. pectinatu, is the largest of British mollnsks; and the P. rotundata, inhabiting the Nediterranean, is the largest of the genus. The name given to this shell by Aristotle has survived to this day. Linnrus adopted it to designate the genus, and no attempt to divide so natural a group into further genera has found favour.

Among the foreign species, four-fifths of which are inhabitants of the Old World, and one-fifth only of the New, there are most interesting varieties of sculpture. In $P$. serrata the scales are minute, copious, and sharp ; in P. alta and Cumingii they are curiously tubular and erectly recurved; in P.nolilis and mingosa they are promiscuously distorted; while in many species, as in P. funiata, bicolor, and Philippinensis, the shell is smooth. In examining the Pinnce it is, however, important to observe the species in different stages of growth and from different habitats. Individuals which in a young state are characterized by a profusion of scales, often become roughly laminated and even denuded of sculpture; and the 
self-same species, our British P. pectinata for example, is found scaled in one habitat and smooth in another. All are of a fibrous brittle texture, often brilliant in colour, though a dull horny olive greatly predominates.

\section{Species.}

1. alta, Soro.

2. angustana, Lam.

3. assimilis, II anl.

4. atro-purpurea, Sow.

5. attenuata, Reeve.

6. bicolor, Chemn.

7. bullata, Swain.

8. Carolinensis, Hanl.

9. Chemnitzii, $i d$.

10. Cumingii, id.

11. deltorles, Irenke.

12. D'Orbignyi, Hanl.

13. electrina, Reeve.

14. euglypta, Hanl.

15. fimbriatula, Reeve.

16. flabellum, Lam.

17. fumata, Hanl.

18. Gouldii, $i d$.

19. Hanleyi, Reeve.

20. hystrix, Hanl.

21. incurvata, Chemn.
22. inflata, Chemu.

23. Japonica, Hanl.

24. lanceolata, Sow.

25. lurida, Reeve.

26. madida, $i d$.

27. Maura, Sow.

28. Menkii, Hanl.

29. muricata, Linn.

30. mutica, Reeve.

31. nobilis, Linn.

32. nigra, Chenm.

33. papyracea, $i d$.

34. pectinata, Lim.

35. pernula, Chemn.

36. Philippinensis, Hanl.

37. penna, Reeve.

38. ramulosa, $i d$.

39. regia, Hanl.

40. rigida, Dillw.

41. rotundata, Limn.
42. rudis, $\operatorname{Lim}$.

43. rugosa, Sow.

44. Rumphii, Hanl.

45. saccata, Lim.

46. sanguinolenta, Reeve.

47. seminuda, Lam.

48. semicostata, Conrad.

49. serra, Reeve.

50. serrata, Sol.

51. squamifera, Sow.

52. Strangei, Hanl.

53. Stutchburii, Reeve.

54. subviridis, $i d$.

55. truncata, Phil.

56. tuberculosa, Sow.

57. vespertina, Reeve.

58. vexillum, Born.

59. virgata, Menke.

60. Zebuensis, Reeve.

61. Zelanica, Gray.

\section{Figure.}

Pinna semicostata. Pl. 29. Fig. 170. Shell of a semitransparent horny substance, copiously scaled throughout.

\section{Genus 2. MYIILUS.}

Animal; ollong; mantle sometimes fieely open, sometimes closed, with two siplional orifices and an opening for the foot; manthe margin pimately fringed in front, simple below; adductor muscles unequal; foot narrow, ligulate, with a byssal groove.

Shell ; cquivalie, oblinuely fan-shuped, more or less triangular; umboes sharp, nearly straight, terminal; anterior side often 
compressly expanded, posterior somewliat contracted; epidermis generally horny, sometimes hairy; linge toothless, sometimes slightly crenulated, with the ligament marginal and partially internal.

Two very characteristic groups of Mussels are included in this genus, the Mytili proper, numbering upwards of fifty species, and the Dreissence, of which there are some eight or ten. In the first, which are inhabitants of the sea, ranging widely over both hemispleres, the lobes of the mantle are freely open; but in the last, which inhabit brackish and fresh water, the mantle-lobes are united, except for the passage of the byssus-spimning foot, and where two siphonal openings are formed for inhaling water and for ejection. In this peculiarity we have an indication of a character which prevails under various modifications in all the lower acephala. The simple orifice is first fringed, then tuberl, until in MIya and Panoprea it becomes a huge proboscis, formed of the tubes enclosed together in a sheath.

The Mrytili are characterized by an elongately fan-shaped growth, more or less beaked torrards the umboes, having the anterior side for the most part compressly expanded and the posterior arcuately contracted. Two species, M. ungulatus and Californianus, attain a large size. M. tortus and hirsutus are chiefly remarkable for the densely-fringed epidermis with which the animal invests them. As examples of smooth, brilliantly coloured, horny epidermis over a ground of pearly nacre, II. pictus and smaragdinus may be quoted. All have a well-developed byssus spun from a groove in the animal's foot.*

The Nytili are used largely by fishermen for bait, and some amusing statistical reports are given of the number of millions of individuals consumed in this manner in the course of a season. The consumption of mussels as an entremet or general article of food is more limited, many having taken alarm at the stories that are told, and which, for aught we know, may be true, of their unwholesomeness and deleterious qualities. M. crassus, with a small Crepidula-like deck within the umbonal extremity of the valve, has been selected for the type of a nerr genus, with the name Septifer.

\section{Species.}
1. Adamsianus, Dunk.
3. Africanus, V.an Ben.
5. atropurpureus, Dunk.
2. Afer, Gmel.
4. Americanus, Recl.
6. angustus, Phil.

* "The byssus consists of a bundle of horny fibres or threads connected to the animal within the shell on the one hand, and to the rock on the other. How this connection is effected was first discovered and explained, in his usual copious and clear manner, by Réaumur. By placing mussels, Mytilus edulis, in vases of sea-water, he found the following to be their manner of proceeding: -Opening their valses the foot was first protruded, and, with various strains and stretches, gra- 
7. bifurcatus, Conr.

8. borealis, Lam.

9. Californianus, Conr.

10. Charpentieri, Dunk.

11. Chiloensis, Phil.

12. cochleatus, Kickx.

13. compressus, Phil.

14. crassus, Dunk.

15. cubitus, Say.

16. Cumingianus, Recl.

17. cruciformis, Reeve.

18. curvatus, Dunk.

19. Domingensis, Recl.

20. Dunkeri, Keeve.

21. edulis, Linn.

22. excisus, Wieg.

23. exustus, Lam.
24. Galloprovincialis, Lam.41. obscurus, Dunk.

25. glomeratus, Gould. 42. ovalis, Lam.

26. gracilis, Reeve.

27. granulatus, Hanl.

28. Grunerianus, Dunk.

29. hamatus, Say.

30. hirsutus, Lam.

31. horridus, Dunk.

32. latus, Lam.

43. pallio-punctatus, Dunk.

44. Perna, Linn.

45. pilosus, Recluz.

46. polymorphus, Pallas.

47. Rossmasleri, Recl.

48. rostratus, Dunk.

49. Sallei, Recl.

33. Lavalleanus, D'Orb. 50. sinuatus, Dunk.

34. Magellanicus, Chemn. 51. smaragdinus, Chemn.

35. Menkeanus, Phil. 52. tenebrosus, Reeve.

36. minimus, Poli.

37. Morchianus, Recl.

38. Morrisi, Dunk.

39. Nicobaricus, Chemn.

40. obesus, Dunk.
53. tenuistriatus, Dunk.

54. tortus, $i d$.

55. ungulatus, $\operatorname{Linn}$.

56. ustulatus, Lam.

\section{Figure.}

Mrtilus hornidus. Pl. 29. Fig. 171. Shell, showing its elongated faushaped growth, and hairy fringe-like epidermis.

\section{Genus 3. MODIOLA, Lamarck.}

Animal; oblong; mantle margins closed anteriorly, open belind, sometimes forming puckered branchial lips and a produced anal tube; foot narrow, lignlate; byssal gland more or less cylindrical.

Shell; oblong, equivalve, more or less ventricose; umboes small, rather swollen, not terminal, anterior side often expanded, posterior arched, contracted; hinge linear, with the ligament marginal and partially internal.

Naturalists are not all agreed upon the propriety of separating MIocliola

dually thrust out, until at length the elongation was carried to the desired extent, sometimes to fully two inches. It was now employed in feeling or testing all the objects within reach, directed to the right or to the left, backwards or forwards. After all this prelude, to ascertain apparently the security of the intended holdings, the point of the foot is settled and retained for a short time on the chosen spot, when it is again suddenly removed and immediately withdrawn entirely within the shell, leaving behind a thread that reaches from the spot to the base of the foot. By many repetitions of this operation, carried on patiently day after day (for not above four or five threads are spun in the twenty-four hours), and by attaching the disk-like extremities of the threads to different places, the mussel at last completes its cable and secures a safe anchorage." -Johuston, Introd. Conch. p. 143. 
from Mytilus, yet there are differences in both the animal and shell which claim attention. The animal of Mocliola, so far as it has been examined, has the mantle lobes closed in front, with puckered or pouting orifices, like rudimentary siphons learling to the branchia. This peculiarity, however, though not in Mytilus proper, exists in the Dreissena section of that genus. The shell of Mortiola presents the most obvious difference, being oblong-ventricose and romul-shouldered, as it were, instead of elongately fan-slaped, and it is of lighter substance. The animal has, also, the faculty of constructing a sort of entangling nest for itself out of its byssus-material, which has not been observed in Mytilus.

The Modiole are more numerous in species than the preeeding genus, and are equally widely distributed. The genera Crenella and Hudiolarea express the best-marked subdivisions.

\section{Species.}

1. albicosta, Lam.

2. arata, Dunk.

3. arcuatula, Hanl.

4. arborescens, Chemn.

5. Australis, Gray.

6. barbata, Lam.

7. Brasiliensis, Chemn.

8. bulla, Dunk.

9. capax, Conrad.

10. cicercula, Möller.

11. costulata, Risso.

12. Cumingiana, Dunk.

13. discors, Limn.

14. elegans, Gray.

15. elongata, Swain.

16. emarginatus, Bens.

17. faba, Fabr.

15. flavida, Dunk.

19. Fortunei, $i d$.

20. glaberrima, $i d$.

21. glandula, Totten.
22. gubemaculum, Dunk. 43. plicatula, Lam.

23. impacta, Herm. 4t. recta, Conrad.

24. Japonica, Dunk. 45. rhombea, Berk.

25. levigata, Gray. 46. rhomboidea, Hanl.

26. lignea, Reeve. 47. Senhausii, Recve.

27. Magellanica, Dunk. 48. setigera, Dunk.

28. maxmorata, Forbes. 49. speciosa, $i d$.

29. Metcalfei, Hanl. 50. splendens, $i d$.

20. modiolus, Linn. 51. striatula, Hanl.

31. nana, Dunk. 52. strigata, $i d$.

32. nexa, Gould. 53. subpurpurea, Dunk.

33. nigra, Gray. 5 $\quad$. subramosa, Hanl.

34. nitens, Cavp. 55. subsulcata, Dunk.

35. nitida, Hanl. $\quad 56$. subtorta, $i d$.

36. opifex, Say. 57. sulcata, Lam.

37. pectinula, Gould. 58. Trailii, Reeve.

38. perfragilis, Dunk. 59. tristis, Dunk.

39. Petagnæ, Scacchi. 60. tulipa, Lam.

40. phaseolina, Phil. 61. undulata, Dunk.

41. Philippinarum, Hanl. 62. vagina, Lam.

42. plicata, Gmel. 63. vexillum, Reeve.

\section{Figure.}

Modiola elongata. Pl. 29. Hig. 172. Shell illustrative of the oblong, round-shouldered form, and light texture. 
Modiola (Crenella) nexa. Pl. 29. Fig. 173. Shell illustrative of the short arcuated group.

\section{Genus 4. LITHODOMUS, Cuvier.}

Animal; simitar to that of Modiola.

Shell; cylindrically oblong, equivalve, covered with a reddish chestnut epidermis, sometimes incrusted with chall; extremities rounded; posterior side very short; umboes small, incurved; linge linear, with the ligament marginal.

The Sea Dates of the Mediterranean seem to have been better known to the epicure than to the naturalist. Long after Cuvier distinguished the Lithodomi as a genus, Lanarck included them with the Hodiole, and the animal was not described in detail by either. With the additions male to them by Mr. Cuming, we have a group of some thirty species, presenting a very expressive association of characters. The shell is always of a peculiarly oblong-cylindrical or wedge-shaped form, and of a peculiar substance. The aninal, unlike the rest of the family, is a borer, and is found imbedded in stone, chalk, coral, and in the valves of Spondylus shells, though often extremely delicate in structure. There is scarcely a species which is not beautifully striated, and there are several curiously sculptured with feathery wrinkles or furrows. Another peculiarity consists in the shell being frequently incrusted with a deposit of chalky matter, which is sometimes sculptured, and in some few instances is produced beyond the extrenity of the valves. Among the small species a few are bearded with bristles.

The geographical range of the Lithodomi is wide-spread, but partial. There are more species in the West Indies than in any other locality, but the genus is known to inhabit the Philippine Islands, New Zealand, Chili, Mazatlan, and the Galapagos Islands. The edible Sea Date of the Nediterranean, $L$. lithophagus, was described by the older naturalists as a Pholus. It is to the boring of this mollusk that the celebrated perforations in the columns of the Temple of Jupiter Serapis are due.

\section{Species.}
1. Antillarum, Phil.
6. bi-excavatus, Reeve.
11. coarctatus, Dunk.
2. appendiculatus, $i d$.
7. canaliferus, Hanl.
12. corrugatus, Phil.
3. argenteus, Reeve.
8. castaneus, Dunk.
13. Cumingianus, Dunk.
4. attenuatus, Desh.
9. caudigerus, Lam.
14. divaricatus, Phil.
5. barbatus, Reeve.
10. cinnamominus, Chemn.15. Gossei, Reeve.

voL. II. 
16. gracilis, Phil.

17. Grumeri, $i d$.

18. Hanleyanus, Dunk.

19. laniger, $i d$.

20. lithophagus, Linn.

21. Malaccanus, Reeve.
22. Malayanus, Phil.

23. nasutus, $i d$.

24. obesus, $i d$.

25. pessulatus, Reeve.

26. plumula, Hanl.

27. rugiferus, Dunk.
28. semigranatus, Reeve.

29. splendidus, Dunk.

30. stramineus, $i d$.

31. subula, Reeve.

32. teres, Phil.

33. truncata, Gray.

Figure.

Limiodomus lithophagus. Pl. 31. Fig. 181. Shell of the Mediterranean Sea Date.

\section{Family 5. TRIDACNACEA.}

Shell ; either fiee or affued, regular, equivalve, inequilateral, with the lumule sometimes largely gaping; linge composed of two compressed unequal teeth in each valve, of which the anterior interlock; muscular impression bipartite.

The well-known Horse-foot and Giant Clams which constitute this family are purely tropical mollusks. They lave no representative on our own shores, nor even in the Mediterranean, but direll imbedded among the coral reefs of the Indian and Pacific seas. From the observations of MM. Quoy and Gaimard, whose interesting figure of the living Tridacna squanosa we give at Plate $N$, it rould appear that the animal's position in the shell is the reverse of that in other bivalves, the foot of the Tridacna being next the lunule of the shell, instead of in front. The hinge, composed of two compressed unequal teeth in each valve, of which the front ones interlock, is the same in both the genera, Tridacna and Hippopus; but in Hippopus the lunule does not gape, neither is there a byssus.

TridacNa.

Hrppopus.

\section{Genus 1. TRIDACNA, Bruguière.}

Animal ; oval, heart-shaped, having the lobes of the mantle united almost thronghout, three openings, two posterior and inferior for evacuation and respiration, one anterior corresponding to the opening of the lunule, giving passage to a stout cylindrical byssus-spinning foot.

Shell; ovate, or oblong-ovate, gaping at the lumule, disposed in 


\section{diverying arched ribs, more or less densely furbelowed with erect high-vaulted scales.}

The furbelowed Clams, one of which, T. gigas, from its being the largest of all mollusks, is called the Giant Clam, are a tribe of sluggish animals living in beds of many specimens together among the coral reefs of the Indian and Pacific Seas. It is recorded that the animals are extremely brilliant in colour, whilst the shells are mostly colourless and thickly incrusted with dirt, and that to look down upon a bed of them, through the clear blue water, when the valves are open, is really a sight to see. M. Quoy describes with much enthusiasm the beautiful iridescent glare of blue and violet and yellow, variegated with fantastic markings that is presented by these submarine parterres. None of the shells have any marking, but some are elegantly toned with a hue of saffron or pink. All are characterized by a broad opening at the lunule, through which passes a foot capable of spinning a powerful tendinous byssus. The species differ from one another in form, but mostly in the character of the scales; some are furbelowed with distant high-vaulted scales, and some are furbelowed with a profusion of small scales; in the Giant Clam, Tridacna gigas, the scales are mostly obsolete from its thickened and continuous growth.*

\section{Species.}
1. elongata, Lam.
4. scapha, Meusch.
6. serrifera, Lam.
2. gigas, Linn .
5. scutrum, $i d$.
7. squamosa, $i d$.

3. mutica, Lam.

\section{Figure.}

Tridacna squamosa.. Plate $N$. Shell, with the valves open to expose the animal. The upper orifice is the mouth, with its labial palps. The orifice, through which the foot and byssus passes to the gaping lunule of the shell, is concealed from view.

* 'The French conchologists call the shells of this species 'Bénitiers,' from their having been used at the doors of churches as vessels for holy water. Much has been said about the Bénitiers of St. Sulpice in Paris, presented by the Venetians to Francis I., but I doubt if they are so large as a pair of Bénitiers in the window of an oyster shop, the favourite resort of actors and literary men, in Maiden Lane, Covent Garden. Often when indulging in a luncheon of Ostrea edulis, fresh-murdered, with the gills spread neatly round the nice plump visceral mass, a bonne bouche for an emperor, have I looked upon the giant clam which fills the entire background of the oyster-vendor's window, and longed to get a waggon and horses to carry them off; but Mr. Rule, like a true naturalist, will not be tempted to part with them. The windows of his little back parlour are filled with Wardian cases of healthy growing ferns, and on the wall may be secn portraits of some of our literati, presented by the sitter. 


\section{Genus 2. HIPPOPUS, Meuschen.}

Animal; simitar to that of Tridacna, but wanting a byssus.

Shell ; traperiform, many-ribbed, fimbriately imbricated throughout, and richly coloured; lunule almost obsolete.

Of the Ilippnpus, or Horse-foot Clam, only a single species is known. The animal is like that of Tridacna, except that it has no byssus, or only the rudiment of a byssus, whilst the lunule of the shell is closed, or nearly so. The shell, which is a common ornament in every house where shells are collected or admired, is alike conspicuous for the beautiful symmetry of its growth, the elegance of its sharply imbricated frilled sculpture, and the richness of its colouring of crimson spots upon a yellow ground.

\section{Figure.}

Hippopes maculatus. Pl. 30. Fig. 176. Shell, with one valve dropped to show on one side the marginal ligament, on the other the hollow serrated lunule.

\section{Order 2. BIMUSCULOSA.}

Shell; attached to the animal by two distant lateral muscles.

The remainder of the headless mollusks are for the most part of a more oblong and even elongated growth, and the shells are attached to the animal by two adductor muscles, one at each end. The hinge is of a more complicated structure, composed of teeth more strongly interlocking with each other, and they have little of the fibrous laminar texture of so many of the unimuscular order.

$\begin{array}{lll}\text { Chamaded. } & \text { Cardiacea. } & \text { Myaria. } \\ \text { Naiades. } & \text { Conchacea. } & \text { Solenacea. } \\ \text { Trigonacea. } & \text { Nymphacea. } & \text { Pholadaria. } \\ \text { Arcacea. } & \text { Lithophaga. } & \text { Tubicola. } \\ & \text { Mactracea. } & \end{array}$

Family 1. CHAMACEA.

Shell; irregular, inequivalve, affixed, with a single thick oblique tooth in each valve, which is sometimes obsolete. 
The two genera associated under this head have little real affinity, and ought rather to be taken as the types of distinct families. Chama is a vigorous growing, profusely ornamented sea mollusk; Etheria is a dull freslwwater bivalve, inhabiting the rivers of North Africa and the Amazon. The hinge is of very rude structure, consisting of no more than a blunt oblique tooth, which is sometimes obsolete.

\section{Genus 1. CHAMA, Linncens.}

Animal; with the mantle closed, the margins being united by a filamentary fringe, except at the siphonal orifices, uhich are small and distant; foot cylindrical, bent.

Shell; orbicular, ovate, or oblong-ovate, irregulur, profusely ornamented with spines, scales, or lamella, Tower valte more or less deeply convex, upper valve flatter; umboes unequal, clistant, involuted sometimes to the right, sometimes to the left, in the same species.

Excepting the Oysters, there is no genus of bivalves whose shells are liable to so much variation of form and general aspect, according to circumstances of habitation, as Chama. Being strictly of parasitical habit, and inlabiting the most confined situations in crevices of rock and fissures of madrepore, without the power, possessed by terebrating mollusks, of removing the obstacles to their growth, the shells are mostly more or less distorted, according to their place of attachment. Yet notwithstanding this, they are characterized by vivid colouring and a most luxuriant growth, developed in all sorts of varieties of spines, scales, and fronds. The species are difficult of definition, and the difficulty increases when it is found that the same species varies materially in growth in different habitats. When allowed to develope its foliations in placid water, surrounded by food most favourable for the secretion of colour, the shell is hardly to be recognized as the same stunted form that has had to contend with the buffeting of the storm.

Above fifty species are known from Central America, Australia, and the Pacific and Eastern Seas; and some are found to be reversed. The same species may be observed with its umboes involuted sometimes to the right, sometimes to the left.

\section{Species.}

$\begin{array}{lll}\text { 1. appressa, Reeve. } & \text { 3. aspersa, Reeve. } & \text { 5. Broderipii, Reeve. } \\ \text { 2. arcinella, Linn. } & \text { 4. brassica, } i d . & \text { 6. Carditæformis, } i d .\end{array}$




\begin{tabular}{|c|c|c|}
\hline 7. cistula, Reeve. & 23. gryphina, Lam. & 39. planata, Reeve. \\
\hline 8. coralloides, $i d$. & 24. imbricata, Brod. & 40. prætexta, $i d$. \\
\hline 9. cornucopia, $i d$. & 25. iostoma, Conrad. & 41. pulchella, $i d$. \\
\hline 10. corrugata, Brod. & 26. Janus, Reeve. & 42. radians, Lam. \\
\hline 11. cristella, Lam. & 27. Jukesii, $i d$. & 43. reflexa, Reeve. \\
\hline 12. divaricata, Reeve. & 28. lazarus, Linn. & 44. rubea, id. \\
\hline 13. echinata, Brod. & 29. lingua-felis, Reeve. & 45. Rüppellii, $i d$. \\
\hline 14. exigua, Reeve. & 30. lobata, Brod. & 46. sarda, $i d$. \\
\hline $\begin{array}{l}\text { 15. exogyra, Conrad. } \\
\text { 16. ferruginea, Reeve. }\end{array}$ & $\begin{array}{l}\text { 31. macrophylla, Chemn. } \\
\text { 32. multisquamosa, Reeve. }\end{array}$ & $\begin{array}{l}\text { 47. Senegalensis, } i d \text {. } \\
\text { 48. sinuosa, Brod. }\end{array}$ \\
\hline 17. fibula, $i d$. & 33. nivalis, $i d$. & 49. sordida, $i d$. \\
\hline 18. fimbriata, $i d$. & 34. obliquata, $i d$. & 50. spinosa, $i d$. \\
\hline 19. florida, Lam. & 35. Pacifica, Brod. & 51. sulphurea, $i d$. \\
\hline 20. foliacea, Quoy. & 36. Ponamensis, Reeve. & 52. tumulosa, $i d$. \\
\hline 21. fragum, Reeve. & 37. pellis-phocæ, $i d$. & 53. variegata, $i d$. \\
\hline 22. frondosa, Brod. & 38. pellucida, Brod. & enosa, $i d$. \\
\hline
\end{tabular}

Figure.

Crrama Lazarus. Pl. 30. Fig. 174. Shell of a young specimen, rather highly coloured.

\section{Genus 2. E'THERIA, Lamarck.}

Animal; oblong, thick, with the mantle lobes freely open; labial palps large, no foot.

Shell; irregular, affixed, of a glaucons green colour, somewhat pearly within, the nacre being mostly blistered; teeth obsolete.

The fresh-water Oysters of the Nile, as the traveller Bruce called them, collected abundantly by another eminent traveller in the same locality, M. Cailliaud, differ from the rest of the freshwater bivalves in their Chamalike character of adhering to foreign bodies, and even attaching themselves one upon another in masses. M. Cailliaud collected them in Upper Nubia as high up as the cataracts of Robâtâs, where he found that the animal was eaten by the natives as a common article of food, and the shells collected by them for decorating their tombs. Lately the genus has been found in the river Amazon. The shell is of a peculiar livid, glaucous green colour, the interior being lined with a nacre, which is in most specimens raised into blisters, and the outer surface is sometimes rudely tubularly scaled. 


\section{Species.}

1. Cailliaudi, Féruss. 3. semilunata, Lam. 4. Stefanensis, Moric.

2. elliptica, Lam.

\section{Figure.}

Etreria Cailladdi. Pl. 30. Fig. 175. Shell of glaucous green, showing its external tubular structure, and blistering of the internal nacre.

\section{Family 2. NAIADES.}

Shell ; equivalve, more or less inequilateral, pearly, covered with a thick olive-green epidermis; linge extremely variable, generally two or more solid cardinal teeth, with or without lateral teeth, sometimes toothless.

The freshwater Mussels, which according to the latest census* number 539 species, form an extremely natural group, but vary remarkably among themselves. The most unticeable characteristic of the animal is an unusually large development of the foot. The shell is of pearly substance, covered with an olive-green epidermis; sometimes it is thin and toothless, generally it is thick and very strongly toothed. The principal home of the Naides is in the great rivers of North America, but they exist in the principal rivers of both the Eastern and Western hemispheres. Our own island has four species.

Mr. Lea divides the family into two genera, to which he gives the names of Margaron and Plativis; and these he divides into nine subgenera. Under Margaron he has Triquetra (which answer to Hyria and Prisodon), Unio, Margaritana, Monocondylaa, and Dipsas, which five subgenera constitute our Unio; and he has Anodonta. Platyris comprises Iridina and Spatlia, which we include in one, and Mycetopus. Our genera will therefore stand thus :-

UNIO.

HYrIA.

IrIdINA.

Anodonta.

Mycetopus.

Genus 1. UNIO, Retzius.

Animal; thick and fleshy, with the mantle freely open; foot large and broadly compressed.

* Lea, Synopsis. 
Shell; generally thick and solid, with the hinge variously composed of more or less solid cardinal and lateral teeth, sometimes groovestriated, either of which may be wanting; outer surface of the shell frequently tubercled or wrinkled, sometimes, but very rarely, spined; inner surface silver-pearly, sometimes purple or pink; ligament external.

In some of the canals and rivers of England are found, somewhat sparingly, three kinds of toothed bivalves, called respectively the Painter's Mussel, Unio pictorum, the Pearl Mussel, Unio margaritifera,* and the Swollen Mussel, Cinio tumidus; but these are merely stragglers of a type whose centre of creation is in the great rivers of North America. The Ohio, Mississippi, and other rapids of the States, swarm with individuals of upwards of 330 species; in South America some fifty species have been collected, and the genus is represented in Asia, chiefly in India and Siam, by about the same number; Europe, including Britain, has only ten species, Africa eight, and New Holland three.

The animal of Crio, and, indeed, of the family generally, presents a structure intermediate between that of the Oysters in which the mantlelobes are entirely free, and that of the Myas in which the lobes are united, and have two tubular orifices belind for imbibing and rejecting. The mantle-lobes of Linio, Anodonta, and the rest of the Naiades, are open in front, and have a broad tongue-like foot exserted between them, and closed behind, forming orifices which are, as it were, the rudiments of siphons, the upper one being small and simple, whilst the lower is larger and fringed with a beard of short jagged cirrhi.

The shells of Lnio have been imported from North America in such quantities, packed frequently in casks, that the collector sometimes tires of the genus ; but they are of the highest interest, often beautifully sculptured without, and richly iridescent with purple or silvery pearl within. The pearl-producing Unios are chiefly those which inhabit rocky and turbulent streams. In Britain it is from the Unio margaritifera of North Wales that pearls are mostly extracted. It is in the roaring Conway, which flows from the mountainous districts of the Principality, and is met in its rugged course at every turn with boulders and splinters of rock, that the Unio margaritifera is most disturbed in its calcifying operations, and sputters its nacre in clumsy heaps of nodules, or in the superfluous pea-like balls which go to decorate the necklace or tiara. In the rapids of Cumberland,

* "The shells of this genus have frequently been used by painters for containing their colours, and some of the species furnish pearls. The animals are not eaten in our country, but in the south of Europe-where everything in the shape of shell-fish is devoured with an avidity which defies starvation as long as rivers and seas yield mollusca in their present abundance-they are cooked for food, either roasted in their shells, and drenched with oil, or covered with bread crumbs and scalloped."-Forbes and Hanley, Brit. JIoll., vol. ii. p. 139. 
Westmoreland, and Northumberland, the Unio margaritiferus is also found with pearls. Before the pearls of Britain were discarded for those of more attractive lustre of exotic climes, the fishing for them might repay the lucky finder of a gem. But it was no slight labour. One Unio in a hundred might contain a pearl, and about one in a hundred of the pearls was tolerably clear. Sir Robert Redding, speaking of the pearl fisheries of bygone times in some of the rivers of Ireland, in a paper contributed to the Philosophical Transactions of the Royal Society in 1693, describes how the poor people fished them in the warm months before harvest-time, when the rivers were low. They took them with their toes or-wooden thongs, or by thrusting a stick into the shells which they caught sight of anong the stones as they lay in part opened, with the white foot protruded like a tongue out of the mouth. "Some gentlemen of the country," continues Sir Robert, "made good advantage thereof, and I myself whilst there, saw one pearl bought for fifty shillings that weighed thirty-six carats, and was valued at forty pounds." Pennant affirms that the British Crown still contains a pearl of great price obtained from a Unio in the Conway in the time of Charles II., and presented to Catherine his Queen by her chamberlain, Sir Richard Wynne, of Girydir.* The pearls of the large American Unios are rather opake and stony, but there are, doubtless, some clear and lustrous.

\section{Species.}

1. abacus, Hald.

2. abbreviatus, Gold.

3. abductus, Phill.

4. Aberti, Con.

5. acquilina, Sow.

6. acutus, $i d$.

7. acutissimus, Lea.

8. aduncus, Soro.

9. aruginosus, More.

10. Esopus, Green.

11. affinis, Lea.

12. aheneus, $i d$.
13. Alabamensis, Con.

14. alatus, Say.

15. altilis, Con.

16. ambiguus, Sow.

17. amœnus, Lea.

18. amygdalum, $i d$.

19. angusta, Klein.

20. angustatus, Lea.

21. angustus, Lam.

22. anodontoides, Lea.

23. Ansticei, Sow.

24. antiquior, Strick.
25. antiquus, Sow.

26. apiculatus, Say.

27. approximus, Lea.

28. aratus, Lea.

29. arcaformis, $i d$.

30. arctatus, Con.

31. arctior, Lea.

32. arcula, $i d$.

33. arcus, Con.

34. argens, Küst.

35. argenteus, Lea.

36. asper, $i d$.

* "In Wales the Conway has been long celebrated for pearls, and the fishery still exists, though, according to Dr. Macculloch, it is the source of anything but good-' a lottery which produces universal poverty among the people who pursue it.' A recent account (Mag. Nat. Hist. vol. ii. p. 132) represents the case more favourably, and informs us that there are a number of persons who live by this alone; and where there is a small family to gather the shells and pick out the fish, it is preferable to any other daily labour. The pearls are disposed of to an overseer, who pays for them by the ounce, the price varying from $1 s$. $6 d$. to $4 s$. What is done with them seems to be involved in mystery ; they are, with few exceptions, useless as ornaments, and the exceptions seem scarcely sufficient to support any profitable speculations." -Johnston, Introd. Conch., p. 56.

VOL. II. 
37. asperrimus, Lea.

38. asterianus, Dup.

39. atratus, Lea.

40. atratus, Gold.

41. atro-costatus, Lea.

4.2. atro-marginatus, $i d$.

43. auratus, $i d$.

44. Australis, Lam.

45. Aztecorum, Phil.

46. Baudinii, Kïst.

47. Barnesianus, Lea.

48. Barratii, $i d$.

49. Batavus, Lam.

50. Bengalensis, Lea.

51. Beskeanus, Dunk.

52. biangulatus, Lea.

53. Bigbyensis, $i d$.

54. Biggorensis, Millet.

55. bilineatus, Lea.

56. Binneyi, $i d$.

57. Blandingianus, $i d$.

58. Bonellii, $i d$.

59. Bonneaudii, Eyd.

60. Bournianus, Lea.

61. Boscianus, Dunk.

62. Boydianus, Lea.

63. Boykinianus, $i d$.

64. brevidens, $i d$.

65. Brownii, $i d$.

66. Brumbyanns, $i d$.

67. Buckleyi, id.

68. Buddianus, $i d$.

69. Burroughianus, $i d$.

70. Buschianus, $i d$.

71. buxeus, $i d$.

72. cælatus, Con.

73. cæruleus, Lea.

74. Caffer, Kranss.

75. Caillaudii, Fér.

76. calceolus, Lea.

77. caliginosus, $i d$.

78. calimatorum, More.

79. callosus, Lea.

80. Cambodiensis, id.

81. camelus, $i d$.

82. camptodon, Say.
83. capax, Green.

84. caperatus, Lea.

85. capsæformis, $i d$.

86. carbonarius, $i d$.

87. carbonarius, Bronn.

88. cariosus, Say.

89. Carniolicus, Zeigl.

90. Casablancæe, Pliti.

91. castaneus, Lea.

92. centralis, Sow.

93. Charruanus, D'Orb.

94. Childreni, Gray.

95. Cincinnatiensis, Lea.

96. circulus, $i d$.

97. Claibornensis, $i d$.

98. Clarbrianus, $i d$.

99. clavus, Lam.

100. coccineus, Lea.

101. collinus, Con.

102. Coloradoensis, Lea.

103. complanatus, $i d$.

104. compressus, Sow.

105. compressissimus, Lea.151. delumbis, Con.

106. concavus, id.

107. concinnus, Sovo.

108. confertus, Lea.

109. confragosus, $i d$.

110. Congaræus, $i d$.

111. Comradicus, $i d$.

112. constrictus, Con.

113. contradens, Lea.

114. Cooperianus, $i d$.

115. cor, Con.

116. cordiformis, Sow.

117. coriaceus, $D u n k$.

118. cornutus, Bar.

119. Corrianus, Lea.

120. Corrientesensis, $D^{\prime} O r .166$. Dorfeuillianus, $i d$.

121. corrugatus, Ret.

122. crassidens, Lam.

123. crassissimus, Sovv.

124. crissiusculus, $i d$.

125. crassus, Retz.

126. creperus, Lea.

127. crocatus, $i d$.

12S. crocodilorum, More. 174. ebenus, $i d$.
129. cucumoides, Lea.

130. cultelliformis, Con.

131. Cumberlandianus,Lea.

132. Cumingii, $i d$.

133. cuneolus, $i d$.

134. cuprinus, $i d$.

135. Curryanus, id.

136. Cuvierianus, $i d$.

137. cylindricus, Say.

138. cyrenoides, Phil.

140. Damnoica, D'Orb.

142. decissus, $i d$.

143. declivis, Say.

144. decoratus, Lea.

145. dehiscens, $i d$.

146. dehiscens, Say.

147. delodontus, Lam.

148. delphinus, Grun.

149. delphinulus, More.

152. depressus, Lam.

153. depressus, Sow.

154. destructilis, Fill.

155. digitatus, More.

156. diluvii, $D^{\prime} \mathrm{Or} \cdot$.

157. discoideus, Lea.

158. discus, $i d$.

159. distortus, Beau.

160. divaricatus, Lea.

161. divergens, Bens.

162. dolabraformis, Lea.

163. dolabelloides, $i d$.

164. dolobratus, Sow.

165. donaciformis, Lea.

167. Duprei, Recl.

168. dorsuosus, Gould.

169. dromas, Lea.

170. Drouetii, Dup.

171. Dunkerianus, Lea.

172. Durieui, Desh.

173. Duttonianus, Lea. 
175. Edgarianus, Lea.

176. effulgens, $i d$.

177. Egyptiacus, Caill.

178. elegans, Lea.

179. ellipsis, $i d$.

180. ellipticus, $i d$.

181. elongatus, Pfeif.

182. emarginatus, Lea.

183. errosus, Say.

184. Estabrookianus, Lea. 230. glaucinus, Zeigl.

185. Etowaensis, Con.

186. evanescens, Mous.

187. exiguus, Lea.

188. exilis, $D u n k$.

159. eximius, Lea.

190. exolescens, Gould.

191. explicatus, More.

192. faba, D'Orb.

193. fabalis, Lea.

194. fabula, $i d$.

195. famelicus, Gould.

196. fatuus, Lea.

197. favidens, Bens.

198. Fellmani, Desh.

199. Fisherianus, Lea.

200. flavescens, $i d$.

201. Floridensis, $i d$.

202. foliaceus, Gould.

203. foliatus, Hild.

204. folliculatus, Lea.

205. Fontainiana, $D^{\prime}$ Orb

206. Forbeseanus, Lea.

207. Formanianus, $i d$.

208. fossciculiferus, D'O.b 254. Holtonis, id.

209. fragosus, Con.

210. Franciscanus, Mror.

211. fraternus, Lea.

212. fuliginosus, $i d$.

218. fulgidus, $i d$.

214. fulvus, $i d$.

215. furvus, Con.

216. fuscatus, Lea.

217. gangrenosus, $S c h$.

218. Gaudichaudii, Eyd.

219. Geddingsianus, Lea.

220. generosus, Gould.
221. Georgianus, Lea.

222. gibber, $i d$.

223. gibbus, Zeigl.

224. Gibbesianus, Lea.

225. gibbosus, Bar.

226. gigas, Lea.

227. glaber, $i d$.

228. glabrata, Lam.

229. glans, Lea.

231. Gouldii, Ler.

232. gracilis, Barnes.

233. graniferus, Lea.

234. granosus, Brug.

235. granulifera, Dunk.

236. gravidus, Lea.

237. Grayanus, $i d$.

238. Greenii, Con.

239. Griffithianus, Lea.

240. Gronlandicus, Schröt.286. lanceolatus, $i d$.

241. Gualterii, Fit.

242. Guarayanus, Moric.

243. Hainesianus, Lea.

244. Haleianus, $i d$.

245. Hanleyanus, $i d$.

246. Haysianus, $i d$.

247. hebes, $i d$.

24.8. Hembeli, Con.

249. heterodon, Lea.

250. hippopæus, $i d$.

251. Hildrethianus, $i d$.

252. Holstonensis, id.

253. Holstonius, $i d$.

255. Hopetonensis, id.

256. Housei, $i d$.

257. humilis, $i d$.

258. hyalinus, $i d$.

259. hybridus, Sow.

260. Hydianus, Lea.

261. hylæus, D'Orb.

262. incrassatus, Lea.

263. ineptus, $i d$.

264. intlatus, $i d$.

265. infucatus, Con.

266. Ingallsianus, Lea.
267. inormatus, Lea.

268. intermedius, Con .

269. interruptus, Lea.

270. iris, $i d$.

271. irroratus, $i d$.

272. isocardioides, $i d$.

273. Jacqueminii, Dup.

274. Javanus, Lea.

275. Jayensis, $i d$.

276. jejunus, $i d$.

277. Juliana, Rang.

278. Katherinæ, Lea.

279. Keinerianus, $i d$.

280. Keraudreni, Eyd.

281. Kirtlandianus, Lea.

282. Kleinianus, $i d$.

283. lacrymosus, $i d$.

284. Lamarckianus, $i d$.

285. lamellatus, $i d$.

287. Largillierti, Phil.

288. latecostatus, Lea.

289. Lazarus, $i d$.

290. Leaii, Gray.

291. Lecontianus, Lea.

292. lenior, $i d$.

293. lens, $i d$.

294. Lesueurianus, $i d$.

295. liasinus, Sov.

296. lienosus, Con.

297. ligula, Mouss.

298. ligamentinus, Lan.

299. limatulus, Con.

300. limosus, Nilss.

301. lineatus, Lea.

302. Listeri, Sovo.

303. litoralis, Drap.

304. longirostris, Ziegl.

305. lugubris, Lea.

306. luridus, $i d$.

307. luteolus, Lam.

308. luteus, Lea.

309. lutulentus, Gould.

310. macropterus, Dunk.

311. maculatus, Con.

312. Mantellii, Tit. 
313. margaritiferus, Linn. 359. nigerrimus, Lea.

314. marginalis, Lam.

315. marginatus, Lea.

316. Martinii, Fit.

317. Masoni, Con.

318. Medellinus, Lea.

319. melinus, Con.

320. membranaceus, Lea.

321. Menkei, Koch.

322. Menkianus, Lea.

323. merus, $i d$.

324. metastriatus, Con.

325. metanevrus, Raf.

326. Mexicanus, Plitl.

327. minor, Lea.

328. minuanus, $D^{\prime} \mathrm{Or} b$.

329. Mississippiensis, $C$

330. modestus, Fér.

331. modiolaris, Sov.

332. modioliformis, Lea. 333. mœstus, $i d$.

334. monodontus, Say.

335. Momroensis, Lea.

336. Moravicus, Jay.

337. Moussonianus, Lea. 338. Moreleti, Desh.

339. Morini, More.

340. mucronatus, Bar.

341. Muhlfeldianus, Lea. 342. multidentatus, Plil. 343. multiplicatus, Lea. 344. multiradiatus, $i d$. 345. multistriatus, $i d$. 346. Murchisonianus, $i d$. 347. musivus, Speng. 348. mutatus, Mouss. 349. Myersianus, Lea. 350. mytiloides, Raf. 351. mytiloides, Desh. 352. Napeanensis, Con. 353. Nashvillianus, Lea. 354. nasutus, Say.

355. Newcombianus, Lea. 356. neglectus, $i d$.

357. Nicklinianus, $i d$. 358. nigellus, $i d$.

361. nigricus, Lea.

362. Niloticus, Fer.

363. Nilssoni, Koch.

364. nitens, Lea.

365. nitidens, Fér.

366. nucleus, Lea.

367. nodulosus, $i d$.

368. notatus, $i d$.

372. nucleopsis, Con.

373. nuculinus, Phil.

374. nuperus, Zeig.

376. nux, id.

378. obesus, Lea.

379. obliquus, Lam.

380. obscurus, Lea.

381. obtusus, Potiez.

382. obtusus, Lea.

383. obtusus, Fér.

384. occidens, Lea.

386. occultus, Lea.

387. ochraceus, Say.

388. olivarus, Lea.

392. orientalis, $i d$.

393. orientalis, Fér.

395. Osbeckii, Phil.

396. ostreatus, More.

397. ovalis, Turt.

398. ovatus, Say.

399. oviformis, Con.

401. pallescens, Lea.
360. nigricans, Menke.

369. Novæ-Hollandiæ, Gy.415. paulus, $i d$.

370. Novi-Eboraci, Lea. 416. pellucidus, $i d$.

371. nuciformis, Hibb.

On.375. Nuttallianus, Lea.

377. nux-persica, $D_{u} \iota n k$.

385. occidentalis, Con.

389. orbiculatus, Hild.

390. Orbigni, Deville \&. H. 436. Philippii, Dup.

391. Oregonensis, Lea. 437. pictorum, Retz.

394. orthonotus, Con.

400. paliatus, Ravenal.

402. paludicolus, Gould.

403. paludosus, Mlore.

404. papyraceus, Gould.
405. Paraguayanus, Moric.

406. parallelopipedon, Lea.

407. parallelus, Con.

408. parallelus, Sorv.

409. Paranensis, Lea.

410. Parchappii, D'Orb.

411. Parreyssi, V.d. Busc.

412. parvus, Bar.

413. Patagonicus, D'Orb.

414. patulus, Lea.

417. penitus, Con.

418. Pequottinus, Linsley.

419. perdix, Lea.

420. peregrinus, Phil.

421. pernodosus, Lea.

422. perovalis, Con.

423. perovatus, $i d$.

424. perplexus, Lea.

425. perplicatus, Con.

426. personatus, Say.

427. perstriatus, Lea.

428. petrosus, Mort.

429. Petrovichii, Kiist.

430. Petterianus, $i d$.

431. Pfeifferi, Dunk.

432. phaselus, Lea.

433. phaseolus, Hild.

434. phaseolus, Sow.

43ว. Phillipsii, Con.

438. pictorum, Lam.

439. pictus, Lea.

440. pilaris, $i d$.

441. pileus, $i d$.

442. placitus, $i d$.

443. platyrhyncus, Rossm.

44. platyrhynchoideus, $D$.

445. plectophorus, Con.

446. plenus, Lea.

447. plexus, Con.

448. plicatus, Leach.

449. plicatus, Lesueur.

450. pliciferus, Lea. 
451. plombarius, Villa. 452. Poeyanus, Lea. 453. politus, Mouss. 454. ponderosus, Lea. 455. porrectus, Sowo. 456. Powellii, Lea. 457. prasinus, Con. 458. preciosus, Fér. 459. pressus, Lea. 460. Prevostianus, $i d$. 461. primigerius, Con. 462. profugus, Lea. 463. productior, $i d$. 464. productus, Con. 465. productus, Mouss. 466. pinuinosus, Schmedt. 467. pruneosus, Zeig. 468. proximus, Lea. 469. psammoicus, $D^{\prime} O r b$. 470. psoricus, More. 471. pulcher, Lea. 472. pullus, Con. 473. pulchellus, Fér. 474. pulvinulus, Lea. 475. pumilis, $i d$. 476. puniceus, Hald. 477. purpuratus, Lam. 478. purpuriatus, Say. 479. pusillus, Lea. 480. pustulatus, $i d$. 481. pustulosus, $i d$. 482. pygmæus, $i d$. 483. pyramidatus, $i d$. 484. quadrulus, Say. 485. radiatus, Lam. 486. radiatus, Lea. 487. Rajahensis, $i d$. 488. Rangianus, $i d$. 489. raristellus, More. 490. Ravenelianus, Lea. 491. rectus, Lam. 492. Reeveianus, Lea. 493. regularis, $i d$. 494. Retzii, Küst. 495. retusus, Lam. 496. rhombeus, $\mathrm{W}$ ag.
497. rhomboideus, Ward. 543. Stewardsonii, Lea.

498. robustus, Sow.

544. Stonensis, $i d$. 499. Roanokensis, Lea. 500. Roisii, Mich. 545. stramineus, Con. 546. striatus, Lea. 501. rotundatus, Lam. 502. Rousii, Dup. 503. rubellus, Con. 504. rubiginosus, Lea. 505. rufusculus, $i d$. 506. rugosus, $i d$. 507. Rumphianus, $i d$. 508. rusticus, $i d$. 509. sagittarius, $i d$. 510. sagittiformis, $i d$. 511. Sapotalensis, $i d$. 512. satur, $i d$. 513. saxeus, Con. 514. saxulum, MTort. 547. strigosus, $i d$. 548. suavidicus, $i d$. 549. subangulatus, $i d$. 550 . subconstrictus, Soro. 551. subovatus, Lea. 552. subplanus, Con. 553. subsinuatus, Koch. 554. subrotundus, Lea. 555. substriatus, $i d$. 556. subtentus, Say. 557. subtruncatus, Fit. 558. succissus, Lea. 559. sulcatus, $i d$. 560. superbus, $i d$. 561. symmetricus, $i d$. 515. Scamnatus, More. 516. Schoolcraftensis, Lea. 562. Taitianus, $i d$. 517. scobinatus, $i d$. 563. Tampicoensis, $i d$. 518. scutulatus, More. 564. Tappanianus, $i d$. 519. securis, Lea. $\quad 565$. Teconiatensis, id. 520. semiplicatus, Trosch. 566. tellinarius, Goldf. 521. Shepardianus, Lea. 567. tener, Lea. 522. Shurtleffianus, $i d$. 568. tenerus, Rav. 523. Shuttleworthii, id. 569. Tennesseensis, Lea. 52t. simus, $i d$. 525. simplex, $i d$. 526. Sloatianus, $i d$. 527. Smithii, Gray. 528. Solandri, Sovo. 529. solidus, Lea. 530. sordidus, $i d$. 531. Sowerbianus, $i d$. 532. sparsus, $i d$. 533. spatulatus, $i d$. 534. spheniopsis, More. 535. spinosus, Lea. 536. Spinelli, Villa. 537. splendidus, Lea. 538. Staffenensis, Forbes. 539. stapes, Lea. 540. stagnalis, Con. 541. stegarius, $i d$. 542. Stevenianus, Kryn.
570. tenuis, Gray.

571. testudineus, More. 572. teretiusculus, Phil. 573. terrenus, Mlort. 574. tetralasmus, Say. 575. Tigris, Fér. 576. tortivus, Lea. 577. trapezoides, $i d$. 578. triangularis, $B a r$. 579. trigonus, Lea. 580. trigonus, Rom. 581. Tripolitanus, Fér. 582. Troostensis, Lea. 583. Troschelianus, $i d$. 584. trossulus, $i d$. 585. truncatus, Schum. 586. truncatus, Speng. 587. truncatus, Swain. 588. truncatosus, Potiez. 
589. truncatosa, Mich. 590. tuberculatus, Bar.

591. tuberculatus, Fir.

592. tuberculosa, Valen.

593. tuberosus, Lea.

594. tumescens, $i d$.

595. tumidus, Retz.

596. tumidulus, Lea.

597. tumulatus, Mort.

598. turgidus, Lea.

599. 'Turtonii, Payr.

600. 'I'uomeyi, Lea.

601. umbrosus, $i d$.
602. undulatus, Bar.

603. undulatus, Lea.

604. unicolor, $i d$.

605. uniformis, Sow.

606. Urii, Flem.

607. utriculus, Lea.

608. Valdensis, Mant.

609. Vanuxemensis, Lea.

610. variabilis, $i d$.

611. varicosus, $i d$.

612. Vaughanianus, $i d$.

613. ventricosus, $B a r$.

614. venustus, Lea.
615. Verreauxianus, id. 616. verrucosus, Bar.

617. vibex, Con.

618. vindiflavus, Küst.

619. Voltzii, Koch.

620. Watereensis, Lea.

621. Whentleyanus, $i d$.

622. Whiteianus, $i d$.

623. Woolwichii, ITore.

624. Zeiglerianus, Lea.

625. Zeyheri, Mrenke.

626. zigzag, Lea.

627. Zimermani, Steutz.

\section{Figure.}

Unio tublrculatus. Pl. 33. Fig. 183. Shell, showing strongly developed lateral and cardinal teeth, the latter of which is striately grooved.

\section{Genus 2. HYRIA, Lamarck.}

Animal; simitar to that of Unio, but with the posterior orifices prolonged into siphons.

Shell; obliquely triangularly anriculated on each side; linge composed of two lateral tecth, the anterior in each value, elongated, the posterior multipartite, approaching the form of $u$ cardinal tooth.

The genus Hyria, which corresponds to Mr. Lea's subgenus Triquetra, has been limited until lately to three species, natives of South America, in which the animal has its posterior orifices, according to Dr. Gray, prolonged into siphons, whilst the shell is characterized by a peculiar obliquely triaugular form, eared on each side, with a hinge of two lateral teeth, of which the anterior is much elongated, whilst the posterior is much shorter and has more the form of a cardinal tooth. In $1857 \mathrm{Mr}$. Lea referred to this genus a curiously twisted elongated Naiad from China, H. contorta, but this shell appears to me to be very far removed from the South American type. 


\section{Species.}
1. Bromniana.
2. contorta.
3. corrugata.
4. subviridis.

Figure.

Hyria corrugata. Pl. 31. Fig. 179. Shell, showing its obliquely triangular form, and symphynote-cared growth, with the elongated lateral tooth of the linge.

\section{Genus 3. ANODONTA, Bruguière.}

Animal ; similar to that of Unio.

Shell; somewhat obliquely transverse, thin; hinge without tecth, working only by a prolonged marginal ligament.

The Anodons are a tribe of Naiads, thin-shelled and toothless, affecting still, muddy waters. The animal is in all respects like that of Unio, the mantle-margins are open in front, giving passage to a large tongue-like foot, and closed behind with two pouting siphonal orifices, the lower of which is invested with a jagged fringe. They are much more numerous in individuals in Britain than the Unios; but we have only one species. All the Anodons of Europe are, indeed, pronounced to belong to the single species $A$. cygnea, although it has been described under different phases more than twenty times over. The shell varies interminably, according to the conditions of food, race, and circumstances of habitation, and none of the varieties appear to have any definite limit.* The proportion of Anodons to Unios in North America, in respect of species, is about one to eight; in South America they are nearly equal in number to the Unios; from Asia we have only eight Anodons as yet, whilst of Unios from that district between forty and fifty have been described; two Amodons are recorded from Africa, and one from Australia.

* "After a wearisome cxamination of a multitude of forms, both native and forcign, not only must we dissent from the division of this polymorphous bivalve into those numerous species into which it has been scparated by the continental writers, but even demur to the possibility of arranging the diversities of shape and colouring into strictly defined varietics, so imperceptibly docs one form glide into another, searcely indicating by any prepronderance of peculiarities under which heading it should be ranked."-Forbes and Ilanley, Brit. Mloll., vol. ii. p. 156. "The Anodons live in lakes, ponds, marshes, and muddy rivers, crawling slowly on the mud, and leaving a more or less marked groove after them. In the winter, and especially in the summer when the water dries up, they bury themselves in the inud. They fecd on decomposed animal and vegetable substances, and the size and solidity of the shell depends on the abuudance of the food and the state of quietness or motion and of calcareous matter in the water in which they happen to reside." Gray, Turton's Man., p. 273. 
Species.

1. Abyssina, More.

2. angulata, Lea.

3. anserina, Spix.

4. antiqua, $D^{\prime} O r b$.

5. arenata, Fér.

6. arcuata, Caill.

7. argentea, Lea.

8. Arkansensis, $i d$.

9. atrovirens, Phil.

10. aurata, Kiist.
45. Footiana, Lea.

46. fragilis, Lam.

47. fragilis, Menke.

48. Georginæ, Gray.

49. gibbosa, Say.

50. gibba, Bens.

51. gigantea, Lea.

52. gigantea, Midd.

53. glabra, Zeigl.

54. glauca, Valen.

11. Bambousearum, Mrore. 55. globosa, Lea.

12. Benacensis, Filla.

13. Benedictensis, Lea.

14. Blainvilliana, $i d$.

15. Buchanensis, $i d$.

16. Burroughiana, Chemn.

17. Californiensis, Lea.

18. Chaiziana, Rang.

19. Charpentierii, Küst.

20. Chinensis, Fér.

21. ciconia, Gould.

22. cimbulia, Villa.

23. Cordieri, $D^{\prime} O r b$.

24. cornea, Phil.

25. crassa, Swain.

26. crassa, Menke.

27. crepera, Lea.

28. crispata, Lam.

29. Cumingii, Lea.

30. curvata, Fér.

31. cylindracea, Lea.

32. cygnea, Lam.

33. decora, Lea.

34. denigrata, $i d$.

35. Dunlopiana, $i d$.

36. edentula, $i d$.

37. elongata, Swain.

38. ensiformis, Spix.

39. esula, Jan.

40. exilis, Lea.

41. ferruginea, $i d$.

42. Ferrusaciana, $i d$.

43. fluviatilis, $i d$.

44. folium, Fér.
56. gracilis, $i d$.

57. grandis, Say.

58. Gualliani, Recluz.

59. Harpethensis, Lea.

60. Heldii, Küst.

61. Housatonica, Linsl.

62. imbecilis, Say.

63. implicata, $i d$.

64. impura, id.

65. inoscularis, Gould.

66. Jobæ, Dupuy.

67. lato-marginata, Lea.

68. leprosa, Parr.

69. Lininæana, Lea.

70. longina, Spix.

71. lucida, $D^{\prime}$ Orb.

72. lugubris, Say.

73. lurulenta, More.

74. magnifica, Lea.

75. Margattana, $i d$.

76. Montezuma, $i d$.

77. Moulinsiana, Dup.

78. Mortoniana, Lea.

79. Nilssoni, Kiist.

81. oblita, $i d$.

82. obtusa, Spix.

83. Onowensis, Lea.

84. Oregonensis, $i d$.

85. opaca, $i d$.

86. ovata, $i d$.

87. Parishii, Gray.
80. Nuttaliana, Lea.
88. Patagonica, Lam.

89. pavonia, Lea.

90. Pepiniana, $i d$.

91. picta, Swain.

92. plana, Lea.

93. placita, Hald.

94. polita, Mouss.

95. porcifer, Gray.

96. puelchana, $D$ 'Orb.

97. purpurea, Valen.

98. Saliveniana, Gould.

99. salmonia, Lea.

100. Schaefferiana, $i d$.

101. Schröteriana, $i d$.

102. Sedacowii, Siemasko.

103. siliquosa, Spix.

104. sinuosa, Lam.

105. sinuosa, Swain.

106. sirionos, $D^{\prime}$ Orb.

107. soleniformis, Ben.

108. soleniformis, $D^{\prime} O r$.

109. solidula, Dev. \& Hup.

110. Spixii, D'Orb.

111. Stewartiana, Lea.

112. subcrapa, $i d$.

113. subcylindrica, $i d$.

114. suborbiculata, Say.

115. subvexa, Con.

116. Tawaii, Rang.

117. tenebricosa, Lea.

118. tenuis, $i d$.

119. tetragona, $i d$.

120. tortilis, $i d$.

121. trapezialis, Lam.

122. trigona, Spix.

123. Troutwiniana, Lea.

124. undulata, Say.

125. uniopsis, Lam.

126. virens, Lea.

127. Wahlamatensis, $i d$.

128. Wardiana, $i d$.

129. Wheatleyi, $i d$.

130. Woodiana, $i d$. 


\section{Figures.}

Anodonta cygnea. Pl. $P$. Shell, with animal, showing the fringed siphonal orifices and protruded tongue-like foot.

Anodonta angulata. Pl. 31. Fig. 180. Shell of a peculiar trapeziform shape, showing the toothless ligamentary hinge.

\section{Genus 4. IRIDINA, Lamarck.}

Animal; similar to that of Unio, with the posterior orifices prolonged into two short unequal siphonal tubes.

Shell ; ovate or elongated, with the linge toothless, but crenately tubercled.

As in Hyria, the posterior orifices of the animal of Iridina are prolonged into two short unequal siphons. The shell is not so thin as in Anodonta, but it is never massive as in Unio; the hinge is, nevertheless, toothless. In the place of teeth a number of crenated tubercles are formed along the linge margin, and in the species we have selected for illustration they are developed very largely and wrinkle-like.

The Iridina do not consort either with the Unios or Anodons. They are all natives of Africa, living abundantly in the Nile along with another genus peculiar to that habitat, Galathea radiata. The shells are used, says the African traveller M. Cailliaud, by the natives of Lower Egypt in preparing flax, and also as spoons for measuring oil, butter, and different kinds of provisions. The latest discovered species, I. Spekii, was collected by Captain Speke in the great freshwater Lake Tanganyika in Central Africa. It is of the same type as $I$. ovata, selected by Courad as the type of a genus with the name of Pleiodon.

\section{Species.}
1. cælestis, Lea.
4. Leaii, Sorw.
7. Spekii, Woodwo.
2. dubia, $i d$.
5. ovata, Swain.
8. valens, Parr.
3. exotica, Lam.
6. rubens, Lam.
9. Wallergi, Krauss.

\section{Figure.}

Iridina ovata. PI. 33. Fig. 184. Shell, with a valve dropped to show the crenately tubercled hinge. 


\section{Genus 5. MYCETOPUS, D’Orbigny.}

Animal; with the mantle-lobes disunited; siphonal tubes none; foot very lony, cylindrical, produced and inflated into a knob at the extremity.

Shell; thin, much elongated, cylindrical, gaping at each end, particularly at the anterior end; umboes central; hinge linear, toothless; ligament marginal.

A Naiad of very distinct typical character from the rest of the family, of which three species were discovered in the Bolivian Republic of South America by M. D'Orbigny, and a fourth has been found there since. The peculiarities of the animal are that it has no siphonal tubes or orifices, the mantle-margins being entirely free, and it has an clongated club-like foot, which does not appear to be drawn within the shell. This supposition is moreover favoured by the conspicuous gaping of the shell at its front extremity.

\section{Species.}

1. siliquosus, $D^{\prime} O r b$. 3. ventricosus, $D^{\prime} O r b$. 4. Weddellii, Poey.

2. Soleniformis, D'Orb.

\section{Figure.}

Mrcetopus Soleniformis. Pl. 32. Shell, showing the lateral and ventral sinus with gaping extremities.

\section{Family 3. TRIGONACEA.}

\section{Genus 1. TRIGONIA, Bruguière.}

Animal; shaped litie the shell, with the mantle-lobes disunited about three-fourths of their extent, and rather thicliened and crimped at the edge; foot long, and sharply angled, bordered by two crenulated ridges.

Shell ; equivalve, obliquely triangularly ovate, lined internally with Tustrous ividescent nacre; linge composed of two oblong divaricate lamelliform teeth in one valve, regularly striately grooved on both sides, interlocking with three to four teeth in the other valve, grooved on one side only; ligument external, marginal. 
Of all bivalve shells the single genus Trigonia, constituting a fimily of itself, is the most remarkable, on account of the lustre and brilliant iridescence of its internal nacre. It has, too, of all bivalves, the most closely interlocking hinge. The amateur prides himself on the display which the pearly lining of the Trigonia valves, exquisitely rose or orange-tinted, makes in his cabinet; and when separated, it requires no little ingenuity and neatness of handling to close them again. The animal has a sharply angled crenated-edged foot, and it would appear to possess considerable muscular action; for Mr. Samuel Stutchbury, while collecting Trigonice in Sydney Harbour, placed one on the gunwale of his boat, which leaped overboard, clearing a ledge of four inches. They are confined to the Australian Seas.

\section{Species.}
1. Lamarckii, Gray.
3. nobilis, Adams.
4. Strangei, $i d$.
5. uniophora, Gray.
2. margaritacea, Lam.

\section{Figure.}

Trigonta margarticea. PI. 31. Fig. 177. Shell, with one valve dropped to show its striately grooved hinge and rose-pearly interior.

\section{Family 4. ARCACEA.}

Shell; generally equivalve, with the linge composed with numerous small teeth set either in a straight or a curved line.

The shells of this family are characterized by a peculiarly distinct form of hinge. The interlocking teeth are very numerous, fine, and irregular, varying strikingly in detail in different species, and they are set either comb-like in a straight line or in a curve. The ligament is external in some genera, internal in others; and the shell is in some forms of Arcacea unusually stony and ponderous, while in others it has the lightness and transparency of horn. The aninals have the mantle-lobes freely open, not formed into siphons, and they have mostly a deeply grooved byssusspinning foot. The genera are-

Arca.

Cucullea.

Pectunculus. Solenella. 


\section{Genus 1. ARCA, Linnaus.}

Animal; oblong; mantle frecly open, simple or fringed, no siphons ; foot large, oblong, bent, grooved liroughout its length so as to form a disk, with plain or slightly crimped margins, a byssal gland at its base, byssus compact; mouth surrounded by labia formed out of the extremities of the branchice, no true palps. (Forbes.)

Shell; sometimes equivalve, sometimes inequivalve, ventricose, mostly radiately ribbed, corered with a horny or fibrous hairy epidermis; umboes prominent, more or less distant from each other, according to the width of the ligament area; hinge linear, straight or slightly arched, with the teeth small and vory numerous; ligament external, attached superficially to the area between the umboes.

The Arks or boat-shells comprehend two sections of very distinct composition and sculpture, arising out of a difference in the habit of the animal. The Arce proper have a strongly ribbed shell of marble-white substance, enveloped by a horny or fibrous epidermis, and its mollusk is said to acquire motion by the contraction and expansion of its foot, after the manner of a snail. They live consequently free, and in some instances have shells remarkably solid and ponderous. Another feature of this group is that the right valve of the shell is frequently smaller than the left, dropping a little way into it, and it is always less elaborately sculptured, as if the right mantle-lobe of the animal were weaker in its functions than the left. The section of Byssoarca, as the name denotes, live attached to rocks by a byssus, which passes from the animal's foot through a rude gaping of the shell; and the shells of this group are of much lighter substance, and the hinge is more simple, the teeth are smaller, and the ligament is proportionally weaker. In all the species of this genus the hinge is composed of a somewhat irregular set of plaits, but the valves very closely interlock with them.

The Arks are of world-wide distribution, but the greater number are inhabitants of the western shores of South and Central America. The British fauna includes three species.

\section{Species.}

1. alternata, Reeve.

2. ambigua, $i l l$.
3. Americana, Gray.

4. angicostata, Reeve.
5. angulata, King.

6. anomala, Reeve. 
7. antiquata, Linn.

8. auriculata, Lam.

9. Aviculoides, Reeve.

10. barbata, Linn.

11. Brasiliana, Lam.

12. brevifrons, Sow.

13. bullata, Reeve.

14. cælata, $i d$.

15. cepoides, $i d$.

16. chalcanthum, $i d$.

17. cistula, $i d$.

18. clathrata, $i d$.

19. cometa, $i d$.

20. compacta, $i d$.

21. concinna, Sow.

22. contraria, Reeve.

23. cornea, $i d$.

24. crebricostata, $i d$.

25. cunealis, $i d$.

26. cuneata, $i d$.

27. crenata, $i d$.

28. cymbæformis, $i d$.

29. decussata, $i d$.

30. Deshayesii, Hanley.

31. disparilis, Reeve.

32. divaricata, $i d$.

33. Donaciformis, $i d$.

34. emarginata, Sow.

35. fasciata, Reeve.

36. ferruginea, $i d$.

37. formosa, Sow.

38. fusca, Brug.

39. Gambiensis, Reeve.

40. gibbosa, $i d$.

41. globosa, $i d$.

42. gradata, Brod.

43. grandis, $i d$.

44. granosa, Linn.
45. gubernaculum, Reeve.

46. Hankeyana, $i d$.

47. Helblingii, Brug.

48. hians, Reeve.

49. holoserica, $i d$.

50. illota, $i d$.

51. imbricata, Brug.

52 . inæquivalvis, $i d$.

53. incongrua, Say.

34. Indica, Gmel.

55. inflata, Reeve.

56. Japonica, $i d$.

57. labiata, Sow.

58. labiosa, $i d$.

59. lacerata, Linn.

60. lactea, $i d$.

61. lateralis, Reeve.

62. lima, $i d$.

63. Lithodomus, $i d$.

64. loricata, $i d$.

65. lurida, $i d$.

66. Luzonica, $i d$.

67. maculata, $i d$.

68. maculosa, $i d$.

69. minuta, $i d$.

70. multicostata, Sow.

71. mutabilis, Reeve.

72. myristica, $i d$.

73. navicella, $i d$.

74. navicularis, Brug.

75. nivea, Chemn.

76. Noæ, Linn.

77. nux, Sow.

78. obesa, $i d$.

79. obliqua, Reeve.

80. obliquata, Gray.

81. obtusa, Reeve.

82. occlusa, $i d$.
83. ocellata, Reeve.

84. olivacea, $i d$.

85. ovata, $i d$.

86. Pacifica, $i d$.

87. parva, $i d$.

88. pertusa, $i d$.

89. pexata, Say.

90. pilula, Reeve.

91. pulchella, $i d$.

92. radiata, $i d$.

93. reversa, Gray.

94. rliombea, Born.

95. rotundicostata, Reeve.

96. rufescens, $i d$.

97. scapha, Chemn.

98. sculptilis, Reeve.

99. secticostata, $i d$.

100. semitorta, Lam.

101. senilis, Linn.

102. setigera, Reeve.

103. solida, $i d$.

104. striata, $i d$.

105. symmetrica, $i d$.

106. tenebrica, $i d$.

107. tenella, $i d$.

108. tetragona, Poli.

109. tortuosa, Linn.

110. transversa, Say.

111. trapezia, Desh.

112. trapezina, Lam.

113. truncata, Reeve.

114. tuberculosa, Sow.

115. velata, Reeve.

116. vellicata, $i d$.

117. virescens, $i d$.

118. volucris, $i d$.

119. zebra, $i d$.

120. Zebuensis, id.

\section{Figure.}

Arca Brasiliana. Pl. 34. Fig. 188. Shell, exhibiting the broad black ligament area, and row of teeth set in a slight curve. 


\section{Genus 2. CUCULLAA, Lamarck.}

Animal; similar to that of Arca.

Shell; rather inequilateral, trapeziform, ventricose; linge linear, straight, narrow, very slightly toothed; teeth at the extremities, prolonged; place of adhesion of the posterior muscle in each valve chambered.

This genus is founded upon a character which many conchologists think is not worthy of causing a dismemberment of the species from those of Arca. In many species of Arca the place of attachment of the posterior muscle in each valve is bounded by a gentle ridge. In Cucullcea the ridge is so far developed as to form a chamber; and there is a general peculiarity about the shell in all its details. The hinge is quite marginal, with the teeth almost obsolete, yet at the extremities of the hinge the teeth are prolonged obliquely almost into ribs. Two species have been described, inhabiting China, Nicobar, and the Mauritius, but it is more than probable that they are varieties of the same, originally described by Martini.

\section{Species.}

1. concamerata, MLart. 2. granulosa, Jonas.

Figure.

Cuculiea concamerata. Pl. 34. Fig. 187. Shell, with the left valve dropped to show the posterior chambered ridge and narrow linear hinge.

\section{Genus 3. PECIUNCULUS, Lamarck.}

Animal; orbicular, its mantle freely open with simple margins, which are somewhat enlarged in the branchial and anal regions; foot large, semilunar, deeply grooved so as to form a disk with undulated edges; no byssus; lips formed of a linear prolongation of the branchial lamine. (Forbes.)

Shell; orbicular, lenticular, equivalve, slightly inequilateral, mostly covered with a hairy epidermis; umboes but little separated from each other, the intervening ligament area being small; teeth set in a curve, the middle ones being generally more or less obsolete. 
Compared with the Arks the Pectunculi hare a rounder lens-shaped shell, with the hinge teeth set in a curve. The shell is moreover characterized by a richer display of colour, varying from a dark brown to a rich purple and rose, and even brilliant orange; and the ligament area between the umboes is narrower and more deeply excavated. The animal exhibits strongly the peculiarity noticed in this and the preceding family of the foot being crimped round the edge, and it has no byssus.

The genus is very widely distributed, chiefly about Central America and the West Indies. There is only one British species.

\section{Species.}

1. angulatus, Lam.

2. assimilis, Soro.

3. aurifluus, Reeve.

4. bicolor, $i d$.

5. cancellatus, $i d$.

6. castaneus, Lam.

7. Delessertii, Reeve.

8. flammeus, $i d$.

9. formosus, $i d$.

10. giganteus, $i d$.

11. glycimeris, Turton.

12. holosericus, Reeve.

13. inæqualis, Sow.

14. intermedius, Brod.

15. laticostatus, Quoy.

16. lineatus, Reeve.

17. longior, Sow.

18. maculatus, Brod.
19. marmoratus, Chemn.

20. morum, Reeve.

21. multicostatus, Soro.

22. multistriatus, Desh.

23. nodosus, Reeve.

24. obliquus, $i d$.

25. oculatus, $i d$.

26. oratus, Brod.

27. pallium, Reeve.

28. parcipictus, $i d$.

29. Pectenoides, Desh.

30. pectinatus, Lam.

31. Pectiniformis, id.

32. pennaceus, $i d$.

33. perdix, Reeve.

34. pertusus, $i d$.

35. pilosus, Lam.
36. radians, $i d$.

37. roseus, Reeve.

38. rubeus, Lam.

39. scriptus, $i d$.

40. sericatus, Reeve.

41. Siculus, $i d$.

42. spadiceus, $i d$.

43. spurcus, $i d$.

44. stellatus, Lam.

45. striatularis, $i d$.

46. strigilatus, Sow.

47. Tellinæformis, Reeve.

48. tenuicostatus, $i d$.

49. tessellatus, Sono.

50. undulatus, Lam.

51. violascens, $i d$.

52. vitreus, $i d$.

\section{Figure.}

Pectunculos aurifuuds. Pl. 34. Fig. 1S5. Shell, shoming its rounded form and variegated colour, with tho teeth set in a curve.

\section{Genus 4. NUCULA, Lamarck.}

Animal; subtrigonal, its mantle fiecly open, with or without siphonat tubes and with plain edges; foot deeply grooved and forming an ovate pedunculated dish, with a serrated edge. 
Shell; equivalve, sometimes thin, sometimes rather solid, often pearly within, covered externally with a brownish, or shining olive, horny epidermis; umboes contiguous, the ligament being contained in a central internal pit, on either side of which the teeth are numerous and comb-like.

An interesting and rather extensive scries of bivalves, mostly small, are included under this head, comprising two well-marked divisions. In the first, the Nucula proper, the mantle-lobes of the animal are freely open, without siphonal tubes. In the second division, which, further subdivided, form the genera Leda and Yoldia of authors, there is a pair of small siphonal tubes. The shell is characterized throughout by a row of fine comb-like teeth, and the ligament, instead of being external, is contained within a central internal pit. The substance of the shell is thin, covered mostly by a shining horny epidermis, and the inner surface is generally pearly.

The Nucula are deep-dwelling mollusks, inhabitants chiefly of the boreal and arctic seas.

Species.

1. arctica, Gray. 24. decussata, Sow.

2. Belcheri, Hinds.

3. Bellotii, Adams.

4. bellula, $i d$.

5. buccata, Stimp.

6. crlata, Hinds.

25. delectabilis, Adams.

47. lævigata, Spengl.

26. delphinodonta, Migh. 49. lata, Hinds.

27. divaricata, Hinds.

50. Layardii, Adams.

28. eburnea, Soro.

29. electa, Adäans.

7. Cascoensis, Migh.

30. Elenensis, Soro.

31. elongata, $i d$.

8. castanea, Adams.

9. castrensis, Hinds.

10. Chuva, Gray.

11. complanata, Möll.

32. emarginata, Lam.

51. lepida, $i d$.

52. lepidula, $i d$.

33. excavata, Hinds.

53. limatula, Say.

54. Iucida, Gould.

55. lucida, Lovén.

34. exigua, Sow.

56. lugubris, Adams.

35. fabula, $i d$.

36. fastidiosa, Adams.

57. lyrata, Hinds.

12. concinna, Adams.

13. convexa, Soro.

14. costellata, $i d$.

15. crassa, Hinds.

16. crenifera, Sow.

17. crispa, Hinds.

18. Cumingii, $i d$.

19. cuneata, Sow.

20. curvirostrata, $i d$.

37. fulgida, $i d$.

58. margaritacea, $A d$.

59. marmorea, Hinds.

38. gibba, $i d$.

60. micans, Adans.

39. gibbosa, Sow.

40. glacialis, Gray.

61. minuta, Miill.

41. gloriosa, Adams.

42. hyperborea, Lovén.

62. mirabilis, Adams.

63. mitralis, Hinds.

64. Mülleri, Gray.

43. inconspicua, Adams.

65. myalis, Couth.

44. inornata, $i d$.

66. nana, Hinds.

21. decens, Adams.

22. declivis, Hinds.

45. Jamaicensis, D'Orb.

67. nasuta, Sow.

23. decora, Adams.

46. Japonica, Adams.

68. navicularis, Couth.

69. Nicobarica, Lam. 
70. nitida, Sow.

71. nitidula, Adams.

72. obesa, Stimp.

73. obliqua, Lam.

74. ornata, D'Orb.

75. Patagonica, $i d$.

76. paulula, Adams.

77. Paytensis, id.

78. pella, Linn.

79. pernula, Müll.

S0. pisum, Sow.

81. plicifera, Adams.

82. Polii, Phil.

83. polita, Sow.

84. Portlandica, Hitch.
85. proxima, Say.

86. puellata, Hinds.

87. pulchra, $i d$.

88. pygmæa, Munst.

89. radiata, Hanley.

90. recta, Hinds.

91. recurva, Conrad.

92. retusa, Hinds.

93. rugulosa, Sow.

94. sapotilla, Gould.

95. semisulcata, $A d$.

96. serotina, Hinds.

97. siliqua, Reeve.

98. simplex, Adams.

99. Sowerbyana, D'Orb.
100. splendida, Phil.

101. Strangei, Adams.

102. striata, Sow.

103. striolata, Adams.

104. sulcata, $i d$.

105. sulculata, Gould.

106. Taylori, Hanley.

107. Tellinoides, $W$ ood.

108. tenella, Hinds.

109. tenuis, Mont.

110. tenuisulcata, Couth.

111. 'Thraciæformis, Storer.

112. tumida, Hinds.

113. ventricosa, $i d$.

114. vitrea, $D^{\prime}$ Orb.

\section{Figure.}

Nucula crassa. Pl. 31. Fig. 178. Shell, with the left valve dropped to show the comb-like teeth on either side of a central pit containing the ligament.

\section{Genus 5. SOLENELLA, Sowerby.}

Animal; mantle margins slightly finged, a pair of long and slender united siphonal tubes; foot deeply grooved, forming an oval disk.

Shell; thin, longitudinally oval, equivalve; linge composed of three or four small teeth anteriorly, and a row of mumerous small comb-like teeth posteriorly; ligament elongated, external.

A very characteristic genus, intermediate between Solen and Nucula, founded on a single species collected many years since by Mr. Cuming at Valparaiso. It is very thin in substance and is covered with a shining olive horny epidermis. The hinge is composed of a comb-like row of teeth like those of Nucula, but only in the posterior side, and the ligament is quite external. The animal resembles that of the Leda division of Nuculee, having a pair of siphons.

\section{Figure.}

Solenelda Norrisir. Pl. 43. Fig. 231. Shell, with one valve dropped to show the posterior comb-like teeth and external ligament. 


\section{Family 5. CARDIACEA.}

Shell; equivatve, mostly ventricose and heart-shaped, and, with. rare exception, radiately ribberl ; linge composed of two strong cartinal teeth in each valve; lateral tecth variable; ligament external.

The family Cardiacea is constituted of the well-known genus of Cockles, Curdium, added to on the one side by two exotic genera, Cypricartia and Cardita, which show affinities with Chana; and by the Heart Cockles, Isocarria, on the other, which are more allied to Cyprina. The hinge of the shell is composed of rather strongly-developed cardinal teeth, with, frequently, an elongated lateral tooth on one or both sides. The animal of this family varies in a manner which renders the association of these genera less sntisfactory. In Cardium the mantle-lobes are freely open in front for the passage of a large and active foot, and closed behind with a pair of short siphons; in Cypricartia, according to Mr. Woodward's description of $C$. Solenoides, the lobes are united, with only moderate openings for the foot and siphonal orifices, while in Cardita the lobes are described by M. Deshayes as being entirely disunited and having consequently no siphonal tubes. The probability is that the animal varies in these respects even in the same genus, according to the nature of its habitat, the species living in stoue-borings having a less-developed foot and a more closed-up mantle than the free-living species.

Cypricardia. Cardita. Cardum. Isocardia.

\section{Genus 1. CYPRICARDIA, Lamarck.}

Animal; (of C. Solenoides) with mantle-lobes united, cirrated belind; pedal opening moderate; foot small, compressed, with a large byssal pore near the heel; siplons short, conical, unequal, cirrated externally; orifices fringed. (Woodward.)

Shell ; equivalve, very inequilateral, elongately ovate, never ribbed, anterior side very short, posterior mostly angled; hinge composed of three short teeth beneath the umbo of each valve, and a single elongated, rather remote, lateral tooth, which is sometimes nearly obsolete.

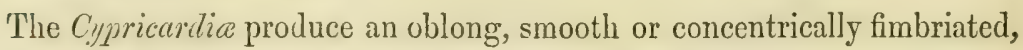
shell of a peculiar opake white substance, delicately and variously tinted with purple, rose, or orange; and the aninal of $C$. Guinaica, collected by 
Mr. Cuming in coral sand on the reefs at Lord Hood's Island, was found to yield a rich violet juice. Many of the species are either borers or crawl into the borings in shells and rocks of other mollusks; and the foot of these species, according to Mr. Woodward, is only feebly developed, whilst the mantle-lobes are united, except for the passage of the small foot, and for the siphonal orifices. The free-living species have, probably, a larger foot, with more freedom of action.

C. oblonga, the largest and most beautifully coloured species of the genus, has been collected both at Australia and the Philippine Islands.

Species.

1. angulata, Lam

2. coralliophaga, $i d$.

6. laminata, Reeve. $\quad$ 10. rostrata, Lam.

3. decussata, Reeve.

7. lirata, $i d$.

11. serrata, Reeve.

8. obesa, $i d$.

12. Solenoides, $i d$.

4. Guinaica, Lam.

9. oblonga, Sow.

13. vellicata, $i d$.

5. incarnata, Reeve.

\section{Figure.}

Crpricardia Guinaica. Pl. 35. Fig. 192. Shell, showing its opake white pink-tinged substance, with the cardinal teeth and remote shelflike lateral tooth.

\section{Genus 2. CARDITA, Lamarck.}

Animal; with the mantle-lobes free, except between the siphonul orifices; branchial margin with conspicuons cirri; foot rounded and grooved, spinning a byssus. (TVoodward.)

Shell; equivalve, very inequilateral, sometimes elongately oblong, sometimes orbicular, strongly radiately ribbed; linge composed of two oblique teeth in one valve, one of which is more or less clongated according to the shape of the shell, interlocking with a single corresponding tooth in the other.

The animal of Carlita has been an object of as much contradictory criticism among malacologists as the Chancleon among travellers. M. Deshayes, following the observations of Poli and De Blainville, declares that the mantle-lobes are disunited throughout their whole extent, and camnot therefore have any siphonal perforations; while MIr. Wooctward, whose description, as being the more detailed, we have adopted above, asserts, that 
the mantle-lobes are unitcd behind between siphonal orifices. M. Deshayes thinks moreover, that Lamarck's suspicion of Carclita having a byssus is without foundation; Mr. Woodward especially describes the foot to be grooved, spinniug a byssus. The question as to the presence or absence of siphonal orifices in different species remains to be determined. A list of fiftecn spccies, presumed to have the habit of spiuning a byssus, are set apart by the Messrs. Adams under the title originally proposed for them by De Blainville, of Mytilicardia.

The shells of the byssus-spinning Curtite, as in the genus Arca, are of lighter structure than those in which there is no byssus, and in which the shell is often massive, with the valves heavily and closely interlocking romud the ventral margin. Many of the shells are very richly variegated with colour, and some are ornamented with a profusion of vaulted scales.

'The genus is widely distributed in both hemispheres, but does not reach so far north as the British shores.

\section{Species.}

1. abyssicola, Hinds. 24. distorta, Reeve.

2. aculeata, Phil.

3. ajar, Adans.

4. amabilis, Desh.

5. angisulcata, Reeve.

6. antiquata, Limn.

7. australis, Quoy.

3. Belcheri, Desh.

9. bimaculata, $i d$.

10. borealis, Conr.

11. calyculata, Brug.

12. conaliculata, Reeve.

13. Cardioides, $i d$.

14. castoruca, Desh.

15. compressa, Reeve.

16. Comradi, Shutt.

17. corbis, Phil.

18. crassicostata, Lam.

19. crassa, Gray.

20. crenulata, Desh.

21. Cumingii, $i d$.

22. Cuvieri, Brod.

23. difficilis, Desh.
25. elegantulus, Desh.

26. Essingtonensis, id.

27. excavata, $i d$.

28. cxcisa, Phil.

29. fabula, Reeve.

30. ferruginosa, Adams.

31. flabellum, Reeve.

32. flammea, Mich.

33. gibbosa, Reeve.

34. Gunnii, Desh.

35. incrassata, Sow.

36. Jukesii, Desh.

37. Koreensis, $i d$.

38. lacunosa, Reeve.

39. laticostata, $i d$.

40. marmorea, $i d$.

41. megastropha, Gray.

42. muricata, Sono.

43. nitida, Reeve.

44. nodulosa, $i d$.

45. ovalis, $i d$.

46. pica, $i d$.
47. Preissii, Menke.

48. procera, Gould.

49. purpurata, Desle.

50. radula, Reeve.

51. rostrata, Gmel.

52. rufescens, Reeve.

53. semen, $i d$.

54. Sowerbyi, Desh.

55. spurca, Sow.

56. squamifer, Desh.

57. sulcata, Lam.

58. tegulata, Reeve.

59. teretiuscula, Phil.

60. tricolor, Sow.

61. tridentata, Say.

62. tumida, Brod.

63. umbilicata, Desh.

64. variegata, Brug.

65. varia, Brod.

66. ventricosa, Gould.

67. vestita, Desh.

68. Zelandica, $i d$. 


\section{Figure.}

Cardita laticostata. Pl. 35. Fig. 191. Shell of a richly varicoloured species, with the left valve dropped to show the strong teeth of the hinge.

\section{Genus 3. CARDIUM, Linnæus.}

Animal; suborbicular, tumicl, its mantle fieely open in front, with plain or, less frequently, fringed edyes, conspicuously fimbriated in the neighbourhood of two very short, slightly-separated siphons, the branchial one of which is ahoays fringed at the orifice; foot very large, cylindrical, geniculate. (Forbes.)

Shell; equivalve, iather inequilateral, mostly globosely ventricose, heart-shaped, sometimes gaping belind, generally strongly ribbed, the ribs being armed with scales or spines; hinge composed of two strong cartinal tecth in each valve interlocking crosswise, and two distant lateral teeth, all of which, in some few species, become partially or wholly obsolete.

A genus abounding in shells of such exquisite varieties of form, colour, and prickly sculpture as Cardium, is naturally one of great interest to the collector; even the British species, of which there are nine or ten, include two of large size and of very claborate sculpture; and among the multitude of exotic forms the shells are truly beautiful. The animal has a largely-developed foot, apt at burrowing or leaping, with a pair of short fringed siphonal tubes pouting from the posterior united portion of the mantle-lobes; and, to judge from what passes on our own shores, is not lightly esteemed as an article of food.*

The foreign species of Curtinn, numbering about a hundred and fifty, have been drafted into sixteen genera and subgenera, of which the following may be regarded as types:-C. costatum (Cardium proper), $C$. Belcheri (Bucardium, Gray), L. Panamense (Trachycardium, Mörch.), C. aculeatum (Acanthocardia, Gray), C. edhule (Cerostoderma, Poli.), C. Granlandicum (Serripes, Beck.), C. ringiculum (Papyridea, Swainson), C. Uulluta (Fulvia, Gray), C. lcevigutun (Lecvicurdium, Swainson), C. cardissa

* Cardium edule, the edible Cockle of the London market, gives place as an article of food to the larger $C$. echinatum in some parts of the country. Turton describes this latter species as being collected in great abundance on the Paignton Sands in Torbay, "where at low spring-tides they may be observed with the fringed tubes appearing just above the surface. The neighbouring cottagers gather them in baskets and panniers, and after cleansing them a few hours in cold spring water, fry the fish in a batter made of crumbs of bread, producing a wholesome and savoury dish. The inhabitants call them red-noses."-Conch. Dith. Ins. Brito, p. 183. 
(Hemicardium, Cuvier), C. fragum (Fragum, Bolten), C. Ihystrix, (Ctenocarlia, Adams), C. retusum (Lunulicartia, Gray), C. edtentula, (Adacna, Eichwald), C. pseutocartia (Monotacna, Eichwald), and C. Donaciformis (Didacna, Eichwald).

The Cartia have an unusually wide distribution both in depth and space. In depth their place of habitation varies from tide-mark to a hundred fathoms and more; and in space their range extends from Greenland and the Falkland Islands to the equator.*

\section{Species.}

1. aculeatum, Limn.

2. Adamsii, Reeve.

3. alternatum, Sow.

4. angulatum, Lam.

5. arcuatum, Mont.

6. arenicolum, Reeve.

7. Asiaticum, Brug.

'8. assimile, Reeve.

9. attenuatum, Sow.

10. aurantiacum, Adams.

11. auricula, Forsk.

12. Australe, Sow.

13. Australiensis, Reeve.

14. Beechei, Adans.

15. Belcheri, Brod.

16. Belticum, Beck.

17. biangulatum, Sow.

18. biradiatum, Brug.

19. blandum, Gould.

20. boreale, Reeve.

21. Brasilianum, Lam.

22. bullatum, $i d$.

23. Californianum, Conr.

24. Californiense, Desh.

25. cardissa, Linn.
27. Caspium, Eich.

28. ciliare, Limn.

29. colorata, Eich.

30. consors, Sow.

31. coronatum, Speng.

32. costatum, Linn.

33. crenulatum, Lam.

34. Cumingii, Brod.

35. Deshayesii, Payr.

36. Dionæum, Sor.

37. Donaciforme, Schr.

38. Dupuchense, Reeve.

39. echinatum, Linn.

40. edule, $i d$.

41. Eichwaldii, Reeve.

42. elatum, Soro.

43. elegantulum, Beck.

44. Elenense, Sow.

45. elongatum, Brug.

46. enode, Sow.

47. erinaceum, Lam.

48. exiguum, Gmel.

49. fasciatum, Mont.

50. ferruginosum, Reeve.

51. fimbriatum, $W_{\text {ood. }}$

52. fornicatum, Sorv.
53. foveolatum, Sow.

54. fiagile, Reeve.

55. fragum, Linn.

56. Grœnlandicum, $\mathrm{Ch}$.

57. graniferum, Brod.

58. hemicardium, Linn.

59. hians, Broc.

60. hiulcum, Reeve:

61. hystrix, $i d$.

62. Icelandicum, Chem.

63. imbricatum, Sow.

64. impolitum, $i d$.

65. incarnatum, Reeve.

66. isocardia, Linn.

67. Kalamantinum, Adams.

68. lacunosum, Reeve.

69. lævigatum, Linn.

70. læviuscula, Eich.

71. Lamarckii, Reeve.

72. latum, Born.

73. leucostoma, $i d$.

74. lima, Reeve.

75. lyratum, Sow.

76. maculatum, $i d$.

77. maculosum, Wood.

78. magnum, Born.

* "We find the great central assemblage of Cockles in the Indian Ocean, a region where about a third of the species are congregated. Around this centre the number of specific forms dimi. nishes, though found in every sea. They are most plentiful everywhere within the tropics, and diminish as we proceed northwards and southwards; but some of the forms most prolific in individuals, and most gregarious in habit, are present in cold climates, and make up by abundance for the absence of variety. The genus contains several remarkable abnormal forms; some of the most singular are to be found in the Caspian and other relies of the great Aralo-Caspian Sea,the demonstration of which mighty inland ocean is among the finest discoveries of Sir Roderick Murchison."-Forbes and Hanley, Brit. Moll., vol, ii. p. 3. 
79. medium, Linn. 103. papyraceum, Chemn. 127. senticosum, Sow. 80. Mindanense, Reeve. 104. pectinatum, Linn. 128. serratum, Limn. 81. modestum, Adams. 105. Pennantii, Beck. 129. setosum, Redf. 82. Mortoni, Conr. 106. pinnulatum, Conr. 130. Sinense, Sow. 83. multipunctatum, Sow. 107. planicostatum, Sow. 131. speciosa, Adams. 84. multispinosum, id. 108. plicata, Eich. 132. stellatum, Reeve. 85. mundum, Reeve. 109. procerum, $i d$. 133. striatulum, Sovv.

86. muricatum, Linn. 110. pseudocardia, Desh. 134. subelongatum, id.

87. muticum, Reeve. 111. pseudo-fossile, Reeve. 135. subretusum, id.

88. nebulosum, $i d$. 112. pseudo-lima, Lam. 136. subrugosum, $i d$. 89. nivale, $i d$. 113. pulchellum, Reeve. 90. nodosum, Mont. 114. pulchrum, $i d$. 137. substriatum, Conr. 91. Nuttallii, Conr. 115. pulicarium, $i d$. 138. Suediense, Reeve.* 92. oblongum, Linn. 116. quadrarium, $i d$. 139. sulcatum, Gmel. 93. obovale, Sow. 94. orbita, $i d$. 95. ovale, $i d$. 117. radiatum, id. 140. tenuicostatum, Lam. 141. trigonoides, Pall. 142. tumoriferum, Lam. 118. retusum, Linn. 143. unedo, Limn.

96. oviputamen, Reeve. 97. ovuloides, $i d$. 119. rigidum, Wood. 144. unicolor, Sow. 98. oxygonum, Sow. 99. pallidum, Reeve. 100. papillosum, Poli. 101. paucicostatum, Sow. 102. Panamense, $i d$. 120. ringens, Chem. 145. unimaculatum, $i d$. 121. ringiculum, Sow. 146. variegatum, $i d$. 122. rubicundum, Reeve. 123. rubrum, Mont. 147. vertebratum, Jonas. 124. rugatum, Gron. 148, virgo, Reeve. 125. rugosum, Lam. 149. vitrea, Fich. 126. rusticum, Linn. $\quad$ 150. vitellinum, $i d$.

\section{Figure.}

Cardium echinatum. Pl. $P$. Shell, with animal, showing the large geniculate foot and short pouting siphonal orifices.

Cardium Asiaticum. Pl. 36. Fig. 194. Shell, illustrative of the globose ribbed form of the genus, showing the cardinal and wide-spread lateral teeth.

\section{Genus 4. ISOCARDIA, Lamarck.}

Animal; globose, rather small compared with the shell, open in front for the passage of a compressed triangularly pointed foot, and belind for two sessile orifices edged with a ciliary finge.

* Having been the first to describe this species, which forms part of our British Fauna, I regret that Professor Lovén, followed by Forbes and Hanley and by the Messrs. Adams, have considered it necessary to alter my name of Suediense to Suecicum. If they had turned to their Ainsworth they would have found that Suedia is as good Latin for Sweden as Suecia, and Suediense, therefore, as Suecicum. 
Shell ; heart-shaped, globose, ventricose, very inequitateral, concentrically ridged or striated, with the umboes distant and divaricately involuted; linge composed of two small cardinal tecth interlocking, and one clongated lateral tooth; ligament external, drawn by the divaricating of the umboes into a bifurcation.

In the Irish Chamnel and the surrounding ocean, ranging from Falnouth to the Hebrides, and in the Mediterranean, dwells a bivalve mollusk partaking of the characters of Chamu, Carlium, and Cyprina, and producing a shell of comparatively large size, unique in these latitudes both in genus and in species. Its clief peculiarity consists in the umboes divaricating from one another, and turning symmetrically inwards. In the Chinese, Japanese, and Philippine seas this very remarkable and beautiful type again appears, not, however, in a large shell of inflated growth, covered with a dingy olive epidermis, but in one of small dimensions, of which there are four different specific forms elegantly concentrically ridged, devoid of epidermis, and with a surface like carved and polished ivory.

The animal of Isocartia is known only by observations made on the large species, I. cor, by Poli, on Mediterranean specimens, and by the Rev. James Bulwer, chiefly, on Irish specimens. The mantle is described as completely lining the shell, the siphonal tubes being short, ciliated at their orifices, and the foot muscular, triangular, and pointed.*

"It is capable, with the assistance of its foot, of fixing itself firmly in the sand, generally choosing to have the umboes covered by it, and the orifices of the tubes of the mantle nearly perpendicular. Resting in this position on the margin of a sandbank, of which the surrounding soil is mud, at too great a depth to be disturbed by storms, the Isocardia of our Irish Sea patiently collects its food from the surrounding element; assisted in its choice by the current it is capable of creating by the altcrnate opening and closing of its valves."

\section{Species.}
1. cor, Linn.
3. Moltkiana, Chem.
5. vulgaris, Reeve.
2. Lamarckii, Sow.
4. tetragona, Adams.

* "On bcing placed in a vessel of sea-water the valves of the Isocardia gradually opened; and the feelers or ciliated fringe of the upper orifice of the mantle moved slowly as if in search of animalcules. Having remained in this situation about ten minutes, water was ejected with considerable force from the lower orifice, which till now had remained motionless. The expulsion of the water appeared to be affected by a sudden contraction of the muscles, because this was never done without the valves nearly closing at the same instant. The animal appears to be insensible both to sound and light, as the presence or absence of either did not at all interrupt its movements : but its sense of feeling appeared to be very delicate. Minute substances dropped into the orifices of the mantle instantly excited the animal, and a column of water strongly ejected expelled them from the shell." - Bulwer in Zool. Journ., vol. ii. 
Isocardia vulganis. Pl. 36. Fig. 196. Shell, of the China type, showing its concentrically ridged ivory-like texture, and delicately involuted umbo.

\section{Family 6. CONCHACEA.}

Shell ; mostly orbicular or obliquely orbicular; linge composed of three strong teeth, more or less, in each valve; lateral tecth sometimes wanting; ligament external.

In this family there is more variety and character in the shell than in the animal. The animal is characterized throughout by a well-developed foot, and by a pair of siphons which, according to the genus, are either separated or united, with the margins sometimes plain, sometimes frilled. The shell is mostly of solid porcellanous substance extremely rich in colour, decorated with strange fantastic patterms, and often beautifully sculptured with spines, foliations, scales, and very elaborate lattice-work. The linge is composed of rather strongly developed teeth, and the ligament is external. The Conchacea are part marine and part fluviatile; the fluviatile genera are limited in species, of sombre exterior, very little sculptured, and there are rather strongly marked diflerences in the animal.

Marine.
TAPES.
Cythera.
Venus.
Antemis.

LUCINOPSIS.

Astarte.

Fluviatile.

Galathia.

Cyrena.
Cyclas.

\section{Genus 1. TAPES, Megerle.}

Animal; shaped as the shell, rather thich, having the mantle freely open in front, its margins either plain or partially plain, or if fringed, bordered by fine filaments; siphons moderately lony, more or less separated, both branchial and anal orifices bordered by cirrhi, those of the former ciliuted; foot lanceolate, thick, with a byssal groove. (Forbes.)

Shell; equivalve, inequilateral, transversely oblong, sometimes obliquely triangular, anterior side generally mele the stiorter; hinge composed of three contignons teeth in each vulve, of which two are usually bifid; no lateral teell.

VOL. II. 
The chief peculiarity of the animal of Tapes (Pullastra, Sorr.), as distinguished from the rest of the Conchacea, is the presence of a byssal groove in the foot. The sleell-and there are upwards of eighty species-is characterized throughout by an oblong or obliquely oblong growth, densely concentrically groove-striated, and of a uniform dull or rusty buff colour, sometimes passing into pink, most frequently painted with sharply angled hieroglyphic marks.

Not more than about a tenth of the Tapes have been collected in the Western Hemisphere. Throughout the Eastern Hemisphere they are abundant, ranging from Australia to Northern Europe, four very characteristic and good-sized species inhabiting Britain. Of these one, T. virginea, well illustrates the buff colour, passing into a delicate pink.

\section{Species.}

1. acuminata, Sow.

2. Adenensis, Phil.

3. amabilis, $i d$.

4. anatina, Sovo.

5. arenosa, Phil.

6. aspersa, Lam.

7. aurea, Gmel.

8. Belcheri, Sov.

9. Binguieri, Hanl.

10. catenifera, Lam.

11. Ceylonensis, Sovo.

12. Chilensis, $i d$.

13. corrugata, Gmel.

14. crassicosta, Quoy.

15. Cumingii, Sow.

16. dactyloides, $i d$.

17. declivis, $i d$.

18. decussata, Linn.

19. denticulata, Sow.

20. Deshayesii, Hanl.

21. discors, Sow.

22. disrupta, $i d$.

23. diversa, $i d$.

24. Dombeyi, Lam.

25. edulis, Gmel.

26. euglypta, Phil.

27. exarata, $i d$.

28. expallescens, $i d$.
29. florida, Lam.

30. floridella, $i d$.

31. fluctuosa, Gmel.

32. fluctuosa, Gould.

33. fuscolineata, Sov.

34. galactites, Lam.

35. geographica, Chemn.

36. grata, Say.

37. Hanleyi, Sow.

38. hiantina, Lam.

39. incerta, Sow.

40. Indica, Hanl.

41. inæqualis, Sow .

42. intermedia, Quoy.

43. Lajonkarii, Payr.

44. laterisulca, Lam.

45. linia, Sowo.

46. lirata, Phil.

47. lithoidea, Jonas.

48. litterata, Chemn.

49. Luzonica, Sow.

50. Malabarica, Chemn.

51. maxima, Phil.

52. Meroæformis, Sow.

53. nebulosa, Pult.

54. opaca, Sow.

55. papilionacea, Lam.

56. perplexa, Sow.
57. petalina, Lam.

58. Philippinarum, $A d$.

59. pinguis, Chemn.

60. polita, Sow.

61. pullastra, Wood.

62. purpurata, Sow.

63. radiata, Chemn.

64. rariflamma, Lam.

65. recens, Chemn.

66. rimosa, Phil.

67. rimularis, Lam.

68. semirugata, Phil.

69. sinuosa, Lam.

70. straminea, Con.

71. subquadrata, Sow.

72. substriata, Mont.

73. sulcaria, Lam.

74. sulcosa, Pliil.

75. tenuistriata, Sow.

76. tessellata, $A d$.

77. textile, Gmel.

78. texturata, Lam.

79. tricolor, Sow.

80. tumida, $i d$.

81. turgida, Lam.

82. variabilis, Born.

83. variegata, Hanl.

84. virginea, Linn. 
Figure.

Tapes textilis. Pl. 35. Fig. 193. Shell of an usually smooth species, showing the hinge of three close cardinal teeth, destitute of lateral teeth.

\section{Genus 2. CYTHERAA, Lamarck.}

Animal; oblong, with its mantle freely open, and plain at the margins; foot large, linguiform, not furnished with a byssul groove; siphons united nearly to their extremities; orifices of both with simple cirrtii. (Forbes.)

Shell ; obliquely subtriangularly orbicular, mostly smooth and porcellanous, sometimes concentrically lamellately striated, very rarely spined around the posterior; linge composed of three divaricate cardinal teeth in one valve, interlocking with four in the other, the outer one of which diverges more or less into the form of a lateral tooth.

Of this genus we have a grand typical example on our own shores in $C$. Chione, and it is the only Cythercea, out of a hundred and sixty-four, that inhabits Britain, excepting a small one of the subdivision Circe. The animal has no byssal groove in the foot, as in Tapes, and the cirrhi of both orifices of the siphons are simple. Three well-marked groups are indicated by the following:-C. Chione, of which type the species are far the most numerous, is the representative of a series with shells of large size and porcellanous surface, sometimes concentrically grooved, but not otherwise sculptured, richly banded, rayed, or spotted with brown, rust-brown, and purple-brown, and sometimes blue. C. Dione represents a type much more limited in species, of which the shell is smaller and densely concentrically lamellately ridged. The spines which are so remarkable a feature in $C$. Dione do not belong to the group, but only to two other species, C. lupinaria and multispinosa, and it is even doubtful whiether all three are not varieties of one and the same species. C. scripta (Donax scripta, Lamarck), with a flat wedge-shaped shell, represents another group, of which there are only seven species; and fifteen species have been separated under the name of Circe, with a stout squarely orbicular pinched shell, whose animal varies in laving the margins of the siphonal orifices fringed, and is more allied in this respect to Cyprina. 


\section{Species.}

1. abbreviata, Lam.

2. acuminata, Sow.

3. xquivoca, Chemn.

4. affinis, Brod.

5. albina, Lam.

i. albo-cincta, Soro.

7. albo-dorsata, id.

S. angulitera, $i d$.

9. apicalis, Phil.

10. Arabica, Chemn.

11. argentina, Soro.

12. aurantia, Hanl.

13. australis, $\mathrm{Cir}$.

1.. Belcheri, Sow.

15. bicolor, Gray.

16. Birmanica.

17. brevispinosa, Sozo.

18. bullata, $i d$.

19. calypiga, Born.

20. casta, Gmel.

21. castrensis, Linn.

22. Chione, $i d$.

23. circinata, Born.

24. citrina, Lam.

25. compressa, Sow.

26. concinna, $i d$.

27. consanguinea, C.B.Ad.71. interrupta, Lam.

28. convexa, Say.

29. corbicula, Lam.

30. costata, Chemn.

31. Crassatelloides, Conrad.75. lentiginosa, Chemn.

32. crocea, Gray.

33. cygnæus, Lam.

34. Cyrelli, Phil.

35. damaoides, Gray.

36. Dione, Linn.

37. dispar, Chemn.

38. disrupta, Sow.

39. divaricata, Gmel.

40. Dolabella, Sow.

41. dubia, $i d$.

4.2. eflossa, Hanl.

4:3. elegans, Koch.

4t. eiliptica, Sow.
45. erycina, Linn.

4. erycinella, Lam.

47. erythrea, Jonas.

49. excavata, Hanl

49. fastigiata, Soro.

50). festiva, Paris Mrus.

51. florida, Lam.

52. fluctuata, Sow.

53. formosa, $i d$.

54. fulminata, Valen.

55. gibbia, Lam.

56. gigantea, Linn.

57. gracilior, Soro.

5. grata, Desh .

59. Hanleyani, Sow.

60. Hebræa, Lam.

(i). hieroglyphica, Conr.

62. Hindsii, Hanl.

63. incerta, Sow.

65. inconspicua, $i d$.

(55. indecora, Phil.

66. inflata, Sow.

67. impar, Lam.

68. impudica, Chemn.

69. innocens, Soro.

70. intermedia, $i d$.

72. iridescens, Sow.

73. Kingii, Gray.

74. læta, Linn.

76. lepida, $i d$.

77. ligula, Anton.

78. lilacina, Lam.

79. limatula, Sow.

80. lineata, $i d$.

81. lineolata, $i d$.

82. lupinaria, Less.

83. lusoria, Lam.

84. lyrata, Sow.

85. mactroides, Dillwo.

86. maculata, Limn.

87. Manillæ, Sovo.

88. menstrualis, Menke.
89. meretrix, Linn.

90. minima, Mont.

91. modesta, Sow.

92. morphina, Lam.

93. multiradiata, Sow.

94. inultispinosa, $i d$.

9. multistriata, $i d$.

96. nitidula, Lam.

97. nobilis, Reeve.

98. nummulina, Lam.

99. obesa, Sow.

100. oblonga, Gray.

101. oculata, Say.

102. ovum, IIanl.

103. pacifica, Dillzo.

104. pallescens, Sow.

105. pannosa, $i d$.

106. pectinata, Linn.

10\% pectoralis, Lam.

108. pellucida, $i d$.

109. petechialis, $i d$.

110. Pfeifferi, Pliil.

111. Philippinarum, IIanl.

112. picta, Schum.

113. piperita, Sow.

114. planulata, Brod.

115. plebeja, Hanl.

116. plicatina, Lam.

117. polita, Sow.

118. pulchra, Gray.

119. punctata, Lam.

120. purpurata, $i d$.

121. Quoyi, Hanl.

122. radiata, Sow.

123. rivularis, Menke.

124. rosea, Brod.

125. rostrata, Koch.

126. rugifera, Lam.

127. rugosa, $i d$.

128. rutila, Sow.

129. scripta, Linn.

130. scripta, $i d$.

131. semilamellosa, Chénu.

132. seminuda, Phil. 
133. semisulcata, Sow.

134. simplex, $i d$.

135. Sinensis, Chemn. 136. Solandii, Gray.

137. spathulata, Sow.

138. splendens, $i d$.

139. squalida, $i d$.

140. striata, Gray?

141. subelliptica, Soro.

142. subinflata, $i d$.

143. subquadrata, $i d$.
144. subpellucida, Sow.

145. sulcatina, Lam.

146. Tellinoiden, Sow.

147. tigerina, Lam.

148. tigrina, Reeve.

149. tortuosa, Brod.

150. trigonella, Lam.

151. trimaculata, $i d$.

152. tripla, Linn.

153. tumefacta, Sow.

154. umbonella, Lam.
155. undatina, Lam.

156. undulata, Sorv.

157. unicolor, $i d$.

158. vaginalis, Menke.

159. varians, Hanl.

160. Venetiana, Lam.

161. ventricosa, Brit. Mus.

162. virginea, Adams.

163. vulnerata, Brod.

164. zonaria, Lam.

\section{Figure.}

Cýmera tuptraria. Pl. 35. Fig. 189. Shell illustrative of the small group, distinguished by a profusion of long spines set around the posterior.

\section{Genus 3. VENUS, Linnæus.}

Animal ; ovate or suborbicular, thich, its mantle open throughout, and fringed or furbelowed at the margins; siphons separate, and diverging, or partially, or even entirely united to their extremities, where the orifices are surrounded by fringes of cirrhi; foot linguiform, apiculate, not furnished with a byssal groove. (Forbes.)

Shell ; ovate or triangularly orbicular, generally claborately sculplured; linge composed mostly of thick, interlocking, diverging, cardinal teeth in each valve; lunule conspicuous.

The Goddess of beauty is not unfitly represented by the series of shells associated in this genus. Not only do they display an almost endless variety of colour and marking, but an exquisite variation of sculpture. Of a hundred and thirty species, chiefly tropical and subtropical, the majority are frilled in concentric order, with most curious varieties of lamellar ridges, daintily rayed and tinted, and the range of habitation, even in the same species, varies from the water-edge to considerable oceanic depths.*

\footnotetext{
* "Venus striatula and Venus ovata live indifferently at the margin of the sea, and beneath a depth of more than one hundred fathoms. Such capacities for enduring great differences of pressure warn us not to lay too great stress on that influence as a regulator of distribution, the more so as examples of these mollusks drawn suddenly up from very great depths appear to ex. perience no inconvenience from the rapid change of conditions, and display their siphons and other organs as readily in a busin of sea-water as they could ever have done in the profound recesses of their birth." - Forbes and Hanley, Brit. Jioll, vol. i. p. 400.
} 
The animal, according to the observations of Professor Forbes, presents differences in different species, which in some families have been regarded of sufficient importance for the distinction of genera. The siphons are described as being either separate and diverging, or partially or even cntirely divided.

\section{Species.}

1. Africana, Mrühlf.

2. aftinis, Soro.

3. agrestis, Plit.

4. albina, Sow.

5. albo-radiata, $i d$.

6. alta, $i d$.

7. Amathusia, Phil.

8. aphrodina, Lam.

9. asperrima, Sow.

10. Astartoides, P/hil.?

11. australis, Sow.

12. Berryi, Gray.

13. Californiensis, Brod.

14. callosa, Conrad.

15. calophyla, Hanl.

16. cancellata, Linn.

17. Cardioides, Lam.

18. casina, Linn.

19. Chemnitzii, Hanl.

20. cincta, Chemn.

21. cingulata, Lam.

22. cingulina, - ?

23. Cochinensis, Thorpe.

24. Columbiensis, Sow.

25. compta, Brod.

26. corbis, Lam.

27. cor, Sow.

28. costellata, $i d$.

29. costellifera, $A d$.

30. crebrisulca, Lam.

31. crenifera, Sow.

32. crenulata, Chemn.

33. Cumingii, Sow.

34. Cypria, $i d$.

35. decipiens, Hanl.

36. declivis, Sow.

37. decorata, Brod.
38. discina, Lam.

39. discrepans, Sow.

40. donacina, Chemn.

41. dysera, $i d$.

42. elegans, $A d$.

43. encausta, - ?

44. exalbida, Chemn.

45. fasciata, Don.

46. flexuosa, Linn.

47. fluctifraga, Sow.

48. foliacea, Phil.

49. foveolata, Sorv.

50. fumigata, $i d$.

51. gallina, Limn.

52. gallinula, Lam.

53. gemma, Tolten.

54. Gnidia, Brod. et Sow.

55. granulata, Gmel.

56. granulifera, Sow.

57. gravescens, Menke.

58. histrionica, Sow.

59. incompta, Phil.

60. imbricata, Sow.

61. intersecta, $i d$.

62. Kellettii, Hinds.

63. Kochii, Phil.

64. Labuana, $A d m$.

65. lacerata, Hanl.

66. lævigata, Sow.

67. Lamarckii, Gray.

68. lamellata, Lam.

69. laqueata, Sow.

70. Lemannii, Payr.

71. lenticularis, Sow.

72. Listeri, Gray.

73. lyra, Hanl.

74. macrodon, Lam.
75. magnifica, Sow.

76. marica, Linn.

77. mercenaria, $i d$.

78. minuta, Koch.

79. monilifera, Sow.

80. multicostata, $i d$.

81. nodulosa, $i d$.

82. oblonga, Gray.

83. ornatissima, Brod.

84. ovata, Penn.

85. Paphia, Linn.

86. parva, Sow.

87. paupercula, Chemn.

88. pectinula, Lam.

89. pectorina, $i d$.

90. Peronii, $i d$.

91. Peruviana, Sovo.

92. plicata, Gmel.

93. polita, Quoy.

94. præparea, Say.

95. puerpura, Linn.

96. punctifera, Gray.

97. pygmea, Lam.

98. quadrangularis, $A d$.

99. radiata, Phil.

100. resticulata, Sow.

101. reticulata, Linn.

102. rigida, Dillw.

103. roborata, Hanl.

104. rosalina, Rang.

105. rostrata, Sow.

106. rugosa, Gmel.

107. scabra, Hanl.

108. scalarina, Lam.

109. simillima, Sow.

110. sinuata, I'urt.

111. sphærisulca, Desh. 
112. spissa, Quoy.

113. spurca, Sow .

114. squamosa, Linn.

115. striata, Chemn.

116. striatula, Costa.

117. striatissima, Sow.

118. strigosa, Lam.

119. Stultzii, Dovan.
120. Stuchburii, Gray.

121. subimbricata, Sow.

122. subrostrata, Reeve.

123. subrostrata, Lam.

124. subrugosa, Sow.

125. tenuilamellata, $i d$.

126. thiara, Dillw.

127. truncata, Lam.
128. undatella, Sow.

129. undulosa, Lam.

130. variabilis, Linn.

131. varicosa, Sow.

132. verrucosa, $\operatorname{Linn}$.

133. Yatei, Gray.

134. ziczac, Linn.

\section{Figure.}

Venus Gnidia. Pl.36. Fig. 195. Shell sculptured throughout with concentric lamellæ of festooned erect scales.

\section{Genus 4. ARTEMIS, Poli.}

Animal ; suborbicular, its mantle freely open, the margins entive or only partially serrated; siphonal tubes long, united to their extremities, margins of their orifices finbriated; foot semilunar. (Forbes.)

Shell; orticular, concentrically striated or vidged; ridges sometimes laminated at the sides, especially at the posterior side, area of the ligament generally excavated; lumule mostly well defined; linge composed of three strong divergent teeth in one valve and four in the other; impression of the sinus of the mantle lanceolately triangular.

Artemis differs from the preceding genera of this family in the form of the foot, in the siphons being united to their extremities, and in the mantle having a triangularly lanceolate sinus, which is conspicuously impressed on the shell. The peculiarities observable in the shell, in addition to that of the pallial sinus, are its orbicular compressed form, its very uniform concentric sculpture and the general absence of colour and pattern, although A. scalaris, rufa, juvenitis, Chinensis, and a few others, including even our British $A$. exoleta, are sometimes very expressively rayed with colour. The shell has not the polished smoothess of Cythercea or the sculptural ornamentation of Venus, but the species are well distinguished from each other in detail.

As in the case of Tapes not more than a tenth of the species are found in the Western Hemisphere; the remainder are natives of the Eastern 
Hemisphere, ranging from Australia to our own shores, on which the genus has its northern limit in $T$. lincta and exoleta. 'Three light inflated species, without a lunule, are referred to genus Lucinopsis.

\section{Species.}

1. Adansoni, Phil. 26. excisa, Chemn.

2. Africana, Gray. 27. exoleta, Linn.

3. alata, Reeve.

4. Amphidesmoirles, $i d$.

5. angulosa, Phil.

6. anus, $i d$.

7. aspera, Reeve.

8. bilunata, Gray.

9. biscocta, Reeve.

10. cærulea, $i d$.

11. calcalus, $i d$.

12. canaliculata, Sow.

13. Chinensis, Chemn.

14. compta, Loven.

15. concentrica, Gmel.

16. concinna, Sovo.

17. contusa, Reeve.

18. corrugata, $i d$.

19. cretacea, $i d$.

20. Cumingii, id.

21. discus, $i d$.

22. distans, - ?

23. Dunkeri, Phil.

24. duplicata, Reeve.

25. exasperata, Phil.
28. ferruginea, Reeve.

29. fibula, $i d$.

30. glauca, $i d$.

31. Gruneri, Phil.

32. hepatica, $i d$.

33. incisa, Reeve.

34. Isocardia, Dunk.

35. Japonica, Reeve.

36. jurenilis, Gmel.

37. juvenis, Chemn.

38. lamellata, Reeve.

39. laminata, $i d$.

40. lenticularis, Sow.

41. lincta, Pult.

12. lirata, Sow.

43. livida, Phil.

44. Lucinoides, Reeve.

45. lunaris, Lam.

46. modesta, Reeve.

47. nanus, $i d$.

49. nitens, $i d$.

49. Orbignii, Dunk.

50 . orientalis, Sow.
51. Patagonica, Phil.

52. penicillata, Reeve.

53. plana, $i d$.

54. ponderosa, Gray.

55. prostrata, Linn.

56. pubescens, Phil.

57. radiata, Reeve.

58. rubicunda, Phil.

59. rufa, Lam.

60. scabriuscula, Pliil.

61. scalaris, Menke.

62. sculpta, Reeve.

63. sericea, $i d$.

64. Sieboldii, $i d$.

65. simplex, Hanl.

66. sinuata, Turt.

67. solidula, Sow.

68. striatissima, $i d$.

69. subrosea, Gray.

70. subtrigona, Sow.

71. tenuilamellata, $i d$.

72. tenuis, $i d$.

73. torrida, Reeve.

74. trigona, $i d$.

75. variegata, Gray.

\section{Genus 5. LUCINOPSIS, Forles and Hanley.}

Animal; suborbicular, its mantle freely open, the margins entive; siphonal tubes short, diverging, separate, the branchial siphon with its orifice fringed, the anal simple; foot lanceolate. (Forbes.)

Shell ; thin, rather inflated, squarely orbicular, slightly flexuous, dull white tinged with rust, surface finely, but irregularly, concentrically striated; linge composed of two diverging teeth,-- 
one of which is bifid, - in one valve, interlocking with threethe centre of which is bifid-in the other.

This genus was instituted for the reception of a solitary type of bivalve, plentifully distributed round the British coast in depths varying from a few to eighty fathoms; but it has a fine representative, amongst others, in West Columbia in Lucinopsis (Artemis) sulquadrata. The foot, mantle, and siphons are all different in detail from those of Tenus and ditcmis, while the shell is of light substance, and, among other equally important differences, has no lunule.

\section{Species.}

1. decussata, Pliil.

2. gibbosa, Gmel.

3. inflata, Sow.

4. Kroyeri, Phil.
5. macilenta, Reeve.

8. substriata, Mont.

6. saccata, Gould.

7. subquadrata, Hanley.
9. tenuis, Recl.

10. undata, Penn.

\section{Genus 6. ASTARTE, Sowerby.}

Animal ; of the shape of the shell and never exceeding it, its mantle freely open, with plain margins, slightly united posteriorly at two points so as to form two siphonal orifices, both with simple ealges; foot linguiform, strong, but not large. (Forbes.) Shell; nearly orbicular, generally concentrically strongly ridged und grooved, sometimes smooth, covered by a thich fulvous-chestnut epidermis; linge of two diverging teeth in each valve.

The genera Astarte and Cyprina possess characters in common which render them somewhat removed from the preceding genera of Conchacea. The animal has no siphons, but simply siphonal orifices, the shell is invested in both genera with a stout sombre epidermis, and, with one exception, they are confined to the boreal and arctic seas of Europe and America. A single species of Astarte reaches southwards to the Meditcrranean, but Cyprina is not found living in that sea.

The shells of Astarte are of a uniform dark fulvous-chestnut colour, some are deeply concentrically ridged and furrowed, and some are smooth. They are all of comparatively small size. 
Species.
1. Aretica, Gray.
7. fusca, Poli.
12. semisulcata, Leach.
2. Banksii, Leach.
8. intermedia, Sow.
13. subæquilatera, Sow.
3. castanea, Say.
9. lactea, Brod.
14. sulcata, $D a$ Costa.
4. compressa, Mont.
10. oblonga, Sov.
15. triangularis, Mont.
5. crebricostata, Forbes.
6. elliptica, Brown.
11. quadrans, Goseld.
16. undata, Gould.

\section{Figure.}

Astarte sulcata. Pl. 34. Fig. 186. Shell, showing the divergent toothed linge and dark fulvous epidermis.

\section{Genus 7. CYPRINA, Lamarck.}

Animal; with its mantle freely open, the edges being either plain or serrated; siphons projecting a little, with the margins of their orifices fringed; foot large, linguiform.

Shell; obliquely cordate, comerly depressed, no lumule, covered with a glossy, fibrous epidemis; linge of two to three divergent cardinal teeth and a remote lateral tooth in each valve.

Of this genus only a single species is known, of large size, measuring sometimes upwards of four inches in diameter. As its specific name denotes, the Cyprina is purely a boreal mollusk, dwelling abundantly in the North Atlantic seas, and ranging throughout the shores of Britain and Ireland. Like Asturte the animal has no siphons, but the orifices project more. The shell is of rather an opake white substance, covered with a very decided glossy fibrous epidermis, of an o!jve or fulvous-brown colour.

\section{Figure.}

Cyprina Islandica. Pl. 35. Fig. 190. Shell, showing the linge with its remote lateral tooth.

Genus 8. GALATHAA, Bruguière.

Animal; with the mantle freely open, margins simple; siphons elongated, separate; foot large, oblong, compressed, stightly angulated in front. 
Shell; triangular or oblong ovate, very thick and solid, covered with a glabrous hormy epidermis; linge composed of two to three triangularly disposed cardinal teeth in each valve, which are sometimes indistinct or partially obsolete.

The freshwater Conchacea begin with Galathcea, a siphoned bivalve of comparatively large size, whose habitat is restricted to the Nile and the rivers of Western Africa. The shell is quite unique in its composition, being of a peculiar marble-like substance, more or less delicately rayed or tinted with rose-purple or bluc; and it is covered with a strong epidermis, not of a fibrous texture like that of Cyymina, but hard, glabrous, and horny, of a rich olive or olive-green colour. Twelve species have been described.

\section{Species.}

1. Bengöensis, $D k r$.

2. Cailliaudi, Bern.

3. concamerata, $D u v$.

4. Cumingii, $D k r$.
5. Heukelomi, Bern.

6. Kochii, $i d$.

7. læta, Phil.

8. Lubakii, Bern.
9. paradoxa, Born.

10. rubicunda, Plite.

11. tenuicula, Phil.

12. versicolor, MIorel.

Figure.

Galathea paradoxa. Pl. 36. Fig. 197. A very characteristic illustration of the original species, showing its dense hinge structure.

\section{Genus 9. CYRENA, Lamarck.}

Animal ; mantle-lobes united in their posterior third; siphons separated to their base. (Deshayes.)

Shell; mostly solid, sometimes concentrically ridged, covered with an olive or blackish epidermis; hinge composed of three cartinal teeth in one valve and two in the other, and two, often conspicuous, lateral teeth in each valve.

A characteristic and somewhat variable series of freshwater bivalves, some of which are of large size, richly violet-stained in the interior, some roughly formed and more or less eroded, some strongly ploughed across with ridges and furrows. The animal partakes of the characters of Tenus and Cyclas, simulating the latter genus more particularly in having the 
siphons separated to their base. They inhabit rivers and estuaries in the tropical countries of both hemispheres, but are most abundant in the peninsulas and islands of the easteru seas, where they live imbedded in the mud of mangrove-swamps. In Europe the genus is represented by Cyclas.

\section{Species.}

1. æquilateralis, Desh. 38. Floridana, Conr.

75. occidens, Bens.

2. affinis, $i d$.

3\%. Fontainei, D'Orb.

76. orientalis, Lam.

3. Africana, Krauss.

40. fluminalis, Miïl.

4. ambigua, Desh.

4. fluminea, $i d$.

5. angulata, $i d$.

42. fluviatilis, $i d$.

77. ovalina, Des7.

78. pallida, $i d$.

6. anomala, $i d$.

7. arctata, $i d$.

8. atrata, $i d$.

9. australis, $i d$.

43. Galatheæ, Morch.

79. Panormitana, Biv.

44. Gauritziana, Krauss.

80. Papua, Less.

4.5. grandis, Desh.

81. Paranensis, D'Orb.

46. humerosa, $i d$.

82. placens, Hanl.

83. placida, Desh.

47. impressa, $i d$.

St. producta, $i d$.

4. incerta, $i d$.

49. incrassata, $i d$.

50. inflata, $i d$.

85. pulchella, Mouss.

86. pullata, Pliil.

12. Brasiliana, id.

13. Buschii, Pliil.

14. Caroliniana, Bosc.

51. inquinata, $i d$.

87. pusilla, $i d$.

88. radiata, Hanl.

15. Cashmiriensis, Desh.

16. Ceylanica, Chem.

52. insignis, $i d$.

89. radiata, Phil.

53. Isocardioides, $i d$.

17. Charpentieriana, $B$. 5t. Jayensis, Lea.

15. Childrenæ, Gray.

55. Jukesii, Desh,

19. compressa, Mouss.

20. compta, Desh.

56. Keraudrenia, Less.

57. Largillierti, Phil.

58. lauta, Desh.

59. lenticularis, $i d$.

90. Raymondi, $B$.

91. recurvata, Eyd.

92. rivalis, Busch.

93. rotundata, Lea.

94. salmacida, Mor.

21. consobrina, Caill.

22. corbuloides, Desh

23. convexa, $i d$.

24. cor, Lamarck.

25. cordiformis, Recl.

26. Cumingii, Desh.

27. cuneata, Jonas.

28. cyclostoma, Bourg.

29. cyprinoides, Quoy.

30. decipiens, Desh.

60. limosa, Naton.

61. Mactroides, Desh.

62. maritima, Adams.

95. semisulcata, Desh.

96. similis, $i d$.

97. similis, Gray.

98. sinuosa, Desh.

99. solida, Phil.

63. megadesma, Desh. 100. sordida, Hanley.

64. Moquiniana, Bourg. 101. squalida, Desh.

65. Moussoni, Desh. 102. striatella, $i d$.

66. Nepeanensis, Less. 103. sublobata, id.

67. nitens, Phil.

10t. suborbicularis, Phil.

31. Deshayesiana, $B$

68. nitida, Desh.

105. subquadrata, Desh.

32. divaricata, Desh.

69. nitidula, $i d$.

106. sulcatina, $i d$.

70. notabilis, $i d$.

107. Sumatrensis, Sow.

71. obesa, Hinds.

34. eximia, Dunk.

72. oblonga, Quoy.

108. tenebrosa, Hinds.

35. Essingtonensis, Des/.

36. expansa, Mouss.

73. obscura, Desh.

109. triangula, Plit.

110. triangularis, Desh.

37. fallax, Desh.

74. obsoleta, id.

111. triangularis, Metc. 
112. trigona, Desh.

113. triquetra, $i d$.

114. tumida, Desh.
115. turgida, Lea.

116. Vanikorensis, Quoy. 119. violacen, Lam.

117. variegata, $D^{\prime} O \cdot$ b. 120. Woodiana, Lea.

\section{Figure.}

Cymena fluminea. Pl. 37. Fig. 198. Shell illustrative of a concentrically ridged species, showing the two extended lateral teeth.

\section{Genus 10. CYCLAS, Bruguière.}

Animal; suborbicular, its mantle freely open in front and anteally united posteriorly, to form a produced siphon, which is sometimes divided into two nearly equal tubes, edges of the mantle and of the siplional tubes not fringed.

Shell; ovately globose, thin, covered with a slight olivaceous epidermis; linge composed of two small cardinal teeth, one of which is bifid, in one valve, and one in the other, two rather remote lateral teeth in each valve.

The Cyrence of the Tropics are represented in the boreal and subtemperate zones by a tribe of closely allied animals of very much smaller size, some even minute, with thin, olive, horny shells. They include two sections, named respectively Cyclas and Pisitium. In the first the siphons are separated; in the second they are united in a sheath and the species are smaller. In both the edges of the mantle and siphonal orifices are plain. They live buried in mud in ditches and pools, or in gentle streams, drains, etc.

\section{Species.}

1. abdita, Hald.

2. abrupta, $i d$.

3. acuminata, $P r$.

4. albula, $i d$.

5. altilis, $i d$.

6. amnica, Mï̈ll.

7. argentina, $D^{\prime} O r b$.

8. aurea, Prime.

9. australis, Phil.

10. Bahiensis, Spix.
11. bulbosa, Anth.

12. cærulea, Prime.

13. Canariensis, Shut.

14. Capensis, Krauss.

15. cardissa, Prime.

16. casertana, Poli.

17. castanea, Prime.

18. Chilensis, D'Orb.

19. cicer, Prime.

20. compressa, $i d$.
21. consobrina, Féruss.

22. constricta, Anth.

23. contorta, Prime.

24. cornea, Linn.

25. Creplinii, Dkr.

26. dentata, Hald.

27. detruncata, $\mathrm{Pr}$.

28. distorta, $i d$.

29. dubia, Say.

30. duplicata, Pfeif. 
31. eburnea, Anth.

32. edentula, Say.

33. egregia, $i d$.

34. elegans, Adams.

35. elevata, Hald.

36. emarginata, $P r$.

37. fabalis, $i d$.

38. ferruginea, Krauss.

39. flava, Prime.

40. furcata, Rafin.

41. gigantea, $P r$.

42. gracilis, $i d$.

43. Henslowiana, $S 7$.

44. Indica, Desh.

45. inornata, $\mathrm{Pr}$.

46. Jayense, $i d$.

47. Kurtzii, id.

48. lacustris, Miill.

49. lenticularis, Norm.

50. Lumsteniana, Forbes.

51. maculata, Ant.

52. maculata, Mor.

53. minor, Migh.

54. mirabilis, $\operatorname{Pr}$.
55. modesta, $\operatorname{Pr}$.

56. Modioliformis, Ant.

57. nitida, Jen.

58. nitida, Migh.

59. Noveboracensis, $\mathrm{Pr}$.

60. Novæ-Zelandiæ, Desh. 84. semen, Menke.

61. obscura, Prime.

62. obtusalis, Pfeif.

63. orbicularia, Barr.

64. ovalis, Stimp.

65. pallida, Gray.

66. parasitica, Parr.

67. patella, Gould.

68. partumeia, Say.

69. pellucida, Prime.

70. pisidioides, Gray.

71. ponderosa, $\mathrm{Pr}$.

72. proxima, Alder.

73. pulchella, $D^{\prime} O r b$.

74. pusilla, Gmel.

75. pygmæa, Adans.

76. Recluziana, Bourg.

77. rhomboiden, Say.

78. rivicola, Leach.
79. rosacea, Prime.

80. rosea, Scholtz.

81. rotundata, $\mathrm{Pr}$.

82. rubella, $i d$.

83. Ryckholti, Norm.

85. sphæria, Anth.

86. straminea, Conr.

87. Steenbuchii, Möll.

88. Steinï, Schmidt.

89. supina, $i d$.

90. tenebrosa, Costa.

91. tenuis, Prime.

92. tenuistriata, $i d$.

93. Terveriana, Dup.

94. transversa, Say.

95. truncata, Linsl.

96. variabilis, $\operatorname{Pr}$.

97. ventricosa, $i d$.

98. Virginica, Gmel.

99. vitrea, Risso.

100. Wheatleyi, Adams.

101. zonata, Prime.

\section{Figure.}

Cyclas corvea. Pl. 37. Fig. 199. Shell, showing its small cardinal and rather remote lateral teeth.

\section{Family 7. NYMPHACEA.}

Shell; cither transverse or orbicular, sometimes gaping at the sides, posterior side alvanys rounded, anterior mostly attcnuated by a depression radiating from the untboes, which is sometimes fleauous; hinge composed mostly of small central cardinal teeth, with sometimes a callosity on the margin.

The Lamarckian family of Nymplacea is not well constituted. The Donax and Tellen have long widely separated siphons, while the Lucina and Cortis have none, the siphonal orifices being sessile; and Galeomma differs more than all in having the mantle closed, like Tridacna, with only 
a small opening for the passage of the foot. Why then, it may be asked, have we not reconstructed the subdivision of this Order into families? Many changes will have to be made in the method of classification adopted in this work as the animals become known. At present little is known of the malacological characters of the genera of this family except by their British representatives, and the proportion of these to the foreign species, known only by their shells, is small indeed. The strongest conchological characteristic of the genera consists in the posterior or siphonal end of the shell being more or less attenuated by an angular depression which radiates from the umbo and is sometimes flexuous.

$\begin{array}{lll}\text { Donax. } & \text { Tellina. } & \text { Capsa. } \\ \text { Iphigenia. } & \text { Galeomim. } & \text { Capsella. } \\ \text { Lucina. } & \text { Psamiobia. } & \text { Soletelina. } \\ \text { Corbis. } & \text { Psaminotella. } & \text { Sanguinolaria. }\end{array}$

\section{Genus 1. DONAX, Linnaus.}

Animal; oblong, its mantle freely open in front, with fringed, or partially fringed, margins; siphons comparatively short, divergent, the branchial sijhon with pinnated cirrhi around its orifice, the anal with simple denticulations; foot large, apiculated, sharp edged.

Shell ; triangularly ovate or oblong, more or less wedge-shaped, sometimes flexuous, equivalve; hinge composed of two cardinal ieeth in one valve, and one in the other; bifid at the upper part, two, or one, more or less distant lateral teeth in each valve.

There is scarcely any assemblage of bivalves so distinct in their generic character as those which have been associated without change since the time of Linnæus under the head of Donax. As in most of the Nymphacea the animal has its siphons separated to the base; but in Donax they are rather short, and there is a peculiarity in the margins of the orifices, one being pinnately cirrhated, the other simply denticulated. In Tellina the margins of the siphonal orifices are plain, or, at least, very indistinctly denticulated. There are more characteristic distinctions in the shell of these mollusks than in the soft parts; in Donax the shell is typically of a triangular wedge-shape, the anterior side being long and rounded, the posterior very short and abruptly truncated, and of rather solid growth. They have, with rare exception, little sculpture, and they present a stroug uniformity of colour, a fulvous or dull grey, frequently tinted with rays. 
The Donaces are distributed somewhat promiscuously throughout the temperate and tropical seas. There are three British species.

Species.

1. acuminata, Desh.

2. acutangula, $i d$.

3. ænea, Mörch.

4. affinis, Desh.

5. anatinus, Lam.

6. asper, Hanl.

7. bella, Desle.

8. bicolor, Lam.

9. bitincta, Reeve.

10. Californica, Conr.

11. carinata, Hanl.

12. Cayennensis, Lam.

13. clathrata, Desh.

14. columbella, Lam.

15. compressa, $i d$.

16. Conradi, Desh.

17. contusa, Reeve.

18. culter, Hanl.

19. cuneata, Iinn.

20. deltoides, Lam.

21. denticulata, Linn.

22. dentifera, Hanl.

23. Dysoni, Desh.
24. gracilis, Hanl.

25. granifera, Desh.

26. Hanleyana, Phil.

27. incarnata, Chemn.

28. incerata, Reeve.

29. interupta, Desh.

30. introradiata, Reeve.

31. Lamarckii, Desh.

32. lævigata, $i d$.

33. lubrica, Hanl.

34. lunularis, Plit.

35. Madagascariensis, $W d .58$. serra, Chemn.

36. meta, Reeve.

37. navicula, Hanl.

38. nitida, Desh.

39. Nuculoides, Reeve.

40. obesa, $D^{\prime} O r \cdot 6$.

41. obesula, Desh.

42. obscura, Reeve.

43. ovalina, Desh.

44. Owenii, Gray.

45. paxillus, Reeve.

46. Peruviana, Desh.
47. petallina, Desh.

45. polita, Poli.

49. pulchella, Hanl.

50. punctato-striata, $i d$.

51. radians, Lam.

52. rugosa, Linn.

53. saxulum, Reeve.

54. scapellum, Gray.

55. scortum, Linn.

56. semistriata, Poli.

57. semisulcata, Hanl.

59. sordida, Reeve.

60. spiculum, $i d$.

61. striatella, Desh.

62. Ticaonica, Hanl.

63. transversa, Sow.

64. trifasciata, Reeve.

65. trunculus, Limn.

66. variabilis, Say.

67. variegata, Reeve.

68. vellicata, $i d$.

69. venusta, Poli.

\section{Figure.}

Donax Deltoides. Pl. 37. Fig. 203. Shell of triangular wedge-shape form, with left valve dropped to show the hinge.

\section{Genus 2. IPHIGENIA, Schumacher.}

Animal; presumed to be nearly allied to Donax.

Shell ; triangularly ovate, nearly equilateral; hinge composed of two cardinal teeth in the right valve, and one cardinal and two nearly obsolete lateral teeth in the other. 
The genus Iphigenia, Schumacher, is substituted for the genus Capsa, Lamarck, a name preoccupied by Bruguière to distinguish the Linnæan Tenus deflorata, which is Lamarck's Sanguinolaria rugosa. The animal has not been described, and the genus has been separated from Donax more on account of its peculiarity of habit than upon conchological grounds. The Iphigenia are confined to brackish waters, inhabiting, so far as has been observed, the estuaries of Senegal, Brazil, and Central America. The hinge of the shell varies a little from that of Donax in having lateral teeth only in one valve, and those often somewhat obsolete.

\section{Species.}
1. altior, Sow.
3. lævigata, Gmel.
5. ventricosa, Phil.
2. Brasiliensis, Lam.
4. media, Shutt.

\section{Figure.}

Iphigenia Lævigata. Pl. 37. Fig. 202. Shell, exhibiting the interior of the left valve, with the lateral teeth almost obsolete.

\section{Genus 3. LUCINA, Bruguière.}

Animal; orbicular, its mantle fiecty open in front, with the edges plain or fimbriated; siphlinal orifices sessite; foot very long, tubular; branchial leaflets of each side united into one.

Shell; mostly orbicular, sometimes flat, sometimes rather gibbons, generally equicatie, moderately inequilateral ; hinge typically composed of two divergent cartinal teeth, and two somewhat distant lateral teeth, now elongated, now short and produced, in each valve, all of which are sometimes obsolete.

Under Lucina we have a most variable assemblage of species connected nevertheless by a uniformity of type which renders the genus easy of recognition. The shells are all orbicularly lens-shaped in form, and, beyond an occasional tinge of yellow or fulvous rust, they are characteristically devoid of colour. The animal, so far as it has been observed by M. Valenciennes and Professor Forbes, differs materially from either Donaw or Tellina. It has no protruding siphons, the siphonal orifices being sessile, and the foot is peculiar in being much elongated and tubular. The branchixe are also distinguished by the pair of leatlets being united on each side into 
one. The species may be grouped under at least a dozen different sections. In the type represented by the large $L$. tigerina and exasperata, including L. punctuta (Codatia, Scopoli), the shell is strongly radiately furrowed or sculptured with scaly decussating ridges, and the imner margin is mostly stained with a deep rose-pink; in L. Jamuicensis (Phacoides, De Blainville) the shell is only sculptured concentrically, and a curious allied type is presented in $L$. Pennsylvanicu, in which the shell is invested with a brittle transparent horny epidermis, that turns back from the ridges in particles, which become solidified like little hailstones; in the remarkable L. Childreni (Miltha, Adams) one valve is flat and smaller than the other; in L. gibba and divaricata and a fer others (Strigella, Turton), the shell is sculptured with obliquely waved divarieating lines; in L. leucoma (Loripes, Turton) the ligament has an unusually decp-seated position; $L$. spinifera (Myrtea, Turton) partakes rather of the character of Artemis in respect of sculpture; L. Zorealis (Triodonta, Schumacher) is a solid densely striated shell, and L. rotundata (Diplodonta, Brown) is characterized by an erect bifid tooth; while in $L$. Philippinamm, whose habit is to bury in sandy mud at the roots of Mang()-trees, we have a type more distinct than all, in which the shell is thim, almost toothless, and the hinge is strengthened in the absence of teeth by a different position of the ligament, which forms a broad strap, as it were, across the dorsal margins of the valves.*

A feature not to be overlooked in the shell of Lucina is the position of the lunule, which bears more on one valve than the other; the shell, instead of opening, as in Artemis, through the centre of the lunule, opens, in most species, on one side of it. The Lucince are variously distributed in the Europen, Eastern, Australian, and Central American Seas, seven species (including Diplodonta) being inhabitants of our own shores.

\section{Species.}
1. Anatellinoides, Reeve.
8. bicornis, $i d$.
15. cornea, Reeve.
2. annulata, $i d$.
9. borealis, Limn.
16. dentifera, Jonas.
3. Antillarum, $i d$.
10. bullula, Reeve.
4. arcuata; Mont.
11. cælata, $i d$.
17. digitalis, Lam.
5. argentea, Reeve.
12. calculus, $i d$.
18. divaricata, Linn.
6. aurantia, Desh.
13. Childreni, Gray.
19. eburnea, Reeve.
7. barbata, Reeve.
14. columbella, Lam.
20. edentula, Chemn.
21. exasperata, Reeve.

*. The school of genus-makers represented formerly by De Montford and Schumacher, then by Swainson, and now by Dr. Gray and the Messrs. Adams, is thus severely admonished by Messrs. Forbes and Hanley in their observations on the genus Lucina:-- "Until our knowledge of the tribe becomes much more minute and accurate than it now is, conchologists had better content themselves with using a single generic term, than, throngh a false ambition of becoming the parents of names, thrust worthless and embarrassing synonyms on a science already considerably cucumbered with rubbish." -Brit. Moll., vol. ii. p. 44 . 


\begin{tabular}{|c|c|c|}
\hline $\begin{array}{l}\text { 2. fabula, Reeve. } \\
\text { 3. ferruginosa, Forbes\&.I } \\
\text { 4. fibula, Reeve. } \\
\text { flexuosa, Don. } \\
\text {. friabilis, Reeve. } \\
\text { funiculata, id. } \\
\text { gemma, id. } \\
\text { gibba, Gray. } \\
\text { globularis, Lam. } \\
\text { icterica, Reeve. } \\
\text { interrupta, Lan. } \\
\text { Jamaicensis, Chemn. } \\
\text { Janeirensis, Reeve. } \\
\text { lenticula, id. } \\
\text { leucoma, Turt. } \\
\text {. leucophrta, Reeve. }\end{array}$ & $\begin{array}{l}\text { 38. malum, Reeve. } \\
\text { 1.39. muricata, Chemn. } \\
\text { 40. nitens, Reeve. } \\
\text { 41. Novo-Zelandica, } i d . \\
\text { 42. obliqua, id. } \\
\text { 43. occidentalis, } i d \text {. } \\
\text { 44. ochracea, id. } \\
\text { 45. ornata, id. } \\
\text { 46. ovulum, id. } \\
\text { 47. ovum, id. } \\
\text { 48. pecten, Lan. } \\
\text { 49. Pennsylvanica, Linn. } \\
\text { 50. Philippiana, Reeve. } \\
\text { 51. Philippinarum, Hant. } \\
\text { 52. pila, Reeve. } \\
\text { 53. pisum, id. }\end{array}$ & $\begin{array}{l}\text { 54. punctata, Rinn. } \\
\text { 55. rotundata, Turt. } \\
\text { 56. rugifera, Reeve. } \\
\text { 57. Sarsii, Loeven. } \\
\text { 58. scabra, Lam. } \\
\text { 59. Senegalensis, Reeve. } \\
\text { 60. sericata, id. } \\
\text { 61. simplex, id. } \\
\text { 62. speciosa, id. } \\
\text { 63. spinifera, Mont. } \\
\text { 6 t. sulcata, Reeve. } \\
\text { 65. Tellinoides, id. } \\
\text { 66. tigerina, Linn. } \\
\text { 67. tumida, Reeve. } \\
\text { 68. venusta, Phil. } \\
\text { 69. virgo, Reeve. }\end{array}$ \\
\hline
\end{tabular}

\section{Figures.}

Lucina boresuis. Plate Q. Shell, with animal showing the long tubular foot and absence of siphonal tubes. From Forbes and Hanley, Hist. Brit. Moll.

Luciva punctata. Pl. 37. Fig. 204. Shell, with the left valve dropped to show the hinge and rose-pink marginal colouring.

\section{Genus 4. CORBIS, Cuvier.}

Animal; mantle open below, with the maryin doubly fringed; siphonal orifice single, with a long retractile tubular valve. (Adams.)

Shell ; transverse, equivalve, nearly equilateral, stout, outer surface claborately latticed; linge composed of two cardinal and two lateral teeth in each valve, one of which is situated near the cardinal teeth, the other is remote from it.

A limited group, allied to Lucina in the animal having no protruding siphons, and possessed of shells of solid growth and of most exquisitely latticed sculpture, resembling in general typical character some of the concentrically ridged forms of that genus. Five species have been described, but the best known are the C. fintriata and Sowerlii from the Muluccas. The latter M. Deshayes identifies with a Grignon fossil found in the 
neighbourhood of Versailles, $C$. Zamellosa, but in this we think he is mistaken.

\section{Species.}

$\begin{array}{lll}\text { 1. } \text { cælata, Adams. } & \text { 3. fimbriata, Lam. } & \text { 5. Sowerbii, Reeve. } \\ \text { 2. elegans, Desh. } & \text { 4. scitula, Adams. }\end{array}$

\section{Figure.}

Corbis Sowerbir. Pl. 37. Fig. 201. Shell, with the left valve showing the elaborately latticed external sculpture, the right valve the showing the hinge.

\section{Genus 5. TELLINA.}

Animal ; ovate, compressed, mantle entirely open in front, its margin fimbriated; siphons long, separate throughout, usually nearly equal, thin, orifices plain or very indistinctly toothed; foot large, triangular, compressed, apiculate. (Forbes.)

Shell; transverse or orlicular, nearly equivalve, moderately inequilateral, posterior side mostly flemously beaked, ventral margin often irregularly flexuous; linge composed of generally two cardina' teeth in each valve, and two lateral tecth, often remote and sometimes wanting.

There are few mollusks so generally distributed over the globe as the Tellens. The species are numerous, and from the arctic to the equatorial seas the genus is represented in one form or another according to latitude and depth of habitat. The animal is distinguished by a longer and more widely separated pair of siphons than we have yet met with in the bivalves, and one is generally longer than the other. The foot, as in Donax, is welldeveloped, bent, and apiculated.* The shells do not vary very materially in form, their general characteristic is to have the posterior side, that is,

* "When the bend in the foot of a bivalve is considerable, forming a sort of elbow, the animal is projected forwards by a succession of short leaps. Such a structure characterizes the Tellince and Donacida. When it is about to make a spring, it firstly, by appropriate motions of the foot, puts the shell on the point or summit, as if aware that this is the position most favourable of any to avoid the resistance which the sand opposes to the moticn. It then stretches out the leg as far as possible, makes it embrace a portion of the shell, and, by a sudden movement similar to that of a spring let loose, it strikes the earth with its leg, and effects the leap." - Tohnston, fide Réaumur and Smellie, Introd., p. 136. 
the ligament side, on which the siphons protrude, flexuously angled or beaked. Some species are a little sculptured or rasped, but the generality are smooth, intensely coloured with various shades of rose and purple and yellow, and often delicately rayed.

\section{Species.}

1. acuminata, Hanl.

2. ala, $i d$.

3. alba, Quoy.

4. albinella, Lam.

5. alta, Conr.

6. alternata, Say.

7. ampullacea, Phil.

8. ancilla, Hanl.

9. angulata, Chemn.

10. Antonii, Plil.

11. assimilis, Hanl.

12. asperrima, $i d$.

13. aurora, $i d$.

14. balaustina, Linn.

15. Balthica, $i d$.

16. bimaculata, $i d$.

17. Bodegensis, Hinds.

18. Brasiliand, Speng.

19. Bruguieri, Hanl.

20. Burneti, Brod. \& Sow. 57. emarginata, Sow.

21. calcarea, Chemn.

22. candida, Lam.

23. capsoides, $i d$.

24. carnea, Limn.

25. carnicolor, Hanl.

26. casta, $i d$.

27. Cayennensis, Lam.

28. Chinensis, Hanl.

29. chloroleuca, Lam.

30. coccinea, Chemn.

31. Columbiensis, Hanl.

32. conspicua, $i d$.

33. Corbuloides, $i d$.

34. crassa, Pen.

35. crucigera, Lam.

36. crystallina, Chemn.

37. culter, Hanl.
38. Cumana, Costa.

39. Cumingii, Hanl.

40. cuspis, $i d$.

41. Cycladiformis, $i d$.

42. cygnus, $i d$.

43. Cyrenoidea, $i d$.

44. decora, Say.

45. decussata, Lam.

46. deltoidalis, $i d$.

47. Deshayesii, Hanl.

48. discus, $i d$.

49. dispar, Conrad.

50. distorta, Poli.

51. Dombei, Hanl.

52. donacina, Linn.

53. eburnea, Hanl.

54. edentula, Brod. \&s Sozv.

55. elegans, Gray.

56. elongata, Hanl.

58. ephippium, Speng.

59. exilis, Lam.

60. Fabricii, Hanl.

61. fabula, Gmel.

62. fausta, Donov.

63. felix, Hanl.

64. fimbriata, $i d$.

65. flexuosa, Say.

66. foliacen, Linn.

67. formosa, Hanl.

68. fragilis, Linn.

69. frigida, Hanl.

70. fusca, Say.

71. Galathæa, Lam.

72. gargadia, Linn.

73. gelida, Hanl.

74. Gouldii, $i d$.
75. grandis, Hanl.

76. gubernaculum, $i d$.

77. Guildingii, $i d$.

78. Guinaica, Chemn.

79. Hiberna, Hanl.

80. hilaria, $i d$.

81. hyalina, Gmel.

82. imbellis, Hanl.

83. inæqualis, $i d$.

84. inæquistriata, Donov.

85. incarnata, Linn.

86. inconspicua, Brod.S $S$.

87. inornata, Hanl.

88. insculpta, $i d$.

89. interrupta, Wood.

90. iridescens, Bens.

91. iris, Say.

92. irus, Hanl.

93. jubar, $i d$.

94. juvenilis, $i d$.

95. laceridens, $i d$.

96. lacunosa, Chemn.

97. lævigata, Linn.

98. lanceolata, Chemn.

99. lata, Quoy. \& Gaim.

100. lilium, Hanl.

101. lingua-felis, Linn.

102. lineata, Turt.

103. Listeri, Hanl.

104. lucerna, $i d$.

105. Lucinoides, $i d$.

106. lutea, Gray.

107. lux, Hant.

108. lyra, $i d$.

109. Madagascariensiš, Gm.

110. magna, Speng.

111. margaritina, Lam. 
112. marginalis, Dillw.

113. Mars, Hanl.

114. mera, Say.

115. micans, Hanl.

116. miles, $i d$.

117. nasuta, Con.

118. nitida, Poli.

119. nobilis, Hanl.

120. nux, $i d$.

121. nymphalis, Lam.

122. obliquilineata, Con.

123. ostracea, Lam.

124. Oudardi, Pay.

125. ovalis, Sowo.

126. Owenii, Hanl.

127. pellucida, Phil.

128. perna, Speng.

129. perplexa, Hanl.

130. petaluin, $V a l$.

131. Pharaonius, Hanl.

132. Philippinarum, $i d$.

133. pinguis, $i d$.

134. pisiformis, Linn.

135. planata, $i d$.

136. planissima, Anton.

137. plebeia, Hanl.

138. plectrum, $i d$.

139. plicata, $V a l$.

140. polita, Say.

141. polygona, Chemn.

142. princeps, Hanl.

143. pristis, Lam.

144. prora, Hanl.
145. proxima, Brown.

146. Psammotella, Lan.

147. pudica, Hanl.

148. pulchella, Lam.

149. pulcherrima, Sow.

150. pumila, Hanl.

151. punicea, Born.

152. purpurascens, Bord.

153. radiata, Linn.

154. rastellum, Hanl.

155. regia, $i d$.

156. remies, Linn.

157. rhodon, Hanl.

158. rhodora, Hinds.

159. rhomboides, Quoy.

160. robusta, Hanl.

161. rosea, Speng.

162. rostrata, Linn.

163. rubescens, Hanl.

164. rubicunda, Gould.

165. rufescens, Chemn.

166. rugosa, Born.

167. scalpellum, Hanl.

168. scobinata, Limn.

169. secta, Con.

170. semen, Hanl.

171. Senegalensis, id.

172. serrata, Costa.

173. similis, Sow.

174. sincera, Hanl.

175. sinuata, Speng.

176. sol, Hanl.
177. solidula, Pult.

178. Souleyeti, Hanl.

179. Sowerbii, $i d$.

180. spectabilis, $i d$.

181. spinosa, $i d$.

182. splendida, Anton.

183. staurella, Lam.

184. striata, Chemn.

185. striatula, Lam.

186. strigosa, Gmel.

187. subrosea, Hanl.

188. subtruncata, $i d$.

189. sulcata, Wood.

190. tenera, Say.

191. tenta, $i d$.

192. tenuis, Da Cost.

193. Timorensis, Lam.

194. Tongana, Quoy.

195. triangularis, Chemn.

196. truncata, Jonas.

197. truncatula, Sow.

198. tulipa, Hanl.

199. umbonella, Lam.

200. undulata, Hanl.

201. Valtonis, $i d$.

202. vernalis, $i d$.

203. verrucosa, $i d$.

204. vestalis, $i d$.

205. virgata, Linn.

206. virgo, Hanl.

207. virgulata, $i d$.

208. vulsella, Chemn.

\section{Figure.}

Telutina foltacea. Pl. 38. Fig. 208. Shell of an Eastern Tellen, showing the posterior flexuous angularity.

\section{Genus 6. GALEOMMA, Turton.}

Animal; oval, mantle very large, double-margined, tuberculiferous, closed in front; siphonal openings posterior, two; foot 
long, ligulate, byssiferous, perforate, projecting from an anterior opening in the mantle. (Forbes.) Shell; small, thin, oblong-oval, equivalce, moderately inequiluteral; a single cardinal tooth in each valve, and these sometimes wanting; ligament part internal, part external.

The little transparent bivalves known as Galeomme, and of which we have an interesting example in G. Turtoni of the Channel Islands and the western Mediterranean, do not properly belong to the family of the $N_{y m}$ phacea, but until something more is known of their characters than at present, the genus cannot be appropriated with any certainty. Nessrs. Forbes and Hanley consider it to be the nearest allied to Arca, Dr. Gray to Solemya and Pandora, M. Mittre to Tridacna, Costa to Gastrochena, and amid these conflicting opinions formed on the investigation of the same species it would be better to wait until the animals of some of the foreign species have been examined.

Galeomma differs from Tellina very conspicuously in having the mantlemargins closed, with only an opening for the passage of the foot, and in the foot being byssiferous; the siphonal orifices are not tubular; and the shell which gapes at the ventral margin is almost, if not altogether toothless, the valves being connected by a ligament, which is partially if not altogether internal. The shell is moreover covered with a transparent horny skin, which Mr. Alder describes as being composed of two lavers, the lower of which is slightly muscular, whilst the outer is granular and corered with tubercles, which possibly, when the animal is alive, may rise into papillie.

The Lamarckian Psummolia anruntia, a native of the Mauritius, is considered to belong to the genus, and a few other species have been added.

\section{Species.}

1. ambigua, Dest.

2. angusta, $i d$.

3. argentea, $i d$.

4. aurantia, Lam.

5. chloroleuca, Desh.
6. formosa, Desh.

7. indecora, $i d$.

8. inflata, $i d$.

9. Layardi; $i d$.

10. macrochisma, $i d$.
11. paucistriata, Desh.

12. polita, $i d$.

13. splendida, $i d$.

14. Turtoni, Soro.

\section{Figures.}

Galeoma Turtoni. Plate $P$. Shell enlarged and widely opened, as in our figure of Tridacna, to show the animal with the mantle closed, and having an opening for the passage of the foot. 
Galeomara Turtoni. Pl. 37. Fig. 200. Shell, with the valves closed to show the gaping at the ventral margin.

\section{Genus 7. PSAMMOBIA, Lamarck.}

Animal; oblong, compressed, its mantle open thronghout and bordered by a fringe of fine sillien filaments; siphons very long, slender, and delicate, marked with longitudinal ciliated lines, uchich terminate in more or less conspicuous cirrhi, few (six or eight in number) surrounding their orifices. (Forbes.)

Shell ; transversely oblong, moderately inequilateral, a little gaping at the side, the posterior mostly flexuously angled; linge composed of two teeth in one valve, generally bifid, and one in the other.

To genus Psammotia is referred a series of sixty exquisitely beautiful bivalves, confined, with one or two abnormal exceptions, to the Eastern Hemisphere, ranging, but with comparative scarcity, from the Hebrides to Tasmania, and represented on our own shores by the elegant $P$. vespertina, Ferroensis, tellinella, and costulata. The animal, like Tellina, has its siphonal tubes of unequal length, widely separated and extended, but they are curiously fluted, so far as regards the British P. tellinella, with six or eight ciliated lines, terminating at the margins of the orifices in cirrhi. The shell presents more dainty varieties of radiated painting, simulating the rays of the setting sun, than in any other genus of Nymphacea, and there are more varieties of concentric striation. In many species the raised strix are not parallel with the lines of gromth, but cross them obliquely, waving flexuously on to the posterior beaked angle; and in a few of the smaller species the angle is carved with elaborately scaled ridges. The Psammobice dwell in sand or gravelly mud, but are not of sluggish habits.

Species.
1. abrupta, Desh.
8. cærulescens, Lam.
15. costulata, Turt.
2. affinis, Reeve.
9. candidula, Desh.
16. denticulata, $A d$ \& $R$.
3. amethystus, IVood.
10. casta, Reeve.
17. dispar, Desh.
4. amœna, Desh.
11. castrensis, Chemn.
18. eburnea, Reeve.
5. angusta, $i d$.
12. compta, Desh.
19. elegans, Desh.
6. anomala, $i d$.
13. convexa, Reeve.
20. Ferroensis, Chemn.
7. bicarinata, $i d$.
14. corrugata, Desh.
21. grata, Desh. 
22. insignis, Desh.

23. lata, $i d$.

24. Layardi, $i d$.

25. Lessoni, De Blain.

26. lineolata, Gray.

27. Malaccana, Reeve.

28. marmorea, Desh.

29. maxima, $i d$.

30. Menkeana, Reeve.

31. modesta, Desh.

32. nivosa, $i d$.

33. occidens, Chemn.

34. oriens, Desh.
35. ornata, Desh.

36. palmata, $i d$.

37. parvula, Reeve.

38. pennata, Desh.

39. petalina, $i d$.

40. præstans, $i d$.

41. puella, $i d$.

42. pulchella, Lam.

43. pulcherrima, Desh.

44. xubicunda, $i d$.

45. rugulosa, $A d$. \& $R v$.

46. solida, Phil.
47. squamosa, Lam.

48. Stangeri, Gray.

49. suffusa, Reeve.

50. Tellinæformis, Desh.

51. Tellinella, Lam.

52. tenuis, Desh.

53. togata, $i d$.

54. tripartita, $i d$.

55 . tristis, $i d$.

56. vaginoides, Reeve.

57. vespertina, Gmel.

58. zonalis, Lam.

\section{Figures.}

Psammobia Tellinella. Plate $Q$. Shell, with the animal, showing, on the anterior side, the foot, and, on the posterior side, the widely separate siphons of unequal length, each passing out between the fringe-edged lobes of the mantle.

Psammobia vespertiva. Pl. 38. Fig. 206. Shell of a British species, showing the delicate violet-rayed painting.

\section{Genus 8. PSAMMOTELLA, Deshayes.}

Animal ; undescribed.

Shell ; transversely ovate, equitateral, gaping at both ends, truncated and slightly beaked at the posterior, mostly violct-coloured, covered with an olive epidermis; hinge composed of two sunall erect cardinal teeth in one valve and one in the other, and of an oblong callosity or fulcrum in each valve.

A genus lately founded by M. Deshayes for the reception of seven shells from the Philippine Islands, Malacea, and the Red Sea, intermediate between Psammotia and Soletellina. The animal is not known, but the oblong callosity of each valve would scem to indicate that the grenus has an affinity with the genus Soletellina founded on the Linnean Solen diphos.

\section{Species.}

1. ambigua, Desh.

2. Malaccensis, $i d$.

3. oblonga, $i d$.
4. Philippinensis, Desh.

5. Ruppelliana, Reeve.
6. Skinneri, Reeve.

7. subradiata, $i d$.

VOL. II. 


\section{Figure.}

Psammotelia Ruppelitana. Pl. 38. Fig. 205. Shell of violet colour beneath an olive epidermis, with right valve dropped to show the oblong callosity.

\section{Genus 9. CAPSA, Bruguière.}

Animal; undescribed.

Shell; transversely oblong, somewhat square, a little gaping at the ends, inequilateral; linge composed of two central teeth in each valve.

This genus contains only the Linnean Venus deflorata, a native of the Eastern Seas, well known in collections, and another very closely allied species from Tahiti. In both species the shell has a densely rasped crenated surface. It is not the genus Capsa of Lamarck; for that, the name Iphigenia, Schumacher, has been revived.

\section{Species.}

1. deflorata, Linn.

2. Taheitensis, Bernardi.

\section{Figure.}

Capsa deflorata. Pl. 38. Fig. 211. Shell, with left valve dropped, showing its densely rasped crenated exterior and hinge.

\section{Genus 10. CAPSELLA, Deshayes.}

Animal ; undescribed.

Shell; transversely oblong, nearly equitateral, with the posterior side somewhat squarely truncated; linge composed of one tooth in the left valve and two in the right valve, bifurcated, with a slight oblong callosity in each supporting the ligament.

Another genus established lately by M. Deshayes while investigating the Cumingian collection of Nymphacea. It includes sixteen species, all from the Eastern Seas, intermediate in character between Capsa and Soletellina, 
and of which only one species, $C$. elongata, referred by Lamarck to Psammobia, had been previously described. The hinge scarcely differs from that of Soletellina, except in the teeth being more developed, and in the oblong callosity or fulcrum being less prominent; but the species present a very natural assimilation of external characters. They are all of a uniform transversely oblong growth, with the posterior side simply truncated into a faintly obtuse angle.

\section{Species.}

1. candida, Reeve.

2. Chinensis, Desh.

3. crassula, $i d$.

4. difficilis, $i d$.

5. elongata, Lam.

6. Layardi, Desh.
7. lunulata, Desh.

8. minor, $i d$.

9. radiata, $i d$.

10. rosacea, $i d$.

11. rufa, $i d$.
12. solenella, Des/l.

13. solida, Reeve.

14. tenuis, Des/.

15. virescens, $i d$.

16. violacea, Reeve.

\section{Figure.}

Capsella radiata. Pl. 38. Fig. 207. Shell, showing the transversely oblong form and faint posterior angulation.

\section{Genus 11. SOLETELLINA, De Blainville.}

Animal; undescribed.

Shell ; transversely oblong, compressed, mostly equivalve, nearly equilateral, covered with a horny epidermis, gaping a little at the sides, the posterior sometimes acuminated, sometimes shortly truncated; linge composed of a single erect tooth in the left valve and two in the right valve, sometimes bifurcated, with a conspicuous fulcrum in each supporting the ligament.

Founded by Blainville on the Linnean Salen diphos, and remodelled with excellent discrimination by M. Deshayes, the shells partaking rather more of the characters of the Solenacea than the preceding genus. The typical forms are clongately oblong and depressed, with the posterior side sometimes acuminated, and they are of a peculiarly sombre leaden-violet colour, covered with an olive horny epidermis. Another type, represented by S. Nuttallii, is of an obliquely orbicular form. The first of these types inhabits the Eastern Seas, the second inhabits California. S. orliculata 
(genus Elizia, Gray) is another orbicular form from Sumatra, and an intermediate form is presented in $S$. nitida from New Zealand. In all these the fulcrum callosity of the hinge is more or less conspicuously developed. Another peculiarity of the genus not unworthy of note is that the posterior side is generally painted with two faint rays.

\section{Species.}

$\begin{array}{lll}\text { 1. acuminata, Desh. } & \text { 8. Donacioides, Reeve. } & \text { 15. orbiculata, Wood. } \\ \text { 2. Adamsii, } i d . & \text { 9. epidermia, Desh. } & \text { 16. obscurata, Desh. } \\ \text { 3. atrata, } i d . & \text { 10. incerta, } i d . & \text { 17. planulata, Reeve. } \\ \text { 4. biradiata, Wood. } & \text { 11. Japonica, id. } & \text { 18. reversa, } i d . \\ \text { 5. consobrina, Desh. } & \text { 12. nitida, Gray. } & \text { 19. siliqua, } i d . \\ \text { 6. Cumingiana, } i d . & \text { 13. Nuttalli, Conr. } & \text { 20. truncata, } i d . \\ \text { 7. diphos, Linn. } & \text { 14. nymphalis, Desh. } & \text { 21. tumens, } i d .\end{array}$

\section{Figure.}

(For figure, see Conch. Icon. vol. x.)

\section{Genus 12. SANGUINOLARIA, Lamarck.}

Animal; mantle freely open and fringed at the edges; siphons long and widely separated; foot compressly linguiform.

Shcll; transversely ovate, rather convex, thin, subtransparent, moderately inequilateral, finely concentrically striated, more or less tinged with blood-rose, anterior side rounded, posterior atlenuated; hinge composed of two small approximating erect bifid teeth in each valve.

The Lamarckian genus Sanguinolaria has been dismembered of all its species excepting the beautiful and very delicate Tellen form, known as $S$. sanguinolent. (S. rosea, Lam., Solen sanguinolentus, Gmelin). To this type have been added four newly-described species of similar character, and a very natural group is the result. The shel] is of transparent delicacy, finely concentrically striated, sometimes white, but mostly tinged more or less with deep blood-rose. On the anterior side it is rounded, on the posterior attenuated, with a faint depression radiating from the umbo. The hinge, in addition to the small cardinal teeth which characterize the Tellens generally, has still the fulcrum callosity of Soletellina in a rudimentary form. 
The habitats are only known of three of the species: S. ovalis is from Central America, S. Tellinoides from California, and S. sanguinolenta from Ceylon.

\section{Species.}
1. ovalis, Reeve.
3. sanguinolenta, Gimel.
5. nitrea, Desh.
2. purpurea, Desl.
4. Tellinoides, Adams.

\section{Figure.}

Sanguinolaria Tellinoides. Pl. 38. Fig. 209. Shell of delicate transparent rose-colour.

\section{Family 8. LI'THOPHAGA.}

Shell ; very inequilateral, irregular, more or less gaping in front; ligament external.

The genera associated in this family are borers, and, like all borers, are of very irregular growth; they differ moreover so much at different periods of their growth, that extensive scries of specimens are requisite to observe their specific relition. The animal resembles that of the Gastrochana form of Tubicola, in having the mantle united in front; but no tubular sheath is formed, nor is it at all certain that the habit of boring is a constant habit. The genera are-

Venerupis. Petricota. Saxicava.

\section{Genus 1. VENERUPIS, Lamarck.}

Animal; oblong, thick; mantle closed in front with an opening for the passage of a compressed lanceolate foot; siphons united for about half their length, their orifice fringed with a double series of cirrti, the longer ones pectinated. (Forbes.)

Shell; ablong, rather compressed, sculptured for the most part with concentric lamina, which in many species are fincly serrated; hinge composed of two cardinal teeth in one valve and three in the other, or with three cardinal teeth in both valves, of which the central is bifid.

Of the three genera composing the family of Lithophaga, the Venerupes 
are those nearest allied to the family of Conchacea. So nearly do the shells of some species assimilate with those of Tapes, that it is difficult, conchologically, to separate them. The animal, according to the well-marked typical $V$. Irus of our own shores, has, however, its mantle closed like Gastrochcona. Twenty-eight species were brought together a few years since by Mr. Sowerby in his 'Thesaurus Conchyliorum,' and the shells are characterized by a remarkable uniformity of detail. They are very unequalsided, the anterior side being particularly short, and their boring habit is pretty well indicated by their irregularity of growth. They are all of a dull white or stone-colour, tinged with yellow or rust, and some are richly purple-stained in the interior. The sculpture is very uniform throughout, the surface being more or less densely frilled with lamellæ, which are sometimes serrated at the edge, sometimes a little festooned. The principal habitats of the species are New Holland, New Zealand, the Philippine Islands, and especially California.

\section{Species.}

$\begin{array}{lll}\text { 1. Carditoides, Lam. } & \text { 11. foliacea, Desh. } & \text { 20. Nuttallii, Conr. } \\ \text { 2. Chinensis, Desh. } & \text { 12. insignis, } i d . & \text { 21. obesa, Desh. } \\ \text { 3. Cordieri, } i d . & \text { 13. interjecta, id. } & \text { 22. oblonga, Sow. } \\ \text { 4. crenata, Lam. } & \text { 14. interstriata, Sow. } & \text { 23. paupercula, Desh. } \\ \text { 5. Cumingii, Desh. } & \text { 15. Irus, Linn. } & \text { 24. planicostata, id. } \\ \text { 6. cylindracea, } i d . & \text { 16. macrophylla, Desh. } & \text { 25. pulcherrima, id. } \\ \text { 7. derelicta, id. } & \text { 17. mirabilis, id. } & \text { 26. rugosa, id. } \\ \text { 8. Diemenensis, Quoy. } & \text { 18. mitis, } i d . & \text { 27. siliqua, id. } \\ \text { 9. exotica, Hanl. } & \text { 19. monstrosa, id. } & \text { 28. tumida, Sow. }\end{array}$

10. fimbriata, Sow.

\section{Genus 2. PETRICOLA, Lamarck.}

Animal; oval; mantle closed in front, except a small opening for a lanceolate pointed foot; siplons united for nearly half their length, their orifices fringed with a double series of cirrli, the longer ones pinnated on one side.

Shell; triangular or narrowly oblong, the anterior side rounded, the posterior more or less attenuated; linge composed of two cardinal teeth in each valve.

The Petricole differ from the Venerupes only in having a shell of lighter substance, attenuated obliquely instead of being subquadrate on the posterior side, and in having a less lamellated sculpture. The sculpture, instead 
of being concentric, in the majority of the species inclines more to radiation, and in some species the radiating ribs are profusely scaled after the manner of Pholas. Though few in number, the Petricola are very generally distributed, one species inhabiting Britain.

\section{Species.}

1. amygdalina, Sow.

2. bicolor, $i d$.

3. bidentata, Gray.

4. bipartita, Desh.

5. Chinensis, $i d$.

6. concinna, Sorv.

7. costellata, Lam.

8. cultellus, Desh.

9. dactylus, Sow.
10. denticulata, Sow.

11. discors, $i d$.

12. divaricata, Chemn.

13. elegans, Desh.

14. elliptica, Sow.

15. flabagella, Lam.

16. gracilis, Desh.

17. lapicida, Chemn.
18. lithophaga, Ret2.

19. nivea, $i d$.

20. Pholadiformis, Lam.

21: robusta, Sow.

22. semilamellata, Lam.

23. serrata, Desh.

24. solida, Sow.

25. typica, Jonas.

Figure.

Petricola Pholadiformis. Pl. 39. Fig. 212. Shell showing its attenuated form and scaled radiations of sculpture.

\section{Genus 3. SAXICAVA, De Bellevue.}

Animal; oblong or claviform; mantle closed in front except for the passage of a digitiform foot, which is furnished with a byssal groove; siphons united nearly to the extremity, orifices large, margined with a fringe of cirrhi. (Forbes.)

Shell; generally oblong, irregular, gaping, linge furnished in some stages of growth with two cardinal teeth, mostly toothless.

Saxicava curiously resembles Gastrochcona in having the mantle closed in front, except for the passage of a narrow finger-like foot, but its shell is of a more solid Venerupis-like growth, and the animal does not form a tubular sheath. The Saxicave are borers, but not always. If there be a crevice, it has been observed by Forbes and Hanley, in rock, shell, coral, or seaweed, into which they can thrust themselves, they do so ; and if near a limestone rock, they perforate it, and form crypts in which to live.*

* "Mr. Osler states that when young they are very active animals, and soon commence to perforate. Both that gentleman and Mr. Garner have noticed that their excavations are not round, nor the sides smoothed off, like those of the holes made by Pholas. As for us, we only know of their boring into calcareous rocks; but Mrr. Clark has noticed an instance of their perforating 
Fifteen species have been described, but the genus was not examined by Mr. Sowerby when figuring Venerupis and Petricola in his 'Thesaurus,' and needs to be monographed. Two species are British, the Linnean S. megosa and Arctica (Hiatella, Turton); others are Californian, Peruvian, and Australian.

\section{Species.}
1. Arctica, Limn.
6. Guerinii, Desh.
10. rugosa, Lam.
2. australis, Lam.
7. legumen, $i d$.
11. solida, Sow.
3. Californica, Conr
8. Pholadis, Lam.
12. tenuis, $i d$.
4. Carditoides, $i d$.
9. purpurascens, Sow.
13. Veneriformis, Lam.
5. distorta, Say.

\section{Figure.}

Saxicava Arctica. Pl. 39. Fig. 214. Shell of a peculiar rhomboid growth.

\section{Family 9. MACTRACEA.}

Shell ; mostly inequilateral, sometimes a little gaping at the sides; ligament partially or wholly internal.

After assorting into families the forms of bivalves represented on one side by Tellina and on the other by $M M_{y}$, there remain a group of genera partaking variously of both types, but yet distinguished in having the ligament wholly or partially internal: these are the Mactracea. In the true Mactra we have a form which differs in a manner clearly enough removed from the neighbouring groups, but in Amphidesma we have a Tellen-Mactra and in Lutraria a Mya-Mactra; and yet there is no sufficient difference in the animals to render their association unnatural. The genera are-

$\begin{array}{lll}\text { Comingia. } & \text { Mesodesira. } & \text { Mactra. } \\ \text { Amphidesira. } & \text { Crassatelia. } & \text { Lutraria. } \\ \text { Ungulina. } & \text { Gnathodon. } & \text {. }\end{array}$

triassic sandstone at Exmouth. Whercver we have a seacoast of mountain limestone, the surface of the rocks is almost invariably riddled by Saxicava. The whole front of the Plymouth breakwater has been attacked by it, and much alarm for its safety excited."-Forbes and Manley, Brit. Moll., vol. i. p. 138. 


\section{Genus 1. CUMINGIA, Sowerby.}

Animal ; unknown.

Shell; equivalve, inequilateral, anterior side rounded, posterior more or less acuminated and a litlle gaping; linge composed of a small anterior tooth in each valve, with two strong lateral teeth in one valve only, the ligament being within an inwardly projecting spoon-shaped cavity.

At the head of the Mactracea we have a genus of which the shell is found in sponges and in fissures of rocks, like the shells of the preceding family, but of which the hinge-ligament is contained within an inwardly projecting spoon-shaped cavity. It was founded in 1833 on some specimens collected by Mr. Cuming on the western coast of South America, presenting, in addition to these characters, the somewhat anomalous one of having two well-developed lateral teeth in one valve and none in the other. Four species were defined on its discovery by Mr. Sowerby; six, from the same locality and the West Indies, were described seventeen years later by Mr. Arthur Adams; and D'Orbigny and Conrad described four species. They are rather slight and colourless, mostly rudely lamellated, and all of them gape a little posteriorly. They seem to be allied to Amplidesma, but their place in the system cannot be satisfactorily determined until the animal is known.

\section{Species.}

1. Antillarum, D'Orb.

2. Californica, Conr.

3. Clerii, Adams.

4. coarctata, Sow.

5. fragilis, Adams.
6. lamellosa, Sow.

7. mutica, Sow.

8. Petitiana, D'Orb.

9. similis, Adams.

10. sinuosa, id.
11. striata, Adams.

12. Tellinoides, Conr.

13. tenuis, Adams.

14. trigonularis, Sow.

\section{Figure.}

Comingia neutica. Pl. 39. Fig. 213. Shell, with one valve dropped to show the inwardly projecting spoon-shaped cavity containing the ligament. 


\section{Genus 2. AMPHIDESMA, Lamarck.}

Animal ; undescribed.

Shell; equivalve, inequitateral, oblong-oval or rounded, posterior side generully more or less fleanous; hinge composed of one or turo teeth in each valve, with an obliquely elongated pit lying between them containing the ligament; there is also a thin external ligament.

The genus Amplidesma shows rather a want of scientific spirit among naturalists residing and collecting abroad. Ifad any one of the sixty beautiful species at present known been a native of the shores of Europe or of North America, its animal would have been described long ago; but half a century, nearly, has elapsed since Lamarck drew attention to the peculiarities of the shell of Amphictesina, and abundance of specimens, of bold dimensions and attractive colouring, have been brought from the western coast of South and Central America, from Australia, from the Philippine Islands, yet no one has preserved the animal, and authors are altogether silent on the matter.

Limpliulesma has a particularly characteristic hinge. It has two ligaments, one internal, solid, and conspicuous, contained within a pit running obliquely on the posterior side; the other thin and external. The shell is mostly of an oblong-circular or oval form, with the posterior or hinge side more or less truncated and flexuous. The sculpture consists chiefly of irregular concentric ridges, often in densely packed lamellæ, neatly frilled, with the interstices profusely cancellated. The species have all a light and delicate aspect, though in several instances they are rather solid; some are white, some are painted with rose and pale yellow.

\section{Species.}

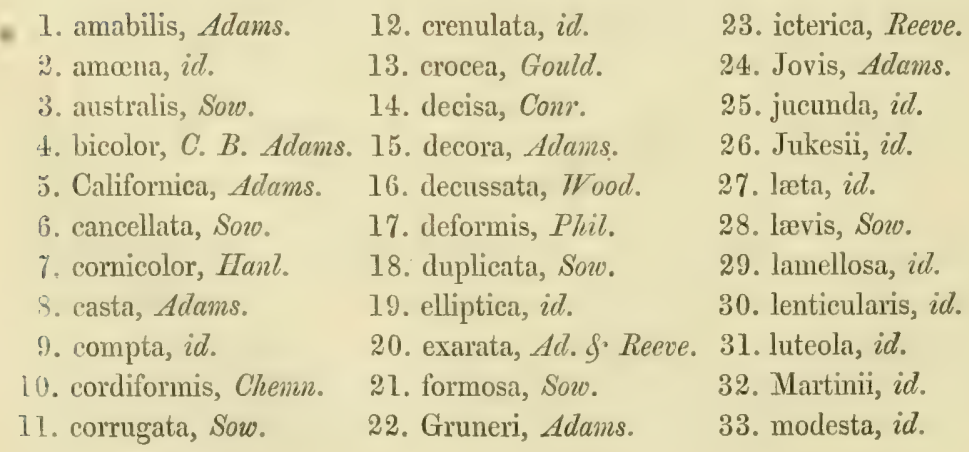


34. obliqua, Wood.

35. orbiculata, Say.

36. pallida, Sovo.

37. proxima, C. B. Ad.

38. pulchella, Adams.

39. pulchra, Sow.

40. punctata, id.

41. purpurascens, Sow.

42. radiata, Riipp.

\author{
43. reticulata, Sow. \\ 44. rosea, $i d$. \\ 45. rubro-lineata, Conr. \\ 46. rupium, Sow. \\ 47. scabra, Hanl. \\ 43. simplex, Ad. \&. Reeve. \\ 49. Sinensis, Adams. \\ 50. solida, Gray. \\ 51. sponsa, Adams.
}

52. striatii, Riipp.

53. subtruncata, Sow.

54. tortuosa, C. B. Adams.

55. ventricosa, $i d$.

56. venusta, Adams.

57. vestalis, $i d$.

58. virginea, $i d$.

59. Zebuensis, Hanl.

\section{Figure.}

Ampridesma obliqua. Pl. 39. Fig. 216. Shell with one valve dropped to show the oblique posterior pit containing the ligament.

\section{Genus 3. UNGULINA, Daudin.}

Animal; with the mantie open below, fringed; siphonal orifice single; foot vermiform, thickened at the end and perforated, projecting from the base of the shell, or folded up between the gills. (Woodward.)

Shell; suborbicular, equivalve, nearly equilateral, covered with a thick brown epidermis; linge composed of a short central bifid tooth in each valve, with an additional small one in one valve only; no lateral teeth; ligament in a narrow oblique marginal pit.

Unzulina is a mollusc of very peculiar labits, producing a very peculiar shell. Three species only are known, and they are found on the shores of the Mediterranean and Red Seas, either buried in sand or mud, or excavating winding galleries in coral. The shell is covered externally by a dark chestnut-brown horny epidermis; internally it is sometimes tinged with patches of blood-red. The hinge so far resembles the hinge of Amphidesma, that it has an oblique narrow pit containing the liganent, and it has the central bifid tooth in an obtuse somewhat undefined form. The general outline of the shell varies in being oblong or trausverse according to the nature of its place of habitation. 
Species.
1. alba, Rang.
2. transversa, Lam.
3. rubra, Roissy.

\section{Figure.}

Ungulina transversa. Pl. 39. Fig. 217. Shell with one valve dropped to show the central bifid tooth and ligamentary pit.

\section{Genus 4. MESODESMA, Deshayes.}

Animal; with the lobes of the mantle united about two-thirds of their length, open posteriorly for the passage of two short siphons; foot flat, triangulur, partially concealed by the branchia. Shell; ovate, transierse, or triangular, equivalve, rather thick, compressed; hinge composed of turo lateral teeth in each valve, between which is a deep triangular cavity containing the ligament.

Under MTesolesma we have a somewhat promiscuous series of shells of rather solid pallid substance, distinguished by a hinge of corresponding solidity. The ligament is contained in a conspicuous triangular cavity, not obliquely curved, as in the two preceding genera, but perpendicular, and the valves interlock on either side by strong lateral teeth. Some of the species from New Zealand inhabit the sands of estuaries.

\section{Species.}

1. arctatum, Gould. 7. donacillum, Desh.

2. Chemnitzii, Desh. 8. donacium, id.

13. planum, Hanl.

3. corneum, $i d$.

9. erycina, $i d$.

14. Quoyi, Desh.

4. cuneatum, $i d$.

10. glabellum, $i d$.

15. Solenoides, King.

5. cycladum, $i d$.

11. glabratum, $i d$.

16. striatum, Desh.

6. deauratum, Hanl.

12. Jauresii, Joannis.

17. trigonum, $i d$.

18. triquetrum, Hanl.

\section{Figure.}

Mesodesua Nove-Zeiandie. Pl. 43. Fig. 233. Shell, showing the linge. 


\section{Genus 5. CRASSATELLA, Lamarck.}

Animal ; mantle-lobes united only by the branchial septum; inhalent margins cirrhated; foot moderate, compressed, triangular, grooved; gills smooth, unequal. (Woodward.)

Shell; equivalve, everywhere closed; hinge composed of two central teeth in one valve and one in the other, and a deep central pit containing the ligament; an obscure lateral tooth in each valve.

A beautiful genus, having shells of solid growth covered by a very characteristic chestnut-brown epidermis, often richly toned and rayed, and sometimes developed in elegant concentric furrows. The ligament is strong, contained in a conspicuous central pit, as in Mesodesma, but not so perpendicularly produced. The animal differs in not having the lobes of the mantle united. Most of the Crassatelle are Australian, but the genus is well represented in the Eastern Seas, as well as on the western coast of South America and in the West Indies.

\section{Species.}

1. Antillarum, Reeve. 12. Donacina, Lam.

2. bellula, Adams.

3. castanea, Reeve.

13. gibbosa, Sow.

14. jubar, Reeve.

4. compressa, $A d$. \& $R v$. 15. Kingicola, Lam.

5. compta, Adams.

6. concinna, id.

7. Corbuloides, Reeve.

8. corrugata, $A d . \& R v$.

9. Cumingii, Adams.

10. decipiens, Reeve.

11. divaricata, Chemn.
16. lævis, Adams.

17. lapidea, Reeve.

18. nana, Ad. \& Reeve.

19. obscura, Adams.

20. ornata, Gray.

21. pallida, Ad.\& Reeve.' 32. ziczac, Reeve.

22. picta, $i d$.
23. pulchra, Reeve.

24. radiata, Sow.

25. rostrata, Lam.

26. speciosa, Adams.

27. subradiata, Lam.

28. sulcata, $i d$.

29. triquetra, Reeve.

30. truncata, Adams.

31. undulata, Sow.

\section{Figure.}

Crassatella pulchra. Pl. 39. Fig. 215. Shell, with one valve dropped to show the central tooth and ligamentary pit. 


\section{Genus 6. GNATHODON, Gray.}

Animal; with the mantle freely open in front; margins plain; siphons short, partly united; foot very thick, tongue-shaped.

Shell; equivalve, obliquely oval, rather gibbous, covered with an olive-green epidermis; hinge composed of a central and two lateral tecth in one valve interloching with two central and two lateral tecth in the other, enclosing the ligament in a deep central pit.

This genus was instituted for the reception of a bivalve of quite peculiar character, inhabiting Lake Pont-Chartrain, New Orleans. The animal has the mantle freely open in front for the passage of a large tongue-shaped foot like that of Anodon and Uirio, and the shell has the same freshwater aspect, being covered by an olive-green epidermis, more or less eroded towards the umboes. The shell internally is, however, of a more transparentwhite substance, and the hinge has its ligament enclosed, like Mactra and Crassutella, within an internal cavity. Only one species is known.

\section{Figure.}

Gnathodon cuneatus. Pl. 40. Fig. 218. Shell, with one valve dropped to show the strong dentition of the hinge on either side of a central pit in which the ligament is contained.*

\section{Genus 7. MAC'TRA, Linnaus.}

Animal; triangular or oblong, its mantle freely open in front as far as the siphons, the margins more or less distinctly fringed; siphons united to their extremities, which are surrounded with fringes of simple cirrtir; foot strong, changeable in shape, linguiform and geniculated. (Forbes.)

Shell; ovately triangular or oblong, a little gaping at the sides;

* "Gnathodon cuneatus was formerly eaten by the Indians. At Mobile, on the Gulf of Nexico, it is found in colonies along with Cyrena Carolinensis burying two inches deep in banks of mud; the water is only blackish, though there is a tide of three feet. Banks of dead shells three or four feet thick are found twenty miles inland. Mobile is built on one of these shellbanks. The road from New Orleans to Pont-Chartrain, six miles, is made of Gnathodon shells procured from the east end of the lake, where there is a mound of them a mile long, fifteen feet high, and twenty to sixty yards wide; in some places it is twenty feet above the level of the lake." - Iyell. 


\section{linge composed of compressed plicately channelled cardinal teeth, and, on either side, compressed lateral teeth, enclosing a pit containing the ligament.}

Although the genus Mactra, of which we have five well-marked species on our own shores, has been split up into half-a-dozen genera, there are few lamellibranchiate groups of which it is more easy to determine the generic characters. The animal has its mantle open in front as far as the siphons, and the siphous are more or less distinctly serrately fringed; the shell has with little variation a characteristic triangular form, more or less transversely ovate or oblong, and the hinge is distinguished by a conspicuous central triangular tooth in one valve, which interlocks unusually closely with the opposite valve. The Mactra shclls are mostly devoid of colour, but some are very prettily tinged and rayed with rose or purple. In sculpture they are somewhat wanting, having seldom more than concentric grooves and stria or plait-like ridges. The anterior or front half of the shell is, with few exceptions, the shorter, and this is sometimes concentrically grooved and striated, while the posterior side is smooth. Beneath the umboes on the anterior side a neat heart-shaped lunule is generally formed, and the striæ of the valves mostly converge on the shield of this in a more regularly and gracefully developed manmer. On the posterior side the ligamentary area is more broadly spread, it is mostly angled on each side.

Some of the Mactre, more especially those inhabiting the Northern Seas, are ponderous and Mya-like; ${ }^{*}$ the majority of the species inhabiting tropical seas are thin, some almost transparent, and most elegantly wavewrinkled and striated. The genus is widely distributed over the globe, from the Arctic Seas, along both sides of the African contiment to Tasmania in one hemisphere, and from North America to Panama and Columbia in the other, and it is more than probable that its southern limit is not as yet known.

\footnotetext{
Species.

1. achatina, Chemn.

3. Egyptiaca, Chemn.

5. alata, Speng.

2. Adansoni, Phil.

4. æquilatera, Desh.

6. Anatimoides, Reeve. * Speaking of the Mactra solidissima of Massachusetts, Dr. Gould says, "This is character-
ized at maturity by its great magnitude, which entitles it to the name of Giant Clam. No other
species of the genus approaches it in size, except $M$. ovalis. The largest specimen I have seen
measures $6 \frac{1}{4}$ inches in length, 4 in height, and $2 \frac{1}{2}$ in breadth. It is found about sandy beaches on
all our coast, and its inhabitant is much esteemed by some as an article of food. At low-water
it is dug out of the sand with shovels. At higher tides, when the shell is open, the fishermen
wade into the water, thrusting a pointed stick into the sand before them as they walk along. If
the stick happens to pass between the valves, they are closed upon it by the animal, and the
shell is thus drawn up." - Invert. MIassachusetts, p. 52 .
} 
7. angulata, Gray.

8. angulifera, Desh.

9. angusta, $i d$.

10. antiquata, Speng.

11. Aphrodina, Desh.

12. apicina, $i d$.

13. aspersa, Sowo.

14. attenuata, Desh.

15. bilineata, C.B. $A d$.

16. Byronensis, Gray.

17. Californica, Des/.

18. canaliculata, Say.

19. capillacea, Dest.

20. carinulata, $i d$.

21. complanata, $i d$.

22. contraria, $i d$.

23. corallina, Linn.

24. corbiculoides, Desh.

25. Corbuloides, $i d$.

26. cordiformis, $i d$.

27. cornea, $i d$.

28. Cumingii, id.

29. cuneata, Chemn.

30. cyprinus, Gray.

31. decora, Desh.

32. depressa, Speng.

33. discors, Gray.

34. dissimilis, Desh.

35. dolabrata, $i d$.

36. Donaciformis, Gray.

37. Dysoni, $i d$.

38. edulis, King.

39. egena, Desh.

40. elegans, Sovo.

41. elliptica, Brovon.

42. elongata, Quoy.

43. epidermia, Desh.

44. exalbida, Gray.

45. eximia, Desh.

46. exoleta, Gray.
47. explanata, Desh.

48. fasciata, Lam.

49. fragilis, Chemn.

50. gibbosula, Desh.

51. glauca, Born.

52. hians, Phil.

53. hepatica, Desh.

54. inæqualis, $i d$.

55. incarnata, $i d$.

56. incongrua, $i d$.

57. inflata, Brown.

58. lævis, Chemn.

59. Largillierti, Phil.

60. lateralis, Say.

61. Lurida, Phil.

62. Luzonica, Desh.

63. maculata, Chemn.

64. maxima, Midd.

65. mera, Desh.

66. Meritriciformis, $i d$.

67. mitis, $i d$.

68. Murchisoni, id.

69. nitida, Schro.

70. nucleus, Conr.

71. Nuttallii, id.

72. obesa, Desh.

73. olorina, Phil.

74. opposita, Desh.

75. ornata, Gray.

76. ovalina, Lam.

77. ovalis, Say.

78. ovata, Gray.

79. pellicula, Desh.

80. pellucida, Chemn.

81. plicataria, Linn.

82. plicatilis, Desh.

83. polita, Chemn.

84. pulchra, Gray.

85. pura, Desh.
86. quadrangularis, $i d$.

87. radiolata, $i d$.

88. Reevei, $i d$.

89. Reevesii, $i d$.

90 . rostralis, $i d$.

91. rostrata, Speng.

92. rufescens, Lam.

93. rugosa, Chemn.

94. Sauliæ, Gray.

95. Sayi, $i d$.

96. scapellum, Desh.

97. semistriata, $i d$.

98. semisulcata, $i d$.

99. Senegalensis, Phil.

100. sericia, Desh.

101. silicula, $i d$.

102. Solandri, Gray.

103. solidissima, Chemn.

104. Spengleri, Linn.

105. striatella, Lam.

106. stultorum, Linn.

107. sublanceolata, Desh.

108. subrostrata, $i d$.

109. subtruncata, Mont.

110. sulcataria, Des/.

111. symmetrica, $i d$.

112. Thracioides, $A d . \& R$.

113. Tellinoides, Conr.

114. transversa, Desh.

115. triangula, Renieri.

116. triangularis, Lam.

117. tristis, Desh.

118. truncata, Mont.

119. tumida, Chem.

120. velata, Phil.

12]. Veneriformis, Desh.

122. violacea, Chemn.

123. virgo, Desh.

124. vitrea, Gray.

\section{Figures.}

Mactra stultoruxr. Pl. Q. Fig. 8. Shell, with animal, showing the serrately fringed siphons. 
Mactra plicataria. Pl. 40. Fig. 220. Shell, with one valve dropped to show the compressed cardinal and lateral teeth and central ligament-pit.

\section{Genus 8. LUTRARIA, Lamarck.}

Animal ; thick, oblong, with much produced siphonal tubes, mnited almost to their extremities; mantle closed except a rather large anterior opening for a foot of considerable dimensions, both it and the siphons partially invested with an epidermic sheath. (Forbes.)

Shell; equivalve, oblong-ovate, generally rather compressed, gaping at the sides, dirty-volite, covered more or less with a brown or olive-brown epidermis; hinge composed of two flat spoon-like teeth and an erect triangular lamina, no lateral teeth.

A genns of bivalves peculiar to the Eastern Hemisphere, in which the animal commences to invest its elongately produced siphons with an epidermic sheath like MIya ; and the shell has a MIya-like aspect with a MIactra-like hinge. Sixteen species are known, all of a sombre colour and compressed oblong form, of which two are British. They bury in soft oozy mud, at low-water mark or at very moderate depths, with the aid of a rather largely-developed foot, and their shells exhibit very little variation of character. Mr. Darwin would probably argue that the absence of Lutrarias on the shores of North America may arise from their having been exterminated in the struggle for life by the giant Nactras of that locality (see ante, p. 143, note).

The most abnormal species of the genus are those which have been separated by Dr. Gray under the title of Zenatia, comprising $L$. acinaces, Des. Rayesii, and Cumingii. Lutaria lanceolata is the genus Resania of Gray.

\section{Species.}

1. acinaces, Quoy.

2. arcuata, Desh.

3. australis, $i d$.

4. Capensis, id.

5. Cumingiana, id.

6. curta, $i d$.
7. Deshayesii, Reeve.

8. dissimilis, Desh.

9. elliptica, Lam.

10. elongata, Gray.

11. impar, Desh.
12. maxima, Jonas.

13. oblonga, Turton.

14. Philippinarum, Desh.

15. rhynchæna, Jonas.

16. Sieboldtii, Desh. 
Figure.

Lutraria arcuata. Pl. 40. Fig. 219. Shell, with one valve dropped to show the Mactra-like teeth and ligament-pit.

\section{Family 10. MYARIA.}

Shell; mostly yaping at each end; ligament sometimes internal, supported by a spoon-shaped process, in connection in mainy instances with a detached ossicle, sometimes external, supported on a thickened ledge or fulcrum.

The genera of this family are extremely varied in character, and yet they are linked together by a marked sequence of affuity. Chamostrea is a convex Chema-like adherent genus, but the ligament, which is internal, has in connection with it a detached shelly appendage or ossicle, which appars in Anatinu, the type of a cuite distinct section. In Anatina the animal's siphons are enclosed in a wrinkled epidermic sheath, which is developed to a very large extent in Mya, Panopea, Glycimeris, and Pholadomyu, yet so inconstant is the structure of the shell's hinge, that whilst in one genus it is internal, lorlged in a projecting cavity, in another it is exterual, supported on a ledge or fulcrum. The genera are thirteen, as follows :-

Chamostrea.

Mrochama.

Myodora.

Pandora.

Lyonsia.
Anatina. MY̌a.

Thracia.

NemRA.

Corbula.
PANOPEA.

Glycimeris.

Pholadomya.

Genus 1. CHAMOSTREA, Roissy.

Animal; mantle-lobes united by their extreme edge between the pedal orifice and siphons; petal opening small, with a minute vential orifice betind it; siphons a little apart, very short, denticulated; body oval, terminating in a small compressed foot. (Hancock.)

Shell; inequivalve, Chuma-shaped, with the untoes involute, somewhat pearly in the interior, attached to rocks by the anlerior side of the right valve, which is very convex; left valve fat, with a small conical tooth fitting into a corresponding pit to form the 
linge; ligament in connection with a curved shelly appendage or ossicle.

De Roissy's Chanostiea, bettcr known amongst conchologists as the Cleidotharus of Stutchbury, is a molluse of somewhat anomalous character, of which only a single species, inhabiting New South Wales, is known. It has a shell like Chana, with the umboes spirally involute, and like that genus it dwells attached firmly to the rocks, or in clusters one upon another; but the ligament is internal, and it is furnished with a detached shelly appendage or ossicle similar to that of the geuera of Myaria among which it is arranged. The animal has been examined by Mr. Haucock, and his observations go to confirm the correctness of this arrangement. Interually the shell is lined with a greenish silvery-pearl, externally it is tinged with yellow and brick-red.

\section{Figuie.}

Chamostrea albida. Pl. 41. Fig. 224. Shell placed on its flattened attached side, with the involute umboes nearest the observer.

\section{Genus 2. MYOCHAMA, Stutchbury.}

Animal ; mantle-lobes united; pedal opening and siphons surrounded by separate areas; siphons distinct, unequal, small, slightly fringed; foot small, conical. (Hancock.)

Shell; incquivalve, attached by the right valie to shells or stones, and modified by form of surface of attachment; left valve gibbous; linge composed of two diverging central teeth in each valve, enclosing a cavity for the ligament, comnected with which is a shelly appendage or ossicle.

Myochama is another remarkable ossicle-hinged parasite peculiar to New South Wales, of which the animal has been described by Mr. Hancock. The shell is, however, very different from that of Chamostrea. It is much smaller, not stout and involutcly spired, but ovate and slight, having its surface modified in growth according to the irregularity of the surface upon which it is attached. Mostly the Myochance are found adhering to Trigonias, and although the upper valve is free, yet being formed symmetrically along with the under or adhering valve, it partakes of the same ribbed structure which is imparted to the adhering valve by the ribbed 
Trigonia shell. The genus has been collected abundantly in the neighbourhood of Moreton Bay by Mr. Strange, attached to the shells of Trigonia, Pectunculus, and Crassatella, as well as to stones; and five species have been made of them.

\section{Species.}

1. Anomioides, Stutch. 3. Strangei, Adams. 5. transversa, Adams.

2. Keppelliana, Adams. 4. Stutchburyi, $i d$.

\section{Figure.}

Mrocmana Axomoides. Pl. 41. Fig. 227. Shell, adhering to a Trigonia, shorring the ribbed growth of its upper valve occasioned by the Trigonia ribs beneath the lower valve.

\section{Genus 3. MYODORA, Gray.}

Animal; undescribed.

Shell; tricugularly ovate, inequivalve, right valve conccuve, left valve flat; umboes somewhat imolutely beaked; lininge composed of two prolonged interlocking lateral teeth, generally more or less obsolete, enclosing a central triangular pit containing the Tigament, having generally a sickle-shaped ossicle in connection with it.

A small group of white shells, pearly in the interior, of rather solid growth and characteristic triangularly beaked form, in which the margin of one valve becomes consolidated into a tooth-like ledge or projection diverging on each side from the umbo, and fitting into projections of similar construction in the other. Between the diverging points of these somerrhat obsolete ledge-like lateral teeth a triangular pit is formed for the ligament, and in comection with it is a detached sickle-shaped ossicle. The animal has not been described, but there can be little doubt of its affinity with Pandora and Anatina.

MIyadora striala, the principal type of the genus, is a native of New Zealand; the smaller species were collected by Mr. Cuming at the Philippine Islands. 


\section{Species.}

1. brevis, Stutch.

2. crassa, $i d$.

3. curvata, Reeve.

4. oblonga, $i d$.
5. ovata, Reeve.

6. Pandoræformis, Stutch.

7. plana, Reeve.

8. striata, Desh.

9. tincta, Reeve.

10. trigona, $i d$.

\section{Figure.}

Myodora striata. Pl. 41. Fig. 226. Shell, showing its flattened triangular form.

\section{Genus 4. PANDORA, Bruguière.}

Animal; oval, compressed; the mantle closed except for the passage of a narrow tongue-shaped foot; siphons very short, mited nearly to their orifices, which are divergent and firinged. (Forbes.)

Shell ; inequivalve, inequilateral, white, pearly in the interior, one valve flat, the other more or less convex; linge composed of a diverging ledge-like tooth in one or both valves, with corresponding pits; ligament lodged by the side of the tooth.

To genus Pandora is referred a series of small semitransparent pearlwhite shells, light in substance, of which the left valve is convex and the right valve flat, and the hind part of the shell, from which issue the animal's siphons, is mostly flexuously drawn out, compressed, and beaked. The hinge is composed of two ledge-like teeth in one or both valves, diverging as in Placuna, and the ligament is lodged in a cicatrix or superficial pit alongside. Considering the variable depth of habitat and wide range of geographical distribution of the Pantore, the species are very few in number. They inhabit mudkly soil, at depths varying from five to a hundred fathoms, on our own shores and those of North America and Spitzbergen, the Mediterranean, and parts of India, New 'Zealand, and Panama.

\section{Species.}
1. arenata, Sozo.
4. claviculata, Carp.
7. discors, Sow.
2. Ceylanica, $i d$.
5. cornuta, C. B. Adams.
8. flexuosa, Donov.
3. cistula, Gould.
6. depressa, Sow.
9. glacialis, Leach. 

10. oblonga, Sow.
13. radiata, Soro.
16. tabacea, Gronov.
11. obtusa, Leach.
14. rostrata, Lam.
17. trilineata, Say.
12. punctata, Conr.
15. striata, Quoy.
18. unguiculus, Sow.

\section{Figure.}

Pandora rostrata. Pl. 41. Fig. 223. Shell, showing the elongated flexuously beaked growth of the posterior side.

\section{Genus 5.. LYONSIA, Turton.}

Animal ; oblong; mantle closed except a fimbriated opening anteviorly for the passage of a tongue-shaped grooved foot; siphons very short, minted nearly to their orifices, which are fringed. (Forbes.)

Shell; inequivalve, more or less inequilateral, truncated and a little gaping posteriorly; both valves convex, left valve rather the larger; surface of the shell often striated and invested with an epidermis; hinge composed of an oblique toothless plate in each valve sustaining the ligament in connection with a detached ossicle.

The Lyonsice, like the Pandore, are fer in number, widely and deeply distributed. Though found in arctic, temperate, and tropical seas, only a dozen species liave been described, and they are not very well known amongst collectors. The MIya Norvegica of Chemnitz (Lyonsia Norvegica, Turton; Osteodesma Corluloides, Deshayes), inhabiting our North British shores, is the type of the genus, and it may be readily distinguished from Puntora by its more convex and less flexuously beaked form. The surface is, moreover, striated, and covered with a very perceptible epidermis.

\section{Species.}
1. anatina, Gray.
5. brevifrons, Sow.
9. nitida, Gould.
2. arenosa, Möll.
6. Chilensis, Pliil.
10. Norvegica, Chemn.
3. bracteata, Couth.
7. elongata, Gray.
11. Solemyalis, Lam.
4. Brasiliensis, id.
8. hyalina, Couth.
12. striata, Bosc. 


\section{Figure.}

I.yonsia striata. Pl. 41. Fig. 222. Shell, showing its convex form, striated surface, and truncated posterior end.

\section{Genus 6. ANATINA, Lamarck.}

Animal; with the mantle closed except for the passage of a foot, which is sometimes small, sometimes broad and compressed; siphons long, either slender and separated, or united and enclosed in a wrinkled epidermic sheath.

Shell; oblong, inequilateral, nearly equivalve, thin, ventricose, gaping; linge composed of a spoon-shaped process in each valve, containing the ligament, with sometimes two central teeth in front of each.

Under genus Anatina I include tro well-marked forms represented by the genera Periploma and Anatinella. The Anatince proper, so far as the animals are known, have rather lengthened siphons mited together within a wrinkled epidermic sheath after the manner of $M I_{y} a$ and Panopaa; their shell is of very light transparent silvery-white substance, inflated and ventricose, and mostly produced behind into a pouted beak. 'In A. pretenuis (Cochlodesma, Courthouy; Periploma, Schumacher) the spoonshaped process is more distinctly ovate and prominent, and the animal is said to have its siphons divided in their whole extent. In $A$. candida (Anatinella, Sowcrby), of which the animal is not known, the spoon-shaped process is more conspicuous still, and there are two cardinal or central teeth in front of it in each valve. These differences may prove hereafter to afford good distinguishing characters for genera, but the group needs to be investigated and monographed. Several fine species are known in collections without names. The folloning are all that have been described. One species only, A. pratenuis, is British, the rest are from the seas of Japan, India, and the Philippine Islands, New Zealand, and North and South America.

\section{Species.}

1. alta, C. B. Adams.

2. angulifera, Pliil.

3. anserifera, Speng.

4. argentaria, Conr.
5. elegans, Plil.

6. globulosa, Lam.

7. imperfecta, $i d$.

8. inæquivalis, Schum.
9. lanterna, Born.

10. Leana, Conr.

11. lenticularis, Sow.

12. papyracea, Say. 
13. planiuscula, Sno.

14. prætenuis, Pult.

15. prismatica, Sow.
16. rugosa, Lam.

17. Sibbaldii, Sow.

18. subrostrata, Lan.
19. trapezoides, Lam.

20. truncata, $i d$.

\section{Figures.}

Anativa subrostrata. Pl. 42. Fig. 22S. Shell, showing the pouted gaping extremity.

Avatisa (Avativelda) Sibbaldit. Pl. 41. Fig. 225. Shell, with one valve dropped to show the conspicuous spoon-shaped process containing the ligament.

\section{Genus 7. THRACIA, Leach.}

Animal; with the mantle closed except for the passage of a compresed lingniform foot; siphlions rather long, separated to their origins, and furnished with fimbriated orifices, which are often inflated into a globular form. (Clark.)

Shell; ovate or oblong, more or less inrquivalve and inequilateral, sometimes depressed, sometimes yiblours, whitish, generally granosely scubrons, partially covered with a thin epidermis; hinge with a horizontal thicliened fulcrum in each valie, internally excalated, receiving the ligament; ligamentary cavity open in front, having in connection with it a detached crescent-shaped ossicle; ligament partly external.

In Thracia the hinge-cartilage, or ligament, is partly cxternal partly in. ternal, and the structure represented in the preceding genera by a spoonshaped process takes the form of a thickened fulcrum in each valve. When the valves are closed and the fulcra are in contact with the liganent between them, an opening appears internally on the anterior side, and in counection with this opening there is a detached ossicle of a crescent shape. It is seldom that the ossicle is preserved. Notwithstanding the care with which Mr. Cuming has collected the finest series of Thracia shells known, he has never obtained the ossicle. Being detached from the shell, it is doubtless lost when the animal is extracted. The hinge of the different species is, however, greatly modified, and it is by no means certain that they all have an ossicle. It was by an English nuturalist, Dr. Leach, that the genus was founded, two of the largest and most characteristic species being natives of our own shores. The earlier British 
writers had a Mya declivis, which may have been a Thracia, but the identification of it is mingled with doubt. Pennant had a IIy a declivis, which he describes as furnishing a favourite dish among the gentry of the Hebrides; but this, it will be seen from its liabitat, must have been the MTyet arenaria. Donovan, Conrad, and Turton had each their MIya declivis, and they have proved to be true Thracice, but all different species, representing respectively T. pubescens, Conradi, and pliaseolina.

The geographical distribution of the Thracia is curious. Two large species, T. convexa and pubescens, are British, but they have only been found at the south-westem extremity of our island, on the shores of Devon and Cornwall. Two other large species of similar type are known, one inhabiting the western Mediterranean, the other the Bay of Massachusetts, United States. Lower down on the American continent, at Honduras, California, and St. Thomas's Island, West Indies, is the home of a very distinct type of Thracia, in which the shell is waved obliquely with large plicated wrinkles, T. plicata and magnifica, and this type curionsly appears in the China Sea in T. gramulosa. Passing to below the Equator in the New World, one more presents itself at Brazil, and this strangely enough is of the old European type. In the scas of Europe there is a small species, T. phaseolina, which extends as far north as Sweden; and there is a species, T. myopsis, which is confined to the shores of Greenland. All the species of Thracia hitherto spoken of have the outer surface of the shell characterized by a peculiar shagreen sculpture of scabrous granules. In the ferw southern species of the genus this peculiarity ceases, and the shell partakes of the local structural peculiarities of other allied genera. $T$. Australica and Novo-Zelandica, from the localities indicated by their names, present the general typical characteristics of the New Zealand Iryadora striata; and T. Anatinoides, inhabiting New South Wales, is characterized by the peculiar typical form of the beaked Anatince of that district.

In addition to the species alrearly mentioned as British there is a smaller one, T. distorta, which, as the name indicates, has its shell variously distorted, from the habit of dwelling in rock. It has very much the appearance of a borer, and has been separated as a genus by M. Fleurian de Bellevue under the title of Rupicola. The inequality of the sides of this species is reversed, the posterior being very much the larger instead of the smaller; and there are two species, 'T. cuneolus and rudis, the latter from Malacca, presenting the same characters, and probably of similar rockdwelling habits.

\section{Species.}

1. Anatinoides, Reeve. 2. Australica, Reeve. 3. conciuna, Gould. VOL. II. 
4. convexa, Wood.

5. Conradi, Courth.

6. Corbuloides, Desh.

7. cuneolus, Reeve.

8. distorta, Mont.

9. fabula, Reeve.

10. granulosa, $A d$. and $R v$.
11. magnifica, Jonas.

12. Myopsis, Möll.

13. Novo-Zelandica, $R v$.

14. oblonga, id.

15. phaseolina, Lam.

16. plicata, Desh.
17. pubescens, Pult.

18. rudis, Reeve.

19. siliqua, $i d$.

20. similis, Courth.

21. squamosa, Carp.

22. villosiuscula, Macg.

Figure.

Thracia Conradi. Pl. 42. Fig. 230. Shell, with one valve dropped to show the thickened linge-fulcrum, and external portion of the ligament.

\section{Genus 8. NEARRA, Gray.}

Animal; oblong; mantle closed in fiont, except "plain-erlyed orifice for the passage of a lanceolate foot; siphons short, united, unequal, the branchial laryest, both bearing a fow long filiform cirrlit at their sides, ertending beyond the orifices; and siphon with a very extensile membranous valve. (Forbes.)

Shell; oblong-pyriform, more or less bealied and gaping posteriorly, sometimes smoolh, sometimes striated; valves mostly strengthened internally by a transverse posterior ridge; linge composed of a spoon-shaped fulcrum in cach valve, sometimes with a small tooth and a more or less developed posterior lateral tooth; ligament partly internal, partly external.

Neara is a genus of small deep-drelling bivalres, whose siphons, furnished at the extremity with long tentacle-like cirrhi, protrude from a characteristic posteriorly-beaked prolongation of the shell; and the shell is mostly of fragile glassy substanice. The species are not very numerous, but they are widely distributed throughout the seas, both of temperate and tropical countries, and we have three in Britain.* The hinge has a spoon-

* "When the only species of this genus, hitherto figured as British, was first made known, our conchologists were inclined to question its indigenousness and to regard it as accidentally introduced. Yet now, not only is the Necera caspidata extant in many British collections, but two other species have been added to keep it company within the last three years; of those two, one until very recently was known only in the fossil state, and both till within the last three years were supposed to be peculiar to the Nediterranean. Such advances in our knowledge of a genus so little known to most collectors as Necra have been due entirely to the more active employment of the dredge, and the greater energy and adventure of the naturalists who have, with such excellent results, kept that invaluable instrument of submarine research in continual motion."-Forbes and Hanley, Brit. Moll. vol. i. p. 194. 
shaped fulcrum, with an extcrual ligament passing internally into it; on the posterior side it is sometimes strengthened with teetl, and in a fer instances with an over-arching rilge. One species from the China Seas, $N$. rostruta, of which we have given a figure, is remarkable beyond all the rest for its size and thickness.

\section{Species.}

1. abbreviata, Forbes.

2. alternata, $D^{\prime} O r b$.

3. attenuata, Forbes.

4. casta, Hinds.

5. Cleryana, D'Orb.

6. cochlearis, Hinds.

7. concinna, $i d$.

8. costata, Sow.

9. costellata, Desi.
10. cuspidata, Oliv.

11. didyma, Hinds.

12. elegans, $i d$.

13. fragilis, Adams.

14. Gouldiana, Hinds.

15. hyalina, $i d$.

16. iridescens, $i d$.

17. lata, $i d$.

18. Moluccana, $A d$. \& $R v$.
19. nitida, $A d$. \& $R v$.

20. ornatissima, D'Orb.

21. opalina, Hinds.

22. Philippinensis, $i d$.

23. rosea, $i d$.

24. rostrata, Chemn.

25. Singaporensis, Hinds.

26. trigona, $i d$.

\section{Figures.}

Nezra cuspidata. Pl. Q. Fig. 2. Shell, with animal, showing the tentacle-like cirrhi on its siphons, protruding from the beaked posterior extremity of the shell.

Nezra rostrata. Pl. 41. Fig. 221. Shell, showing the beaked posterior extremity.

\section{Genus 9. CORBULA, Bruguière.}

Animal; short, with the mantle closed eacept in fiont, foi the passage of a rather laige foot; siphons very short, united, with the orifices fimbriated; anal siphlion with a protructing tubular membrane.

Shell ; inequivalve, globose or oblong, mostly very thick and solid, and more or less bealied or anyularly produced posteriorly; left valve generally the smaller; hinge composed of a solid sulmer. curved central tooth in one or both valves, with corresponding pits, and a deep pit on one side containing the ligament.

Closely allied to the Necerce, but with very solid and often richly-coloured shells, are the Corbula, a group more numerous in species, and even more 
widely distributed over the globe. Including Sphrenia, a small species partaking of the characters of Saxicava, we have only three in Britain; among the islauds of the Eastern Archipelago and on the westeru coast of Soutl Amcrica they are more abundant, and in the latter region the genus passes into the estuaries and becomes modified to the consequent difference of habit. The fresh-water species liave been separated from the marine under the titles Potamomya and Azara. The valves of Corluta are in most of the species remarkably mequal in growth, the right valve not only overlapping the left one at the ventral margin, but projecting over it in a most conspicuous manner at the umbo, while there is almost always a peculiarly rude gibbousness of growth in the shell. The Corlunle are deepdwelling mollusks, and have been little collected except by those who, like Mr. Cuming and Sir Edward Belcher, have been accustomed to dredging. Speaking of the British C. nucleus, it has been remarked by Forbes and Hanley that whilst the naturalist, whose efforts at collecting are confined to the rocks, sands, briny pools, and streamlets of our coast, is apt to regard the species as of unfrequent occurrence, its extreme prevalence is a subject of almost perpetual complaint from the liabitual dredger.

\section{Species.}

1. adusta, Hinds.

23. elliptica, C. B. $A d$.

45. nucleus, Lam.

2. æqualis, C. B. Adams. 24. erodina, Lam.

3. æquivalvis, Phil. 25. erythrodon, $i d$.

46. obesa, Hinds.

4. alba, Phil.

26. faba, Hinds.

5. albuginosa, Hinds:

27. fasciata, $i d$.

6. Barrattiana, C. B. Ad. 28. fragilis, $i d$.

7. bicarinata, sow.

29. fulva, C. B. Adams.

8. Binghami, Turt.

30. inflata, $i d$.

47. ochreata, $i d$.

48. operculata, Phil.

49. Philippinensis, Adams.

50. princeps, $i d$.

51. procera, Hinds.

9. biradiata, Soro.

31. Kjoriana, $i d$.

52. rosea, Brown.

53. rotalis, Hinds.

10. Blandiana, C. B. Ad. 32. Knoxiana, $i d$.

11. Californica, Conr.

33. Krebsiana, $i d$.

12. carnosa, Hinds.

34. labiata, $i d$.

13. Catlowæ, Reeve.

35. lævis, Hinds.

14. Chittyana, C.B.Ad.

36. marmorata, $i d$.

54. rubra, C. B. Adans.

55. Ruppellii, Adams.

56. scaphoides, Hinds.

57. semen, Lam.

15. contracta, Say.

16. crassa, Hinds.

37. Mediterranea, Costa.

58. semistriata, Hanley.

17. crispa, $i d$.

18. cuneata, $i d$.

38. Mindorensis, $A d$. \& $R$.

59. similis, Hinds.

19. decurtata, C.B.Ad.

39. modesta, Hinds.

40. monilis, $i d$.

61. speciosa, id.

41. nasuta, Sorv.

62. sulcata, Brug.

20. decussata, Desh.

21. Dietziana, C.B.Ad.

42. Newtoniana, C.B.Ad.

43. nimbosa, Sow.

63. Swiftiana, C. B. Ad.

2.). elournea, Hinds.

H. nuciformis, $i d$.

65. tenuis, Sorv.

66. trigona, Hinds. 
$\begin{array}{lll}\text { 67. trigonalis, C.B. Ad. } & \text { 69. tunicata, Hinds. } & \text { 71. variegata, } A d . \& R v . \\ \text { 68. truncata, Hinds. } & \text { 70. ustulata, Reeve. } & \text { 72. ventricosa, } i d .\end{array}$

\section{Figure.}

Corbula sulcata. Pl. 45. Fig. 239. Shell, showing the overlapping growth of the right valve over the left valve.

\section{Genus 10. MYA, Linnceus.}

Animal; mantle closed in front except for the passage of a moderate conical foot; siphons very long, united nearly to their extremilies, which luave fimbriated orifices, and enclosed in a wrinkled epidermic sheath.

Shell; oblong-ovate, equivalve, gaping at each extremity; hinge composed of a broad, ascending, spathulate tooth in the left valve, comnected by a short thick internal ligament with a corresponding socket in the right valve.

The genus Mrya embraces two very distinct types, one represented by the well-known $M$. arenaria and truncata, which have a wide range of habitation, especially throughout the north temperate and arctic seas, the other by a few semitransparent dinatina-like forms (genus Tugonia, Gray) peculiar to the shores of west Africa. In the former, which have shells of rather large size and of comparatively solid structure, the linge has a broad ascending tooth in the left valve only, in the Tugonio group the ascending tooth occurs in a modified form in both valves, the shell is of more delicate transparcut substance, and it is more globose, with the posterior end very widely orbicularly gaping. Of Tugonia the animal is not known. Of the aretic and best-known group the animal lives buried deep in the mud, with its siphons proportionally lengthened and protected by an epidermic wrinkled sheath.* The NIye are eaten in North Britain and in North America, and it is related by Fabricius that they are sought after by the walrus, the arctic fox, and by various birds.

* "This shell," remarks Dr. Gould of the Mya arenaria, "is familiar to every one who re. sides on the seacoast. It is always to be scen in every market and on every quiet shore. Its residence is always between high and low tide, or in such places as allow it to be partially exposed to the air a part of the time. Such are our sandy beaches, muddy inlets, and mouths of streams emptying into the sea. It usually lies just below the surface, and over it is a round 
Species.

1. anatina, Gmel.

2. arenaria, Linn.

3. caucellata, Coni:
4. nobilis, Adams.

5. præcisa, Gould.

6. semisulcata, Adams.
7. truncata, Iinn.

8. Uddevallensis, Forbes.

\section{Figures.}

Miya truxcata. Pl. Q. Fig. 5. Shell, with animal, shoming at the anterior end the foot, and at the posterior end the wrinkled epidermic sheath enclosing the siphons.

Mya arevaria. Pl. 42. Fig. 229. Shell, showing the broadly spathulate ascending tooth.

\section{Genus 11. PANOPAA, Ménard.}

Animal; with the mantle closed except in front, for the passage of a short stout foot; siphons very lony, more or less united at their catremities, cnclosed within a strong, mecular, wrintiled epictermic sheath.

Shell; somewhat squarely oblong, equivalice, inequilateral, gaping at both cut.s; hinge composed of a single central tooth, sometimes obsolete, in each valve, and a thickened fulcrum supporting a lengthened external ligament.

Panopae is a large bivalve, the largest of bivalves excepting the colossal Clams of the family Triflacnacea, of similar structure and of the same mud-dwelling habits as Mlya; but the shell, though bearing a general resemblance to that of IIya, has more the lininge of Solen, the ligament being external, supported by a thickened fulcrum. While speaking of the $\mathrm{Ce}$ phialoporls (ante, vol. i. p. xi.) I remarked that the Nautilus and Spirula are the solitary living remnants of a numerous extinct race of mollusks, represented by the fossil Ammonites; the Panopea presents a similar history. Nearly a hundred and forty species are known in a fossil state, occurring in every part of the world where secondary or tertiary strata have been found, but of living species we have only eleven, all of more or less rarity, and some of them very imperfectly known. The animal has not been met with until lately. About twenty-two years back, "the officers

hole through which the animal cjects a jet of water to a considerable height above the sand; and if the shallow water is observed where they are known to dwell, it will be perceived to be kept in constaut eddies by the suction and cjection of the water. It is valuable as an article of food, in the fisheries, and for manure."-Invert. Massachusetts, p. 41. 
of a French frigate," as related by Messrs. Forbes and Hanley from an account given by Professor Valenciennes in the Archives dı Muséum, Paris, 1839, "visiting Port Natal, observed the tubes of a mollusk projecting from the sand in one of the bays. The sailors endeavoured to draw the creature out of its habitation by the tube, but in vain; for the siphons, after offering considerable resistance, in every instance gave way, and often were withdrawn entire in spite of the grasp of its persecutor. Curious to know the nature of the being that thus escaped them, they dug for it with spades, and at length uncovered the Panopcee, buried several feet below the surface of the sand, and gregarious." A few years later the Rev. L. B. Larking happened to be residing at Messina during an unusally tempestuous season, when the Panopaa represented at Plate $O$ was captured alive. How the creature had been liberated from its muddy bed he could not ascertain, but it was extremely animated, and it lived in a vessel of sea-water several days after. So violent was the sea about this time that many thousands of dirgonaut shells were washed ashore, in a manner such as had not been seen before. Mr. Larking himself showed me on his return to England more than twclre liundred which he had brought away; and he at the same time showed me this Panopac preserved in spirits. Subsequently it passed into the possession of W. V. Guise, Esc., of Elmore Court, Gloucester, by whom it was presented to the local museum, and permission was given to Mr. Woodward to open it. On lifting the right side of the mantle and laying bare the internal organs, the whole structure was found to resemble that of Myg arenaria, except in the minor characters of the palpi being shorter and the gills more unequal. I remember perfectly MIr. Larking describing that he kept the creature alive for some days in a large tub of sea-water, and that for a time it threw its siphomal sheath about with great violence against the sides of the tub, discharging the water rigorously from its anal siphon. But this excitement shortly ceased and the animal became enfeebled and died.

The shell of an arctic species of smaller size, Panopaa Norvegica, described by Spengler, was taken a few yeat's since at Scarborough by MIr. Bean, and it has been dredged from a depth of ninety fathoms by Mr. M'Andrew in the vicinity of Zetland. It has also been captured, according to $\mathrm{M}$ r. Alder, in deep water off the Northumberland and Durham coasts.* This species has the gills more tapering, and more prolonged into the bran-

* "We have obtained at Scarborongh three specimens of this, in every sense of the word, gigantic prize. To some of the fishermen of our coast it appeared to be well known by the name of the 'bacca-box,' from a fancied resemblance to one of their most useful household gods. They were all caught by the hook, and resened from destruction in a singular manner. The first was destined for a tobacco-box, the second had the honour of holding the grease belonging to the boat-establishment, and the third, after amusing them (the members of a philosophical society) by squirting water to the ceiling, was at last seen by a learned friend, purchased for a trifle, and generously placed in our cabinet."-Bean, in Mag. Nat. Hist. vol. viii. p. 562 . 
chial siphons than the Mediterranean $P$. Aldrovandi, while the siphons are more separated at their extremities, and the impressed mark of the mantle on the shell presents a broken appearance at the edge.

\section{Species.}
1. abbreviata, $\overline{V a l}$.
5. generosa, Gould.
9. Norvegica, Speng.
2. Aldrovandi, Lam.
6. Japonica, Adams.
10. Solandri, Gray.
3. antarctica, Gould.
7. Middendorfii, $i d$.
11. Zelandica, Quoy.
4. australis, Sow.
8. Natalensis, Woodw.

\section{Figure.}

Panopea Aldrovandi. Pl. O. Shell, with the animal, its siphonal sheath being much contracted from being preserved in spirits. From a specimen in the Gloucester Museum, brought alive to the Rev. L. B. Larking while residing at Messina.

\section{Genus 12. GLYCIMERIS, Lamarck.}

Animal; with the mantle thickiened, and closed except in front, for the prassage of a small foot; siphons anited in a very. fleshy cylindrical mass, never withdraun within the shell. (Audouin.) Shell; equivalve, gaping widcly at both ends, of thick opake-volite substance, covered with a haid, black, horny epidermis; hinge toothless, composed of a thickened fulcrum supporting a rather lengthened external ligament.

Allied to Panopcea, and of similar habits, is another genus, Glycimeris, of which the shell has in like manner an external ligament supported on a thickened fulcrum, while the siphons of the animal are also extended and united within a leatlicry wrinkled sheath. Internally the shell is a peculinr opake-white substance, showing in unusually strong relief the impression of the soft parts; externally it is covered with a hard, shining-black, horny cpidermis, passing somewhat over the margin. The Glycimeris, of which there is only a single species, is strictly a mative of the Arctic Seas. 
Figure.

Glycmineris siliqua. Pl. 43. Fig. 234. Shell, showing its widely gaping extremity and shining-black horny epidermis.

\section{Genus 13. PHOLADOMYA, Sowerby.}

Animal; with the mantle thin, closed except in front for the passage of a small foot, which has an accessory bifurcate foot; siphons long and large, enclosed within a coarsely wrinkled epidermic sheath, the branchial one having at its base a supplementary valvular aperture; branchice undivided. (Owen.) Shell; oblong, thin, ventricose, pearly within, very inequilateral, anterior end very short, rounded; posterior elongately fanshaped, gaping; hinge toothless, composed of a slight fulcrum supporting a moderate external ligament.

In Pholadomya we have another instance of a long-siphoned, closemantled, mud-inhabiting bivalve, possessing in like manner a shell with an external ligament supported on a ledge or fulcrum. But notwitlstanding the similarity betwcen the organization of the soft parts, as well as the shell's hinge, of Panopraa and Glycinneris, and those of Pholadomya, the difference in the form and substance and general aspect of the shells is very great. The shell of Panopcea is comparatively solid, almost colourless, and destitute of any sculpture beyond a multitude of somewhat irregular lines of growth; the shell of Glycimeris is of a peculiar opake chalk-white substance, very dense, secretions from thicker mautle-lobes, and covered in a conspicuous degree extermally by a shining-black horny epidermis. The shell of Pholadomya is a light, ventricose, papyraceous shell, symmetrically cancellatcly ribbed, covered with a light brown epidermis externally, and internally slightly nacreous.

Genera of Mollusca are often unavoidably founded in error. The shell is generally the first portion of the creature brought to light, and the conchologist has no alternative but to guess at its affinities by analogy. Mr. Sowerby considered the shell of Pholadomya to partake of the characters of the genera of which he compounded the name. When a specimen collected alive at the island of Tortola by Mr. Stutchbury was submitted to Professor Oren for dissection, it was comparatively easy to answer "the question requiring a reply" of M. de Blainville, "Qu'cst-ce que le genre Pholadomie de quelques auteurs Anglais?" The animal was found to have the nearest affinity with that of Panopaa, distinguisher nevertheless by an accessory bifurcate foot, by the presence of a supplementary valvular aperVOL. II. 
ture at the base of the branchial siphon, supposed to serve as an inlet for respiratory currents, by the branchiæ being undivided, and by a few other minor differences.*

\section{Figure.}

Pholadomya candida. Pl. 43. Fig. 232. Shell, showing its cancellately ribbed structure.

\section{Family 11. SOLENACEA.}

Shell; oblong-ovate or very narrouly elongated, with the anterior portion in such cases mostly very considerably lengthened, while the posterior is short and abruptly truncated.

In this family are associated the four genera of which the shells are represented in Plate 4\%. Their general characteristic is to have the anterior portion of the creature unusually more developed than the posterior; but it is in the Solens, or Razor-shells, that this peculiarity is most conspicuons. The foot issuing from an opening in the mantle, which is otherwise closed, is a prominent organ for burrowing; the siphons are in some short and united, in others long and only partially united. A few are inhabitants of brackish water in estuaries or the mouths of rivers. The genera are-

Solemy. Glauconome. Solen. Solecurtus.

\section{Genus 1. SOLEMYA, Lamarck.}

Animal; mantle open in fiont for the passage of a truncated proboscis-litie foot, and belind with a single siphonal orifice; margins of both openings cirrliated; foot excavated at its extremity, which has fimbriated edges.

Shell; equivalve, very inequilateral, somewhat squarely obiong, rather thin, convexly compressed, covered with a shining, dark, britlle, hormy epidermis, passing conspicuously over the margin ;

* Professor Oren's detailed memoir 'On the Anatomy of the Pholadomya candida' of which I have an uncorrected proof, was contributed by the author, and set in type, along with a mernoir 'On the Anatomy of Lithedaphus,' for an appendix to my 'Conchologia Systematica;' but by some unaccountable negligence the drawings were lost while in the hands of the Secretary of the Zoological Society, in whose 'Proceedings' only a brief abstract of the memoirs appeared, and they have never, I bclicve, been published. 
linge sometimes toothless, sometimes with an obscure central tooth or arch, furnished with a slightly thickened rib-like fulcrum supporting the ligament, which is chiefly internal.

The curious genus Solemye has been placed at the head of this family on account of the resemblance of its shell to that of the Siliqua form of Solecurtus on the one hand, and to the shell of Glycimeris on the other. Like the former it is of a thin oblong-square shape, rayed, and rounded at the ends, and the ligament, though chiefly internal, is lodged upon a shelly process, which may be regarded as a modification of the hinge-fulcrum of this and the preceding family. Like the latter it is enveloped by a dark shining-horny epidermis passing over the margin, and the epidermis in this case passes over considerably, and from its curiously brittle nature becomes much split and jagged. The animal of Solemya has not, however, the sheathed siphons of either of those genera, the mantle having only a simple orifice in front, of which the elges are cirrhated. The foot is, moreover, excavated or funnel-shaped at the extremity, and the animal has been observed to swim about in the water and to make surprising leaps with it, though habitually dwelling imbedded in mud or sand.

The geographical distribution of Solemya is as anomalous, so far as our knowledge of this bivalve at present goes, as the nature and affinities of its organization. There are four species; one is a native of the shores of Australia and New Zealand, another inhabits the Mediterranean and West African coast, and the remaining two are found on the shores of the northern United States.

\section{Species.}

1. Australis, Lam. 3. Mediterranea, Lam. 4. velum, Say.

2. borealis, Tott.

\section{Figure.}

Solemya Australis. Pl. 44. Fig. 235. Shell, showing its peculiar overlapping, jagged-edged, shining-horny epidermis.

\section{Genus 2. GLAUCONOME, Gray.}

Animal; manlle closed except in fiont for the passage of a small, compressed, tongue-shaped foot; siphons very long, united. nearly to their ends; orifices fringed. 
Shell; oblong, inequilateral, angularly lengthened befind, covered with a bright light-gieen epidermis, which sometimes passes over the margin; hinge composed of three teeth in each valve, one of which is generally biful; no lateral tecth; liganent caternal.

The Glanconone, of which eleven species have been described, is a kind of Sulen-Anodon, inhabiting the mouths of rivers in China, Borneo, and the Philippine Islands. The animal has a tongue-shaped foot like dnodon, but it has siphons long, and united nearly to their extremities, like those of Solecurtus. The shell has, moreover, the same divergent-toothed hinge, with an external ligament; it is of a light half-pearly substance, covered in most instances with a bright light-green epidermis, often thinly inflected over the margin, and there is a great uniformity both in the form and colour of it in all the species. The Gilunconones live in brackish water, partially imbedded in the mud, and have not been found out of the above localities. One of the species was linown to Limneus. His nane, Solen virens, may be seen, together with the specimen, in Limmus's handwriting, in the original collection of the author of the 'Systema Nature,' now in the possession of the Linnean Society of London.

Species.

$\begin{array}{lll}\text { 1. angulata, Reeve. } & \text { 5. curta, Hanl. } & \text { 9. rugosa, Reeve. } \\ \text { 2. cerea, id. } & \text { 6. psammotella, Desh. } & \text { 10. straminea, id. } \\ \text { 3. Chinensis, Gray. } & \text { 7. radiata, Reeve. } & \text { 11. virens, Linn. } \\ \text { 4. corrugata, Reeve. } & \text { 8. rostralis, Desh. } & \end{array}$

\section{Figure.}

Glaccovomr rugosa. Pl. 44. Fig. 23S. Shell, showing its light-green epidermis and external ligament.

\section{Genus 3. SOLECURTUS, Blainville.}

Animal; with the mantle widely open in front for the passuge of a large tongue-sluaped foot; siphons more or less long, separated at their entremities; branchia continued into the branchial siphon.

Shell; elongately or ovately oblong, very inequivalve, gaping at 
both ends, sometimes having the outer surface crossed obliquely with stria, which end abruptly on an anterior angle; hinge composed of two divergent central teeth in each valve; ligament external, supported on a moderately thickened fulcrum.

Before the animal of Solecurtus had been observed, conchologists were pretty well agreed on the propriety of separating the richly coloured, delicately rayed, oblong-ovate Solens, some of them inhabiting brackish waters, from the narrowly attenuated Solens proper. Even a further subdivision of Solecurti has been made into the genera Pharus (Ceratisolen, Forbes), Pharella, Cultellus, Siliqua, and Noraculina; but in all these the differences of the animal are chiefly modifications of a greater or less extension and separation of the siphons, to which it may be useful to have regard at some future time when more species shall have been discovered, or when, according to Mr. Darwin's theory, they will have become more numerous by intermarriage. In the Solens or Razors proper the animal has a peculiarly elongated cylindrical form, and the siphons are short and united.

The Solecurti have for the most part a beautifully painted shell, rayed often in the most delicate manner with violet or rose, and some are marked with waved lines crossing the shell obliquely over the lines of growth and ending in a singularly abrupt manner on an anterior angle radiating linearly from the umbo. It is in the $S$. strigillatus, a native of the Mediterranean, in which this peculiarity is most conspicuous, but it also appear's in the British S. cantidus of the same type. Professor E. Forbes remarks of both these species that he has seen them dilate their siphons to such a degree as to break them up into fragments.

The fresh-rrater species, separated under the head of Novaculina, have more elongated shells, of more sombre hue, and inhabit cliefly the mouths of rivers in India and China. They abound also in some of the American rivers. The more delicate rajed forms, such as $S$. varliatus and violacens, constituting Müllfellt's genus Siliqua, inhabit the tropical shores of India and China, and the type is also represented in the Arctic seas by a few characteristic species.

\section{Species.}

$\begin{array}{lll}\text { 1. acuminatus, Hanl. } & \text { 8. coarctatus, Gmel. } & \text { 15. Javanicus, Lan. } \\ \text { 2. acutidens, Brod. } & \text { 9. constrictus, Lam. } & \text { 16. legumen, Linn. } \\ \text { 3. albus, Mart. } & \text { 10. costatus, Say. } & \text { 17. maximus, Gmel. } \\ \text { 4. albidus, Ad. S. Rv. } & \text { 11. cultellus, Linn. } & \text { 19. medius, Sow. } \\ \text { 5. bidentatus, Speng. } & \text { 12. exaratus, Phil. } & \text { 19. minimus, Gmel. } \\ \text { 6. Californianus, Conr. } & \text { 13. Gangeticus, Bens. } & \text { 20. Nuttallii, Conr. } \\ \text { 7. candidus, Ren. } & \text { 14. gibbus, Speng. } & \text { 21. olivaceus, Melc. }\end{array}$


22. politus, Wood

23. Quoyi, Dest.

24. radiatus, Limn.

25. rufus, Bosc.
26. scalprum, Gould.

27. solidus, Gray.

28. squama, Blainv.
29. strigillatus, Linn.

30. subteres, Conr.

31. violaceus, Desh.

\section{Figure.}

Soleccutus strigilditus. P1. 14. Fig. 237. Shell, showing in one valve the divergent tooth and external ligament supported on fulcrum; and in the other valve the obliquely waved striæ.

\section{Genus 4. SOLEN, Linnaus.}

Animal; wry marouly elongated, with the mantle open widely at the anterior end for the passage of a large, thick, truncated foot; siphons short, nnited, frilled at the orifices; branchice contimed into the branchial siphon.

Shell; very long and narrow, equivalve, very inequilateral, posterior end very short, anterior enormously lengthened, both ends gaping; linge usually composed of one or turo small diverging teeth in each valve, with an external ligament supported on a shelly fulcrum.

The Solens, or Razor-fishes, present the greatest length and least breadth of all bivalves. The animal is an elongated cylindrical mass, enclosed in a linear pod-like shell, protruding a large thick truncated foot through the anterior gaping extremity, and a pair of short united siphons through the posterior. Between the extremities the mantle is closed throughout, and the creature thus enveloped, and protected in addition to its shell by a strong overlapping epidermis, lives buried in mud or sand in a vertical position to the depth of a foot and more. Aristotle, to whom the Solens mere well known, relates that they bury themselves to the depth of two feet, and can rise and sink at pleasure, and that they are alarmed by noise and bury thenselves rapilly when frightened. "Such an enumeration of character," add Messrs. Forbes and Hanley, "indicates how carefully the great philosopher studied Razor-fishes, and with what interest he watched their doings and chronicled their fears."* "But the Razor-fishes," continue

* "If the Solen be taken out of its hole, and placed upon the sand, it immediately prepares to re-bury itself. It stretches out its foot to full length, and then bends it so as to use the extremity as a kind of auger. When the end has sunk into the sand, it draws up its shell, which, first oblique, and afterwards perpendieular, soon becomes immersed and rapid]y disappears. M. 
the authors of the 'British Mollusca,' "would scarcely have attracted such attention had it not been for their cxcellent qualities as articles of food. They are among the most delicious of shell-fish when properly cookedbroiling is the best method -and are eaten in many parts of Britain as well as abroad."

'The hinge and umboes of the shell, which are the nuclei of growth, are situated so near to the posterior extremity, that the shell would appear to be developed almost wholly in the anterior direction. The tendency of the creature's muscular action is obviously great in that direction. Though limited in species the Solens are widely distributed in seas of all temperature.

\section{Species.}

1. acinaceus, Hantey. 12. Guineensis, Gray.

2. albus, Martyn. 13. linearis, Chemn.

23. Schultzianus, Dunk.

3. Americanus, Beck.

i4. mactra, Molin.

24. sicarius, Gould.

4. Beckii, Phil.

15. magnus, Schum.

25. siliqua, Limn.

5. brevis, Gray.

16. marginatus, Koch.

26. Sloanii, Gray.

6. corneus, Lam.

17. obliquus, Speng.

27. Tehuelcha, D'Orb.

7. cylindraceus, Hanl.

18. orientalis, Dunk.

28. vagina, Linn.

8. ensis, Linn.

19. pellucidus, Penn.

29. vaginatus, Gray.

30. vaginoides, Lam.

9. exaratus, Phil.

20. Philippinarum, Hanz.

10. Gaudichaudii, Chemn. 21. pictus, Phil.

31. versicolor, Phil.

11. gracilis, Phil.

22. scalprum, King.

32. viridis, Say.

33. Zelanensis, Leach.

\section{Figure.}

Solen cultellus. P1. 44. Fig. 236. Shell, of a delicate abnormal form of Solen, the Razor-shells of our own shores being sufficiently well known.

\section{Family 12. PHOLADARIA.}

\section{Shell; valves gaping more or less videly anteriorly; linge with}

\footnotetext{
Deshayes, during his Algerian researches, observed a remarkable instinct of Solen marginatus to swim when desirous of changing its locality. When it finds itself on ground too hard to be penetrated by its foot, it fills the cavity of its mantle with water, and then contracting, and closing at the same time its siphonal orifices, elongates its foot; then re-contracting that organ, it ejects the water with force from the tubes, and thus propels itself, after the manner of a cuttle-fish, for a foot or two forwards. Then, if it finds the surface favourable, it bores and buries itself; but if not, makes another leap, to try its chance anew."-Farbes and Hanzey, Brit. Moll. vol. i. p. 245.
} 
only very mudimentary teeth or ligament, capped externally with an accessory plate or plates.

The species of this group have very strongly marked characters, and may be distributed either into a dozen genera, or into one only. For the present we alopt the latter course, uniting all the varieties of forms, including even Xylophaga, under Pholas. The hinge of the shell has only a very rudimentary indication of teeth or ligament, and is, with rare exception, capped externally by one or more accessory shelly plates. Anteriorly the shell more or less widely gapes for the passage of a largely developed foot, which aids in the boring habits of the creature; posteriorly it gapes a little for the outlet of the siphons, which are extended in an epidermic sheath.

\section{Genus 1. PHOLAS, Limans.}

Animal ; thick, club-shaped, with the mantle united except in front, for the passage? of a conspicuonsly developed suctier-litic foot, which is reflected dorsally orer the umboes to form callosities and accessory plates; siphons long, united within a fleshy sheath, divided at the extremities; orifices bordered with cirrhi, sometimes surrounded by a cirrhated disk.

Shell ; elongately anger-shaped, equivalve, gaping especially in fiont; apertures somelimes closed at maturity by a shelly wall, outer surface sculptured anteriorly with ridges in prickly festoons, josteriorly smooth; linge composed of a rudimentary superficial ligament with external accessory plates of different forms in connection with it; umboes mostly covered externally by a reflected callosity, internally furnished with a curved hooklike apophysis.

The Pholads, or Borers, are a tribe, of the true nature of which mere collectors of shells are liable to form a very erroneous impression. The habit of the mollust involves an entirely new construction of hinge; the valves of the shell are not connected by interlocking teeth or by elastic ligament, but by a prominent hook, called an apophysis, springing from within the umbo of each valve, and entering into the flesh of the animal in comnection with the pedal muscle. Teeth and liggament are quite rudimentary; outwardly the hinge is capped with varionsly shaped accessory plates, and either the plates may be wanting in the collector's specimen, or, what is more commonly the case, the plates may be glued to the spe- 
cimen in a manner different from that in which they are cemented in nature. The collector, moreover, finds a piece of wood, or of hard clay, or of chalk, or of coal-shale, or, even, of limestone or sandstone, riddled through and through with Pholads, of all sizes, in the same relative position, and wonders how any mollusk with so delicate and sharply sculptured a shell could have bored its way into it. Here then is an instance in which a knowledge of the general organization and habits of the animal, to say nothing of its anatomy, is more than commonly essential. In Pholas we have a lamellibranchiate mollusk allied to the Myaria, but having its soft parts and shell largely modified for the performance of the boring functions assigned to it; and so variable are these modifications, so variably does nature shift to provide for this change of habit, that the characters of species are almost as strongly marked, and as distinct from each other, as the characters of ordinary genera. We shall presently see that the fifty known species of Pholas may be distributed into at least eleven well-defined sections.

Seeing that the habit of Pholas is to bore into substances and live and die in them, the conchologist should examine his specimen with this in view. The anterior portion of the shell will be found to gape, in some species abruptly and largely, for the passage of a foot well constructed for the work it has to do. The foot is more than usually developed, and even when seen in a retractile state through the pedal opening of the mantle, may be observed to terminate in a kind of sucker. Though many theories have been advanced to account for the mode in which the boring operations are carried on, some persons alleging that the means are purely chemical, others that they are purely mechanical, the process has never yet been accurately determined. The balance of opinion is much in favour of the mechanical theory, but it is more than probable that the process is a combination of both. The cavities of the Pholas not unfrequently exhibit marks of the attrition caused by the rotatory motion of the shell, a motion to promote which the foot would seem to be specially constructed, aided, it may be, in some cases by the presence in the skin of particles of silica; and the wall of the cavity is softened, doubtless, by a solvent or by the action of currents of water, in such a manner that the shell may rotate without damage to the prickly scales of its sculpture. But thie foot has another office to perform; it is reflected back over the hinge for the secretion of callosities and plates. The natural position of Pholas, like Mya on the one hand and like Aspergillum on the other, is with the foot downwards, and it consequently bores in that direction; the siphons, as in those genera, are extended perpendicularly to some distance through the lesser anterior gape of the shell, and they are also united in a similar, or nearly similar, epidermic sheath. The boring functions of the Pholads are exercised chielly in an early stage of growth; generally, the

vol. II. 
younger the shell the wider is the anterior gape. When the bore is complete and the Pholas, safely lodged in the wood or stone, arrives at maturity, the boring functions of the foot are dispensed with, and it terminates its building operations by closing in vearly the whole of the gape with shell matter. The Pholas papyracea (Pholadidea, Forbes and Hanley) does this; but in the foreign $P$. striata and its allies the peculiarity is much more conspicuous.

We have now to notice the modifications of the hinge plates. In the large $P$. costata of Linnæus, regarded as the type of Pholas proper, there are two plates, one anterior and one posterior; in the British $P$. ductylus (Dactylina, Gray) there are two oblong plates side by side with a small transverse plate, and a long lanceolate plate behind them; the British $P$. candida and parva represent another section (Barnea, Risso) in which the hinge is capped with only a single plate in the form of an umbonal shield; in another section, represented by the British P.crispata (Zirplcae, Leach), the accessory plates are wanting, and their place is supplied by a more dense secretion of the anterior marginal reflection, covered by a conspicuous epidermic membrane; in $P$. subglobosa and two others, small species inlabiting sponge, the hinge plate is in a single piece, reflected over the umboes; the British P. papyyracea (Pholadidea, Turton) is the type of a section in which the hinge plates are almost obsolete, minute, and of a rhomboidal form, the anterior gape of the shell is walled in at maturity by a thin layer of shell, and a horny cup is formed at the posterior end for the protection of the siphons which, in this species, are framed with a star-like disk at the extremity; P. explanata (Talona, Gray) forms a horny beak at the posterior end, and the valves have a curiously winged transverse plate against their abruptly terminated anteriorly reflected edges; another section, of which there are four species, is represented by the curious $P$. Cumingii (Jouannetia, Gray), with the left valve overlapping the right valve, the front gape closed in at maturity, and a single dorsal plate; P. Janellii (Pharapholas, Conrad), with two dorsal plates, also closed in anteriorly and curiously divided obliquely by a groove on each side, represents another small section; P. striata (MIartesia, Leach), also divided by a groove on each side, closed in anteriorly, with the addition of on one side a lanceolate, on the other a peltate plate, represents a more numerous section, sometimes inlabiting brackish water; and, lastly, the little globose $P$. dorsalis (Xylophaga, Leach) is the representative of a section in which the shell approaches that of Teredo divested of its siphonic tube, and has two little wing-like hinge plates.

The geographical distribution of the Pholades is almost world-wide. 


\section{Species.}

1. aperta, Sorv.

2. Australasiæ, Gray.

3. australis, $i d$.

4. Bakeri, Desh.

5. Beaniana, Recluz.

6. branchiata, Gould.

7. Burmanica, Plil.

8. calva, Sow.

9. Campechensis, Gml. 10. candida, Linn.

11. concamerata, Desh.

12. constructa, Sow.

13. costata, Lim.

14. crispata, $i d$.

15. crucifera, Sow.

16. Cumingii, $i d$.

17. cuneiformis, Say. 18. curta, Sow.
19. dactylus, $\operatorname{Lim}$.

20. Darwinii, Sow.

21. dorsalis, Turt.

22. Erythrea, Gray.

23. fragilis, Sow.

24. globosa, $i d$.

2ว. globosa, Quoy \& Gaim. 42. quadrizonalis, Speng.

26. jalan, $A d$.

27. Janellii, Desh.

28. latissima, Sow.

29. Manillensis, Pliil.

30. melanusa, Sow.

31. multistriata, $i d$.

32. nucifera, O. Fab.

33. obtecta, Sow.

34. orientalis, Gmel.

35. ovoidea, Gould.
36. ovum, Gray.

37. papyracea, Sol.

38. parva, Lim.

39. patula, Gould.

4.0. pectinata, Conr.

41. quadra, Sow.

43. rivicola, Sow.

44. similis, Gray.

45. spathulata, Soro.

46. striata, Linn.

47. subglobosa, Gray.

48. sulcata, Brown.

49. tenuis, Gray.

50 . tridens, Sow.

51. truncata, Say.
52. tubifera, Sow.

\section{Figures.}

Pirolas ortentalis. Plate 45. Fig. 243. Shell laid on its ventral edge to show the large accessory shield-like plate which caps the hinge, with a small transverse plate behind it.

Pholas (Xylophaga) grobosa. Pl. 45. Fig. 241. Shell, showing its small globose form and gaping extremities, the smaller posterior siphonal aperture being seen through the large anterior pedal aperture.

\section{Family 13. 'TUBICOLA.}

Shell; with or without teeth or ligament, enclosed within a sheath of various dimensions.

The Tulicola, or tube-inhabiting lamellibranchiates, are so called from drelling in a tubular sheath in which it is their habit to enclose themselves. They burrow into sand, wood, coral, or even stone, and according to the extent of their burrow so the mantle and siphons of the animal become elongated; and shelly matter is secreted during this elongation of the mantle and siphons independent of the normal bivalve. Owing to the difficulty of obtaining specimens, and of securing the specimens entire, few species are at present known; but they afford characters of great interest, 
and their habits are now pretty well understood. The modifications of the animal, and of its shell-secreting functions, serve for their distribution into four genera-

Teredo. Gastrochena. Clatagelia. Aspergillum.

\section{Genus 1. TEREDO, Adanson.}

Animal; vermiform; mantle tubular, slightly open anteriorly; siphons very long, bifurcating at their extremities; orifices fringed, a muscular ring into which are inserted two varionslyshaped ossicles or pallets at the part where the siphons divide; branclice continued into the siphonal tube; foot rudimentary, sucker-shaped. (Forbes.)

Shell; globose or hoop-like, equivalve, very largely gaping anterioily, with a slender elongated apophysis springing from within the umbo, or what is homologous with the umbo, of each valve; linge ligament obsolete, no accessory plates.

It is chicfly to the destructive habits of the Teredo that we are indebted for the care with which its listory has been investigated. Though described as a morm by Theophrastus, Pliny, Orid, and succeeding writers, including eren Limmeus, more than a century has elapsed since it was made known by Sellius to be a mollusk; and its ravages in the wood of ships and harbours have been the theme from time to time of numerous memoirs, including the reports of at least three official government commissions.* The Teredo may be likened to a Pholas, of the Xylophaga form, whose habit is to enclose itself within a tube, sometimes club-shaped, free or agglutinated in numbers together, but mostly tunneling into wood to the length of from a few inches to between two and three feet. The siphons, together with the mantle, are elongated through the posterior gape of the shell to these various lengths according to the species, the tube being secreted as the creature advances in boring, and the siphons of which the bifurcated extremity remains at the posterior or narrow end of the tube are strengthened by a muscular collar, out of which spring a pair of shelly

* "In 1733 Holland was seriously threatened by the boring of our little shell-fish, and Dutch. men by that of his biographers. Strange to say, its history, 'civil and natural,' was worked out, not by zoologists, but by political writers, and with much care did they execute their task. 'Ihe investigators were Pierre Massuet, Jean Rousset, and Godfrey Sellius. They worked independently of each other. . . Sellius was a native of Dantzic. His work on the Teredo, a small quarto of 360 pages, is a most remarkable production. In it all the learning of the ancients and of the moderns up to his time is brought to bear upon the history of the shipworm, or to oruament by apt quotations the digressions suggested by his subject. Nearly two hundred authors are cited. More than once, among the many scraps of ancient poetry with which he 
spathulate pallets which act as an operculum. In some species (Xylotrya, Leach) the pallets are very much elongated. In the free-living species, included erroneously by Lamarck in his genus Fistulana, they are short and of the form of a spear-head.

It has been lately shown by Mr. Jeffreys, assisted by Dr. Lukis, that we have as many as fifteen species of Teredo indigenous to Britain; and the exotic species, of which only ten have been described, are probably very much more numerous. Each species has its own peculiar tube, valves, and pair of pallets, and each, apparently, its allotted length of bore.* Of the British Teredines four, according to Mr. Jefireys, inhabit fixed wood, and the remainder occur in drift-wood as occasional visitants.t Among the exotic species one, T. gigantea (Septaria arenaria, Lamarck), is of very colossal dimensions, forming a tube of considerable length and thickness; and three, T. clava (Fistuland gregate, Lamarck), corniformis, and lagenula (Uperotis, Guettard), are not borers, but form free club-shaped tubes like Gastrochana.

\section{Species.}
1. bipartita, Jeffr.
8. fimbriata, Jeffi.
15. minima, Blain.
2. bipinnata, T'urt.
9. fusticulus, $i d$.
16. nana, Turt.
3. clava, Gmel.
10. gigantea, Limu.
17. Norvegica, Speng.
4. corniformis, Lam.
11. lagenula, Lam.
18. palmulata, Lam.
5. cucullata, Norm.
12. malleolus, Turt.
19. pedicellata, Quatr.
6. elongata, Quatr.
13. marina, Sellius.
20. pennatifera, Blain.
7. excavata, Lukis.
14. megotara, IIanl.
21. Senegalensis, $i d$.

lightens the tedium of his monograph, he quotes with admiration those lines of Ovid, in which the poet makes unquestionable mention of the Teredo:-

\footnotetext{
"For as the ship by hidden shipworm spoiled;

Or as the rock by briny wavelet mined;

$\mathrm{Or}$ as the rusted sword by rust is soiled;

Or book unread the tiny moths unbind:

So gnawed and nibbled, without hope of rest,

By cares unceasing is my tortured breast."
}

Sellius was the first to hold and prove that the Teredo is a mollusk, thus anticipating Adanson, and showing more sagacity than Linnæus, who long after persisted in placing the shipworm alongside of the Serpula." - Forbes and Hanley, Brit. Moll. vol. i. p. 64.

* "No artist ever applicd a shell to so noble a purpose as Mr. Brunel did when the borings of a Teredo revealed to him the plan of tunneling the Thames. On a visit to this distinguished cngineer by Professor Pictet and Dr. Brewster, he mentioned to them that the idea was suggested to him by the tunneling of a Teredo."-Jolonstone, Introd. Conch. p. 66.

+ "The Teredines constitute a peaceful though not a social community, and they have never been known to work into the tunnel of any neighbour. If they approach too near to each other, and cannot find space in any direction to continue their operations, they enclose the valves or anterior part of the body in a case consisting of one or more hemisphericil layers of shelly matter. Sellius supposed that the Teredo ate up the wood which it excavated and had no other food; and labouring under the idea that it could no longer exist after being thus voluntarily shut up, he considered it to be the pink of chivalry and honour in preferring to commit suicide rather than infringe on its neighbour."-Jeffreys, in Ann. and Mag. Nat. Hist., August, 1860. 
22. spatha, Jeffir.

25. truncata, Quatr.

23. Stutchburyi, Blain.

\section{Figure.}

Teredo marin.. Pl. 46. Fig. 24S. Shell, showing the posterior aperture through the large anterior aperture, with the slender inner apophyses. Above is the shelly tube.

\section{Genus 2. GASTROCHANA, Spengler.}

Animal; cuneiform, or, when the siphons, which are separated only at their extremities, are extculed, clongated; orifices fringed; mantle closed, and thickened where exposed, with a very small opening for the small pointed curved finger-shaped foot, which sometimes spins a delicate byssus. (Forbes.)

Shell ; ovately or clongately wedge-sleriped, equivalve, largely gaping anteriorly; hinge toothless, but furmished with a small spathulate lamina and an external ligament; tube calcareons, clubshaped, fiee or attached, often incomplete.

Gastrochena is a genus of thirty species distributed in all parts of the world, combining the organization of two very distinct though nearly allied families. The animal is like that of Saxicava and Petricola rather than of Pholas, having only a small finger-shaped foot, and a shell whose valves are connected by a regular exterual ligament; but the shell largely gapes in front, and the animal, with its mantle thickened where exposed, is not only a borer, but has the faculty of constructing for its place of habitation an elongately club-shaped, or a rude flask-shaped, sheath. How this is effected has never yet been satisfactorily shown. The sheath, except in G. mumia (Fistulana clava, Lamarck), appears to offer few characters peculiar to the species,-few, that is to say, which vary with the variations of the shell; but there are not many species of which the tube has been observed. It is sometimes free, sometimes attached to shells or stones, sometimes it is incomplete; and when the creature makes for itself a cavity in madrepore or other substance, it lines the walls with shelly matter and the sheath is dispensed with altogether. More observations are needed of the exotic species of this very interesting mollusk before generalizing further upon its habits. 
Species.

1. agglutinans, Desh. 11. hyalina, Sow.

2. apertissima, $i d$. 12. impressa, Desh.

21. ovata, Sow.

13. indistincta, $i d$.

22. Philippinensis, Desh.

3. brevis, Sow.

14. interrupta, $i d$.

23. plicatilis, $i d$.

4. cucullata, Des/.

15. intersecta, $i d$.

16. lævigata, $i d$.

24. pupina, $i d$.

5. denticulata, $i d$.

25. rostrata, Speng.

6. difficilis, $i d$.

17. lamellosa, $i d$.

18. macrochisma, $i d$.

26. rugulosa, Sow.

7. dubia, Penn.

8. grandis, Desh.

19. mumia, speng.

27. Rüppellii, Desh.

9. hians, Chemn.

10. humilis, Desh.

20. mytiloides, Lam.

28. spathulata, $i d$.

29. tenera, $i d$.

30. truncata, Sow.

\section{Figures.}

Gastrochena ovata. PI. 45. Fig. 24.0. Shell, taken from its crypt and placed on its ventral edge to show the anterior gape and posterior external ligament.

Gastrochena (Fistulana) musita. Pl. 46. Fig. 246. Shell, with the valves open, as contained within the club end of the tube. The tube above shows the form of it before being broken to extract the valves.

\section{Genus 3. CLAVAGELLA, Lamarck.}

Animal; mantle closed in front except a minute slit for the passage of a small rudimentary foot; edges of the mantle sometimes furnished with small tentacular processes corresponding with tubular processes of the shell; siphons united and extended, the branchial siphon having the branchice continued into it.

Shcll; ovate or oblong ovate, irregular, sometimes rudimentary; left valve fixed to the wall of the burrow, right valve free; sheath variously elongated, subcylindrical, expanded at the top like a flower, sometimes encircled with a frill or succession of firlls, lower end of the sheath enclosing the shell terminating with a rudely shaped disk, liaving a minute central fissure, and bordered by irregular spine-like tubes.

Clavagella presents an interesting intermediate link between Gastrocheana and Aspergillum; but there is no great difference in the animal beyoud the modifications of organs leading to a change in the construction 
of the shell. In Gastroctiana the animal has a pair of well-developed symmetrical valves, allied to those of Saxicava; teeth are dispensed with in the hinge, but there is a well-defined ligament, and the animal encloses itself within a club-shaped sheath, very subordinate in importance to the shell. It is often incomplete, sometimes it is not present at all, and it does not carry with it any very marked specific characters. In Clavagella the valves are of very rude construction; not only the teeth but also the ligament disappears, and only one of the valves is free, the other being cemented to the wall of the burrow. The tube in this genus is of more importance to the creature. It passes up through stone and coral and expands at the siphonal extremity like a flower forming, not unfrequently, a succession of frills indicating periodical advancements of growth.* At the chamber end it closes orer the bivalve with a disk, and a few irregular tubes are sometimes formed at the edge by corresponding processes in the mantle of the animal, while the disk has a central slit indicating the position of the animal's foot. In Aspergillum the bivalve is cast aside in a very early stage of the animal's existence, and altogether imbedded in the wall of a sheath of larger and still more elaborate construction. It exhibits characters more obriously peculiar to the respective species, and the tubes of the imbedded end are, by a more crowded development of filaments from the mantle, elaborated into a rose, like the rose of a watering-pot.

Six species of Clavayella have been observed, inhabiting the Mediterranean, Australia, and the Pacific, dwelling at extremely variable depth. "C. australis," remarks Mr. Broderip on observations made by Mr. Cuming, "was so near the surface at low-water, that it was detected by its ejection of the fluid; C. elongata, from the nature of the coral in which it is chambered, could not have been living far beneath the surface; whereas C. lata was dredged from a depth of sixty-six feet."

\section{Species.}

1. aperta, Sovo.

3. balanorum, Scacchi.

5. lata, Brod.

2. australis, $i d$.

4. elongata, Brod.

6. Melitensis, $i d$.

\section{Figure.}

Clanvagella aperta. Pl. 45. Tig. 242. Shell, imbedded in limestone rock, with a piece of the rock removed to show the free valve, the

* "The frills are formed by the siphonal orifices when the animal continues elongating after having fixed its valve and ceased to burrow; or perhaps in some instances when it is compelled to lengthen its tube upwards by the accumulation of sediment."-Woodward, Manual, p. 326. 
left valve being cemented to the wall of the burrow. Above is the frilled extremity of the tube, the lower frill showing where the tube once terminated, and the animal rested for a time.

\section{Genus 4. ASPERGILLUM, Lamarck.}

Animal; elongated; mantle closed in front except a minute slit for the passage of a small conical foot; edges of the mantle furnished with munerous tentacular filaments, sometimes profisely so; branchice long and narrow, continued into the branchial siphon.

Shell ; with two equal, minute, ovate valves, mostly angled posteriorly, soldered into the lower wall of a long sheath; sheath at the upper part open, sometimes attemuted, with the edge simple, sometimes nearly straight, with the edge rather largely two to eight times furbelowed, at the lower part club-shaped, closed by a perforated, generally tubularly fringed, disk.

The Aspergillum, as is doubtless the case with the other genera of Tubicola, ceases in an early stage of its existence to live free, and while yet no more than the eighth of an inch in length, sinks into the sand or adheres to shell or stone, and directs its calcifying functions to the formation of a very long tubular sheath. The little valves, at this stage of the animal's metamorphosis, if it may be so called, appear to be discarded, and taking henceforth no part in the economy, they become soldered into the wall of the sheath. Upwards the sheath enlarges with the growth of the mantle and siphons for their special protection; downwards the animal closes in the sheath by a disk, not only fissured and perforated, but bordered, in most species, by a profusely tubuled frill. The mantle of the animal, observed by Dr. Riippell, on the shores of the Red Sea, changes and enlarges, and a number of tentacles are emitted from the edge, each one corresponding with a tubular perforation of the shell. Frequent distortion is imparted to the shell, more especially to the disk end of it, according to the circumstances of its place of habitation, and when affixed to shell or stone the disk may be scarcely recognizable. Shells with the strength of growth even of Spondylus, become distorted by their inability to contend with the outward pressure of foreign bodies. Shells, therefore, of the delicate and comparatively fragile growth of Aspergillum, would be liable to extreme contortion; and so it is. Aspergillunit vaginiferum, which sinks into sand, as may be seen by the particles agglutinated to the shell, throws up a bold VOL. II. 
erect sheath without let or hindrance, and when it reaches the surface, the edge, as in Clavagella, becomes elegantly furbelowed. A season of rest cusues; another effort is made to extend the sheath, the growth is pushed on, but the calcifying energies of the mollusk either are not needed, or are enfeeblect. A little is added to the sheath, and the edge is again furbelowed, and in some specinens as many as eight times this process has been repeated. In adherent species, such as $A$. Strangei, one specimen of which was found affixed to the inner cleft of a mussel-hinge and the other to a stone, the disk is completely smashed in, as it were, and the sheath being free, not pushed through sand or any debris of shells or pebbles, is smooth and tortuous, faintly coloured by an enveloping periostracum. I incline to dissent from Dr. Gray's views that the sheath of the adhering A. Strangei is an enlargement of the primitive pair of valves, while in the non-adhering species it is analogous to the tubular sheath of the Teretlo. The sheath of Aspergillum has, as in all the Tulticolex, a specific limit and mode of growth, but whether by a stretch of philosophical induction it be regarded as an enlargement of the primitive pair of valves or not, the relation between the valves and the sheath I hold to be the same, whether living buried in sand or adhering in an exposed manner to shell or stone. Dr. Gray also draws a distinction between species which have a wavy depression round the pair of valves, and those which have not, regarding the wavy depression as a part of the valies of which only the umboes are exposed. My own view is, that, at the time of the metamorphosis of the mollusk, the valves are wot larger in any species than are defined by the smaller outline. When it is considered that the valves are cast at this time, but not entirely, inasmuch as they are appropriated as material for a nucleus from which to develope a sheath, it is only reasonable to suppose that the new sheathmatter would, for a time, obtain a ravy deposit corresponding with the outline of the nucleus.

Nineteen species of Aspergillam are described and figured in my monograph of the genus in 'Conch. Iconica,' but it is more than probable that they may be reduced by further researches to about a dozen. They have been named in Mr. Cuming's collection by Dr. Chenu and M. Deshayes, and I have preferred to give them as they left them, except in a fer instances, where the illentity with others was too obvious to be overlooked. More specimens of the seven or eight doubtful species are needed before rejecting them as synonyms, or discussing their characters with anything like critical accuracy. There are six well-marked types of Aspergillum :1. A. vaginiferum (Warnea, Gray), in which the sheath is furbelowed at the top, and has a well-fringed disk at the bottom, with a wavy depression around the valves. 2. A. Cuningianum, in which the sheath has a clumsy distorted growth peculiar to the species, and is closed at the bottom by a rudely convex disk, perforated by a bunch of tubes, not radiating in a frill; 
the formation of the sheath commences round the valves in a depressed wavy manner, as in the preceding species, and Dr. Gray places it for this reason in his genus Warnea. I do not regard this wavy depression as having existed whilst the mollusk was in the bivalve stage of its existence, and would refer A.Cumingianum to another section. 3. A. Javanum, pulchrum, and radix (Aspergillum, Penicillus, and Clepsidra, Gray), in which the sheath is attenuated, and is closed in at the bottom by an elaborately perforated disk, with a more or less densely branched, finely tubed frill. 4. A. tuberculatum and clavatum (Arytene, Gray), in which the sheath is slender, agglutinating sand and fine pebbles, and is closed at the bottom by a disk of small size, only lightly promiscuously perforated, encircled by a regular well-developed frill of a characteristic sloping growth; the valves of this type have the shelly wall of the sheath projected over them in a peculiar biforked mamer. 5. L. agglutinans and Philippinense (Foegia, Gray), in which the tube is club-shaped, densely agglutinated with sand, pebbles, and shell-debris, and is contracted below the disk, taking the form of a small clump of short, wider tubes. 6. A. Strangei (Humplireyia, Gray), the adherent species already described, of which Dr. Gray constitutes a separate subfamily.

All the Aspergilla belong to the Eastern Hemisphere. A. vaginiferuni inlabits the Red Sea, A. Javanum and its allies inhabit the eastern seas, about the Philippine Islands, Java, Ceylon, and Singapore, and the more distorted forms are from Australia and New Zealand.

\section{Species.}

1. agghutinans, Lam.

2. annulosum, Desh.

3. clavatum, $i d$.

4. Cumingianum, Chenu.

5. Delessertianum, $i d$.

6. dichotomum, $i d$.

7. disjunctum, Desh.
8. incertum, Chenu.

9. incrassatum, $i d$.

10. Javanum, Lam.

11. Novæ-Zelandiæ, $i d$.

12. Philippinense, Chenu.

13. pulchrum, Desh.
14. radix, Desh.

15. semifimbriatum, $C / \%$.

16. Strangei, Adams.

17. tuberculatum, Chenu.

18. vaginiferum, Lam.

19. Zebuense, Chenu.

\section{Figure.}

Asprergilidum vaginiferum. Pl. 46. Fig. 247. Shell, originally a small bivalve, imberded in the wall of a sheath, which is thrown up through the sand, particles becoming agglutinated to its surface, the extremity emerging from the sand, bearing three frilled edges, each of which has formed the termination of the sheath at different periods. The lower end of the sheath below the imbedded bivalve is covered in 
with a disk perforated with tubes, cach tube having been secreted by a corresponding tentacle-like filament of the mantle.

\section{Cuass 5. BRACHIOPODA.}

Animal; bodly small, not furnished with branchice but enveloped by a fringed mantle, of which the loles are not lateral, but dorsal and ventral, having a system of vascular branchia incorporated with them, and cach secreting a shelly valve; no head or eyes; mouth furnished with two extended ciliary processes or arms, which are sometimes fiee, folded in coils, sometimes supported on a more or less complicated cartilaginous or calcareons sliclcton; muscular system elaborate, comprising five to six pairs of adductor, cardinal, pecticle, and capsular muscles. Shell; aluays bivalve, the valves being ventral and dorsal, unconnected by any ligament, but sometimes closely interlocking with curved tooth-like processes, one ialie free, the other agglutinated or affixed by a pedicle to foreign substances.

The Brachiopods are a tribe of very peculiar structure, intermediate in the general features of their organization between the Lamellibranchiate Bivalves and the Cirrhipedes. Like the former, they secrete a bivalve shell, but the valves are not side-valves, connected dorsally by a ligament and opening ventrally. The valves are themselves dorsal and ventral, unconnected by any ligament, and the mantle-lobes which secrete them perform also the offices of respiration. The branchix are incorporated with the mantle-lobes in the form of a system of vessels, hence the term Palliobrancliata, or mantle-breathing, sometines given to these mollusks, a much more appropriate term, as we shall presently see, than the alınost universally adopted one of Bractioporda. Projecting from the mouth of these creatures, one on each side, corresponding with the labial palps of the lamellibranchiate bivalves, are two extended, cirrhated, tubular processes, which are sometimes folded into spiral coils, sometimes attached to and supported by a cartilaginous or calcareous skeleton termed the apophysis. These cirrhated processes, called, through some fanciful analogy, arms, were supposed originally to be exserted in constant activity, like the cirrhi or cirrhated arms of the Cirrhipcdes, with which they seem to have some affinity; but the arms of the Brachiopod are not feet, in the sense in which the cirrhi are feet in the Cirrhipedes, nor are they feet in the sense in which the belly is a foot as an organ of locomotion in the Gasteropod. 
They do not assist in collecting food, nor do they aid in effecting any change of place.

There are three forms of Brachiopod of distinctive habit, apart from the features of their organization, which serve for their distribution into genera. In Terebratula and Rhynchonella the natural position of the mollusk is to repose upon its back, the dorsal valve is undermost, and a mooring is secured by means of a tendinous pedicle let down from the ventral or upper valve, which is beaked over on one side for the purpose. In Crania and Orbicula the position of the mollusk is the limpet position,- the ventral valve is the undermost, and either the pedicle of adhesion passes through it, or the pedicle is dispensed with and the shell itself, like the under valve of Calyptraa, is agglutinated to the place of attachment. In Lingula the position of the mollusk is again different: the bivalve elongates its pedicle from the place of attachment to the length of two to six inches and more, and makes its way perpendicularly through mud or sand. More than two-thirds of the Brachiopods belong to genus Terebratula, in which the valves strongly interlock at the hinge-margin, and are held besides by a complicated crossing of adductor and cardinal muscles, in addition to which there are also pedicle and capsular muscles. They inhabit chiefly deep water, and are scattered, somewhat scantily, through all seas. To the geologist the Brachiopods are interesting on account of their great antiquity. They have existed in every epoch of the world's history. Not quite eighty recent species are known, but of fossil more than eleven hundred, and at least three ordinal types of species among the fossil are now extinct. The class may be divided at once into genera.

$\begin{array}{ccc}\text { Terebratula. Rhynchonella. } & \text { Crania. } \\ \text { Orbicula. } & \text { Iingula. }\end{array}$

Genus 1. TEREBRATULA, Bruguière.

Animal; attached chiefly by a tendinons pedicle; arms strongly cirrhated, variously looped and folded, united and fixed to the apoplyysary skeleton by a membrane, sometimes spiral at their extremities.

Shell; inequivalve, equilateral, globosely or triangularly ovate, sometimes smooth, sometimes striated or ribbed, always minutely punctured; upper or ventral valve beaked over the hinge, the beak being more or less perforated for the passage of a tendinous pedicle, and mostly separated from the linge by a triangular plate called the deltidium, composed of one or more pieces; 
liinge composed of a sharply hooked tooth-like process at each corner of the deltidium in the upper valve, very closely fitting a corresponding socket and process in the under valve; no ligament; under valve developed into a shicld at the umbo, which passes into the upper valve at the axis of the linge below the deltidium, and has in connection with it, internally, an extended apoplysary system of varionsly looped horny or calcareous processes.

We include in genus Teretratula all the Brachiopods, fifty-four in number, having shells of the form of an inverted Roman lamp, minutely punctured throughout. Three other Brachiopods (genus Rhynchonella) have similar lamp-shaped shells, but they are not punctured, and along with this simple conchological difference, there are differences both of a malacological and a geological character. Terebratula are found in all parts of the world, (three very characteristic species, T. caput-serpentis, cranium, and cistellula inhabiting our own seas) often at very great depths, adhering to stones, shells, and corals, and many of them, especially from the tropics, are beautifully coloured, often deep rose or scarlet variegated with red stripes. The valves being dorsal and ventral, not lateral, with respect to the soft parts, as in the Lamellibranchiate order of bivalves, the animal seems to dwell in an inverted position; the smaller valve upon which it rests is the dorsal, and the ventral valve projects over the hinge in the form of a beak, perforated and serving for the passage of a tendinous pedicle, by which the creature is moored to its place of attachment. The valves of Terebratula are hinged without the intervention of any ligament. Beneath the ledge of the beaked projection of the upper valve is a hooked tooth, which fits closely into a corresponding socket and tooth-like process in the lower valve, and the umbonal extremity of the lower valve passes deeply into the beaked portion of the upper valve, and is dove-tailed into it, so to speak, in many species, by a plate of one or more pieces, called the deltidium. Inwardly the under valve forms a kind of shield, and in connection with it is a variously elaborated system of apophyses, or looped skeletons, which give support to the remarkable development of cirrhated arms or brachia, after which the class is named.

The modifications of the hinge and of the brachial apophyses of Terebratula are rather numerous, and afford abnndant characters for subdivision. In T. vitrea (Terebratula proper) the loop is short and formed of two ribbon-shaped lamellx proceeding from the shield or crural base; in T. caput-serpentis (Terebratulina, D'Orb.) the internal appendage is very small, arched and vaulted below ; in T. dilatata (Waldheimia, King) the loops are long; in T. Chilensis (Terebratella, D'Orb.) the loops are also long, but the crura give off about their middle a flat, wide, horizontal pro- 
cess affixed to a central septum; in T. crenulata (Magas, Sowerby) there is a central septum with two pairs of lamellæ; in T. tulipa (Bouchardia, Davidson) the shell has only a minute foramen for the pedicle and the apophysis is anchor-shaped; in T. truncata (Mergerlia, King) two short diverging branches arise from the extremity of the septum; in T. Capensis (Kraussia, Davidson) the apophysis consists of a small forked process arising from the septum; in $T$. Anomioides (Morrisia, Davidson) a minute form, two branches arise from the centre of the valve and they are not reflected; in T. cistellula (Argiope, Deslongchamps), another minute form, the apophysis is represented by one or more internal ribs; and, lastly, in T. Mediterranea (Thecidium, Defrance) the loop is folded into two or more lobes resting in corresponding hollows of the upper valve. With these modifications of the apophysary system there are also other general modifications of the shell and of the animal, of which the importance will, doubtless, increase as more observations are made, and they are better understood.

\section{Species.}

1. abyssicola, $A d$. \& Rv. 19. cuneata, Riss.

2. angusta, $i d$.

20. decollata, Gmel.

3. Anomioides, Scac.

4. Bouchardii, Dav.

5. Californica, Koch.

6. cancellata, $i d$.

7. Capensis, $A d . \& R v$.

8. caput-serpentis, Linn.

9. caurina, Gould.

10. Chilensis, Brod.

11. cistellula, Wood.

12. cognata, Chemn.

13. Coreanica, $A d$. \& $R v$.

14. cranium, Miell.

15. crenulata, Sow.

16. cruenta, Dill.

17. Cumingii, Dav.

18. Cumingii (Mag.), D. 36. Patagonica, Gould.
37. picta, Cheinn.

38. pisum, Lam.

39. pulchella, Sow.

40. pulvinata, Gould.

41. rubella, Sow.

42. rubicunda, $i d$.

48. rubra, Pall.

44. sanguinea, Chemn.

45. septentrionalis, Couth.

46. septigera, Loven.

47. Sowerbyi, King.

48. Spitzbergensis, Dav.

49. transversa, Sowo.

50. truncata, Linn.

51. tulipa, Blainv.

52. uva, Brod.

53. Valencienni, Dav.

54. vitrea, Linn.

\section{Figures.}

Terebratula caput-serpentis. Pl. $P$. Fig. 1 . Shell, showing the natural position of the mollusk, affixed by a tendinous pedicle lowered from the beaked projection of the upper valve. 
Terebratula rubra. Pl. P. Fig. 2. Shell, with the valves opened to show the internal apophysary skeleton.

\section{Genus 2. RYNCHONELLA, Fischer.}

Animal; with spirally coiled arms, not fixed by any looped cartilaginous apophysis, but supported at the base only by two short curved processes.

Shell; inequivalve, equilateral, subglobose, grooved or striated, never punctured; upper valve sharply beaked over the lower; beak entire, triangularly perforated below; no deltidium; lower valve furnished at the linge-margin on either side with a projecting curved blade.

Rhynchonella, of which the well-known R. psittacea, or Parrot's-beak Terebratula, is the type, differs essentially from the preceding genus. The animal has no cartilaginous apophysis for the support of its cirrhated arms. A hooked blade projecting from the hinge-margin of the lower valve on either side supports each arm at its origin, and beyond this they are disposed in six or seven free spiral gyrations which are unfolded and protruded outwards, and again retracted at pleasure. The position of the animal is the same as in Terebratula, but the foramen in the upper valve, for the passage of the tendinous pedicle, is not at the extremity of the beak, but under it, the beak being sharply over-hooked. The shell, moreover, is not punctured, and it is a feature in the geological history of Rhynchonella that as many as two hundred and eighty species are known in a fossil state, while only two are found living, one a native of the northern Atlantic seas, the other of the seas of New Zealand.

\section{Species.}

1. nigricans, Sow.

2. psittacen, Chemn.

Figure.

Rhynchonella pstrtacea. Pl. P. Fig. 3. Shell, placed on end to show the foramen beneath the hooked beak. 
Genus 3. CRANIA, Retzius.

Animal; with two large cirrlated appendages forming a pair of spiral arms, curved inwards, unprovided with any apopliysary skieleton, but directed towards a concavity of the upper valve, in which it is supported by a central prominence in the lower valve; mantle extending to the edges of the valves and closely adhering, its margins plain.

Shell; inequivalve, inequilateral, squarely orbicular, rather compressed, the upper valve being limpet-like; under valve flat, imperforate, agglutinated to foreign substances; no linge or ligament.

In the two preceding genera of Brachiopods we have seen that it is the natural position of the mollusk to repose upon its back; the lower valve of the shell is the dorsal valve, and the upper or ventral valve, from which anchorage is obtained, projects over one side, like a beak, for lowering the anchor. In Crania the position of the mollusk is reversed, the ventral valve is undermost, and having no need, or even space, for a tendinous anchor, the valve becomes agglutinated at once to the place of attachment. But it will be observed, that in the genus Orbicula the shell is not so closely adherent, and there is a tendinous muscle of attachment passing through a central fissure of the under valve; and it is conjectured that the same thing obtains in a rudimentary form in Crania in an early stage of its development. The arms, or brachial appendages, of Crania have no internal apophysary skeleton for their support ; they are folded into a pair of spiral coils, which are directed towards the concavity of the upper valve, a limpet-like plate, and, indeed, described as a Patella by liontagu, and they are supported in the concavity of the upper valve by a central prominence rising up between them from the lower. This central prominence has somewhat the form of the human nose, and the scars of the anterior adductor muscles above it, regarded as eyes, give to the valve no very unfanciful resemblance of a face. The under valve of Crania, as with other adherent shells, varies much in thickness according to the nature of its place of attachment. When adhering to branches of coral or any uneven bottom, the animal secretes a thick and solid valve; when affixed to the flat: surface of shells or stone, the valve is often so thin as to be overlooked.

The Cranice are all of deep-dwelling habits, one species, $C$. anomala, is dredged in the seas of North Britain and ranges throughout the Scandinavian waters, the others are from the Mediterranean and seas of India and South Australia. 
Species.
1. anomala, Mïll.
3. radiosa, Gould.
5. rostrata, $i d$.
2. personata, Lam.
4. ringens, Haning.

\section{Figures.}

Crania anomala. Pl. P. Fig. 9. Shell, in its natural position, attached to stone. Fig. 8, and Pl. 26. Fig. 152. Shell, showing the musclescars and nose-like projection on the immer surface of the adherent valve.

\section{Genus 4. ORBICULA, Lamarck.}

Animal; with tuo rather short cirrhated arms, unprovided with any apophysary skeleton, folded within the concavity of the upper. valve; foot with an adluerent tendinous pedicle passing through a slit in the lower valve.

Shell; inequivalve, orbicular, hormy; upper valve convex, limpetlike, louer valve fissured for the passage of a tendinous pedicle, and furnished internally with a process for the support, at their origins, of the cirrhated arms.

Like the Cranice the Orbicula are closely adherent mollusks, and the ventral valve is the undermost; the shell is, however, of a less calcareous substance, horny and flexible, and does not become agglutinated to the place of attachment. Adhesion to forcign bodies is acquired by means of a tendinous pedicle, not passing out of a beaked projection of the upper valve, as in Terelratula, but through a fissure in the valve upon which the animal rests. The brachial appendage, which has no supporting apophysary skeleton, is folded within the concavity of the upper valve.

One species, O. lavis, is Scandinavian, the rest are chiefly from the shores of Chili and Peru.

\section{Species.}
1. Cumingii, Brod.
4. lamellosa, Brod.
6. strigata, Brod.
2. Evansii, Dav.
5. striata, Sow.
7. tenuis, Sow.
3. lævis, Sow. 
Figures.

Orzicula tevis. Pl. P. Fig. 10. Shell, attached to stone. Pl. 26. Fig. 151. Shell, removed from its place of attachment, and turned over to show the slit in the lower valve.

\section{Genus 5. LINGULA, Bruguière.}

Animal; with the cirrliated arms elongated and fleshy, disposed in about six coils; mantle-lobes distinct and frilled all round, firmly adhering to the shell and united to the epidermis.

Shell; nearly equivalve, oblong, compressed, gaping at each end, thin, horny, flexible, mostly blue-yreen, attemuted and forming a beaked umbo in each valve at the posterior end, where it is affixed to a transparent horny pedicle, from one to six inches in length; no linge.

The Molluscan series of invertebrate animals closes with a Brachiopod of similar organization to the previous genera, having well-developed cirrhated arms folded in coils, and wide-spread frilled mantle-lobes, but it is of different habit, and forms a very different kind of shell. The Lingule do not live attached to rocks, but are found imbedded in the mud of shallow bays and harbours, or in sand, which it appears to perforate. They affix themselves to foreign substances, but they bear away from their place of attachment by the aid of a variously lengthened flexible pedicle, tubular and horny, like the pedicle of a cirrhipede, and the body, elongated at the end of it, secretes an oblong horny shell, almost as flexible as the pedicle, of the shape of a duck's bill. The mollusk reaches in this way from its place of attachment to the length of six or eight inches and more.

Though not common, the Lingule abound in their particular haunts in low-water. Mr. Cuming once saw as many as twenty bushels of $L$. anatina washed ashore in the Bay of Manila after a stormy typhoon. Another favoured locality appears to be about Moreton Bay, Australia. Three of the species are from the Sandwich Islands, California, and the West Indies.
1. albida, Hinds.
5. exusta, Reeve.
9. ovalis, Reeve.
2. anatina, Lam.
6. hians, Swain.
10. semen, Brod.
3. Antillarum, Reeve.
7. hirundo, Reeve.
11. tumidula, Reeve.
4. Audebarti, Brod.
8. Murphiana, King. 


\section{Figures.}

Livgula axatina. Pl. P. Fig. 7. Shell, with the fringed border of the lobes of the mautle protruding from its edges, attached to its elongated pedicle.

Livgula iIIans. Pl. 26. Fig. 155. Shell, attached to its pedicle.

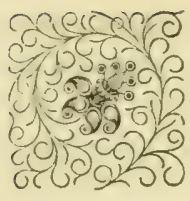




\section{APPENDIX.}

\section{SPECIES OF ELENCHUS.}

1. apicinus, Menke.

2. Australis, Quoy. 3. badius, Wood.

4. bellulus, Dunk.

5. elegans, Gmel.
6. gracilis, Anton.

7. iriodon, Quoy.

8. lætus, Phil.

9. leucostigma, Menke.

10. lineatus, Lam.
11. minor, Trosch.

12. roseus, Lam.

13. rutilus, $A d$.

14. splendidulus, Swain.

15. virgulatus, Phil.

\section{SPECIES OF BANKIVTA.}

1. major, $A d$.

2. nitida, $A d$.

3. varians, Beck.

\section{SPECIES OF LITTORINA.}

l. aberrans, Phil.

16. cincta, Quoy.

31. Fortunei, Reeve.

2. Adamsii, Reeve.

17. cingulata, Phil.

32. Fraseri, $i d$.

3. Africana, Phil.

18. columellaris, $D^{\prime} O r b$.

33. glabrata, Phil.

4. ahenea, Reeve.

19. conica, Phil.

34. glans, Reeve.

5. albicans, Metc.

20. coronaria, Lam.

35. grandis, Midd.

6. ambigua, Nutt.

21. Cumingii, Phil.

22. debilis, $i d$.

36. grano-costata, Reeve.

7. araucana, $D^{\prime}$ Orb.

23. decollata, Krauss.

24. Diemenensis, Quoy.

37. granosa, Phil.

8. arboricola, Reeve.

9. arctica, Möll.

10. balteata, Reeve.

11. brevicula, Phil.

12. bullata, Mart. 25. dilatata, $D^{\prime} O r \cdot b$.

38. granularis, Gray.

39. Grœnlandica, Menke.

26. fabalis, Turton.

27. fasciata, Gray.

40. guttata, Phil.

41. intermedia, Gray.

42. irrorata, Say.

28. Feejeensis, Reeve.

29. filosa, Sow.

43. Knysnaensis, Krauss.

44. lævis, Phil.

14. carinifera, Menke.

30. flammea, Phil.

45. lemniscata, Phil. 
46. littoralis, Limn.

47. littorea, $i d$.

48. luctuosa, Reeve.

49. Malaccana, Phil.

50. Mauritiana, Lam.

51. melanostoma, Gray.

52. mespilum, Miihl.

53. millegrana, Phil.

54. minima, $W_{\text {ood }}$.

55. modesta, Phil.

56. muricata, Linn.

57. Natalensis, Krauss.

58. nebulosa, Lam.

59. Neritoides, Linn.

60. Newcombi, Reeve.

61. nodosa, Gray.

62. Novæ-Zelandix, Rve.

63. obesa, Sow.

64. obligata, Say.
65. pagodus, Limn.

66. pallescens, Phil.

67. palliata, Say.

68. Paludinella, Reeve.

69. Philippiana, $i d$.

70. picea, $i d$.

71. picta, Phil.

72. Pintado, Wood.

73. Planaxis, Nutt.

7t. porcata, Plit.

75. pulchra, Sow.

76. punctata, Ginel.

77. pyramidalis, Quoy.

78. rudis, Donov.

79. rufa, Recluz.

80. rugosa, Menke.

81. saxatilis, Johnston.

82. Sayi, Phil.

83. scabra, Linn.
84. Sieboldii, Phil.

85. simplex, Reeve.

86. Sitchana, Phil.

87. spinulosa, $i d$.

88. striata, King.

89. subnodosa, Plil.

90. sulculosa, $i d$.

91. tectum-Persicum, Linn.

92. tenebrosa, Mont.

93. tenuis, Plil.

94. tessellata, $i d$.

95. Thersites, Reeve.

96. trochoides, Gray.

97. undulata, $i d$.

98. varia, Sow.

99. ventricosa, Phil.

100. vilis, Menke.

101. zebra, Wood.

102. ziczac, Chemn.

\section{SPECIES OF TROCHUS.}

1. acutangulus, Chemn.

2. Adansoni, Payr.

3. Adelaidæ, Phil.

4. Adriaticus, $i d$.

5. Agathensis, Recl.

6. agrestis, Phil.

7. alabastrum, Beck.

8. alternatus, Phil.

9. alveolatus, $i d$.

10. amuenus, Gould.

11. angulatus, Quoy.

12. annulatus, Mart.

13. Antonii, Koch.

14. architectonicus, $A d$.

15. ardens, Salis.

16. argyrostoma, Chemn.

17. armillatus, $W_{0 o d}$

18. articularis, $A d$.

19. articulatus, $i d$.

20. artizona, $i d$.

21. asperulatus, $i d$.

22. asperulus, Lam.
23. asperus, Chemn.

24. aster, Phil.

25. ater, Lesson.

26. atrovirens, Phil.

27. balteatus, $A d$.

28. balteatus, Phil.

29. Benzi, Krauss.

30. bicanaliculatus, $D k r$.

31. bicarinatus, $A d$. $\& \cdot R$.

32. bicarinatus, Pot.

33. bicinctus, Phil.

34. bicingulatus, Lam.

35. Brasiliensis, Menke.

36. brunneus, Phil.

37. crelatus, $A d$.

38. calcar, Linn.

39. Californicus, $A d$.

40. callichrous, Phil.

41. callicoccus, $i d$.

42. calliferus, Lam.

43. calyculus, Wood.

44. canaliculatus, Mart.
45. Candei, $D^{\prime}$ Orb.

46. canus, Koel.

47. Capensis, Gmel.

48. caperatus, Plitl.

49. capillaceus, $i d$.

50. carbonarius, $i d$.

51. cariniferus, Beck.

52. carneus, Gmel.

53. castaneus, $A d$.

54. Cecillei, Phil.

55. Chemnitzii, id.

56. chloromphalus, $A d$.

57. chlorostoma, Menke.

58. cicatrosus, Jonas.

59. ciliaris, Menke.

60. cinerarius, Linn.

61. cingulatus, Brocc.

62. cingulatus, Quoy.

63. cingulifer, $A d$.

64. Cumingii, $i d$.

65. Cunninghami, Gray.

66. comptus, $A d$. 
67. concavus, Linn. 68. concinnus, Phil.

69. conicus, Gray.

70. concolor, $A d$.

71. conspersus, Gmel.

72. constrictus, Macl.

73. conuloides, Lam.

74. conulus, Linn.

75. coracinus, Trosch.

76. comosus, $A d$.

77. corrugatus, $i d$.

78. corrugatus, Koch.

79. corvus, Phil.

80. costatus, Gmel.

81. costulatus, Lam.

82. crenulatus, Brocc.

83. crenulatus, Lam.

84. crenulatus, Menke.

85. crenuliferus, $A d$.

86. crinitus, Phil.

87. cruciatus, Chemn.

88. declivis, Försk.

89. decoratus, Plil.

90. decussatus, $A d$.

91. delicatulus, Phil.

92. dentatus, Försk.

93. depressus, Gmel.

94. divaricatus, Linn.

95. dubius, Phil.

96. duplicatus, $A d$.

97. elegantulus, $i d$.

98. elegantulus, $W_{\text {ood }}$.

99. elongatus, $i d$.

100. erythræus, Clemn. 101. eucosomus, Plitl.

102. euglyptus, $A d$.

103. eugramma, Phil.

104. eustephes, id.

105. exasperatus, Penn. 106. excavatus, Lam.

107. eximius, Reeve.

108, familiaris, Petiv.

109. fanulum, Gnel.

110. fasciatus, Anton.

111. fasciatus, Born.

112. fastigiatus, Adams.
113. fenestratus, Gmel.

114. ferruginosus, Phil.

115. filosus, Wood.

116. firmus, Phil.

117. flammulatus, Lam.

118. flavus, Anton.

119. Forskalii, Bolt.

120. fragrum, Plitl.

121. fulguratus, $i d$.

122. fuligineus, $A d$.

123. fulvus, Phil.

124. fuscescens, $i d$.

125. gemmosus, Reeve.

126. gibberosus, Chemn.

127. gibberulus, Adams.

128. gillinus, Forbes.

129. gilvus, Phil.

130. Gmelinii, $i d$.

131. goniostoma, Menke.

132. granifer, $A d$.

133. granularis, Bolt.

134. granulatus, Born.

135. Gruneri, Phil.

136. Gundlachi, $i d$.

137. guttatus, Koch.

138. Hanleyanus, Reeve.

139. heliacus, Phil.

140. helicoides, $i d$.

141. heliotropium, Mart. 187. melaleucos, Link.

142. Hotteserianus, D'Orb.188. melaleucos, Jonas.

143. hyacinthiuus, Ren. 189. melanoloma, Menke.

144. ignobilis, Phil.

145. impervius, Menke.

146. impressus, Anton.

147. incarnatus, Phil.

148. incrassatus, $i d$.

149. incrassatus, Lam.

150. indecorus, Plit.

151. indistinctus, $W_{\text {ood }}$.

152. instrictus, Gould.

153. interruptus, $W_{\text {ood }}$.

154. iris, Humpl.

155. Japonicus, $A d$.

156. Javanicus, Lam.

157. jucundus, Gould.

158. jujubinus, Limn.
159. kalinota, $A d$.

160. kalisoma, $i d$.

161. Kochii, Phil.

162. Kotschyi, $i d$.

163. lævigatus, $i d$.

164. Lehmanni, Menke.

165. lepidus, Koch.

166. leucogaster, Adams.

167. leucophæa, Phil.

168. leucostictus, $A d$.

169. leucostigma, $i d$.

170. lineatus, $D a$ Costa.

171. liratus, $A d$.

172. lima, Plitl.

173. lineatus, Lam.

174. livido-maculatus, $C \cdot A d$.

175. luctuosus, D'Orb.

176. lugubris, Gmel.

178. maculatus, Linn.

179. maculatus, Plil.

180. maculosus, $A d$.

181. maculo-striatus, $C . A d$.

182. mœstus, Jonas.

183. magus, Limn.

184. marginatus, Nutt.

185. Mauritianus, Gmel.

190. Menkei, $A d$.

191. merula, Chemn.

192. meruloides, Krauss.

193. metaformis, Plitl.

194. midus, $i d$.

195. millegranus, $i d$.

196. Mindorensis, $A d$.

197. mitra, Anton.

198. modestus, Koch.

199. moniliger, $A d$.

200. Montagui, Gray.

201. morum, Trosch.

202. multicolor, Krauss.

203. mutabilis, Phil.

204. Nassaviensis, Chemn. 
205. nebulosus, $A d$. 206. nebulosus, Phil. 207. Neritoides, Born. 208. nigerrimus, Chemn. 209. nigerrimus, Gmel. 210. nigricans, $A d$. 211. Niloticus, Linn. 212. nitidulus, Phil. 213. nivosus, $A d$. 214. nobilis, Phil. 215. nocturnus, $i d$. 216. nodicinctus, $A d$. 217. nubilus, Plizl. 218. nucleus, $i d$. 219. obscurus, Wood. 220. obtusus, Chemn. 221. ochroleucos, Gmel. 222. odontis, Wood. 223. olivaceus, Anton. 224. omplaalium, Phit. 225. ornatus, Lam. 226. pallidulus, Adanzs. 227. parvulus, Phil. 228. pellis-serpentis, $W_{\text {ood.274 }}$, rugulosus, Koch. 229. perdix, Koch. 230. perspectivus, $i d$. 231. Pfeifferi, Phil. 232. Phæbia, Bolt. 233. Philberti, Recl. 234. Philippii, Ad. 235. picturatus, $i d$. 236. pictus, $W_{\text {ood }}$. 237. piperinus, Phil. 238. pisum, $i d$. 239. planus, Gmel. 240. polychroma, $A d$. 241. porcatus, $i d$. 242. porcatus, Phil. 243. prasinus, Menke. 244. Preissianus, Pliil. 245. puichellus, $i d$. 246. pulcher, C. B. $A d$. 247. pulcherrimus, $A d$. 248. pulcherrimus, Wood. 249. pulligo, Mart. 250. pumilio, Phil. 253. puncturatus, $i d$. 255. purpuratus, $i d$. 256. pusillus, $A d$. 258. pyramis, Born. 259. pyrgos, Phil. 267. rigatus, Plil. 268. roseus, Gmel. 271. rudis, $i d$. 272. rufozona, $i d$. 273. rugosus, $i d$. 275. rusticus, Gmel. 276. saga, Pliil. 277. sagittifera, Lam. 280. sauciatus, Koch. 281. Saulii, D'Orb. 282. scaber, Linn. 284. scalaris, Anton. 285. Schayeri, Trosch. 286. scitulus, $A d$. 287. scobinatus, $i d$. 288. scorpio, Gray. 289. selectus, Chemn. 291. solaris, Chemn. 292. solidus, Phil. 293. sordidus, $i d$. 294. speciosus, $A d$. 295. spectabilis, $i d$.
251. punctatus, Anton.

297. spinosus, Chemn.

252. puncto-costatus, $A d$. 298. squamigerus, $A d a m s$. 299. squarrosus, Lam. 254. punctulatus, Mart. 300. squarrosus, Phil. 301. sticticus, $A d$. 302. striatus, Linn. 257. pustulosus, Phil. $\quad 303$, strigatus, $A d$. 304. strigosus, Gmel. 305. suavis, Pliil. 260. quadratus, Gmel. 306. subrostratus, Gray. 261. quadricarinatus, $G m l .307$. sulcatus, $W_{o o d}$. 262. quadricostatus, $W_{\text {ood.308. }}$ sulcosus, $A d$. 263. quadrisulcatus, Phil. 309. suturalis, $i d$. 264. radiatus, Gmel. 310. Swainsoni, id. 265. radula, Parreyss. $\quad 311$. tabularis, Krauss. 266. reticulatus, Wood. 312. treniatus, Quoy. 313. tenebrosus, $A d$. 314. tener, Trosch. $\begin{array}{ll}\text { 269. rubricatus, Plil. } & 315 . \text { tentorium, Gmel. } \\ \text { 270. rubropunctatus, } A d . & 316 . \text { tessellatus, } A d .\end{array}$ 317. tiaratus, Quoy. 318. Ticaonicus, $A d$. 319. tigrinus, Chemn. 320. tigris, Mart. 321. torquatus, Anton. 322. Tranquebaricus, $C h$. 323. tricingulatus, $A d$. 278. Sandwichensis, Eyd. 324. tridentatus, Pot. 279. sanguineus, Gray. 283. scabriculus, Busch. 290. semigranosus, $A d$. 296. Spengleri, Chemn.
325. tripidophorum, $A d$. 326. triserialis, Lam. 327. Troschelii, Plit. 328. tumidus, Mont. 329. turbinatus, Born. 330. turbiniformis, Salis. 331. turboides, Bolt. 332. turris, Phil. 333. umbilicalis, Da Costa. 334. umbilicaris, Linn. 335. undosus, $A d$. 336. undulosus, $i d$. 337. unicinctus, $i d$. 338. unidentatus, Plill. 339. ustus, $i d$.

340. variegatus, Anton. 341. variegatus, Risso. 342. varius, Linu. 
343. venustus, $A d$. 344. vernalis, Chemn. 345. verrucosus, Gmel. 346 . viridis, Chemn.
347. viridulus, Gmel. 348, viridulus, Menke. 349. zebra, Wood. 350. zebrides, $A d$.
351. zebrinus, Phil. 352. Zebuensis, Ad. 353. Zelandicus, $i d$.

\section{SPECIES OF MONODONTA.}

1. acuminata, $A d$.

2. agrestis, Chemn.

3. albina, $A d$.

4. alveolata, $i d$.

5. amœna, Koch.

6. angulata, $A d$.

7. anus, Phil.

8. asper, Chemn.

9. atro-purpurea, Gould. 10. Australis, Lam.

11. baccata, Menke.

12. Bertheloti, D'Orb.

13. brunnea, $A d$.

14. canalifera, Lam.

15. candida, Petit.

16. carinata, $A d$.

17. catenulata, Phil.

18. cerasina, $i d$.

19. cerodes, $A d$.

20. cingulifer, $i d$.

21. circulata, Anton.

22. circumcincta, $A d$.

23. clanguloides, $W_{o o d}$.

24. clangulus, $i d$.

25. clathrata, $A d$.

26. conspersa, $i d$.

27. coralina, Gmel.

28. dama, Phil.

29. denigrata, Chemn.

30. disculus, Plill.

31. Dunkeri, Koch.

32. duplicata, $A d$.

33. edentula, $i d$.

34. elegans, Kock:

35. erubescens, Plitl.

36. exasperata, $A d$.
37. exigua, $A d$.

38. flagellata, Plitl.

39. foveolata, $A d$.

40. geminata, Gould.

41. gibbosa, $A d$.

42. glomus, Pliil.

43. Guineensis, Gmel.

44. Guttadauri, Plil.

4.5. horrida, $i d$.

46. incisa, Menke.

47. inconspicua, Phil.

48. Jussieui, Payr.

49. Kraussii, Phil.

50. labio, Limn.

51. lactea, Phil.

52. Largillierti, $i d$.

53. lenticularis, Chemn.

54. limbata, Quoy.

55. Judwigi, Krauss.

56. lupina, Menke.

57. maculosa, $A d$.

58. Maugeri, Wood.

59. margaritaria, Phil.

60. Mediterranea, Wood.

61. microdon, $A d$.

62. miniata, Anton.

63. minor, $A d$.

64. morum, Phil.

65. multigrana, $i d$.

66. Neritoides, $i d$.

67. nigricans, $A d$.

68. nodolirata, $i d$.

69. norlulosa, $i d$.

70. obliqunta, $i d$.

71. omalomphala, $i d$.
72. ormoplora, Ad.

73. oxytropis, Plil.

74. parva, Trosch.

75. Patagonica, $D^{\prime} O{ }^{\prime} l$.

76. personata, Plizl.

77. Pharaonia, Limn.

78. Philippina, $A d$.

79. Philippii, Koch.

80. pullata, Phil.

81. punctigera, Ad.

82. punicea, Phil.

83. ringens, Mente.

84. Rotellæformis, Phil.

85. ruba, $A d$.

86. rugulosa, $i d$.

87. scabrosa, Phil.

88. Smithii, Wood.

89. spadicen, Phil.

90. spilota, $A d$.

91. stigmataria, $i d$.

92. Strangei, $i d$.

93. sulcaria, $i d$.

94. sulcifera, $i d$.

95. tectum, Gmel.

96. textilosa, $A d$.

97. tuberculata, $i d$.

98. tricingulata, $i d$.

99. turbinata, Gmel.

100. turbinoides, $A d$.

101. turgidula, Brocc.

102. unedo, $A d$.

103. unidens, Lister.

104. variegata, $A d$.

105. virides, Lam.

106. zebrides, $A l$. 
GENERA FIGURED IN THE PLATES, BUT NOT DESCRIBED IN THE TEXT.

\section{Genus SEPARATISTA, Gray.}

Animal ; unknown.

Shell; turbinate, subdiscoidal, the first whorls contignous, the last more or less separated; aperture expanded, stightly angulated; the margin everted, umbiticus very wide, infundibuliform, with the whorls visible as far as the apex.

This slightly convoluted shell represents a genus of which four species have been described. The animal is not known, and the place to which it has been assigned in the system,-near to Leptoconchus, among the Purpura tribe, - - seems hardly natural.

\section{Species.}

1. Blainvilleana, Petit.

3. Grayi, Adams.

4. laxa, Say.

2. Chemnitzii, Adams.

\section{Figure.}

Sefaratista Cineminitzit. Pl. 19. Fig. 102. Shell, showing its loosely convoluted mode of growth.

\section{Genus PEDICULARIA, Swainson.}

Animal ; undescribed.

Shell; ovate-oblong, surface irregular, radiately ribbed in the young state; spire minute; apex lateral, inclined towards the left side; aperture very wide, channelled in front.

A small, pink, Limpet-like shell, living attached parasitically on Mediterranean corals like the Purpura Madreporarum, to which it is probably allied. The shell is radiately ribbed in a young state, but in the adult the ribs become more or less obsolete. The animal is imperfectly known. Mr. Adams describes having seen a specimen in which he detected eyes at the outer bases of the tentacles, and he observed that the mantle-margin 
was thickened, and that there was no operculum. The following is the only species.

\section{Figure.}

Pedicularia Sicula. Pl. 22. Fig. 128. Shell, showing its mode of attachment on a branch of coral.

\section{Genus FOSSARUS, Phitippi.}

Animal; furnished with two frontal lobes between the tentacles; operculum ovate, subspiral.

Shell; semiglobose, whorls ribbed or cancellated, axis perforate; aperture semirotundate, entire, outer lip acute.

The small Purpura-like shell represented at Fig. 23, a native of the coast of Senegal, was described originally by Adanson, the contemporary of Linnæus, with the name Le Fossar. Dr. Philippi, perceiving its peculiarities, founded a genus upon it, Fossurus, identified with Adanson's name. Two other species have been described from the Mediterranean, and eleven have been added from the Eastern Seas and from South America.

Species.

1. abjectus, C.B. Ad.

2. ambiguus, Linn.

3. angiostoma, C.B. Ad.

4. bicarinatus, Adams.

5. clathratus, $P$ hit.
6. costatus, Bocc.

7. Cumingii, Adams.

8. excavatus, C. B. Ad. 13. trochlearis, $i d$.

9. foveatus, $i d$.

10. megastoma, $i d$.
11. pusillus, Gould.

12. reticulatus, Adams.

14. variegatus, $i d$.

Figure.

Fossarus claturatus. Pl. 5. Fig. 23. Shell, showing its Purpura-like form.

\section{Genus NEMATURA, Benson.}

Animal; undescribed.

Shell; oval, compressed, apex of spire rather acuminate; whorls 
few, the last large and ventricose; aperture nearly orbicular, small, oblique, contracted; lip continuous, entire.

Nematura is a genus of small freshwater shells, of which the animal has not been described, inhabiting the margins of ponds in India and in the islands of the Eastern Archipelago. They attach themselves mostly to the under surface of floating leaves. The shell has an unusually small aperture, of which the margin is continuous.

\section{Species.}

1. coarctata, Lea. 4. minima, Bens. 7. puncticulata, $A d$.

2. Deltæ, Bens. 5. olivacea, Adams. 8. ventricosa, Quoy.

3. glabrata, Adams. 6. polita, Cantor.

Figure.

Nevatura Delt.e. Pl. 20. Fig. 108. Shell, showing its small rounded aperture.

\section{Genus ASSIMINEA, Leach.}

Animal; with short obtuse tentacles, the eyes being placed near their ends.

Shell; ovately conical, with the spire more or less produced; whorls convex, scarcely umbilicated; aperture ovate; lip simple.

A small amphibious mollusk, inhabiting brackish water on the Kentish shores of the Thames, a little resembling Paludina. The genus is also found in India, China, Australia, and the Pacific Isies.

\section{Species.}
1. Francesia, Benson.
2. Grayana, Leach.

Figure.

Assiminea Oparensis. Pl. 18. Fig. 96. Shell, of a new species from the Island of Opara, showing its Paludina-like form. 


\title{
INDEX TO PLATES OF ANIMALS.
}

\author{
VOL. II.
}

\begin{tabular}{|c|c|c|c|c|}
\hline Plate & & Page & Plate & \\
\hline & 1. Fissurella maxima & 26 & P. 4. Anadonta cygnea...... & \\
\hline & 2. Fissurella megatrema .. & $i b$. & 5. Galeomma Turtoni .... & 1 \\
\hline & 3. Sigaretus concavus .. vol. $i$. & 165 & 6. Cardium echinatum.... & \\
\hline & 4. Haliotis tuberculata.... & 13 & 7. Lingula anatina & \\
\hline$K$. & Carinaria fragilis & 43 & 8. Crania anomala & \\
\hline$L$. & Dolabella Rumphii .... & 6 & 9. Crania anomala & \\
\hline$M I$. & 1. Aply & 4 & 10. Orbicula lævis .... & 18 \\
\hline & Australis. . & 28 & Q. 1. Psammobia Tellinella .. & \\
\hline & $\ldots \ldots \ldots$ & 3 & spidata ..... & \\
\hline$N$. & flata........ & 61 & 3. Corbula nucleus ..... & 1 \\
\hline & mosa .... & 75 & 4. Solecurtus coarctatus .. & \\
\hline & loideum. . & 61 & 5. $\mathrm{M}_{\mathrm{y}}$ & \\
\hline$O$. & Panopæa Aldrovandi .. & 160 & 6. Solen marginatus ..... & \\
\hline$P$. & a caput-serpentis & 183 & 7. Lucina borealis .... & \\
\hline & $\begin{array}{l}\text { ra...... } \\
\text { sittacea. }\end{array}$ & $\begin{array}{r}184 \\
i b .\end{array}$ & stultorum..... & \\
\hline
\end{tabular}





\title{
INDEX 'TO PLATES OF SHELLS.
}

\author{
VOL. II.
}

\begin{tabular}{|c|c|c|c|}
\hline & 1 & & \\
\hline 3. Bulla albocincta & 3 & 152. Crania anomala & \\
\hline ta....... & 17 & 153. T & \\
\hline notis..... & 14 & $a \ldots \ldots$. & \\
\hline - Uml & 3 & 5. $\mathrm{Li}$ & \\
\hline Dolabella Rumphii ...... & 6 & 156. An & \\
\hline icula & & 157. P & \\
\hline is membrana- & & 158. & \\
\hline & 7 & $159 . \mathrm{C}$ & \\
\hline$s \ldots$. & 9 & is $\ldots .$. & \\
\hline$\ldots \ldots$ & 13 & narum .. & \\
\hline ta $\ldots$ & 28 & 162. 1 & \\
\hline na.. & $i b$. & 163. I & \\
\hline sum .... & 21 & yloideum .. & \\
\hline$\ldots \ldots \ldots$ & 23 & $\ldots \ldots \ldots$ & \\
\hline$a \ldots$. & 10 & 166. & \\
\hline s... vol. i. & & $\ldots \ldots$ & \\
\hline 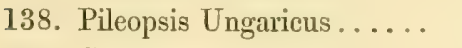 & 18 & 168. 1 & \\
\hline 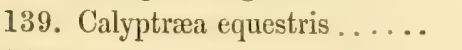 & 20 & 169. C & \\
\hline ( & 35 & $\begin{array}{l}170 . \mathrm{P} \\
171 . \mathrm{N}\end{array}$ & \\
\hline . & 31 & 172. 1 & \\
\hline 1a $\ldots .$. & 26. & 173. 1 & \\
\hline$\ldots \ldots \ldots$ & 29 & $174 . \mathrm{C}$ & \\
\hline ii ..... & 26 & 175. $\mathrm{E}$ & \\
\hline$\cdots \cdot$ & 34 & 176. & \\
\hline$\cdots \cdots$ & 38 & 177. $\mathrm{T}$ & \\
\hline inum .. & 41 & 178. & \\
\hline is $\ldots$. & 39 & 179. Нy & \\
\hline anulatus .. & 20 & 180. An & \\
\hline & & & \\
\hline
\end{tabular}




\begin{tabular}{|c|c|c|c|}
\hline & Page & Fig. & \\
\hline 82. Mycetopus Solenif & 90 & 216. Amphidesma obliqua & \\
\hline 183. Unio tuberculatus & 86 & 217. Ungulina transversa.... & 140 \\
\hline 34. Iridina ovata & 89 & 218. Gnathodon cuneatus.... & 142 \\
\hline 185. Pectunculus aurifluus $\ldots$ & 95 & 219. Lutraria arcuata & 146 \\
\hline 6. Astarte sulcata. & 114 & 220. Mactra plicataria & 145 \\
\hline 187. Cucullæa concamerata .... & 94 & 221. Neæra rostrata........ & 155 \\
\hline 88. Arca Brasiliana & 93 & 222. Lyonsia striata. . & 151 \\
\hline 189. Cytherea lupinaria & 109 & 223. Pandora rostrata & 150 \\
\hline 90. Cyprina Islandica..... . . . & 114 & 224. Chamostrea albida & 147 \\
\hline 191. Cardita latic & 101 & a Sibbaldii...... & 152 \\
\hline 192. Cypricardia Guinaica .... & 99 & 226. My & 149 \\
\hline 193. Tap & 107 & mnioides. . . . & 148 \\
\hline iaticum ...... & 103 & a subrostrata ...... & 152 \\
\hline 195. Ve & 111 & 229. MI & 158 \\
\hline garis. . . . . . & 105 & 230. Thrac & 154 \\
\hline xa ...... & 115 & sii ....... & 97 \\
\hline 198. Cyr & 117 & adida. . . . . . & 162 \\
\hline 199. Cy & 118 & e-Zelandia & 140 \\
\hline 00. Gale & 129 & 234. Gly & 161 \\
\hline 1. Co & 124 & 235. Sol & 163 \\
\hline 202. Iph & 121 & 236. Sol & 167 \\
\hline 203. Do & 120 & igillatus . . . & 166 \\
\hline 204. Luc & 123 & rugosa...... & 164 \\
\hline uppelliana. . & 130 & 239. Corl & 157 \\
\hline espertina .... & 129 & aæna ovata ...... & 175 \\
\hline 207. Caps & 131 & globosa.......... & 171 \\
\hline$\ldots \ldots \ldots$ & 126 & 242. Clavagella aperta....... & 176 \\
\hline Tellinoides.. & 133 & 243. Pholas orientalis .. & 171 \\
\hline 210. Lucinopsis undata & 112 & 244. Hyalæa tridentata .... & 4.4 \\
\hline 1. Capsa deflorata & 130 & 245. Cleodora cuspidata & $i b$. \\
\hline 212. Petricola Pholadiformis & 135 & 246. Gastrochæena mumia..... & 175 \\
\hline 213. Cumingia mutica & 137 & 247. Aspergillum vaginiferum .. & $17 !$ \\
\hline 214. Saxicava Aretica ....... & 136 & 248. Teredo marina & 174 \\
\hline 15. $\mathrm{Cr}$ & $1+1$ & & \\
\hline
\end{tabular}




\section{INDEX TO VOL. II.}

\begin{tabular}{|c|c|c|c|c|c|}
\hline & Page & & Page & & age \\
\hline Acanthocardia.... & 101 & Capulacea & 17 & Crucibulum..... . & 21 \\
\hline Adacna ....... & 102 & Cardiacea & 98 & Ctenocardium & 102 \\
\hline Acinæa $\ldots . .$. & 30 & Cardita ....... & 99 & Cucullæa ........ & 94 \\
\hline Amphidesma .... & 138 & Cardium....... 1 & 101 & Cultellus... & 165 \\
\hline Amusium........ & 56 & Carinaria ..... & 42 & Cumingia........ & 137 \\
\hline Anatina & 151 & Cemoria........ & 27 & Cuvieria ........ & 44 \\
\hline Anatinella ...... & 151 & Ceratisolen...... I & 165 & Cyclas ......... & 117 \\
\hline Anodonta....... & 87 & Cerostoderma .... 1 & 101 & Cyclobranchiata .. & 31 \\
\hline Anomia ....... & 47 & Cervicobranchiata . & 8 & Cypricardia ...... & 98 \\
\hline Aplysiana........ & 3 & Chama ....... & 77 & Cyprina ....... & 114 \\
\hline Aplysia ....... & 4 & Chamacea ...... & 76 & a........ & 115 \\
\hline Arca $\ldots . . .$. & 92 & Chamostrea $\ldots 1$ & 146 & Cytheræa........ & 107 \\
\hline Argiope ....... & 183 & Chiton ....... & 35 & Dactylina....... & 170 \\
\hline Artemis ....... & 111 & Chitonacea ...... & 35 & Dentalium ..... & 40 \\
\hline Arytene ....... & 179 & Chitonellus...... & 38 & Didacna ....... & 102 \\
\hline Aspergillum..... . & 177 & Cirrhobranchiata . & 40 & Diplodonta ...... & 122 \\
\hline Astarte & 113 & Circe ........ 1 & 107 & Dolabella........ & 5 \\
\hline Atlanta ...... & 44 & Clavagella ...... 1 & 175 & Donax ......... & 119 \\
\hline Avicula $\ldots \ldots$.... & 62 & Cleidotharus .... 1 & 146 & Dreissena....... & 70 \\
\hline Aviculacea ..... & 62 & Cleodora. ....... & 44 & Emarginula...... & 26 \\
\hline Azara ............ & 156 & Clepsidra ..... 1 & 179 & Etheria ....... & 78 \\
\hline Barnea......... & 170 & Cochlodesma .... 1 & 151 & Fissuracea ..... & 23 \\
\hline Bimusculosa .... & 76 & Codativa ....... 1 & 122 & Fissurella....... & 24 \\
\hline Bouchardia...... & 183 & Corcum $\ldots \ldots \ldots$ & 41 & Fissurellidea .... & 24 \\
\hline Brachiopoda .... & 180 & Conchacea ...... 1 & 105 & Fistulana....... & 173 \\
\hline Bucardium ..... & 101 & Corbis & 123 & Foegia.......... & 179 \\
\hline Bulla ......... & 1 & Corbula ...... 1 & 155 & Fragum $\ldots \ldots \ldots$ & 102 \\
\hline Bullacea ........ & 1 & Crania & 185 & Fulvia ........ & 101 \\
\hline Byssoarca ..... & 92 & Crassatella...... 1 & 141 & Gadinia $\ldots . .$. & 31 \\
\hline Calyptræa $\ldots . .$. & 19 & Crenatula & 67 & Galathea ...... & 114 \\
\hline Capsa & 121 & Crenella....... & 72 & Galeomma ... & 126 \\
\hline Capsa & 130 & Crepidula . . . . . & 22 & Gastrochæna .... & 174 \\
\hline $\begin{array}{c}\text { Capsella } \\
\text { vor. }\end{array}$ & 130 & Creseis $\ldots \ldots$. & 44 & Glauconome ... & 163 \\
\hline
\end{tabular}




\begin{tabular}{|c|c|c|c|c|c|}
\hline & Page & & Page & & Page \\
\hline Glycimeris ..... & 160 & Modiolarca...... & 72 & Pharella... & 165 \\
\hline Gnathodon ...... & 142 & Monodacna...... & 102 & Pliarus & 165 \\
\hline Gryplicen........ & 51 & Mouretia & 31 & Pholadaria & 167 \\
\hline Haliotis & 11 & Morrisia........ & 183 & Pholadidea ...... & 170 \\
\hline Hemicardium ... & 102 & Mya .......... & 157 & Pholadomya...... & 161 \\
\hline Iemipecten...... & 58 & Myaria & $1+6$ & Pholas.......... & 168 \\
\hline Hiatella ........ & 136 & Mycetopus...... & 90 & Pileopsis . . . . . . . & 17 \\
\hline Hinnites ....... & 55 & Myochama...... & 147 & Pilidium ........ & 30 \\
\hline Hipponyx ..... & 18 & Myodora. . . . . . . & $1+8$ & Pinna ... & 68 \\
\hline Hiррориs. . . . . . . & 76 & Myrtea & 122 & Pisidium. & 117 \\
\hline Humphreyia...... & 179 & Mytilacea ..... & 67 & Placuna & 49 \\
\hline Hyalæa ....... & 44 & Mytilicardia .... & 100 & Placunanomia ... . & 48 \\
\hline$\ldots \ldots \ldots$ & 86 & Mytilus ........ & 69 & Pleiodon ........ & 89 \\
\hline Iphigenia. ...... & 120 & Naiade's & 79 & Pleurobranchiata .. & 1 \\
\hline Iridina . . . . . . . & 89 & Narica & 15 & Pleurobranchus .. & 6 \\
\hline Isocardia ........ & 103 & Nerera & $15+$ & Plicatula ....... & 54 \\
\hline Jouannetia ..... & 170 & Neritopsis . . . . . & 14 & Potamomya..... & 156 \\
\hline Kraussia .. & 183 & Novaculina...... & 165 & Propilidium...... & 30) \\
\hline Lavicardium & 101 & Nucula & 95 & Psammobia ...... & 128 \\
\hline Lamellaria ...... & 16 & Nucleobranchiata . & 42 & Psammotella .... & 129 \\
\hline Lamellibranchiata. . & 44 & Nymphacea..... . & 118 & Pteropoda ...... & 43 \\
\hline Teda & 96 & Orbicula....... & 156 & Pullastra....... & 106 \\
\hline Lima & 59 & Osteodesma...... & 150 & Resania & 145 \\
\hline Lingula . . . . . . & 157 & Ostracen....... & 46 & Rimula & 27 \\
\hline Lithodomus. . . . . & 73 & Ostrea & 50 & Rupicola ....... & 153 \\
\hline Lithophaga ...... & 133 & Otina.......... & 16 & Rynchonella...... & 184 \\
\hline Loripes ....... & 122 & Palliobranchiata.. & 180 & Sanguinolaria .... . & 132 \\
\hline Lottia & 30 & Pandora......... & 149 & Saxicava ......... & 135 \\
\hline Lucina. & 121 & Panopra........ & $15 \mathrm{~S}$ & Semiphyllidiana .. & 6 \\
\hline Lucinopsis .... . & 112 & Parapholas...... & 170 & Scutella ....... & 34 \\
\hline Lumulicardia .... & 102 & Papyridea & 101 & Septaria ....... & 173 \\
\hline Lutraria . . . . . . & 145 & Parmophorus .... & 28 & Septifer $\ldots \ldots$ & 70 \\
\hline Lyonsia & 150 & Patella & 32 & Serripes & 101 \\
\hline Macrochisma .... & 25 & Patellacea ...... & 32 & Siliqua......... & 165 \\
\hline Macrostomata .... & 10 & Patelloidea...... & 30 & Siliquaria....... & 10 \\
\hline Mactra. ........ & 142 & Patina ....... & 33 & Siphonaria . . . . & 29 \\
\hline Mactracea ...... & 136 & Pecten & 55 & Solecurtus ... & 164 \\
\hline Mingas ......... & 183 & Pectinacea ...... & 52 & Solemya & 162 \\
\hline Malleus & 6.5 & Pectunculus. & $9 \dot{4}$ & Solen .. & 166 \\
\hline Martesia ........ & 170 & Pedum .. & 61 & Solenacea.... & 162 \\
\hline Meleagrina ...... & 62 & Penicillns & 179 & Solenella .... & 97 \\
\hline Mergerlia....... & 153 & Perma.......... & 66 & Soletellina .. & 131 \\
\hline Mesodesma ...... & $1+0$ & Periploma ..... & 151 & Spondylus ... & 52 \\
\hline Miltha & 122 & Petricola.... & $13+$ & Stomatella ..... & 13 \\
\hline Modiola ........ & 71 & Pliacoides & 122 & Stomatia. & 13 \\
\hline
\end{tabular}


INDEX.

\begin{tabular}{|c|c|c|c|c|c|}
\hline & Page & & Page & & Page \\
\hline Strigella .. & 122 & Tridacnacea & 74 & Vanikoro... & 15 \\
\hline Talona......... & 170 & Trigonacea... . & 90 & Velutina & \\
\hline Tapes & 105 & Trigonia....... & 90 & Venerupis .... & 133 \\
\hline Tectura & 30 & Triodonta & 122 & Venus & 10 ? \\
\hline Tellina. . & 124 & Trochita.... & 22 & Vermetus.. & \\
\hline Terebratella.. & 182 & Tubicola.... & 171 & Vola & \\
\hline Terebratula . & 181 & Tubispiracea & 8 & Vulsella & \\
\hline Terebratulina & 182 & Tugonia....... & 157 & IValdheimia...... & 18 \\
\hline Teredo. & 172 & Umbrella & 7 & Warnea & 17 \\
\hline Thecidium & 183 & Ungulina & 139 & Xylophaga & 1 \\
\hline Thracia & 152 & Unimusculosa... & 46 & Yoldia. & \\
\hline Trachycardium... & 101 & Unio ....... & 79 & Zivphrea & 17 \\
\hline Tridacna & 74 & Uperotis...... & 173 & Zenatia & \\
\hline
\end{tabular}

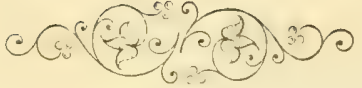






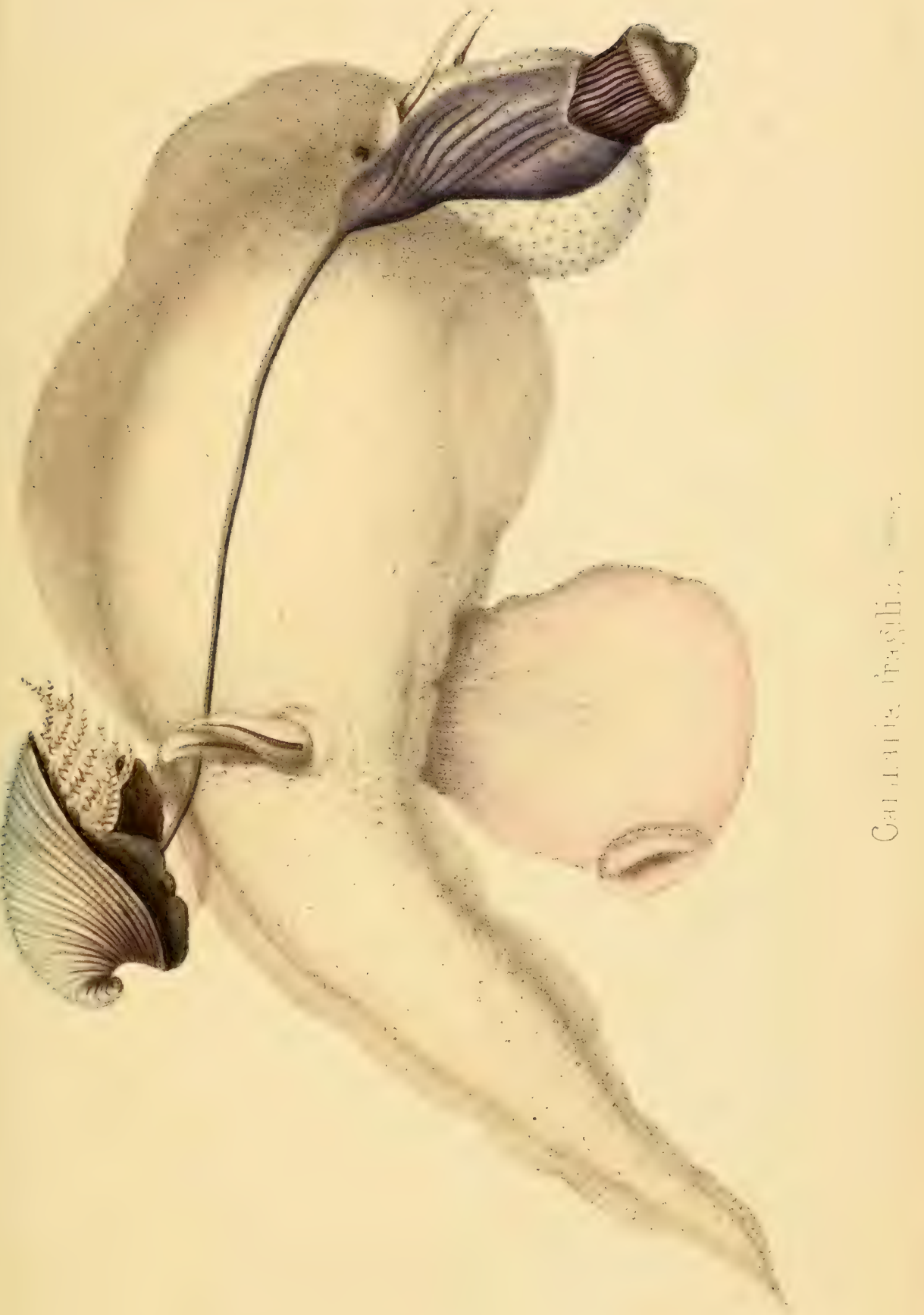





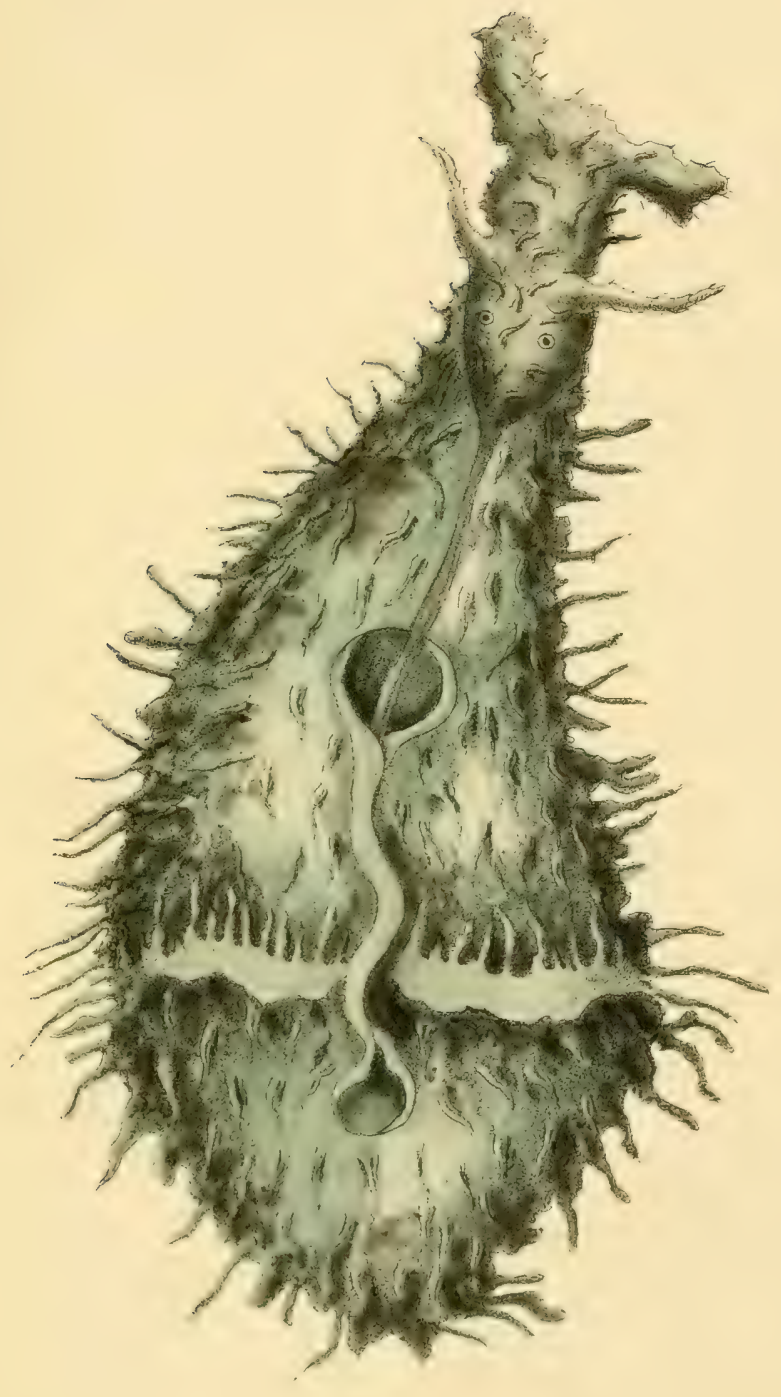






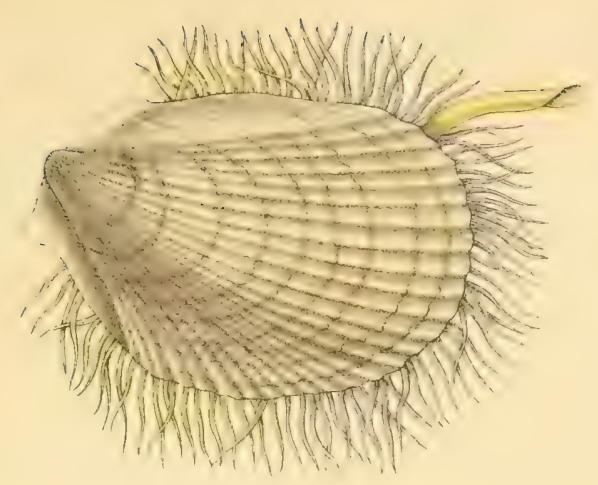

Iima intlía, Lamench.

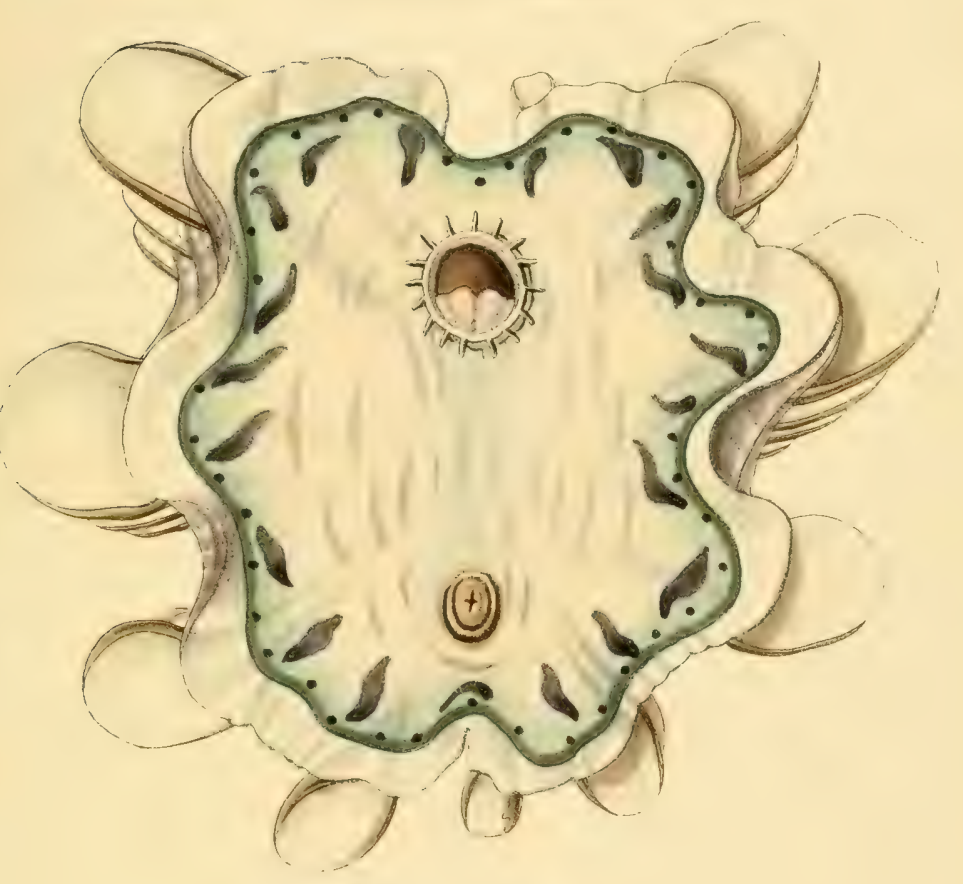

Tridacna squamosa, Lamarck

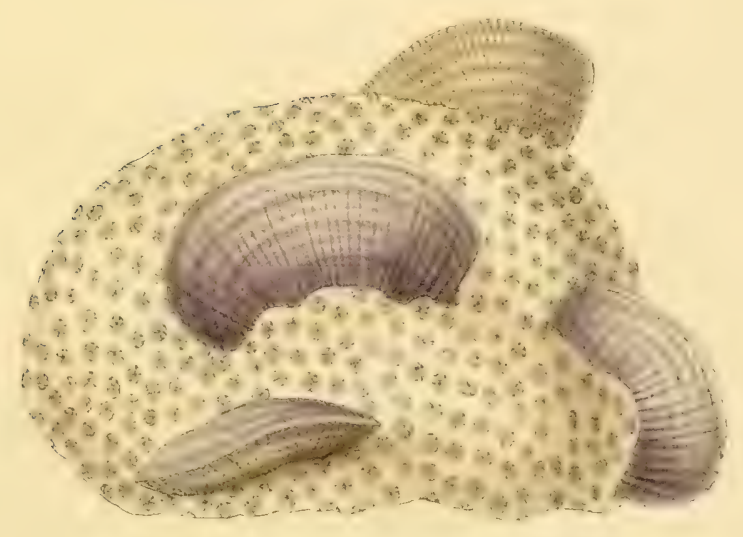





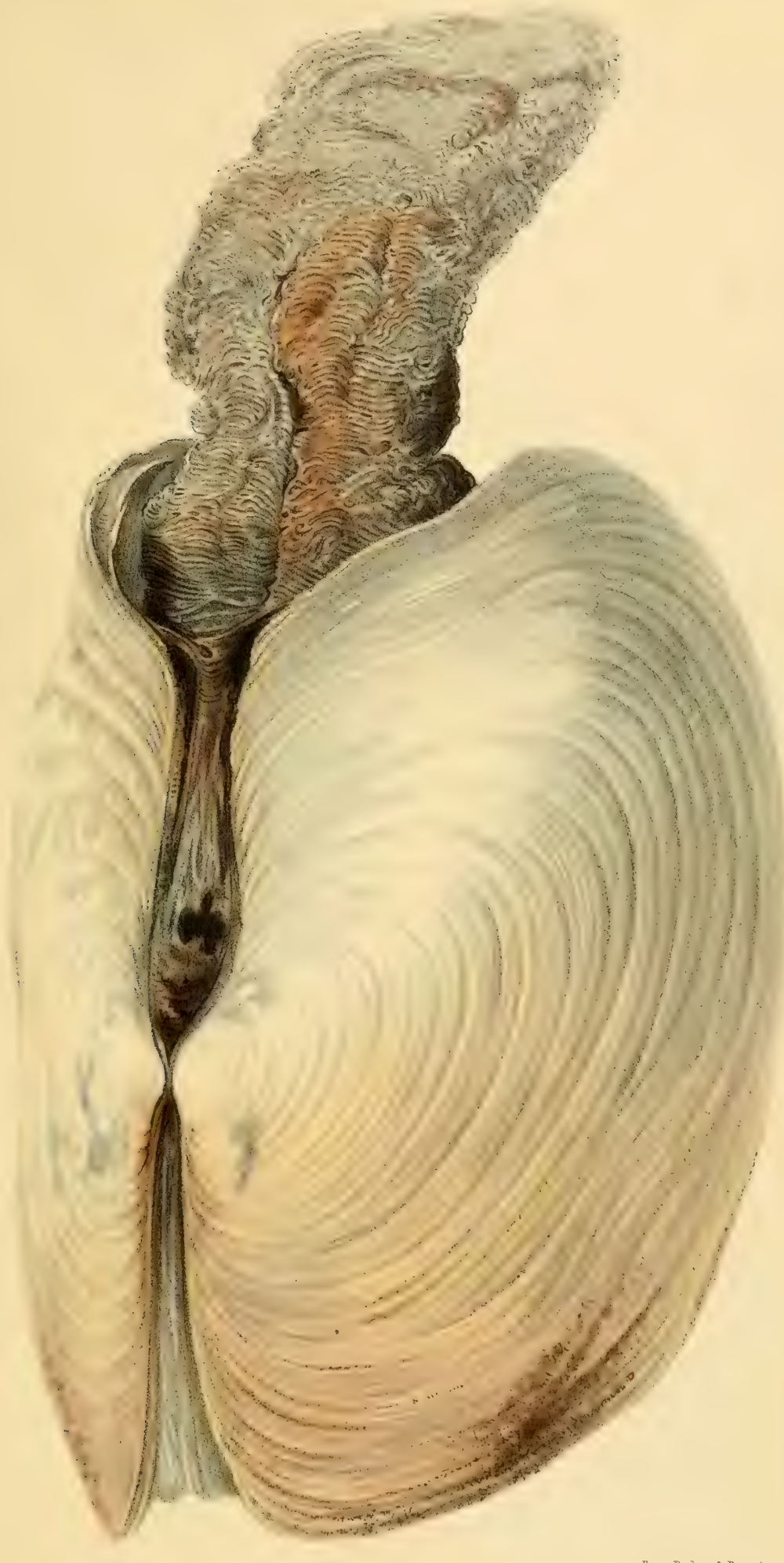

Heeve, Benha $m$ \& Reere, imp

Panopæa Aldrovandi, Iamark. 



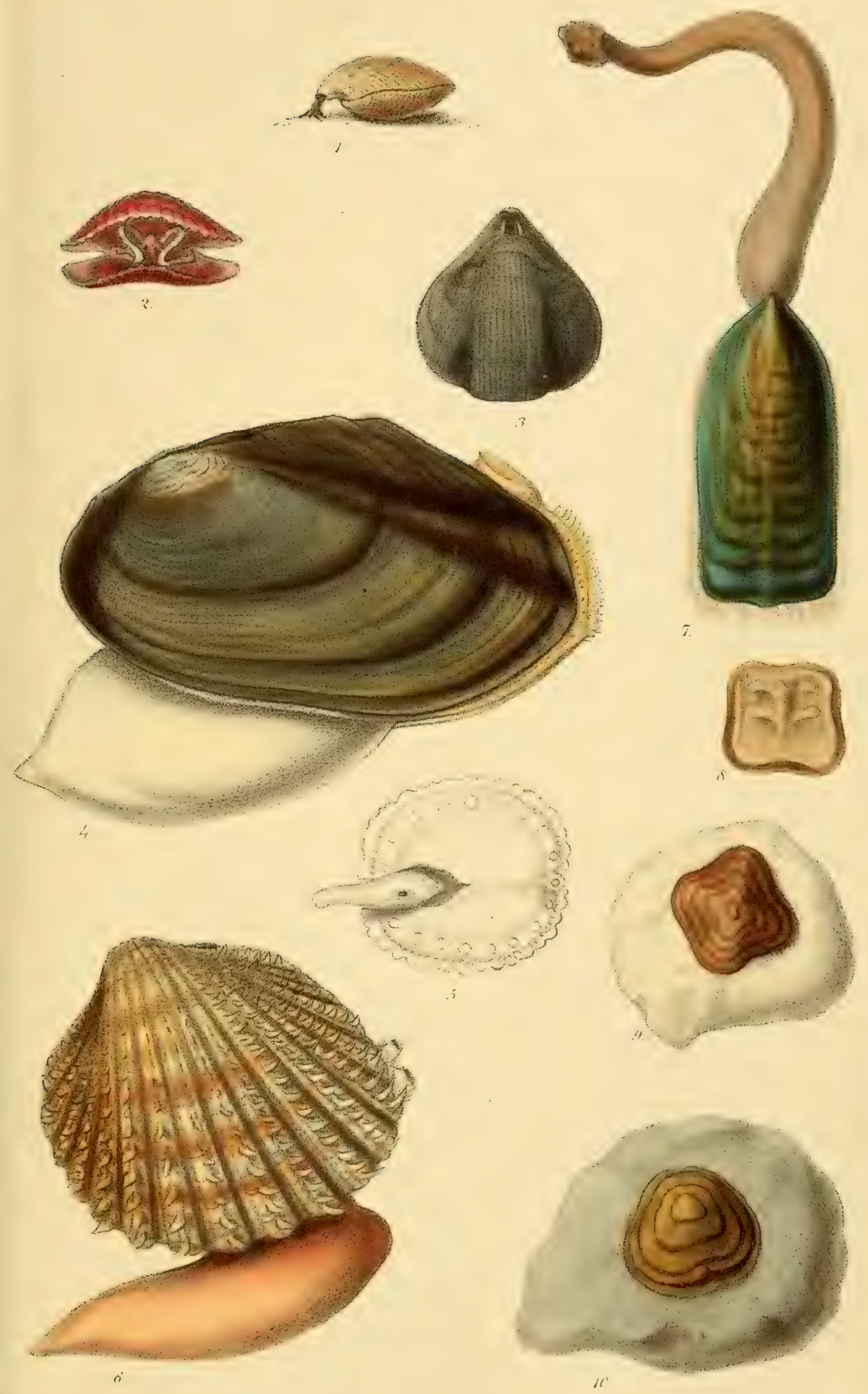




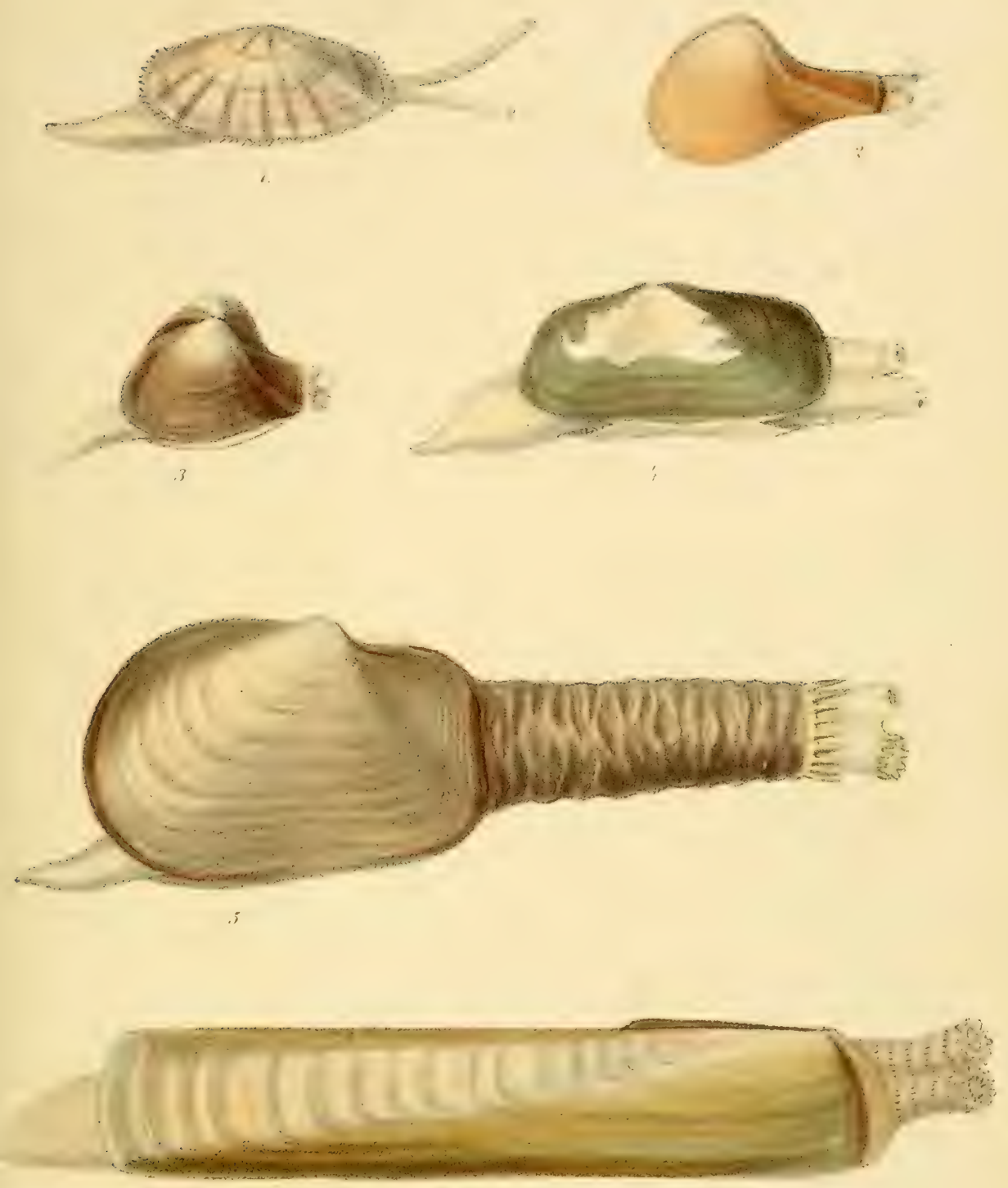

i
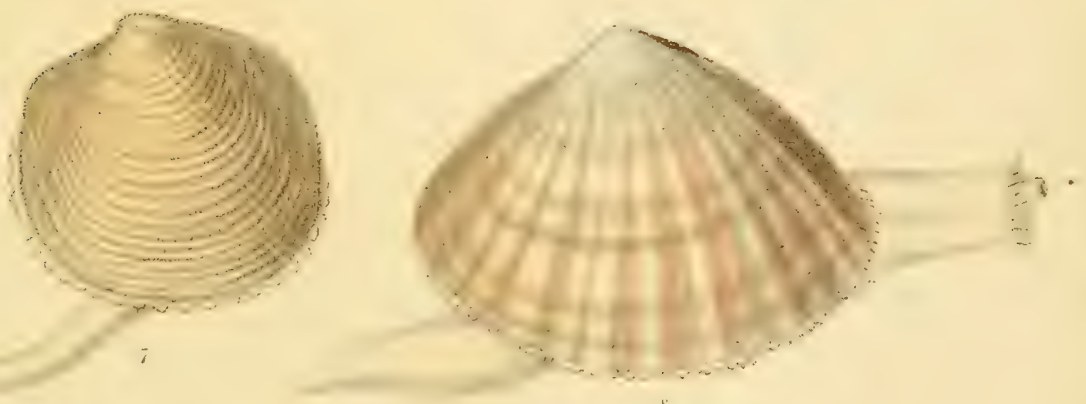


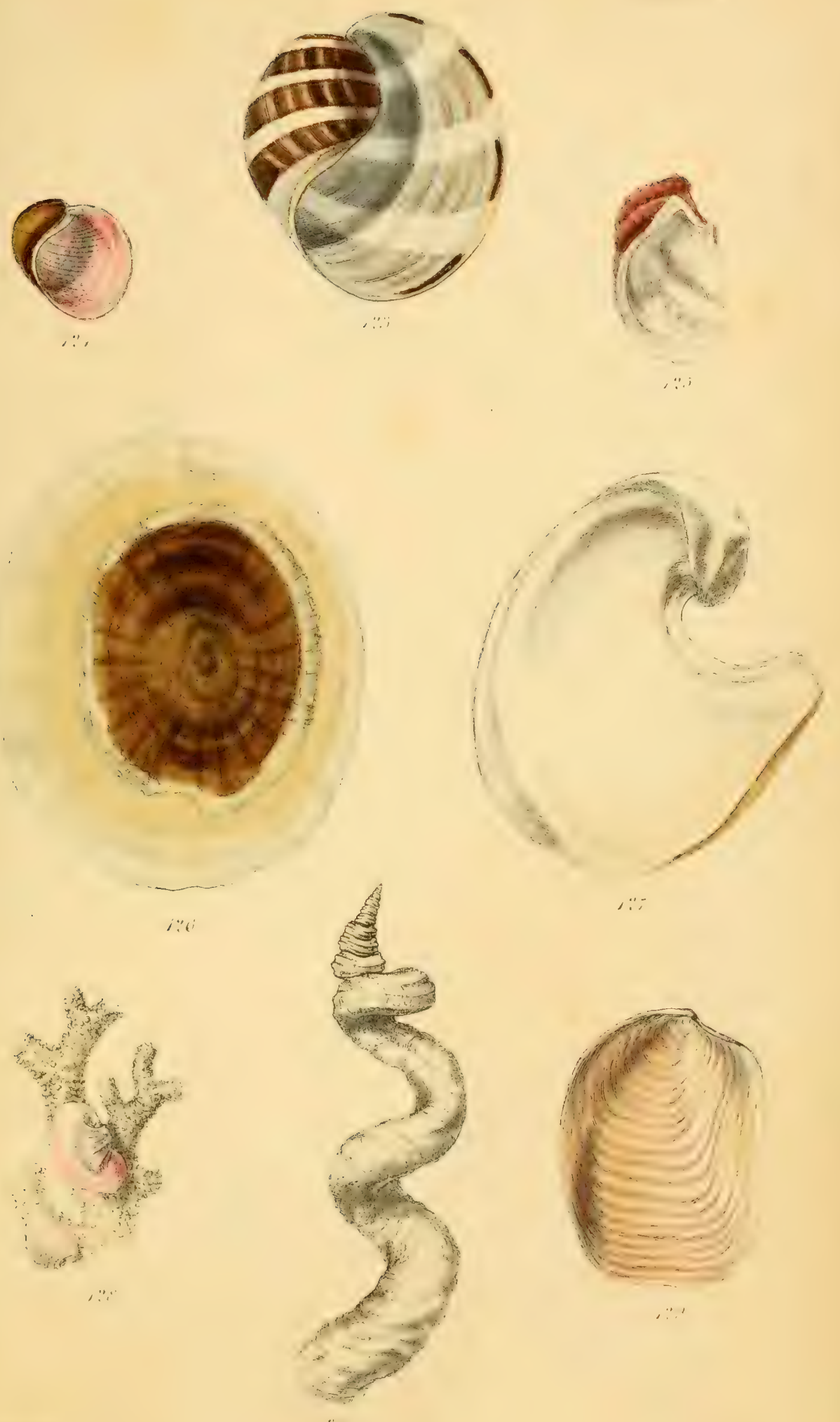


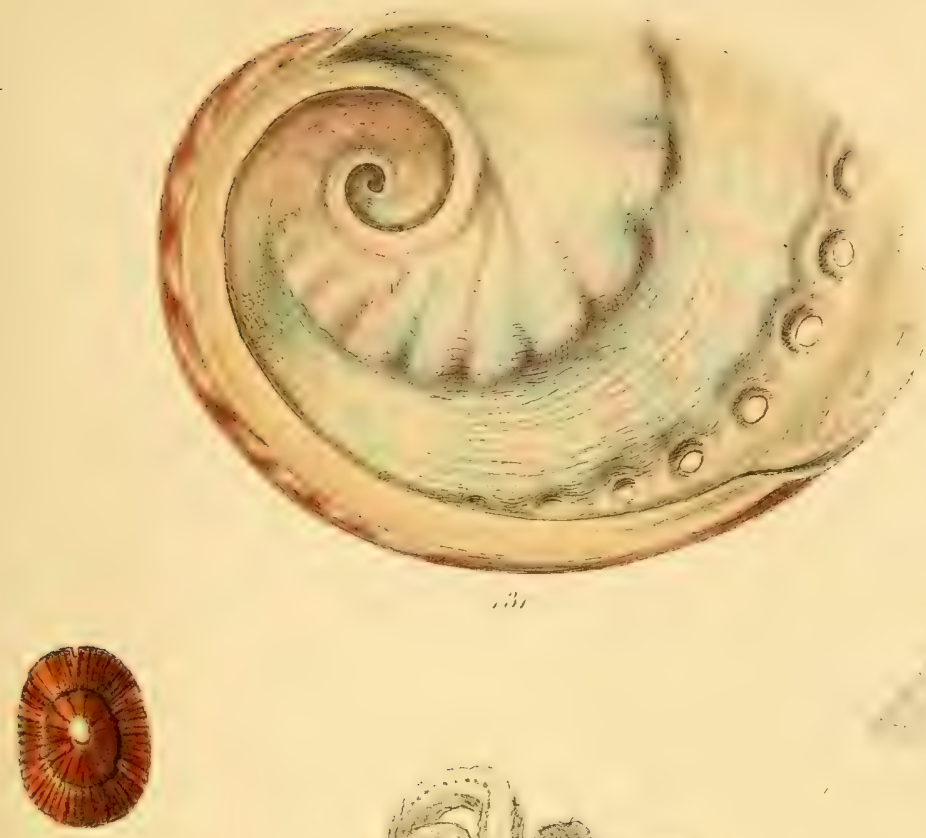

..".
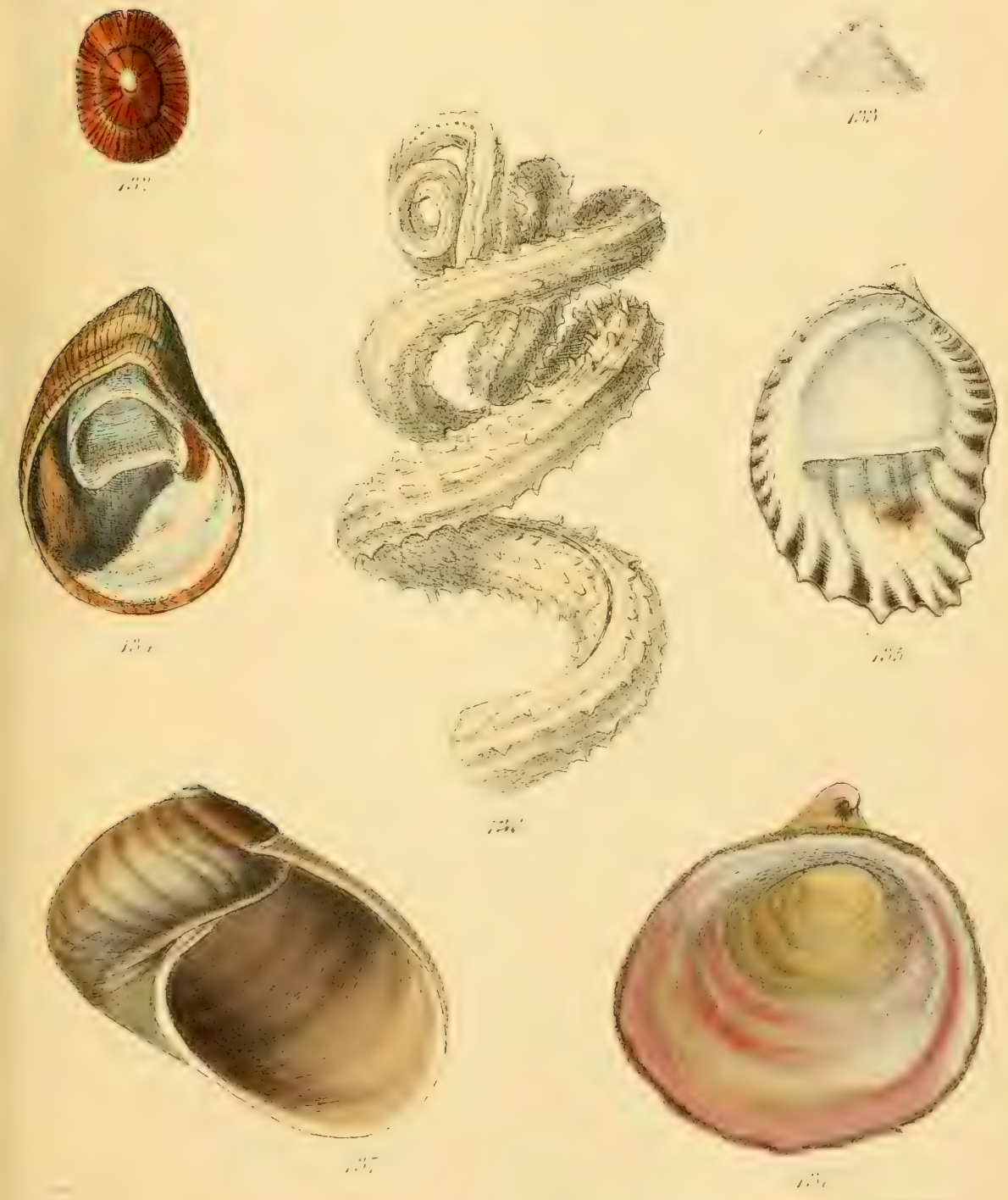


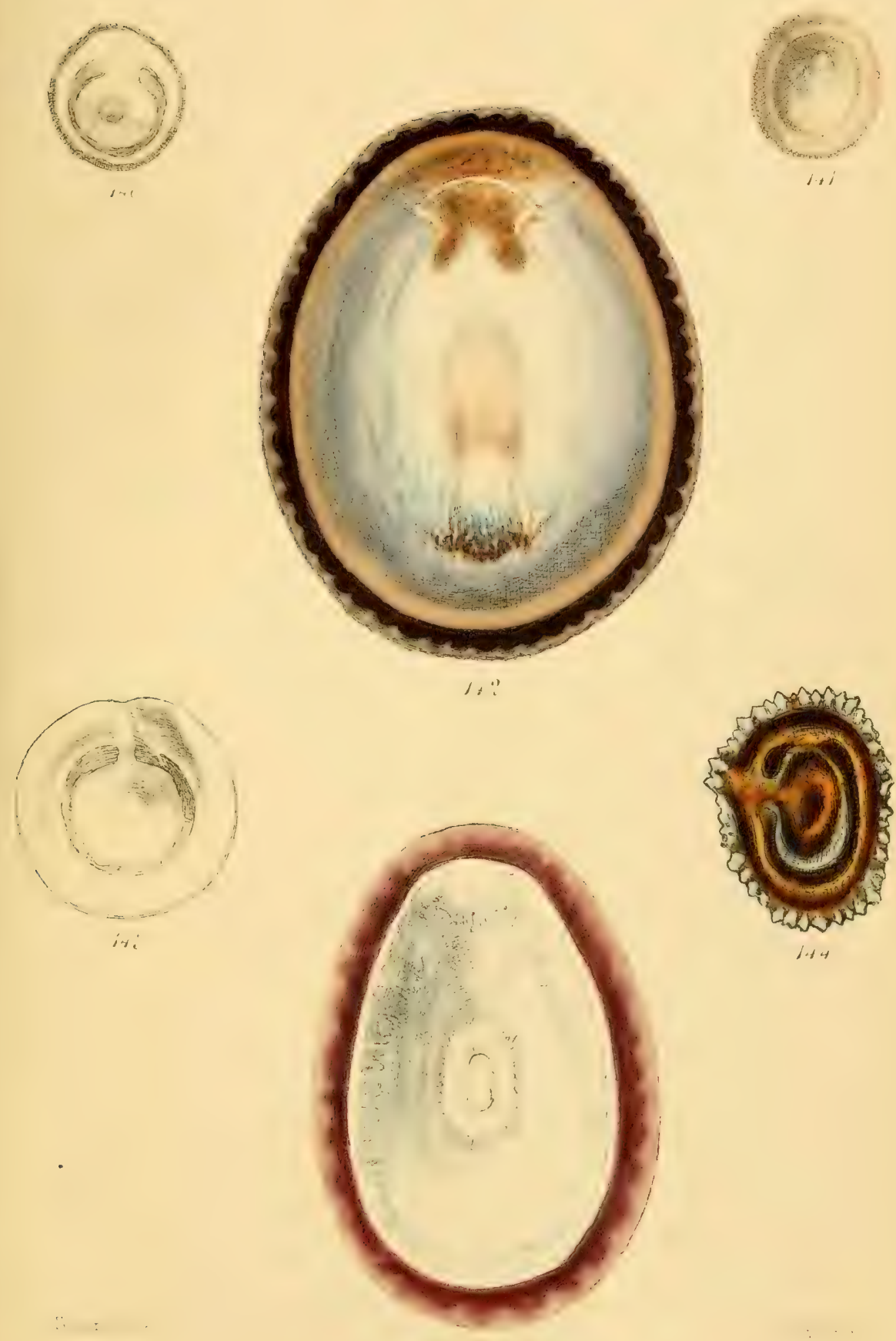



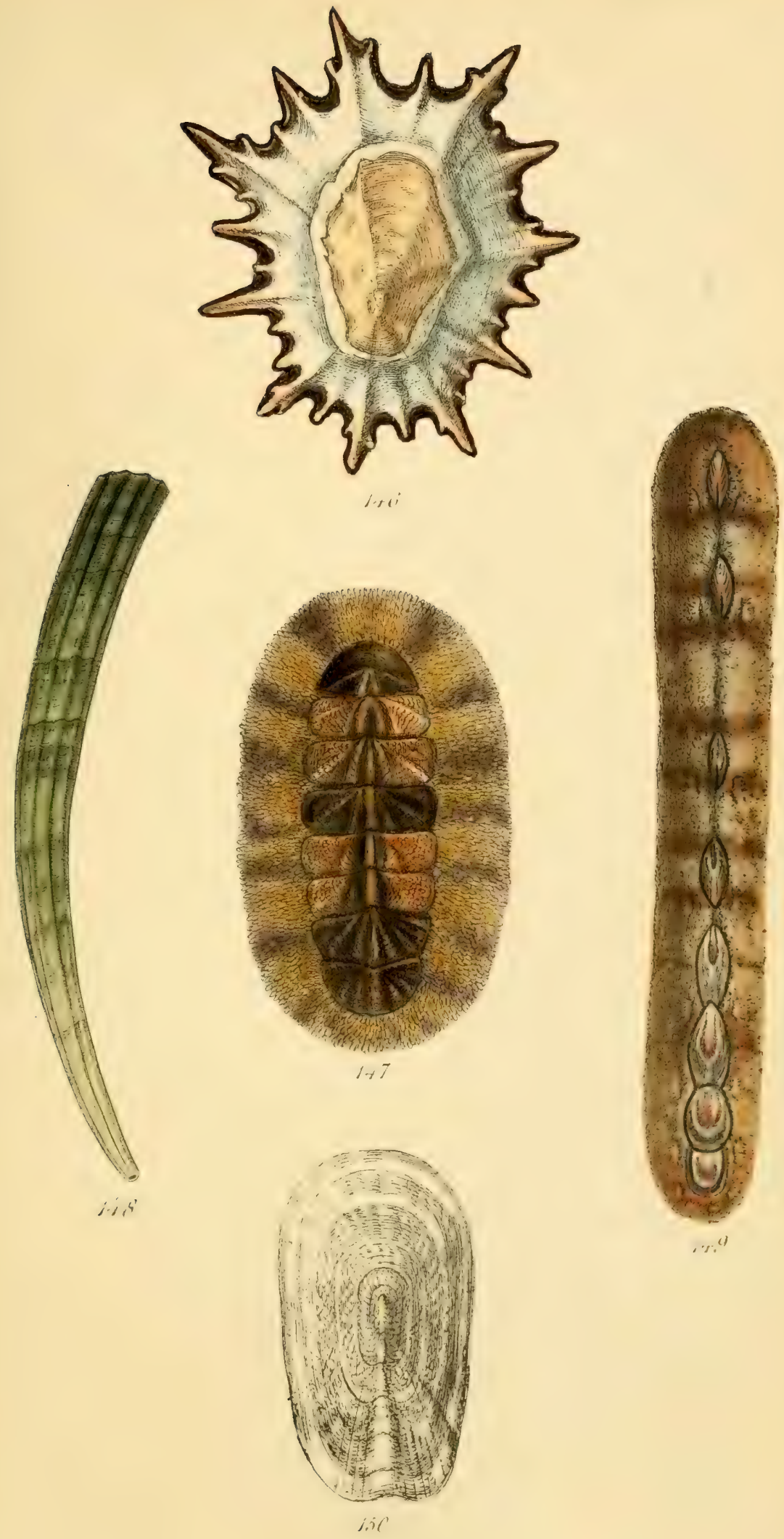



Plate, 26 .

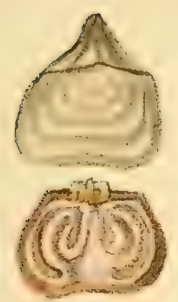

15.3.

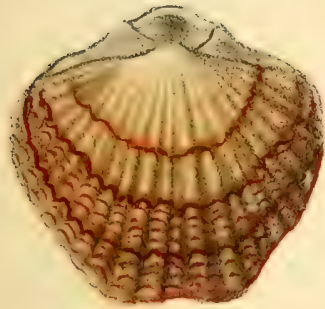

154
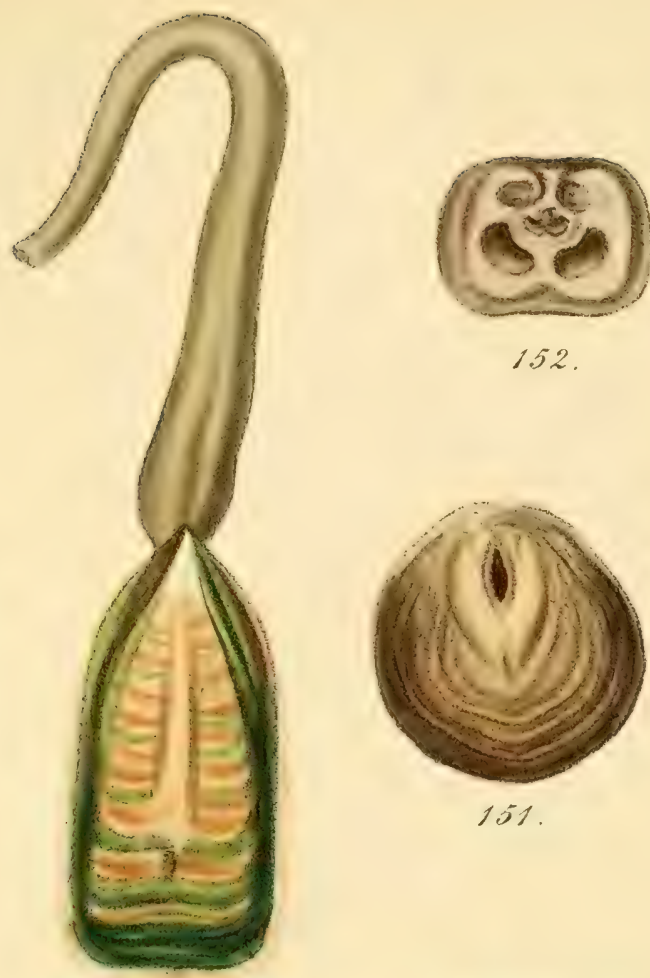

152

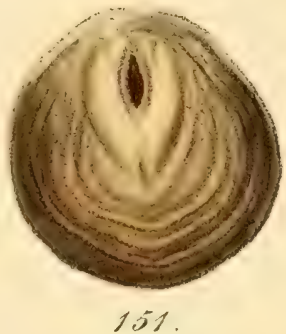

155

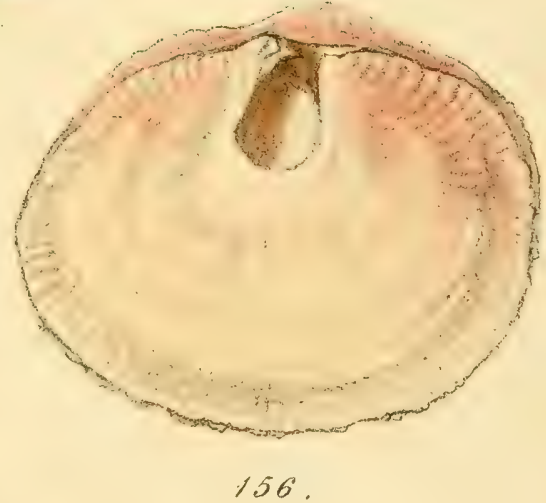

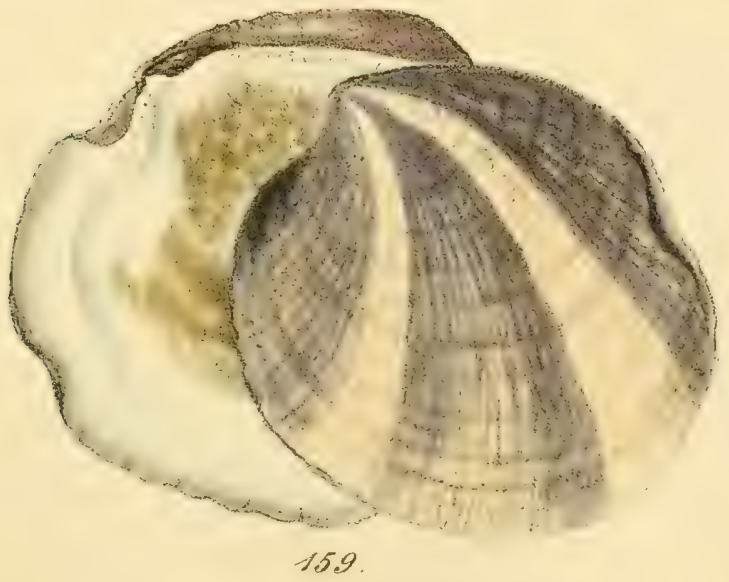




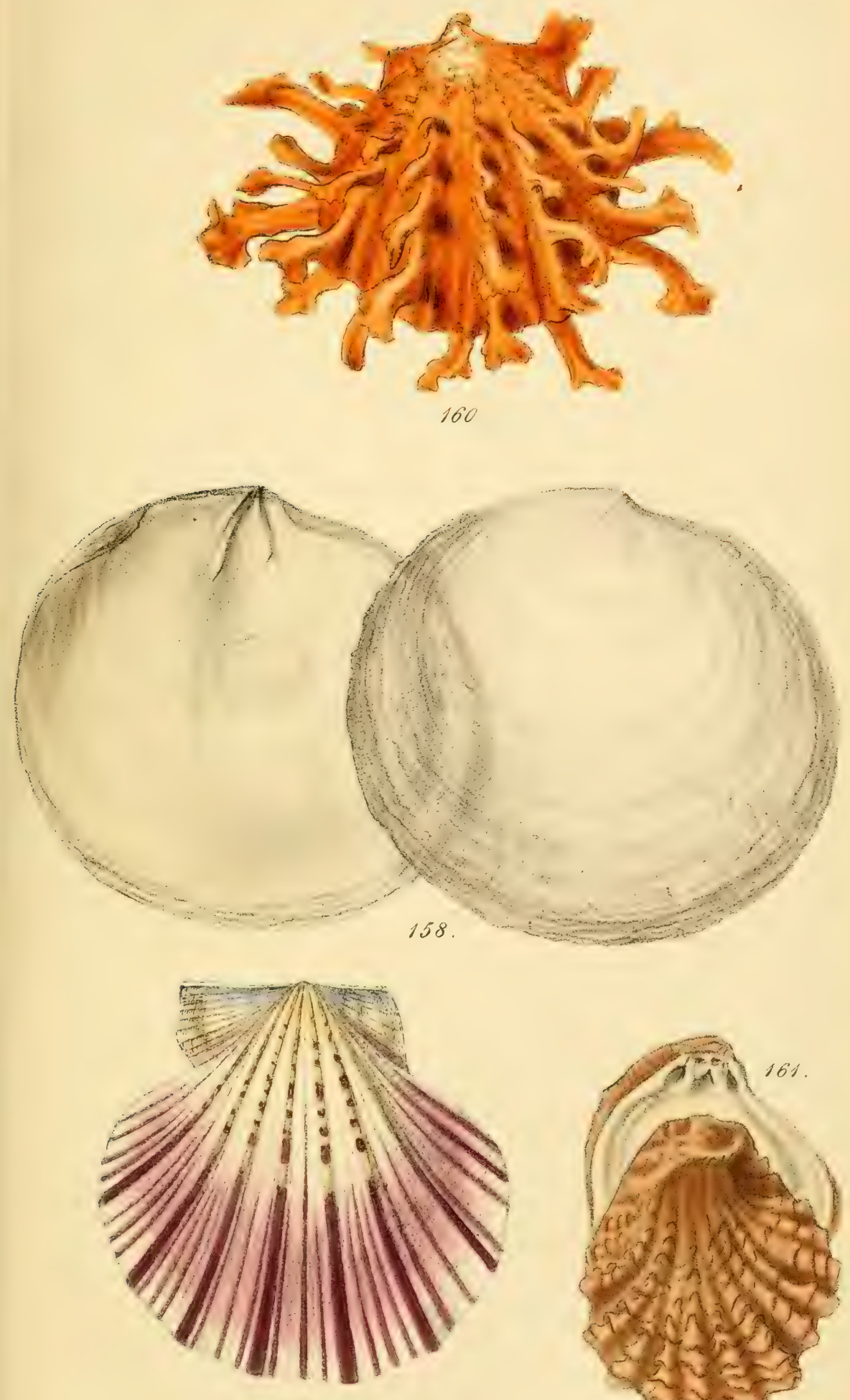

162

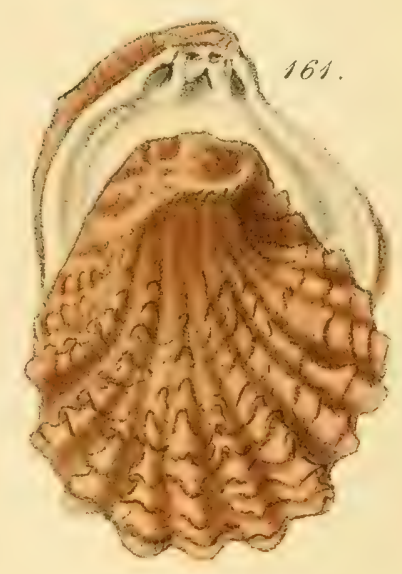




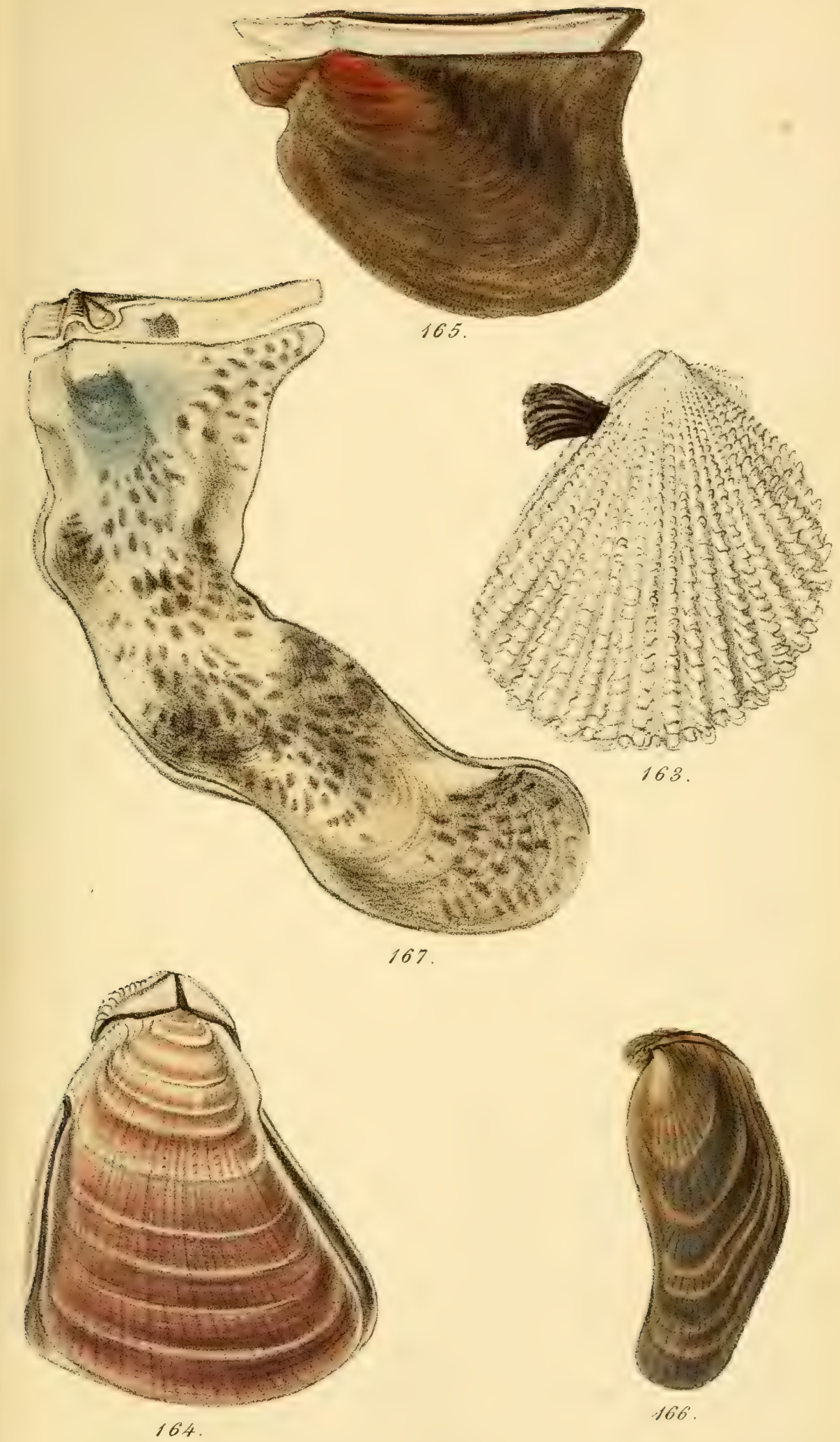



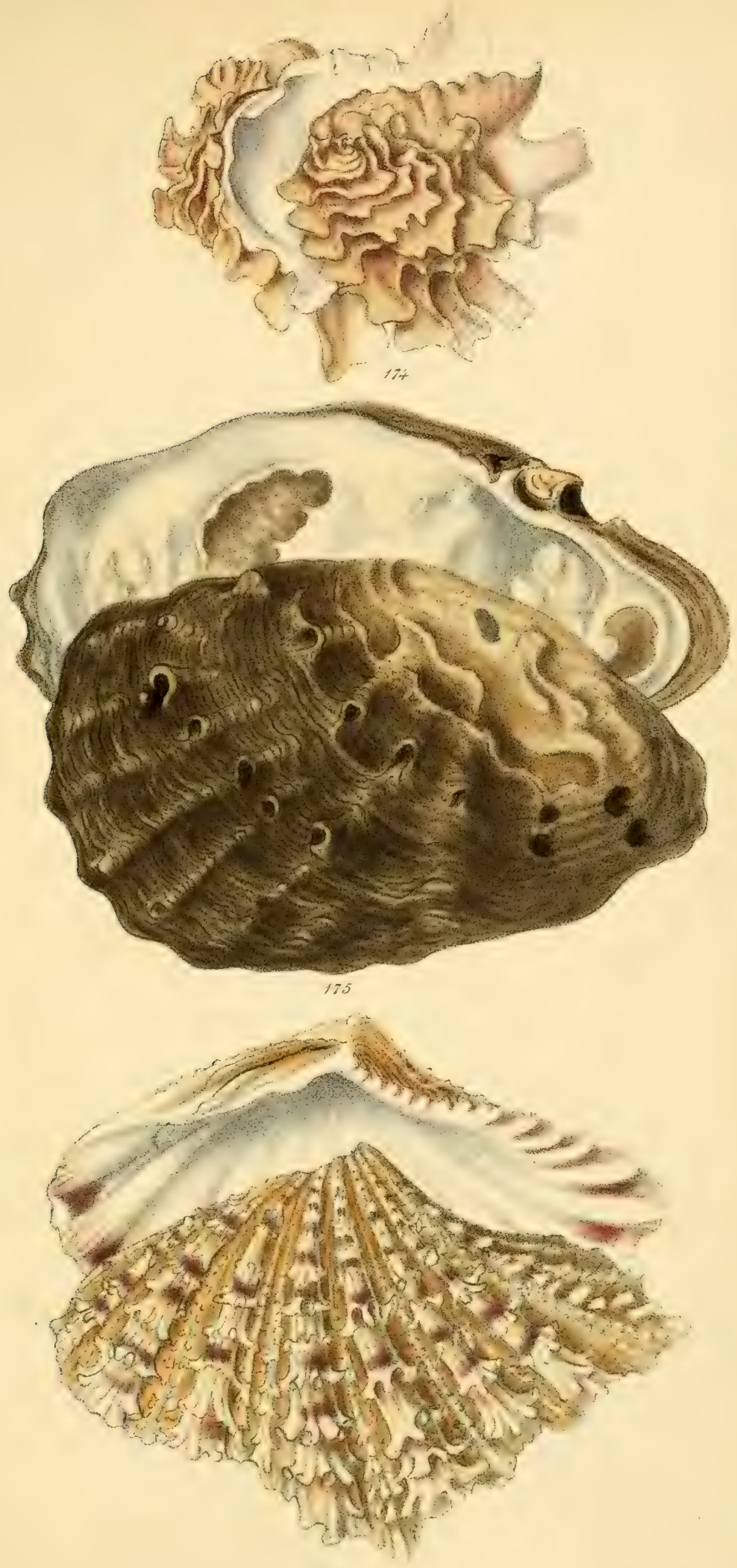

Plate 31.
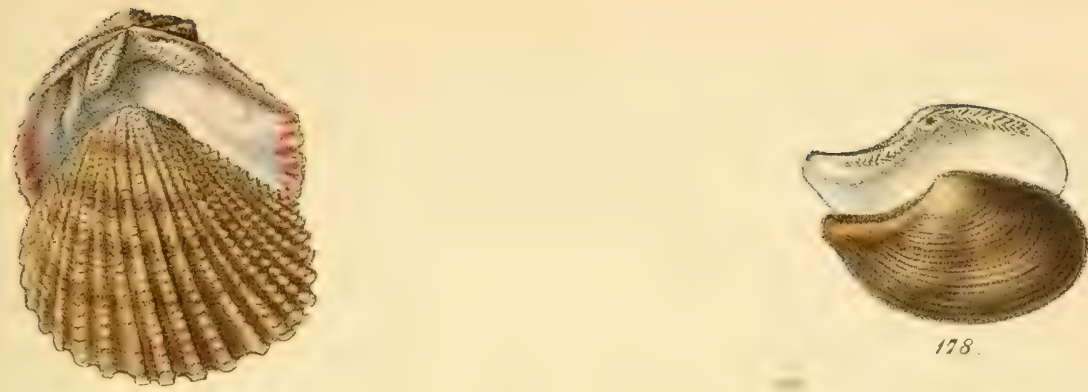

78

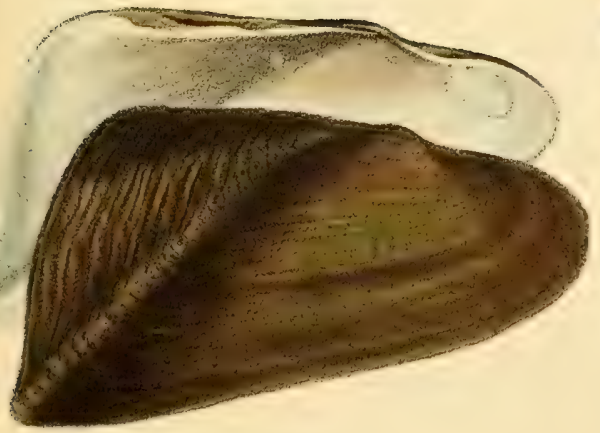

180

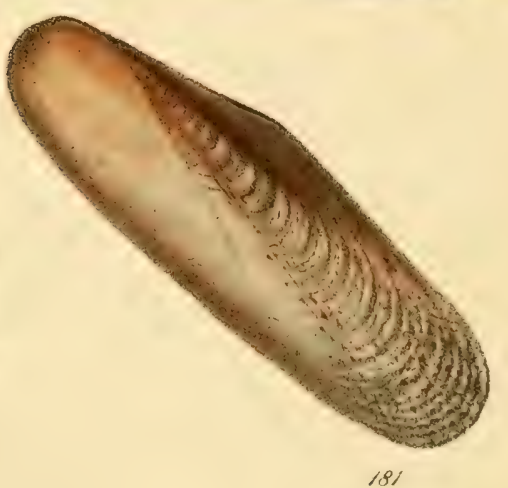




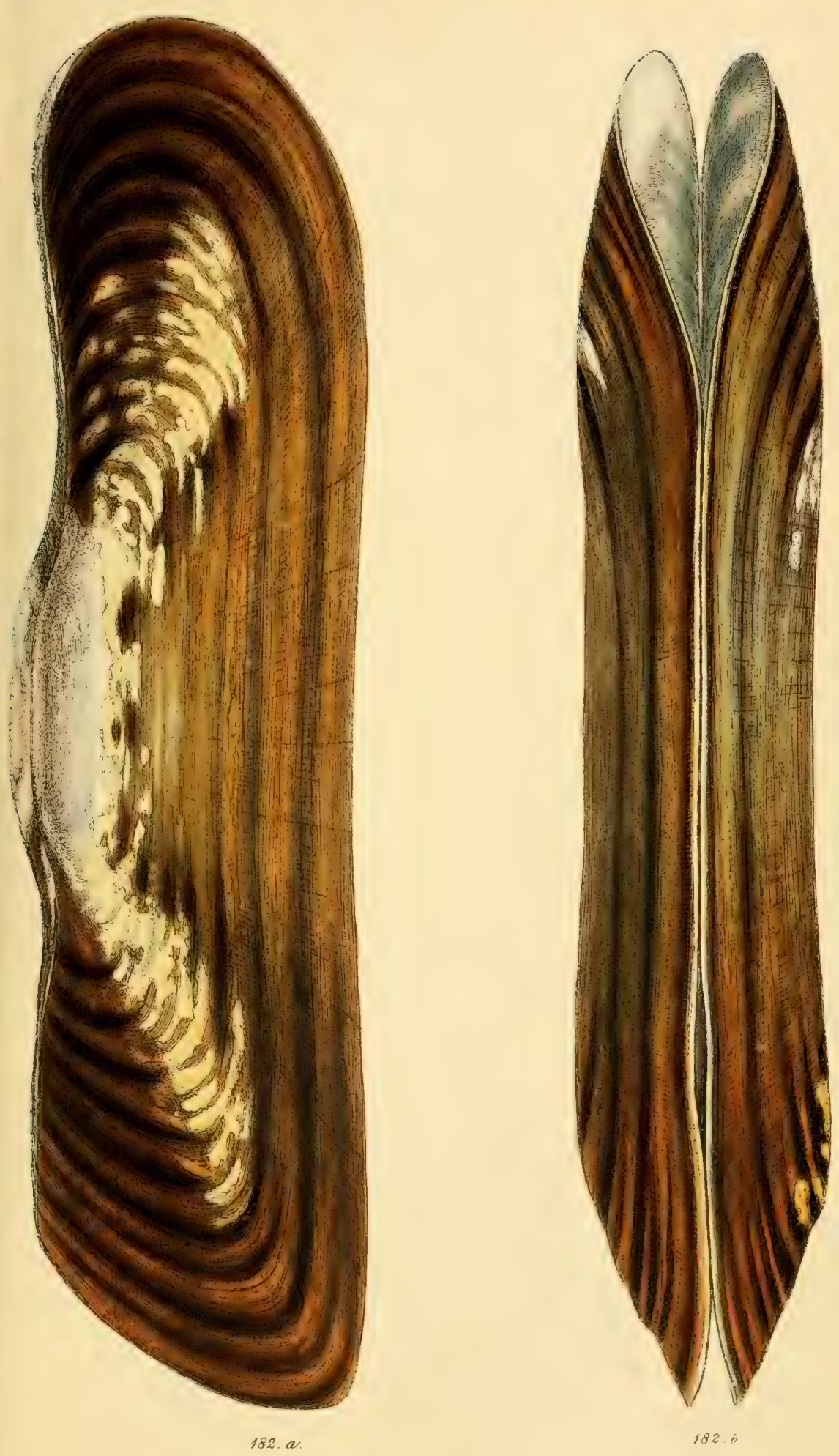



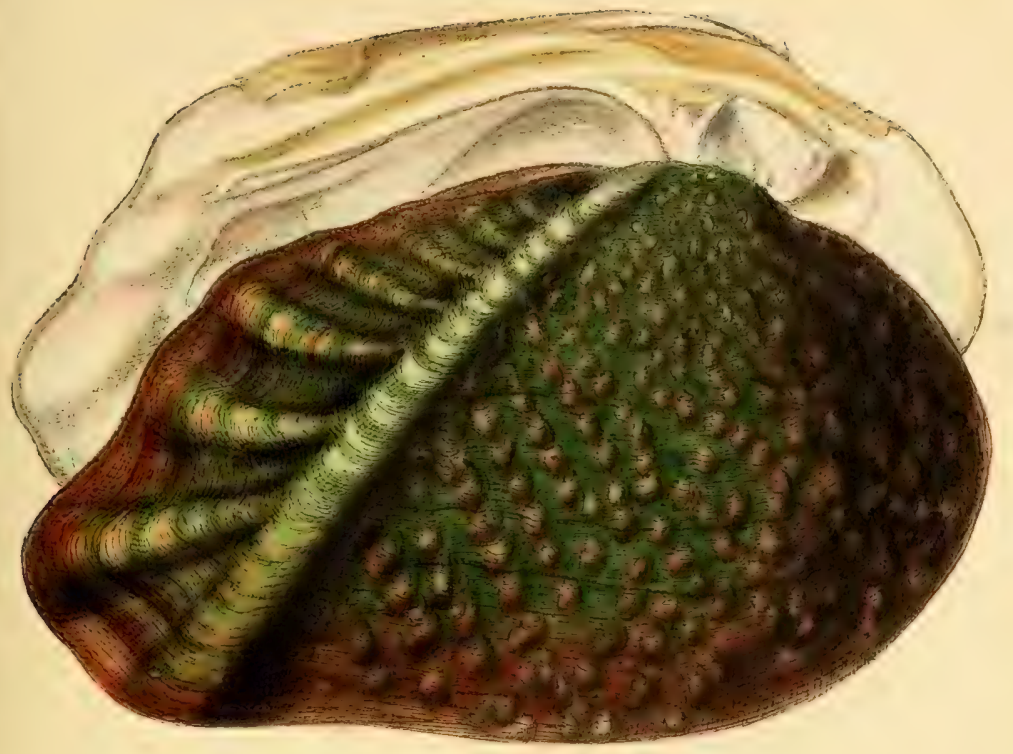

14.3

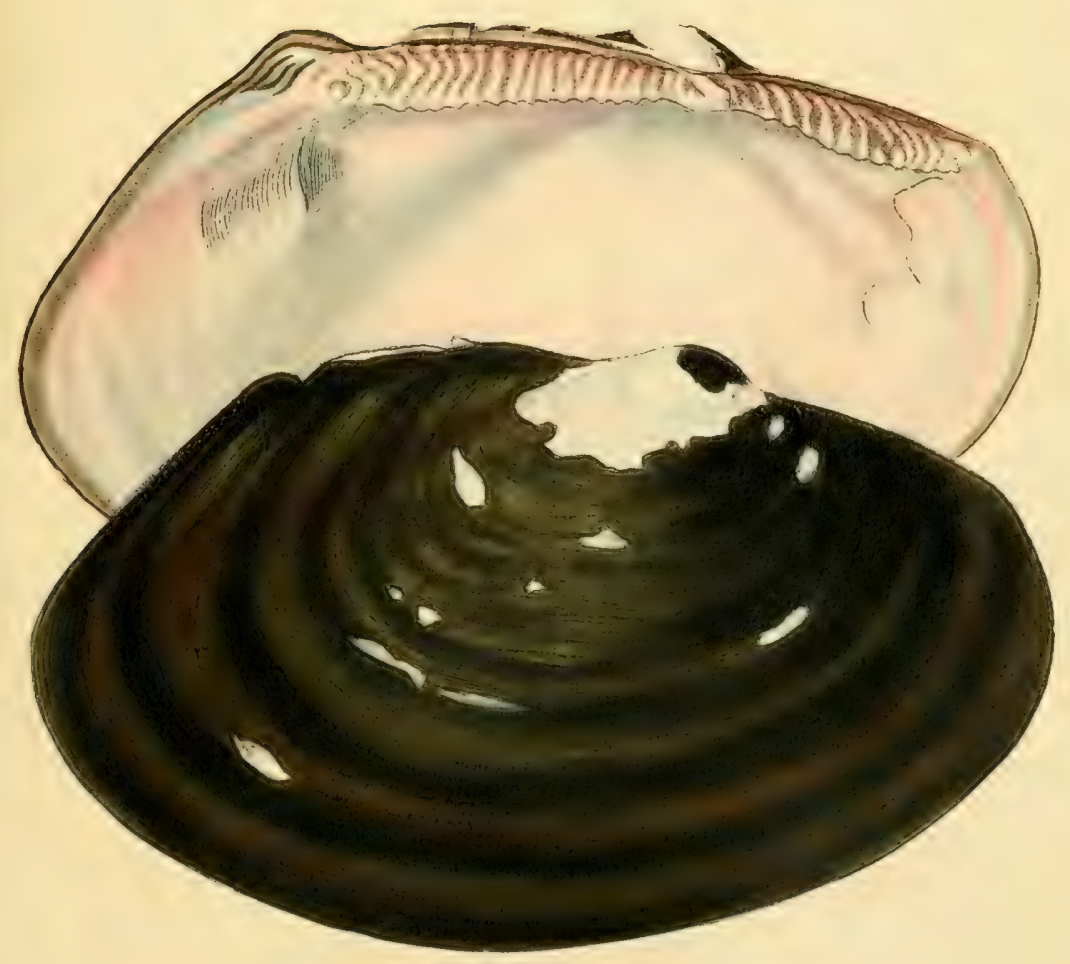





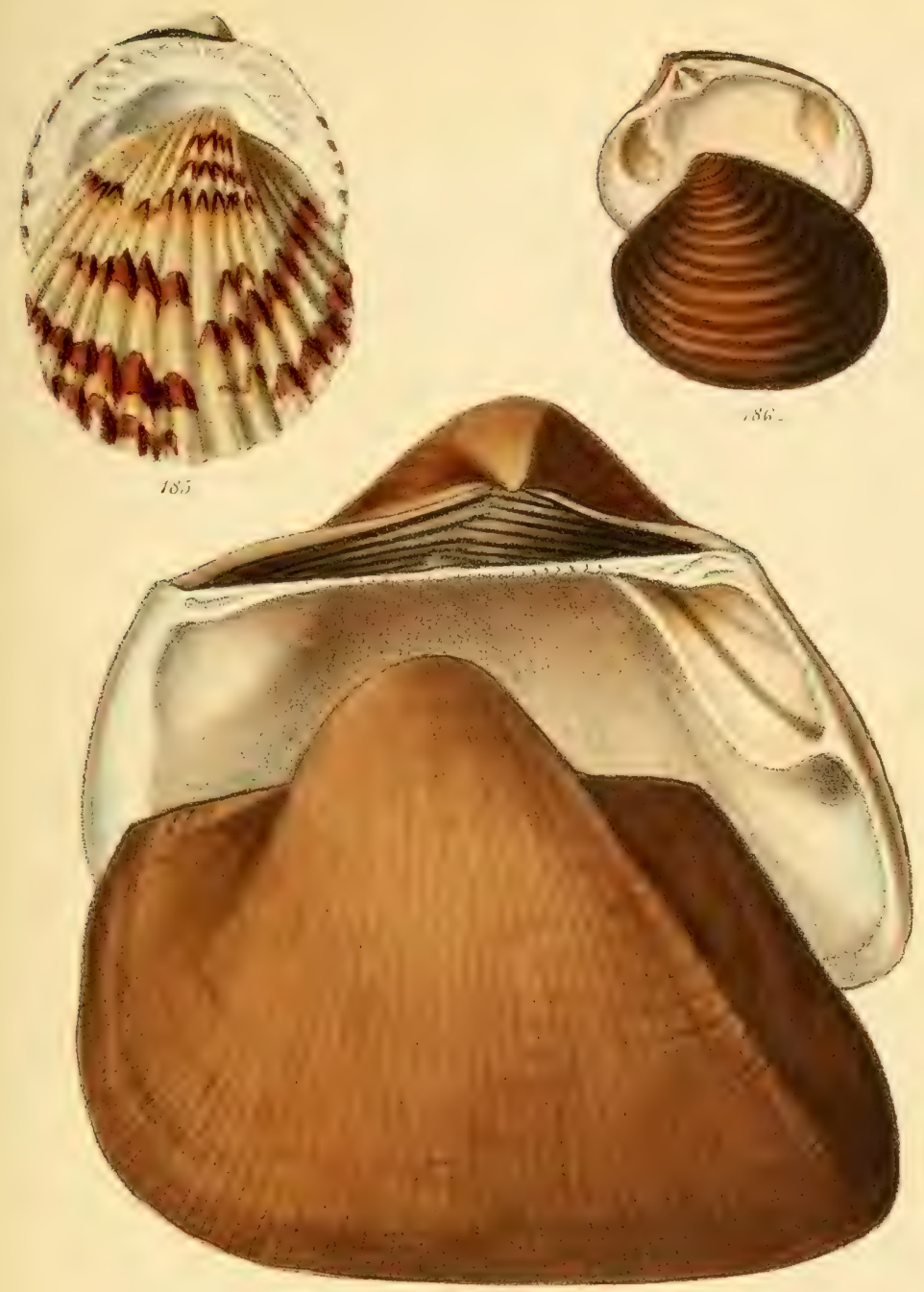

1ST

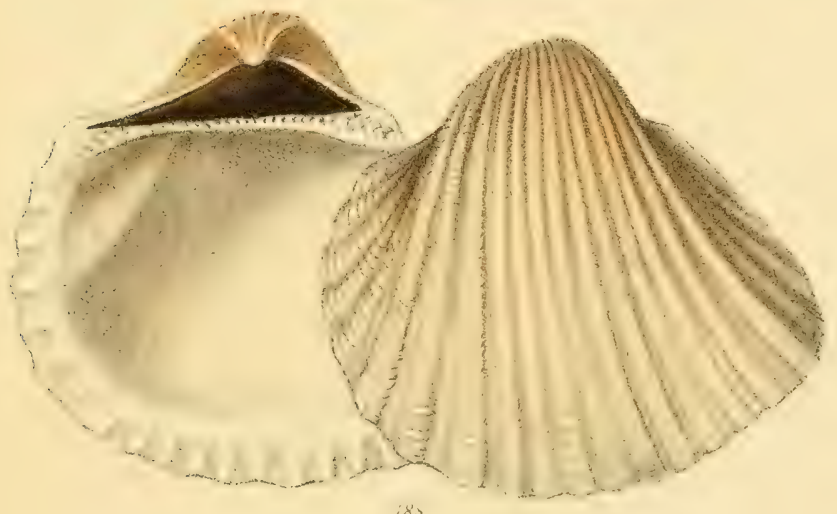




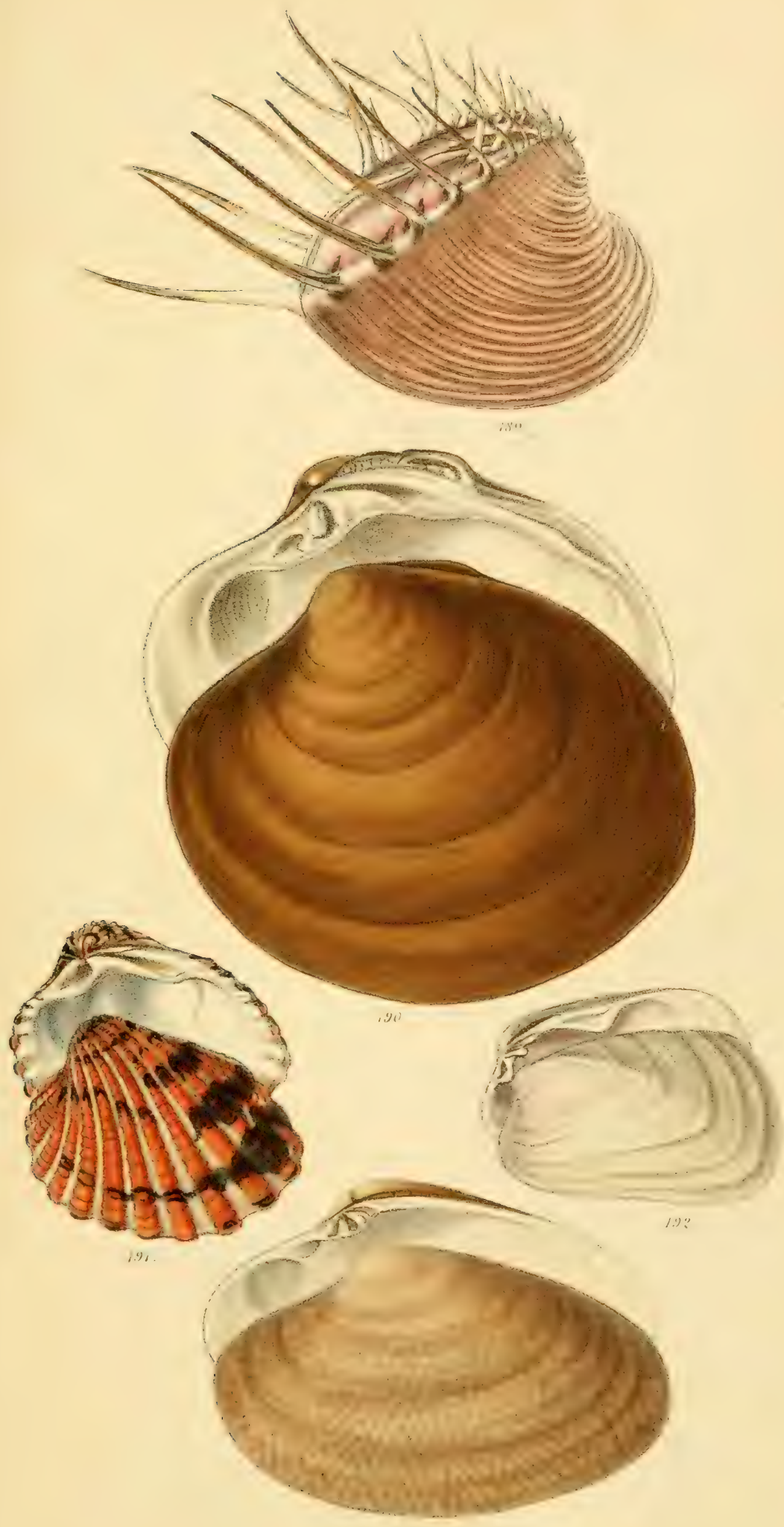



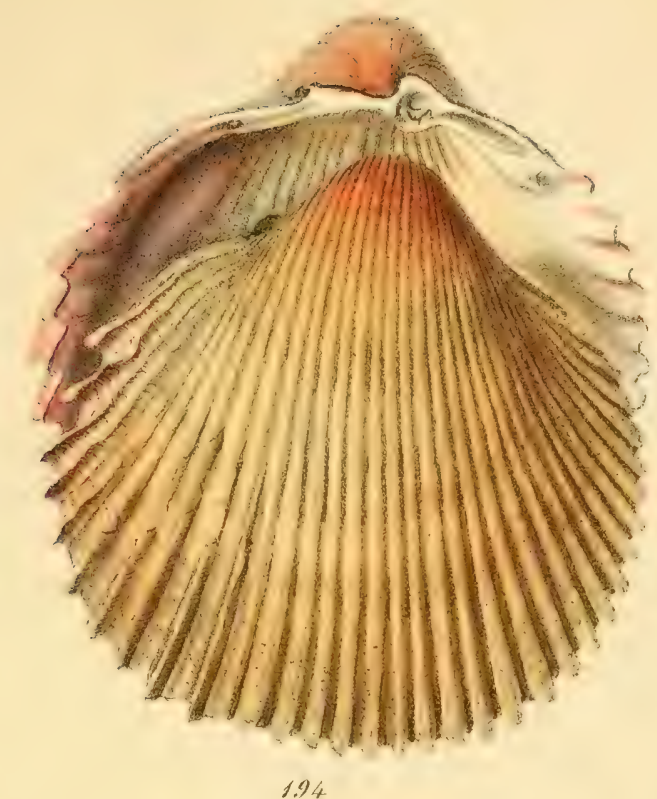

Plate XNTT.

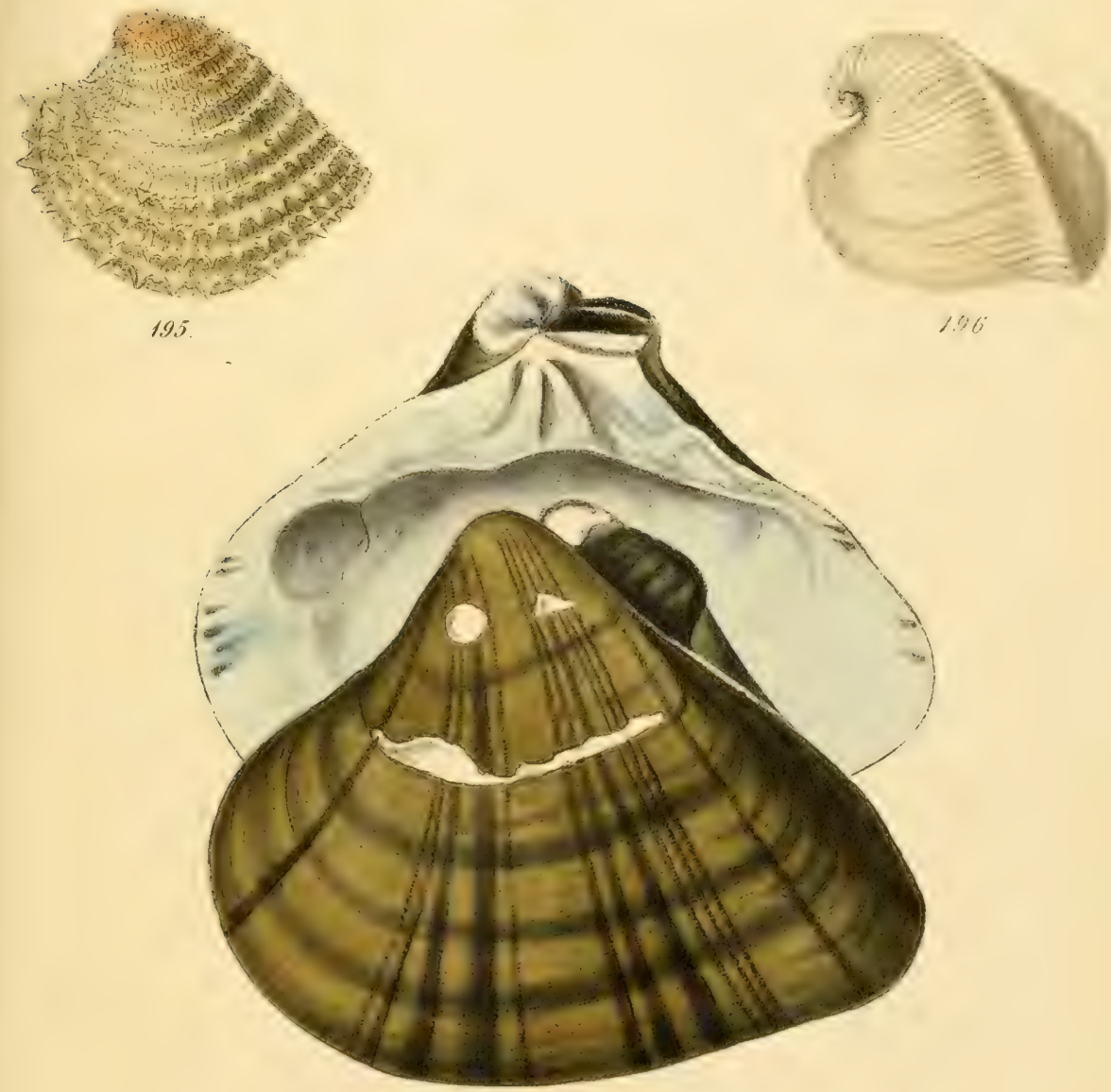



Plate XYTI
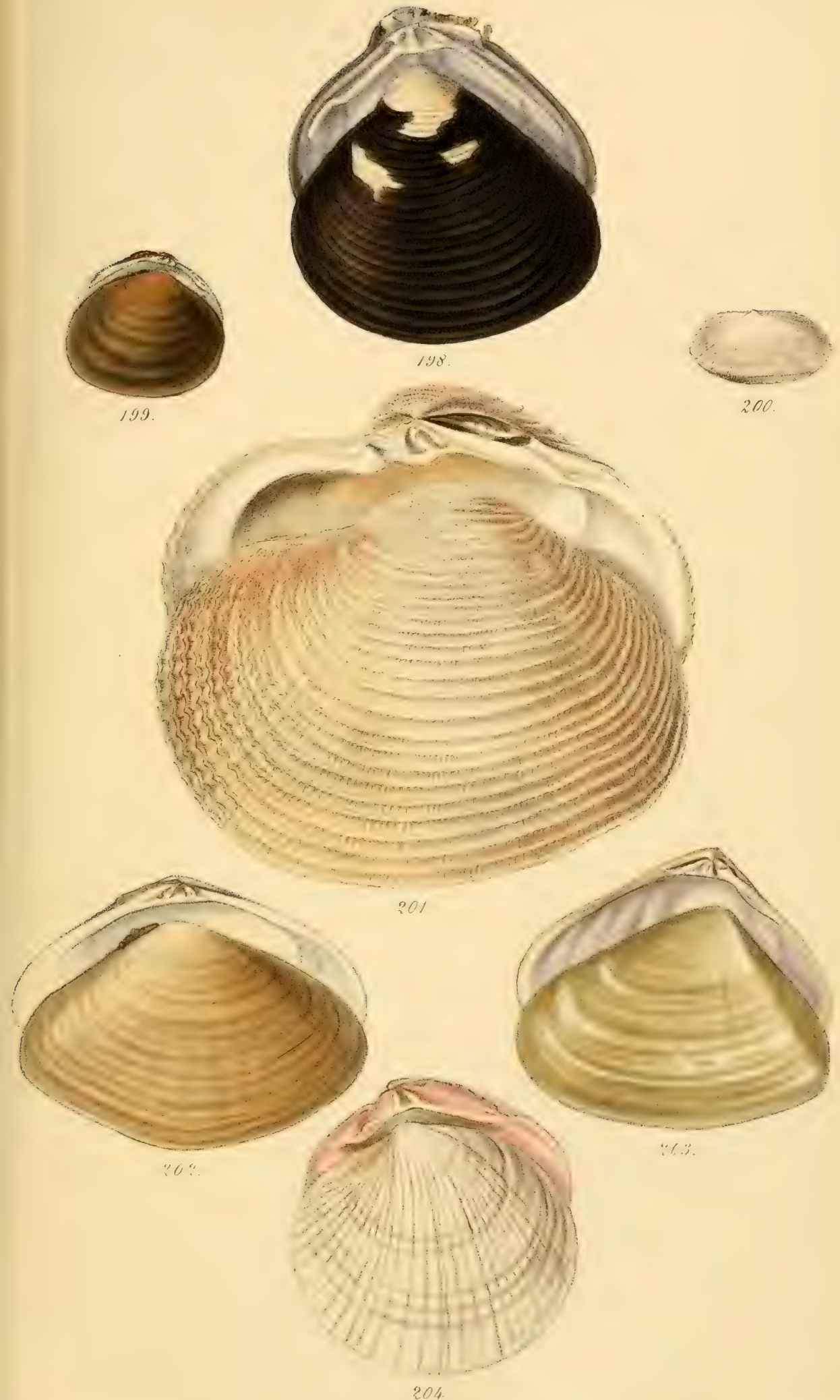


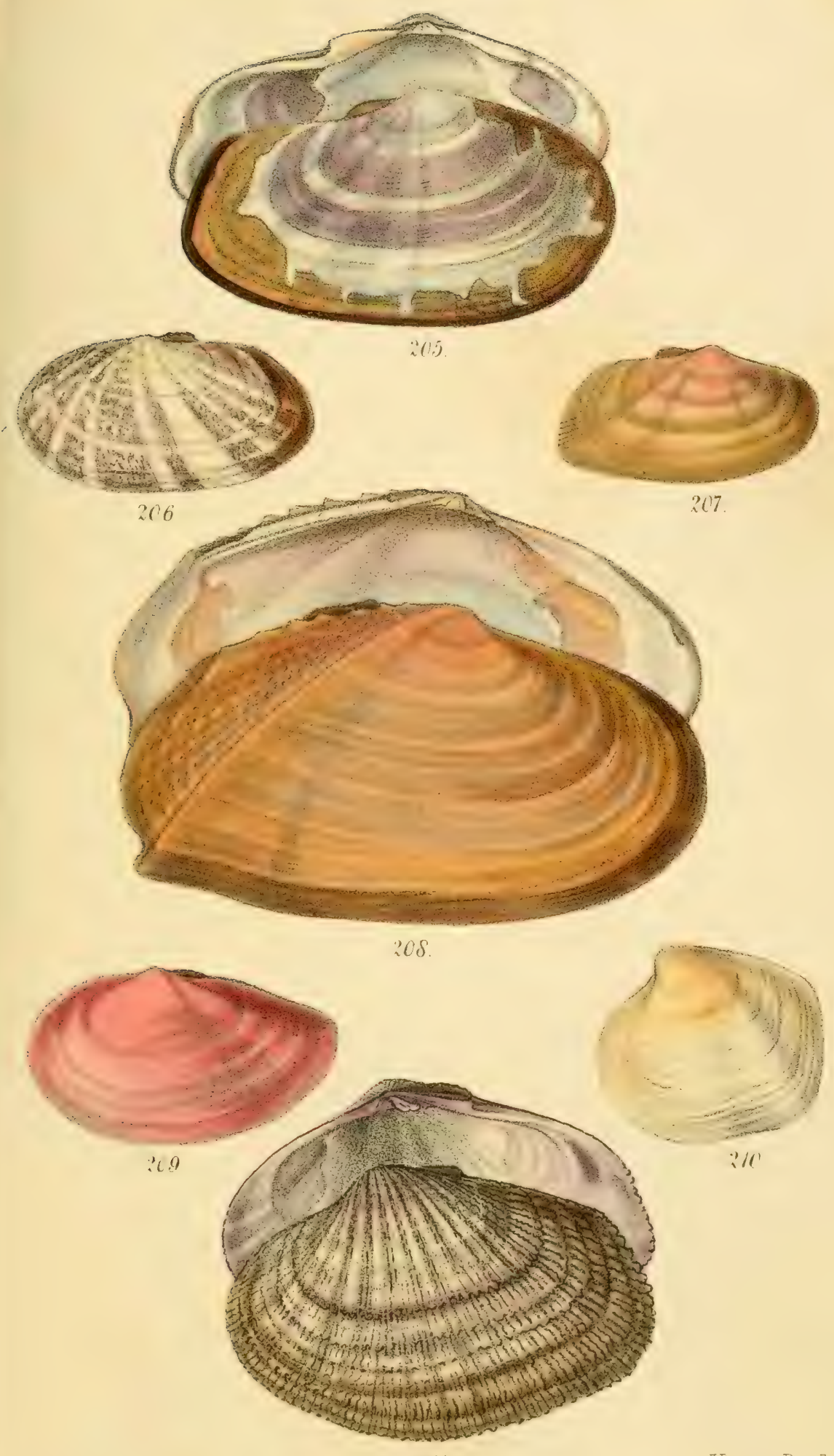


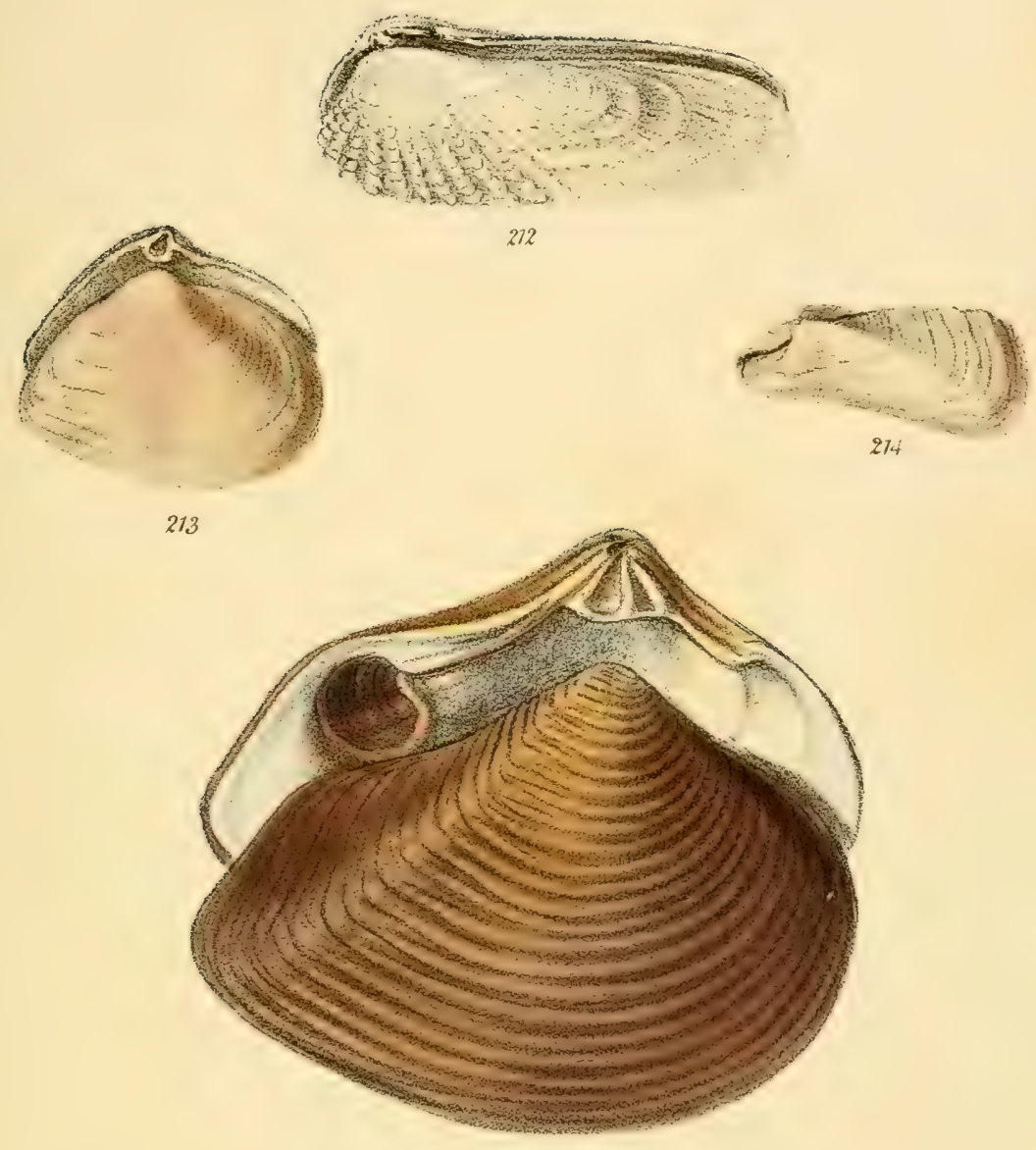

275

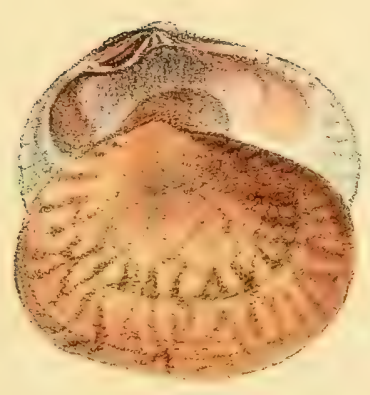

216

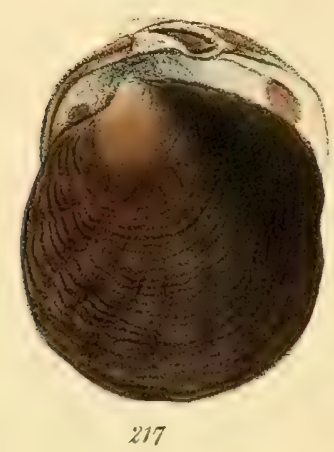





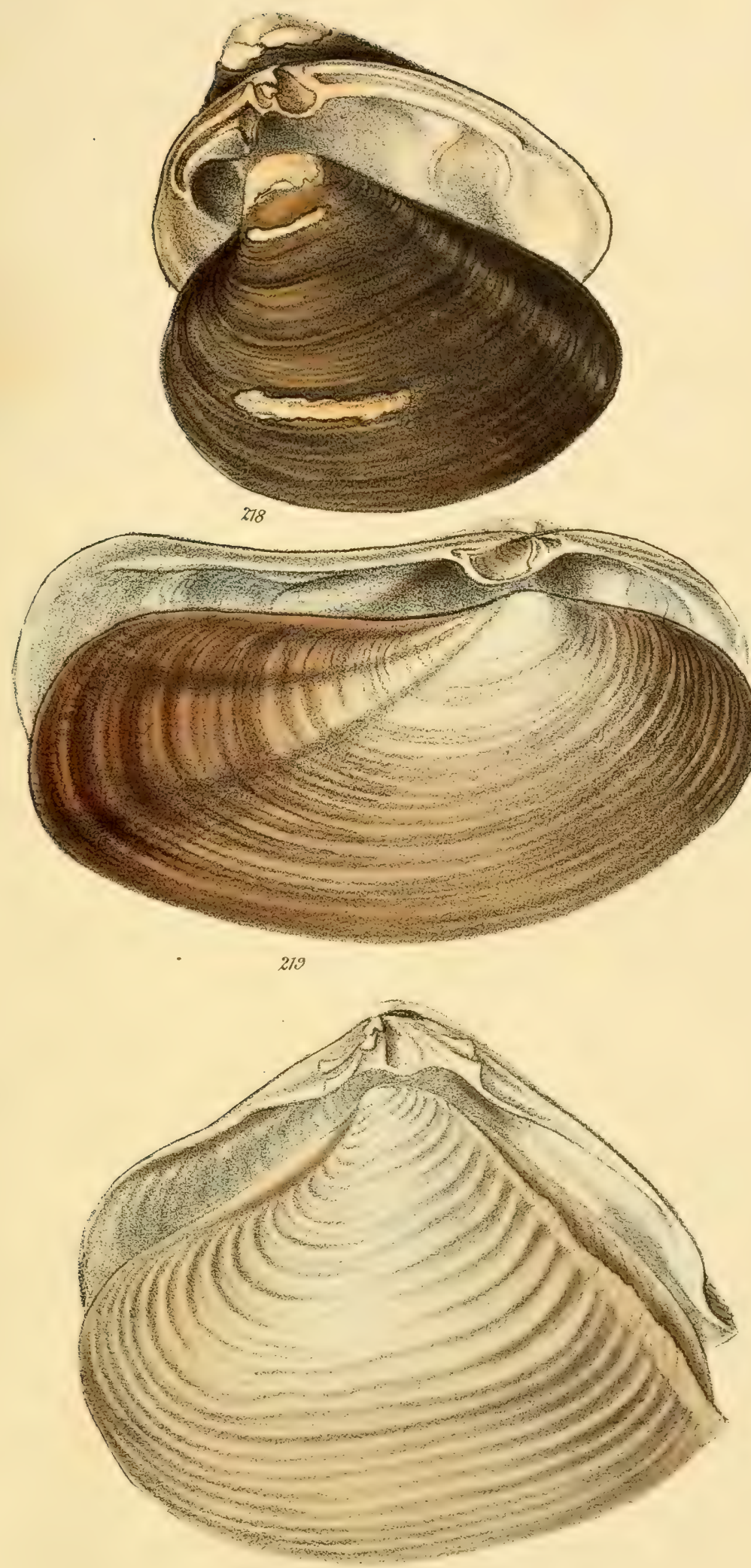





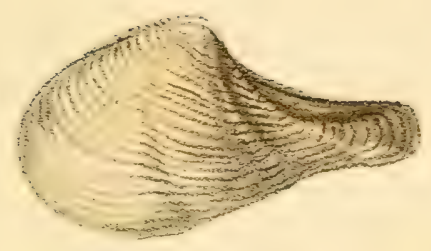

221

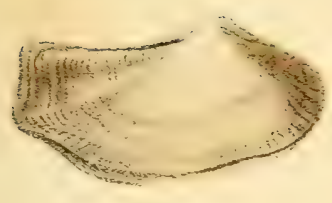

22.2
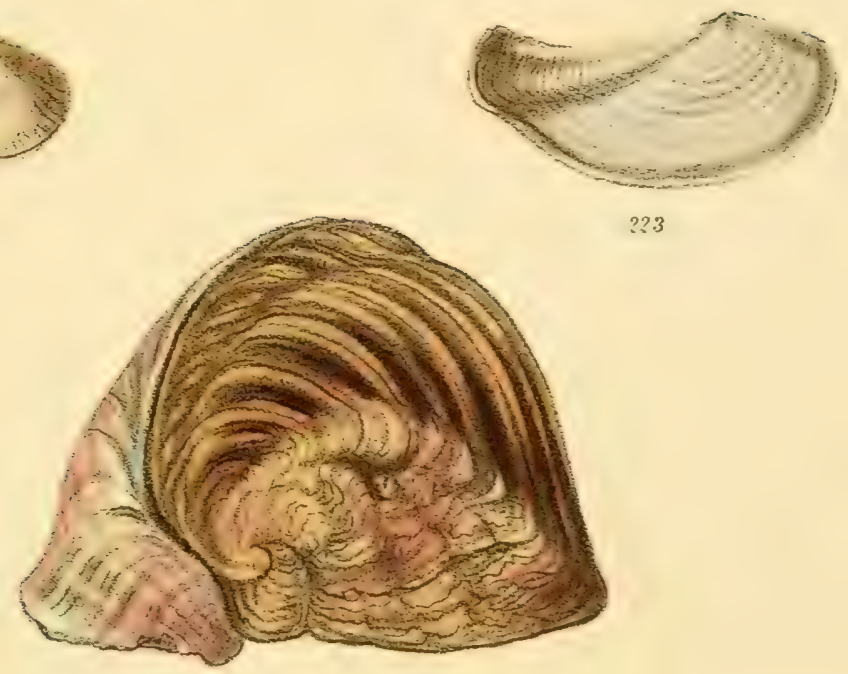

$? ? 3$

224
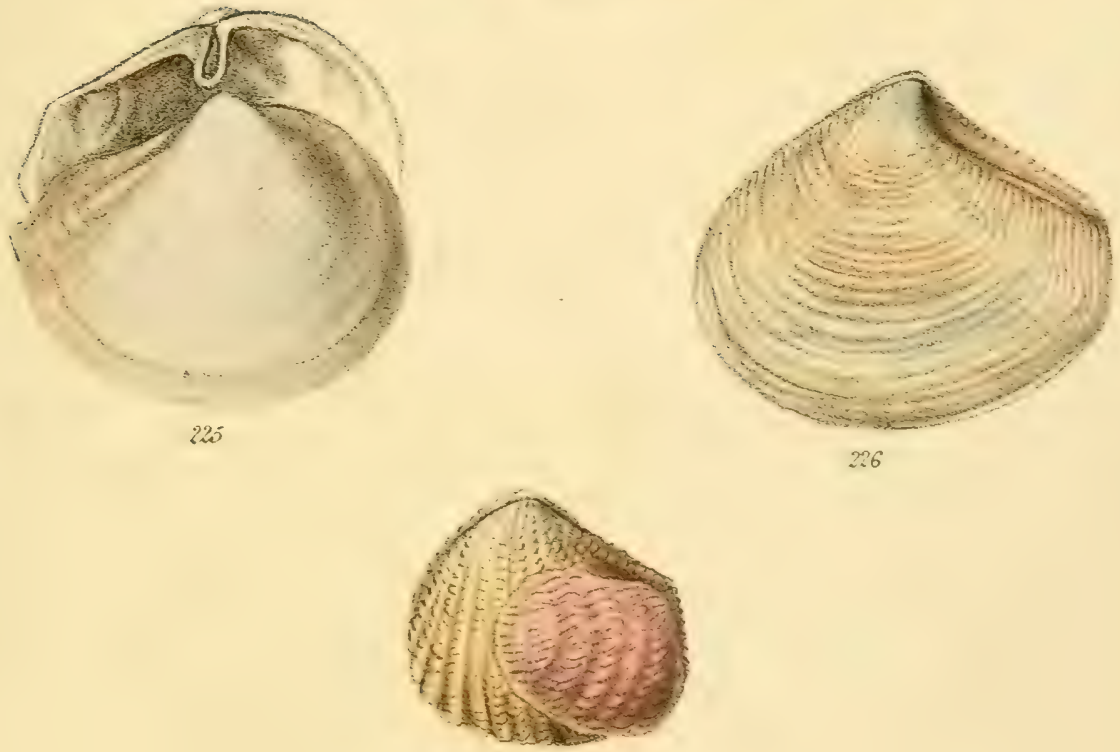

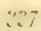





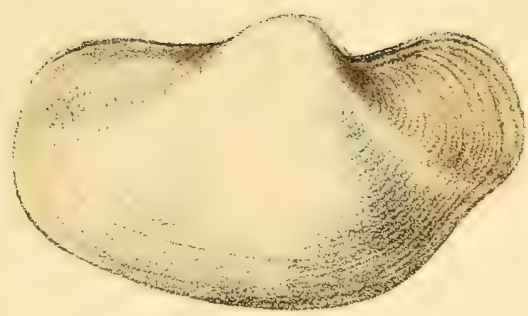

Plate XIII.

228
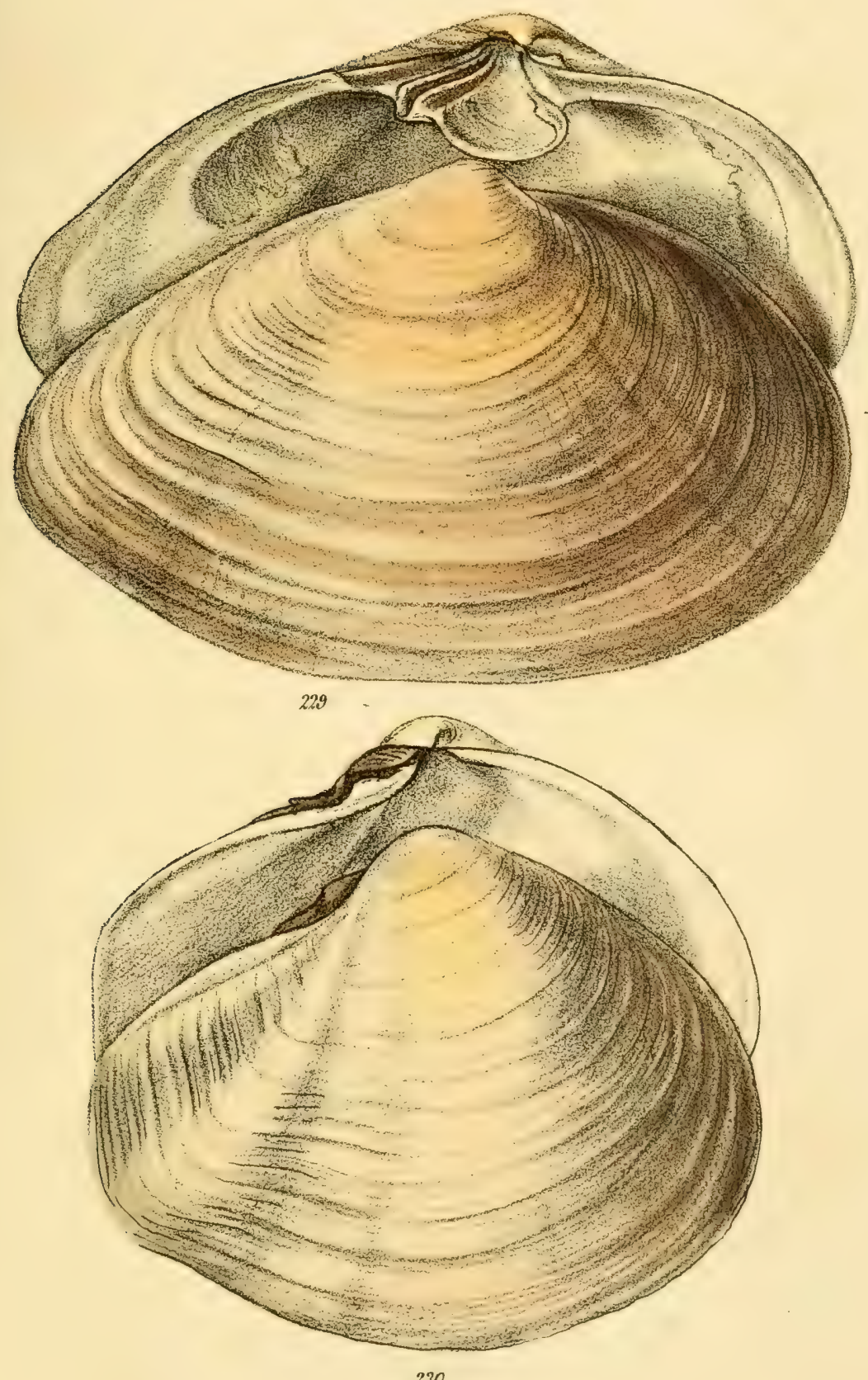




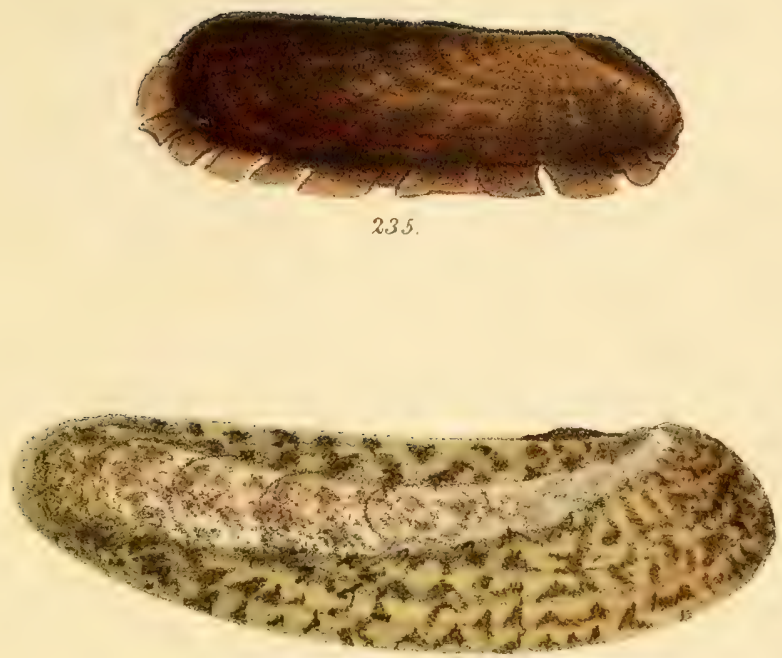

236 .

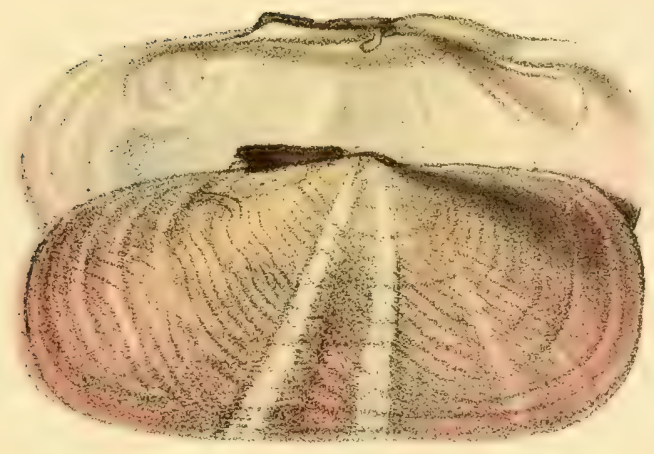

237

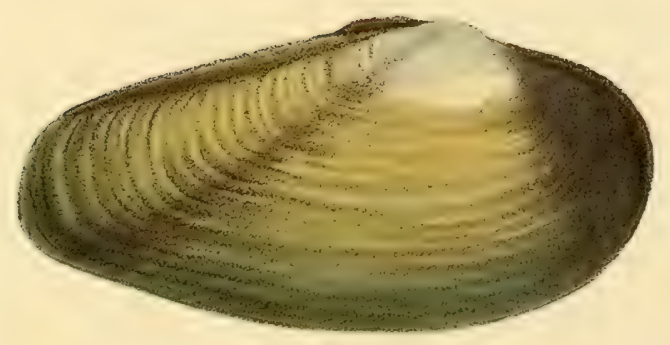

$\because 3,5$ 



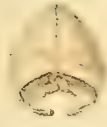

241
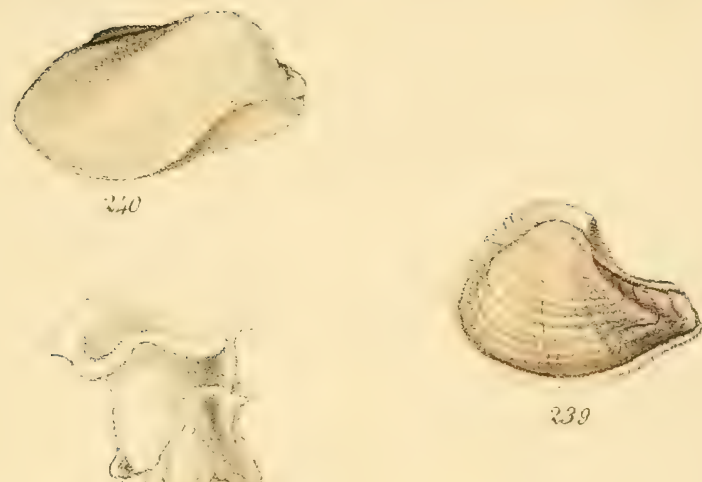

239

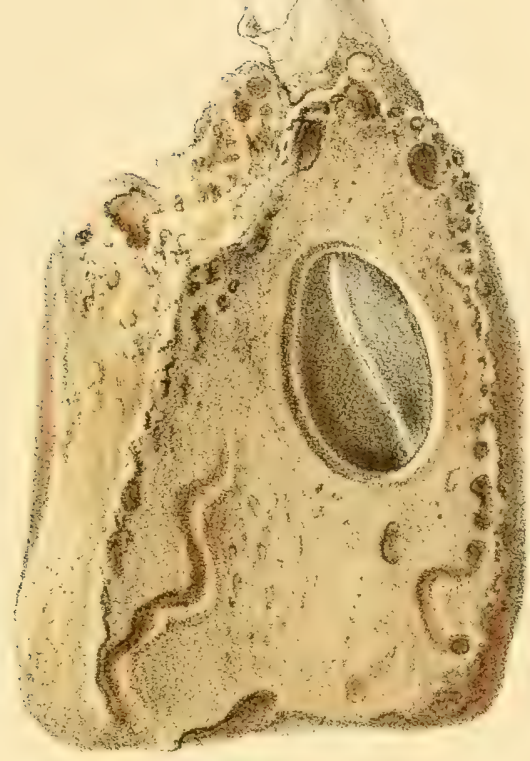

242.

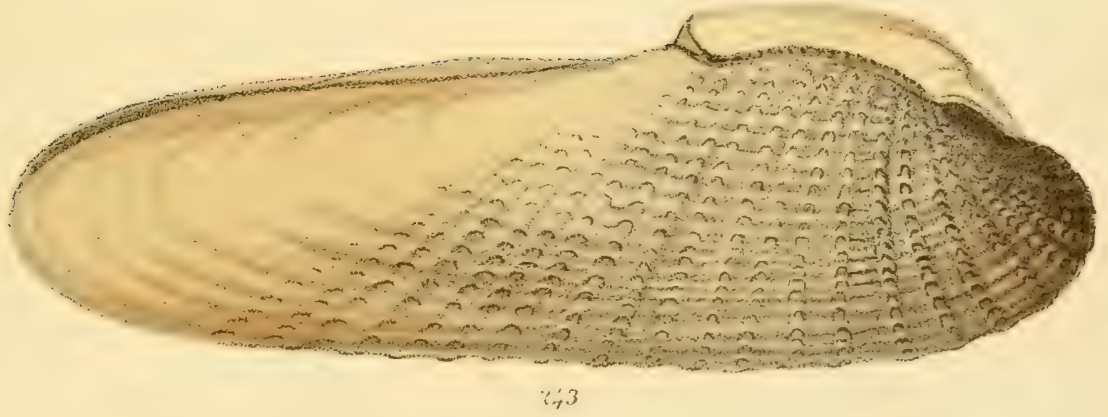




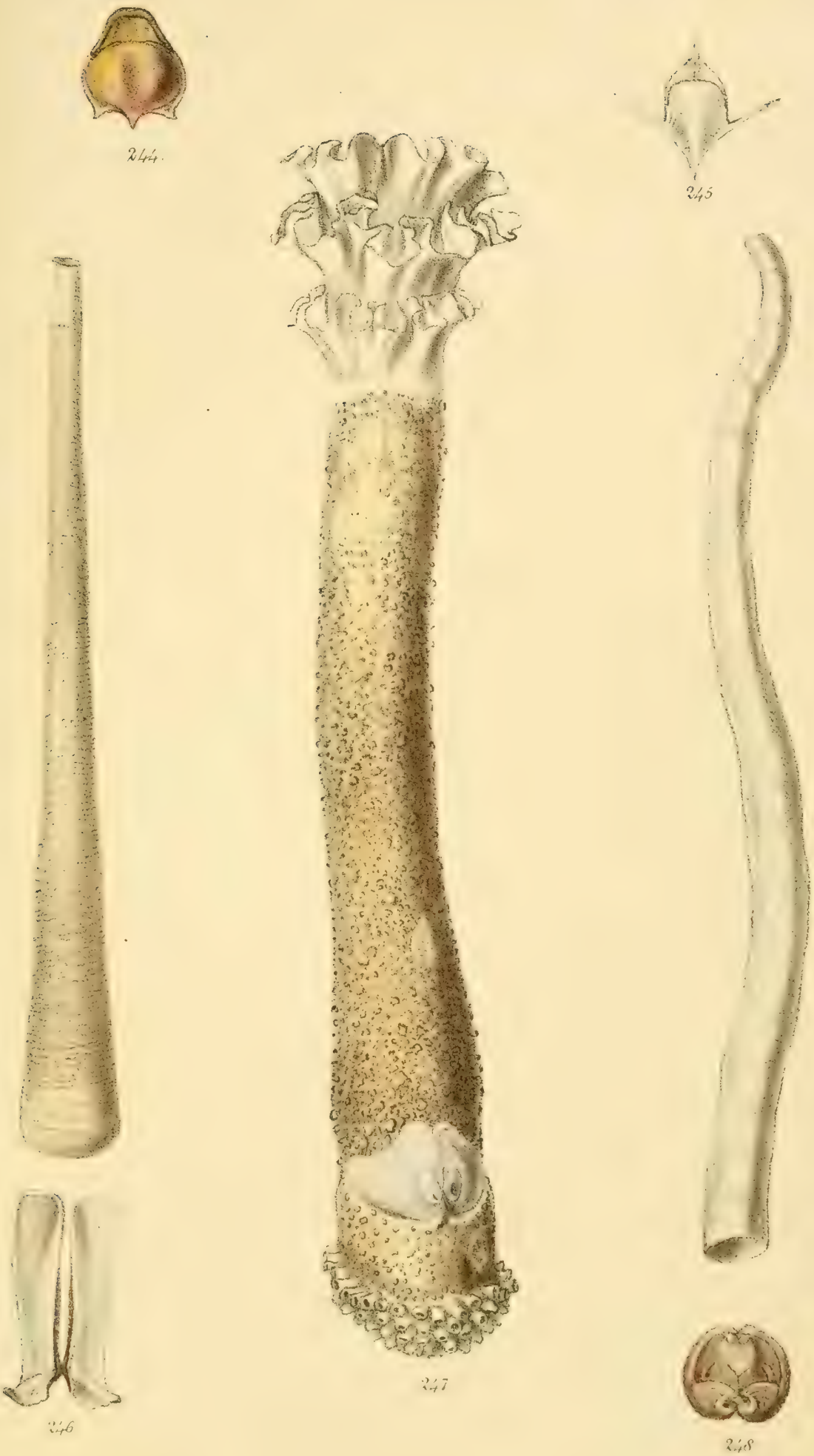

Sowcridy, del ct lith 




230353503

(3)

32375

52323

$32353 \% ?$

inis $\rightarrow$ sin

$3230725 ?$

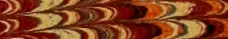

(3) 33003520

3335,35

(3) 525

35050

325

(2) 3. 320

32232

(2)

()) 20012

233

(3) $\rightarrow 5350250525$

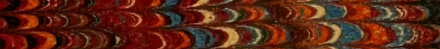

(3) 30,2010

35

2) $230 x, 2 \geqslant 3$

2) $32>3>02$

35.250 .25

(2) 353

35020020

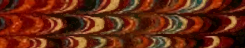

$3,3, \infty, \infty, \frac{5}{3}$

$33)(30), 3$

53

$3 \times 3 \times 3$

$3>>0$

$\frac{3}{3} \frac{9010}{907}$

33,300

3,300

(2), 300

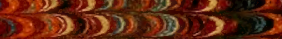

$325>3$

$\left(\frac{3}{3}\right)>30203$

ais

$39303 \times 300035$

20

$503: 53$

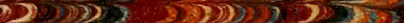

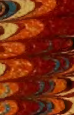

3,50003

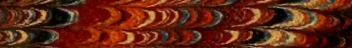

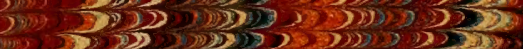

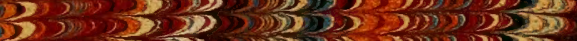

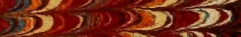

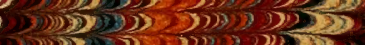

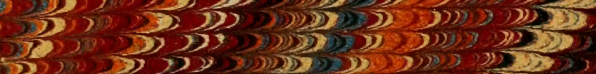
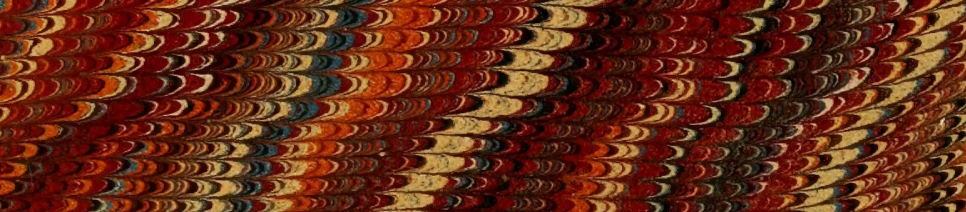

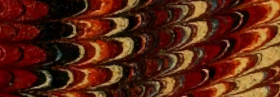

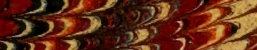
$3,3,20,3,2$ 325 3203 (7) $>3$
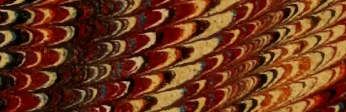

()) $\rightarrow 3$

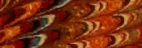

320
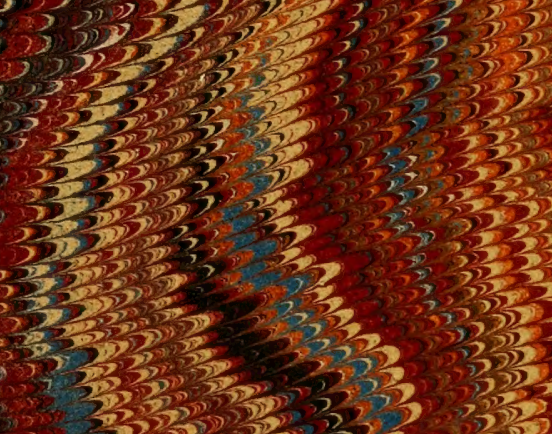

27003525

3003203202

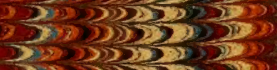

303202,22

(2) 32530.32

$\sum_{x \rightarrow 2030}$

3253503

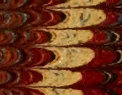

(3)

\section{?}

3335

(3) $>>3>0$

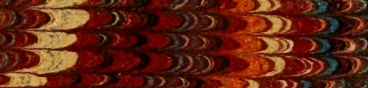

(3)

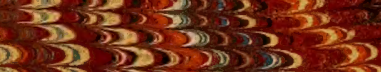

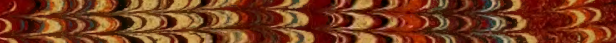

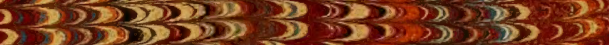

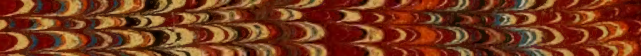

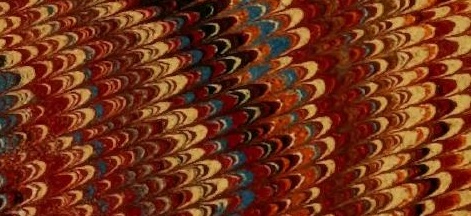

$3,5392,325$

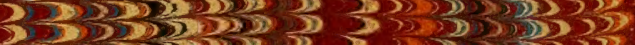

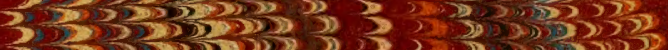

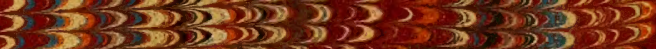

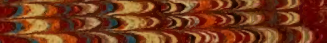

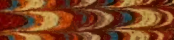

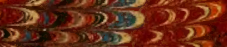

II) 320

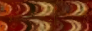

350255

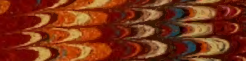

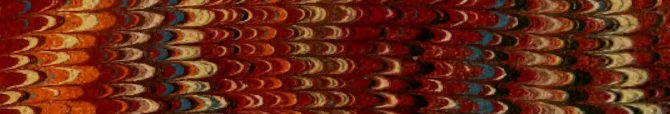

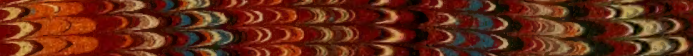

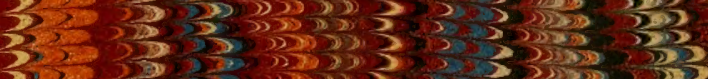

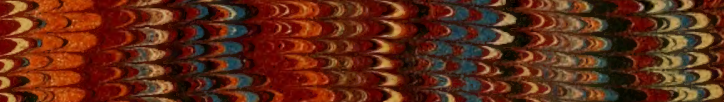

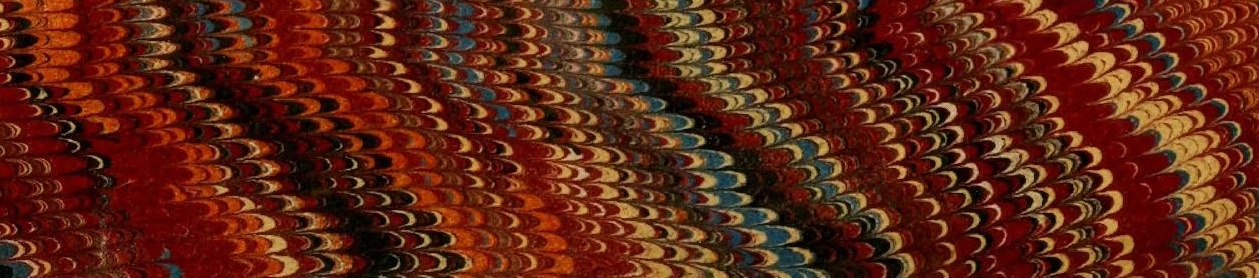

3

$3_{3}, 3$

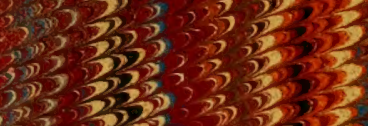

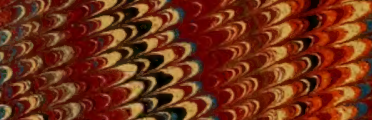
3, 333 , 33 , 3 , 3 , 3

$3,>3,2$

(2) 
DS

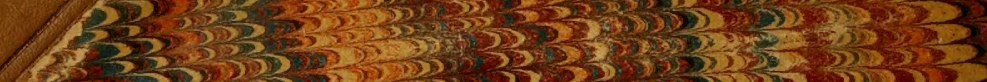

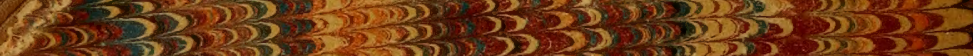

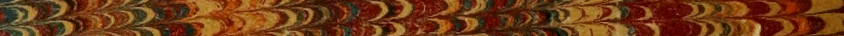

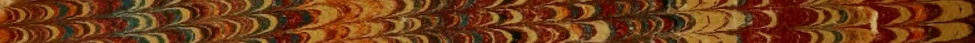

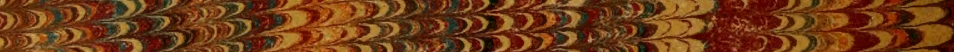

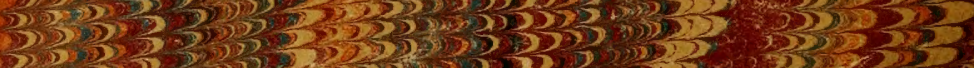

3 2302

(5) 3020

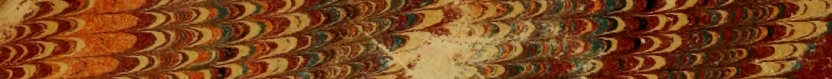

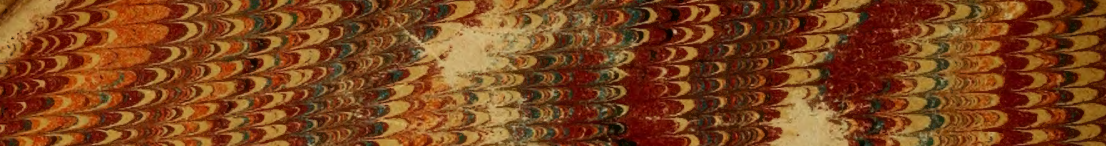

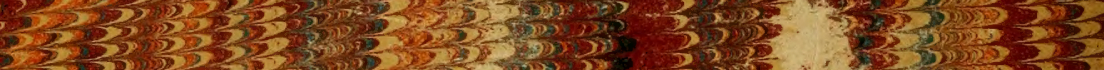

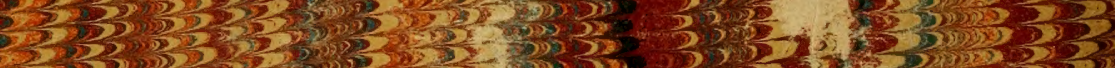

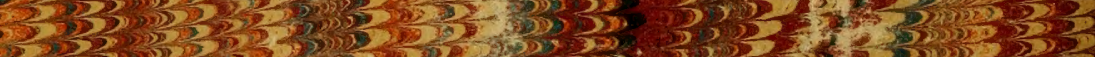

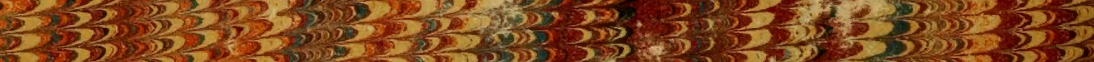

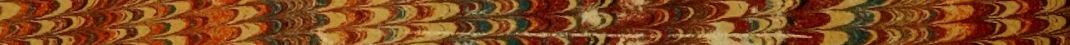

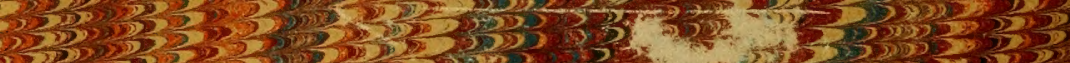

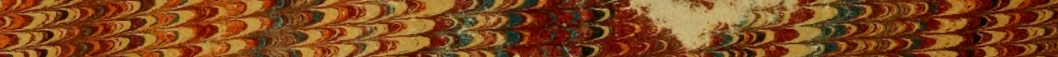

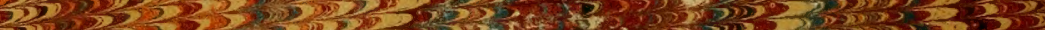

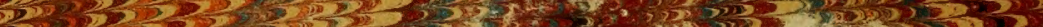

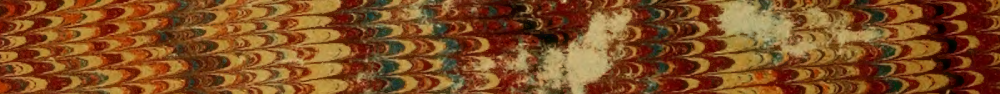

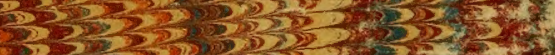

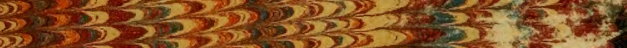

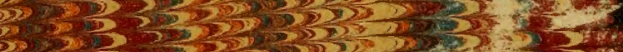
$3,2330053,3$

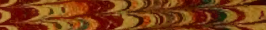

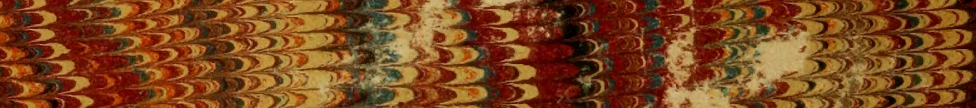

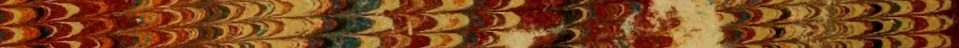

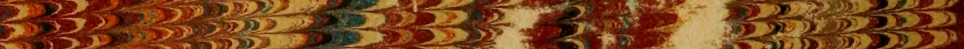

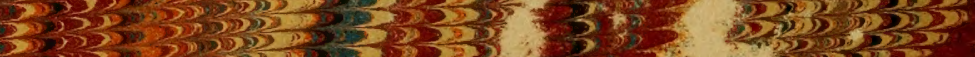
30,33030003025

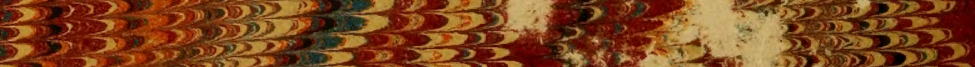

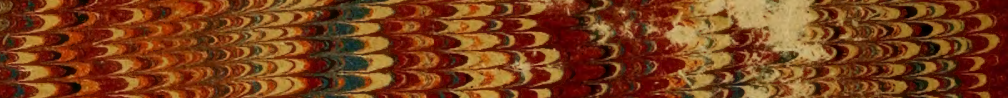

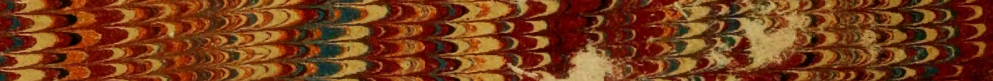

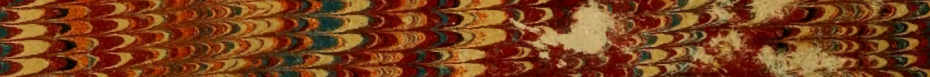

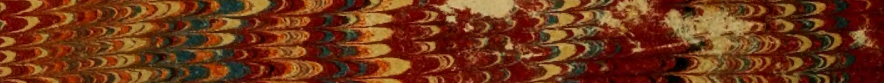

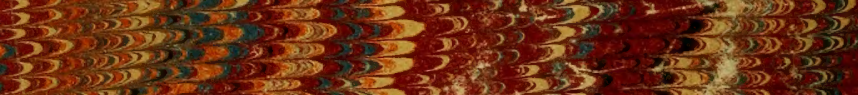

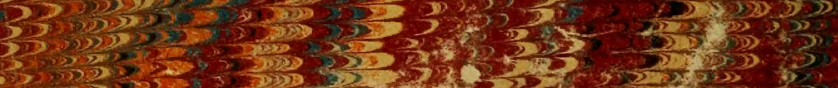

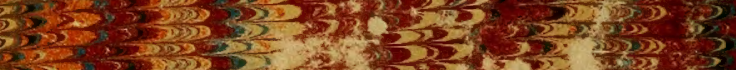

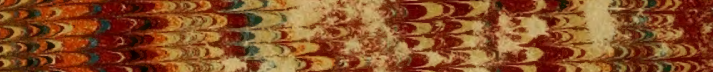

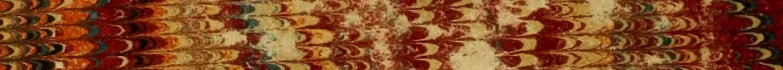

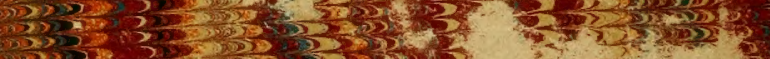

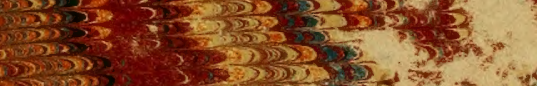

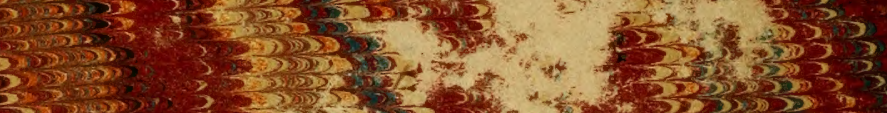

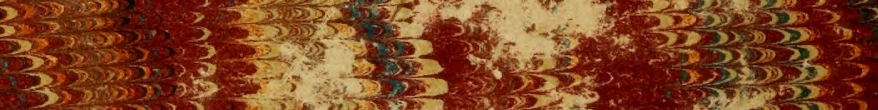

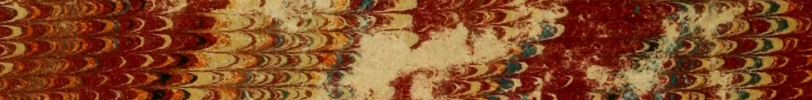

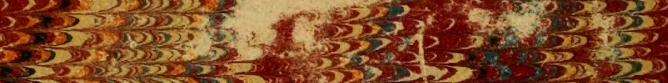

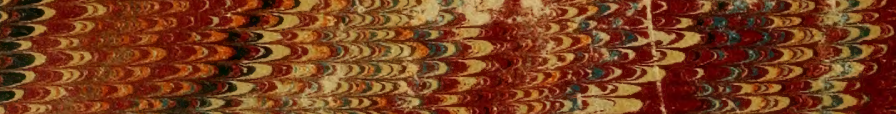

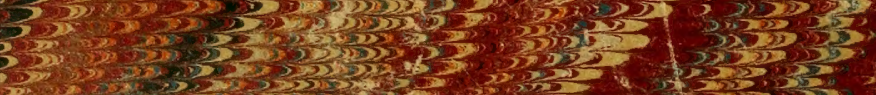

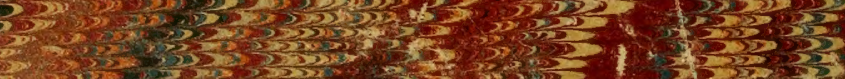
$\lim _{3} 3$ 37 1. $3 \frac{3}{3}$
$\frac{3}{3}$
30
30
53
3
3 